\title{
FEMINISMO/S 29
}

\section{La (in)visibilidad de las mujeres en la Educación Superior: retos y desafíos en la Academia}

Marcos Jesús Iglesias Martínez e Inés Lozano Cabezas (Coords.)

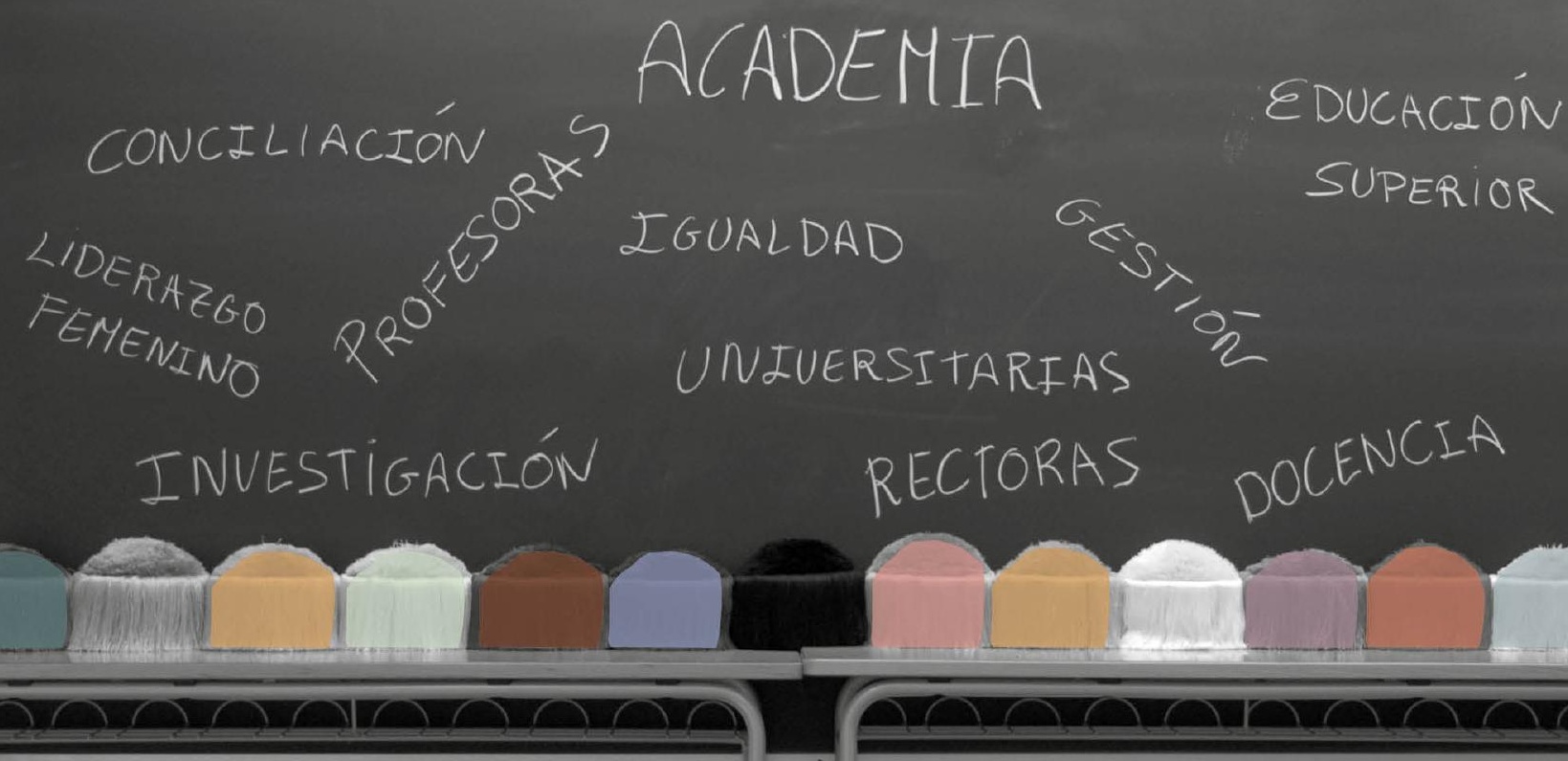





\section{FEMINISMO/S}

Revista del Instituto Universitario de Investigación

de Estudios de Género

de la Universidad de Alicante

Número 29, junio de 2017

\section{La (in)visibilidad de las mujeres en la Educación Superior: retos y desafíos en la Academia}

Marcos Jesús Iglesias Martínez e Inés Lozano Cabezas (Coords.) 



\title{
FEMINISMO/S \\ Revista del Instituto Universitario de Investigación de Estudios de Género de la Universidad de Alicante
}

\author{
Revista semestral \\ Editada por el Instituto Universitario de Investigación de Estudios de Género \\ de la Universidad de Alicante \\ con la colaboración del Vicerrectorado de Investigación y Transferencia de Conocimiento
}

Número 29, junio de 2017

Directora: Helena ESTABLIER PÉREZ (Universidad de Alicante)

Secretaria: Maribel PeÑALVER VicEA (Universidad de Alicante)

CONSEJO DE REDACCIÓN

Mar ESQUembRe CERDÁ (Universidad de Alicante)

Purificación Heras GonZÁlez (Universidad Miguel Hernández)

Carmen MAÑAS Viejo (Universidad de Alicante)

Nieves Montesinos SÁnChEZ (Universidad de Alicante)

Mónica Moreno SeCo (Universidad de Alicante)

$\mathrm{M}^{\mathrm{a}}$ Dolores Ramos (Universidad de Málaga)

María Pilar RodríGuez Pérez (Universidad de Deusto)

$\mathrm{M}^{\mathrm{a}}$ Teresa Ruiz CAntero (Universidad de Alicante)

CONSEJO ASESOR

Nieves BARANDA LETURIO (UNED)

Ester BARberÁ HeRedia (Universidad de Valencia)

Karine BERGĖs (Université de Cergy-Pontoise)

Mabel BuRín (Universidad de Buenos Aires)

Silvia CAPorale Bizzini (Universidad de Alicante)

Àngels CARABí (Universidad de Barcelona)

Rosa Cово BEdía (Universidade da Coruña)

Pilar CUdER DOMínguez (Universidad de Huelva)

Bradley S. EPPS (University of Cambridge)

Joaquín DE JUAN (Universidad de Alicante)

$\mathrm{M}^{\mathrm{a}}$ Victoria GoRDILlo (Universidad Complutense de Madrid)

Angela O'HAGAN (Glasgow Caledonian University)

Annabel Martín (Dartmouth College)

Montserrat PALAU (Universitat Rovira i Virgili)

Eulalia PÉRez Sedeño (Consejo Superior de Investigaciones Científicas)

Alicia PulEo (Universidad de Valladolid)

Carme RiERA Guilera (Universitat Autònoma de Barcelona)

Begoña SAN Miguel del Hoyo (Universidad de Alicante)

Marta SegarRa (Universidad de Barcelona)

Cristina SEgura Graíño (Universidad Complutense de Madrid)

María del Carmen SimÓn PALMER (Consejo Superior de Investigaciones Científicas)

Meri TORRAS (Universidad de Barcelona) 


\title{
REDACCIÓN
}

Instituto Universitario de Investigación de Estudios de Género de la Universidad de Alicante

Campus de Sant Vicent del Raspeig

Apdo. 99 E-03080 Alicante

Tel. 965909415 - Fax 965909803

e-mail: revistafeminismos@ua.es; iuieg@ua.es -web: http://ieg.ua.es

\section{SUSCRIPCIÓN}

Instituto Universitario de Investigación de Estudios de Género de la Universidad de Alicante Campus de Sant Vicent del Raspeig

$$
\text { Apdo. } 99 \text { E-03080 Alicante }
$$

Tel. 965909415 - Fax 965909803

e-mail: iuieg@ua.es -web: http://ieg.ua.es

Precio de cada ejemplar: $12 €$

\author{
Publicaciones de la Universidad de Alicante \\ Campus de San Vicente s/n \\ 03690 San Vicente del Raspeig \\ publicaciones@ua.es \\ http://publicaciones.ua.es \\ Teléfono: 965903480
}

\section{Edita:}

Instituto Universitario de Investigación de Estudios de Género de la Universidad de Alicante con la colaboración del Vicerrectorado de Investigación y Transferencia de Conocimiento

Cuenta con una Ayuda para la Publicación de Revistas Científicas del Vicerrectorado de Investigación y Transferencia de Conocimiento

ISSN: 1696-8166

DOI: 10.14198/fem.2017.29

Depósito legal: A-910-2003

\footnotetext{
Diseño de cubierta: candela ink

Ilustración de cubierta: Antonio Giner Gomis, Marcos Jesús Iglesias Martínez e Inés Lozano Cabezas

Maquetación: Marten Kwinkelenberg

Impresión: Guada Impresores
}

Feminismo/s no se identifica necesariamente con los contenidos de los artículos firmados

Prohibida la reproducción total o parcial de los artículos sin la autorización previa.

La revista está indizada en las bases de datos ISOC (Base de datos del Centro de Información y

Documentación Cientifica del CSIC), ERIH PLUS (European Reference Index for the Humanities and Social Sciencies), MLA (Modern Language Association) CIRC, DICE, MIAR, Latindex, Dialnet, Ulrich's web y Google Scholar. 


\section{ÍNDICE}

Marcos Jesús Iglesias Martinez e Inés Lozano Cabezas

Introducción.

Mónica Arenas Ramiro

La igualdad de oportunidades en la carrera universitaria: conciliación

y corresponsabilidad como medios para conseguirla.

Equal opportunities in the university career: balance and corresponsibility as

a means to achieve it

Tomás J. Campoy Aranda, Manuela Balcázar Fines y Viviana Vega Duette

Los estudiantes universitarios ante la violencia de género

The university's students and gender violence

Aurelia Flores Hernández y Lorena Jiménez Montes

Socialización y sociabilidad de género en un escenario universitario

altamente masculinizado.

Socialization and sociability of gender in a masculinized university context

Aquilina Fueyo Gutiérrez

¿Ya somos iguales? Visibilización de las desigualdades de género

en la educación mediática de las estudiantes universitarias

Are we already equals? Visibility of gender inequalities in media education

of higher education female students

Nazareth Gallego-Morón

Más allá de las estadísticas. Invisibilización y negación

de la discriminación de género en la Universidad

Beyond statistics. Invisibilization and denial of gender discrimination at university

Ana García-Arroyo

Realidades y paradojas en la Educación Superior de India:

(in)visibilidad de la mujer.

Realities and paradoxes of India's Higher Education: woman's (in)visibility

Sara González Gómez y Andrés Payá Rico

Ciencia y género: investigadoras en formación a finales del franquismo .. 173

Science and gender: researchers in training at the end of Francoism

Lubi Granada Angulo

Discriminaciones interseccionales: percepciones de mujeres afrodescendientes en espacios de Educación Superior en Bogotá..... 201 Intersectional discriminations: perceptions of Afrodescending women in spaces of Higher Education in Bogotá 


\section{Estrella Montes López}

La ausencia de corresponsabilidad, freno para el desarrollo

de la carrera laboral femenina en la Academia.

The lack of joint responsibility, brake for the development of the female career

in Academia

Elena Navarro-Astor, Arianna Guardiola-Víllora y Luisa Basset-Salom

El profesorado de la Universitat Politècnica de València desde

la perspectiva de género

Universitat Politècnica de València's faculty from a gender perspective

Laura Nuño Gómez y Enrique Álvarez Conde

Androcentrismo académico: la ficción de un conocimiento neutral 279

Academic androcentrism: the fiction of neutral knowledge

María Inmaculada Pastor Gosálbez, Paloma Pontón Merino y

Ana Acosta Sarmiento

El acceso a la carrera investigadora desde la perspectiva de género

¿punto de inflexión?

The access to the research career from a gender perspective. A turnig point?

Helena Rausell Guillot y Marta Talavera Ortega

Dificultades de la coeducación en la formación del profesorado

Difficulties in coeducation in teaching training

Emanuela Sala y Roberta Bosisio

Gender inequalities in Italian academia. What future for female

academics?

Desigualdades de género en la Academia italiana. ¿Cuál es el futuro para

las mujeres académicas?

Marina Tomàs-Folch

El liderazgo en la Universidad: el papel que tienen ellas 369

Leadership in university: the role that women have

Esther Torrado Martín-Palomino y Ana M. González Ramos

Redes de cooperación: una herramienta para minimizar

las desigualdades de género en la ciencia....

Cooperation networks: a tool to minimize gender inequalities in science

Reseña bio-bibliográfica 417

Cómo presentar un original 429 


\title{
INTRODUCCIÓN
}

\author{
Marcos Jesús IGLESIAS MARTíNEZ \\ marcos.iglesias@ua.es \\ Inés LOZANO CABEZAS \\ ines.lozano@ua.es \\ Instituto Universitario de Investigación de Estudios de Género \\ Facultad de Educación \\ Universidad de Alicante
}

«Y, además, no puedo quejarme: lo difícil que es para nosotras todo, hace más valioso cualquier pequeño triunfo»

Emilia Pardo Bazán (citado por Acosta, 2007, p. 538)

La infrarrepresentación femenina en la Academia continua siendo una realidad en la Educación Superior, concretamente en lo que se refiere a las cátedras universitarias y a los cargos de gestión, a pesar de que el acceso a la Universidad es mayoritario entre el alumnado femenino. Ante este desequilibrio emergen diversas investigaciones sobre esta temática, con el propósito de visibilizar a las académicas, a través de sus propias voces y reflexiones sobre las posibles situaciones de desigualdad que se presentan en las universidades. Los estudios en esta línea ayudan a fomentar el debate, planteando propuestas de tipo político, social y cultural que traten de evidenciar la necesaria presencia femenina en el contexto universitario, pero para que se produzca una igualdad efectiva y práctica, únicamente se puede constatar a través de las reflexiones de las mujeres sobre sus experiencias (Kearney y Lincoln). Además, los estudios de género fomentan y potencian la emergencia de investigaciones haciendo que la Educación y el Género sea un campo dinámico y fluido para plantear nuevas concepciones y teorías para responder a las demandas de la sociedad actual, por tanto, sigue siendo un campo de estudio nuclear de cambio (Bailey y Graves). En este sentido, el debate actual del feminismo en la Academia está

Feminismo/s 29, junio 2017, pp. 9-16

Los contenidos de la revista se publican bajo una licencia de Creative Commons Reconocimiento 4.0 Internacional (CC BY 4.0) 
presente, siendo considerado como una temática relevante y actual. Así, por ejemplo, recientemente Seher Ahmad realiza una exhaustiva revisión de la literatura existente sobre los principales obstáculos de las profesoras universitarias centrándose, principalmente, en la conciliación familiar-laboral, que en numerosas ocasiones impide continuar con la productividad investigadora de las académicas, como han constatado recientes investigaciones (Aiston y Jung; Scharber, Pazurek y Ouyang; Winchester y Browning; Wullum Nielsena). Nosotros compartimos la conclusión de Seher Ahmad (2017) en la necesidad de «draw on integrative theoretical frameworks such as opportunity-cost framework, feminist perspectives, and critical race perspectives» (232), para que la revolución de la igualdad no quede estancada.

En este número se presentan diversas líneas de investigación referidas a la Educación Superior y el Género, en las que se revisa y analiza la presencia actual de las mujeres en la Academia desde perspectivas basadas en desarrollo profesional docente. En este sentido, los estudios indagan acerca de las reflexiones sobre la igualdad entre las docentes, investigadoras y científicas en la Educación Superior, así como la presencia del liderazgo femenino universitario en la gestión y en los grupos de investigación. Asimismo, reflejan con especial interés la escasa presencia de las académicas en las áreas de conocimiento más masculinizadas, y de entre los obstáculos y barreras a lo largo de la carrera universitaria destacan, en cierta medida, la conciliación familiarlaboral, aspecto que abordan algunas investigaciones del presente volumen. En cualquier caso, este monográfico comprende un total de dieciséis artículos que recogen los resultados de investigaciones de instituciones universitarias españolas, europeas, indias e iberoamericanas, y que en buena media abordan la mayoría de las temáticas que pretende recoger esta edición centrando su atención en el desarrollo profesional docente e investigador de las académicas, la presencia femenina en las áreas de conocimiento, la visibilidad del liderazgo femenino universitario en los cargos de gestión universitaria, las problemáticas referidas alumnado universitario y género, y el planteamiento de la conciliación familiar-laboral en la Universidad.

En «La igualdad de oportunidades en la carrera universitaria: conciliación y corresponsabilidad como medios para conseguirla», Mónica Arenas Ramiro desarrolla un ensayo teórico jurídico sobre la normativa que garantiza la igualdad de oportunidades entre mujeres y hombres. A pesar de la existencia de diversas acciones para evitar la discriminación, aún sigue sin demostrarse que las mujeres gocen de las mismas oportunidades que los hombres. Su argumento se focaliza en la necesidad de cambios a nivel constitucional y normativo en lo que respecta a la conciliación y corresponsabilidad familiar con el propósito 
de no perpetuar los estereotipos de género que tradicionalmente se producen en estos ámbitos.

Tomás J. Campoy Aranda, Manuela Balcázar Fines y Viviana Vega Duette en «Los estudiantes universitarios ante la violencia de género» identifican, a través de una encuesta a 467 estudiantes de todas las titulaciones universitarias en la Universidad Nacional del Este de Paraguay, que la violencia de género y discriminación de la mujer están presentes en la cultura, lo cual no genera una reacción entre los estudiantes universitarios por considerarlas como actitudes normales en la sociedad. Las autoras concluyen con la necesidad de diseñar e implementar programas de intervención desde la educación primaria y secundaria para prevenir la violencia y promover la igualdad.

«Socialización y sociabilidad de género en un escenario universitario altamente masculinizado» presenta los resultados de un estudio cualitativo sobre las prácticas sociales y de convivencia de las estudiantes universitarias en un contexto androcéntrico. Así lo identifican Aurelia Flores Hernández y Lorena Jiménez Montes analizando las entrevistas en profundidad que reflexionan sobre las experiencias de sociabilidad en espacios de la Facultad de Ciencias Básicas, Ingeniería y Tecnología de una universidad de México. Sus principales conclusiones derivan que estudiar una carrera universitaria en un contexto altamente masculinizado «es tener un arma de doble filo», ya que esta presencia masculina les obliga a demostrar continuamente sus aptitudes y habilidades.

Aquilina Fueyo Gutiérrez en su artículo «¿Ya somos iguales? Visibilización de las desigualdades de género en la educación mediática de las estudiantes universitarias» nos describe la importancia de formar a los profesionales de la educación para minimizar las desigualdades que también se manifiestan en los medios audiovisuales. A través de un método innovador como es el caso de la educación mediática, Aquilina Fueyo concluye que este tipo prácticas educativas suponen visibilizar la percepción que tienen las universitarias sobre las desigualdades de género, pero asimismo manifiestan la necesidad de crear y potenciar discursos alternativos en diferentes medios digitales para trabajar los procesos de empoderamiento.

El artículo presentado por Nazareth Gallego-Morón, «Más allá de las estadísticas. Invisibilización y negación de la discriminación de género en la Universidad», expone los resultados de un proyecto de investigación financiado por el Programa Marco Europeo de I+D en el marco del Programa Marie Curie Action. Concretamente la investigación analiza la discriminación de género en la Universidad de Argentina a través de los datos estadísticos contrastándolos con las percepciones que tienen los docentes universitarios argentinos. Las principales conclusiones exponen que los hombres no reconocen la existencia 
de la discriminación, pero las académicas evidencian las dificultades y los obstáculos en la carrera universitaria, especialmente en el acceso a los cargos de gestión, y en este sentido la autora concluye que para eliminar estas barreras para las académicas, la institución universitaria debe comportarse como un espacio esencialmente meritocrático.

La calidad de la vida académica es un hecho que afecta también a otros contextos universitarios, como es el caso de la Educación Superior en la India, aspecto que analiza Ana García-Arroyo en su artículo «Realidades y paradojas en la Educación Superior de India:(in)visibilidad de la mujer». La autora analiza el informe en cifras en el que se presenta la situación de la mujer en la Educación Superior india. Las conclusiones principales de este texto están relacionadas con el pensamiento de Martha Nussbaum en el que el progreso del modelo educativo universitario indio ha de potenciarse mediante la igualdad y el respeto para mantener los valores éticos y humanos de una democracia, y no continuar con un modelo occidental dirigido al mercado que deshumaniza el modelo educativo universitario e invisibiliza a las mujeres.

La visibilidad de las académicas en el ámbito científico es una temática que está inscrita en la historia de las mujeres, aspecto que revisan y analizan de manera exhaustiva los docentes Sara González Gómez y Andrés Payá Rico en su texto titulado "Ciencia y género: investigadoras en formación a finales del franquismo». En él nos presentan cómo fue el acceso de las mujeres a la ciencia en la etapa previa a la democracia española. Este artículo revisa las convocatorias que se publicaban en la etapa del franquismo para el desarrollo de actuaciones en la formación del personal investigador y visibilizar la presencia de las investigadoras en estos procesos. Los firmantes del texto concluyen que la desigualdad fue patente en lo que se refiere a las áreas de conocimiento donde las investigadoras noveles aún no encontraban espacios para desarrollar su investigación, dando evidencias del «techo de cristal» para el acceso y la promoción en la Academia.

Las aportaciones que se recogen en este monográfico, en su mayoría, son investigaciones finalizadas. Sin embargo también se han presentado proyectos de investigación en curso, lo cual constata que las problemáticas en el Educación Superior y el Género siguen siendo consideradas como un estado de la cuestión a investigar en el campo de los estudios de Género. En este sentido, el artículo presentado por Lubi Granada Angulo, «Discriminaciones interseccionales: percepciones de mujeres afrodescendientes en espacios de Educación Superior en Bogotá», analiza los pensamientos de tres mujeres afrodescendientes a través de una metodología participativa basada en aportes teóricos que permiten reflexionar sobre la discriminación negativa en la vida 
académica universitaria y laboral de las participantes. La principal reflexión que expone la autora es que el racismo aún sigue manifestándose en distintos escenarios académicos que tienden a desarrollarse con los roles académicos y las capacidades cognitivas en las mujeres participantes en este proyecto. Por tanto, es necesario activar políticas requeridas por la comunidad afrodescendiente para potenciar oportunidades igualdad tanto a nivel macro como micro, tal como concluye la autora.

«La ausencia de corresponsabilidad, freno para el desarrollo de la carrera laboral femenina en la Academia» presentado por Estrella Montes López evidencia uno de los obstáculos más visibles en la promoción del personal docente e investigador: la corresponsabilidad familiar y laboral. Desde un enfoque cualitativo la investigadora analiza entrevistas realizadas a docentes universitarios en las que participan profesoras y profesores con diferentes categorías profesionales y que reflexionan sobre las dificultades que generan la conciliación laboral y familiar en el contexto universitario. Las principales conclusiones constatan que las mujeres siguen con la doble dedicación al trabajo productivo y reproductivo, y no se identifica una visión negativa hacia que los profesores (hombres) se despreocupen por el ámbito familiar. La autora concluye que es necesario reflexionar sobre el modelo de desarrollo de ciencia que deseamos, que sigue siendo a costa de las vidas de las personas que trabajan como investigadoras/es en la Universidad, en el que peso de la responsabilidad compartida continua considerándose como un desafío en esta profesión y, por tanto, un obstáculo más para las académicas.

En el artículo «El profesorado de la Universitat Politècnica de València desde la perspectiva de género», las autoras Elena Navarro-Astor, Arianna Guardiola-Víllora y Luisa Basset-Salom realizan una revisión de corte cuantitativo en la que evidencian el desequilibrio en la institución universitaria estudiada y en concreto en la que se inscriben mayoritariamente áreas de conocimiento vinculadas a las enseñanzas técnicas y, por tanto, la presencia de las mujeres sigue siendo «anecdótica». El estudio concluye que a pesar de que existe cumplimiento de las leyes por parte de la universidad, es necesario aumentar el compromiso desde una formación en conciencia de equidad y género, y de esta manera lograr datos y cifras más equilibrados entre hombres y mujeres en este tipo de Universidades Politécnicas.

Desde la reforma del Espacio Europeo de Educación Superior ha transcurrido bastante tiempo y por ello resulta interesante conocer el estado de la cuestión en las universidades públicas españolas en relación a la incorporación de la perspectiva o los estudios de género en las titulaciones. Laura Nuño Gómez y Enrique Álvarez Conde realizan esta revisión en «Androcentrismo 
académico: la ficción de un conocimiento neutral» con el propósito de plantear un modelo de excelencia inclusivo para dotar a la Academia de formación universitaria con perspectiva de género. A pesar de las problemáticas que impiden actualizar el citado modelo, principalmente por una perspectiva androcéntrica que aún se mantiene en la Educación Superior, los argumentos de la teoría política feminista y las reflexiones sobre la desigualdad ayudan a continuar en esta línea.

La carrera académica en el sistema universitario español se inicia mediante becas pre y postdoctorales para posteriormente continuar como docentes e investigadores en la Educación Superior. Este es aspecto que abordan las autoras María Inmaculada Pastor Gosálbez, Paloma Pontón Merino y Ana Acosta Sarmiento en su artículo «El acceso a la carrera investigadora desde la perspectiva de género ¿punto de inflexión?» Analizando los datos obtenidos mediante una encuesta y una entrevista en profundidad, las autoras concluyen que a pesar de que el sistema de promoción en la carrera docente e investigadora en la Universidad está basado en méritos, aún se detectan limitaciones formales e informales en las becarias y los becarios en lo que se refiere al tipo de beca y al acceso a la misma, la distribución de la carga docente, las responsabilidades familiares o las salidas laborales, en los que las investigadoras noveles aún siguen siendo las perjudicadas. Es por ello necesario reflexionar sobre los inicios en la carrera universitaria, base para la consecución de una igualdad de oportunidades.

Helena Rausell Guillot y Marta Talavera Ortega en «Dificultades de la coeducación en la formación del profesorado» revisan la formación con perspectiva de género en un Máster de investigación y formación del profesorado en didácticas específicas, con el propósito de analizar la situación y proponer una metodología para integrar la dimensión de género en este tipo de titulaciones universitarias. Las investigadoras observan una ausencia de la representación de género en este Máster, lo cual supondrá una escasa interpretación de la realidad social que pueda ayudar a iniciar nuevas líneas de investigación por el alumnado universitario y contribuir a la mejora de la igualdad y equidad en la sociedad, aspecto especialmente relevante en este tipo de estudios, ya que la educación, gracias a su doble función, puede generar conocimiento y cultura a través de la perspectiva de los estudios e investigaciones en el campo de la educación y el género.

«Gender inequalities in Italian academia. What future for female academics?» presentado por las investigadoras italianas Emanuela Sala y Roberta Bosisio, analiza las políticas en igualdad desarrolladas por el Ministerio italiano de Educación, Universidad e Investigación para promover el contrato laboral 
fijo de las/los investigadoras/es universitarias/os. Sin embargo no hay evidencias sobre la eficiencia de estas reformas legislativas en lo que se refiere a las mujeres y a los hombres. Su principal conclusión es que la promoción de las/ los jóvenes investigadoras/es no se basa en el mérito y por ello se observan desigualdades con respecto a las investigadoras, lo cual supone un futuro incierto para esta promoción de mujeres que inician su carrera en la Academia italiana. En síntesis, a largo plazo las reformas ministeriales no obtendrán los efectos esperados para las investigadoras junior.

En el artículo «El liderazgo en la Universidad: el papel que tienen ellas», Marina Tomás-Floch sintetiza los resultados de tres estudios de carácter cualitativo y cuantitativo que evidencian la percepción de los modelos estereotipados en relación al liderazgo en la cultura institucional universitaria, destacando las diferencias de cada estilo entre los hombres y las mujeres, lo cual manifiesta la invisibilidad de las académicas cuyos factores están motivados por la predominancia de las dimensiones sociales, culturales y organizativas en la institución universitaria. En el desarrollo de esta interesante investigación se detallan una serie de rasgos de liderazgo femenino como atributos que tienen las directoras de los departamentos en contraposición a los que deberían tener según la cultura androcéntrica.

El desarrollo de redes de colaboración entre las docentes e investigadoras universitarias promueve excelentes oportunidades en el desarrollo profesional y científico. En este sentido Esther Torrado Martín-Palomino y Ana M. González Ramos cierran el monográfico con el artículo titulado «Redes de cooperación: una herramienta para minimizar las desigualdades de género en la ciencia». Desde una muestra significativa y tomando como referencia los estudios de casos generado por el proyecto Genera: Generación de una economía del conocimiento más inclusiva y competitiva, financiado por el Ministerio de Economía y Competitividad, las autoras analizan la utilidad de las redes cooperativas institucionales y no institucionales, como una herramienta revolucionaria que visibiliza y potencia el conocimiento científico de las investigadoras frente a las estructuras androcéntricas. Este tipo de redes, concluyen las autoras, constituye un instrumento de apoyo mutuo, colaboración y cooperación entre las científicas actuando como una herramienta imprescindible para evitar la continuidad de la cultura científica patriarcal.

La presencia de estudios de género sobre la Educación Superior aún supone una constatación de que la igualdad entre hombres y mujeres en lo que se refiere a la Academia continúa siendo un aspecto pendiente y que en algunos casos el «techo de cristal» sigue presente para muchas académicas. En este sentido estamos de acuerdo con el argumento de la filósofa Amelia Valcárcel 
en el que manifiesta que la igualdad planetaria todavía es un asunto pendiente $y$, por ende, consideramos que aún es necesario continuar indagando sobre esta problemática en el contexto de las teorías feministas. Las investigaciones interdisciplinares sobre el feminismo (Gallego y Moreno; Ros) incrementan la posibilidad de mejorar la igualdad en la sociedad global en la que vivimos (Valcárcel). Nosotros consideramos que este monográfico incluye propuestas y mejoras para contribuir a este propósito, es decir: generar nuevas concepciones para la teoría feminista las cuales se nutren de las diversas investigaciones que se desarrollan en el campo de la Educación y el Género (Bailey y Graves), tal y como recoge este volumen. Esperamos que la publicación de estas investigaciones ayude a resolver la problemática de la igualdad de oportunidades en la Educación Superior, asunto aún pendiente y que requiere de la colaboración de toda la comunidad universitaria.

\section{REFERENCIAS BIBLIOGRÁFICAS}

Acosta, Eva. Emilia Pardo Bazán. La luz en la batalla. Barcelona: Lumen, 2007.

Ahmad, Seher. «Family or Future in Academy?» Review of Educational Research 87.1 (2017) 204-239.

Aiston, Sarah Jane y Jisun Jung. «Women academics and research productivity: an international comparison». Gender and Education 27.3 (2015) 205-220.

Bailey, Lucy E. y Karen Graves. "Gender and Education». Review of Research in Education 40 (2016): 682-722. DOI: 10.3102/0091732X16680193

Gallego Franco, Henar y Mónica Moreno Seco (editoras). Cómo enseñamos la historia (de las mujeres). Barcelona: Icaria: Asociación Española de Investigación de Historia de las Mujeres (AEIHM), 2017.

Kearney, Mary-Louise y Daniel Lincoln. «Gender research: women, the academy and the workplace». Studies in Higher Education 41.5 (2016) 799-800.

Ros, Josefa. Feminism: Past, Present and Future Perspectives. New York: Nova Science Publishers, Inc, 2017.

Scharber, Cassandra, Angelica Pazurek y Fan Ouyang. «Illuminating the (in) visibility of female scholars: a gendered analysis of publishing rates within educational technology journals from 2004 to 2015». Gender and Education (2017) 1-29. DOI: 10.1080/09540253.2017.1290219.

Valcárcel, Amelia. Feminismos en el mundo global. Madrid: Ediciones Cátedra, 2009.

Winchester, Hillary P. M. y Lynette Browning. «Gender equality in academia: a critical reflection». Journal of Higher Education Policy and Management 37.3 (2015) 269-281. DOI: http://dx.doi.org/10.1080/1360080X.2015.1034427

Wullum Nielsena, Mathias. «Gender inequality and research performance: moving beyond individual-meritocratic explanations of academic advancement». Studies in Higher Education 41.11 (2016): 20144-2060. DOI:10.1080/03075 079.2015.1007945. 
Para enlazar con este artículo / To link to this article:

http://dx.doi.org/10.14198/fem.2017.29.01

Para citar este artículo / To cite this article:

Arenas Ramiro, Mónica. «La igualdad de oportunidades en la carrera universitaria: conciliación y corresponsabilidad como medios para conseguirla». En Marcos Jesús Iglesias Martínez e Inés Lozano Cabezas (coords.), La (in) visibilidad de las mujeres en la Educación Superior: retos y desafios en la Academia. Feminismo/s, 29 (junio 2017): 17-43, DOI: 10.14198/fem.2017.29.01

\title{
LA IGUALDAD DE OPORTUNIDADES EN LA CARRERA UNIVERSITARIA: CONCILIACIÓN Y CORRESPONSABILIDAD COMO MEDIOS PARA CONSEGUIRLA
}

\author{
EQUAL OPPORTUNITIES IN THE UNIVERSITY CAREER: \\ BALANCE AND CORRESPONSIBILITY AS A MEANS TO \\ ACHIEVE IT
}

\author{
Mónica ARENAS RAMIRO \\ Universidad de Alcalá \\ monica.arenas@uah.es \\ orcid.org/0000-0002-9329-2246
}

\section{Resumen}

A pesar de la elevada presencia femenina en el mundo universitario, y de la existencia de normas que garantizan formalmente la igualdad entre mujeres y hombres, la realidad sigue demostrando que las mujeres no gozan de las mismas oportunidades que los hombres para participar en la vida universitaria y, mucho menos, para hacer carrera académica. La perpetuación de estereotipos de género, así como la falta de medidas efectivas de conciliación y corresponsabilidad en las tareas domésticas y de cuidados provocan que las mujeres no tengan las mismas oportunidades que los hombres para su desarrollo personal y profesional. El necesario reconocimiento constitucional de las mujeres como sujetos de derechos y de las medidas de conciliación y de corresponsabilidad como herramientas antidiscriminatorias, unido a una verdadera implicación de la institución académica y de sus integrantes, permitirá, con las mismas reglas de juego, tener las mismas oportunidades y hacer visibles a las mujeres en un mundo diseñado por y para los hombres, contribuyendo a diseñar un modelo de Universidad y de carrera académica más justo e igualitario.

Palabras clave: conciliación vida familiar y laboral, corresponsabildad, género, igualdad de oportunidades, Universidad. 


\begin{abstract}
Despite the high female presence in the University, and the existence of norms that formally guarantee equality between women and men, reality continues to show that women do not enjoy the same opportunities as men to participate in university life. And, much less, to make an academic career. The perpetuation of gender stereotypes, as well as the lack of effective measures of conciliation and co-responsibility in domestic tasks and care, mean that women do not have the same opportunities as men for personal and professional development. The necessary constitutional recognition of women as subjects of rights and measures of conciliation and co-responsibility as anti-discrimination tools, coupled with a true involvement of the academic institution and its members, will allow, with the same rules of the game, to have the same opportunities and make women visible in a world designed by and for men, contributing to the design of a model of university and academic career more just and equal.
\end{abstract}

Keywords: work-life balance, co-responsibility, gender, equal opportunities, university. 


\section{INTRODUCCIÓN}

Son numerosas las normas, a nivel internacional, comunitario y nacional, que evidencian el enorme avance que en materia de igualdad se ha producido en nuestras sociedades en el último siglo. Pero nuestro día a día nos demuestra que, aunque formalmente parezca que todos tenemos las mismas oportunidades, algo debe estar fallando porque todavía persisten importantes desigualdades entre hombres y mujeres, porque esa igualdad formal no tiene su reflejo en una «igualdad de resultados» (Figueruelo Burrieza 194-195), y un claro ejemplo lo encontramos en la Universidad.

Para entender y solucionar el problema debemos analizar la situación con perspectiva de género, teniendo en cuenta que la mayoría de las diferencias entre sexos parten, en realidad, de estereotipos sociales, esto es, de características construidas socialmente (Carmona Cuenca 74; Tomás Morales 17-32). Sólo de esta forma podremos concebir el verdadero efecto discriminador que produce su mantenimiento, alejándonos de conseguir una igualdad real y efectiva entre mujeres y hombres.

En este orden de ideas, las desigualdades entre mujeres y hombres se han hecho más perceptibles desde que la mujer accede al mercado laboral y hace tambalear los cimientos de la tradicional práctica por la que la mujer se ocupa de las labores domésticas y de cuidado de la familia y el hombre se encarga del trabajo y de «traer el dinero a casa». Era cuestión de tiempo que el barco hiciera aguas, pues estos cambios económico-sociales no tuvieron su repercusión en la práctica y las mujeres siguieron, y siguen, asumiendo el rol acaparador de la esfera doméstica y de los cuidados de la familia sin que se haya producido el necesario reparto de las responsabilidades en ese terreno. Esto ha perpetuado el hecho de que las oportunidades de las mujeres para formar parte de la esfera pública, del mundo laboral, se vean disminuidas, o incluso cercenadas, a causa de la doble carga y al sobreesfuerzo que las mismas deben soportar.

Por este motivo, es más que evidente que si queremos conseguir una igualdad real entre hombres y mujeres, y que las mujeres tengan las mismas oportunidades que los hombres, los cambios económicos, sociales y culturales deben ir acompañados de «transformaciones sustanciales en la escala de 
valores» (Ortiz Ceberio 74). Y a esta necesidad obedecen, entre otras medidas, los derechos de conciliación de la vida familiar y laboral (Aguilera Izquierdo 70). Con estas medidas se consigue, además, una mejor calidad de vida y se evitan problemas tales como el absentismo, la disminución de la productividad, el estrés laboral, el descenso de la natalidad y las repercusiones económicas aparejadas, motivados por la incompatibilidad de mantener ambas facetas, y cuyo incumplimiento crea situaciones "contaminantes" y poco sostenibles con el entorno económico, social y demográfico» (Orive Álvarez, Asián Chaves y González Limón 522; Walton 11-21; León Llorente 250 y 257; Abbott, De Cieri 303-320; Rosende 32; Sarrió Catalá 44). No obstante, a pesar de estos beneficios económicos, no podemos caer aquí en trivializar estas medidas y quedarnos en su faceta laboral como medidas de promoción del empleo, destinadas a que se trabaje más y mejor y a que las mujeres puedan compatibilizar trabajo y familia (Orive Álvarez, Asián Chaves y González Limón 523-524; Macinnes 35-71).

Para que estas medidas funcionen debe romperse también la actual tendencia (fruto de los citados estereotipos) de que sean las mujeres las que, en gran medida, recurran a los derechos de conciliación ${ }^{1}$. De ahí las necesarias medidas de corresponsabilidad que deben acompañarles, pues sólo si hay un equilibrio a la hora de asumir las responsabilidades personales y familiares, lograremos avanzar en la igualdad real de oportunidades entre mujeres y hombres (Carbonell Pérez y Ramos Santana 1275).

La conciliación no es "cosa de mujeres». La solución a los problemas de igualdad de oportunidades no pasa por conciliar la vida laboral y familiar de las mujeres, perpetuando los tradicionales roles y estereotipos de género de distribución de tareas fuera y dentro del hogar (Lousada Arochena 8). La idea es conseguir la corresponsabilidad en dichas tareas de la esfera privada y que tanto hombres como mujeres tengan las mismas oportunidades de acceder y prosperar en la esfera pública, sin que la mochila de uno sea más pesada que la del otro.

En este punto damos incluso un paso más y añadimos que la conciliación no debería ser sólo cuestión de hombres y mujeres por igual, sino que la magnitud constitucional del tema obligaría a que fuera "cosa de los poderes públicos». Existe una responsabilidad política y social que los poderes públicos deben asumir, sin descargarla en los ciudadanos y, más concretamente, en las mujeres, a las que por los estereotipos de género, el tomar la decisión de elegir entre trabajo y familia, les afectará en mayor medida (Ortiz Ceberio

1. Así lo ha reconocido el Pacto Europeo por la Igualdad de Género (2011-2020) [Conclusiones del Consejo, de 7 de marzo de 2011, sobre el Pacto Europeo por la Igualdad de Género (DOUE C 155, de 25.05.2011)]. 
75-76 y 78; Belking 1-11)², y las acabará convirtiendo en el auténtico soporte del Estado social.

Así las cosas, la Universidad no escapa a estas cuestiones. Desde que a finales del siglo XIX, en 1872, se matriculara con un permiso especial (en la Facultad de Medicina de la Universidad de Barcelona) la primera mujer española, María Elena Maseras, y, en 1916, otra mujer, Emilia Pardo Bazán, consiguiera la primera cátedra (en la Universidad Central de Madrid), el número de mujeres en la Universidad española ha ido creciendo, e incluso superando al número de hombres. Se ha pasado de estar marginadas a estar integradas en el mundo universitario (García Lastra 357 y 361-362; López de la Cruz 291-293) 3.

Pero esto no significa que en el ámbito universitario no exista desigualdad. Así, aunque la Universidad está mayoritariamente copada por mujeres y el número de mujeres graduadas es mayor que el de hombres, la realidad nuevamente, dos siglos después, nos muestra, por un lado, la persistencia de estereotipos de género en las aulas (Sánchez García y otros 331-354); y, por otro lado, que las mujeres no ocupan puestos relevantes en la institución y que su carrera académica no corre paralela a la de sus compañeros varones (Ion, Durán-Bellonch y Bernabeu Tamayo 126 y 130; Donoso, Figuera y Rodríguez Moreno 187-212; Elizondo Lopetegui 25-34; Ballarín Domingo, Gallego Méndez y Martínez Benlloch) ${ }^{4}$. La Universidad parece resistirse a una igualdad real en sus dominios amparada en la creencia de que es «una institución neutra» porque sus normas de organización y funcionamiento así lo proclaman y porque se basa en la exigencia del mérito y la capacidad para el acceso y promoción en la carrera académica (Ventura Franch 2008, 160-161).

2. El sacrificio que vienen realizando muchas mujeres de su carrera profesional por su vida familiar ha alcanzado cifras tan altas, que en países como Estados Unidos el fenómeno ha recibido el nombre de la «Revolución del Abandono» («Opt-Out-Revolution»).

3. Recordamos aquí la Real Orden, de 8 de marzo de 1910, del Ministerio de Instrucción Pública y Bellas Artes, que derogaba la Real Orden, de 8 de junio de 1888, por la cual la mujer tenía que pedir un permiso especial si quería matricularse oficialmente en estudios superiores; y la Real Orden, de 2 de septiembre de 1910, del Ministerio de Instrucción Pública, por la que se abrió la posibilidad a las mujeres de opositar y concursar para los mismos puestos que los hombres.

4. Podemos citar entre otros estudios oficiales que recogen esta realidad, el publicado en 2007 por el Ministerio de Educación y Ciencia, Académicas en Cifras 2007 (http://www. amit-es.org/sites/default/files/pdf/publicaciones/academicas\%20en\%20cifras.pdf); el publicado en 2010 por el Ministerio de Sanidad, Política Social e Igualdad, Igualdad de Mujeres y Hombres en las Universidades españolas (http://www.inmujer.gob.es/areasTematicas/estudios/serieEstudios/docs/igualdadUniversidades.pdf); o el publicado en 2016 por el Ministerio de Economía, Industria y Competitividad, Científicas en Cifras 2015 (http:// www.idi.mineco.gob.es/stfls/MICINN/Ministerio/FICHEROS/Informe_Cientificas_en_ Cifras_2015_con_Anexo.pdf). 
Por ello, las medidas antidiscriminatorias suelen generar ciertas resistencias, y las situaciones de discriminación perduran, especialmente, en las condiciones y promoción profesional de su profesorado (Mentado Labao, Montané y Olivé Ferrer 1155; Caruncho Luz y Díaz Amada 1155). Pero esto no sólo ocurre a nivel europeo, sino que estudios comparados evidencian que en la mayoría de los países las mujeres sufren discriminación en el terreno universitario (Lecuona Naranjo 145; López Chocero y Sanchís Vidal 964). El problema vendrá porque en este terreno, «las desigualdades proceden de elementos informales más difíciles de detectar, analizar y resolver» (Gómez Cama 10).

Pero esto no deja de ser, cuanto menos curioso, si partimos de la base de que la universidad es una institución que contribuye al desarrollo de las personas, a su formación en valores y a la creación de un pensamiento crítico. Difícilmente podrá educar en igualdad si la misma no existe en sus aulas ni entre el personal que la compone. La Universidad debe ser el espejo de la sociedad que queremos tener, pues es la encargada de formar personas, a los profesionales del futuro, y en pleno siglo XXI esto lo debe hacer defendiendo la igualdad efectiva entre mujeres y hombres, formando a personas concienciadas con esta perspectiva de género (López-Francés y Vázquez Verdera 242; Lecuona Naranjo 158) y, por este motivo, debe predicar con el ejemplo. Así, a ello van a contribuir las medidas de conciliación, acompañadas de la correspondiente corresponsabilidad con las que se logrará no sólo una mejor calidad de vida y una sociedad más competitiva, sino una sociedad más justa y comprometida, eliminando toda forma de discriminación basada en el género, posibilitando que en el terreno académico se dé una verdadera igualdad de oportunidades entre mujeres y hombres.

\section{MARCO NORMATIVO}

Sin ánimo de hacer un recorrido exhaustivo sobre la normativa de igualdad y antidiscriminatoria existente, citamos a continuación las normas que regulan la igualdad y las medidas tendentes a conseguirla haciendo especial mención a su incidencia en el terreno de la Educación Superior.

No obstante, para empezar, es de obligada referencia recordar que fue en la IV Conferencia Mundial de Mujeres, celebrada en Pekín en 1995, donde se puso de relieve la necesidad de aplicar una perspectiva de género a la hora de analizar la situación de las mujeres en la sociedad. Asimismo, en el terreno de la corresponsabilidad, como un mecanismo tendente a conseguir la igualdad efectiva entre hombres y mujeres, la Convención sobre la Eliminación de todas las formas de Discriminación contra la Mujer, aprobada por la Asamblea General de las Naciones Unidas en 1979, exigía que los Estados signatarios así 
lo reconocieran y lo hicieran efectivo (art. 5); obligación de igualdad y conciliación que también se recoge en el ámbito del Consejo de Europa en la Carta Social Europea de 1961 (arts. 2, 4, 8, 16 y 17), y que ha venido siendo puesta de manifiesto por la Organización Internacional del Trabajo (OIT) desde su Recomendación 123, de 22 de junio de 1965, sobre el Empleo de las Mujeres con responsabilidades familiares, donde se ponía de manifiesto que la necesidad de conciliar vida laboral y familiar no es una cuestión exclusiva de las mujeres, sino de la familia y de la sociedad en su conjunto (Preámbulo).

Al margen de la normativa internacional, debemos indicar aquí que ha sido a nivel comunitario, desde la Unión Europea, desde donde se han elaborado y aprobado las normas más avanzadas y completas en materia de género (Freixes Sanjuan 15-66). Tanto el Derecho originario, Tratados constitutivos y la Carta de Derechos Fundamentales de la Unión Europea (CDFUE) integrada en los mismos, así como el Derecho comunitario derivado (con especial atención a las Directivas comunitarias) han entendido la igualdad como objetivo prioritario de la Unión y un valor fundamental de la misma (arts. 2 y 3 TUE, arts. 8, 153 y 157 TFUE y Título III (arts. 20 a 26, especial referencia a arts. 21 y 23) CDFUE), y han contribuido a que los Estados no sólo incorporen en sus ordenamientos internos medidas tendentes a erradicar la discriminación por razón de género, sino a hacer compatible la vida familiar y laboral como medio para conseguir la igualdad real y efectiva entre hombres y mujeres.

A nivel nacional, nuestro texto constitucional consagra tanto la igualdad formal como la material en sus artículos 14 y 9, respectivamente. Estas exigencias han tardado en ver un desarrollo legislativo. Así, en 1999 se aprobó la Ley 39/1999, para Promover la Conciliación de la vida familiar y laboral de las personas trabajadoras (Ley de Conciliación); en 2006, con el fin de contribuir a una mejor conciliación, se aprobó la Ley 39/2006, de Promoción de la Autonomía Personal y Atención a las personas en situación de dependencia (Ley de Dependencia); o, en 2012 se aprobó una batería de medidas con la Ley 3/2012, de Medidas urgentes para la reforma del Mercado laboral, tendente a flexibilizar normas relacionadas con el ámbito laboral y las cotizaciones a la Seguridad Social. Pero las normas esenciales en este terreno, que van a establecer una exigencia de igualdad y la prohibición de discriminación por razón de género van a ser la Ley Orgánica 1/2004, de Medidas de Protección Integral contra la Violencia de Género (LOVG), y la Ley Orgánica 3/2007, de Igualdad efectiva de oportunidades entre mujeres y hombres (LOI), introduciendo esta última, una relevante perspectiva en nuestro ordenamiento jurídico: la exigencia de una necesaria transversalidad, mainstreaming, de la igualdad de género con medidas encaminadas a ello como el permiso de paternidad (art. $44 \mathrm{LOI}$ ) (Desdentado Daroca 95; Ion, Durán-Bellonch y Bernabeu Tamayo 125; Rees). 
La influencia de estas normas en el mundo universitario no se hizo esperar, y aunque la Ley Orgánica 10/1983, de Reforma Universitaria, recogía la exigencia de una igualdad formal entre hombres y mujeres en la Educación Superior, la actual Ley Orgánica 6/2001 de Universidades (LOU) -con la reforma operada por la LO 4/2007, de Modificación de la LOU- recoge el guante lanzado por la LOI y la LOVG (arts. 25 LOI y 4.7 LOVG) e incorpora entre sus objetivos una política educativa que fomente la enseñanza y la investigación sobre el significado y alcance de la igualdad entre mujeres y hombres, erradicando todo tipo de discriminación, incluyendo la violencia de género como una de las manifestaciones más odiosas de discriminación contra la mujer por el mero hecho de serlo (Ventura Franch 2008, 167-168; Martín Bardera 205-206).

Debemos señalar aquí que, si bien las citadas normas en relación con el ámbito universitario contemplan el compromiso de la institución con los valores de igualdad y dignidad de la persona, y se prevé fomentar los estudios de género a nivel formativo, docente e investigador, por otro lado no terminan de desarrollarse los mecanismos para conseguirla, centrándose únicamente en aspectos formales como el reconocimiento del derecho de los estudiantes a la igualdad de oportunidades y a recibir un trato no sexista (art. 46.2.b) y j)), así como su derecho a un acceso y a becas y ayudas en condiciones de igualdad (arts. 42.3 y 45), la presencia equilibrada de hombres y mujeres en los órganos colegiados de gobierno (art. 13) y en los equipos de investigación (art. 41.4) $)^{5}$, la contratación basada en los principios de igualdad, mérito y capacidad garantizando la igualdad de oportunidades (arts. 48.3 y 64 y $75.2,76.3$ ) y la creación de Unidades de Igualdad para desarrollar los temas relacionados con la igualdad entre mujeres y hombres (Disp. Adic. Duodécima de la LO 4/2007, de modificación de la LOU), entre los que se incluyen los conocidos «Planes de igualdad» que las Universidades deberán aprobar, dentro del marco de los Planes Estratégicos de Igualdad de Oportunidades previstos por la LOI a nivel estatal (art. 17 LOI).

Debemos concluir, centrándonos en nuestro país, que si bien es cierto que la aprobación de la LOI supuso un importante avance en materia de igualdad, no es menos cierto que el hecho de que la exigencia de igualdad -ya reconocida en nuestra Constitución como un derecho fundamental y un principio inspirador de la actuación de los poderes públicos- se haya tenido que plasmar en

5. En el terreno de la Ciencia y la Investigación, la Ley 14/2011, de la Ciencia, la Tecnología y la Innovación reconoce la perspectiva de género en la investigación científica y técnica, garantizando la igualdad efectiva, la igualdad de oportunidades, entre hombres y mujeres en este ámbito (ver, entre otros, los artículos 4, 14, 16, 25, 26, 28 y, especialmente, la Disp. Adic. Decimotercera). 
normas obedece a que en la sociedad española persiste «una resistencia social a la igualdad en el tema de mujeres y hombres» (Ventura 2007, 523). Y sucede lo mismo en el terreno universitario. Esto pone de manifiesto que, a pesar de las normas citadas, en la Universidad no se garantiza una igualdad real de oportunidades entre mujeres y hombres y que la discriminación de la mujer proviene, en gran medida, del hecho de que la mujer se encuentre diluida e invisible en el ámbito doméstico (Añón Roig 15; Martín López y Díaz Fernández 636). De ahí que tengamos que analizar el origen del problema para buscar una solución al mismo más allá de las normas.

\section{EL PROBLEMA DE FONDO: LOS ROLES SOCIALMENTE ADMITIDOS}

Es innegable que, más allá de las cuestiones formales, ya sea en el sector público o en el privado, tanto el acceso o incorporación, como la promoción y las condiciones de trabajo de las mujeres no son iguales a las de los hombres. El origen de esta desigualdad injustificada, de esta discriminación de la mujer, no es otro que la pesada carga de la tradición, de lo que se entiende que son «sus obligaciones naturales» reproductivas y de cuidado (Esquembre Valdés 43-44; Martínez Sampere 54; Jennings 183), de los roles tradicional y socialmente admitidos.

Ya ha quedado dicho que la incorporación de la mujer al mundo laboral supuso un cambio de la estructura social y económica de los países, entre ellos, España. En España, a pesar del tránsito a la democracia, y de la prosperidad económica y los cambios legislativos que fueron aparejados (Ruíz de la Cuesta Fernández y Bajo García 132-133), no se produjo ningún cambio en la mentalidad de una sociedad tradicionalmente patriarcal, en la que existían unos roles bien definidos de lo que debían hacer los hombres y de lo que les correspondía a las mujeres, que era todo lo relacionado con las labores domésticas, reproductivas y el cuidado de los miembros de la familia (Martín López y Díaz Fernández 633; Lousada Arochena 7).

La cuestión es que estos estereotipos se aprenden, graban y reproducen por los individuos «como si de una segunda piel se tratara, actuando como una profecía autocumplida» (Sarrió Catalá 46; Merton 193-210), y acaban creando «una realidad discriminadora y segregada» (Sarrió Catalá 41). Por este motivo, la transformación laboral sufrida a lo largo de este último siglo debe ir acompañada de un reposicionamiento de los roles que los individuos tienen en la sociedad, pero tanto los de los hombres como los de las mujeres (Kaufmann Hahn 29 y 32), con el fin de que la ética del cuidado no sea sólo cosa de las mujeres, las relaciones de poder no se vuelquen al mismo lado de la balanza 
siempre, y romper así los estereotipos de género generadores de una evidente discriminación.

La cuestión de los roles se asimiló de la misma manera en el mundo académico, esto es, como si fuera una cuestión «intrafamiliar y femenina» (León Llorente 248). Todo ello, además, bajo el error de partida de creer que en la Universidad no hay desigualdad, provocando «un sesgo de género que perjudica claramente a las mujeres» integrantes de la comunidad universitaria: estudiantes, personal de Administración y Servicios (PAS) y, especialmente, al personal docente e investigador (PDI) (Ventura Franch 2008, 161).

La realidad y las cifras muestran que hay un mayor número de mujeres que de hombres en las aulas y con un nivel de estudios más altos -aunque debemos señalar que con diferencias importantes por ramas de conocimiento(Mentado Labao, Montané, Olivé Ferrer 1155) ${ }^{6}$. Pero esta excelencia se queda en la base. Se produce por lo tanto, tanto una discriminación horizontal como una discriminación vertical, y así, se habla de ramas de conocimiento feminizadas y de niveles de académicos desocupados (Caruncho Luz y Díaz Amada 1147; García Lastra 363). La presencia de mujeres en cargos directivos o en las estructuras de poder de la Universidad así como en las escalas más altas de la carrera universitaria es decepcionante (Ventura Franch 2007, 527-528; Tomás Folch y Guillamón Ramos 254-255)7. Y lo mismo sucede respecto del Personal de Administración y Servicios (PAS), donde las bases y los niveles más bajos los ocupan las mujeres y los grupos más altos son ocupados por hombres. Se evidencia la existencia del manido «techo de cristal» (López Chocero y Sanchís Vidal 964), o más bien, deberíamos hablar de un «suelo pegajoso», que atrapa a las mujeres impidiéndolas o dificultándolas acceder a puestos superiores (Tomás Folch y Guillamón Ramos 257; Heward). Esto es una muestra de que algo falla en el mundo académico. Y la respuesta no puede esconderse bajo el argumento de la tardía incorporación de la mujer al mercado laboral o al mundo universitario. La respuesta la encontramos nuevamente en la realidad dormida, en el ámbito privado, esto es, en las labores de cuidado y reproducción, en el número de hijos y el tiempo de dedicación a los mismos y al resto de

6. Para comprobar datos numéricos y cifras, remitimos al Plan Estratégico de Igualdad de Oportunidades (PEIO) 2014-2016, editado por el Instituto de la Mujer y el Ministerio de Sanidad, Servicios Sociales e Igualdad, pp. 37-41.

7. En el curso 2015/2016, el número de catedráticas era de 2.053 frente a los 7.779 catedráticos, tan sólo un $20,88 \%$. Y si atendemos a la máxima representación de la institución universitaria, a 2017 sólo existían 11 Rectoras frente a 73 Rectores. Cifras extraídas del Instituto de la Mujer, de las Estadísticas sobre Educación, Profesorado. 
la familia y las labores domésticas ${ }^{8}$. Esto unido, por un lado, a los estereotipos de género, donde la mujer «debe» tener una conducta cooperativa, marcada por la ausencia de ambición de poder, y, por otro lado, al hecho de que para las mismas se produce un conflicto moral y un estrés continuo por sentir no estar al $100 \%$ entregadas a la familia y a su formación y productividad (Alonso Sanz 227; Jiménez Rodrigo y Márquez Lepe 5), pueden ser la respuesta a la ausencia de mujeres en los cargos directivos y representativos en la Universidad (Tomás Folch y Guillamón Ramos 268). Así pues, son estos roles los que mantienen la «segregación en la elección de los estudios, por las implicaciones que tiene en relación a la división sexual del trabajo y el estatus de las carreras feminizadas» (Caruncho Luz y Díaz Amada 1146; Ion, Durán-Bellonch y Bernabeu Tamayo 126; Lunn 77-90; Leathwood y Read). De esta forma, se priva a la sociedad de un modelo femenino de referencia «y de éxito» vinculado al mundo académico (García Lastra 364).

Así las cosas, con el fin de contribuir a una igualdad efectiva entre hombres y mujeres, y propiciar que las mujeres tengan las mismas oportunidades que los hombres, las medidas de conciliación y la exigencia de corresponsabilidad parecen ser las medidas más apropiadas para conciliar vida familiar y laboral y asumir las tareas familiares y domésticas de manera corresponsable y democrática por los miembros de la familia.

Pero debemos hacer especial hincapié en que para que estas medidas no sigan perpetuando los citados estereotipos de género y se queden en papel mojado, las mimas no deben concebirse como una cuestión femenina, ni quedarse y solucionarse en la esfera privada de los individuos. Los poderes públicos tienen la misión de actuar en este terreno. La solución contraria conllevaría, como ha quedado dicho, a la perpetuación de los roles de género y al hecho de que sean las mujeres las que sientan la presión y el estrés de tener que elegir entre una vida familiar y una vida laboral, o la forma de conciliar ambas con el malabarismo de llevar a cabo una doble jornada de trabajo (Aguilera Izquierdo 69; Ruíz de la Cuesta Fernández y Bajo García 133; Carbonell Pérez y Ramos Santana 1275; Presser 46-76; Tobío; Méda). Hay que evitar, como ha reconocido nuestro Tribunal Constitucional (SSTC 185/2005 y 233/2007), que el uso de los derechos de conciliación dificulte la integración laboral de la mujer y la destierren profesionalmente. Si el Estado mantiene los roles tradicionalmente asumidos, lo que hace, además de permitir una discriminación por razón de

8. Los datos demuestran que de las personas entre 25 a 54 años que tienen hijos, mientras la tasa de empleo en los hombres es del 78\%, en las mujeres es del $57,8 \%$. Datos extraídos de las Estadísticas del Instituto de la Mujer, en colaboración con el Instituto Nacional de Estadística sobre Hombres y Mujeres en España 2014. 
género, es convertir a las mujeres en «supermujeres» que cargan con la obligación que a él le corresponde de soportar los costes del Estado social (Añón Roig 16 y 18; Moreno Fernández 45; Escudero Rodríguez 127).

\section{LA NECESIDAD DEL CAMBIO: LA CONCILIACIÓN Y LA CORRESPONSABILIDAD COMO RESPUESTA}

Las medidas de conciliación y, por ende, la exigencia de corresponsabilidad que las mismas fomentan (León Llorente 256), se enmarcan dentro del objetivo de promover y fomentar la igualdad de oportunidades entre mujeres y hombres. No podemos olvidar que «estableciendo relaciones igualitarias de poder se contribuye a una democratización de la sociedad y de la vida doméstica» (Orive Álvarez, Asián Chaves y González Limón 525). Si no se produce ese reparto igualitario de tareas domésticas se hace difícil conciliar vida personal y profesional, lo que, de perpetuarse los tradicionales estereotipos de género, acaba produciendo una situación discriminatoria para la mujer.

Con la batería de medidas de conciliación previstas en la LOI -desde los permisos retribuidos (por maternidad y por paternidad, o por lactancia, por ejemplo) a los permisos no retribuidos (como la reducción de jornada o las excedencias), entre otras-, se pretende romper con las desigualdades existentes en la forma de asumir responsabilidades familiares. El problema respecto de estas medidas se plantea, entre otras cuestiones, porque las mismas -que suelen conllevar una reducción del salario- van unidas, por regla general, a un momento en el que en la esfera privada se produce un aumento de los gastos, lo que dificulta aún más la capacidad de decisión del sujeto que las solicita (Ruíz de la Cuesta Fernández y Bajo García 136), lo que a día de hoy se viene haciendo de forma asimétrica y perjudicando claramente a las mujeres (Añón Roig 25-26).

Por este motivo, en el terreno de la igualdad no basta con proclamar y reconocer su existencia -lo que hemos visto que se produce-, sino que es necesario hacerla efectiva. Para ello hay que asumir, también, que las propuestas de mejora se van a encontrar con la dificultad de superar las tradicionales estructuras sociales, económicas y laborales existentes (Figueruelo Burrieza 195). Creemos que el punto de partida de dichas propuestas, tomando como base la relevancia constitucional del tema y la erradicación de cualquier tipo de discriminación (Reche Tello), debe estar enfocado en la gestión del tiempo. Si nos fijamos en las diferencias existentes entre hombres y mujeres, por los roles que tienen asumidos, el tiempo que cada sexo dedica a tareas familiares, domésticas y profesionales no es el mismo, y es la gestión del mismo, a través de medidas de conciliación y corresponsabilidad, lo que conllevará que «al 
final del día», tanto hombres como mujeres hayan tenido el mismo tiempo y las mismas oportunidades para desarrollarse personal y profesionalmente ${ }^{9}$.

Hay un aspecto en el que no entraremos por exceder el ámbito de este trabajo, pero que queremos dejar señalado por su importancia, más allá de las cuestiones de género aquí analizadas. Las medidas propuestas serán más eficaces si a la hora de gestionar el tiempo entran en juego no sólo poderes públicos, sino también el mercado. En este sentido, se habla de los llamados "planes de tiempo de las ciudades» a través de los cuales se armonizan horarios laborales, escolares y comerciales (León Llorente 255-256; Orive Álvarez, Asián Chaves y González Limón 523) ${ }^{10}$.

Así las cosas, centrándonos en las medidas de conciliación y corresponsabilidad, uno de los primeros requisitos para avanzar en la igualdad de oportunidades será reconocer la faceta constitucional de las mismas, dotándolas de la relevancia jurídica que se merecen. Con este enfoque, si trasladamos dichas medidas al ámbito universitario -donde los Planes y las Unidades de Igualdad de las universidades jugarán un importante papel-, con cambios concretos en el acceso a la carrera universitaria, en la promoción y en las condiciones en las que la misma se desarrolla, teniendo en cuenta los estereotipos de género, podremos hablar de una igualdad de oportunidades real y efectiva entre mujeres y hombres en el terreno académico.

\subsection{El enfoque constitucional}

Todas las medidas que podamos proponer en este terreno quedan vacías de contenido si no tienen el respaldo y reconocimiento que jurídicamente se merecen.

Las medidas de conciliación, y las inseparables medidas de corresponsabilidad, tienen como objetivo contribuir a la igualdad de oportunidades con el fin de que las mujeres compitan en igualdad de condiciones que los hombres, erradicando así las discriminaciones que esas diferencias ocasionan (Carmona Cuenca 73). De ahí la relevancia constitucional del tema (Reche Tello). Este es el motivo, en tanto que vinculados funcionalmente con la prohibición de discriminación, por el que los derechos de conciliación no deberían ser entendidos como una cuestión más propia de la legislación laboral, esto es, de la legislación ordinaria. Así se ha venido pronunciando nuestro Tribunal Constitucional

9. Sobre el tiempo dedicado a la familia y al hogar, mientras las mujeres dedican 4,7 horas diarias, los hombres le dedican 1.5. Datos extraídos de las Estadísticas ofrecidas por el Instituto de la Mujer, en relación con la Conciliación y los Usos del Tiempo.

10. En este sentido, la Asociación para la Comisión Nacional para la Racionalización de los Horarios Españoles (ARHOE) ha propuesto algunas medidas: impulsar el horario europeo, con objeto de armonizar comercialmente España con el resto de países. 
(Sentencias 240/1999, 203/2000, 3/2007, 233/2007 y 26/2011) que, reforzando la tutela de los derechos de conciliación, ha destacado que debemos ser conscientes de que está en juego una cuestión de relevancia constitucional en tanto que tiene como trasfondo la erradicación de cualquier forma de discriminación y no sólo la defensa de la igualdad (Fernández López 240, 243, 246 y 254; Ruíz-Rico Ruíz 19).

Pero vamos incluso un paso más allá. Con las medidas de conciliación y corresponsabilidad no se da sólo respuesta a cuestiones relacionadas con la prestación de trabajo, sino que las mismas van encaminadas, también, a proteger otro bien constitucionalmente garantizado: la familia (artículo $39 \mathrm{CE}$ ). Este bien constitucionalmente protegido debe garantizarse y desarrollarse en un régimen de corresponsabilidad, sin que sus cuidados recaigan exclusivamente sobre la mujer por el mero hecho de serlo, pues de lo contrario estaríamos incurriendo nuevamente en una causa de discriminación por razón de género.

Esta idea, enlazada con la de tener en cuenta ese ámbito doméstico, la distribución del tiempo y la posición de la mujer como sujeto de derechos, nos vuelve a plantear nuevamente la necesidad de reformular la posición de la mujer en nuestro texto constitucional (Añón Roig 20). No podemos, ni queremos cerrar este trabajo sin señalar que se hace necesario reformar el texto constitucional no sólo formalmente, sino sustancialmente, «a fin de incluir como sujetos políticos y jurídicos a las mujeres para posibilitar la configuración de las relaciones humanas en igualdad» (Esquembre Valdés 36, 49 y 50; Martínez Sampere 66; Durán Ferrer 285-287).

Sólo de esta forma será posible que la mujer participe y se relacione en la sociedad en condiciones de igualdad. Mientras, a la hora de elaborar nuestras normas y en nuestra Norma suprema, se siga ignorando la esfera privada, donde han permanecido ancladas e invisibles las mujeres, su situación desigual seguirá existiendo, pues no se les reconocerán los derechos en las mismas condiciones que a los hombres y, por lo tanto, no tendrán las mismas oportunidades para hacerse visibles como ellos (Figueruelo Burrieza 207). De ahí también la importancia de que los poderes públicos asuman el papel que les corresponde (Ruíz-Rico Ruíz 3-4).

En este sentido, las universidades, como agentes de desarrollo del pensamiento crítico y transmisoras de valores, deben contribuir a construir una sociedad más democrática e igualitaria. Esto pasa no sólo por formar personas concienciadas, sino por el hecho de que la propia institución predique con el ejemplo y reconozca el ámbito privado y sus efectos en los textos que regulan su organización y funcionamiento y que configuran y condicionan la 
carrera académica de las mujeres, para que pueda desarrollarse en igualdad de oportunidades.

\subsection{Los Planes y las Unidades de igualdad}

Los Planes de Igualdad son la herramienta estratégica de la que disponen las Unidades de Igualdad para incluir todos aquellos objetivos, estrategias y prácticas tendentes a eliminar la discriminación por razón de género (artículo 46 LOI) (López Chocero y Sanchís Vidal 978). Y como una estrategia más, los citados Planes pueden incluir las medidas de conciliación y corresponsabilidad tendentes a conseguir la igualdad real y efectiva entre mujeres y hombres.

Esta es la idea que subyace en las Unidades de Igualdad, y entre ellas, en las de las universidades, a pesar de que las mismas, así como los Planes de Igualdad fueron creados por imperativo legal (Disp. Adic. Duodécima LO 4/2007, de Modificación de la LOU). En este sentido, a día de hoy, todas las universidades cuentan con ellas ${ }^{11}$. Pero este cumplimiento formal de nada sirve si los Planes de igualdad no logran una igualdad efectiva, si no van acompañados de un compromiso institucional, así como de un correcto mecanismo de difusión, de seguimiento, y de evaluación que permita ver la efectividad de los mismos en el terreno de la igualdad de oportunidades entre hombres y mujeres en la arena universitaria (Mentado Labao, Montané y Olivé Ferrer 1163; Martínez, Lusa, Calvet, Gallego, Pons y Tura).

La mayoría de los Planes de igualdad aprobados por las universidades centran su atención en el Personal docente e investigador, y muchos de ellos contienen medidas novedosas con el fin de conciliar la vida personal y profesional, así como destinadas a facilitar la asunción de responsabilidades familiares. El problema, nuevamente, es que en la práctica, son las mujeres las que se encargarán de dar visibilidad al Plan, de recordar que la Universidad lo tiene, y de acogerse a las medidas que el Plan recoge. Por ello, es necesario que las medidas que se contengan en el mismo tengan en cuenta los ya mencionados roles de género y que vayan destinados a superarlos (Díaz Rosas y Cuevas López 2-3; Pulido Rivera 273-283). Para ello, deberán contener medidas que tengan en cuenta las desigualdades de género en el acceso, promoción y condiciones de trabajo de las universitarias, y gestionar el tiempo como variable a tener en cuenta, con el objetivo de que las mujeres tengan las mimas oportunidades que los hombres en su carrera académica.

11. Las mismas forman parte de la Red de Unidades de Igualdad de Género para la Excelencia Universitaria (RUIGEU). Pueden verse en http://www.redunidadesdeigualdad.udl.cat/ la-red/quien-forma-parte/. 


\subsection{El diseño del curriculum: un cambio en el acceso y la promoción}

A pesar de que la Universidad recoge y proclama entre sus valores principales la igualdad de oportunidades, la institución se basa en un sistema meritocrático de funcionamiento, que en último término contribuye a la exclusión de las mujeres de los puestos de poder (Ion, Durán-Bellonch y Bernabeu Tamayo 124 y 131; Alonso Sánchez 465-475), demostrando que los principios de mérito y capacidad no son suficientes para garantizar la igualdad de oportunidades en la carrera académica (Martín Bardera 246-247).

Para entender la carrera académica y la importancia del curriculum y de su diseño a lo largo de la misma, lo que acredita el mérito y capacidad de las docentes y su excelencia para concursar a las diferentes plazas que componen la carrera universitaria, debemos comenzar por recordar que la carrera universitaria es una carrera de fondo que comienza con el Doctorado que suele durar una media de unos 5 años. Señalamos este dato para hacernos una idea de que la carrera universitaria de una persona comenzará generalmente alrededor de los treinta años. Así, estaremos en presencia de una persona avanzada la treintena, sin un trabajo estable (con las consecuencias económicas que ello conlleva), en un momento de la vida en el que suele coincidir con la edad en la que formar una familia (Martín Bardera 238-239).

Así las cosas, al margen de esta cuestión vital, pero sin olvidarla, el curriculum académico se irá confeccionando, no sólo con labores docentes y de gestión, sino también con las de investigación. Y así se medirá la excelencia de los candidatos a las plazas de profesorado universitario. En un curriculum académico, entre otros méritos, además de la docencia y las labores de gestión, se tiene en cuenta la adquisición de sexenios de investigación, que se consigue a través de publicaciones de artículos en Revistas científicas o de monografías, la asistencia y participación en Congresos (nacionales e internacionales), la dirección de Tesis doctorales, la dirección de grupos de investigación o la obtención de proyectos -aunque existe un número elevado de mujeres en grupos de investigación, incluso superior al de los hombres en las ramas jurídicas, sociales y humanísticas, la cuestión reside en que no es así respecto de los puestos de dirección de los mismos (Caruncho Luz y Díaz Amada 1148)-.

La cuestión por otro lado, es que los procedimientos están formalizados. Pero el problema no es la forma, sino el fondo, la valoración de los méritos citados. Un requisito aparentemente neutro en el acceso a la carrera académica o a una plaza de profesorado universitario puede discriminar a las mujeres por no haber tenido las mismas oportunidades para alcanzarlo. Así, por ejemplo, 
nos vamos a encontrar primero con el problema de las Comisiones encargadas de acreditar las competencias y méritos de los aspirantes a las plazas de acceso a los cuerpos docentes funcionarios (Titularidad y Cátedra); y, después, con el problema de los Tribunales o Comisiones de selección que evalúan a los candidatos previamente acreditados. El problema no será la composición de los mismos, en tanto que la LOU exige la paridad en su composición (arts. 57 y 62 LOU) ni en los requisitos exigidos para demostrar la excelencia académica, sino en el hecho de si todos han podido alcanzar la misma de la misma manera, y sólo entonces se podrá hacer una valoración en igualdad de condiciones (Ventura Franch 2007, 529).

Si la valoración no se hace de forma igualitaria, la consecuencia de la desigualdad de trato es clara: las docentes e investigadoras confeccionan su curriculum con una menor promoción que la de sus compañeros, lo que conlleva que las mismas se queden en categorías más bajas (porque son las que menos requisitos exigen y los requisitos que menos tiempo demandan para ser adquiridos, aunque por contrapartida, suponen ingresos inferiores), lo que, a su vez, les priva de conseguir otros méritos académicos necesarios para escalar en la carrera académica, como por ejemplo, la dirección de proyectos de investigación o la dirección de tesis doctorales (Martín Bardera 242), lo que, a su vez, también, las hace menos relevantes en la vida universitaria y, por lo tanto, menos visibles que los hombres que sí que han ido acumulando dichos méritos porque han tenido tiempo para conseguirlos dado que su presencia en la vida doméstica y familiar no se consideraba imprescindible (Ion, DuránBellonch y Bernabeu Tamayo 131).

Como vemos, en la Universidad existen desequilibrios tanto en la etapa de formación como en la profesional y de consolidación basados en los aspectos a valorar en el curriculum académico, un curriculum cuyos criterios de evaluación «están construidos al servicio el ciclo vital y profesional masculino» (Tomás Folch y Guillamón Ramos 266-267).

Hay que tener en cuenta, por lo tanto, la gestión del tiempo en conexión con la asunción de los roles de género y la posición de poder de la mujer en el mundo académico. Lo que les falta a las mujeres para poder estar en igualdad de condiciones que sus compañeros académicos no es capacidad ni mérito, sino tiempo. Es más que evidente. Por poner sólo un ejemplo, las mujeres que deseen ser madres se van a ver obligadas a interrumpir o dejar de lado, al menos por un tiempo, su carrera profesional para dedicarse al cuidado de sus hijos. Este «parón» académico, que suele coincidir con la época de mayor productividad académica, al comienzo de la misma, influye negativamente en 
el curriculum profesional (Lecuona Naranjo 147) ${ }^{12}$. Y esta cuestión no puede obviarse.

Por este motivo, la cuestión no es sólo valorar los mismos méritos académicos para los hombres que para las mujeres, sino si las mujeres han podido conseguirlos en igualdad de condiciones y si deben existir medidas de acción positiva que contribuyan a que todos salgan del mismo punto de partida. Y la respuesta debería ser que sí. En este sentido se pronunció el Tribunal de Justicia de la Unión Europea en su Sentencia de 6 de julio de 2000, caso Göteborg, en el que se analizó el acceso de las mujeres a la Universidad en igualdad de condiciones que los hombres. Aquí, la universidad nombró catedrática a una mujer, con un curriculum inferior al del hombre con el que competía por la plaza, aplicando una medida de acción positiva conforme a la cual en caso de competir por una misma plaza, en igualdad de condiciones, se daría la plaza al sexo menos representado en esa categoría. Así, el Tribunal argumentó que la decisión se había tomado dentro de los límites de poseer una capacitación suficiente y sin vulnerar la objetividad de la contratación. Se legitimaba así la posibilidad de introducir medidas de acción positiva en los concursos de acceso a cátedra (Ventura Franch 2007, 530).

En este sentido, medidas como, por ejemplo, la iniciativa promovida por la Universidad de Barcelona de estudiar la posibilidad de dotar de ayudas económicas a las mujeres que quieran asistir a Congresos para cubrir los gastos de contratación de cuidadores, o bien, destinar ayudas económicas a facilitar la movilidad internacional de toda la familia, son un claro ejemplo a seguir. En idéntico sentido, a imitación de universidades nórdicas o anglosajonas, es realmente interesante la medida de establecer un periodo sin carga docente ni de gestión después del disfrute de un permiso por maternidad o paternidad o por el cuidado de una persona dependiente con el fin de «reparar» el periodo de interrupción científica producido (Ysàs Molinero 47). El no tener en cuenta estas cuestiones demuestra la poca sensibilidad de la Universidad, para quien con su actual proceder da a entender que la mujer durante su permiso de maternidad no ha sido productiva científicamente porque no ha querido y que con la reincorporación a su actividad deberá producir como si en su vida personal no hubiera cambiado nada que la pudiera distraer.

Por este motivo, se hace indispensable «favorecer la promoción y la excelencia erradicando posibles desequilibrios indirectos en las actividades realizadas» (Ysàs Molinero 46). Se hace necesario que los Planes de igualdad

12. Así lo puso de manifiesto la Comisión Europea en su Informe Política científica de la Unión Europea. Promover la excelencia mediante la integración de la igualdad entre géneros. Luxemburgo: Oficina de Publicaciones Oficiales de la Comunidad Europea, 2001. 
cuenten no sólo con medidas como las legalmente establecidas de tener en cuenta los periodos de crianza y de cuidado de personas dependientes (los permisos por conciliación que la ley garantiza), sino con otra serie de medidas de acción positiva que propicien una igualdad real y efectiva de oportunidades para las mujeres.

\subsection{Las condiciones de trabajo: un cambio en la permanencia}

Acabamos de comprobar cómo entre las causas de las diferencias existentes a la hora de elaborar un curriculum profesional, uno de los hándicaps más importantes es el tiempo, o más bien la falta del mismo, provocada por los estereotipos de género. Así las cosas, la ordenación del tiempo de trabajo constituye un factor esencial para conciliar la vida familiar y laboral y conseguir una real igualdad de oportunidades.

En relación con las condiciones de trabajo debemos señalar que el mundo universitario, especialmente el docente, debe superar, en este punto, otro tipo de estereotipos sociales relacionados con el tiempo de trabajo desarrollado para y en la institución. El profesorado universitario debe superar la errónea percepción que se tiene de su «flexibilidad horaria» (Ysàs Molinero 46), pues en el mundo académico en la práctica dicha flexibilidad significa un abierto 24/7 para trabajar, especialmente en el terreno de la investigación. Incluso más allá del erróneo estereotipo social sobre la labor universitaria, podríamos decir que es la propia Universidad, la que fomenta el «mito del académico como una persona "casada" con la ciencia», alejado del mundanal ruido, haciendo parecer incluso impensable, su compatibilidad con cualquier tipo de vida personal y familiar (Ortíz Ceberio 79).

Partimos, en este sentido, del hecho de que nuestras universidades responden a un modelo de organización muy masculinizado, patriarcal o con unos roles de género tradicionales, que todavía muestran cierta resistencia-incluso inconsciente, queremos pensar-a la presencia de las mujeres en la institución y que ha diseñado su organización, el acceso y la promoción a la misma en base a unos valores y roles masculinos (Ion, Durán-Bellonch y Bernabeu Tamayo 132; Guillamón Ramos 77-112).

Todo esto acaba provocando, según el estado de las cosas, que las mujeres queden relegadas a una posición de inferioridad respecto de sus compañeros varones en tanto que, por los roles tradicionalmente asumidos, ellas sí que están casadas con su «componente humano», generándoles, como ha quedado dicho, una sensación de estrés y culpabilidad por no poder compatibilizar todas las facetas de su vida como si fueran ellas las únicas obligadas a conciliar y las únicas responsables de los cuidados domésticos y familiares. 
En este orden de cosas, partiendo de estas peculiaridades del mundo docente universitario, con el fin de conciliar vida personal y laboral, sería necesario sin que ello suponga un estrés por renunciar a alguno de dichos ámbitos o sufrir una merma en la carrera docente, diseñar medidas de conciliación y corresponsabilidad para ambos sexos relacionadas con el desarrollo y desempeño de la actividad docente e investigadora. Y aquí, es relevante tener en cuenta la gestión del tiempo y un diseño de horarios que permita dicha conciliación. En este sentido, dejando de lado la dificultad de que, a día de hoy, horarios escolares, institucionales y comerciales cambien, y ante la ausencia de los ya citados «planes de tiempo de las ciudades», descendemos al terreno universitario para poner el granito de arena en este terreno.

En este sentido, los Planes de igualdad deben recoger medidas relacionadas con el centro y las condiciones de trabajo adaptadas a las necesidades de conciliación de la vida personal y laboral. Se deberían estudiar e implementar mecanismos para que los horarios docentes, la distribución de la docencia, fuera sensible y tuviera presente las necesidades del profesorado que tiene cargas familiares. Incluso podemos decir más aún, ya que las universidades mostrarían nuevamente su sensibilidad ante este tema si, al margen de esgrimir cuestiones presupuestarias, fueran más proclives a cubrir las bajas causadas por los permisos de maternidad con el fin de evitar una situación que conocen que se produce fruto de su negativa: el hecho de que la docencia se asuma por el resto de docentes del Área, Departamento o Unidad, con el consiguiente mal ambiente laboral, la reincorporación anticipada o una elección no deseada (Ysàs Molinero 47).

Al margen de estas cuestiones, por poner algunos ejemplos, entre las medidas por las que están apostando ya algunas universidades y otras que sería necesario tener en cuenta, creemos que sería conveniente la creación de zonas de juego infantiles, la creación de escuelas infantiles garantizadas no sólo para profesores, sino también para estudiantes con hijos, la creación de cambiadores para bebés o salas de lactancia (Alonso Sanz 234); y más relativas a los horarios y su flexibilización, la existencia de unas reglas (que no recomendaciones) sobre las preferencias para escoger horarios, unido a medidas como la existencia de sistemas rotativos que limiten el número de días en que un o una docente asumen los horarios más inconvenientes, que las clases de primera hora de la mañana o de última hora de la tarde no sean asumidas por profesorado que tengan hijos menores o personas a su cargo, o el hecho de prohibir convocar y realizar reuniones en días u horas conflictivas (Ysàs Molinero 46-47). Estas medidas, entre muchas otras, pueden contribuir no sólo a conciliar, sino también a fomentar la corresponsabilidad. 
Por último, si a estas medidas le unimos la potencialidad del teletrabajo, haciendo uso de las nuevas tecnologías, que evitan la presencia permanente en el puesto de trabajo -o en las aulas el caso de las estudiantes, aunque esta cuestión se tendría que compatibilizar con la exigencia de evaluación continua y presencial prevista en el Plan Bolonia-, podemos vaticinar unos buenos resultados tendentes a lograr una igualdad de oportunidades entre hombres y mujeres.

\subsection{La representación: un cambio en la visibilidad}

Como venimos repitiendo a lo largo de estas páginas, a pesar de la elevada presencia femenina en la Universidad, se produce una escasa presencia no sólo en las categorías académicas más altas, sino en los órganos de dirección y representación académicos. El origen de esta ausencia se debe a los motivos anteriormente expuestos y relacionados con la categoría académica ocupada por la mujer y, por lo tanto con el curriculum académico de la misma que le ha permitido ocupar dicha plaza.

Por lo tanto, vemos cómo para ocupar estos altos puestos en la Universidad la mujer se va a encontrar tanto con barreras internas como externas y va a seguir suponiendo una minoría, a pesar de que formalmente tanto la LOI como la LOU reconocen la presencia femenina en los cargos de gestión y representación (Díaz Rosas y Cuevas López 5 y 17-18; Carrasco Macías 75-87; Tomás Folch y Guillamón Ramos 253-275; Vázquez Cupeiro 185-219).

Finalmente, dejamos aquí señalado, sin ánimo de extendernos más en nuestro estudio, que con relación a la exigencia de la presencia de mujeres en los órganos de gobierno y de representación universitaria, se reabre el tema de las cuotas y la idea de colocar a alguien en un puesto no por su valía sino por su sexo. No podemos estar más de acuerdo con el hecho de que nos resulta curioso plantear este problema en una institución como es la Universidad que funciona a base de porcentajes y cuotas de representación de los distintos miembros de la comunidad universitaria «y nadie se cuestiona a quién se va a enviar a formar parte de un determinado órgano» (Ventura Franch, 528-529).

El problema de fondo que trasciende a esta falta de representación es la falta de proyección de un modelo femenino que rompa con los estereotipos de género tradicionalmente asumidos por la institución y que sigue manteniendo invisibles a las mujeres en el ámbito doméstico. 


\section{A MODO DE CONCLUSIÓN}

Vaya por delante el hecho de que partimos del firme convencimiento de que el reposicionamiento y emancipación de la mujer se queda en papel mojado «si persiste la desigualdad privada», si no se tiene en cuenta la esfera doméstica y su repercusión en la pública, si no se reconocen situaciones de poder iguales y si no se reconoce a las mujeres como sujetos de derechos (Esquembre Valdés 47).

Más aún, el problema no se soluciona sólo con reformular la Constitución en clave de género, sino que a esa igualdad formal -en la que se reconozca, entre otras cosas, la constitucionalidad de los derechos de conciliación (por las consecuencias discriminatorias que su no reconocimiento provoca)-, la tenemos que acompañar de las adecuadas medidas de corresponsabilidad, rompiendo los tradicionales estereotipos de género y superando la actual «crisis de los cuidados», demostrando que las responsabilidades familiares no son sólo «cosa de mujeres» y que el Estado debe asumir también su papel (Añón Roig 21; Moreno Fernández 41-56).

La Universidad como transmisora de valores debe contribuir a la ruptura de la estructura androcéntrica en la que se asienta, teniendo en cuenta la esfera privada y la gestión del tiempo, permitiendo que las mujeres accedan a las aulas, trabajen en la institución y progresen haciendo carrera académica, y sean visibles en la misma en igualdad de condiciones y con las mismas oportunidades que los hombres. Por ello, a través de sus Unidades y Planes de Igualdad, la Universidad debe apostar por implementar medidas más equilibradas y visibles, y sobre todo que respondan a la realidad y tengan en cuenta la esfera doméstica, enfatizando la corresponsabilidad (Carbonell Pérez y Ramos Santana 1295-1296). La Universidad debe contribuir a que las mujeres tengan las mismas oportunidades que los hombres a la hora de ser evaluadas, valoradas, reconocidas y situadas no sólo en la institución, sino en la sociedad en su conjunto. Todo depende de la sociedad que queramos construir, de la calidad de vida que queramos tener y de lo justos y democráticos que queramos ser, y ello no se puede hacer obviando a una parte de la población.

\section{REFERENCIAS BIBLIOGRÁFICAS}

Abbott, Jacqui y Helen De Cieri. «Influences on the provision of Work-life benefits: Management and employee perspectives». Journal of Management and Organization 14.3 (2008): 303-320.

Aguilera Izquierdo, Raquel. «Los derechos de conciliación de la vida personal, familiar y laboral en la Ley Orgánica para la Igualdad efectiva de mujeres y hombres». Revista del Ministerio de Trabajo y Asuntos Sociales 2 extra (2007): 69-119. 
Alonso Sanz, Amparo. «Conciliación de la vida estudiantil, familiar y laboral de una madre universitaria». Revista de Antropología Experimental 16 (2016): 223-236.

Alonso Sánchez, María José. «Las académicas. Profesorado universitario y género». Revista de Educación 328 (2002): 465-475.

Añón Roig, María José. « ¿Una legislación para transformar la realidad social? A propósito de la Ley para la Igualdad Efectiva de Mujeres y Hombres». Medidas de conciliación de la vida personal, laboral y familiar. Coord. María Belén Cardona Rubert. Albacete: Bomarzo, 2009, 11-38.

Ballarin Domingo, Pilar y M. Teresa Gallego Méndez e Isabel Martínez Benlloch. Libro Blanco de Los Estudios de las Mujeres en las Universidades españolas 197591. Madrid: Ministerio de Asuntos Sociales / Instituto de la Mujer, 1995.

Belking, Lisa. «The Opt-Out Revolution». New York Times Octubre, 26 (2003): $1-11$.

Carbonell Pérez, Amparo y Genoveva Ramos Santana. «La percepción de hombres y mujeres respecto a la conciliación vida laboral, personal y familiar: el caso de la Universidad de Valencia». I+G. Aportaciones a la Investigación sobre Mujeres y Género (2014): 1274-1296.

Carmona Cuenca, Encarna. «Lección 5. Igualdad de género y Derecho antidiscriminatorio. La Constitución Española de 1978». Diversidad de género e igualdad de derechos. Coord. Encarnación Carmona Cuenca. Valencia: Tirant lo Blanch, 2012, 67-79.

Carrasco Macías, María José. «Participación y poder de la mujer en las organizaciones educativas». XXI Revista de Educación, 6 (2004): 75-87.

Caruncho Luz, Varela, y Traba Díaz Amada. «Diagnóstico de la igualdad en la Universidad. Un caso práctico». Actas II Congreso Universitario Nacional Investigación y Género, 2010: 1139-1163.

Desdentado Daroca, Eva. «Lección 7. La Ley Orgánica 3/2007, de 22 de marzo, para la igualdad efectiva de mujeres y hombres (I)» Diversidad de género e igualdad de derechos. Coord. Encarnación Carmona Cuenca. Valencia: Tirant lo Blanch, 2012, 89-102.

Díaz Rosas, Francisco y Mercedes Cuevas López. «Género y liderazgo en la universidad española». Archivos Analíticos de Políticas Educativas 23(106) (2015): $1-26$.

Donoso, Trinidad, Pilar Figuera y María Luisa Rodríguez Moreno. «Barreras de género en el desarrollo profesional de la mujer universitaria». Revista de educación 355 (2011): 187-212.

Durán Febrer, María. «La constitucionalización de los derechos de género». Género, Constitución y Estatutos de Autonomía. Coords. Teresa Freixes Sanjuán, y Julia Sevilla Merino. Madrid: Instituto Nacional de Administración Pública, 2005.

Feminismo/s 29, junio 2017, pp. 17-43 
Elizondo Lopetegui, Arantxa. «La presencia de mujeres y hombres en las universidades españolas». Aequalitas: Revista jurídica de igualdad de oportunidades entre mujeres y hombres 21 (2007): 25-34.

Escudero Rodríguez, Ricardo. «Lección 9. Las políticas de igualdad de género en el ámbito laboral». Diversidad de género e igualdad de derechos. Coord. Encarnación Carmona Cuenca. Valencia: Tirant lo Blanch, 2012, 113-130.

Esquembre Valdés, Mar. «Género y Ciudadanía, Mujeres y Constitución». Feminismo/s 8 (2006): 35-51.

Fernández López, María Fernanda. «Conciliación de la vida laboral y familiar: una visión constitucional». Medidas de conciliación de la vida personal, laboral y familiar. Coord. María Belén Cardona Rubert. Albacete: Bomarzo (2009): 239-254.

Figueruelo Burrieza, Ángela. «Políticas públicas previstas para la igualdad real y efectiva». Igualdad ¿para qué? A propósito de la Ley Orgánica para la igualdad efectiva de mujeres y hombres. Eds. Ángela Figueruelo Burrieza, y M. ${ }^{a}$ Luisa Ibáñez Martínez, y Rosa M. ${ }^{a}$ Merino Hernández. Granada: Comares, 2007, 193-208.

Freixes Sanjuán, Teresa. «La igualdad de mujeres y hombres en el Derecho de la

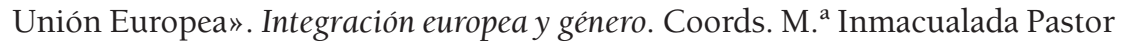
Gosálbez, y Laura Román Martín, y Ana Giménez Costa. Madrid: Tecnos, 2014, 15-66.

García Lastra, Marta. «La voz de las mujeres en la Universidad». RASE 3.3 (2010): 357-368.

Gómez Cama, M. ${ }^{\text {a }}$ del Carmen. Presencia, evolución y participación de las mujeres en la Universidad: la Universidad de Cadiz. Tesis Doctoral (inédita), 2015.

Guillamón Ramos, Cristina. «Los condicionantes de la carrera investigadora en la Universidad que encuentran las mujeres». La Universidad vista desde una perspectiva de género. Coord. Marina Tomás Folch. Barcelona: Octaedro, 2011, 77-112.

Heward, Christine. «Women and carrers in higher education. What is the problem?». Breaking Boundaries: Women in Higher Education. Eds. Louis Morley y Val Walsh. Bristol: Taylor \& Francis, 1996, 11-24.

Ion, Georgeta, María del Mar Durán-Bellonch y María Dolores Bernabeu Tamayo. «El profesorado y su percepción sobre la igualdad de género en la Universidad». Revista Complutense de Educación 24.1 (2013): 123-140.

Jennings, Ann L. «¿Público o privado? Economía institucional y feminismo». Más allá del hombre económico. Eds. Marianne A. Ferbder, y Julie A. Nelson. Madrid: Cátedra, 2004.

Jiménez Rodrigo, María Luisa y Esther Márquez Lepe. «Ir a la Universidad después de los 30: dificultades y factores facilitadores». Aula Abierta 42 (2014): 1-8. 
Kaufmann Hahn, Alicia E. «Lección 2. Psicosociología de género: los orígenes de la desigualdad familiar». Diversidad de género e igualdad de derechos. Coord. Encarnación Carmona Cuenca. Valencia: Tirant lo Blanch, 2012, 29-40.

Leathwood, Carole y Barbara Read. Gender and the changing face of higher education: a feminized future. Buckingham: Open University Press, 2008.

Lecuona Naranjo, M. ${ }^{a}$ del Pino. «Género y Universidad». Enseñanza 23 (2005): 143-160.

León Llorente, Consuelo. «Estrés laboral femenino y políticas de igualdad y flexibilidad en España». Feminismo/s 27 (2016): 243-261.

López Chocero, Sandra y Amelia Sanchís Vidal. «Mujeres en la Universidad». Actas del IV Congreso Universitario Nacional Investigación y Género. Sevilla: Universidad de Sevilla, 2012, 963-988.

López de la Cruz, Laura. «La presencia de la mujer en la Universidad española». Revista Historia de la Educación Latinoamericana 4 (2002): 291-299.

López-Francés, Inmaculada y Victoria Vázquez Verdera. «La perspectiva de género y el papel de la Universidad en el siglo XXI». TESI 15(4) (2014): 241-261.

Lousada Arochena, José Fernando. Permiso de paternidad y conciliación masculina. Albacete: Bomarzo, 2008.

Lunn, Michelle. «Women Academicians: Gender and Career Progression». Journal Pendidikan 32 (2007): 77-90.

Macinnes, John. «Diez mitos sobre la conciliación de la vida laboral y familiar». Cuadernos de Relaciones Laborales 23.1. (2005): 35-71.

Martín Bardera, Sara. Concepto de género: de las teorías feministas a las políticas públicas La universidad pública española como estudio de caso. Tesis doctoral (inédita), 2014.

Martín López, M. ${ }^{a}$ del Milagro y M. ${ }^{a}$ del Carmen Díaz Fernández. «El rol de la mujer en la Universidad: un estudio de género». Actas II Congreso Universitario Nacional «Investigación y Género», 2010, 631-647.

Martínez Sampere, Eva. «Hacia la plena ciudadanía». Género, Constitución y Estatutos de Autonomía. Coords. Teresa Freixes Sanjuán, y Julia Sevilla Merino. Madrid: Instituto Nacional de Administración Pública, 2005.

Martínez Costa, Carme, Amaia Lusa García, María Dolores Calvet Puig, Isabel Gallego Fernández, Olga Pons Peregort y Marta Tura Solvas, Guía para el diseño y la implantación de un Plan de Igualdad en las universidades. Valencia: Institut Català de les dones, 2006.

Méda, Dominique. El tiempo de las mujeres: conciliación entre vida familiar y profesional de hombres y mujeres. Madrid: Narcea, 2002.

Mentado Labao, Trinidad, Alejandrá Montané y $\mathrm{M}^{\mathrm{a}}$ Carmen Olivé Ferrer. «Espacio de género. Una política en las Universidades españolas a favor de la igualdad». Actas IV Congreso Universitario Nacional «Investigación y Género», 2012.

Merton, Robert K. «The self-fulfilling prophecy». Antioch Review 8 (1948): 193-210. 
Moreno Fernández, Louis. «Bienestar meditarráneo y «supermujeres»». Revista Española de Sociología 2 (2002): 41-56.

Orive Álvarez, M. ${ }^{a}$ José, Rosario Asián Chaves y Myriam González Limón. «Percepción de las medidas de conciliación en el personal PAS y PDI de la Universidad de Sevilla: una aproximación a su alcance». I+G. Aportaciones a la Investigación sobre Mujeres y Género (2014): 520-543.

Ortiz Ceberio, Cristina. «La (imposible) conciliación de la vida familiar y la laboral en la Universidad Norteamericana: problemas de fondo». Cuestiones de género 1 (2006): 73-86.

Presser, Harriet B. «Employment in a 24/7 economy: Challenges for the family». Fighting for time: Shifting Boundaries of Work and Social Life. Eds. C.F. Epstein y A. Kalleberg. Nueva York: Russell sage Foundation, 2004, 46-76.

Reche Tello, Nuria. La dimensión constitucional del derecho a la conciliación de la vida personal y laboral. Tesis Doctoral (inédita), 2016.

Rees, Teresa. Mainstreaming Equality in the European Union: Education, Training and Labor Market Policies. New York: Routledge, 1998.

Rosende, Magdalena. «Perspectiva comparada: medidas de conciliación de la universidad de Lausanne para el personal académico y el personal de la administración y servicios». RIDEG 01/11 (2011): 31-44.

Ruíz de la Cuesta Fernández, Sol e Irene Bajo García. «Conciliación de la vida familiar y laboral». Feminismo/s 8 (2006): 131-142.

Ruíz-Rico Ruíz, Catalina. «La problemática constitucional del derecho a conciliar la vida laboral, familiar y personal». RGDC 14 (2012): 1-19.

Sánchez García, Marifé, Magdalena Suárez Ortega, Nuria Manzano Soto, Laura Oliveros Martín-Varés, Sara Lozano Santiago, Belén Fernández D’Andrea y Beatriz Malik Liévano. «Estereotipos de género y valores sobre el trabajo entre los estudiantes españoles». Revista de Educación, 355 (2011): 331-354.

Sarrió Catalá, Maite. «Coeducación, empoderamiento y gestión de la diversidad para la conciliación de la vida privada y laboral». Medidas de conciliación de la vida personal, laboral y familiar. Coord. María Belén Cardona Rubert. Albacete: Bomarzo, 2009, 39-61.

Tobío, Constanza. Madres que trabajan: Dilemas y estrategias. Madrid: Ediciones Cátedra, 2005.

Tomás Folch, Marina y Cristina Guillamón Ramos. «Las barreras y los obstáculos en el acceso de las profesoras universitarias a los cargos de gestión académica». Revista de Educación 350 (2009): 253-275.

Tomás Morales, María Susana de. «La labor del Consejo de Europa en materia de igualdad de género». Formación y objeto del Derecho antidiscriminatorio de género: perspectiva sistemática de la igualdad desde el Derecho público. Dir. Manuela Mora Ruíz. Barcelona: Atelier, 2010, 17-32. 
Vázquez Cupeiro, Susana. «El discurso de las mujeres líderes». La segunda brecha digital. Dir. Cecilia Castaño. Madrid: Cátedra Feminismos, 2008, 185-219.

Ventura Franch, Asunción. «La integración de los estudios de las mujeres, feministas y de género en la Universidad española». Igualdad ¿para qué? A propósito de la Ley Orgánica para la igualdad efectiva de mujeres y hombres. Eds. Ángela Figueruelo Burrieza, y M. ${ }^{a}$ Luisa Ibáñez Martínez, y Rosa M. ${ }^{a}$ Merino Hernández. Granada: Comares, 2007, 523-537.

Ventura Franch, Asunción. «Normativa sobre estudios de género y Universidad». Feminismo/s 12 (2008): 155-184.

Walton, Richard E. «Quality of work life». Sloan Management Review 15.1. (1973): 11-21.

Ysàs Molinero, Helena. «Planes de igualdad y conciliación en las universidades públicas catalanas». RIDEG 01/11 (2011): 45-48. 

Para enlazar con este artículo / To link to this article:

http://dx.doi.org/10.14198/fem.2017.29.02

Para citar este artículo / To cite this article:

Campoy Aranda, Tomás J., Manuela Balcázar Fines y Viviana Vega Duette. «Los estudiantes universitarios ante la violencia de género». En Marcos Jesús Iglesias Martínez e Inés Lozano Cabezas (coords.), La (in)visibilidad de las mujeres en la Educación Superior: retos y desafios en la Academia. Feminismo/s, 29 (junio 2017): 45-70, DOI: 10.14198/fem.2017.29.02

\title{
LOS ESTUDIANTES UNIVERSITARIOS ANTE LA VIOLENCIA DE GÉNERO
}

\section{THE UNIVERSITY'S STUDENTS AND GENDER VIOLENCE}

\author{
Tomás J. CAMPOY ARANDA \\ tjcampoy@gmail.com \\ orcid.org/0000-0002-1095-8955 \\ Manuela BALCÁZAR FINES \\ mbalcazar203@hotmail.com \\ orcid.org/0000-0001-6873-2871 \\ Viviana VegA DUeTte \\ v.vegaduette@gmail.com \\ orcid.org/0000-0003-3699-5217 \\ Universidad Nacional del Este (Paraguay)
}

\section{Resumen}

El objetivo de este estudio ha sido conocer las creencias sobre igualdad y violencia de género que tienen los estudiantes de la Universidad Nacional del Este (Paraguay), así como determinar las causas y factores de riesgo, con vistas a proponer intervenciones, desde la prevención, eficaces contra el problema, que conlleven a un cambio de la sociedad desde la educación. Realizado en el 2015, abordó como objeto las representaciones y las vivencias que tienen los universitarios sobre la violencia de género, a través de una encuesta aplicada a una muestra de 467 estudiantes de todas las carreras, seleccionados por muestreo aleatorio por conglomerados, de una población de 5678 estudiantes. Los resultados dan cuenta de la presencia de pautas arraigadas en la cultura que podrían hacer persistente la violencia y discriminación hacia la mujer, y de la necesidad de programas que promuevan pautas culturales diferentes que desarraiguen la discriminación y violencia de género.

Palabras clave: género, violencia, igualdad, estudiantes, Universidad.

Feminismo/s 29, junio 2017, pp. 45-70

Los contenidos de la revista se publican bajo una licencia de Creative Commons Reconocimiento 4.0 Internacional (CC BY 4.0) 


\begin{abstract}
The aim of the study has been to learn about the beliefs the student body of the National University of the East (Paraguay) has about equality and gender violence as well as to determine the causes and risk factors so as to propose effective interventions that will help prevent occurrence of the problem and that will bring about change in society through education. The study was carried out in 2015 and it focused on students' representations and experiences regarding gender violence, a survey was conducted among a sample of 467 students from all academic programmes at the university. The sample, from a total population of 5678 students, was put together through random sampling of conglomerates. The findings suggest that there are deep-rooted cultural norms that lead to a persistent violence and discrimination against women and that it is necessary to create programmes that will promote different cultural norms which will eradicate discrimination and gender violence.
\end{abstract}

Keywords: gender, violence, equality, student body, university. 


\section{INTRODUCCIÓN}

La larga historia de desigualdad de la mujer, los avances positivos en este campo, pero al mismo tiempo lenta inserción en la cultura y calidad de vida de la mujer en la sociedad actual, sigue planteando perspectivas de análisis de la violencia de género en los contextos y la necesidad de una intervención más efectiva.

En este sentido Guil Bozal, Solano Parés y Álvarez Girón, señalan que:

A las mujeres se les permite, desde hace tiempo, trabajar en ámbitos públicos y cobrar un sueldo por ello, pero a la hora de tomar decisiones y ocupar los cargos de mayor responsabilidad, salario y prestigio social, se sigue prefiriendo a los varones. Para denominar a este fenómeno, se acuñó en los años ochenta el término «techos de cristal» que define de manera clara la sutileza e invisibilidad del proceso, del que la mayoría de la población, incluso a veces las propias protagonistas, son ajenas. (16)

Desde hace algún tiempo, la presión por la excelencia en el mundo científico y empresarial, unida a la constatación de que son las mujeres quienes tienen hoy en día los mejores expedientes académicos, ha propiciado que desde distintos organismos, tanto públicos como privados, se comience a exigir políticas de igualdad que faciliten a las mujeres la plena incorporación profesional.

También la llegada de las mujeres al mundo del trabajo público ha traído consigo una nueva necesidad aún por atender, que mientras las mujeres permanecieron en el hogar no se detectó; cual es la imprescindible conciliación entre la vida laboral, familiar y personal de hombres y mujeres, pues la gran mayoría se ven obligadas a llevar una doble jornada laboral en casa y fuera de ella.

La asimetría entre los géneros, la desigualdad de oportunidades y de derechos entre estos y el poder de un género sobre otro, aún son incuestionables para muchas personas y entre ellas para muchos docentes de las escuelas o universidades. Las prácticas pedagógicas institucionales a veces, inconscientemente, consolidan relaciones asimétricas.

Cada institución de la sociedad civil y del Estado y sus formaciones culturales: lenguaje, mitos, ideologías, valores, tradiciones, creencias y normas, inciden, influencian, determinan y reproducen las desigualdades entre los 
géneros para mujeres y hombres, en el conjunto de la sociedad y en la cultura (López Safi y Cañete Ribeiro)

Aunque mucho se ha avanzado principalmente en materia formativa y de inserción de la problemática en el debate público, la sociedad actual se caracteriza todavía por una serie de exclusiones aceptadas como «normales» porque forman parte de una cultura arraigada y por tanto imperceptible. Aún no se ha traducido en términos de renta, de igualdad efectiva de derechos y reconocimiento social. En varios países del mundo, las mujeres siguen percibiendo retribuciones menores a igual trabajo que los hombres.

Algunas cifras, como las mencionadas por Ovelar ${ }^{1}$ alertan lo mucho que aún falta hacer en este sentido, pues:

- La ruptura de la servidumbre, aún no ha llevado, ni siquiera en los países más avanzados, al pleno disfrute de los derechos, a la libertad y la igualdad efectivas.

- Dos tercios de los 700 millones de analfabetos del mundo, son mujeres.

- El número de mujeres afectadas por la pobreza rural se ha duplicado en 20 años en el mundo.

- De 1300 millones de pobres extremos que hay en el mundo, el 70\% son mujeres.

- Cada vez más recae sobre la mujer el peso del mantenimiento del hogar, en los países en desarrollo, 1 de cada 3 son hogares encabezados por mujeres solas.

Los roles tradicionales de mujeres y hombres, es decir, de la reproducción de la relaciones desiguales de poder entre los géneros, muchas veces, en la cotidianeidad de las aulas, tanto entre estudiantes, como entre profesoras y profesores, como entre estas/os y aquellas/os y administrativas/os, etc., de manera muy natural. Se entiende aquí que relaciones de poder serían todas aquellas relaciones existentes entre los seres humanos (amorosas, laborales, comunitarias, económicas, pedagógicas, evaluativas, institucionales, investigativas, económicas, políticas, entre otras) en las que unas personas tratan de orientar, conducir e influir en la conducta del otro.

Pero el tema más preocupante, en este contexto, no es solo la discriminación o relación de desventaja, que muchas veces se perciben como normales, sino la violencia.

La violencia de género es una realidad que afecta a un número importante de mujeres. Una parte de ellas aparecen en las estadísticas de víctimas de

1. Blanca Ovelar, Senadora Nacional, ex Ministra de la Educación de Paraguay. Disertación realizada en el III Seminario Taller sobre equidad de género en las Instituciones de Educación Superior, 20 de agosto de 2014. 
violencia de género y otra parte sigue sufriendo cada día situaciones violentas y abusivas que les afectan en diferentes aspectos de sus vidas. Se observa que el tipo de relacionamiento: concubino/a, esposo/a, pareja es el tipo de relacionamiento más frecuente entre víctima y victimario de la violencia (Corte Suprema de Justicia-Secretaría de Género).

En Paraguay, es innegable que hay avances en materia de lucha por la igualdad de género y la no violencia contra la mujer y niños, prueba de ello es la promulgación e implementación de la Ley 1600/2000, contra la Violencia Doméstica, la apertura del Ministerio de la Mujer, y la recientemente aprobada (noviembre del 2016) ley de Protección Integral a las Mujeres contra toda forma de Violencia, entre otros, además de los grandes esfuerzos que desde los diferentes movimientos y grupos de mujeres e instituciones se vienen realizando para luchar por el empoderamiento de la mujer y aminorar el problema de la discriminación y la violencia. Se cuenta con instancias encargadas de atención y prevención, hay un trabajo interinstitucional al respecto, pero los índices de hechos de violencia contra la mujer se mantienen altos y muchas veces con ampliada gravedad.

La violencia intrafamiliar sigue alta y quien más sufre el flagelo es la mujer. El mismo informe del Observatorio de Género de la de la Corte Suprema de Justicia de Paraguay señala que en el año 2014 se registraron 6065 casos de denuncias sobre violencia doméstica y en el año 2015 fueron 6984 casos. Se observa un aumento del 13\%. El número de denuncias de violencia de mujeres sigue siendo 7 veces mayor que el de hombres.

De hecho, la violencia contra las mujeres no puede analizarse ni enfrentarse de manera aislada sino vinculada a los factores de desigualdad económica, social y sobre todo cultural que operan en las relaciones de poder entre hombres y mujeres, como señala CEPAL (ver Informe anual del Observatorio de Igualdad de Género de América Latina y el Caribe).

Además, señala $\mathrm{Casco}^{2}$, la violencia contra las mujeres no es un problema de las mujeres solamente, es de toda la sociedad. Si solo nos concentramos en aumentar la pena y no trabajamos la educación nada va cambiar. Es importante contar con una Ley de Protección a las Mujeres, pero también es hora de instalar el debate en la sociedad y trabajar desde la educación.

2. Rocío Casco, Presidenta de la Comisión de Equidad Social y Género, de la Cámara de Diputados, durante el lanzamiento de la campaña «Por ellas», en setiembre del 2014. 


\section{IGUALDAD Y VIOLENCIA DE GÉNERO}

La violencia de género es un fenómeno que afecta a todas las mujeres de todos los países del mundo, independientemente de la clase social, cultura o edad, y que no se supera con una mayor formación académica (Straus 809). Ya en el año 2004, las Naciones Unidas indicaban que se daba en una de cada tres mujeres en el mundo. En Paraguay, estudios recientes, señalan que una de cada cinco personas sufrió violencia física y el $63 \%$ de ellas no sobrepasa los nueve años de edad.

La Declaración sobre la eliminación de la violencia contra la mujer de las Naciones Unidades, en el artículo I, define que:

Violencia contra la mujer se entiende todo acto de violencia basado en la pertenencia al sexo femenino que tenga o pueda tener como resultado un daño o sufrimiento físico, sexual o sicológico para la mujer, así como las amenazas de tales actos, la coacción o la privación arbitraria de la libertad, tanto si se producen en la vida pública como en la vida privada.

En la misma declaración de la Asamblea General en relación a la violencia de género, en su artículo 2, considera que abarca los siguientes actos:

a) La violencia física, sexual y psicológica que se produzca en la familia, incluidos los malos tratos, el abuso sexual de las niñas en el hogar, la violencia relacionada con la dote, la violación por el marido, la mutilación genital femenina y otras prácticas tradicionales nocivas para la mujer, los actos de violencia perpetrados por otros miembros de la familia y la violencia relacionada con la explotación.

b) La violencia física, sexual y psicológica perpetrada dentro de la comunidad en general, inclusive la violación, el abuso sexual, el acoso y la intimidación sexuales en el trabajo, en instituciones educacionales y en otros lugares, la trata de mujeres y la prostitución forzada.

c) La violencia física, sexual y psicológica perpetrada o tolerada por el Estado, donde quiera que ocurra.

En la actualidad, hay que reconocer los avances que se han producido en los últimos años respecto a la igualdad de oportunidades entre hombres y mujeres, tales como regulación legal, medidas de sensibilización, atención jurídica a las víctimas, investigaciones, etc. No obstante, aún queda mucho camino que recorrer, ya que «la violencia de género ha adquirido proporciones epidémicas» ${ }^{3}$.

La violencia contra las mujeres es una manifestación de las relaciones de poder históricamente desiguales entre mujeres y hombres, que han conducido

3. Margaret Chan, directora general de la OMS, con relación al Informe «Estimaciones mundiales y regionales de la violencia contra la mujer: prevalencia y efectos de la violencia conyugal y de la violencia sexual no conyugal en la salud» de 2013. 
a la dominación masculina, a la discriminación contra las mujeres por parte de los hombres y a impedir su pleno desarrollo. La violencia contra las mujeres tiene su origen en pautas culturales que perpetúan la condición inferior que se asigna a las mujeres en la familia, en el lugar de trabajo, en la comunidad y en la sociedad (Conferencia Mundial de Bejing).

\subsection{La situación de la violencia de género en el contexto internacional}

Según datos de Naciones Unidas, si bien es cierto que el porcentaje de mujeres en los parlamentos se ha casi duplicado en los últimos 20 años, frente a una única mujer que aparecía en dicha lista en 1998; la protección jurídica contra la violencia de género ha aumentado considerablemente, como también otras legislaciones que garantizan la igualdad entre hombres y mujeres; casi todas las regiones en desarrollo han logrado la paridad de género en educación primaria. Sin embargo el progreso ha sido inaceptablemente lento, con estancamientos e, incluso retrocesos, en algunos contextos. Todavía mueren 800 mujeres al día al dar a luz por causas que podrían evitarse. Las mujeres dedican 16 millones de horas al día a buscar agua en países de África Subsahariana (frente a los 6 millones de horas que dedican los hombres). Las mujeres ganan entre un 10 y un 30\% menos que los hombres por realizar el mismo trabajo. Asimismo siguen representando el $60 \%$ de las personas analfabetas a escala mundial. Una de cada tres mujeres sigue sufriendo violencia física o sexual en algún momento de su vida; y, entre 1992 y 2011, solo el 9\% de los negociadores en las mesas de negociación de la paz eran mujeres.

En la Unión Europea (EU), entre las medidas que se vienen aplicando para combatir la violencia contra las mujeres se incluyen la «Directiva sobre la víctimas de delitos» (2012/29/EU) y el «Convenio del Consejo de Europa» (también conocido como Convenio de Estambul) para prevenir y combatir la violencia contra la mujer y la violencia doméstica.

La Agencia de Derechos Fundamentales (FRA) de la EU ha hecho público en 2014, los resultados de una encuesta sobre violencia de género cuyos resultados reflejan que la escalada de violencia contra las mujeres en la UE es grande y que no puede ignorarse. La enormidad del problema prueba que la violencia contra las mujeres no afecta solo a unas pocas.

En 2015, a 20 años de la Conferencia de Beijing, el informe de la ONU de 31 de diciembre de 2015 sobre el empoderamiento de las mujeres y su vínculo con el desarrollo sostenible reconoce que los Estados y otros agentes hoy otorgan gran importancia a la igualdad de género y el empoderamiento de las mujeres, pero que esto no se ve reflejado en la aplicación concreta de políticas ni en la práctica. En casi todos los sectores y regiones persiste la brecha entre 
los géneros y la discriminación contra las mujeres y las niñas. A pesar de los avances educativos que se han dado en la juventud todavía existe una fuerte resistencia al cambio, que es necesario detectar para poder realizar intervenciones que contribuyan a su superación.

El 1 de enero de 2016 entró en vigor la agenda 2030 para el Desarrollo Sostenible que viene a sustituir a la agenda del Milenio y los ODM. La nueva agenda mundial, marcará la senda para construir un mundo más justo y equitativo; entre los que se reconoce la igualdad de género y el empoderamiento de las mujeres, en un objetivo específico y a nivel transversal con metas concretas.

Estudios que se viene realizando sobre la violencia de género dan cuenta sobre la todavía grave situación en este campo, específicamente, en el ámbito universitario. La investigación realizada por Larena y Molina (215), sobre «Violencia de género en las universidades españolas» financiada por el Ministerio de Igualdad/Instituto de la Mujer (Plan Nacional I+D+I, 2004-2007), puso de relieve que la violencia de género, además de ser independiente de la edad, clase social, cultura y nivel académico, también existe en los contexto universitarios.

Asimismo, el «Estudio sobre la juventud universitaria ante la igualdad y la violencia de género» (Universidad Complutense de Madrid) destaca que el sexismo y la violencia de género no son fatalidades biológicas, sino productos culturales, en los que se reproduce un modelo social ancestral por medio de mecanismos que están muy arraigados.

Hay que señalar que se están implementando medidas de prevención e intervención en las universidades europeas, aunque es necesario ampliar actuaciones, pues se trata de que las universidades constituyan un espacio libre de violencia y en avanzar en la construcción de sociedades más igualitarias.

En cuanto a igualdad y violencia de género en el contexto latinoamericano y Caribe, la preocupación de los Estados de la región por erradicar la violencia contra las mujeres ha conducido al logro de diversos e importantes avances en los últimos 20 años. La Comisión Económica para América Latina y el Caribe (CEPAL), con los organismos y las instituciones que conforman el Observatorio: la Organización Panamericana de la Salud (OPS), la Entidad de las Naciones Unidas para la Igualdad de Género y el Empoderamiento de las Mujeres (ONU-Mujeres), el Fondo de Población de las Naciones Unidas (UNFPA), la Secretaría General Iberoamericana (SEGIB) y la Agencia Española de Cooperación Internacional para el Desarrollo (AECID), presentan anualmente un informe de la situación.

Desde el observatorio, se reconocen avances importantes, concentrados en el ámbito del reconocimiento de derechos, las reformas legales y la 
implementación de políticas promisorias; pero la violencia familiar o doméstica y las distintas formas de violencia contra las mujeres, han mostrado la persistencia.

Datos del informe anual de la CEPAL dan cuenta que en el 2013, 88 mujeres fueron asesinadas por sus parejas o ex parejas íntimas en Colombia; 83 en Perú; 71 en República Dominicana; 46 en El Salvador; 40 en Chile; 25 en Uruguay; 20 en Paraguay y 17 en Guatemala. Encuestas muestran que 63 de cada 100 mujeres en México y 60 de cada 100 mujeres en Ecuador han padecido algún incidente de violencia, ya sea por parte de su pareja u otra persona. Esta violencia ocurre con mayor frecuencia entre quienes tienen o han tenido pareja (casadas, unidas, separadas, divorciadas o viudas): 48,7\% en Ecuador, 47\% en México y 45,4\% en Uruguay.

Pese al avance normativo, la Comisión Económica para América Latina y el Caribe (CEPAL) advierte sobre la falta de políticas públicas e instituciones capaces de asegurar su efectiva aplicación en los países. En este sentido, recomienda mejorar la producción de información sobre la violencia de género; llevar a cabo, cuando sea necesario, procesos de reforma legislativa con debates participativos; lograr una coordinación institucional fuerte, de alta jerarquía y gran capacidad técnica; e instaurar un sistema verdaderamente integral de atención, capaz de articular las políticas sociales con las respuestas judiciales.

Asimismo para su prevención y erradicación no bastan únicamente cambios legislativos y presupuestarios, pues hace falta un enfoque integral del problema. Son necesarias medidas de protección a corto plazo acompañadas de un trabajo sostenido para una transformación cultural y un cambio de conciencia en todos los ámbitos.

Entre las sugerencias emanadas de la consulta, se recomienda a América Latina abordar las causas estructurales de la desigualdad y la discriminación de género; línea en la que se enmarca esta investigación, considerando que la persistencia de la desigualdad real, se debe a muchos factores, pero en especial a factores culturales.

Es en este contexto donde la educación en general y, en especial, la Educación Superior, debe establecer estrategias integras y de fuerza suficiente para apuntar al cambio cultural en este sentido. Pero muchas veces, en el seno de la universidad latinoamericana, se repite la misma socialización en relaciones de género que hay fuera de sus paredes y hasta se conserva aún una fuerte estructura jerárquica que favorece relaciones desiguales. 


\subsection{La igualdad y violencia de género en Paraguay}

En cuanto a la violencia de género Bott, Guedes, Goodwin y Mendoza (6) señalan que la violencia física y sexual contra las mujeres es un problema aún muy extendido en América Latina; Paraguay, está entre los 10 países de la región con más violencia de género. Más del 20 por ciento de las paraguayas ha sufrido alguna vez violencia doméstica, según un estudio realizado a 180 mil mujeres en 12 países de la región. Pero como advierte Guedes ${ }^{4}$, los datos podrían ser incluso mayores ya que en ocasiones el miedo a represalias en el hogar o a que la información pueda filtrarse lleva a las mujeres a no denunciarlo. Entre las mujeres que indicaron haber sufrido algún tipo de violencia, entre el 28 y el 64 por ciento dijeron que nunca había buscado ayuda, ni había contado su situación a nadie por vergüenza, por miedo a represalias o no saber dónde ir. El estudio destaca que es posible prevenir la violencia contra la mujer. Sin embargo, todos los entornos informaron de violencia contra la mujer y que la prevalencia variaba según el entorno, lo cual indica que los altos niveles de violencia no son una característica inevitable de la sociedad.

Los datos también revelan que la raíz de la violencia de las mujeres está en los papeles desiguales de género, en sociedades que promueven la sumisión de la mujer y la dominación por parte del hombre, por lo que cualquier acción, según los expertos, requiere promover la igualdad de género y el fomentar el papel de la mujer.

Diferentes estudios (CEPEC, 2012; Bott, Guedes, Goodwin y Mendoza; CEDAW, 2011), recomiendan en este sentido:

- Trabajar con miras a transformar instituciones utilizando una perspectiva de género; en particular integrar la atención a la violencia contra la mujer.

- Promover el empoderamiento social y económico de mujeres, niñas y niños.

- Involucrar a hombres y niños varones para promover la no violencia y la equidad de género.

- Concienciar a actores clave del ámbito de la niñez y adolescencia para realizar acciones de prevención, identificación, seguimiento y denuncia de casos de abuso sexual en la niñez a través de medidas tales como

4. Asesora regional de violencia interfamiliar para la Organización Panamericana de la Salud (OPS) y coautora del estudio sobre Violencia contra la mujer en América Latina y el Caribe, en entrevista con Efe, durante la presentación del libro en 2014. 
capacitaciones, campañas y difusión de información con enfoque de derechos y género.

- Impulsar la visualización de la violencia contra las mujeres y de género como problemas sociales con consecuencias individuales colectivas, médicas, legales y de derechos humanos.

- Buscar generar cambios en la visión sobre las relaciones de género orientadas a la equidad, la igualdad y la no violencia a través del sistema de educación formal como campañas que enfoquen los derechos humanos

- Intensificar esfuerzos por aumentar la concienciación entre los funcionarios públicos, especialmente las fuerzas del orden, los funcionarios judiciales, los proveedores de salud y los trabajadores sociales, y refuerce la concienciación de que esa es una violencia social y moralmente inaceptable, una violación de sus derechos humanos.

La violencia de género, la violencia doméstica y la violencia contra la mujer por parte de su pareja, a pesar de todas las normativas y acuerdos aprobados, sigue en aumento en el Paraguay.

Estudios recientes, como la Primera Encuesta sobre Violencia Intrafamiliar basada en Género-Área Urbana (Ministerio de la Mujer 103-108), señala en su informe final que encontró, entre otros:

- $\quad 80,5 \%$ de las mujeres sufrieron violencia psicológica intrafamiliar más de una vez, y el 88,9\% sufrieron violencia física intrafamiliar «más de una vez».

- 6 de cada 10 personas que sufrieron violencia viven en pareja.

- De las personas que sufrieron violencia física, según la persona que le agredió, prevalece la pareja como el esposo/a o compañero/a permanente (que suma el 53\% de los casos), le sigue en tercer lugar el/la ex esposo/a con el 11,9\%.

- De las personas que sufrieron violencia psicológica según la persona que le agredió nuevamente se visualiza al esposo/a o compañero/a permanente en $53,6 \%$, levemente superior a lo registrado en la violencia física.

- 1 de cada 5 mujeres afirmó que estaba embaraza cuando sufrió violencia física o psicológica.

- 7 de cada 10 personas que sufrieron violencia física no denunciaron, y 9 de cada 10 personas que sufrieron violencia psicológica tampoco lo hicieron. 
A más de estudios, como el citado precedentemente, y los índices demarcados por el Observatorio de la Corte Suprema de Justicia sobre casos denunciados en juzgados de Paz del país, que reflejan aumento de las denuncias de hechos de violencia doméstica e intrafamiliar; unos pocos titulares de periódicos nacionales, de los últimos años, muestran que la violencia de género tal vez se acrecienta.

Informaciones recogidas de la presa paraguaya señalan que hubo casi 90 mujeres asesinadas en cuatro años. De las 86 mujeres asesinadas entre 2011 y 2015 en Paraguay, en situaciones de violencia doméstica, 66 fueron ultimadas a manos de sus concubinos, esposos o ex concubinos (ABC Color: 29 de enero 2016). Entre 2010 y mediados de 2015, un total de 359 mujeres fueron asesinadas en diferentes circunstancias en Paraguay, un país con una cultura marcadamente machista. A su vez, el Ministerio de la Mujer atendió, sólo el año pasado, 1.877 casos de violencia (ABC Color: 28 de enero 2016). El 80\% de las consultas que se realizan en el servicio de Gineco-Obstetricia del Hospital de Clínicas, revela que las mujeres han sufrido algún tipo de violencia de género (ABC Color, 25 de noviembre 2014). Tan solo en el Ministerio de la Mujer se reportaron en 2013 un total de 2267 casos de violencia contra la mujer, cifra que revela crecimiento con respecto a años anteriores, según se expresa en estadísticas (HOY, 8 de Enero 2014).

Estas citas muestran que en Paraguay la violencia contra la mujer es aún una lacra cotidiana y que merece atención desde diferentes ámbitos y que el contexto descrito, brevemente, requiere atención de la justicia y la educación. Principalmente este último, pues según Bourdieu (Lamas 45) sostiene que el orden social masculino está tan profundamente arraigado que no requiere justificación, se impone a sí mismo y es tomado como natural gracias al acuerdo casi perfecto e inmediato que obtiene de las estructuras sociales y la división sexual del trabajo, y, por otra, de las estructuras cognitivas inscritas en los cuerpos y en las mentes.

Los conceptos de género estructuran la percepción y la organización concreta y simbólica de toda la vida social. La diferenciación a partir del género ubica a la mujer en una posición de desventaja, discriminándola en base a su rol reproductivo, que es tomado como fundamento para naturalizar y justificar su subordinación y opresión. Las diferentes funciones esperadas de los varones y las mujeres no son vistas como algo aprendido a través del proceso de socialización y la educación, sino como características naturales e innatas de cada sexo.

Respecto de la inserción femenina en el escenario de la Universidad, Casimiro-Soriguer (37-54) considera que las mujeres se incorporan 
abiertamente al campo laboral, lo que hace emerger el dilema de la igualdad en el mundo de lo público, pero que lo desplaza al mundo de lo privado.

Sin duda el planteamiento de la igualdad y la representación de hombres y mujeres en el espacio público presenta dificultades, fundamentalmente porque si partimos del principio de que las personas somos complejas en nuestra individualidad y diversas en las formas de socialización, es imposible imaginar un tratamiento exactamente igual.

En el escenario de la Academia este debate cobra un singular dinamismo, pues en un contexto centrado en ser equitativo e igualitario desde el discurso, algunas acciones evidencian desequilibrios entre los sexos, tales como la segregación de las carreras, la ausencia relativa de las mujeres en los órganos de toma de decisiones y sobre todo, la exclusión o tal vez autoexclusión, priorizando a su carrera, la atención de los requerimientos familiares, sociales y otros.

\section{MÉTODO}

El estudio de carácter descriptivo, enfoque cuantitativo, ex post-facto, tipo encuesta, se realizó en el contexto de la Universidad Nacional del Este (UNE, Paraguay), durante 2015.

\subsection{Participantes}

La población estuvo constituida por estudiantes de las 7 facultades y las 25 carreras, de la que se ha extraído una muestra representativa mediante muestreo probabilístico, estratificado, aleatorio proporcional.

Tabla 1. Participantes

\begin{tabular}{|l|l|}
\hline \multicolumn{2}{|c|}{ FICHA TÉCNICA } \\
\hline Población & 5678 \\
\hline Muestra invitada & 374 \\
\hline Muestra productora & 467 \\
\hline Diseño de muestreo & Muestreo aleatorio por conglomerados \\
\hline Nivel de confianza & $95 \%$ \\
\hline
\end{tabular}

El porcentaje de hombres ha sido de $43,5 \%$ y el de mujeres 56,5 (media 1,44 y una $\sigma$ de, 496 . La edad media ha sido de 22,97, rango de 40 años (edad mínima 17 y máxima 57). 
Tabla 2. Frecuencia de hombres y mujeres por carreras y cursos

\begin{tabular}{|c|c|c|c|c|c|}
\hline FACULTAD & CURSO & TOTAL & TOTAL & HOMBRES & MUJERES \\
\hline \multirow{2}{*}{$\begin{array}{l}\text { INGENIERÍA } \\
\text { AGRONÓMICA }\end{array}$} & Ing. Agrónoma & 16 & \multirow{2}{*}{25} & 7 & 9 \\
\hline & Ing. Ambiental & 9 & & 4 & 5 \\
\hline \multirow{3}{*}{$\begin{array}{l}\text { CIENCIAS } \\
\text { ECONÓMICAS }\end{array}$} & Administración & 24 & \multirow{3}{*}{127} & 12 & 12 \\
\hline & Contabilidad & 80 & & 27 & 53 \\
\hline & Economía & 23 & & 8 & 15 \\
\hline \multirow{7}{*}{ FILOSOFÍA } & CC. Educación & 5 & \multirow{7}{*}{84} & 2 & 3 \\
\hline & Psicología & 47 & & 14 & 33 \\
\hline & CC. Comunicación & 15 & & 7 & 8 \\
\hline & Letras & 2 & & 1 & 1 \\
\hline & Matemática & 11 & & 5 & 6 \\
\hline & Filosofía & 2 & & 1 & 1 \\
\hline & Historia & 2 & & 1 & 1 \\
\hline \multirow{4}{*}{ POLITÉCNICA } & $\begin{array}{l}\text { Análisis de } \\
\text { sistemas }\end{array}$ & 24 & \multirow{4}{*}{98} & 18 & 6 \\
\hline & Ingen. Eléctrica & 36 & & 29 & 7 \\
\hline & Lic. en turismo & 14 & & 1 & 13 \\
\hline & Ing. de sistemas & 24 & & 15 & 9 \\
\hline \multirow{3}{*}{$\begin{array}{l}\text { DERECHO } \\
\text { Y CIENCIAS } \\
\text { SOCIALES }\end{array}$} & Derecho & 68 & \multirow{3}{*}{85} & 31 & 37 \\
\hline & CC. Políticas & 5 & & 2 & 3 \\
\hline & Notariado & 12 & & 3 & 9 \\
\hline \multirow{2}{*}{$\begin{array}{l}\text { CIENCIAS DE } \\
\text { LA SALUD }\end{array}$} & Medicina & 27 & \multirow{2}{*}{39} & 8 & 19 \\
\hline & Enfermería & 12 & & 3 & 9 \\
\hline \multirow{4}{*}{$\begin{array}{l}\text { ESCUELA } \\
\text { SUPERIOR DE } \\
\text { BELLAS ARTES }\end{array}$} & Artes Visuales & 3 & \multirow{4}{*}{9} & 1 & 2 \\
\hline & Danza & 2 & & 1 & 1 \\
\hline & Música & 2 & & 1 & 1 \\
\hline & Teatro & 2 & & 1 & 1 \\
\hline & & & TOTAL & 203 & 264 \\
\hline
\end{tabular}

\subsection{Instrumento de recolección de datos}

Para la recogida de la información se ha elaborado la «Escala sobre Igualdad y Prevención de la Violencia de Género». Este instrumento en la redacción definitiva consta de 28 ítems a los que se ha sometido a un análisis factorial. El valor de KMO es ,842 y sig. ,000. El método de rotación ha sido varimax. 
El análisis de componentes principales nos indica que el porcentaje total de la varianza explicada es de 54,65 para 4 factores; el gráfico de sedimentación también nos sugiere un total de 4 dimensiones. El primer factor «Percepción de la mujer» consta de 8 ítems, el segundo factor «Relación de pareja» (dominio y sumisión) consta de 8 ítems, el tercer factor «Relación de pareja» (como reacción) consta de 8 ítems y el cuarto factor «Relaciones de convivencia» consta de 4 ítems. La fiabilidad del instrumento (consistencia interna alfa de Cronbach) es ,830.

Las variables generales (sexo, edad, carrera, curso, estado civil, tener hijos, trabajo remunerado, estudios padre, estudios madre, se han sometido a la prueba de bondad de ajuste, cuya Significalidad estadística se recoge en el siguente cuadro.

Tabla 3. Significalidad estadística

\begin{tabular}{|c|c|c|c|c|c|}
\hline \multirow{2}{*}{ Sexo } & Asimetría & Curtosis & Variable & Prueba binomial & $\mathrm{P}$ valor \\
\hline &, 257 & $-1,942$ & discreta & 7,627 & ,007 \\
\hline \multirow{2}{*}{ Edad } & Asimetría & Curtosis & Variable & K-S & $P$ valor \\
\hline & , 104 & $-1,405$ & discreta & 10,070 &, 000 \\
\hline \multirow{2}{*}{ Carrera } & Asimetría & Curtosis & Variable & Chi-cuadrado & $\mathrm{P}$ valor \\
\hline & ,104 & $-1,405$ & discreta & 539,479 &, 000 \\
\hline \multirow{2}{*}{ Curso } & Asimetría & Curtosis & Variable & Chi-cuadrado & $\mathrm{P}$ valor \\
\hline & 1,092 &, 845 & discreta & 666,488 & ,000 \\
\hline \multirow{2}{*}{ Estado civil } & Asimetría & Curtosis & Variable & Chi-cuadrado & P valor \\
\hline & 2,983 & 9,551 & discreta & 1315,024 &, 000 \\
\hline \multirow{2}{*}{ Hijos } & Asimetría & Curtosis & Variable & Prueba binomial & $\mathrm{p}$ valor \\
\hline & $-2,110$ & 2,465 & discreta & 244,234 &, 000 \\
\hline \multirow{2}{*}{ Trabajo } & Asimetría & Curtosis & Variable & Prueba binomial & $\mathrm{P}$ valor \\
\hline &,- 073 & $-2,003$ & discreta & ,619 & ,459 \\
\hline \multirow{2}{*}{$\begin{array}{l}\text { Estudios } \\
\text { Padre }\end{array}$} & Asimetría & Curtosis & Variable & Chi-cuadrado & $\mathrm{P}$ valor \\
\hline &, 004 & $-1,269$ & discreta & 16,484 &, 000 \\
\hline \multirow{2}{*}{$\begin{array}{l}\text { Estudios } \\
\text { Madre }\end{array}$} & Asimetría & Curtosis & Variable & Chi-cuadrado & $\mathrm{P}$ valor \\
\hline &,- 034 & $-1,323$ & discreta & 10,469 &, 000 \\
\hline
\end{tabular}

\subsection{Análisis de los datos}

Una vez realizada la prueba de bondad de ajuste se determinaron los estadísticos a aplicar para establecer las diferencias significativas. Para ello se ha 
aplicado la prueba de chi-cuadrado con la finalidad de observar si los datos siguen una distribución uniforme. La prueba de Kruskal-Wallis para determinar las medianas de los grupos que difieren cuando tienen datos que no son simétricos (estadística no paramétrica).

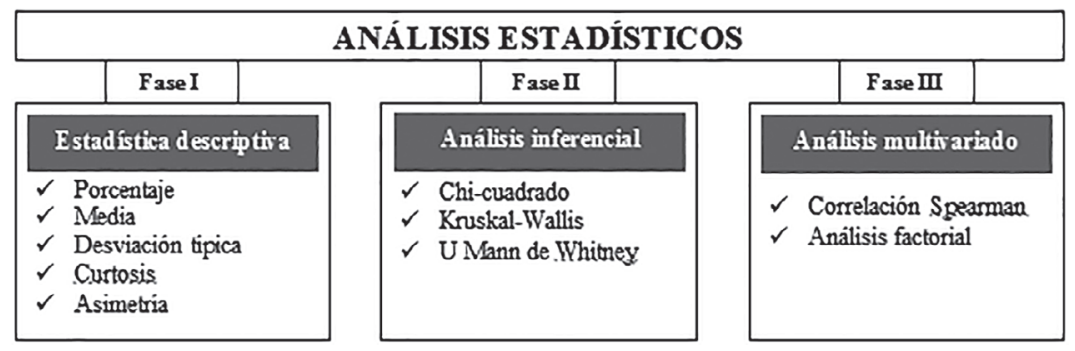

Figura 1. Funciones estadísticas utilizadas

\section{RESULTADOS}

\subsection{Percepción de la mujer}

Esta dimensión ha tenido por objetivo conocer creencias respecto a las mujeres y su rol en la sociedad y qué conductas de las mismas son consideradas «adecuadas» o no. Como resultados en esta dimensión, en base al análisis de los ítems que lo conforman, se ha obtenido:

\section{DIMENSIÓN I: PERCEPCIÓN DE LA MUJER}

V17. Las mujeres intentan ganar poder controlando a los hombres.

V18. En el fondo, las mujeres feministas pretenden que la mujer tenga más poder que el hombre.

V19. Las mujeres feministas están haciendo demandas completamente irracionales a los hombres.

V20. Con el pretexto de pedir «igualdad» las mujeres buscan privilegios especiales, tales como condiciones de trabajo que favorezcan a ellas sobre los hombres.

V21. Las mujeres interpretan comentarios o conductas inocentes como sexistas, es decir, como expresiones de prejuicio o discriminación contra ellas.

V22. Las mujeres exageran los problemas que tienen en el trabajo.

V23. Existen mujeres que, para burlarse de los hombres, primero se insinúan sexualmente a ellos y luego rechazan los avances de éstos.

V24. Las mujeres no aprecian lo que los hombres hacen por ellas.

Figura 2. Ítems de la Dimensión Percepción de la Mujer 


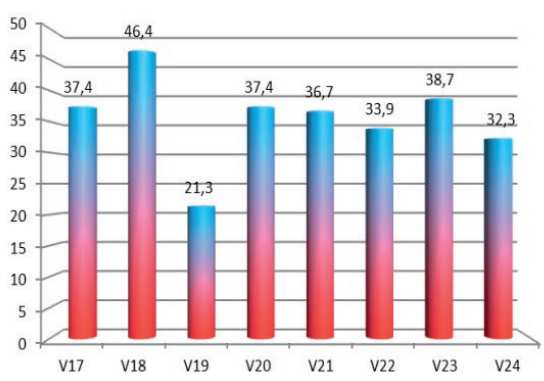

Figura 3. Percepción de la mujer paraguaya

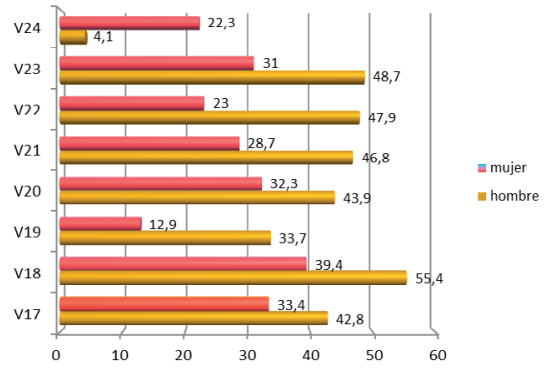

Figura 4. Percepción de la mujer pya (por sexo)

El 37,4\% de los estudiantes piensa que las mujeres intentan ganar poder controlando a los hombres. Hay diferencias significativas en función del sexo (chi-cuadrado, p-valor=, 050). Pero no hay diferencias significativas en función del nivel de estudios de los padres, lo que puede indicar hasta qué punto está todavía enraizada la visión tradicional que se tiene de la mujer en la sociedad paraguaya. Esta opinión está más presente en los estudiantes más jóvenes en las edades comprendidas entre 17 y 20 años (Kruskal-Wallis, sig.,009) y en los solteros (chi-cuadrado, p-valor $=, 004$ ).

El 46,4\% de los estudiantes considera que lo que pretenden las mujeres feministas es que la mujer tenga más poder. En función del sexo (chi-cuadrado, p-valor $=, 001)$, los hombres $(55,4 \%)$ están más de acuerdo que las mujeres $(39,4 \%)$. La edad también es una variable que establece diferencias (KruskalWallis, sig.,002), en especial, los estudiantes más jóvenes. También el estado civil es una variable a considerar, pues los solteros coinciden más (chi-cuadrado, p-valor=,037). El 30,2\% de los estudiantes cree que las feministas hacen demandas irracionales a los hombres. Hay un 39,9\% que no tiene clara su respuesta. Hay diferencias en función del sexo (chi-cuadrado, p-valor $=, 000$ ) y la edad (Kruskal-Wallis, sig. =007). El 33,7\% de los hombres así lo considera frente al $12,9 \%$ de las mujeres.

El $37,4 \%$ de los estudiantes piensa que las mujeres con el pretexto de pedir igualdad buscan privilegios. El $68,2 \%$ no tiene opinión. Hay diferencias significativas en función del sexo, el 43,9\% de los hombre así lo cree frente al $32,3 \%$ de las mujeres (chi-cuadrado, p-valor=,037). Por estado civil, los solteros $(38,7 \%)$ son los que más coinciden (chi-cuadrado, p-valor=,021). El $36,7 \%$ de los encuestados considera que las mujeres exageran los comentarios 
o conductas sexistas. Hay un $33 \%$ que no tiene respuesta clara. Hay diferencias significativas en función del sexo (chi-cuadrado, p-valor=,000 y el estado civil ,039). Uno de cada tres encuestados (33,9\%) piensa que las mujeres exageran los problemas que tienen en el trabajo. Hay un $29,7 \%$ de indecisos. Se dan diferencias significativas en función del sexo (chi-cuadrado, p-valor=,000); estudios del padre (p-valor=,011), estudios de la madre (p-valor=,010). El $38,7 \%$ de los estudiantes piensa que hay mujeres que se insinúan sexualmente a los hombres para luego rechazarlos. Hay diferencias significativas en función del sexo (chi-valor, p-valor=,000) y la edad (Kruskal-Wallis, sig. ,033). Los hombres creen que las mujeres se insinúan $(48,7 \%)$, pero llama la atención que el $31 \%$ de la mujeres también lo piensan.

\subsection{Relaciones de pareja (dominio y sumisión)}

Una de las manifestaciones del sexismo es la tendencia a legitimar las relaciones de dominio/sumisión entre hombre y mujer, de manera que se convierte en factor de riesgo. En las relaciones de pareja primero se llega al dominio y sumisión, y después al control. El control se puede ejercer sobre cualquier aspecto de la autonomía de la mujer a la que se busca subordinar. A continuación se recogen los ítems considerados en esta dimensión para analizar los resultados obtenidos:

\footnotetext{
DIMENSIÓN II: RELACIONES DE PAREJA (DOMINIO Y SUMISIÓN)

V25. Las personas no pueden ser felices en sus vidas a menos que tengan pareja.

V26. Por bien de tus hijos/as, aunque la mujer tenga que soportar la violencia de su pareja, conviene que no lo denuncie.

V27. Está justificado que un hombre agreda a su pareja cuando ella decide dejarle.

V28. Para tener una buena relación de pareja es deseable que la mujer evite contrariar al hombre.

V29. Cuando una mujer es agredida por su pareja algo habrá hecho para provocarle.

V30. La violencia que se produce dentro de la casa es un asunto de la familia y no debe salir de ahí.

V31. Si una mujer es maltratada por su pareja y no le abandona será porque no le disgusta del todo esta situación.

V32. Está bien que los hombres salgan con muchas mujeres, pero no al revés.
}

Figura 5. Ítems de la Dimensión de Relaciones de Pareja 


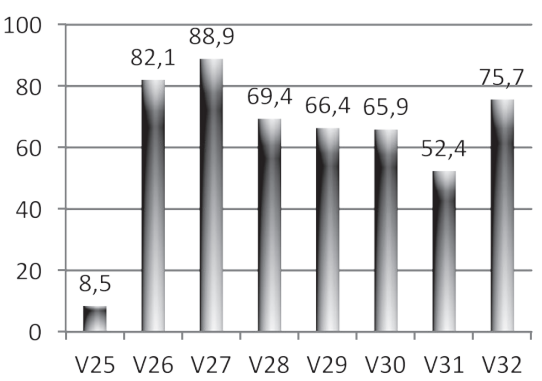

Figura 6. Relación de pareja

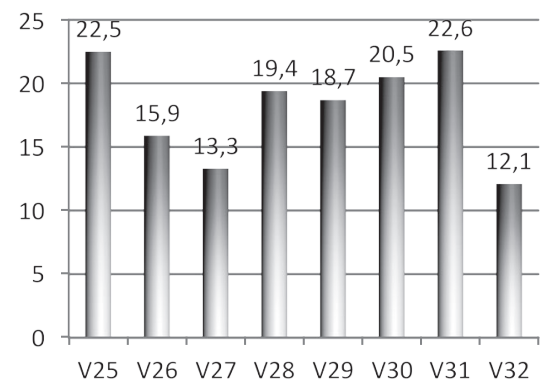

Figura 7. Relación de pareja (indecisos)

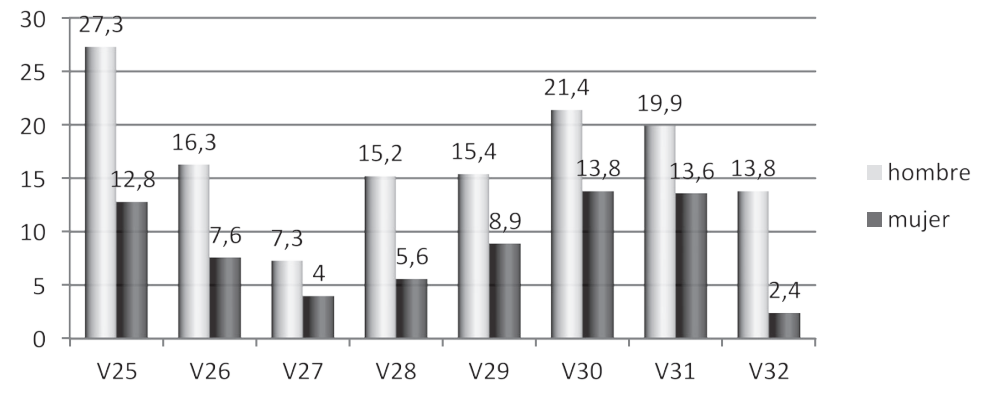

Figura 8. Diferencias en el grado de acuerdo por sexo

Algo más de la mitad de los estudiantes $(55,4 \%)$ no cree necesario tener pareja para ser felices. Hay un 22,5\% de indecisos. Hay diferencias significativas en función del sexo (chi-cuadrado, p-valor=,000). Son los hombres $(27,3 \%)$ los que más sienten la necesidad de tener pareja para ser felices que las mujeres $(12,8 \%)$. Uno de cada cinco encuestados $(11,4 \%)$ es partidario de que por el bien de los hijos la mujer tiene que soportar la violencia sin que haya denuncia; el $82,1 \%$ es partidario de presentar denuncia. Los hombres son más partidarios de que no se produzca ninguna denuncia (16,3\%) que las mujeres $(7,6 \%)$. El $5,6 \%$ estudiantes piensa que está justificado que el hombre agreda a su pareja cuando ella decide dejarlo. Los hombres están más de acuerdo $(7,3 \%)$ que las mujeres (4\%). El 11,8\% de los estudiantes justifica la violencia de género, es decir, piensa que cuando una mujer es agredida por su marido es porque algo habrá hecho. Hay diferencias en función de la edad (Kruskal-Wallis, sig.,025), pues los más jóvenes son los que más justifican esta actitud. Asimismo el porcentaje de hombres que no tiene una opinión clara es $29,1 \%$ y el de mujeres $16,2 \%$. Son madres con estudio universitarios las que más justifican esta actitud $\mathrm{y}$ los de nivel de estudio primario las que menos (chi-cuadrado, p-valor=,050). 
El 17,2\% de los estudiantes opina que la violencia que se produce dentro de la casa es un asunto de familia y que no se debe dar a conocer. Hay diferencias significativas en relación a la edad (Kruskal-Wallis, sig.,020). Los más partidarios de guardar silencio son los más jóvenes. El 16,7\% de los estudiantes piensa que si una mujer es maltratada por su compañero y no le abandona será porque no le disgusta del todo esta situación. Hay un alto porcentaje de indecisos $(31,4 \%)$. El porcentaje de hombres que justifica esa actitud de la mujer es 19,9 y el de las mujeres 13,6.

En relación a si está bien que los hombres salgan con muchas mujeres, pero no al revés, hay un 17,2\% que está de acuerdo. Hay diferencias en relación a los estudios de la madre (chi-cuadrado, p-valor=,002), pues son las mujeres con mayor nivel de estudios la que están más a favor.

\subsection{Relaciones de pareja (como reacción)}

Los estereotipos de género no sólo se mantienen sino que se agudizan en algunos casos. Aunque son las mujeres las que más han cambiado en casi todos los aspectos, los valores de libertad y autonomía personal se han impuesto y chocan con el estereotipo femenino tradicional que frena los avances en igualdad. Las cualidades masculinas más valoradas tienen que ver con el poder, la fuerza, la valentía o la firmeza; mientras que en las mujeres son la sensibilidad, la capacidad de perdón y la generosidad.

A continuación los Ítems que forman parte de esta dimensión:

\begin{tabular}{|l|}
\hline \multicolumn{1}{|c|}{ DIMENSIÓN III: RELACIÓN DE CONVIVENCIA (COMO REACCIÓN) } \\
\hline V33. Los hombres deben proveer seguridad económica a las mujeres. \\
V34. Un buen padre debe hacer saber a su familia quién es el que manda. \\
V35. El hombre que parece agresivo es más atractivo. \\
V36. Está justificado agredir a alguien que te ha quitado lo que era tuyo. \\
V37. Es correcto pegar a alguien que te ha ofendido. \\
V38. Para tener una buena relación de pareja conviene que el hombre sea un poco \\
$\quad$ superior a la mujer, en edad, en el dinero que gana, en la toma de decisiones. \\
V39. Hay que disculpar los celos porque son una expresión de amor. \\
V40. Si alguien te pega, pégale tú. \\
\hline
\end{tabular}

Figura 9. Ítems de la Dimensión de Relación de Convivencia

En opinión de los estudiantes, solo el 23,7\% de los encuestados no está de acuerdo con que los hombres deben proveer económicamente a las mujeres. El porcentaje de mujeres que está en descuerdo es 37,3 y el de hombres 52,9.

El $72,9 \%$ de los estudiantes considera que un buen padre debe dejar claro a su familia quien es el que manda. Hay diferencias significativas en función 
del sexo (chi-cuadrado, p-valor=,000) y de la edad (Kruskal-Wallis, sig. 001). Los hombres son más partidarios de hacer saber a su familia quién es el que manda $(18,5 \%)$ que la mujer $(7 \%)$.

El porcentaje de estudiantes que no está de acuerdo con que un hombre que muestra conductas agresivas resulta más atractivo es 5,0. Un 13,4\% de indecisos. Hay diferencias significativas en relación al sexo (chi-cuadrado, p-valor=,000), edad (Kruskal-Wallis, sig. 015) y estado civil (chi-cuadrado, p-valor=,036). El hombre está más de acuerdo $(6,8 \%)$ que la mujer $(3,6 \%)$. En los hombres el 22,5\% no tiene postura.

El 8,2\% de los estudiantes piensa que se justifica agredir a alguien que te ha quitado algo. El $17,1 \%$ de los encuestados no tiene postura. Hay diferencias significativas en función del sexo (chi-cuadrado, p-valor=,000), de la edad (Kruskal-Wallis, sig. 001) y el nivel de estudios del padre (chi-cuadrado, p-valor $=, 021)$. Los hombres $(11,2 \%)$ manifiestan una actitud más agresiva que las mujeres (5,8\%). Además hay diferencias en cuanto a la opción de indecisos (25,5\% los hombres y 10,4\% las mujeres). La agresividad se manifiesta más en los estudiantes más jóvenes, solteros y cuyos padres tienen hasta estudios secundarios.

El 7,4\% de los estudiantes considera que es correcto pegar a alguien que te ha ofendido. El porcentaje de indecisos es 16,9\%. Se establece diferencias en función del sexo (chi-cuadrado, p-valor=,000). El 13,8\% de los hombres está más de acuerdo con la conducta de agresión que las mujeres (2,4\%). El $12,8 \%$ de los estudiantes piensa que para tener una buena relación de pareja conviene que el hombre sea superior a la mujer. Hay diferencias en función del sexo (chi-cuadrado, p-valor=,002) y de la edad (Kruskal-Wallis, sig. 001). El porcentaje de mujeres que están «muy en desacuerdo» es 55,8\% y el de hombres es $38,5 \%$. Algo más de la mitad de los estudiantes rechaza que los celos son una expresión de amor motivo por el que hay que disculparlos $(55,6 \%)$. Además hay un 26,5\% que no tiene una postura clara. El porcentaje de mujeres que está de acuerdo $(12,5)$ es menor que el de hombres $(24,9)$ (chi-cuadrado, p-valor $=, 001)$.

El 18,2\% de los estudiantes opina que si recibe una agresión hay que devolverla. El 17,2\% no tiene opinión. Las mujeres están menos de acuerdo en devolver la agresión (12,1\%) que los hombres (25,8\%) (chi-cuadrado, p-valor $=, 034$ ).

Del amplio análisis de los resultados se deduce que:

- En general, entre un 25\% y un 30\% de los estudiantes no rechaza la violencia de género y reconoce el «poder» del hombre sobre la mujer. 
- Las mujeres rechazan más el poder y jerarquía del hombre.

- Hay un porcentaje alto de estudiantes que no tienen opinión formada sobre las cuestiones que se plantean (oscila entre el 13\% y el 31\%).

- Los estudiantes más jóvenes (entre 17 y 20 años) mantienen posturas más extremas y justifican más las conductas violentas.

- El 44,4\% de los estudiantes no rechaza los celos porque son una expresión de amor.

\subsection{Relaciones de convivencia}

Las relaciones interpersonales están presentes en todos los ámbitos en que nos manejemos, siendo un aspecto básico y esencial de nosotros. La convivencia constituye uno de los aspectos más importantes en las relaciones humanas. Como manifestación natural de estas relaciones pueden surgir desavenencias, desacuerdos, comunicación inadecuada, etc., que pueden dar lugar a conflictos interpersonales y derivar en conductas violentas.

Los ítems de este factor analizado son los que siguen:

\begin{tabular}{|l|}
\hline \multicolumn{1}{|c|}{ DIMENSIÓN IV: RELACIONES DE CONVIVENCIA } \\
\hline 41. Las mujeres deben ser queridas y protegidas por los hombres. \\
\hline $\begin{array}{l}\text { 42. Si alguien quiere pelearse contigo, trata de convencerle de que hay otra forma de } \\
\text { resolver los problemas. }\end{array}$ \\
\hline 43. Si alguien me insulta, lo ignoro. \\
\hline 44. Una buena relación de pareja debe establecerse de igual a igual. \\
\hline
\end{tabular}

Figura 10. Ítems de la Dimensión Relaciones de Convivencia

Los resultados de nuestro estudio indican:

El 83,0\% de los estudiantes está de acuerdo con que las mujeres deben ser queridas y protegidas por los hombres. Hay un 10,2\% de indecisos. Hay diferencias significativas en función de la edad (Kruskal-Wallis, sig.,003). Los estudiantes a partir del $3 .^{\circ}$ año son los que más coinciden con el ítem.

El 87,2\% de los estudiantes afirma que es mejor ignorar a alguien que te insulta. Hay un $17,1 \%$ que no tiene una postura clara. No hay diferencias significativas entre las variables de agrupación y los distintos ítems.

Cuatro de cada cinco estudiantes $(81,0 \%)$ piensa que si alguien quiere pelearse hay que hacer ver que hay otra forma de resolver los problemas 


\section{CONCLUSIONES}

El objetivo general del estudio ha sido conocer, a través de la opinión del alumnado universitario, las creencias del mismo, con relación a la igualdad y a la violencia de género, considerando qué percepción tiene de la mujer; cómo son las relaciones de pareja, en relación al dominio y sumisión; las relaciones de pareja, como reacción; y las relaciones de convivencia.

Con relación a la percepción sobre la mujer, se concluye que:

- «Sombrea» sobre los hombres un pensamiento machista.

- Persisten ideas tales como que las mujeres intentan controlar a los hombres, piden privilegios, y exageran sus problemas.

- Hay una creencia extendida de que a las mujeres les gusta insinuarse sexualmente a los hombres, para luego rechazarlos.

- Casi un tercio piensa que las mujeres están agradecidas por lo que los hombres hacen por ellas.

En cuanto al factor relaciones de pareja (dominio y sumisión):

- Los hombres sienten más necesidad de tener pareja que las mujeres.

- El 30,6\% considera que las mujeres deben dar la razón al hombre para una buena relación de pareja.

- Un tercio de los estudiantes no rechaza que el hombre agreda a la mujer.

- Un tercio de los estudiantes justifica la violencia doméstica y que hay que guardar silencio.

- Casi la mitad de los estudiantes $(48,1 \%)$ no rechaza la actitud de maltrato hacia la mujer.

- El 34,1\% de los estudiantes no ve mal que un hombre pueda salir con varias mujeres.

En la dimensión de relaciones de pareja, como reacción:

- Las mujeres rechazan más el poder y jerarquía del hombre.

- Un porcentaje significativo (hasta el 31\%) de los estudiantes no tienen una opinión formada sobre los temas que se plantean.

- Los estudiantes más jóvenes (17-20 años) justifican más las conductas violentas

- Cerca de la mitad de los estudiantes $(44,4 \%)$ no rechaza los celos porque son una expresión de amor. 
Con referencia al objetivo relacionado al tratamiento de igualdad y violencia de género:

- La igualdad y prevención de la violencia de género recibe escasa atención en la UNE. Se trata a lo sumo de alguna actividad puntual, pero no existe una visión amplia sobre estos temas que se concrete en acciones planificadas y coordinadas, orientadas a toda la comunidad educativa.

- Los estudiantes demandan charlas informativas sobre estos temas. Sólo un porcentaje reducido considera que se debe trabajar desde la formación.

Con relación a conocer las creencias sobre igualdad y violencia de género que tiene el alumnado de la Universidad Nacional del Este, se destaca que los resultados obtenidos muestran que hay una relación de poder del hombre sobre la mujer, el 30\% de los hombres reconoce el poder y la jerarquía de éste sobre la mujer, el 46,4\% de los hombres piensa que las mujeres buscan dominar al hombre. Hay porcentajes preocupantes donde se llega a justificar la violencia ejercida sobre la mujer, incluso siendo más acusado en los estudiantes más jóvenes. No rechazan que el hombre agreda a la mujer cuando ésta decida dejarlo y un 48,1\% no rechaza la violencia sobre la mujer.

Como causas y factores de riesgo resultan preocupantes los aspectos culturales con pautas arraigadas, por las que muchas de las formas de violencia contra la mujer son minimizadas o tomadas como normales, no generan reacción de los estudiantes. Al contrario, se manifiesta una especie de valoración del silencio - no denuncia - de la mujer como forma de evitar más violencia, o el de soportar la violencia por el bien de sus hijos. En general, hay una tendencia a mantener una postura pasiva, de no denuncia, de mal menor y conformismo.

El pensamiento machista persiste $(44,4 \%)$. Los estudiantes no rechazan totalmente los celos porque son una expresión de amor y tampoco ven mal que un hombre pueda salir con varias mujeres. Incluso los estudiantes más jóvenes justifican determinadas conductas machistas.

Como factor de riesgo, también se evidencia la escasa atención o la insuficiencia de las actividades realizadas en el contexto universitario para la generación de un cambio cultural, y tal vez en todo el sistema educativo nacional; pues si los mismos estudiantes universitarios muestran escasa conciencia con relación a la gravedad de la violencia contra la mujer, es un indicativo de que estos temas no se han abordado suficientemente en su proceso formativo.

Los resultados evidencian que son los estudiantes más jóvenes quienes justifican o están de acuerdo con determinadas conductas machistas, por lo que se considera de importancia para promover la igualdad y prevenir la violencia 
de género reforzar los programas de intervención desde la educación, en la etapa adolescente.

\section{REFERENCIAS BIBLIOGRÁFICAS}

Benítez, Aldo. «La violencia contra la mujer en números». ABC Color: Asunción, Paraguay. 28 de enero 2016.

Benítez, Aldo y Flavia Borja. «Hubo casi 90 mujeres asesinadas en cuatro años». ABC Color: Asunción, Paraguay. 29 de enero 2016.

Bott, Sara, Alessandra Guedes, Mary Goodwin y Jennifer Adams Mendoza. «Violencia contra la mujer en América Latina y el Caribe», 2013. <http://www.paho.org/ hq/index.php?option=com_docman\&task=doc_view\&gid=21425\&Itemid > consultado el 12-10-2014.

Bourdieu, Pierre. «La Lógica de los Campos». Revista Zona Erógena 16 (1993). <http://es.scribd.com/doc/127889702/bourdieu-pierre-la-logica-de-los-campos-entrevista>, consultado el 03-06-2014.

Casimiro-Soriguer, Milagrosa. «Las mujeres en la Ciencia». La ausencia de las mujeres en los contenidos escolares. (2004): 37-54. 12 de octubre de 2014.

CEPAL, FAO, ONU Mujeres, PNUD, OIT «Trabajo decente e igualdad de género. Políticas para mejorar el acceso y la calidad del empleo de las mujeres en América Latina y el Caribe», 2013. <http://www.ilo.org/wcmsp5/groups/public/ americas/--ro-lima/--sro-santiago/documents/publication/wcms_233161.pdf>, consultado el 12-10-2014.

Comisión Económica para América Latina y el Caribe (CEPAL). «Informe anual 2013-2014. El enfrentamiento de la violencia contra las mujeres en América Latina y el Caribe», 2014. <http://repositorio.cepal.org/bitstream/ handle/11362/37185/S1500499_es.pdf, consultado el 24-05-2014

Corte Suprema de Justicia - Observatorio de Género. «Violencia doméstica e Intrafamiliar 2014 y 2015, denunciados en Juzgados de Paz del país», 2015. <www.pj.gov.py/contenido/136-secretaria-de-genero/609>, consultado el 16-01-2016.

Diario $\mathrm{ABC}$ «Consultas revelan violencia». $A B C$ Color: Asunción, Paraguay. 25 de noviembre 2014

Diario Hoy. «El macho paraguayo sigue pegando: solo 7 mujeres por día se atreven a denunciarlo». HOY: Asunción, Paraguay 8 de Enero 2014.

Guil Bozal, Ana, Ana Solano Parés y Manuela Álvarez Girón. La Situación de las Mujeres en las Universidades Públicas Andaluzas. Sevilla: Consejo Económico y Social de Andalucía, 2005.

Lamas, Marta. La perspectiva de género una herramienta para construir equidad entre mujeres y hombres. México: Sistema integral para el Desarrollo de la Familia (DIF), México, 1997. 
Larena, Rosa y Silvia Molina. «Violencia de género en las universidades: Investigaciones y medidas para prevenirla». Revista de Investigaciones en Intervención Social, 1.2 (2010): 202-219.

Ministerio de la Mujer, Centro Superior de Estudios de Administración y Finanzas. «Primera Encuesta Sobre Violencia Intrafamiliar Basada en Género-Área Urbana, 2014. <http://www.mujer.gov.py/index.php/publicaciones>, consultado el 15-03-2016.

Naciones Unidas. Declaración sobre la eliminación de la violencia contra la mujer, 1993. <http://www.ohchr.org/SP/ProfessionalInterest/Pages/ViolenceAgainstWomen. aspx>, consultado el 12-08-2014.

Naciones Unidas. Informe Anual 2014-2105 de ONU Mujeres, 2015. <http:// www.unwomen.org/es/digital-library/publications/2015/6/annualreport-2014-2015>, consultado el 07-11-2015.

Naciones Unidas. Informe de la Cuarta Conferencia Mundial sobre la Mujer, 1996. <http://www.un.org/womenwatch/daw/beijing/pdf/Beijing\%20full\%20 report\%20S.pdf>, consultado el 04-06-2014.

Straus, Murray A. (2004) «Prevalence of violence against Dating Partners by Male and Female University Students Worldwide». Violence Against Women, 10.7 (2004): 790-811. 12 de octubre de 2014.

Universidad Complutense de Madrid, Ministerio de Sanidad, Servicios Sociales e Igualdad. «La juventud universitaria ante la igualdad y la violencia de género», 2013. <http://www.upm.es/sfs/Rectorado/Gerencia/Igualdad/Documentos/ Juventud_Universitaria_ante_igualdad_y_violencia_de_genero_\%202012. pdf>, consultado el 12-10-2014. 
Para enlazar con este artículo / To link to this article:

http://dx.doi.org/10.14198/fem.2017.29.03

Para citar este artículo / To cite this article:

Flores Hernández, Aurelia y Lorena Jiménez Montes. «Socialización y sociabilidad de género en un escenario universitario altamente masculinizado». En Marcos Jesús Iglesias Martínez e Inés Lozano Cabezas (coords.), La (in) visibilidad de las mujeres en la Educación Superior: retos y desafíos en la Academia. Feminismo/s, 29 (junio 2017): 71-98, DOI: 10.14198/fem.2017.29.03

\title{
SOCIALIZACIÓN Y SOCIABILIDAD DE GÉNERO EN UN ESCENARIO UNIVERSITARIO ALTAMENTE MASCULINIZADO
}

\author{
SOCIALIZATION AND SOCIABILITY OF GENDER IN \\ A MASCULINIZED UNIVERSITY CONTEXT
}

\author{
Aurelia FLORES HERNÁNDEZ \\ aure7011@hotmail.com \\ orcid.org/0000-0002-8465-7485 \\ Lorena JIMÉNEZ MONTES \\ anerolflor@hotmail.com \\ orcid.org/0000-0002-4227-1373
}

Secretaría de Educación Pública del estado de Tlaxcala (México)

\section{Resumen}

El propósito de este trabajo es explorar los desafíos y las tensiones que enfrentan estudiantes universitarias en las prácticas de sociabilidad y modos de convivencia a los que recurren para relacionarse con otros en la cotidianeidad de un espacio educativo construido y reconocido socialmente para el género masculino y donde la presencia de las mujeres se mimetiza. Para tal fin se recurre a la reflexión teórica sobre socialización diferencial de género y sociabilidad, adoptando a la antropología de la experiencia como un paradigma metodológico, mediante la aplicación directa de entrevistas. El estudio es de corte cualitativo. Los hallazgos sugieren que, en el sistema escolar universitario estudiado, las prácticas de sociabilidad y convivencia están mediatizadas por camuflajes de género, útiles y convenientes para la continuidad de un sistema de sexismo y violencia, que si bien nace antes de la Universidad, en ésta se consolida.

Palabras clave: género, sociabilidad, socialización, Universidad 


\begin{abstract}
The purpose of this article is to identify and to understand the challenges that university students face in the practices of sociability and codes of coexistence that they use as skills to interact with other people, in the daily life of a university context built socially for the masculine gender and, in which woman mimic the actions of those around them. We discuss the concepts of gender differential socialization and sociability, adopting the anthropology of experience like a methodological perspective, we use the application of interviews, and the study is qualitative. Findings suggest that in the university school system these practices of socialization and codes of coexistence are mediated by gender camouflage, useful and convenient for the continuity of a sexist and violent system that, although born before university, is remarkably resilient.
\end{abstract}

Keywords: gender, sociability, socialization, university 


\section{INTRODUCCIÓN}

En la última década, se ha observado un creciente aumento de estudios que documentan los avances en el conocimiento sobre las variadas circunstancias que las mujeres de modo aguerrido desafían para ingresar, permanecer, egresar y laborar en disciplinas fuertemente masculinizadas. En el contexto de este estudio, en este artículo se discute la clara ausencia en la reflexión de este tema en la Universidad Autónoma de Tlaxcala. Aún más, a nivel institucional, el camino hacia procesos de igualdad es muy corto, en particular en escenarios educativos de alta incidencia masculina como la Facultad de Ciencias Básicas Ingeniería y Tecnología (FCBIyT). Con este trabajo se pretende explorar los desafíos y las tensiones que enfrentan estudiantes universitarias en las prácticas de sociabilidad y modos de convivencia a las que recurren para relacionarse con otros en la cotidianeidad de un espacio educativo construido y reconocido socialmente para el género masculino y donde la presencia de las mujeres se mimetiza.

Inicialmente se debaten teóricamente dos conceptos fundamentales, la socialización diferencial de género y la sociabilidad. Además se distingue la influencia de la socialización y las prácticas de sociabilidad en las relaciones de género en la Universidad. Para tal efecto, se expone un apartado que aborda las investigaciones efectuadas en contextos educativos universitarios de alta concentración masculina en varios países de Latinoamérica. La revisión se hizo con el fin de reconocer ciertas peculiaridades del ingreso y tránsito de las mujeres en estos espacios, así como el impacto de estas prácticas entre diversos agentes universitarios. Los frentes que a las mujeres les toca sortear tanto en las interacciones como en los mecanismos institucionales indican una férrea y casi inamovible estructura universitaria de fuerte arraigo patriarcal.

En la segunda sección se aclara el procedimiento metodológico, el cual se centra en el enfoque de la antropología de la experiencia que coloca el interés en las experiencias de las participantes, organizadas mediante narrativas, vía la aplicación de técnicas cualitativas (entrevista temática y observación). El estudio fue aplicado en una universidad pública mexicana, ubicada en la región centro de este país. Como característica de este organismo universitario de cuatro décadas de formación, se observa un escenario formativo y laboral 
de alta segregación del género femenino en campos tradicionales e incipiente presencia de políticas institucionales pro-igualdad.

A la luz de las experiencias narradas por las estudiantes en tres espacios (físicos, las aulas y simbólicos), en los resultados se estructuran los principales hallazgos en el contorno de dos categorías analíticas: sociabilidad y convivencia con el estudiantado, y sociabilidad y convivencia con el profesorado.

A modo de conclusión se indica que a pesar de los costos de ingresar en seis disciplinas formativas (matemáticas aplicadas, química industrial, química, sistemas electrónicos, computación y mecatrónica), de los avatares que significa formarse y de los retos de ejercitar la profesión, las mujeres están y forman parte de nuevos profesionales en esos campos. No obstante, para transitar por los espacios universitarios, y ante la presencia de prácticas de sociabilidad y convivencia que ellas no sienten seguros y miran con desconfianza, ellas recurren a estrategias de resguardo para pasar desapercibidas y egresar, convencidas de que están en carreras de su elección porque cuentan con el intelecto para lograrlo.

\section{EL ENCUADRE TEÓRICO}

La socialización es un proceso mediante el cual el ser humano se ajusta a las formas y modo de vida de un grupo social en particular, es decir, el comportamiento humano debe adaptarse a las normas socioculturales de su hábitat. Peña y Buschiazzo (15), retomando la conceptualización de Rocher (1980), indican tres aspectos fundamentales de la socialización: la adquisición de la cultura, su internalización en la personalidad y la adaptación al entorno social. En este proceso de aprendizaje, los elementos socioculturales se recrean y las personas los matizan en sus propias vivencias a lo largo de toda su existencia.

La socialización primaria o principal permite al sujeto transformarse en un ser social y adquirir las pautas básicas esperadas para cada individuo en una sociedad instaurada. Los agentes socializadores centrales en esta dinámica son la familia, el grupo de pares, la escuela, la iglesia, el Estado y el mercado, entre otros, y funcionan como instituciones ideológicas, laborales o políticas responsables de este proceso. Sobre estas bases se instituye la socialización secundaria, en la cual las personas asumen como suyos determinados patrones -hábitos, comportamientos y normas- (Peña y Buschiazzo 17).

La socialización es un recurso útil para inculcar a hombres y mujeres los papeles o roles pre-asignados, apropiados en la infancia y reproducidos durante el ciclo vital. La familia (medio familiar) y la escuela (medio social) son dos de las instancias básicas de reproducción de prácticas socializadoras y en ellas se forjan códigos, valores, normas y expectativas socioculturalmente esperadas 
para cada género (Preciado et al 44). La socialización de género modela la feminidad y la masculinidad a partir de cánones establecidos según se nace hombre o mujer. En esta dinámica, los sujetos asumen funciones prescritas en los márgenes de una tradicional, rígida e histórica división sexual del trabajo. Lo culturalmente conveniente es que los hombres y las mujeres se adapten y adopten las normas sociales para formar parte del núcleo familiar y social que los resguarda.

En razón de que cada sociedad posee diferentes visiones de lo que es ser hombre o mujer, el valor asignado a cada género es flexible. Esta visión social varía según cultura, época histórica, espacio geográfico y otras categorías (edad, raza, estilo de vida, color de piel, la preferencia sexual, etcétera). Sin embargo en cada una se encuentra presente una constante: las mujeres son concebidas jerárquicamente inferiores y existe una distribución desigual de recompensas sociales valoradas con base a estereotipos de género, donde el proceso de socialización delimita el accionar del binomio masculino/femenino (Peña y Buschiazzo 18).

A través de la socialización diferencial, que está presente como un proceso inherente a la sociedad misma, se logra que los individuos adecuen su comportamiento y su identidad previamente normalizados y definidos a los modelos y a las expectativas creadas para los sujetos masculinos o femeninos. La socialización de género constituye un proceso de aprendizaje cultural de los papeles atribuidos a cada quien según su sexo. Las mujeres y los hombres en este aprendizaje reconocen los espacios que les corresponden de acuerdo a esquemas heteronormativos de género (Peña y Buschiazzo 17, Lorente 27).

En el sistema educativo, la escuela funciona como institución formadora y al mismo tiempo como sitio donde el sistema sexo/género es legitimado. En su papel de agente de socialización, refuerza los cimientos para la generación y la difusión de esquemas sexistas, prejuicios, estereotipos y representaciones sociales diferenciales (Larena y Molina 203).

La sociabilidad simboliza «el gusto por estar juntos». Las interacciones con los pares, el gozo de asociarse, de tener compañeros(as) y amigos(as), representa un aspecto lúdico de reunirse con otros (Simmel 95) y emotivo-afectivo que estimula a los sujetos a relacionarse e interaccionar con sus semejantes (Navarro 1994, citado en Pérez e Ibarra 4). Además de que en cada grupo se establecen normas y valores propios que implican la socialización entre pares (Weiss 1269). Pérez e Ibarra precisan:

La socialización es el proceso mediante el cual el sujeto se adapta a la estructura social [...] Por su parte la sociabilidad nos explica la forma en que 
interaccionamos o nos comunicamos entre sí en una sociedad determinada; es decir, las formas en que nos vamos haciendo individuos de esa sociedad concreta. Ambos conceptos socialización y sociabilidad nos ayudan a entender los estilos de sociedad o como se constituyen las sociedades (4).

De modo específico, la función de la escuela, no solo como replicadora de información/conocimiento, sino como espacio de intercambio de socialización entre sexos, reproductora de la identidad, de la sexualidad y de esquemas binarios de género, es puerta abierta a la perpetuación de la socialización diferenciada (Flores 74, Martínez y Solís 166). Empero, el contexto político, económico y social actual demanda alejarse de una escuela homogeneizadora y «reconocer que las desigualdades sociales atraviesan también las paredes de las escuela» (Malegarie y Tavernell 120). Por tanto, es urgente una educación basada en una socialización en igualdad que dignifique la vida humana (Cantillo y Rocha 2, Lorente 34).

En la escuela, como entidad de aprendizaje y de educación, se sostiene no sólo la desigualdad, sino también la violencia a través del recurso de la socialización (Lorente 27). De este modo, es permisible que durante el recreo las niñas permanezcan arrinconadas en lugares lejanos para protegerse y evitar pelotazos o golpes, mientras los niños ensanchan el uso de los espacios de juego (Costa y Rogério 4). De igual modo, las actividades deportivas que constituyen un espacio ilimitado de vida cultural al mismo tiempo visibilizan la discriminación hacia las mujeres (Gallego y Estebaranz 1). El ejercicio físico estimula el desarrollo social y ciudadano (perseverancia, equilibrio, liderazgo), y ciertos indicadores de sociabilidad (solidaridad o participación social). No obstante, la práctica deportiva es casi siempre menos frecuente entre las mujeres, en parte por el difícil acceso a las instalaciones deportivas (Gallego 1).

Empero, si bien los sistemas educacionales son funcionales a la socialización por la claridad y delimitación de su misión (Peña y Buschiazzo 26), no todos los espacios educativos son homogéneos, pues cada caso se encuentra regido por normas internas. En la escuela, las relaciones entre jóvenes se manifiestan en diferentes formas, interacciones grupales o intergrupales (y de inter e intra géneros) en ajuste casi siempre a las reglas de los centros educativos. En estas relaciones ocurren sucesos contradictorios, desde actos de discriminación, estigmas, exclusión y de violencia hasta la presencia de eventos solidarios, expresiones de reciprocidad afectiva positiva, responsabilidad e identidad grupal (Paulín et al 2). 


\subsection{La Universidad como espacio de continuidad de la socialización}

Los espacios de sociabilidad y su forma de apropiación son diferenciales según género, edad, condición social, entre otras categorías, aunque éstos serán definidos por la valoración otorgada social y culturalmente a lo femenino y a lo masculino. En todo caso, los sitios de sociabilidad también funcionan como espacios de socialización, la Universidad es uno de ellos. Esta institución educativa ha asumido un papel formativo integral donde la socialización de género se ha convertido en una extensión perene de prácticas de sociabilidad oscilantes entre sus contornos dentro y fuera. La escuela -y la Universidad- es un espacio de sociabilidad donde quienes se identifican en ella aprenden a relacionarse, a conocerse a sí mismos, colocan en acción su identidad, la redefinen o la asumen, al mismo tiempo que al contacto con otras identidades, la fortalecen (Rebolledo 90).

La Universidad custodia aún una sólida y férrea estructura jerárquica e ideológica que continúa alentando relaciones de desigualdad y, por supuesto, de socialización diferenciada de género (Larena y Molina 203, Cantillo y Rocha 1). Un trato diferenciado en función del sexo es un atentado contra la construcción de una vida digna; perjudica las posibilidades y potencialidades de las personas e invalida el desarrollo de ciertas capacidades. Esta diferenciación socializadora conforma actitudes, creencias y modos de relacionarse con los demás y el mundo (López et al 358).

Entre los aspectos que se han reflexionado en el binomio Universidad y violencia se encuentran precisamente las implicaciones diferenciales de la socialización de género, que supone comportamientos y creencias divergentes entre el estudiantado, enraizadas desde la familia, que conducen a prácticas sexistas, discriminación y violencia. El reconocimiento de la violencia de género como un problema sistémico que afecta de forma significativa la experiencia de las universitarias y atraviesa la convivencia cotidiana dentro de la Universidad se manifiesta en variadas aristas (Mingo y Moreno 144). En la cotidianeidad de la vida universitaria, la circulación de un ambiente adverso hacia las mujeres es un «pan de todos los días» que se ancla no sólo en la dinámica relacional entre grupos y sexos, sino en los programas de estudio, en los debates de las aulas y en la compleja «cultura institucional de género» (Mingo y Moreno 139, Larena y Molina 208).

En ese mundo cultural universitario, el ejercicio de la masculinidad tiene múltiples manifestaciones, en su mayoría cargadas de fuerte violencia (Maceira 202) y modos sutiles y simbólicos de expresión. Por ejemplo, el nombrado «dominio conversacional masculino», que permite la interrupción del turno de habla de las mujeres o el uso mayor de tiempo por parte de los hombres, 
constituye una forma de control de la voz y de los contenidos de las conversaciones (Martínez 27). De igual modo, esta superioridad de la palabra se traduce en mayor dedicación en cuanto a tiempo por parte del profesorado y con ello también orientación sobre el tema tratado, aunque se tiende a justificar que los hombres reciben mayor atención porque requieren más disciplina y necesitan controlar su comportamiento (Coates 189).

En otras investigaciones (Castro y Vázquez 612; Vázquez y Chávez 63) se ha reconocido que entre universitarios uno de los temas predilectos para murmurar son precisamente «las mujeres» (sexualidad, cuerpo, albures, apariencia física). Este tema se convierte en un elemento de identificación de ser hombre y un vínculo socializador entre varones. Ante el maltrato del que las mujeres padecen y son objeto, ellas manifiestan reacciones y sentimientos ambivalentes que se balancean entre aguantar, sufrir, callar, o bien protestar, rechazar y resistir (Camacho 141). García et al. (15) afirman que las universitarias prefieren relacionarse entre sí para compartir secretos, sentarse juntas en la clase y estudiar.

\subsubsection{Sociabilidad en escenarios formativos masculinizados}

Para las mujeres, transitar en campos educativos universitarios «celosamente masculinos» tan hostiles es un desafío que simula caminar en terrenos minados. La presencia de las mujeres en la Universidad -en particular en los campos con alta concentración de hombres- irrumpió los modelos y estereotipos de género hegemónicos (Preciado et al 43). Pero la escasa participación de las mujeres en las nombradas «ciencias duras» propició el encuentro de diversos estudios y corrientes reflexivas para su comprensión, específicamente, la escuela feminista se ha interesado en el orden de género prevaleciente en estos escenarios universitarios (Guevara y García 10, Mingo 28).

La inmersión de las mujeres en carreras «no convencionales» resulta de mecanismos sociales de selección y exclusión, algunos de ellos directamente asociados con el régimen de género y arraigado en el imaginario social (Arango 152). Esta situación las hace aparecer y figurar casi siempre como «invisibles o extranjeras» (Mingo 31), «recién llegadas» (Ballarín 36), «invitadas» (Peña y Buschiazzo 6), «intrusas» (Buquet et al 9) o «invasoras». Aunque algunos opinan que la palabra invasión está mal empleada, puesto que no consideran que ciertas profesiones sean privativas del género femenino. Lo que ocurre simplemente es que los hombres accedieron a un espacio que desde siempre estuvo allí y ahora las «mujeres han ocupado cada vez más espacio en la universidad, pero aún no la habitan» (Ballarín 19). Tal afirmación se hace evidente 
al mostrar los fuertes privilegios que mantienen los hombres, especialmente en áreas tradicionales e históricamente forjadas para ellos (Preciado et al 20).

Entre las mujeres, la decisión de ingresar en alguna ingeniería tiene respuestas ambivalentes. Por un lado, puede estar asociada a estímulos recibidos en el plano familiar (Arango 143) o por el contrario a la renuencia social para apoyar esta decisión (Álvarez et al 10). Al respecto, Oliveros et al (93) destacan que en la Ingeniería Aeroespacial de la Universidad Autónoma de Baja California, México, la motivación de la elección de esta carrera entre las mujeres se cimienta en decisiones informadas y responde a precedentes familiares, aunque en la mayoría de los casos ninguna mujer integrante de las familias de las estudiantes se representó como modelo femenino a seguir, lo que muestra los casi nulos ejemplos de mujeres exitosas en este campo del conocimiento.

Por su parte, Guevara y García encuentran en su estudio que, para las estudiantes entrevistadas, la elección de estudiar ciencias -exactas y naturales- se manifestó como un reto personal plagado de intereses, necesidades y deseos, búsqueda de reconocimiento, prestigio y desarrollo intelectual; así como «la opción por una identidad disciplinaria asociada a una actividad que no corresponde al mundo tradicional de las mujeres» (12). Las autoras refieren que en este contexto fueron fundamentales tanto el apoyo familiar (padres/madres) y el estímulo del profesorado como los logros individuales obtenidos por su potencial académico.

No obstante, según resultados del trabajo de investigación de Buquet et al. en la Universidad Nacional Autónoma de México (UNAM), las mujeres muestran un mayor logro en indicadores de rendimiento (por ejemplo, el avance en créditos) en el campo de las Ciencias Físico-Matemáticas e Ingenierías. Este resultado no favorece la contratación laboral femenina a futuro y ellas son quienes menos potencialidad tienen de obtener un empleo bien remunerado, pues prevalece un sistema de estereotipos que les atribuye menores capacidades para estas áreas y otorga mayor reconocimiento a los hombres como los más aptos.

También en esa máxima casa de estudios mexicana, Mingo explora el trato y las prácticas discriminatorias que las mujeres padecen. El estudio muestra los agravios hacia las estudiantes en un ambiente universitario adverso, hostil y desequilibrado, no sólo en cifras, sino en términos del discurso. Según la autora, las mujeres deben lidiar en el día a día con chistes sexistas, lenguaje soez, albures, murmullos, injurias, descalificaciones, hostilidad, risas sonoras, tensiones por excesiva carga académica, sensación de aislamiento y de encontrarse al margen, soledad, fatiga y malestar. Estas realidades representan «ejemplos de la energía extra que [ellas] han de invertir para batallar con los actos con los que se delimita la posesión masculina de un territorio» (33). 
Con la intención de indagar en la experiencia de mujeres en la educación profesional en dos facultades de Ingeniería-Mecánica y Electrónica, y Civil- de la Universidad de Colima, México, Preciado et al. (41) proponen un análisis en tres niveles donde se focaliza la opresión/resistencia: el género, la raza y la clase. Los autores matizan que en el contexto cultural del grupo se afianza y continua la reproducción de una «cultura de ingeniería masculina» y de violencia simbólica a través del lenguaje (comentarios y bromas machistas). Además, en estos dos espacios, las estudiantes vivencian discriminación de género por parte de profesores y de sus compañeros, frente a lo cual ellas aparentan ser uno más de ellos.

El camuflaje que significa «disfrazarse» es el método que permite a las estudiantes en contextos educativos altamente masculinizados «pasar de largo» e indistinguibles durante toda su formación. Las estudiantes adoptan esta estrategia para acomodarse en ambientes lacerantes machistas, pues les permite parecerse o asemejarse al resto de la comunidad universitaria, pasar desapercibidas. Para lograrlo, la vestimenta es central. Mingo (32) comenta que las jóvenes de su estudio limitan su forma de vestir para evitar «el chifladero», de modo que este hecho funciona como un efecto inhibidor.

Esta situación es muy similar a la que encuentran Peña y Buschiazzo (60 89 y 118) entre estudiantes de la ingeniería de la madera, donde de acuerdo a su opinión ellas enfrentan un medio adverso que las obliga a masculinizarse -vestir como hombre y actuar como tal-, pues es la alternativa para validarse en ese mundo. Asimismo, las estudiantes identifican dos mecanismos para reducir la discriminación en su contra. Primero, demostrar continuamente que son capaces de ocupar ese lugar, retando y compitiendo con sus congéneres para validar su presencia y confirmar su intelecto (inteligencia femenina); ante esta actitud, los hombres que se insertan en este tipo de carreras no tienen nada que aclarar. Segundo, representar actitudes de indiferencia frente al menosprecio de parte del profesorado que las coloca como poco aptas para la vida científica y muy hábiles para los quehaceres domésticos.

Otras disciplinas caracterizadas por mantener «un sello masculino», pero que aparentemente suponían en su origen mayor apertura para las mujeres (en razón de habilidades manuales y condición física) debido al manejo de innovaciones tecnológicas, que son distintas a carreras masculinas tradicionales, no lograron del todo la inclusión femenina de modo igualitario. Arango (152) afirma que la ingeniería en computación es una de las profesiones más apreciadas en la sociedad colombiana, cubre bajos porcentajes de participación femenina y una marcada preferencia de parte de las mujeres por involucrarse en áreas gerenciales, tarea que implica trato directo con usuarios, encierro en 
oficinas y acciones prácticas empresariales, y de menor cobertura en habilitación para el diseño de programas.

Estos escenarios masculinos que se consideran «más armónicos» para el tránsito de las mujeres durante sus estudios, las atribuyen al aprovechamiento de habilidades propias de su sexo. La experiencia de estudiantes en la carrera de arquitectura en Colombia indica que ellas acceden a esta profesión porque mantienen la idea de contar con dotes manuales, alta creatividad y visión de lo estético, herramientas que seguramente les ayudarán a diseñar ambientes agradables para el ser humano. La investigación también detecta que las relaciones entre mujeres y hombres son aisladas, distantes y de aguda competencia académica (Cantillo y Rocha 7).

En general, los resultados de las investigaciones revisadas sugieren que la socialización diferencial de género, que germina en la familia y en los primeros contactos relacionales, es vigorizada con la participación de cada uno de sus agentes en la Universidad. Sin embargo, ninguno de estos trabajos puede considerarse como concluyente. La realidad se transforma continuamente y, en ocasiones, un ambiente puede ser totalmente distinto a otro, aun cuando en apariencia sostengan las mismas características o perfiles. Por tanto, es posible decir que estos escenarios de socialización y sociabilidad son estrechos y «cerrados», y en ellos las mujeres deben permanentemente demostrar su capacidad, más allá de las virtudes «naturales» impuestas pues la circulación cotidiana de actos de subestimación, discriminación y violencia, que casi siempre, las obliga a recurrir a la mimetización como un mecanismo de resguardo y protección. Para contribuir a la reflexión de estas complejas aristas, este artículo se interesa por la comprensión de las prácticas de sociabilidad y modos de convivencia que las universitarias emprenden en un contexto escolar fuertemente masculinizado y, sobre todo, las contradicciones de la socialización diferenciada de género.

\section{LO METODOLÓGICO}

La antropología de la experiencia es una perspectiva que coloca a la agencia humana en la comprensión y construcción de toda vida social (Díaz 7). Esta plantea que las experiencias traducidas mediante las narrativas -como construcción social- se organizan y dan significado a la experiencia individual. Estas estructuras sirven como guía de interpretación, incluyen pensamientos, deseos, temores, sentimientos y disposiciones. Esta mirada antropológica convino como un punto de partida metodológico de gran apoyo para extraer las voces de las participantes. La proposición metodológica de este estudio se centra en el plano de las experiencias, reconociendo que éstas pueden ser flexibles y 
referirse a lo habitual o a lo reflexivo, pero siempre en perspectiva de lo subjetivo (Álvarez-Gayou 51). Se recurre a las interacciones y los significados a la luz de las narrativas -la palabra-y su interpretación de quienes son participes en la investigación.

El trabajo es de corte cualitativo, perspectiva favorable porque permite reconocer la capacidad de interpretar y significar las experiencias por las propias personas (Martínez y Solís 149). La particularidad de la metodología reside en que se centra en el estudio de los sujetos con la intención de reflexionar acerca de la situación vivida para comprender lo que ocurre. En específico, es de interés la identificación de las relaciones y los significados de la problemática estudiada sin importar la representación estadística de los hechos (Sánchez 118). Se utilizó una «muestra de conveniencia» (Hernández 145), cuya pretensión no es responder a criterios estadísticos ni buscar una representatividad del fenómeno estudiado o alcanzar la generalización de resultados.

\subsection{Instrumentos y recuperación de la información}

El plan de investigación se estructuró en tres etapas, la primera comprende el diseño del protocolo y la ubicación del contexto de estudio; la segunda corresponde a la elaboración de los instrumentos de recopilación de la información y el desarrollo del trabajo de campo; y la etapa final cubrió la sistematización, el análisis y la interpretación de la información.

Las actividades de trabajo de campo se desarrollaron en un periodo de seis meses (junio a noviembre del año 2015), plazo en el cual se participó activamente en distintos escenarios y eventos de la Facultad de Ciencias Básicas, Ingeniería y Tecnología. En esta etapa se cumplieron dos propósitos: (1) notas derivadas de observaciones in situ durante los dos primeros meses, aunque la técnica de observación se mantuvo a lo largo de todo el periodo y (2) detección de potenciales candidatas a participar y aplicación de entrevistas.

La selección de las participantes comprometía su colaboración voluntaria. Previa explicación de los propósitos del estudio, las entrevistas se aplicaron durante dos meses en un plazo intermedio, en horarios diversos y en sitios convenidos por las propias estudiantes, todos ubicados en el interior de la universidad. El total de participantes fue de diecisiete estudiantes inscritas en diferentes semestres de seis disciplinas formativas del campo de las ingenierías.

La entrevista utilizó un guion temático, incluyendo los siguientes ejes:

a. Datos generales de la entrevistada (edad, semestre cursando, carrera, sexo, procedencia)

b. Motivos de elección de la carrera y circunstancias presentes 
c. Experiencias de sociabilidad en espacios físicos de la facultad estudiada (biblioteca, oficinas administrativas, auditorio, sala de computación o laboratorios, cubículo de fotocopiado, sanitarios, estacionamientos, canchas deportivas, cafetería, áreas verdes y pasillos)

d. Experiencias de sociabilidad en las aulas (el salón de clases)

e. Experiencias de sociabilidad en espacios simbólicos (eventos universitarios como: homenajes -formar parte de la escolta, del grupo de edecanes o emitir un mensaje-, conferencias, talleres, actividades deportivas, graduaciones o fiestas juveniles institucionales, elecciones estudiantiles para representantes de grupo o formar comités o representaciones ante el consejo universitario)

Con la intención de reconocer las prácticas de interacción, modos de convivencia y sociabilidad entre el estudiantado y con el profesorado también se utilizaron las notas de campo en los tres escenarios. Las notas de campo se centraron en la identificación de anuncios, avisos en murales, grafiti, situaciones rutinarias, eventos, festejos, hechos significativos que se desarrollan en este centro universitario, diálogos formales e informales, gestos, tonos de voz, pausas, lenguaje corporal, volumen de la conversación, vestimenta, accesorios utilizados, colores, actitudes corporales, entre otros.

\subsection{Sistematización y análisis de la información}

Para el procesamiento y análisis de los datos cualitativos se retomó la propuesta de Mejía (48), quien sugiere hacer una lectura de las narrativas o de los textos y se efectúe una examinación en espiral de cada caso y del conjunto, donde se incluya la recuperación de información de las notas de campo, logrando un análisis detallado y profundo del tema tratado.

Después se hizo una lectura relacional siguiendo el orden de los apartados centrales de la entrevista. Con esta disposición se logró identificar características distintivas, lo que permitió distinguir similitudes y diferencias, las cuales son expuestas mediante las narrativas, eligiendo aquellas que denotaran la singularidad del conjunto de casos. Es importante decir que las experiencias de sociabilidad se distinguieron a través de las prácticas relacionales que las entrevistadas sostenían con el estudiantado y con el profesorado, razón por la cual la estructuración de los resultados retoma dos categorías analíticas expositivas: sociabilidad y convivencia con el estudiantado, y sociabilidad y convivencia con el profesorado a la luz de las experiencias en los espacios señalados.

El paradigma interpretativo, útil como filtro de la experiencia, apoyó la reflexión, pues centra su interés en la comprensión de las significaciones de las 
experiencias y prácticas en el ámbito escolar. A fin de recuperar la perspectiva de las estudiantes y «comprender el sentido de la acción en el marco de un nivel de análisis intersubjetivo», se reconoce que quien realiza la labor investigativa también contiene en sí subjetividades (Paulín et al 3).

\section{EL ESPACIO UNIVERSITARIO ESTUDIADO}

La Universidad Autónoma de Tlaxcala (UAT) se localiza en el estado de Tlaxcala, México. Se encuentra constituida en cuatro divisiones: 1) Ciencias Sociales y Administrativas; 2) Ciencias y Humanidades; 3) Ciencias Biológicas y 4) Ciencias Básicas, Ingeniería y Tecnología. De esta última forman parte las Facultades de Ciencias Básicas, Ingeniería y Tecnología; y Diseño, Arte y Arquitectura. El estudio fue aplicado en la Facultad de Ciencias Básicas, Ingeniería y Tecnología (FCBIyT), la cual hasta el año 2016 ofertaba seis licenciaturas: Ingeniería en Computación, Ingeniería Mecánica, Ingeniería Química, Sistemas Electrónicos, Matemáticas Aplicadas y Química Industrial.

Esta Facultad surgió en el año 1978 como Departamento de Ingeniería y Tecnología, orientado a diversas áreas de la ingeniería química (petroquímica, automotriz, alimentos, tratamientos de aguas, contaminación, farmacéuticos). De manera inicial, los planes de estudio se estructuraban en 10 semestres o cinco años escolares. En el último año se elegían las especialidades: Química Industrial e Ingeniería Química. En el año 1984 se aprobaron los planes de estudios de ambas licenciaturas y al siguiente año, 1985, se integran otras dos disciplinas: Ingeniería Mecánica e Ingeniería en Computación, y más tarde, en 1987, la Licenciatura en Matemáticas Aplicadas. A partir de este año se reconoció como Departamento de Ciencias Básicas, Ingeniería y Tecnología.

Durante la mitad de los noventa se incorporan dos posgrados (Maestría en Ingeniería Química, Ciencias de la Calidad y Ciencias en Ingeniería en Computación) y al final de la misma década se abrió la Ingeniería en Sistemas Electrónicos (1999). En el año 2005 se reconoció como Facultad de Ciencias Básicas, Ingeniería y Tecnología, y para el año 2009 se creó el Doctorado en Ciencias en Ingeniería Química http://ingenieria.uatx.mx/fcbiyt/vision/.

Como se observa en la tabla 1, la población estudiantil de la FCBIyT es de prevalencia masculina. La admisión porcentual de hombres ha rebasado en los últimos tres ciclos escolares el 66\%; sin embargo, la matrícula de mujeres ha ido en ascenso al menos un punto porcentual anual. En particular, las carreras de computación, química y química industrial tienen una mayor presencia femenina, el resto (sistemas electrónicos, mecánica, y matemáticas) son disciplinas masculinizadas. Esta distribución supone una polarización binaria de la ciencia, que atribuye socioculturalmente estas disciplinas a las ciencias duras 
que conllevan a la comprensión de dimensiones complejas, donde el orden femenino (apegado a la subjetividad) no tiene cabida.

Tabla 1. Matrícula -nivel ingeniería/licenciatura-

Facultad de Ciencias Básicas Ingeniería y Tecnología (2013-2016)

\begin{tabular}{|c|c|c|c|c|c|c|c|c|c|c|}
\hline \multirow{3}{*}{ Ingeniería } & \multicolumn{10}{|c|}{ Ciclo Escolar } \\
\hline & \multicolumn{3}{|c|}{$2015-2016$} & \multicolumn{4}{|c|}{ 2014-2015 } & \multicolumn{3}{|c|}{ 2013-2014 } \\
\hline & Hombres & Mujeres & Total & Hombres & & ijeres & Total & Hombres & Mujeres & Total \\
\hline Computación & 298 & 85 & 383 & 289 & & 99 & 388 & 330 & 112 & 442 \\
\hline $\begin{array}{l}\text { Sistemas } \\
\text { Electrónicos }\end{array}$ & 40 & 14 & 54 & 50 & & 6 & 56 & 61 & 6 & 67 \\
\hline Mecánica & 83 & 6 & 89 & 83 & & 4 & 87 & 77 & 5 & 82 \\
\hline Química & 72 & 83 & 155 & 59 & & 75 & 134 & 64 & 83 & 147 \\
\hline $\begin{array}{l}\text { Química } \\
\text { Industrial }\end{array}$ & 26 & 58 & 84 & 24 & & 42 & 66 & 19 & 31 & 50 \\
\hline $\begin{array}{l}\text { Matemáticas } \\
\text { aplicadas }\end{array}$ & 44 & 38 & 82 & 37 & & 35 & 72 & 40 & 34 & 74 \\
\hline Total & $56366.5 \%$ & $28433.5 \%$ & 847 & $54267.5 \%$ & 261 & $32.5 \%$ & 803 & $59168.5 \%$ & $27131.5 \%$ & 862 \\
\hline
\end{tabular}

Fuente: ANUIES

El campus universitario de la FCBIyT contiene grandes espacios, áreas verdes, deportivas y de esparcimiento (cafetería, cancha de básquetbol/voleibol y campo de fútbol) y zona académica (aulas, cubículos, talleres, laboratorios, centros de cómputo, biblioteca, auditorio, sanitarios, cubículo de fotocopiado) que se encuentran bien delimitadas y equipadas para el ejercicio de múltiples y diversas actividades. El estacionamiento es amplio y es frecuente encontrar letreros indicativos para ubicar las aulas de clase. El edificio académico es moderno con aulas amplias y equipadas para la impartición de diversas asignaturas. También cuenta con un edificio de tres salones grandes con iluminación que se utilizan para la impartición de cursos de posgrados y/o para la presentación de exámenes de grado.

\section{LOS HALLAZGOS EN LAS INGENIERÍAS ESTUDIADAS}

\section{1. ¿Por qué estudiar una ingeniería?: «es algo de lo que todos huyen»}

Uno de los primeros cuestionamientos que se exploró fue conocer las razones e intereses que las mujeres tuvieron para estudiar determinada carrera en la FCBIyT. Se encontraron diversas opiniones que indicaron que las ingenierías 
son un desafío, pues son áreas formativas consideradas racionales y que «elevan la inteligencia».

Las matemáticas es algo de lo que todos huyen, todos se espantan, entonces si es un reto para nosotras pues a pesar de que es complicado, nosotras tenemos una meta, terminar una carrera y a pesar de que sabemos que es difícil o que a veces nos cuesta pasar los exámenes, le echamos ganas y pues ya, al final de cuentas, sacamos la materia (Marly, estudiante de matemáticas)

A pesar de que esta disciplina es considerada como un campo severo y arduo tanto para hombres como para mujeres, en particular ellas refieren es necesario transitarlo como un camino pedregoso, por lo que lo asumen como un desafío que son capaces de superar. Otras opiniones aludieron que las disciplinas que cursan representan áreas innovadoras, novedosas e interesantes. Por ejemplo, la formación en computación permite «el uso de la tecnología» que en opinión de las entrevistadas es «la vanguardia de un mundo cambiante» que les abrirá nuevas expectativas de vida.

Si de igual forma porque me gusta lo que nos enseñan, es la carrera que tiene más amplio campo de trabajo y es muy versátil (Karina, estudiante de computación)

Si a mí me gusta por las materias que nos dan y el campo de trabajo (Ángeles, estudiante de computación)

Algunos puntos de vista de las estudiantes de la carrera de química insinuaron que si bien su disciplina de estudio es complicada, también goza de un campo laboral llamativo tanto profesional como económicamente:

Es precisa, muy interesante, difícil, el campo laboral es extenso y bien pagado (Manuela, estudiante de química)

La carrera exige mucho trabajo y está muy enfocada al campo de la investigación y eso es lo agradable (Mercedes, estudiante de ingeniería química)

Tiene su grado de importancia y su grado de dificultad y te puedes desenvolver en la docencia, la investigación o a nivel industrial (Karla, estudiante de química industrial)

La ingeniería química es un área de apertura laboral, debido al impacto del desarrollo de habilidades en la formación de recursos humanos, la investigación y la inmersión en empresas o laboratorios. Esta característica, según las entrevistadas, permite una continua y permanente capacitación, particularmente la investigación se presenta como un campo innovador de empleo.

Otras respuestas indicaron el interés de estudiar este tipo de carreras porque en el futuro podrán dedicarse a actividades de enseñanza. Esta perspectiva, si bien reproduce la práctica docente dentro de esquemas tradicionales de la 
división sexual del trabajo, también podría considerarse como una coyuntura para seguir abriendo oportunidades profesionales a otras mujeres en la actividad científica y dejar paso a la presencia de modelos femeninos que rompan el mito de «esto es cosa de hombres». No obstante, todavía algunas estudiantes en la Facultad visualizan ciertas limitaciones en las expectativas laborales: «A veces la mayoría de la gente cuando vas a pedir trabajo te dicen: 'No hay, las ingenierías son para los hombres'...» (Roberta, estudiante de mecánica). Estas experiencias las perfila y posiciona frente a tratos desiguales de género en el ejercicio de su futura carrera. Al respecto, dos estudiantes comentan lo que el profesorado les ha dicho:

La profe si nos ha dicho que a la hora de pedir trabajo si vamos a tener problemas (Roberta, estudiante de mecánica)

Nos han comentado que para una mujer es más difícil ser matemático por que llevan la casa, llevan a los niños y la parte académica, entonces es más complicado para una chica (Marly, estudiante de matemáticas)

Es muy posible que las dificultades a las que se refiera Roberta tengan que ver con obstáculos para un ejercicio profesional pleno (encontrar empleo, preferencias de hombres para las contrataciones, ubicaciones de los sitios de empleo, horarios, entre otros), pero también al conjunto de normas socioculturales que estigmatizan los papeles de género, tal como lo enunció Marly.

Del total de las entrevistadas, sólo una estudiante expresó su predilección hacia otras disciplinas de las ciencias sociales. El resto respondió estar bien convencida en el momento de elegir qué estudiar, entre ellas asumieron tener habilidades intelectuales para las carreras elegidas, particularmente el manejo de las matemáticas y del uso de la tecnología computacional. Sin embargo, como lo precisan, esta decisión de estudiar con «mayoría de hombres» ha tenido costos adversos, por ejemplo, sentirse incomodas y hostigadas por comentarios como «esa carrera es de niños», «seguramente porque estudias eso no le das importancia a tu arreglo personal»o «los matemáticos son un poquito fachositos».

Mediante la observación se notó que la vestimenta cómoda, a la moda y según la edad las identificaba como «universitarias», identidad caracterizada por usar habitualmente tenis o zapato bajo, pantalón de mezclilla, sudadera, escasamente ropa formal o zapato de tacón alto. Los accesorios entre ellas eran escasos, lo mismo el uso de maquillaje. Es posible que ésta sea la estrategia para pasar desapercibida y contribuya a esta personificación de imágenes. Incluso una estudiante indicó que no le gusta pasar por el patio grande cuando hay tanta gente y prefiere rodear el edificio para llegar al aula.

En el contexto estudiado, ocasionalmente algunas de ellas participan en eventos académicos como edecanes o en otras actividades escolares 
(presentaciones académicas, cívicas, eventos sociales, entre otros) visten de modo serio: «En la escuela cuando me piden que venga formal puedo tal vez utilizar un vestido» (Ana, estudiante de química); «Ahorita no venimos tan formales, hay lugares y momentos en los que tenemos que vestir bien, también en la manera de como hablamos, somos más correctos al hablar, ya no decimos tantas groserías» (Vero, estudiante de sistemas electrónicos).

De esta manera, las mujeres son encasilladas a «vestir bien» en tanto participen en eventos sociales o académicos dentro del campus universitario, pues como éstos son consideradas actividades oficiales ellas pueden portar vestimentas que de modo habitual no usarían por el riesgo a sufrir burlas o enfrentar situaciones incomodas.

\subsection{Sociabilidad y convivencia entre el estudiantado: «sacan temas que incomodan»}

La convivencia grupal es diversa y de un promedio de siete $\mathrm{u}$ ocho personas, se encuentran grupos de varones donde dos a tres mujeres conversan o grupos de mujeres donde puede estar un hombre, grupos donde suelen platicar sólo mujeres o exclusivamente hombres. Es común encontrar reuniones en las áreas de esparcimiento (jardines, mesas de la cafetería, pasillos), realizando diversas actividades, entre ellas jugar cartas a media mañana. Este es un entretenimiento preferentemente masculino, según comenta una estudiante:

Las cartas o las que juegan de yu-gi-oh pues no, ni le entiendo, luego cada cosa que dicen los chicos de combinaciones de monstruos [risas], ahí que se hagan pelotas ellos y pues para ¿deportes? como que siento que no tengo tiempo, pero si me gustaría jugar básquetbol (Dulce, estudiante de matemáticas)

Además de esta opinión, es posible que el juego de cartas implique apostar dinero (ganar o perder) y, como otro tipo de entretenimientos de hombres, supone la oportunidad de demostrar hombría y poder, acto que corresponde a rituales de la masculinidad hegemónica. En el escenario universitario estudiado, las pláticas en voz alta y las conversaciones bulliciosas, combinadas con el uso de palabras altisonantes y ofensivas, son también formas de expresión masculina que tienen lugar en la cafetería, en el cubículo de fotocopiado o en las canchas deportivas.

Por otra parte, la negación de las mujeres a participar en este tipo de prácticas de esparcimiento tiene como respuesta el desagrado, desconocimiento del juego o no comprenderlo. En concreto, no es de su interés o, como lo señala Dulce, no lo practican por falta de tiempo para aprender y practicar alguna otra actividad deportiva. Es oportuno decir que la difusión de las prácticas 
físicas no logra efectividad, pues «casi no hay mujeres que participen en el deporte», «no jalan para eso», «no a todas les llama la atención lo mismo». Pero la razón principal, según indicaron, es porque no logran reunir el número de integrantes para formar un equipo y por ello se forman grupos mixtos. Las estudiantes permanecen dentro del salón de clase leyendo, haciendo algún trabajo escolar, comiendo o platicando con amigas. En ocasiones, cuando salen del aula, acompañan a los hombres a sus actividades, aunque la mayoría de veces se mantienen como espectadoras.

En concreto, las mujeres muestran mayor interés por los asuntos académicos que las actividades deportivas, mientras que los hombres prefieren practicar fútbol o básquetbol. La cuestión es cómo se espera que las mujeres participen de forma activa en la vida deportiva si no se generan las instancias para hacerlo. La separación de los espacios físicos que ocurre desde la escuela inicial en cuanto a las oportunidades para estimular el deporte continúa en la universidad.

Al seguir explorando, se cuestionó ¿cómo te tratan tus compañeros? Un comentario unísono hizo escuchar un «nos llevamos bien, hay respeto». Sin embargo, relatos más precisos de las estudiantes parecen contradecir esta opinión fuertemente generalizada.

Yo evito hablar con mis compañeros por ciertas razones que se han dado, ya no me siento tan a gusto. Hablan de las chicas del salón, de quién es virgen y quién no (Dulce, estudiante de matemáticas)

Siempre he sido un poco reservada, siempre guardo mi distancia. Me llevo bien con ellos pero hasta cierto punto. Pues los chicos de repente sacan temas que incomodan, de qué tan buena está una chica, pero es buena la relación (Marly, estudiante de matemáticas)

Anteriormente tenía más amigos hombres, pero ahora con ellos no me llevo bien, no me siento en confianza (Mony, estudiante de química industrial)

A veces es como regular, porque unos como hacen sus grupos unos se apoyan y otros no (Roberta, estudiante de mecánica))

De esta manera, la opinión masculina de «sin ellas no sería lo mismo» se convierte en un mero discurso que no corresponde con las acciones. Las voces de las estudiantes indican la necesidad de evitar la conversación con los hombres y marcar su distancia, es decir, desconfiar de los compañeros por temor a que rebasen los límites del respeto. Estos límites se establecen para evitar la transgresión de cuestiones regularmente asociadas a la moral de las jóvenes o a su sexualidad, pero además para evadir las actitudes groseras o indecorosas que ellos manifiestan y que las coloca en una posición de poca confianza y expuesta a recibir ofensas o actitudes de irrespeto. 
Frente a estas experiencias, una estudiante opinó que entre mujeres suelen llevarse mejor y al parecer mantienen relaciones más armónicas y amables: «El grupo no es muy unido, las seis chicas que estamos aquí nos llevamos muy bien, con los muchachos no hemos tenido esa compatibilidad» (Nora, estudiante de mecánica).

Otra forma de socialización sexista transita por el lenguaje corporal y se manifiesta en posturas físicas, gestos faciales y articulación de manos para emitir señas. Algunas de las estudiantes manifestaron incomodidad al sentirse observadas de forma lasciva, porque les hacían guiños o algún otro tipo de movimiento inconveniente (señas obscenas, movimiento de labios). Incluso, en algún caso, se narró una actitud arrogante que denotó prepotencia o menosprecio hacia el resto: «Sí, de repente un compañero tiene una actitud de 'Yo lo sé todo y Ustedes no' son soberbios» (Marly, estudiante de matemáticas). Según Marly, esos comportamientos son más agudos cuando hay una mayoría de mujeres.

En otras narraciones, las estudiantes comentaron que algún compañero puede actuar de esa forma, pero «sin un afán de molestar». Esta afirmación concuerda con una manifestación de la ceguera de género que es un padecimiento normalizado que hace que la gente (mujeres y hombres) no distinga las desigualdades y los actos de discriminación en razón del género, y sienta que no existen tales actos o incluso asuman una posición cobijada por el discurso del sexismo benevolente. Es decir, esas actitudes que consideran de forma estereotipada y limitada a ciertos roles y que se manifiestan en un tono afectivo y positivo.

\subsection{Sociabilidad y convivencia con el profesorado: «me ignora»}

El aula en la universidad es uno de los espacios de interacción donde se continúa generando la reproducción cultural, social y de género, iniciada en el núcleo familiar. El salón de clases es el sitio donde se provee, distribuye y beneficia a ciertos agentes. Las evaluaciones que el profesorado realiza en el aula acreditan o desacreditan al aprendizaje adquirido, al mismo tiempo que se convierten en herramientas de negociación y reconocimiento, lo que puede producir desigualdad de oportunidades. Con la intención de indagar quién tiende a presentar trabajos escolares de mayor relevancia, la respuesta fue que las mujeres, aunque ellas también se declaran como quienes piden mayor apoyo: «Las mujeres porque somos más responsables, los hombres como que no la hacen» (Dulce, estudiante de matemáticas).

Además, las entrevistadas aseguran que sus compañeros opinan que la presentación de los trabajos de ellas es mejor porque «son más detallistas y dedicadas, de hecho desde los apuntes son más ordenadas y le ponen colorcitos 
y uno [los hombres] nada más con color negro». Esta acción podría estar reflejando la necesidad de las mujeres de ser reconocidas intelectualmente, tener mayor disposición, dedicación y tiempo para las tareas escolares. Otras respuestas indicaron que la calidad de los trabajos depende de la pasión por la carrera, ello supone que las mujeres son más sensibles y amorosas, y por tanto estos atributos de género son idóneos para ciertas actividades en este campo.

En cuanto a la expresión sin censura de sus opiniones, la mayoría dijo sentir libertad para hacerlo, pero muchas manifestaron inseguridad, temor a equivocarse o a recibir críticas:

Si bueno tengo la idea pero de eso a expresarla, aun no tengo esa seguridad en mí (Dulce, estudiante de matemáticas)

Tengo miedo a equivocarme y que los demás se burlen (Ana, estudiante de química)

A veces sí y a veces no, sólo con personas que me llevo sí doy mi opinión sino siento miedo al rechazo, timidez (Roberta, estudiante de mecánica)

A lo mejor no tienes clara la idea y dices 'si digo', mejor no digo [risas] y mejor te quedas callada, por miedo mejor te quedas callada, es la inseguridad de tu respuesta, quieres decir esto pero dices 'y isi no estoy bien?' mejor no digo nada, regreso a lo mismo de antes (Silvia, estudiante de sistemas electrónicos)

Frente al temor a expresar sus opiniones o saberes, y para no ser objeto de burlas, las mujeres prefieren no participar, evitarlo, retraerse, aislarse o guardar silencio. En conjunto, estas acciones denotan las estrategias de resguardo/ protección que adoptan en contextos de alta concentración masculina donde al parecer se han acostumbrado a transitar no sólo como seres humanos invisibles o mimetizadas, sino además con voces silenciadas. En opinión de las estudiantes, existe una marcada predilección hacia los hombres que se muestra en mayor atención:

En algunas ocasiones los profesores dan preferencia a compañeros que empiezan a destacar más, 'a él, a él, a él', y a los demás los olvida, o en algunos casos dan preferencia a los que vienen más arreglados (Roberta, estudiante de mecánica)

Al respecto, algunos testimonios ratifican situaciones de desigualdad (de género y de clase) que se vivencian en el aula entre el profesorado y el estudiantado: «Estas pensando en la respuesta y el profesor interrumpe y dice: ‘Espera! que tu compañero responda'...» (Roberta, estudiante de mecánica); «Sí, yo si me he sentido agredida en esa forma, a veces tomamos una clase en la que tengo dudas y pregunto, y me ignora, y pues no sé si hablé muy bajito» 
(Vero, estudiante en sistemas electrónicos); «Con los hombres se lleva más que con nosotras, a nosotras no nos pela» (Tere, estudiante en química industrial).

Las mujeres atribuyen y justifican el hecho de que el profesorado no les ceda la palabra, se la otorgue a otros (lo que refuerza el dominio conversacional masculino) e ignore su presencia se debe al tono y al volumen de la voz o a la empatía que entre varones puede generarse. En ninguno de los casos las estudiantes objetaron, alzaron el tono de la voz o hicieron alguna otra acción asertiva para afirmar su presencia y reclamar sus derechos.

En el disimulo de enseñar se disfrazan imposiciones, ejercicio de autoridad y poder, y hasta distanciamiento entre el profesorado y el estudiantado, particularmente con las estudiantes. Si bien las respuestas indican que para algunas la relación con el profesorado tiende a ser buena, también se puede observar que para otras en algunas ocasiones es poco accesible y sexista:

Si una mujer había hecho bien el ejercicio y un hombre también, primero lo pasaba a él, los hombres son así, si diferencian un poco (Vero, estudiante de sistemas electrónicos)

Regular, siento que es por no me acerco mucho a ellos porque si les preguntas algo te van a regañar o te van a llamar la atención de que no pones atención en la clase (Roberta, estudiante de mecánica)

No te conceden platicar o decir tus razones (Manuela, estudiante de química)

De esta manera, la práctica docente se enmarca en una relación de supremacía que sostiene roles tradicionales y los reproduce, donde el enseñar es un círculo cerrado que no admite dudas en el aprendizaje. En esta dinámica está prohibido resolver dudas y «acercarse para reclamar», especialmente las mujeres, pues el saber docente es adoptado como el bastión de poder masculino. No obstante, se debe señalar que algunos profesores intentan incluir a las mujeres en un mundo académico, en el que parece ellas llegaron tarde: «Los profesores han dicho 'que debemos razonar como matemáticos' [risas] y entonces dije, 'yo tengo que hacer eso'...» (Dulce, estudiante de matemáticas).

Finalmente, si bien parece existir una norma no escrita como expresión de curriculum oculto de género que enuncia que «en este espacio no hay compañeras que le crucen la pierna al profesor», algunos testimonios aseguran conocer el caso de profesores que «piden favores sexuales a las universitarias» y otros que de manera pública manifiestan actitudes ofensivas y sexistas:

Yo sí, porque hay un profesor que habla mucho sobre las mujeres, muy incómodo, muy morboso o sea no específica hacia nosotras, pero yo creo que sí, muy grotesco, por respeto a nosotras no debería hablar así, que lo haga con los hombres (Sara, estudiante de mecánica) 
Guardar silencio, permanecer calladas y no denunciar son enseñanzas aprendidas por las estudiantes. Todas estas prácticas se han forjado desde sus contextos familiares y reforzadas en un sistema educativo patriarcal que reproduce situaciones donde la socialización diferenciada de género y las prácticas de sociabilidad y convivencia están fuertemente enraizadas en los pensamientos y actuares de la masculinidad hegemónica.

\section{A MODO DE REFLEXIÓN}

Las aulas universitarias mixtas son una realidad. Sin embargo aún a mitad de la segunda década del siglo XXI, estudiar alguna carrera en un escenario fuertemente masculinizado es tener un arma de doble filo. Para las participantes en esta investigación, los desafíos se perfilan en tres momentos: al decidir ingresar, al transitar en la formación y durante las expectativas laborales. En todas las circunstancias (entrar, permanecer y ser reconocidas en el campo laboral), el dogma masculino las obliga a demostrar continuamente sus aptitudes y habilidades.

Las mujeres que estudian alguna de las seis ingenierías de la FCBIyT han ingresado para probar sus capacidades y desarrollarse intelectualmente, a pesar de que la vía de acceso no es nada sencilla. La opción es consciente, saben que las disciplinas son áreas de gran dificultad y que demandan alta concentración e inteligencia, atributos que ellas poseen. Sólo una de las diecisiete entrevistadas dijo haber querido estudiar una profesión del área de las ciencias sociales. Esta información indica que las estudiantes cursan la ingeniería que eligieron por convicción, deseo y capacidad intelectual. Pero reconocen que la permanencia no es fácil y su recorrido no es libre, persistir las enfrentará con una montaña a escalar. Las opciones pueden ser «pasar de largo» como una actitud voluntaria para evadir situaciones incomodas, pasar desapercibidas, camufladas con vestimenta que las haga parecer igual al resto -la mayoría varones-, utilizar escaso o nulo maquillaje, norma que puede ser permisible cuando ellas participen de modo oficial en actos públicos e incluso transitar de modo invisible.

Los hombres, por el contrario, sin ningún problema ocupan confortablemente los espacios en esta facultad, juegan, hablan en voz fuerte y con palabras altisonantes. Ellos actúan así porque están en ambientes reconocidos, son de ellos, ellos son los dueños, los propietarios. Las mujeres que eventual y transitoriamente son visitantes o huéspedes, escasamente se dejan ver, apenas se escuchan sus voces. Ellas prefieren arrinconarse, estar juntas, platicar, realizar actividades académicas, hacer uso de la biblioteca o de los laboratorios, pues exponerse las coloca en posición de vulnerabilidad y en «la mira», en el centro 
o el blanco de la atención que a veces puede ser bastante benevolente y otras, la mayoría, punzante y sexista.

Si bien, en la generalidad, las mujeres no distinguen de modo directo algún tipo de malos tratos por parte de los hombres, algunas otras sí lo perciben y otras más justifican el actuar masculino. Recordemos que en estas áreas, la formación pro igualdad es aún una historia no iniciada. Sin embargo, hay ciertos asuntos a reflexionar: los hombres hablan de ellas, de su sexualidad y de sus cuerpos. Ellas son identificadas como objetos que pueden lastimar hablando mal, desprestigiando, haciendo correr rumores sobre su vida íntima. Por su parte, las mujeres de manera inmediata no reaccionan frente a prácticas sexistas, ellas estudian, son disciplinadas, se resguardan, comparten con otras y disfrutan su permanencia en la Universidad.

Para las estudiantes es preferible no mantener contacto o evitar confrontaciones por temor a exponerse y ser la siguiente en la lista de los murmullos malsanos y crueles. Estar junto a ellos no es un buen sitio, se corre riesgos y se tienen que tolerar conversaciones misóginas y denigrantes. Es mejor estar juntas, entre mujeres, hablar de temas que importan, hacer tareas escolares, apoyarse, sentirse bien. Ellas son más responsables, cumplen más, son ordenadas, detallistas, inteligentes, pulcras, atributos que denotan estereotipos de género, pero que utilizan a su favor. Sin embargo, a pesar de todas estas cualidades, no logran solidificar prácticas de asertividad como una habilidad personal que les permita expresar directamente los propios sentimientos, opiniones y pensamientos, y defender sus derechos en el momento oportuno, de la forma adecuada.

A pesar de estas virtudes femeninas, las estudiantes no sienten seguridad para manifestar sus opiniones en el aula. La mayoría permanece callada, no habla, no discute. El temor a equivocarse es uno de los menores, el no sentirse apoyadas por el profesorado que las censura, no les da oportunidad, las ignora o anula sus opiniones, es más fuerte que sus ideas. En contraparte, surge el temor a que no les den su lugar, no les prestan tiempo, no toman en cuenta sus situaciones, son morbosos, se presume piden favores sexuales, las hostigan y no les guardan respeto.

En su futuro próximo distinguen un lugar en la vida laboral cargando a cuestas el dominio del espacio doméstico como exclusivo de ellas, el cual sostiene además la creencia social -de ofertantes de empleo y de la sociedad en conjunto-que estas áreas son para los hombres. El mañana no es alentador para la formación científica, ellas se retratan permaneciendo en «rincones»o encerradas (laboratorios, actividades gerenciales, empresas), de tal forma que la investigación se vuelve un espacio privilegiado y otras áreas de innovación 
tecnológica y apertura laboral se diseminan, y la docencia es cada vez más un empleo precario.

A pesar de todas las dificultades, algunas lo han hecho, lo continúan haciendo y han aprendido a sortear obstáculos y zanjear las brechas de forma tal que el camino andado sea más plano y menos enlosado, y favorezca la incursión de generaciones venideras. La Universidad Autónoma de Tlaxcala, en este gran reto, debe emprender acciones normativas y prácticas para que en este espacio de sociabilidad y convivencia entre géneros sea en un presente y en un futuro inmediato más justo e igualitario para quienes lo habitan.

\section{REFERENCIAS BIBLIOGRÁFICAS}

Álvarez-Gayou Jurgenson, Juan Luis. Cómo hacer investigación cualitativa. México: Paidós Educador, 2004.

Álvarez Liébana, Natalia, Ana Moreno, Vicente Riveira y Carlos Mataix. «Mujeres e Ingeniería. Caso de estudio en la ETSII-UPM». Ponencia presentada en $4^{\text {th }}$ International Conference on Industrial Engineering and Industrial Management. 9 de julio de 2016. Disponible en: http://www.anamorenoromero.net/documentos/Anexo4_ETSII-UPM.pdf

ANUIES. Anuarios estadísticos de Educación Superior. Disponible en: http://www. anuies.mx/iinformacion-y-servicios/informacion-estadistica-de-educacionsuperior/anuario-estadistico-de-educacion-superior, 10-12-2016.

Arango Gaviria, Luz Gabriela. «Género e ingeniería: la identidad profesional en discusión». Revista Colombiana de Antropología 42 (2006): 129-156.

Ballarín Domingo, Pilar. «Los códigos de género en la universidad». Revista Iberoamericana de Educación 68 (2015): 19-38.

Buquet, Ana, Jennifer Ann Cooper, Mingo, Araceli, Hortensia, Moreno. Intrusas en la universidad. México: UNAM, 2013.

Camacho, Gloria. Mujeres Fragmentadas. Quito: CEPLAES, 1997.

Cantillo Barrios, Ligia y Delma Rocha Álvarez. «Las relaciones de género y la educación superior en Colombia. Estudio de caso: Universidad del Atlántico», Estudios de género. Nuestros pasos en el Caribe colombiano. Comp. Rafaela Vos Obeso. Colombia: Universidad del Atlántico, 2007, 1-18.

Castro, Roberto y Verónica Vázquez García. «La Universidad como espacio de reproducción de la violencia de género. Un estudio de caso en la Universidad Autónoma Chapingo, México». Estudios Sociológicos 78 (2008): 587-616.

Coates, Jennifer. Mujeres, hombres y lenguaje. Un acercamiento sociolingüístico a las diferencias de género. México: Fondo de Cultura Económica, 2009.

Costa Ferreira, María Regina y Rogério Goulart Silva. «La cultura del patio de recreo: las relaciones de niños y. Niñas en primaria». Ponencia presentada en el XXVII Congreso de la Asociación Latinoamericana de Sociología. VIII Jornadas 
de Sociología de la Universidad de Buenos Aires (2009) 9 de enero de 2016. Disponible en: http://www.aacademica.org/000-062/823

Díaz Cruz Rodrigo. «La vivencia en circulación. Una introducción a la antropología de la experiencia». Alteridades 7 (1997): 5-15.

Flores Bernal, Raquel. «Violencia de género en la escuela: sus efectos en la identidad, en la autoestima y en el proyecto de vida». Revista Iberoamericana de Educación 38 (2005): 67-86.

Gallego Noche, Beatriz. «La igualdad de género en la práctica deportiva y su contribución a la educación para la ciudadanía y la democracia». Journal for Educators, Teachers and Trainers 5.3 (2014). 17 de julio de 2016. Disponible en: http://rodin.uca.es/xmlui/bitstream/handle/10498/16949/La\%20igualdad\%20 de\%20g\%C3\%A9nero\%20en\%20la\%20pr\%C3\%Alctica\%20deportiva_ solo\%20art\%C3\%ADculo.pdf? sequence $=1$

Gallego Noche, Beatriz y Araceli Estebaranz García. Mujeres que abren camino en el deporte: factores influyentes en las situaciones de igualdad y discriminación. Universidad de Sevilla. 14 de enero de 2016. Disponible en: http://www.mujerydeporte.org/documentos/docs/MUJERES\%20QUE\%20 ABREN\%20CAMINO\%20EN\%20EL\%20DEPORTE\%20FACTORES\%20 IN F LUYEN TES\% 20 EN \% 20 LAS\% 20SITUACIONES\% 20 DE \% 20 IGUALDAD\%20Y\%20DISCRIMINACI\%C3\%93N.pdf

García Pérez, Rafael, Estrella Ruiz Pinto y Ángeles Rebollo Catalán. «Preferencias relacionales de género en el contexto escolar: Una nueva medida para el diagnóstico de relaciones de género en educación». RELIEVE 1, (2016): 1-21.

Guevara Ruiseñor, Elsa y Alba García López. «Orden de género y trayectoria escolar en mujeres estudiantes de ciencias exactas y naturales». Investigación y Ciencia 46 (2010):10-17.

Hernández, Alfonso. «La violencia de género y sus prácticas en la Universidad de Guadalajara». Violencia de Género en Instituciones de Educación Superior en México Coord. Rosa María González Jiménez, México: IPN-CONACYT, 2013, 135-172.

Larena Fernández, Rosa y Silvia Molina Roldán. «Violencia de género en las universidades: investigaciones y medidas para prevenirla». Trabajo Social Global, Revista de Investigaciones en Intervención Social 2 (2010): 202-219. 3 de febrero de 2016. Disponible en http://tsghipatiaeditorial.com/index.php/tsg1

López Francés, Inmaculada, María Isabel Viana Orta y Sánchez Sánchez, Beatriz. «La equidad de género en el ámbito universitario: ¿un reto resuelto?». Revista Electrónica Interuniversitaria de Formación del Profesorado, 19.2 (2016): 349-361. 26 de abril de 2016. Disponible en http://dx.doi.org/10.6018/ reifop.19.2.211531

Lorente Acosta, Miguel. «Violencia de género, educación y socialización: acciones y reacciones». Revista de Educación 342 (2007): 19-35. 
Maceira Ochoa, Luz. «Investigación del currículo oculto en la educación superior: alternativa para superar en sexismo en la escuela». Revista de Estudios de Género. La Ventana 21 (2005): 187-227.

Malegarie, Jessica y Romina Tavernell. «Educación para la integración ¿Cómo se aborda la diversidad en el aula?». Question. Revista Especializada en Periodismo y comunicación 19 (2011): 62-124.

Martínez Lozano, Consuelo Patricia y Daniel Solís Domínguez. «El entorno escolar y familiar en la construcción de significaciones de género y sexualidad en jóvenes de Guadalajara». Revista de Estudios de Género. La Ventana 29 (2009): 146-183.

Martínez Moscoso, Dolores Marisa. Práctica docente con equidad de género. Una guía de trabajo. México: Universidad de Guadalajara, 2012.

Mejía Navarrete, Julio. «Problemas centrales del análisis de datos cualitativos». Revista Latinoamericana de Metodología de la Investigación Social 1 (2011): 47-60. 8 de marzo de 2015. Disponible en: http://www.relmis.com.ar/ojs/index. php/relmis/article/view/11/13

Mingo, Araceli y Hortensia Moreno. «El ocioso intento de tapar el sol con un dedo: violencia de género en la universidad». Perfiles Educativos 148 (2015): 138-155.

Mingo, Araceli. « ¿Ni con el pétalo de una rosa? Discriminación hacia las mujeres en la vida diaria de tres facultades». Revista Iberoamericana de Educación Superior 18 (2016): 24-41.

Oliveros Ruiz, María Amparo, Eduardo Cabrera Córdoba, Benjamín Valdez Salas y Michael Schorr Wienner. «La motivación de las mujeres por las carreras de ingeniería y tecnología». Entreciencias. Diálogos en la sociedad del conocimiento 9 (2016): 89-96.

Paulín, Horacio, Marini Tomasini, Paula Bertarelli, Florencia D’aloisio, Guido García Bastán, Soledad Martínez, Guadalupe Torres y Ailín Vallejo. «Sociabilidad juvenil en la escuela media: Análisis de las prácticas relacionales y los procesos de reconocimiento entre estudiantes». VII Jornadas de Sociología de la UNLP. (2012). 4 de diciembre de 2015. Disponible en: http://www.memoria.fahce. unlp.edu.ar/trab_eventos/ev.2174/ev.2174.pdf

Peña, María Alejandra y Lillo Buschiazzo. Elección de carreras universitarias y género el Caso de trabajo social e ingeniería. Tesis para optar al grado de magister en estudios de género y Cultura, mención ciencias sociales, Universidad de Chile. (2006). 8 de junio de 2016. Disponible en: http://www.ciegchile.com/ wp-content/uploads/2014/05/cs39-penaylillom222.pdf

Pérez Naranjo, Julia y Armando Martín Ibarra López. «La socialización Mediada en las Interacciones juveniles. La Construcción del Yo en Facebook». Revista de Tecnología y Sociedad 4 (2013): 1-12. 
Preciado Cortés, Florentina Karla Kae Kral y María Guadalupe Álvarez Ramón. «Navegando entre dos mares: mujeres en el contexto de la cultura de ingeniería». Revista Iberoamericana de Educación 68 (2015): 39-58.

Rebolledo, Loreto. «Género y Espacios de Sociabilidad. La Escuela como Lugar de Encuentro con los 'Otros'». II Congreso Chileno de Antropología. (1995): 89-97. 9 de junio de 2015. Disponible en: https://www.aacademica.org/ii.congreso. chileno.de.antropologia/16.pdf

Sánchez Silva, Modesto. «La metodología en la investigación cualitativa». Revista Mundo Siglo XXI 1 (2005):115-118. 6 de agosto de 2015. Disponible en: http://132.248.9.34/hevila/MundosigloXXI/2005/nol/8.pdf

Simmel, George. Sobre la individualidad y las formas sociales. Buenos Aires: Universidad Nacional de Quilmes, 2002.

Vázquez García, Verónica y María Eugenia Chávez Arellano. «Masculinidad hegemónica en la Universidad Autónoma Chapingo. Un estudio de caso entre estudiantes». Textual 49 (2007): 41-65.

Weiss, Eduardo. «Más allá de la socialización y de la sociabilidad: jóvenes y bachillerato en México». Educ. Pesqui 41 (2015): 1257-1272. 
Para enlazar con este artículo / To link to this article:

http://dx.doi.org/10.14198/fem.2017.29.04

Para citar este artículo / To cite this article:

Fueyo Gutiérrez, Aquilina. «¿Ya somos iguales? Visibilización de las desigualdades de género en la educación mediática de las estudiantes universitarias». En Marcos Jesús Iglesias Martínez e Inés Lozano Cabezas (coords.), La (in) visibilidad de las mujeres en la Educación Superior: retos y desafios en la Academia. Feminismo/s, 29 (junio 2017): 99-124, DOI: 10.14198/fem.2017.29.04

\title{
¿YA SOMOS IGUALES? VISIBILIZACIÓN DE LAS DESIGUALDADES DE GÉNERO EN LA EDUCACIÓN MEDIÁTICA DE LAS ESTUDIANTES UNIVERSITARIAS
}

\author{
ARE WE ALREADY EQUALS? VISIBILITY OF GENDER \\ INEQUALITIES IN MEDIA EDUCATION OF HIGHER \\ EDUCATION FEMALE STUDENTS
}

\author{
Aquilina FUEYO GUTIÉRREZ \\ Universidad de Oviedo \\ mafueyo@uniovi.es \\ orcid.org/0000-0001-8668-923X
}

\section{Resumen}

En la Educación Mediática para la formación de los profesionales de la educación hemos asumido el desafío de incorporar un enfoque de género en actividades que nos permitan dotar a las jóvenes universitarias de herramientas para identificar las desigualdades que les afectan y elaborar estrategias comunicativas y creaciones audiovisuales para trabajar sobre ellas. En este artículo abordamos los resultados de un proceso de investigación sobre la práctica desarrollado a lo largo de varios años. En él analizamos los contenidos, las características de las creaciones audiovisuales sobre las situaciones de desigualdad, el diseño de las actividades y las decisiones pedagógicas que adoptamos. Además, presentamos dos casos concretos que nos permiten ejemplificar cómo dichas experiencias visibilizan las desigualdades de género que, en ocasiones, permanecen ocultas en las instituciones universitarias y llevan a las estudiantes a adoptar una posición más consciente y activa frente a dichas desigualdades.

Palabras clave: Educación Mediática, pedagogía, enfoque de género, Educación Superior, investigación sobre la práctica. 


\begin{abstract}
In Media Education for educational professionals training we have taken up the challenge of incorporating a gender approach into activities that allow us to equip female university students with tools to identify the inequalities that affect them and to develop communicative strategies and audiovisual creations to work on them. In this article we show the results of a practice based research process wich we develop over several years. In it we analyze the contents, the characteristics of the audiovisual creations about the situations of inequality, the design of the activities and the pedagogical decisions that we adopt. Also we describe two specific cases that allow us to exemplify how these experiences show the gender inequalities that sometimes remain hidden in the higher education institutions and how they make the students to adopt a more conscious and active position against of these inequalities.
\end{abstract}

Keywords: Media Education, pedagogy, innovative practices, gender approach, higher education, practice based research. 


\section{DESIGUALDAD DE GÉNERO EN EL CONTEXTO UNIVERSITARIO. MÁS ALLÁ DE LO POLÍTICAMENTE CORRECTO}

Más de 20 años de trabajo en la docencia universitaria sobre la educación mediática, en una institución con un claro predominio numérico de las mujeres (tanto estudiantes como profesoras), nos han llevado a plantearnos la necesidad de entender cómo, en determinados momentos y en determinadas prácticas, estructuramos las diferencias y las identidades de género y, sobre todo, cómo podemos transformar estas prácticas en orden a conseguir que esas identidades se construyan con mayor justicia para las mujeres jóvenes. Esto nos ha impulsado a enfocar los contenidos sobre educación mediática hacia una formación feminista para el empoderamiento de las estudiantes que no pierda de vista las facetas de su formación como profesionales y como personas.

La reflexión sobre nuestra práctica educativa compartida con otras mujeres (profesoras y estudiantes) nos ha permitido entender cómo nos enseñaron y aprendimos a ser estudiantes primero y profesoras después, y cómo nosotras hemos enseñado a las estudiantes universitarias a ser futuras pedagogas o maestras. Es decir, nos ha permitido identificar los «regímenes pedagógicos» a los que hemos sido sometidas y mediante los que hemos ido elaborando nuestra identidad de género tanto a nivel personal como profesional. Los estudios para arrojar luz sobre estas cuestiones se han desarrollado con mayor profundidad en los contextos no universitarios y solo después se han empezado a explorar, desde diferentes campos, los mecanismos que crean la desigualdad de género en los contextos universitarios y como se produce en ellos la construcción del género (Frutos 344-354; Callejo 197; Guil 31-33).

Es sabido que en la Universidad española el alumnado se distribuye, siguiendo unas pautas muy estereotipadas, según género, de forma que las titulaciones encuadradas en el ámbito de las Ciencias de la Salud y las Humanidades están muy feminizadas, mientras que las carreras Técnicas están muy masculinizadas. Nuestra experiencia en enseñanzas en las que este fenómeno es muy claro (Magisterio y Pedagogía) nos permite decir que en ellas se realizan prácticas que, de alguna forma, seleccionan y segregan a las mujeres a pesar de su mayoría numérica. Esto es especialmente visible cuando se analizan 
esas prácticas en campos donde lo tecnológico ${ }^{1}$ predomina. En la formación que reciben las futuras profesionales de la educación (maestras, pedagogas, profesoras de secundaria) en el ámbito de la tecnología educativa se identifica por un lado una selección del contenido en la que se obvian las desigualdades de género en el acceso y dominio de la tecnología, lo cual contribuye a invisibilizar y reafirmar dichas desigualdades. Por otro, las prácticas que se desarrollan en las aulas universitarias suelen ignorar que chicas y chicos parten de una socialización previa diferenciada sobre todo lo que tiene que ver con la tecnología, lo que determina cómo perciben sus destrezas con respecto a la misma². Las mujeres jóvenes parten, por tanto, de diversas habilidades y conocimientos previos pero, en concreto, ellas tienden a percibirse como menos hábiles y, por ello, se autolimitan en el uso de las herramientas tecnológicas. Cuando se trabaja en grupos de chicos y chicas, en asignaturas donde se usan tecnologías, es habitual que ellos lleven la iniciativa a la hora de manejar las herramientas, tomar decisiones, coordinar la actividad o diseñar los productos audiovisuales, mientras ellas, salvo excepciones, se colocan en un segundo plano.

Los trabajos de muchas autoras y muchos autores (Aguilar Carrington y Bennet; Correa; Lomas; Peña y Fabretti; Zulo; Galarza, Cobo y Esquembre; Cobo; Soria) nos han ayudado a entender la forma en que la "prensa femenina», la publicidad, el cine o la televisión han contribuido mediante los textos de la cultura de masas a construir y difundir a gran escala arquetipos y estereotipos de lo femenino y lo masculino que consagran la desigualdad de las mujeres en los ámbitos de los íntimo y de lo público, y a imponer a las personas una determinada forma de entender las relaciones entre hombres y mujeres. En último término la cultura de masas no solo sirve para construir la identidad sociocultural de las personas sino que proporciona importantes herramientas de consenso, transmisión de estilos de vida, estereotipos e ideologías (Lomas 261). Son muchos estudios los que han identificado, por ejemplo, el total protagonismo masculino en las informaciones de prensa, el predominio absoluto de los hombres en las fotografías que se utilizan para ilustrar las noticias, el

1. Lo tecnológico es un ámbito esencialmente masculino. Asignaturas como Tecnología Educativa o Nuevas Tecnologías aplicadas en la Educación son la referencia de nuestros comentarios.

2. Se viene constatando una socialización previa diferenciada entre niños y niñas en el campo de la tecnología (Anguita y Alario, 2004, 2). Esto se une a que el sistema educativo se orienta oficialmente hacia la igualdad de géneros y tiene, por norma, que promoverla, pero genera, de facto y en la práctica, desigualdad en muchos campos. Esa desigualdad se naturaliza y se explica, a veces, por factores personales o de predisposición en razón del género (Callejo, 2004). Otras veces sencillamente se invisibiliza como ocurre con el tema de la disposición a la tecnología de las mujeres. 
arrinconamiento de las mujeres en las secciones de sociedad, espectáculo y ocio, a la vez que se les excluye de las secciones de política, economía o deportes, el hábito de cualificarlas emocionalmente, por sus circunstancias familiares o por su aspecto externo cuando protagonizan informaciones relevantes, las diferencias que marcan las informaciones en prensa focalizadas en hombres y mujeres con respecto a los roles, las prioridades, etc. (Soria 158-162). La publicidad sigue relegando a las mujeres al ámbito doméstico circunscribiéndolas en su maternidad, su obsesión por la belleza y el consumo caprichoso, mientras valora en los hombres el éxito público, la autoridad y el poder, presentando a unas y a otros de forma totalmente estereotipada tanto en el ámbito doméstico, como en el laboral pasando por el ámbito privado. Si bien es claro que en la actualidad ya no es «políticamente correcto» representar los estereotipos más clásicos en los medios, es obvio que se buscan procedimientos más sutiles para utilizar una representación de hombres y mujeres como reclamo publicitario en la que sigue predominando una mirada mayoritariamente androcéntrica que sitúa a la mujer como objeto de deseo por diferentes procedimientos (Lomas 268-274).

Las redes sociales y los dispositivos móviles han venido a crear nuevas formas de representación provenientes sobre todo de la publicidad, en la que a través de «selfies» (autopresentaciones), en ocasiones muy sexualizadas, las mujeres jóvenes adoptan «identidades de escaparate» en las que ellas se muestran atractivas, subordinadas, fraccionadas y ausentes mientras que ellos, los chicos, se muestran poderosos, activos y presentes (Tortajada, Aruña y Martínez 178). Esas exposiciones a internet suelen estar asociadas «con la internalización del ideal de cuerpo femenino delgado y con la vigilancia del cuerpo en orden a conseguir esa delgadez [...] confirmando el papel de internet y las redes sociales en la amplificación de los efectos de los medios tradicionales sobre las preocupaciones de las mujeres por su imagen corporal» (Tiggemann y Slater 533). Las chicas «se exponen a la crítica sobre su imagen y su apariencia física exhibiéndose en una gran cantidad de fotografías, mucha de ellas espontáneas, pero muchas también posadas [...] se exponen también consciente o inconscientemente a la calificación y refuerzo o rechazo por parte de los demás» (Estébanez y Vázquez 95-96). Aparecen de forma diferenciada las bocas, los besos y los escotes en las fotos de las chicas, y los abdominales y los torsos en las de los chicos. Imágenes sensuales que refuerzan los estereotipos de género clásicos que ya estaban en los la base de los trabajos de Goffman en los años setenta (Bullingham y Vasconcelos 103). Cabe señalar también que, en algunas ocasiones, entra en juego la creatividad y esos estereotipos son sometidos a interesantes procesos de apropiación y reconstrucción personal. 
(García Canclini, Cruces y Castro Pozo 267-268 y Tortajada, Aruña y Martínez 182-184, Estébanez y Vázquez 91-93).

Los medios de comunicación de masas, los nuevos y los antiguos, se han convertido, así, en industrias que construyen un «currículum paralelo» orientado a la construcción de identidades ligadas al consumo y sustentado en eficaces pedagogías públicas en las que «el aprendizaje y la enseñanza son las relaciones intersubjetivas fundamentales de la vida cotidiana que se dan dentro y fuera del aula, siempre están marcadas por el género y son interculturales» (Luke 23). En esos relatos audiovisuales que configuran el currículum paralelo los medios, junto con otras industrias culturales, conforman lo que Roland Barthes (1957) denominó el «mundo natural de la ideología dominante». Es ahí donde se han socializado las mujeres jóvenes con las que trabajamos y es ahí donde han construido su identidad de género, entre otras, por tanto es de ahí de donde arranca nuestra propuesta.

Nuestro trabajo se sitúa, por tanto, en el cruce de dos pedagogías: la que se da en las aulas universitarias feminizadas en las que se trabaja con recursos tecnológicos y la que hacen los medios de comunicación con las mujeres estudiantes con las que desarrollamos nuestro trabajo. En él planteamos que para el empoderamiento de estas mujeres jóvenes es preciso desarrollar su capacidad para verse a sí mismas de forma crítica a través de los medios, pero también para crear narrativas alternativas a las que los medios difunden sobre su papel subalterno. Ello implica desarrollar la conciencia de cómo su identidad de género se ha construido de forma sesgada y de que esta construcción puede limitarlas como futuras profesionales. También implica su participación en actividades de aprendizaje colaborativo para la producción y difusión de mensajes audiovisuales que, tomando como referencia teórica el desarrollo del campo de los «nuevos alfabetismos», incorporen todas las estrategias de «remix digital», de las actividades de «blogueo y mediacasteo» como actividades de participación, el salto a la red, móvil, etc. (Knobel y Lankshear 108-110; Phillippi y Avendaño 67; Estébanez y Vázquez, 93).

Pese a este panorama, cabe señalar que las prácticas de educación mediática en el nivel universitario no han experimentado grandes cambios. En congresos, conferencias y seminarios se tratan la «convergencia de medios», la cultura «transmedia», la «cultura de la participación», los «multialfabetizaciones», etc. mientras que la enseñanza de los contenidos relacionados con los medios de comunicación parece seguir anclada en un tipo de soportes únicos (libros, textos y artículos) y en metodologías también bastante tradicionales y únicas (exposiciones orales, lecturas, etc.). Estas prácticas colocan al alumnado en un papel pasivo en relación con el uso y manejo de los medios de comunicación, un papel que está a años luz de sus experiencias cotidianas con los medios 
digitales y que merma, o directamente aniquila, el gran potencial del aprendizaje que podría conseguirse si parte de esas experiencias se aprovechasen en las aulas (Fueyo, Tornero y Rodríguez-Hoyos).

La convergencia de medios y de formas y prácticas culturales que han posibilitado las tecnologías digitales y los nuevos entornos comunicativos es un referente importante para estos cambios metodológicos que parecen necesarios. El conjunto de intercambios e interacciones que sobre la cultura popular se dan en el ciberespacio convergente son un referente para la formación de los profesionales de la educación. Estos profesionales tendrán que trabajar con niños y jóvenes que están fuertemente socializados en esa cultura y dicha socialización determina de forma importante sus posibilidades de aprendizaje. Por otro lado, los jóvenes estudiantes universitarios utilizan la cultura popular como un recurso simbólico para la creación de sus propios significados e identidades, por lo que su incorporación a los procesos de formación nos permite utilizarla adecuadamente para contribuir a desarrollar los significados e identidades profesionales de los estudiantes (Fueyo y Sánchez; Fueyo, Fueyo, Tornero y Rodríguez-Hoyos).

Los medios son, sin duda, parte de la cultura de las personas jóvenes y debemos partir de su conocimiento y experiencia para capacitarles en su manejo crítico, desarrollar su comprensión del funcionamiento de los mismos, fomentar su participación en la cultura mediática y potenciar tanto su faceta de emisores como de receptores. Pese a que en diferentes ámbitos se alardea de que los jóvenes son «nativos digitales», realmente los espacios virtuales en los que se mueven están más bien ocupados por las nuevas formas de marketing, y en ellos son escasas las producciones culturales realizadas por los propios jóvenes (Fueyo 25-26). Combinar adecuadamente el análisis crítico y la producción, la teoría y la práctica, permite que los estudiantes desarrollen un conocimiento explícito y consciente del funcionamiento de los medios, partiendo de la convicción de que los jóvenes son activos, críticos y, en ocasiones, bastante sofisticados en la lectura y uso de los medios populares (Buckingham 2007, 250-251).

Sabemos también que la producción de contenidos con los medios, de manera grupal y crítica mediante metodologías deliberativas y participativas, tiene muchas ventajas. Por un lado implica una lectura social de los textos mediáticos en la que los significados no se establecen de manera individual, sino a través de la interacción y el diálogo. Cuando dentro del grupo se adoptan posiciones críticas para producir un nuevo discurso, cada uno identifica sus gustos e identidades, y al intervenir directamente sobre la cultura popular, los estudiantes acaban definiéndose activamente a sí mismos en relación con fuerzas sociales, culturales e ideológicas más amplias (Buckingham y Sefton-Green 
1994, 82). Estas actividades de producción no solo desarrollan habilidades técnicas de autoexpresión o creatividad, sino que también posibilitan la comprensión de cómo operan los medios y la adopción de formas reflexivas de uso. La producción mediática ofrece un espacio que permite a las estudiantes explorar sus vínculos emocionales y el disfrute que experimentan con los medios de una manera más subjetiva y lúdica que con análisis críticos más racionalizados.

La producción propia de materiales audiovisuales nos permite, además, abordar aspectos controvertidos de la cultura audiovisual juvenil. Uno de los prioritarios para la formación de los profesionales de la educación es el referido al género. Los estudios culturales de género han hecho importantes contribuciones al conocimiento de cómo funcionan los medios de comunicación actuales en la construcción de la identidad femenina y cómo perpetúan la desigualdad a través de mecanismos sofisticados. El estudio de las representaciones mediáticas de género centrado en el análisis de estereotipos y en la identificación de las imágenes negativas sobre la mujer ha tenido que ser revisado en el nuevo contexto de los medios de comunicación. Las tendencias tradicionales de representación de las mujeres han sido modificadas por la publicidad que, conocedora de los cambios sociales operados en las últimas décadas, ha creado nuevos estereotipos más sutiles, con representaciones de las mujeres encerradas en su feminidad, y nuevas formas de opresión simbólica a través de la hipersexualización de sus cuerpos como base para una estricta política de auto-control y de vigilancia de las mujeres (Gill 2007, 73 y 2012; Cobo 15-16). Estas nuevas tendencias utilizan representaciones en las que las mujeres se muestran poderosas y liberadas y que incorporan mensajes aparentemente feministas pero muy individualizados. Estos mensajes desvirtúan las propuestas feministas convirtiéndolas, a ellas y al propio feminismo, en obstáculos engorrosos para las mujeres jóvenes que parecen impedirles el disfrute de las maravillosas propuestas y la felicidad ilimitada que les promete la economía neoliberal a través del consumo (Tolman 748; Lazar 38-39; McRobbie 2007; 718-721 y 2009, 13-17; Harris, 2015, 147).

\section{EL CONTEXTO LOS CASOS Y LA METODOLOGÍA DE INVESTIGACIÓN}

La experiencias que analizamos en este artículo están vinculadas a la asignatura Tecnología Educativa del grado de Pedagogía, que actualmente es una asignatura de primer curso que tiene como objetivo fundamental formar al alumnado en el análisis, diseño y manejo de los medios, tanto didácticos, como de comunicación para incorporarlos a procesos de enseñanza y aprendizaje de diferente naturaleza. En esta asignatura se desarrollan las competencias de las 
personas jóvenes para analizar con sentido crítico los mensajes de los medios y crear mensajes propios y alternativos sobre su propia realidad usando internet $y$ las redes sociales para difundirlos. Es una asignatura con una carga docente de 6 ECTS, de carácter obligatorio y con un componente práctico del $60 \%$. Se desarrolla con un alumnado mayoritariamente femenino (entre el 80 y el $90 \%$ de mujeres según los cursos) y al estar situada en primer curso las edades del alumnado oscilan entre los 19 y los 21 años. A lo largo del cuatrimestre que dura la asignatura, el alumnado tiene que trabajar de forma transversal sobre «las representaciones de las mujeres en los medios de comunicación» mediante la realización de actividades individuales y colectivas de producción y análisis de mensajes audiovisuales: análisis de publicidad, diseño de una campaña de sensibilización con enfoque de género, realización de un programa de audio, realización de un video y elaboración de un blog colectivo. Todas estas producciones se difunden en el blog y la cuenta de Facebook de la asignatura.

Los resultados incluidos en este artículo se centran en la metodología y el contenido de las actividades para la realización de las «campañas de sensibilización» y son parte de un trabajo de investigación más amplio sobre los procesos de enseñanza y aprendizaje desarrollados durante seis cursos académicos. En esa investigación se utiliza como metodología general la investigación-acción con un enfoque autobiográfico, a la que se ha incorporado como metodología complementaria el estudio de casos. Esta investigación tiene los siguientes objetivos:

- Analizar los resultados de la metodología de creación de representaciones audiovisuales para la educación mediática de las jóvenes universitarias en lo referido a las dimensiones de producción, utilización del lenguaje audiovisual, análisis crítico de los mensajes de los medios, etc.

- Analizar la capacidad de esta perspectiva metodológica a la hora de visibilizar situaciones de desigualdad que afectan a las mujeres jóvenes.

- Estudiar las temáticas y los recursos que utilizan las estudiantes universitarias a la hora de realizar las creaciones audiovisuales.

- Analizar las alternativas metodológicas que se toman ante las diferentes situaciones planteadas en el aula al trabajar estas temáticas.

- Revisar las posibilidades de hacer una enseñanza feminista con enfoque de género a través de la cultura popular.

Las actividades analizadas implicaron a más de 400 estudiantes que realizaron las 64 producciones audiovisuales que se estudian en este artículo. Estas producciones corresponden a las «campañas de sensibilización» que pueden verse en los blogs anuales de la asignatura cuyas direcciones son: 
TecnoEducaAst http://tecnoeducaast.blogspot.com.es/

TecnoEducAst12 http://tecnoeducast12.blogspot.com.es/

TecnoEducAst13 http://tecnoeducast13.blogspot.com.es/

TecnoEducAst14 http://tecnoeducast14.blogspot.com.es/

TecnoEducAst15 http://tecnoeducast15.blogspot.com.es/

TecnoEducAst16 http://tecnoeducast16.blogspot.com.es/

Los instrumentos utilizados para la recogida de la información en el proceso de investigación han sido: un cuestionario de carácter individual que se administraba a las estudiantes al inicio del curso, una «check list» para registrar las temáticas de las producciones audiovisuales, el diario de las sesiones de clases para registrar las notas de las observaciones relevantes sobre cada uno de los casos, las entrevistas grupales finales sobre cada una de las producciones realizadas y 6 grupos de discusión (uno por curso académico) realizados combinando la presencia de estudiantes de cada grupo para contrastar cuestiones metodológicas y el análisis de documentos escritos sobre el diseño de la práctica y sobre las producciones de las estudiantes. Para el estudio al que nos referimos en este artículo centrado en las campañas de sensibilización se realizaron análisis de los datos referidos a tres ámbitos:

1. El contenido de las producciones: se contabilizaron las producciones de cada curso y se identificaron los temas tratados y la frecuencia de cada uno de ellos en los 6 años de estudio.

2. El diseño de la práctica: se analizaron los programas y los materiales escritos que se utilizan para guiar a los estudiantes en la realización de las actividades prácticas que se estudian como casos. Estos materiales se encontraban alojados en el campus virtual de la asignatura.

3. El desarrollo de la práctica: se analizan las producciones de los estudiantes incluidas en el blog anual de la asignatura. Se analizan producciones similares por el contenido o por la línea temática. Se analiza la participación de los estudiantes en el desarrollo de estas actividades a través de los foros y herramientas virtuales del campus en el que se aloja la asignatura. De todo el material disponible destacamos por su interés los documentos de diseño de la campaña que produce el alumnado y las notas de observación de aula tanto de la docente como de la observación participante. Todo ello se ha complementado con los resultados de una entrevista online realizada a los estudiantes sobre su participación en espacios virtuales, antes y después de que hayan cursado la asignatura. 
El proceso de análisis de los datos recopilados sobre la actividad de creación de producciones audiovisuales se desarrolló como sigue:

1. Se hizo un análisis de las producciones para determinar, describir y cuantificar los contenidos que se abordaban en las mismas.

2. Entre todas las producciones se seleccionaron las dos más significativas, considerando como tales los que son representativos de otras producciones sobre contenidos similares o los que tienen en su base un incidente crítico significativo, que al abordarse desencadena una mejora de la práctica coherente con los presupuestos teóricos de partida. Esta fase concluye con la descripción del caso.

3. Análisis de las fuentes de información sobre cada caso y descripción de sus componentes esenciales. Esta fase concluye con tres tipos de resultados:

- Descripción del contenido de cada caso.

- Descripción de la solución práctica que se dio al caso y vinculación con otros casos similares.

- Descripción de los aspectos teóricos que están implicados en la solución práctica dada.

\section{RESULTADOS. ANALIZANDO LAS PRODUCCIONES MEDIÁTICAS DE LAS ESTUDIANTES UNIVERSITARIAS}

Las producciones mediáticas de las estudiantes que vamos a analizar son el resultado de una actividad práctica en la que, en grupos de 5 o 6 estudiantes, se realiza una «campaña de sensibilización» sobre las situaciones de desigualdad que afectan a las estudiantes universitarias, analizadas desde un enfoque feminista. En esta actividad cada grupo elige un tema para la campaña y aborda las siguientes tareas:

- Diseño de los aspectos claves de la campaña respondiendo a las preguntas ¿qué se quiere decir?, ¿a quién y para que se quiere decir?, ¿cómo se quiere decir?, ¿cuándo se quiere decir?, ¿dónde se quiere decir?

- Diseño y realización del material audiovisual para la campaña. Inicialmente, el grupo realiza una serie de imágenes fijas con diferentes ángulos, planos y características de las cuales se seleccionarán las más adecuadas para representar el concepto de la campaña.

- Realización de la presentación audiovisual de la campaña con herramientas del tipo Prezzi, PowerPoint, Movie Maker o similares y difusión a través del blog de la asignatura y en redes sociales. 
En los seis cursos analizados se realizaron un total de 64 campañas que se distribuyen numéricamente como sigue:

Tabla 1. Número de campañas por curso académico y número de estudiantes implicadas

\begin{tabular}{|c|c|c|}
\hline Curso & $\mathbf{N}^{\mathbf{0}}$ Campañas & N. $^{{ }^{\circ}}$ Estudiantes \\
\hline 2011 & 11 & 80 \\
\hline 2012 & 11 & 74 \\
\hline 2013 & 9 & 60 \\
\hline 2014 & 10 & 70 \\
\hline 2015 & 12 & 80 \\
\hline 2016 & 11 & 70 \\
\hline TOTAL & 64 & 434 \\
\hline
\end{tabular}

La relación de temas tratados en esas campañas se recoge en la siguiente tabla y se representa en un gráfico posterior:

Tabla 2. Contenidos tratados en las campañas y frecuencia de los mismos a lo largo del periodo de estudio

\begin{tabular}{|l|c|}
\hline \multicolumn{1}{|c|}{ TEMÁTICA } & Frecuencia \\
\hline Techo de Cristal y empoderamiento & 4 \\
\hline Relaciones sexuales & 2 \\
\hline Deporte & 3 \\
\hline Violencia de género & 11 \\
\hline Desigualdad Laboral & 3 \\
\hline Relaciones de pareja roles & 3 \\
\hline Elección y acceso a los estudios (trabajo) & 3 \\
\hline Aborto & 3 \\
\hline Belleza y Moda & 7 \\
\hline Masculinidad & 3 \\
\hline Estereotipos sociales & 5 \\
\hline Igualdad imaginaria & 1 \\
\hline Control de la pareja & 6 \\
\hline Trastornos alimenticios & 1 \\
\hline Uso del tiempo & 1 \\
\hline Consumo de Alcohol & 1 \\
\hline Lenguaje Sexista & 2 \\
\hline
\end{tabular}




\begin{tabular}{|l|c|}
\hline Discapacidad & 1 \\
\hline Homosexualidad & 1 \\
\hline No somos productos & 1 \\
\hline Micromachismos & 2 \\
\hline TOTAL & 64 \\
\hline
\end{tabular}

Distribución contenido de las campañas: desigualdades que afectan a las mujeres jóvenes

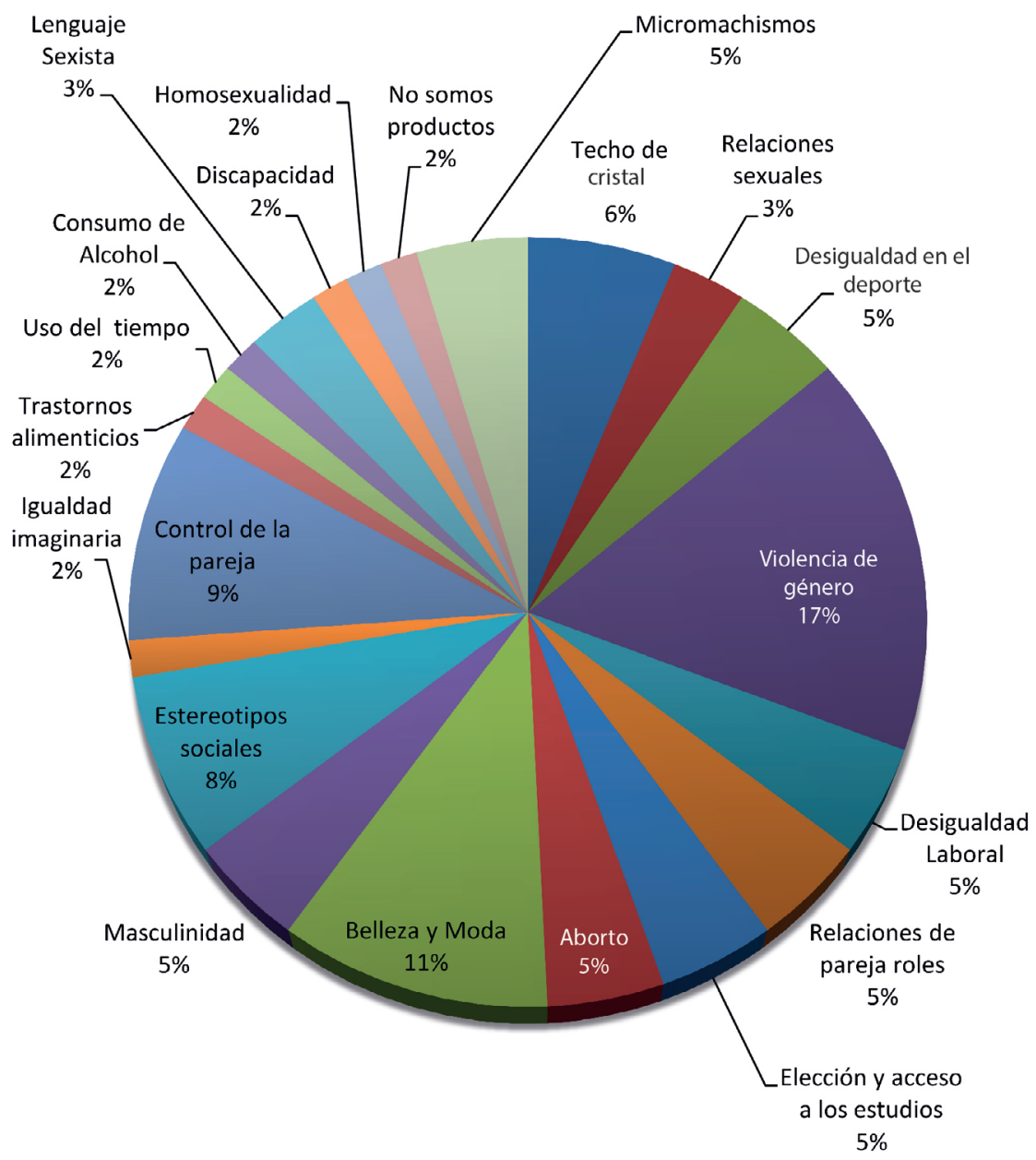

Figura 1. Gráfico de porcentajes de los contenidos de las campañas en el periodo de estudio

Feminismo/s 29, junio 2017, pp. 99-124 


\section{Violencia de Género (17\%)}

La violencia de género parece ser percibida como uno de los factores de desigualdad que más afectan a las mujeres jóvenes. No es sorprendente que las estudiantes identifiquen la violencia de género como un problema que les afecta dada la gravedad que tiene el tema en nuestro país y su amplia repercusión mediática. Lo que sí llama la atención de las observaciones realizadas a lo largo de estos años es la «viveza» con que se describe el problema en las discusiones grupales, lo que puede estar indicando una gran familiaridad con el mismo bien por conocimiento indirecto a través de amigas o conocidas, bien por ser un problema que afecta directamente a algunas de las estudiantes, algo que quedó en evidencia en alguno de los casos.

\section{Belleza y Moda. Cosas de Mujeres (11\%)}

De manera habitual se ha considerado que hay una serie de cuestiones o preocupaciones que son específicas de las mujeres. Desde muy pequeñas las niñas son orientadas hacia una serie de comportamientos estereotipados que definen su condición de mujeres, entre los que destacan los destinados a mantener unos estándares de belleza determinada y a seguir las tendencias de la moda. Si bien los estereotipos de género más tradicionales parece que han comenzado a resquebrajarse y algunos de los «estereotipos femeninos» de culto al cuerpo ya no son una exclusiva de las mujeres, los asuntos relacionados con la belleza y los cuidados del cuerpo al servicio de unos roles determinados muy sexualizados siguen siendo una preocupación importante para las mujeres jóvenes.

\section{Control de la pareja (9\%)}

Aunque para las estudiantes el control que ejercen sobre las mujeres jóvenes sus parejas se presentan como un fenómeno que desligan de la «violencia de género», cuando se analizan las producciones se pone de manifiesto la dificultad de diferenciar estas producciones de otras que hemos incluido en la citada categoría. Son creaciones que se dan sobre todo en los últimos años y que tienen mucho que ver con la extensión del uso del móvil, las redes sociales y aplicaciones como el Whatsapp. Parece obvio que dichas herramientas se están utilizando para desarrollar determinados tipos de controles entre las parejas jóvenes que, si bien afectan más a las chicas como parte controlada, se dan también a la inversa. Ese tipo de control, tal y como aparece descrito en las creaciones de las estudiantes, estaría muy próximo a lo que se ha venido denominando maltrato psicológico. Nuestros resultados coinciden con los de algunos estudios que plantean que las chicas, tanto las que tienen pareja como 
las que no, a veces muestran confusión sobre el papel del control que pueden ejercer en las redes sociales las parejas y algunas consideran que proporcionarle a su pareja su contraseña puede ser una prueba de confianza. Esto es un elemento de desigualdad sustentado en la idea de que las chicas que tienen pareja no han de tener un espacio propio o de intimidad personal (Estébanez y Vázquez 95-96).

\section{Estereotipos sociales ( $8 \%$ )}

Esta categoría abarca creaciones con temáticas que, igual que las incluidas en la categoría que hemos llamado belleza y moda, tratan de los estereotipos sociales atribuidos exclusivamente a las mujeres. En esta categoría agrupamos las que tienen que ver con conductas que se esperan de las mujeres por ser mujeres, actitudes que se penalizan en las mujeres y que se alientan en los hombres, estereotipos en el lenguaje, etc.

\section{Techo de Cristal (6\%)}

Estas creaciones, aunque menos frecuentes que las incluidas en las categorías anteriores son, a nuestro juicio, muy importantes ya que marcan la pauta de una mujeres jóvenes que son conscientes de la desigualdad que les afecta pese a que les cueste ponerla de manifiesto y explicarla. Pese a ello en determinadas condiciones hacen visible esa desigualdad y le dan forma mediantes estrategias comunicativas muy eficaces. Se trata de creaciones en las que se identifica la existencia de un «techo de cristal» que les afecta ya en el momento mismo de su formación. Una barrera invisible que las hace desiguales en algunas facetas de su vida presente en la propia institución universitaria.

Por debajo de estas categorías, con porcentajes inferiores al 5\%, encontramos creaciones que son menos frecuentes, como pueden ser las que se refieren a la desigualdad laboral, la desigualdad de las mujeres en el deporte, en el ámbito de las relaciones sexuales y las relaciones afectivas, etc. También con escasa frecuencia y de aparición más reciente están las creaciones que tienen que ver con la masculinidad, la homosexualidad femenina y los micromachismos. Hablar de todas ellas sería de gran interés pero requeriría un espacio que excede al que disponemos en este artículo. Consideramos que todas ellas representan de manera bastante certera el mosaico de situaciones de desigualdad que están ahora mismo afectando a las estudiantes universitarias. Incluso nos atreveríamos a decir que también los porcentajes son representativos del orden de importancia que estas mujeres jóvenes les dan en su vida cotidiana. 


\section{DOS ESTUDIOS DE CASO: VISIBILIZANDO EL TECHO DE CRISTAL Y DENUNCIANDO LAS «COSAS» DE MUJERES}

Para ilustrar el análisis global realizado se han seleccionados dos casos de estudio que se expondrán atendiendo a sus características básicas y a los aspectos metodológicos que abordaron. El contenido del primer caso no es de los más frecuentes (Techo de cristal 11\%) pero consideramos que es una de las temáticas que tiene más capacidad para visibilizar desigualdades que suelen permanecer ocultas u opacadas para las universitarias y para la institución en general. El segundo de los casos se elige por ser representativo de una de las categorías que con más frecuencia aparecen en los trabajos grupales (Belleza y moda $11 \%$ ).

Caso 1. ¿Que tienen las mujeres en la cabeza?: ¡Visibilizando el techo de cristal!

Descripción del caso:

Uno de los grupos quiere centrar su campaña sobre su papel en la institución universitaria. Se les anima a definir los problemas que tienen en la institución por el hecho de ser mujeres. Después de un largo proceso de reflexión, deciden centrarse en su escasa visibilidad en un centro donde los estudiantes son en su mayoría mujeres. Señalan que esta falta de visibilidad se manifiesta en ciertos fenómenos aparentemente inocuos, pero muy elocuentes: la mayoría de los representantes de los estudiantes son hombres, las mujeres participan en las reivindicaciones estudiantiles pero cuando se trata de tener presencia pública (ruedas de prensa, conferencias, portavocía) nunca están en primer plano, etc. Desarrollan una campaña audiovisual sobre el «Techo de cristal» que tiene un desarrollo técnico sencillo basado en una presentación audiovisual
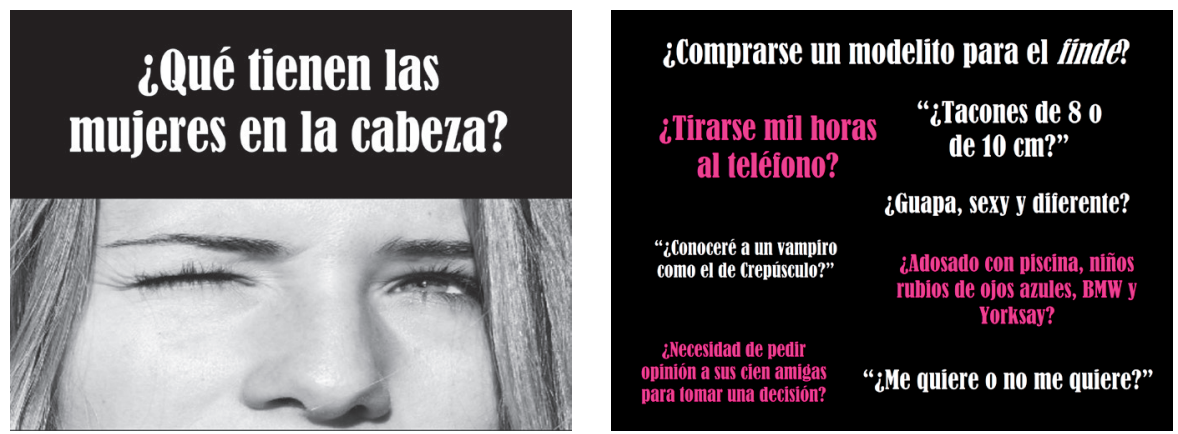

Figura 2. Imágenes y frases del Caso 1 ¿Qué tienen las mujeres en la cabeza? 


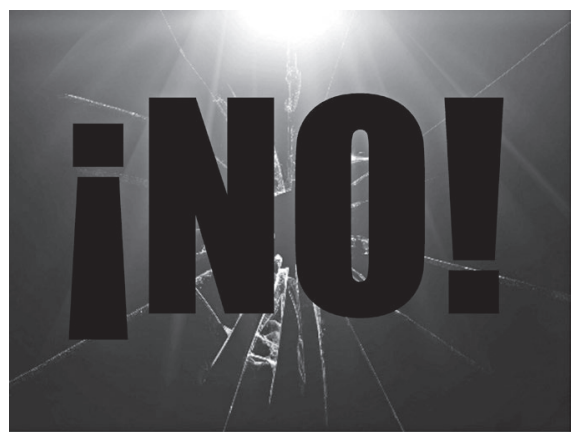

- Hez notar tu presencia.

- opina, participa, discute, cuestiona.

- No te coniormes, reivindica.

- se tí misma, no quien quieren que seas.

- No te subestimes, valórate.

- Sin complejos, sin obstáculos...

\section{ZROWPE TU TEBIO DE BRISTAL}

Figura 3. Ejemplo de frases con propuestas para cambiar su situación en la Facultad

en PowerPoint que da estructura a una serie de imágenes creadas «ad hoc» y asociadas a una banda sonora de «remix» con varias piezas musicales muy bien seleccionadas de cara a reforzar de manera importante el sentido y significado de la campaña.

Solución práctica que se dio al problema que plantea este caso:

Se procuró que las estudiantes pudiesen definir, por sí mismas, cuáles eran sus problemas de desigualdad en la institución para representarlos desde el punto de vista audiovisual. Sólo cuando ellas han definido el problema desde su propia perspectiva, se les indica que ese problema esta conceptualizado en la agenda feminista como el «techo de cristal». También esta metodología abierta permitió que eligieran sus propias formas representativas, crearan frases que describen su visión de la realidad que limita a las mujeres y escribieran varias propuestas para mejorar su propia situación en la Facultad.

Aspectos teóricos de la educación en medios que se implican en la solución: el enfoque de género a través de la cultura popular

El discurso que construyen las estudiantes evidencia su capacidad de análisis crítico de las políticas de representación que utilizan los medios. Su trabajo conecta con las preocupaciones de algunos de los análisis que las teóricas feministas están haciendo sobre estas representaciones post-feministas con las que se simplifica la vida de las mujeres y sus aspiraciones centrando sus intereses en aspectos que tienen que ver exclusivamente con su apariencia física y su sensualidad, o recreando la imagen de mujeres inseguras y poco capaces de tomar decisiones por sí mismas (Gill 2007, Lazar 2011, McRobbie 2009). El tono irónico que se utiliza al señalar el «conocer un vampiro como 
el de Crepúsculo» como una posible aspiración femenina, pone de manifiesto la crítica a una de las producciones de éxito masivo entre la juventud, en esos momentos, en la que una representación de una mujer que, convenientemente envuelta en una historia fantástica de ficción, favorece lecturas bastante conservadoras y sexistas.

Por otra parte, la música seleccionada, las imágenes producidas y el formato elegido para la campaña implican un manejo previo de la cultura popular con la que las estudiantes están familiarizados y que en el momento de la actividad ponen al servicio de la construcción de un relato alternativo basado en un remix de imágenes y textos de producción propia.

Trabajar la producción del material audiovisual, el lenguaje y las audiencias El proceso de producción recorre todas las etapas de elaboración de una campaña de sensibilización y aborda el diseño de cada una de ellas, teniendo como referencia el punto de vista las audiencias. Esto implica un aprendizaje que se basa en la reflexión sobre las diferentes etapas y lo que implica cada una de ellas. Es especialmente importante la creación del discurso audiovisual propio. Son las estudiantes las que hacen las fotos y, a la vez, se convierten en los personajes protagonistas de su historia, utilizan los espacios universitarios como escenarios, e incorporan también a sus compañeras de clase. De esta forma, se apropian del lenguaje audiovisual y lo utilizan para escribir su propia historia. Es importante resaltar que la actividad se desarrolla con imágenes fijas que se toman con una cámara digital, lo cual permite trabajar algunas cuestiones

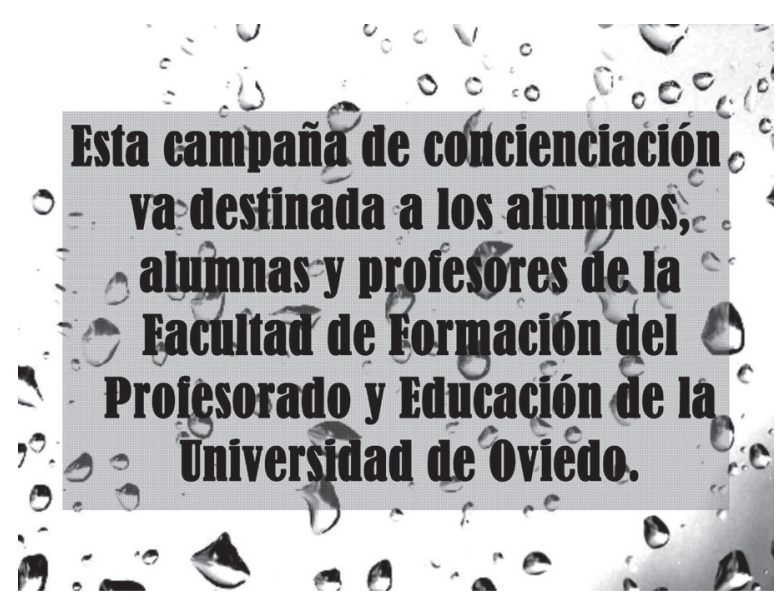

Figura 4. Ampliación de la audiencia de la campaña 
como la selección de material audiovisual, el retoque, la postproducción, el montaje, etc.

El análisis de las notas sobre las discusiones de grupo revela que, a lo largo del proceso, el grupo va adaptando su discurso a las características del público al que va dirigido, sus compañeras de clase. Pero además en un momento determinado, deciden ampliar esa audiencia porque toman conciencia de que el problema tiene su origen en una situación más general que implica también el profesorado.

Se trabaja también la «difusión viral» en red, mediante el blog y el Facebook de la asignatura pero, por decisión propia, usan además a sus propias cuentas de Facebook y Twitter para que el material producido llegue a sus «amistades», lo que supone una apertura de la actividad del aula al mundo real. El material audiovisual creado por las estudiantes también se presenta en algunas actividades culturales organizadas por el alumnado de la Facultad.

\section{El análisis de los problemas reales a través de los medios audiovisuales}

Las notas de observación permiten comprobar que tanto en los resultados de la producción audiovisual, como en los debates que se llevan a cabo para crear la campaña hay referencias al papel de los medios en la producción de
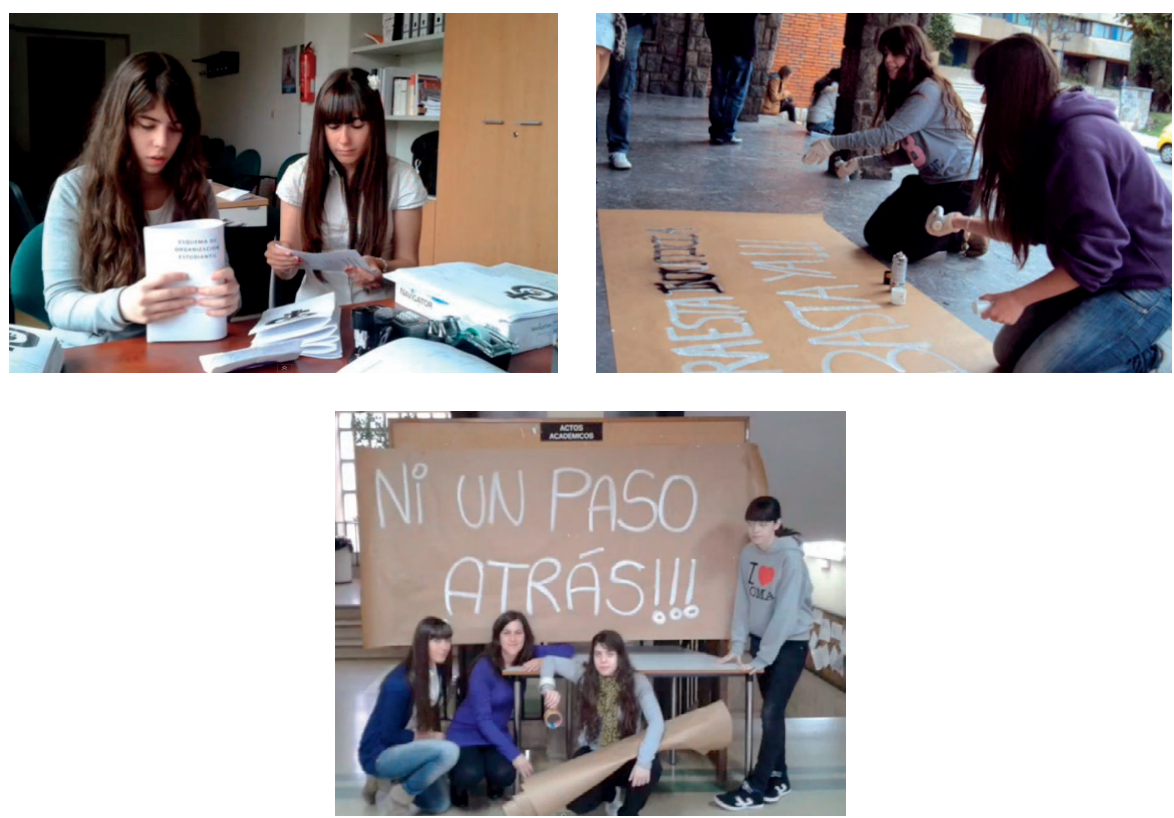

Figura 5. Imágenes de la campaña sobre el Techo de Cristal curso 2011-2012

Feminismo/s 29, junio 2017, pp. 99-124 
las desigualdades: la imagen limitada que dan de las mujeres más jóvenes y el proceso que les lleva a restringir sus aspiraciones e intereses a cuestiones relacionadas exclusivamente con su imagen física y sus roles tradicionales.

Hemos seleccionado este caso por no ser un caso aislado, otros grupos han elegido el mismo tema en cursos posteriores. En uno de ellos la misma temática fue abordada utilizado una estrategia bastante diferente que pasó por una primera fase de documentación que llevó al grupo a la realización de una entrevista en vídeo a pie de calle donde se le preguntó a la gente sobre el «techo de cristal». Este trabajo animó al grupo a poner en marcha una campaña real dentro de la Facultad para sensibilizar a sus compañeras en relación con el techo de cristal que les afecta como estudiantes universitarias y animarlas a ocupar los espacios de poder que les son propios. Esta campaña tuvo una influencia decisiva en el aumento del número de alumnas que se presentaron a las elecciones de representantes en Junta de Facultad y en el Claustro Universitario durante ese curso.

Caso 2. ¡Cosas de mujeres!: denunciando la sexualización y la homogeneización de la feminidad

\section{Descripción del caso:}

Este grupo inicia su trabajo con la idea de tratar la influencia de la moda sobre las mujeres, pero se muestran muy inseguras sobre lo que quieren hacer. Señalan que habían planeado ir con la cámara de fotos a tomar imágenes de los escaparates de un centro comercial que está cerca de la Facultad y tratar sobre la moda destinada a las chicas jóvenes, pero finalmente lo desestimaron. La docente indica que el papel de la moda en la vida de las mujeres más jóvenes parece muy importante y les pregunta cómo creen que la moda influye en sus
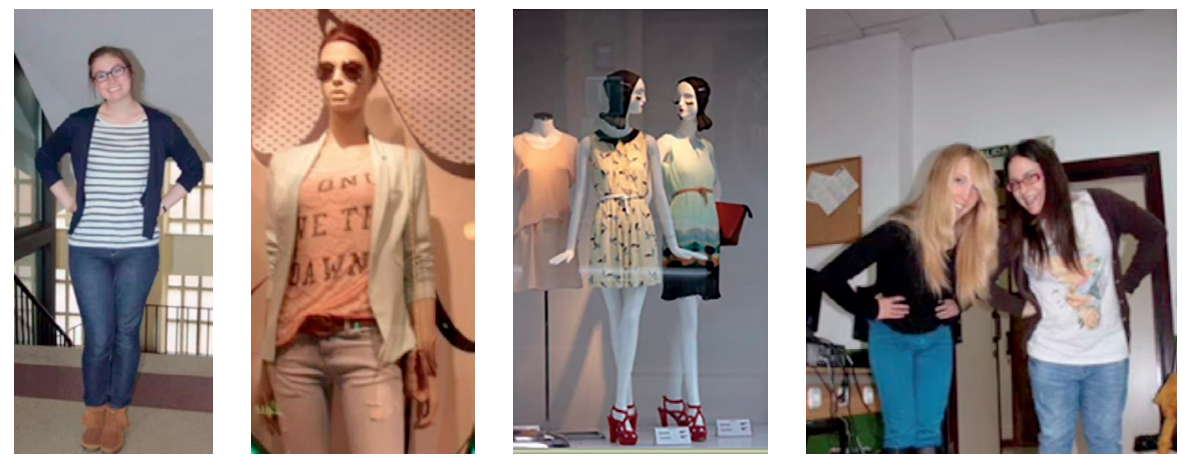

Figura 6. Imágenes del caso 2 «Cosas de mujeres» 
vidas. Tras una larga discusión, consiguen definir el problema: la moda normaliza y homogeneiza la imagen de las mujeres jóvenes y, de alguna manera, les presiona para que usen el mismo tipo de ropa y se adapten a una imagen única de la belleza. Este grupo desarrolló una campaña audiovisual sencilla, pero muy eficaz, utilizando sucesiones de imágenes de maniquíes, intercaladas con sucesiones de imágenes suyas y de sus compañeras de clase, editado con Movie Maker y en el que utilizaron «Material Girl» de Madona como banda sonora.

\section{Alternativa práctica que se dio al problema que plantea este Caso:}

Igual que en el caso anterior, el resultado final del trabajo de este grupo tuvo mucho que ver con el tipo de metodología participativa y deliberativa utilizada y con una mediación docente que va conduciendo progresivamente a las estudiantes a la elaboración de sus propias representaciones audiovisuales de la realidad. Cuando se plantea el problema se desarrollan varios encuentros con el fin de que lleguen a definir por sí mismas cuál es la situación de desigualdad que quieren tratar y qué tipo de mensaje quieren crear para sensibilizar sobre ese problema. Dadas las limitaciones que muestra el grupo para desarrollar la tarea, se opta por una dinámica centrada, inicialmente, en la discusión sobre las imágenes que se van a utilizar para, a partir de ellas, ir fomentando la reflexión. Las estudiantes eligen un esquema muy simple para la representación audiovisual del problema definido, intercalan imágenes con fotos de maniquíes que van dando muestra de la uniformidad que la moda aplica sobre el cuerpo de las mujeres, con imágenes de ellas mismas que van dando cuenta de la identidad de cada una y de cómo la diversidad es lo que da sentido a la belleza propia de cada persona. En la realización de las fotografías el grupo se implica y se hace protagonista de las mismas, pero además involucran a otras compañeras de la clase, lo que en sí mismo genera una dinámica muy interesante de concienciación: las mujeres de la clase saben para qué son las fotos y se muestran dispuestas a protagonizarlas.

\section{Enfoque de género a través de la cultura popular}

El tema elegido y la forma de enfocarlo conecta de manera rotunda con la crítica que se hace a las políticas post-feministas sobre el género en los medios de comunicación, y cómo estos, sobre todo en el caso de la publicidad, han optado por una sexualización del cuerpo de la mujer que la encorseta en una imagen única y predefinida, muy difícil de alcanzar por las mujeres «normales», y que obliga a las que quieren alcanzarlo a realizar esfuerzos sobrehumanos de vigilancia y control del propio cuerpo. La idea de que la feminidad es una 
propiedad del cuerpo (no una estructura social o psicológica) da lugar a toda una política de vigilancia de los cuerpos de las mujeres y a una sexualización, cuando no a una pornificación, de la cultura (Gill 2012, 257).

Las notas de observación sobre las discusiones que mantuvo el grupo para la elección del tema evidencian que las estudiantes viven sumergidas en discursos que incluso a veces son contradictorios, como por ejemplo el derecho teórico que tienen a controlar su propio cuerpo y sus relaciones, frente a la idea que los medios les ofrecen de un cuerpo mercantilizado, cosificado y sexualizado conforme a unos estándares de belleza que les hace muy difícil el tener una identidad propia (Aapola 132). A pesar de la aparente domesticación que los medios ejercen sobre las jóvenes, este tipo de actividades pone de manifiesto cómo ellas tienen una serie de recursos que, en situaciones determinadas, ponen en juego para expresar sus propias opciones y puntos de vista, utilizando los medios como recursos al servicio de su propio discurso.

El tipo de discurso desarrollado por el grupo en esta actividad encajaría en lo que Harris denomina características clave de un feminismo joven «no categorizado» (Harris 27). Esta autora incluye bajo esta etiqueta actividades que tienen que ver con un feminismo diverso, múltiple y abierto a una amplia gama de puntos de vista y que utiliza la tecnología, la cultura popular y los medios de comunicación de forma inteligente.

\section{Trabajar la producción de la representación, el lenguaje y los públicos}

Aunque esta actividad pretende conseguir un conocimiento de las etapas que conlleva la realización de una campaña de comunicación, en el caso de este grupo no se siguió el orden lógico que suelen seguirse en el diseño de este tipo de campañas. Sin tener muy claro el tema, se piensa primero en las imágenes, y el ajuste a la audiencia se hace posteriormente mediante elementos como el ritmo que se imprimió al montaje o la música seleccionada. Este caso muestra cómo, si bien el trabajo de producción no puede reducirse a una suerte de ejercicio de autoexpresión o entretenimiento, no debe obsesionarnos que el alumnado adopte desde el principio una distancia crítica y se lance a una profunda discusión razonada. Es conveniente dejar que entre la parte emocional y permitir que se produzca la búsqueda de significados propios en la tarea, partir de lo que los estudiantes saben, aunque no sea mucho, de quiénes son y no de lo que a nosotros nos gustaría que fueran. Y para ello, la tarea tiene que ser abierta y debe permitirnos jugar con la ambigüedad que puede posibilitar a las estudiantes la creación de sus propios significados, siempre y cuando tengamos claro el tipo de aprendizaje que queremos para ellas. 


\section{El proceso de creación audiovisual implica una reflexión teórica y práctica}

Esta actividad supone un análisis de los problemas reales utilizando recursos de la cultura popular, como son las imágenes de la moda y la música. En ella el alumnado identifica también ciertas industrias que tienen un papel fundamental a la hora de definir las imágenes de las mujeres y los cánones de belleza, y trata cuestiones relacionadas con su imagen como mujeres jóvenes y su feminidad sexualizada con el trasfondo del autocontrol y la disciplina que tienen que infringirse para poder responder al modelo que se les propone.

La producción con los nuevos medios posibilita la reflexión sobre aspectos clave del proceso de producción audiovisual, como son la selección, la construcción de imágenes, el manejo de borradores, la posproducción y el montaje (en el caso del video) que pueden ser muy útiles a la hora de conceptualizar el proceso.

\section{CONCLUSIONES Y PROSPECTIVA}

Las jóvenes que cursan la asignatura objeto de estudio, en su mayoría están entre los 18 y los 21 años. Algunos estudios señalan que los comportamientos de las mujeres de estas edades, a veces, superan en exigencias de libertades a los chicos de su misma edad y dentro de las propias mujeres constituyen un grupo muy activo y proclive a comportarse en términos de igualdad (Aguinaga 2007,59 y 2008, 13). Nuestra experiencia dista mucho de estas apreciaciones. Más bien al contrario podemos señalar que, con el paso de los años, el análisis feminista de la realidad es algo que es recibido con cierto rechazo por un número creciente de estudiantes. Creemos que esto tiene mucho que ver con las estrategias hostiles que los grupos dominantes más conservadores, apoyados en los grandes grupos mediáticos de los cuales son dueños, han desarrollado en contra del feminismo presentándolo como una amenaza radical y sin sentido, ya que la igualdad está conseguida. Por las reacciones de algunas mujeres jóvenes ante la presencia de temáticas feministas en asignaturas, como la que aquí nos ocupa, puede deducirse que ese discurso ha calado en ellas y esa idea de un feminismo radical e innecesario puesto que «ya somos iguales» puebla el imaginario de ciertos sectores de las mujeres jóvenes y campa en estos sectores a su «libre albedrío» sin que haya movimientos o contextos que le pongan freno. Por otro lado las formas de representación en los nuevos espacios mediáticos nos ofrecen un espacio de riesgos y oportunidades fuertemente marcado por el género y por ello se convierten en espacios de negociación de un entorno mediático cada vez más sexualizado. Como nos muestran diferentes estudios, las representaciones de las mujeres que se dan en determinadas redes sociales 
amplifican, extienden y popularizan los clichés más extendidos que son adoptados de forma mimética e irreflexiva por las personas jóvenes (Tortajada, Aruña y Martínez 186; Bulligham y Vasconcelos). Ante estos fenómenos es importante saber que «las prácticas adolescentes en las redes sociales se están nutriendo de otros consumos mediáticos como la omnipresente publicidad y, cómo esto afecta a lo que los y las adolescentes expresan en las redes y a sus definiciones identitarias» (Tortajada, Aruña y Martínez 187). Estos conocimientos nos permitirán contribuir a reconstruir una educación mediática que posibilite una negociación crítica de estas y otras representaciones y fomente modelos alternativos de «feminidad y masculinidad» que contribuyan a una socialización no reproductora de las desigualdades de género.

Consideramos que las prácticas de Educación Mediática en el nivel universitario, que introducen como elemento metodológico fundamental actividades de producción audiovisual de las estudiantes, en relación con las desigualdades de género, resultan ciertamente innovadoras y permiten a las estudiantes identificar las desigualdades que les afectan y profundizar en la naturaleza y el sentido de dichas desigualdades, iniciarse en el uso de la cultura popular para crear sus propios discursos sobre problemas relevantes que les afectan desde el punto de vista personal y profesional, mejorar su conocimiento de los procesos y del lenguaje audiovisual y desarrollar sus capacidades de análisis de la realidad a través de los medios de comunicación. Es preciso, por tanto, profundizar en nuestro conocimiento de estos procesos de creación para tratar de diseñar variantes metodológicas que nos permitan, por un lado, conocer la visión que las mujeres jóvenes tienen de las desigualdades que les afectan y, por otro, trabajar con ellas los procesos de empoderamiento a través de la creación de discursos alternativos propios en diferentes formatos audiovisuales y digitales.

\section{REFERENCIAS BIBLIOGRÁFICAS}

Aguinaga, Josune. Las desigualdades de género entre los jóvenes. Informe de la Juventud. Madrid: Instituto de la Juventud. 2004.

Aguinaga, Josune. «Ni victimismo ni triunfalismo. Logros consolidados y déficit por conseguir en material de igualdad de mujeres jóvenes». Aguinaga, Josune (Coord.): Mujeres Jóvenes en el Siglo XXI. 8.83 Revista de Estudios de Juventud 8.83 (diciembre 2008): 11-26.

Aapola, Sinikka, Marnina Gonick y Anita Harris. Young Femininity: Girlhood, Powerand Social Change. London: Palgrave Macmillan. 2005.

Aguilar Carrasco, Pilar. «El cine. Una educación sentimental». García Lastra, Marta; Adelina Calvo Salvador y Teresa Susinos Rada (Eds.): Las mujeres cambian la educación. Investigar la escuela, relatar la experiencia. Narcea: Madrid, 2008, 260-287. 
Aguilar Carrasco, Pilar. «Papeles e imágenes de mujeres en la ficción audiovisual: un ejemplo positivo». Comunicar 11 (1998): 70-75.

Anguita, Rocio y Ana Isabel, Alario. «Mujeres y educación en la era digital. ¿Nuevas oportunidades para la igualdad?». Red Digital. Revista de Tecnologías de la Información y la Comunicación Educativas 5 (2004): 1-5.

Barthes, Roland. Mythologies. Paris: Editions du Seuil, 1957.

Buckingham, David, Sefton-Green Julian. Cultural Studies goes to school. London: Tylor\&Francis, 1994.

Buckingham, David. Media Education: Literacy, Learning and Contemporary culture. Cambridge: Polity Press, 2007.

Bullingham, Liam y Ana Vasconcelos. «The presentation of self in the online world: Goffman and the study of online identities». Journal of Information Science 39.1 (2013):101-112.

Callejo, Javier, Concepción Gómez y Elena Casado. El techo de cristal en el sistema educativo español. Madrid: UNED Ediciones, 2004.

Carrington, Kerry y Aba Bennet. «Las revistas de chicas y la formación pedagógica de la chica». Luke, Carmen. Feminismos y Pedagogías en la vida cotidiana. Madrid: Morata, 1999, 144-159.

Cobo, Rosa. «El cuerpo de las mujeres y la sobrecarga de sexualidad». En: Investigaciones feministas: papeles de estudios de mujeres, feministas y de género, 6 (2015): 7-19.

Correa, Ramón Ignacio. Todas sois iguales. «El burka invisible de Marylin Monroe y otras perversiones ópticas». Prado y otros: La galaxia digital. Granada: Grupo Editorial Universitario, 2000, 49-55.

Correa, Ramón Ignacio, María Dolores Guzmán y José Ignacio Aguaded. La mujer invisible. Huelva: Grupo Comunicar, 2000.

Estébanez, Ianire y Norma Vázquez. La desigualdad de género y el sexismo en las redes sociales. Bilbao: Servicio Central de Publicaciones del Gobierno Vasco. 2013.

Fueyo, Aquilina y Alejandro Sánchez. «Expandiendo la educación mediática y la competencia digital: Pedagoxía RadioBlog». Segovia: Congreso Educación Mediática \& Competencia Digital, 2010.

Fueyo, Aquilina. "Comunicación y Educación en los nuevos entornos: ¿nativos o cautivos digitales?». Abaco Revista de Cultura y Ciencias sociales. 68-69.2/3 (2011): 22-28.

Fueyo, Aquilina, Tonero, José Manuel, Rodríguez-Hoyos, Carlos. Los territorios de la Educación Mediática. Experiencias en contextos educativos. Barcelona: UOC, 2015.

Frutos, Lola. «Identidad de género en las trayectorias académicas y profesionales de la mujeres». RASE, (2010): 336-356.

Galarza, Emelina, Rosa Cobo y Mar Esquembre. «Medios y violencia simbólica contra las mujeres». Revista Latina de Comunicación Social 71 (2016): 818-8. 
García Canclini, Néstor, Francisco Cruces y Maritza Castro-Pozo. Jóvenes, culturas urbanas y redes digitales. Madrid: Editorial Ariel. Fundación Telefónica, 2012

Gill, Rosalind. «Media empowerment and the «sexualization of culture debates». Sex Roles 66.11 (2012): 736-745.

Gill, Rosalind. Gender and the media. Cambridge \& Malden: Polity Press, 2007

Guil, Ana. «Techos universitarios de cristal blindado». Investigaciones Feministas: papeles de estudios de mujeres, feministas y de género 7.2 (2016): 25-39.

Harris, Anita. «Riding my own tidal wave: young women's feminist work». Canadian woman studies 20/21.4/1 (2001) 27-31.

Harris, Anita. «Theorizing agency in post girlpower times». Continuum. Journal of Media and Cultural Studies 29.2 (2015): 145-156.

Knobel, Michele y Colin, Lankshear. «Remix: la nueva escritura popular». Cuadernos de Comillas 1 (2011): 105-121.

Lazar, Michelle. «The right to be beautiful: postfeminist identity and consumer beauty advertising». Gill, Rosalind \& Christina Scharff. New Femininities postfeminism, neoliberalism and subjectivity. London: Palgrave Macmillan, 2011, 37-51.

Lomas, Carlos. «El otoño del patriarcado. El aprendizaje de la masculinidad y la feminidad en la cultura de masas». Cuadernos de Trabajo Social. 18 (2005): 259-278.

Luke, Carmen. Feminismos y Pedagogías en la vida cotidiana. Madrid: Morata.1999.

MacRobbie, Angela. The aftermath of feminism. Gender, culture and social change, London: Sage, 2009.

McRobbie, Angela. «Top Girls? Young Women and the Post-feminist Sexual Contract.» Cultural Studies 21.4-5 (2007): 718-37.

Peña, Cristina y Carlo Fabretti. La mujer en la publicidad. Madrid: Instituto de la Mujer, 1990.

Phillippi, Alejandra y Claudio Avendaño. «Empoderamiento comunicacional y competencias comunicativas de los sujetos». Comunicar 36 (2011): 61-68.

Soria, María del Mar. «Mujeres y hombres en la prensa española. Interpretación periodística de la realidad». Feminismos 27 (2016): 147-164.

Tiggemann, Marika y Amy Slater. NetGirls: «The Internet, Facebook, and body image concern in adolescent girls». International Journal of Eating Disorders 46.6 (2013): 630-633.

Tortajada, Iolanda, Nuria Araña e Inmaculada Martínez. «Estereotipos publicitarios y representaciones de género en las redes sociales». Comunicar, Revista Científica de Educomunicación 41.21 (2013): 177-186.

Tolman, Deborah. «Female Adolescents, Sexual Empowerment and Desire:A Missing Discourse of Gender Inequity». Sex Roles 66 (2012): 746-757.

Zulo, Julia. «¿Qué significa ser mujer? La construcción textual de la destinataria en las revistas argentinas». Revista iberoamericana de Discurso y Sociedad, 3 (1999): 87-105. 
Para enlazar con este artículo / To link to this article:

http://dx.doi.org/10.14198/fem.2017.29.05

Para citar este artículo / To cite this article:

Gallego-Morón, Nazareth. «Más allá de las estadísticas. Invisibilización y negación de la discriminación de género en la Universidad». En Marcos Jesús Iglesias Martínez e Inés Lozano Cabezas (coords.), La (in)visibilidad de las mujeres en la Educación Superior: retos y desafios en la Academia. Feminismo/s, 29 (junio 2017): 125-152, DOI: 10.14198/fem.2017.29.05

\title{
MÁS ALLÁ DE LAS ESTADÍSTICAS. INVISIBILIZACIÓN Y NEGACIÓN DE LA DISCRIMINACIÓN DE GÉNERO EN LA UNIVERSIDAD ${ }^{1}$
}

\section{BEYOND STATISTICS. INVISIBILIZATION AND DENIAL OF GENDER DISCRIMINATION AT UNIVERSITY}

\author{
Nazareth GALLEGO-MORÓN \\ Universidad Pablo de Olavide \\ nazareth.gallego@gmail.com \\ orcid.org/0000-0002-8172-4515
}

\section{Resumen}

Las cifras estadísticas muestran la existencia de una doble discriminación de género en la Universidad en Argentina: la segregación horizontal y vertical (techo de cristal). Además, la revisión de la literatura confirma la invisibilización y baja concienciación por parte del cuerpo docente universitario. El presente trabajo forma parte de una investigación más amplia sobre la participación de mujeres y hombres en la Universidad Nacional de Salta (Argentina). El principal objetivo consiste en analizar la existencia o no de discriminación de género en la Universidad y profundizar en las percepciones que el profesorado posee acerca de ésta y de las barreras y obstáculos existentes. Para ello, en primer lugar, se ofrece un análisis descriptivo de la participación de hombres y mujeres en el sistema universitario argentino. En segundo lugar, se presentan los resultados de una encuesta aplicada al cuerpo docente de la Universidad Nacional de Salta. Éstos confirman una escasa percepción del problema. Además, esta negación es mayor entre los hombres. La existencia de redes informales de poder es señalada como la principal barrera para la promoción por ambos sexos.

1. Este trabajo de investigación ha sido financiado por la Universidad Pablo de Olavide (Sevilla) en el marco del Proyecto GENDER AND CITIZENSHIP (GENDERCIT). Subprograma People del 7. a Programa Marco Europeo de I+D en el marco del Programa Marie Curie Action. FP7-PEOPLE-2012-IRSES N. ${ }^{\circ} 318960$. 
Palabras clave: discriminación de género, segregación ocupacional, techo de cristal, Universidad, Argentina.

\begin{abstract}
The statistical figures show the existence of a double gender discrimination in Argentine university: horizontal and vertical occupational segregation (glass ceiling). In addition a review of the literature confirms the invisibilization and low awareness by the university teaching staff. This paper is part of a larger research on the participation of women and men at the National University of Salta (Argentina). The main objective of this article is to analyze the existence or not of gender discrimination at university and to deepen the perceptions of teachers have about it and the existing barriers and obstacles. For this, in the first place, a descriptive analysis of the participation of men and women in the Argentine University System. Second, the results of a survey applied to the total teaching staff of the National University of Salta are developed. These confirm a scant perception of the problem. Moreover, this denial is greater among men. The existence of informal power networks is singled out as the main barrier to advancement by both sexes.
\end{abstract}

Keywords: gender discrimination, occupational segregation, glass ceiling, university, Argentina. 


\section{LAS MUJERES EN EL MERCADO DE TRABAJO EN ARGENTINA}

En los últimos 20 años se ha producido un avance considerable con respecto a la incorporación de las mujeres en el mercado de trabajo en América Latina y el Caribe. La participación femenina en la fuerza laboral pasó de un 44,5\% en 1995 a un 52,6\% en 2015 (OIT) como consecuencia de un mayor acceso de las mujeres a niveles educativos más altos y a una serie de transformaciones socioculturales -particularmente el control sobre la maternidad-, junto con la existencia de medidas de conciliación, como la subvención de servicios para el cuidado de la infancia (Busso y Romero).

Sin embargo, como muestra un informe elaborado en 2016 por la Organización Internacional del Trabajo (OIT), los progresos realizados por las mujeres en el mundo educativo no se han traducido en una posición más favorable en el trabajo. De este modo, la tasa de desempleo de las mujeres, para el año 2015, era más alta que la de los hombres tanto a nivel mundial (5,5\% para los hombres y 6,2\% para las mujeres) como en la región de América Latina y el Caribe, donde la diferencia porcentual era aún mayor: 5,4\% de hombres desempleados frente al $8,1 \%$ de mujeres.

La participación de las mujeres en el mercado de trabajo argentino comenzó a aumentar en la década de los sesenta, y, en especial, a partir de 1990 debido a la pérdida de empleo masculino en un contexto de recesión económica (PNUD 20). Tal y como se desprende de las estadísticas, el trabajo de las mujeres ha pasado a convertirse en el principal sustento económico de muchas familias, debido a diversas causas como la existencia de hogares monomarentales, la situación de desempleo o subocupación de los hombres, o la insuficiencia de un único salario. De esta forma, se ha producido un notable crecimiento en las últimas décadas, elevándose en más de diez puntos el porcentaje de mujeres activas desde 1990, cuando representaban el 36,8\% (CTIO).

A pesar del avance que se ha producido, sigue existiendo una situación de desigualdad laboral de género. Al mayor riesgo de desempleo se le suma la precariedad que caracteriza el trabajo femenino: temporalidad, parcialidad, subocupación, baja cualificación, trabajos informales e inseguros, segregación ocupacional (horizontal y vertical) y brecha salarial de género, etc. 


\subsection{Tasa de desempleo, actividad y empleo}

En Argentina, según los últimos datos disponibles de la Encuesta Permanente de Hogares (EPH) proporcionados por el Instituto Nacional de Estadística y Censos (INDEC), la tasa de desempleo nacional se situó en el 8,5\%, en el último trimestre del año 2016. En el caso de las mujeres, el 9,2\% estaban desempleadas frente al $8 \%$ de los varones, lo que llevaba a una brecha de género del orden de 1,2 puntos (Tabla 1).

Tabla 1. Tasa de desempleo de la población de 14 años y más, por sexo. Total 31 aglomerados urbanos. 3. ${ }^{\circ}$ Trim. 2016

\begin{tabular}{|c|c|c|}
\hline Tasa de desempleo total & Tasa de desempleo hombres & Tasa de desempleo mujeres \\
\hline $8,5 \%$ & $8 \%$ & $9,2 \%$ \\
\hline
\end{tabular}

Fuente: Elaboración propia. EPH. INDEC

Durante el tercer trimestre del año 2016, la tasa de actividad argentina era del $57,7 \%$ (Tabla 2). Con respecto al género, existe una brecha considerable de 22,5 puntos: $47,2 \%$ para las mujeres y del $69,7 \%$ para los hombres (INDEC 2016). Esto es consecuencia de una histórica división sexual del trabajo que "parece haber sido universal en toda la historia humana» (Hartmann 255) dentro de una sociedad heteropatriarcal, en la que se han asignado a hombres y mujeres diferentes tareas según la pertenencia a un sexo u otro.

Tabla 2. Tasa de actividad de la población de 14 años y más, por sexo. Total 31 aglomerados urbanos. 3. ${ }^{\circ}$ Trim. 2016

\begin{tabular}{|c|c|c|}
\hline Tasa de actividad total & Tasa de actividad hombres & Tasa de actividad mujeres \\
\hline $57,7 \%$ & $69,7 \%$ & $47,2 \%$ \\
\hline
\end{tabular}

Fuente: Elaboración propia a partir de los datos del EPH. INDEC

Tradicionalmente se han dividido las actividades en función de las características biológicas de las personas, dando lugar a una dicotomía sexual entre el espacio privado/reproductivo -donde las mujeres llevaban a cabo las tareas domésticas y de cuidados no remuneradas-, y el espacio público y productivo -donde los hombres realizaban el trabajo remunerado-. Se trata de una división sexual del trabajo que aún a día de hoy persiste (Torns y Recio 185). Todo ello en base a una teórica complementariedad entre sexos fruto de la especialización y distribución eficiente de tareas (Sarasúa y Gálvez), en la que las 
mujeres han sido consideradas como el sexo débil, quedando relegadas a una situación de «dependencia» respecto a los hombres (Gálvez, Rodríguez, Agenjo y Domínguez 18). Se constituye la lógica del modelo «hombre proveedor de ingresos-mujer ama de casa» (modelo male breadwinner), un contrato social/ sexual (Pateman) según el cual las mujeres deberían satisfacer las necesidades de los varones para que éstos pudieran cumplir con su condición de ciudadano y trabajador asalariado.

La inexistente corresponsabilidad por parte de los hombres da lugar a una menor disponibilidad de tiempo, lo que repercute directamente en la reducción de oportunidades para acceder al mercado de trabajo remunerado (Gálvez y Rodríguez). Como se desprende de los datos proporcionados por las encuestas sobre trabajo no remunerado y uso del tiempo, las mujeres argentinas emplean cada día tres horas más que los hombres para la realización del trabajo doméstico no remunerado, lo que comprende quehaceres domésticos, apoyo escolar y cuidado de personas (INDEC 2014). Sigue habiendo una diferencia de participación en este trabajo de 31 puntos porcentuales a cargo de las mujeres ( $57,9 \%$ los hombres y $88,9 \%$ las mujeres).

Con respecto a la tasa de empleo, ésta se encontraba en el 52,8\% (Tabla 3). Si atendemos a la diferencia por sexos, al igual que ocurriese con la tasa de actividad, la tasa de empleo masculina superaba notablemente a la femenina. Así, el porcentaje de trabajadoras se situaba en el último trimestre del año 2016 en un 42,9\%, mientras que los hombres alcanzaban el 64,1\% (INDEC 2016).

Tabla 3. Tasa de empleo de la población de 14 años y más, por sexo. Total 31 aglomerados urbanos. 3. ${ }^{\circ}$ Trim. 2016

\begin{tabular}{|c|c|c|}
\hline Tasa de empleo total & Tasa de empleo hombres & Tasa de empleo mujeres \\
\hline $52,8 \%$ & $64,1 \%$ & $42,9 \%$ \\
\hline
\end{tabular}

Fuente: Elaboración propia a partir de los datos del EPH. INDEC

\subsection{Segregación ocupacional horizontal}

Analizando la distribución de hombres y mujeres por ramas de actividad, según datos del Boletín de Género realizado por el Observatorio de Empleo y Dinámica Empresarial (OEDE), como se observa en la Tabla 4, para el segundo trimestre del año 2014, las mujeres se agrupaban principalmente en dos ramas de actividad. Por un lado, en el sector servicios, donde representaban el 46,4\% del total de trabajadores/as, y, por el otro, en comercio, con un 34,8\%. Éstas aparecen representadas principalmente en aquellas actividades correspondientes a 
los servicios como es el caso de la enseñanza (73,6\%), los servicios sociales y de salud $(71,2 \%)$ y, los servicios comunitarios, sociales y personales $(45,4 \%)$. Se trata de un conjunto de trabajos que se configuran como una extensión de las tareas y funciones de bienestar y cuidado que tradicionalmente han sido desarrolladas por las mujeres. De este modo, como mantienen Moser y Young, habitualmente las mujeres «trabajan en determinadas ocupaciones cuando tienen algún parecido estructural con su rol familiar» (57).

No obstante, si prestamos atención a la población trabajadora masculina encontramos que su presencia era casi total en la construcción (94,1\%), área fuertemente masculinizada donde prácticamente no trabajan mujeres $(5,9 \%)$ y aquellas que lo hacen realizan trabajos de servicios como la limpieza dentro de este sector. En segundo lugar, su participación sigue siendo mayoritaria entre las actividades primarias $(89,6 \%)$, como la explotación de minas y canteras $(90,9 \%)$ y la agricultura y ganadería $(89,3 \%)$. De igual modo, en el área de la electricidad, gas y agua, el porcentaje de hombres era considerablemente más alto que el de mujeres ( $82,9 \%$ y $17,1 \%$, respectivamente) al igual que sucede en la industria ( $81,4 \%$ de los hombres y $18,6 \%$ de las mujeres).

Tabla 4. Empleo asalariado registrado, privado, por ramas de actividad y sexo. $2 .^{\circ}$ Trim. 2014

\begin{tabular}{|l|c|c|}
\hline Rama de actividad & Mujeres & Hombres \\
\hline Actividades primarias & 10,4 & 89,6 \\
\hline Industria manufacturera & 18,6 & 81,4 \\
\hline Electricidad, gas y agua & 17,1 & 82,9 \\
\hline Construcción & 5,9 & 94,1 \\
\hline Comercio & 34,8 & 65,2 \\
\hline Servicios & 43,4 & 56,6 \\
\hline
\end{tabular}

Fuente: Elaboración propia a partir de los datos del Boletín de Estadísticas de Género y Mercado de Trabajo. OEDE

Esta situación se denomina segregación ocupacional horizontal y hace alusión a la agrupación de hombres y mujeres en ocupaciones y sectores diferenciados, marcados e influenciados por arraigados estereotipos y roles de género (Monreal y Martínez). De este modo, se considera que «hay trabajos remunerados femeninos, cuyo ejercicio es adecuado para las mujeres, mientras que otros son impropios de ellas» (Gómez 123). 
Como consecuencia, el número de empleos a los que las mujeres pueden acceder se ven reducidos, mientras que se encuentran sobrerrepresentadas en otros. Además, aquellos desarrollados principalmente por éstas se caracterizan por una menor valoración y remuneración (Cohen y Huffman). De este modo, en el segundo trimestre de 2014, las trabajadoras argentinas del sector privado cobraban el $76,3 \%$ del salario medio mensual de los hombres (\$9.863 mensuales las mujeres y $\$ 12.922$ los hombres), produciéndose una brecha salarial de género del 23,7. Esta situación se configura como un problema continuo en el tiempo para los/as argentinos/as, puesto que la brecha apenas ha disminuido con el paso de los años, así, en el primer trimestre del año 2012 se encontraba en el 23,8 (OEDE).

\subsection{Segregación ocupacional vertical: el techo de cristal}

A la situación de discriminación horizontal se le suma la discriminación ocupacional vertical, entendida como la escasa presencia de mujeres en las categorías laborales más altas. Se trata del fenómeno del «techo de cristal» (glass ceiling), metáfora utilizada para referirse al conjunto de barreras y obstáculos invisibles, acotados y sólidos que las mujeres deben superar para acceder a los altos cargos y puestos de responsabilidad de la pirámide organizacional y que afecta a las mujeres como grupo, «debido a que son mujeres» (Morrison, White y Van Velsor 13).

Analizando los datos proporcionados por el OEDE, podemos concluir que las mujeres argentinas apenas acceden a las categorías más altas. Como se observa en la Tabla 5, del total de trabajadoras registradas, únicamente el 2,6\% ocupaban los puestos de dirección de las empresas privadas. En el caso de los hombres el porcentaje se elevaba hasta el 3,4\%. En los cargos intermedios, la participación de hombres continuaba siendo mayor que la de las mujeres, 6,8\% y $4,7 \%$, respectivamente. Sin embargo, es en la escala básica, la de ejecución directa, en la que se produce la mayor diferencia porcentual entre sexos. De este modo, el 92,7\% de las mujeres se agrupaban en esta categoría, superando a los hombres en casi tres puntos porcentuales $(89,8 \%)$.

Tabla 5. Composición del empleo según estructura jerárquica, por sexo. 2. ${ }^{\circ}$ Trim. 2014

\begin{tabular}{|l|c|c|c|}
\hline & Directivos/as & Jefes/as intermedios/as & Ejecución directa \\
\hline Mujeres & 2,6 & 4,7 & 92,7 \\
\hline Hombres & 3,4 & 6,8 & 89,8 \\
\hline
\end{tabular}

Fuente: Elaboración propia a partir de los datos del Boletín de Estadísticas de Género y Mercado de Trabajo. OEDE 
Se trata del fenómeno de los «suelos pegajosos» (sticky floor), el cual guarda relación directa con el techo de cristal, y que hace referencia a la acumulación de las mujeres profesionales en las escalas más bajas de las organizaciones (Baxter y Wright). En palabras de Gallego «metafóricamente, parece que las mujeres caminen sobre un suelo que las atrae y les impide continuar avanzando» (65) a lo largo de la estructura jerárquica.

Cabe esperar que el ámbito público, en general, y la Universidad, en particular, se constituyan como espacios de trabajo regidos única y exclusivamente por la meritocracia. Trabajos donde el acceso y los procesos de promoción se rijan por criterios claros y objetivos, basados en la capacidad y méritos del cuerpo docente, alejada de la situación de discriminación de género, que como hemos desarrollado en los párrafos anteriores, las mujeres argentinas encuentran en el sector laboral privado.

Sin embargo, tal y como numerosos/as autores/as e informes institucionales han mostrado (Baylin; Baxter y Wright; Comisión Europea; Fernández; García de León; Jackson y O'Callaghan; Probert; Ogbogu) en la mayor parte de los países del mundo, a pesar de que la participación de las mujeres en la Educación Superior universitaria es mayor que la de los hombres, éstas acceden en menor proporción a la cúspide de la pirámide organizacional y se agrupan en aquellas áreas y campos considerados tradicionalmente femeninos.

En este aspecto reside el interés para la elaboración del presente estudio, con el objeto de realizar una aproximación a la realidad de los y las docentes universitarias argentinas y profundizar en las percepciones que ambos poseen acerca de la discriminación de género en la Academia. Para ello, en primer lugar, se ofrece un análisis descriptivo de la participación de hombres y mujeres en el Sistema Nacional Universitario Argentino. En segundo lugar, se presentan los resultados de una encuesta aplicada al cuerpo docente de la Universidad Nacional de Salta.

\section{METODOLOGÍA}

\subsection{Objetivos}

El presente artículo presenta un doble objetivo. (1) Se pretende conocer la situación de las mujeres en el Sistema Nacional Universitario Argentino, determinando la existencia o no de discriminación de género horizontal y/o vertical. Para ello se realiza un estudio descriptivo a través del análisis de fuentes estadísticas secundarias acerca de la participación de hombres y mujeres (tanto 
entre el alumnado como entre el profesorado) en las diferentes áreas y categorías académicas universitarias.

(2) Se realiza un análisis exploratorio y se profundiza en las percepciones del cuerpo docente de la Universidad Nacional de Salta (UNSa) acerca de la existencia de discriminación de género en el ámbito universitario y de las barreras y obstáculos de género, partiendo de sus propias experiencias personales y profesionales. La bibliografía internacional muestra una baja visibilización del problema por parte del profesorado, incluso por parte de las propias protagonistas, las docentes e investigadoras. Por ello, se indaga sobre esta cuestión y se profundiza en si se producen o no diferencias según el sexo, así como si éstas son significativas. El instrumento utilizado ha sido la encuesta.

\subsection{Muestra}

La UNSa se constituye como una de las universidades más feminizadas del territorio argentino. De acuerdo a los datos proporcionados por el Departamento de Estadísticas Universitarias de la UNSa, en el año 2015 estaba formada por un total de 2.260 personas, de las que las mujeres representaban el $54 \%$, porcentaje superior a la media nacional (48,9\%). Del total de mujeres, el $66 \%$ formaban parte del cuerpo auxiliar docente mientras que el $34 \%$ eran profesoras (62\% y $38 \%$ de hombres, respectivamente). De este modo, además de una alta participación femenina se produce, a priori, una situación de equilibrio con respecto a la participación en los cargos académicos más altos, el del profesorado asociado y titular. Por un lado, el total del profesorado asociado estaba constituido por un $50 \%$ de mujeres y un $50 \%$ de hombres. Por otro lado, en la categoría de titular, el 48,7\% eran mujeres y el 51,3\% eran hombres.

Aunque bien es cierto que en el caso de esta universidad la brecha de género es menor que en el panorama nacional, también lo es que la participación de las docentes va disminuyendo paulatinamente desde el inicio de la carrera hasta los cargos y puestos de responsabilidad y poder, mientras que el de los hombres aumenta continuamente, produciéndose el fenómeno del «tubo que pierde» (leaky pipeline). De igual modo, éstas se agrupan en mayor medida entre los puestos bases de auxiliares, lo que manifiesta la existencia de mayores dificultades para promocionar debido a la existencia de los suelos pegajosos. Además, se produce una situación de segregación horizontal, ejerciendo en áreas tradicionalmente feminizadas, como es la Facultad Ciencias de la Salud, donde representaban el 81\% del total de docentes, o, la Facultad de Humanidades, con el 69,4\% del total (UNSa). 
La muestra de personas que han respondido a la encuesta no es aleatoria. Ésta fue enviada a la totalidad del cuerpo docente conformado por 2.260 personas (1.220 mujeres y 1.040 hombres), durante los meses de julio, agosto y septiembre de 2016, de la que se recibieron 92 respuestas. De éstas, el 59,8\% $(n=55)$ eran mujeres y el 27,2\% ( $n=25)$ hombres. El restante 13\% ( $n=12)$ no reveló su sexo. Con respecto a la edad media de las personas participantes, ésta fue de 46,4 años (46,9 para las mujeres y 43,9 para los hombres). Por otro lado, los/as encuestados/as pertenecían a diferentes áreas académicas y categorías, tal y como se recoge en la tabla 6:

Tabla 6. Área académica y categoría profesional de la muestra

\begin{tabular}{|c|c|c|c|c|c|}
\hline & \multirow{2}{*}{ Frecuencia } & $\%$ & \multicolumn{3}{|c|}{ Sexo } \\
\cline { 4 - 6 } & & & Mujeres & Hombres & Nd \\
\hline Área Académica & & & & \\
Salud & 4 & 4,3 & 1 & 1 & 2 \\
Experimentales & 15 & 16,3 & 7 & 5 & 3 \\
Sociales & 6 & 6,5 & 4 & 1 & 1 \\
Humanidades & 26 & 28,3 & 21 & 4 & 1 \\
Ingenierías & 39 & 42,4 & 22 & 12 & 5 \\
Nd & 2 & 2,2 & - & 2 & - \\
Total & 92 & 100 & & & \\
Categoría Académica & & & & & \\
Profesorado Titular & 6 & 6,5 & 1 & 3 & 2 \\
Profesorado Asociado & 10 & 10,9 & 9 & 1 & - \\
Profesorado Adjunto & 37 & 40,2 & 23 & 8 & 6 \\
Jefe/a Trabajos Prácticos & 30 & 32,6 & 15 & 11 & 4 \\
Auxiliar de Segunda & 1 & 1,1 & - & 1 & - \\
Auxiliar de Primera & 8 & 8,7 & 7 & 1 & - \\
Total & 92 & 100 & & & \\
\hline
\end{tabular}

Fuente: Elaboración propia

La baja respuesta del profesorado coincide con estudios anteriores como el de Antón para el total del profesorado de la Universidad de Alicante, el realizado por Guil, Solano y Álvarez para el total de la Comunidad Andaluza; el de Matus y Gallego para la Universidad Pablo de Olavide o el de Tomás y Guillamón para cuatro universidades catalanas. Además, las conclusiones de éstos apuntan hacia la existencia de barreras y obstáculos, así como hacia la invisibilización y negación del profesorado, coincidiendo con los resultados de esta investigación. 


\subsection{Método}

El método utilizado fue la encuesta simple, diseñada y validada anteriormente a su envío por expertas en la materia durante el mes de mayo de $2016^{2}$. Ésta fue enviada en tres ocasiones a través de correo electrónico por parte del Consejo de Investigación y del Centro de Investigaciones Sociales y Educativas del Norte argentino (CISEN) de la Universidad Nacional de Salta (UNSa), donde se adjuntaba una carta solicitando la participación del cuerpo docente y desarrollando los objetivos del estudio.

En el cuestionario se combinaron varias técnicas: pregunta cerrada dicotómica y categorizada, la Escala de Likert y la pregunta abierta. De este modo podemos diferenciar cinco partes en el cuestionario:

1. Presentación y objetivos del estudio

2. Datos de control sobre las características sociodemográficas de la muestra (sexo, edad, dedicación, área académica, categoría laboral, antigüedad en el acceso y en la categoría actual)

3. Preguntas con respuestas cerradas dicotómicas y categorizadas (8 preguntas a través de las cuáles se pretende conocer directamente la percepción de las personas encuestadas acerca de la existencia o no de discriminación de género en la Universidad tanto en el acceso como en la promoción, así como en el mercado de trabajo en general, y otras cuestiones relacionadas con la participación de las mujeres en la Academia)

4. Un listado de 15 aseveraciones en base a una Escala Likert (se profundiza en la valoración que los/as encuestados/as realizan sobre los diversos tipos de barreras y obstáculos de género en la carrera académica)

5. Pregunta abierta donde se invita a expresar libremente cualquier tipo de comentario u opinión acerca del tema tratado.

Por último, los datos cuantitativos obtenidos de los cuestionarios fueron procesados y analizados a través del programa estadístico SPSS durante el último trimestre de 2016.

2. Intervinieron durante esta fase la Dra. Lina Gálvez, la Dra. M. ${ }^{a}$ del Carmen Monreal y el Dr. Mauricio Matus, pertenecientes a la Universidad Pablo de Olavide (Sevilla), junto con la profesora Dña. Gabriela Cecilia Barrios de la Universidad Nacional de Salta (Argentina). 


\subsection{Limitaciones}

Como principal limitación metodológica de la encuesta cabe señalar la tasa de no respuesta por parte del profesorado, lo que produce que la muestra no sea representativa, por lo que los resultados deben ser considerados con restricciones. A pesar de ésto, esta situación puede ser interpretada como un indicador de la baja o alta sensibilidad por parte de los diferentes grupos de los/as docentes que han respondido o no.

Por otro lado, al no poder implementar una muestra aleatoria, se puede suponer que las personas que han respondido a la encuesta son aquellas que sienten mayor motivación a expresar su opinión positiva o negativa al respecto o que poseen un mayor interés o motivación por los temas de género e igualdad. También es posible que una persona haya respondido dos veces a la encuesta, aunque no hay evidencia empírica para sospechar que esto ha ocurrido. En cualquier caso, la evidencia presentada es un aporte que se complementa al marco teórico y aplicado de anteriores investigaciones, además, la encuesta puede ser tenida en cuenta como un pretest para futuros estudios.

\section{DISCRIMINACIÓN DE GÉNERO EN EL SISTEMA UNIVERSITARIO DE ARGENTINA}

El sistema educativo universitario en Argentina se caracteriza por su feminización. Las cifras estadísticas son contundentes. Según la Secretaría de Políticas Universitarias de la Nación (SPU), para el 2014 -último año con datos disponibles-, en los estudios de pregrado y grado de las universidades argentinas las mujeres eran mayoría (57,2\% de matrículas y $61,5 \%$ de egresos). De igual forma, su participación era más elevada que la de los hombres en las maestrías ( $53,5 \%$ de las matrículas y $49,7 \%$ de egresos). Esta tendencia se continua manteniendo estable incluso entre los/as estudiantes de doctorado, donde el porcentaje de éstas constituían el 56,4\% del total.

Sin embargo, si atendemos a la distribución del alumnado según ramas de estudio, el panorama es distinto. Mientras que en campos como las Ciencias de la Salud o Ciencias Humanas en grado y pregrado las mujeres representaban el 73\% y el 69,4\% del total de matriculaciones, respectivamente, en Ciencias Aplicadas -donde se incluyen carreras como las ingenierías o informática- el porcentaje caía hasta el 36,3\% (SPU, 2014).

Si pasamos a analizar el cuerpo docente (preuniversitarios, universitarios y otros) del total de Universidades Nacionales, según los últimos datos disponibles del Sistema de Recursos Humanos de Universidades Nacionales (RHUN), para el año 2013 estaba formado por un total de 193.316 cargos, de 
los cuales 97.954 estaban ocupados por mujeres $(50,7 \%)$ y 95.632 por hombres (49,3\%). Entre los/as docentes del nivel preuniversitario se encontraba la mayor presencia de mujeres, el 63,3\% del total. Atendiendo al total de cargos docentes únicamente de nivel universitario, el número de éstos era 162.843, y el porcentaje de mujeres disminuía hasta el 48,9\% (Sistema RHUN).

La composición por sexo de las diferentes categorías académicas se reproduce en un gráfico «tijera» (Figura 1). Se puede apreciar una importante pérdida del potencial femenino tras la finalización de la tesis doctoral. Se pasa de una mayoría femenina entre los/as docentes de nivel preuniversitario y en la lectura de tesis doctoral, con un 57,6\% (SPU), a una representación de menos de la mitad del total de docentes universitarios/as, con una caída de más de diez puntos porcentuales. De este modo, éstas pasan de configurar el $48,9 \%$ del total de docentes universitarios/as al $45,4 \%$ del profesorado adjunto. Si avanzamos un escalafón más, el porcentaje cae hasta el 40,2\% del total del profesorado asociado/a. Finalmente, en la cúspide de la pirámide, la cifra de hombres titulares casi duplicaban a las mujeres: el 38,8\% del total de cargos titulares estaban ocupados por las mujeres y el $61,2 \%$ por hombres (Sistema RHUN). Se hace patente la existencia de un techo de cristal en la Universidad, que obstaculiza que las mujeres pueden alcanzar los estratos más altos de la jeraquía académica en igualdad de oportunidades que sus compañeros varones.

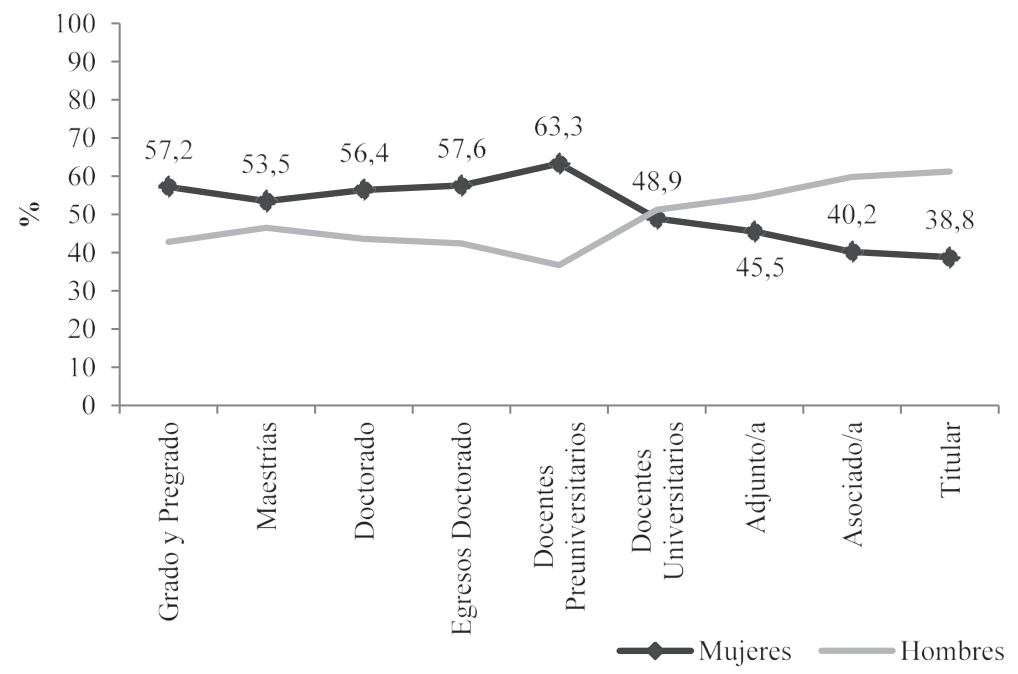

Figura 1. Distribución de hombres y mujeres en la carrera académica de las Universidades Nacionales. Años 2013-2014

Fuente: Elaboración propia sobre datos del SPU (2014) y Sistema RHUN (2013) 
Al analizar la participación del total de mujeres docentes universitarias argentinas entre los diferentes cargos y categorías académicas para el año 2013, encontramos que éstas se distribuían del siguiente modo: más de la mitad del total formaba parte de los/as auxiliares docentes (66,3\%), mientras que sólo 3,3 de cada 10 mujeres docentes eran profesoras, el 33,7\% (57,5\% y 42,5\% en el caso de los varones, respectivamente). Se produce una mayor presencia de las docentes entre los puestos bases (auxiliares docentes), al igual que entre los/as docentes preuniversitarios/as (Figura 2). De este modo, el porcentaje de mujeres profesoras sobre el total de mujeres docentes es superado en casi nueve puntos por los profesores varones. Se manifiesta la existencia de los «suelos pegajosos» (sticky floor) en el ámbito académico y científico -al igual que se produjera en el mercado laboral-, y que muestran, además, las dificultades de las mujeres incluso para acceder a los primeros niveles de la carrera académica (Torres y Pau).

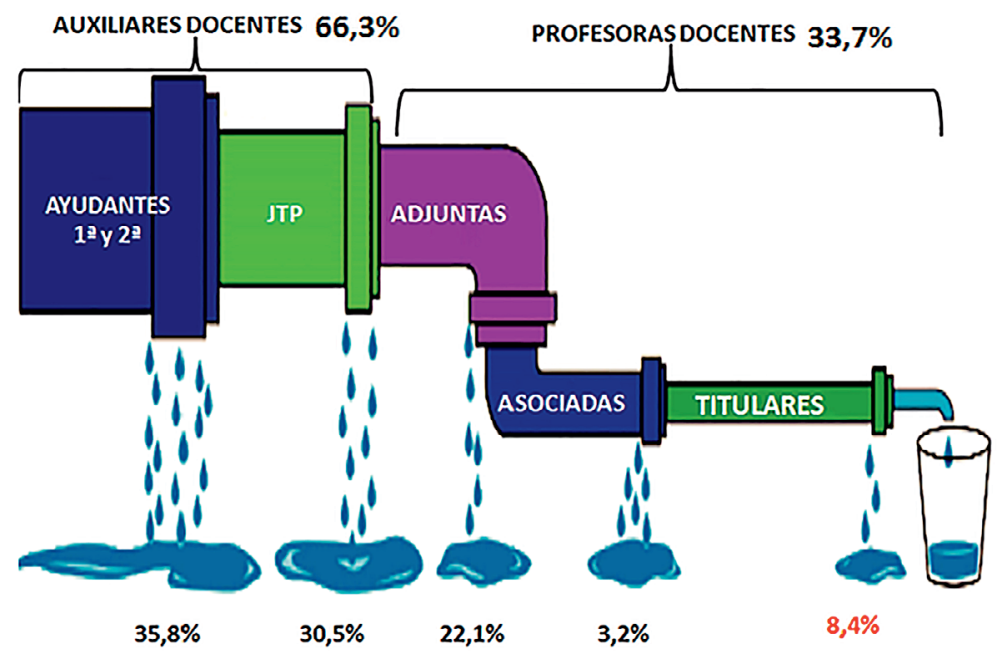

Figura 2. Distribución mujeres por cargos docentes en las Universidades Nacionales clasificados por categoría. Año 2013

Fuente: Elaboración propia a partir de los datos de Sistema RHUN (2013)

Entre las escalas de cada categoría, el 35,8\% de las mujeres docentes se agrupaban en los puestos bases de auxiliares (5,9\% auxiliares de segunda y 29,9\% auxiliares de primera), mientras que en las jefas de trabajos prácticos (JTP) éstas representaban el 30,5\%. Los hombres auxiliares, por su parte, constituían el 31\% del total de hombres docentes (7\% auxiliar de primera y 24\% de 
segunda) y el $26,5 \%$ de JTP. Las cifras van cayendo a medida que se va avanzando en la escala jerárquica, de modo que, entre los cargos del profesorado, el $22,1 \%$ del total de mujeres eran profesoras adjuntas y el 3,2\% profesoras asociadas ( $25,3 \%$ y $4,6 \%$ de hombres, respectivamente). Con respecto a la presencia de mujeres titulares, únicamente el $8,4 \%$ del total ocupaba este cargo, frente al 12,7\% de sus compañeros varones (Sistema RHUN).

Tal y como se desprende de los datos estadísticos, metafóricamente parece que existiera un «tubo que pierde» (leaky pipeline) o, también denominada tesis de la «pipeta», haciendo referencia a la pérdida del potencial femenino según se asciende de categoría o cargo, ya que «a medida que avanza el flujo a lo largo de la pipeta surgen barreras de diferente naturaleza que producen la exclusión de las mujeres» (Estébanez, De Filippo y Serial 9).

Considerando la presencia de la mujer en los puestos de responsabilidad entre las autoridades superiores de las Universidades Nacionales la situación no es mucho más esperanzadora. Al igual que ocurriera en la carrera académica, se produce una presencia mayoritaria de hombres en los principales órganos de gobierno y representación en la Universidad, responsables directos de la toma de decisiones en la misma (Figura 3).

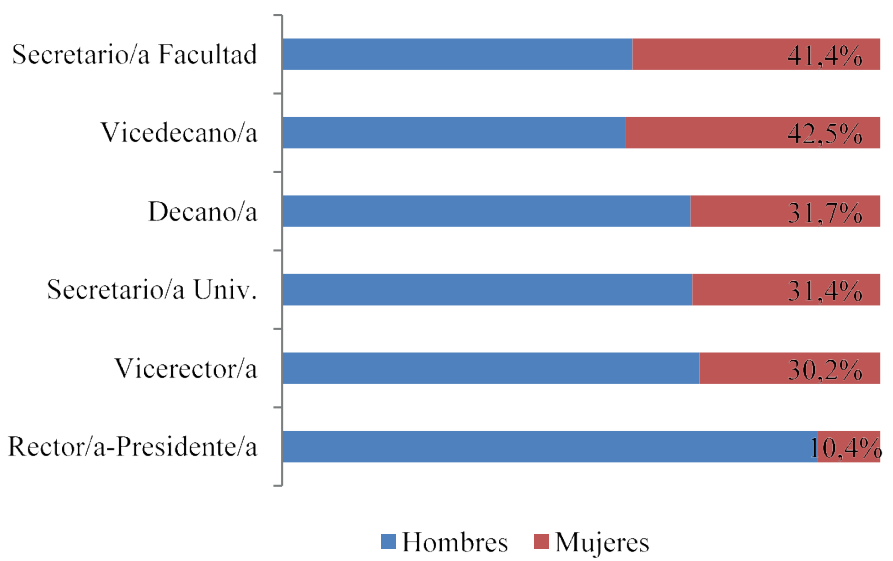

Figura 3. Cargos clasificados por categoría y sexo, total Universidades Nacionales.

Escalafón de Autoridades Superiores. Año 2013

Fuente: Elaboración propia sobre datos del Sistema RHUN (2013)

En el año 2013, del total de las autoridades superiores de las Universidades Nacionales las mujeres representaban solamente el 39,7\%, frente al 60,3\% de hombres. Éstas aparecen agrupadas en su mayoría en los vicedecanatos (42,5\%) 
y secretarías de facultad $(41,4 \%)$. No obstante, los porcentajes comienzan a descender hasta el 31,7\% de decanatos y el 31,4\% de secretarías de Universidad. El porcentaje de vicerrectoras era similar a los correspondientes a los otros cargos $(30,2 \%)$. Sin embargo, si atendemos al puesto de mayor poder en la Academia, el de rectora/presidenta, la representación de éstas disminuye hasta el 10,4\%. En términos absolutos, se traduce en la existencia únicamente de cinco mujeres rectoras en un total de 50 Universidades Nacionales.

\section{RESULTADOS}

En este apartado se presentan los principales resultados obtenidos, desagregados por sexo, y divididos en dos bloques principales. En primer lugar, se profundiza en la percepción que hombres y mujeres poseen de la discriminación de género en el mercado de trabajo, en general, y en la Universidad, en particular. En segundo lugar, se analiza la valoración que las personas encuestadas otorgan a las diferentes barreras y obstáculos existentes durante los procesos de promoción de la carrera académica e investigadora.

\subsection{Negación e invisibilización de la discriminación de género}

En primer lugar, se consultó acerca de la existencia o no de un mayor número de barreras para las mujeres que para los hombres en el mercado de trabajo argentino a la hora de alcanzar las categorías profesionales más altas. El 63\% de las personas consideran que las mujeres deben superar más obstáculos durante su trayectoria laboral. En el caso de las mujeres, el porcentaje de respuestas afirmativas aumenta hasta el 67,3\%. Sin embargo, más de la mitad de los hombres, el $52 \%$, niegan que las dificultades para las mujeres sean mayores que para ellos (Tabla 7 ).

Tabla 7. Opinión sobre la existencia o no de discriminación de género en el mercado de trabajo

\begin{tabular}{|l|c|c|c|c|}
\hline & HOMBRE & MUJER & N.d & TOTAL \\
\hline SI & $48 \%$ & $67,3 \%$ & $75 \%$ & $63 \%$ \\
\hline NO & $52 \%$ & $23,6 \%$ & $25 \%$ & $31,5 \%$ \\
\hline NS/NC & - & $9,1 \%$ & - & $5,4 \%$ \\
\hline
\end{tabular}

Fuente: Elaboración propia

Existe una tendencia por parte de las personas encuestadas a considerar la Universidad como un espacio más igualitario que el mercado de trabajo (63\%). 
Esta mayor sensación de igualdad por parte de los/as docentes puede deberse a la existencia de procesos de selección y promoción que se presuponen objetivos, por lo que hace pensar que la meritocracia opera en la Universidad con más intensidad que en otros sectores en general. Sin embargo, son los hombres aquellos que en mayor medida respondieron afirmativamente a esta pregunta en el $68 \%$ de los casos, frente al $56,4 \%$ de sus compañeras. Éstas, a su vez, en un $30,9 \%$ afirman que ambos espacios, tanto el mercado de trabajo como la Universidad son igual de meritocráticos ( $16 \%$ de hombres). Únicamente el $10,9 \%$ de mujeres y el $12 \%$ de hombres piensan que la igualdad es mayor en el mercado laboral (Tabla 8).

Tabla 8. Opinión sobre si la Universidad se constituye como un sistema más meritocrático que el mercado de trabajo

\begin{tabular}{|l|c|c|c|c|}
\hline & HOMBRE & MUJER & N.d & TOTAL \\
\hline Sí & $68 \%$ & $56,4 \%$ & $83,3 \%$ & $63 \%$ \\
\hline NO, más el trabajo & $12 \%$ & $10,9 \%$ & $8,3 \%$ & $10,9 \%$ \\
\hline NO, igual ambos & $16 \%$ & $30,9 \%$ & $8,3 \%$ & $23,9 \%$ \\
\hline NS/NC & $4 \%$ & $1,8 \%$ & - & $2,2 \%$ \\
\hline
\end{tabular}

Fuente: Elaboración propia

En línea con la creencia mayoritaria acerca de que la Universidad se constituye como un espacio más meritocrático que el mercado laboral, y tal y como la literatura revisada apunta, se produce una invisibilidad de la discriminación de género en la Universidad por parte del cuerpo docente. El 67,4\% del total de encuestados/as dicen no existir discriminación directa o indirecta hacia la mujer en el acceso a la carrera docente e investigadora en la Universidad Nacional de Salta (UNSa) (Tabla 9). El porcentaje cae en 7,4 puntos cuando se trata de negar la discriminación durante la promoción (62\%) (Tabla 10). De este modo, el porcentaje de personas que confirman que las mujeres sí se enfrentan a procesos discriminatorios cuando desean ascender a las categorías profesionales más altas es mayor que el obtenido con respecto a la discriminación en el acceso (32,6\% y 25\%, respectivamente).

$\mathrm{Si}$ atendemos a las diferencias por sexo, se observa que mientras que las mujeres son más conscientes de la existencia de la problemática durante la promoción $(34,5 \%)$ que durante el acceso $(29,1 \%)$, en el caso de los hombres la valoración se da a la inversa ( $16 \%$ de discriminación en el acceso y $12 \%$ en la promoción). Llama la atención que las propias perjudicadas, las mujeres, 
nieguen en un 60\% (acceso) y un 56,4\% (promoción) tal problemática. La negación por parte de los hombres docentes es aún más elevada en ambos casos, 8 de cada 10 hombres no creen que exista discriminación.

Tabla 9. Opinión sobre la existencia o no de discriminación de género en el acceso en la UNSa

\begin{tabular}{|l|c|c|c|c|}
\hline & HOMBRE & MUJER & N.d & TOTAL \\
\hline SI & $16 \%$ & $29,1 \%$ & $25 \%$ & $25 \%$ \\
\hline NO & $84 \%$ & $60 \%$ & $66,7 \%$ & $67,4 \%$ \\
\hline NS/NC & - & $10,9 \%$ & $8,3 \%$ & $7,6 \%$ \\
\hline
\end{tabular}

Fuente: Elaboración propia

Tabla 10. Opinión sobre la existencia o no de discriminación de género en la promoción en la UNSa

\begin{tabular}{|l|c|c|c|c|}
\hline & HOMBRE & MUJER & N.d & TOTAL \\
\hline SI & $12 \%$ & $34,5 \%$ & $66,7 \%$ & $32,6 \%$ \\
\hline NO & $88 \%$ & $56,4 \%$ & $33,3 \%$ & $62 \%$ \\
\hline NS/NC & - & $9,1 \%$ & - & $5,4 \%$ \\
\hline
\end{tabular}

Fuente: Elaboración propia

Como puede observarse en la tabla 11, no existe una opción preferente a la hora de valorar la presencia femenina en los puestos de responsabilidad de la UNSa. En mayor proporción los/as docentes consideran que ésta es acorde con el total del profesorado (35,9\%), seguidos/as por quienes afirman que son bastantes las mujeres que asumen cargos importantes, en un 32,6\%. Sin embargo, el 23,9\% creen que es muy poca. En las dos respuestas de los extremos, «mucha»y «muy poca», los porcentajes disminuyen hasta el $5,4 \%$ y el $1,1 \%$, respectivamente.

Hombres y mujeres muestran opiniones encontradas. Son los hombres aquellos que se encuentran más conformes con la participación actual de las mujeres en altos cargos, de modo que más de la mitad de éstos, el 52\%, afirman que su presencia es acorde con el total del profesorado $(29,1 \%$ en el caso de las mujeres). Entre aquellos/as que consideran que son bastantes las mujeres en estos puestos, se encuentra el 30,9\% de las mujeres y el 32\% de los hombres. Podemos afirmar que aunque son las docentes las más críticas y quienes muestran un mayor descontento ( $30,9 \%$ poca y $1,8 \%$ muy poca), son, a su vez, 
las que seleccionaron en mayor medida la respuesta «mucha», con 5,5\% (1,5 puntos porcentuales por encima de los hombres).

Tabla 11. Opinión sobre la presencia femenina en puestos de responsabilidad en la UNSa

\begin{tabular}{|l|c|c|c|c|}
\hline & HOMBRE & MUJER & N.d & TOTAL \\
\hline MUCHA & $4 \%$ & $5,5 \%$ & $8,3 \%$ & $5,4 \%$ \\
\hline BASTANTE & $32 \%$ & $30,9 \%$ & $41,7 \%$ & $32,6 \%$ \\
\hline ACORDE AL TOTAL & $52 \%$ & $29,1 \%$ & $33,3 \%$ & $35,9 \%$ \\
\hline POCA & $12 \%$ & $30,9 \%$ & $16,7 \%$ & $23,9 \%$ \\
\hline MUY POCA & - & $1,8 \%$ & - & $1,1 \%$ \\
\hline NS/NC & - & $1,8 \%$ & - & $1,1 \%$ \\
\hline
\end{tabular}

Fuente: Elaboración propia

\subsection{Barreras y obstáculos de la carrera académica}

Uno de los resultados más interesantes lo constituye la opinión de los/as docentes cuando se les pregunta acerca de si se han encontrado o no con barreras y dificultades para promocionar a lo largo de su carrera académica. Paradójicamente, a pesar de que la gran mayoría de éstos negaron la existencia de procesos de discriminación directos o indirectos durante la promoción, es decir, el techo de cristal, más de la mitad de las personas encuestadas confirman haber tenido que superar obstáculos para poder acceder a las categorías más altas, el 57,6\% (Tabla 12). No obstante, no existen diferencias notables por sexos, aunque el porcentaje de mujeres que respondieron afirmativamente $(54,5 \%)$ es escasamente superior al de hombres (52\%).

Tabla 12. Opinión sobre la existencia o no de barreras y dificultades para promocionar

\begin{tabular}{|l|c|c|c|c|}
\hline & HOMBRE & MUJER & N.d & TOTAL \\
\hline SI & $52 \%$ & $54,5 \%$ & $83,3 \%$ & $57,6 \%$ \\
\hline NO & $44 \%$ & $43,6 \%$ & $16,7 \%$ & $40,2 \%$ \\
\hline NS/NC & $4 \%$ & $1,8 \%$ & - & $2,2 \%$ \\
\hline
\end{tabular}

Fuente: Elaboración propia 
Por otro lado, cuando se les consulta si creen que las barreras y obstáculos que han tenido que ir superando a lo largo de su trayectoria profesional afectan de igual manera a sus compañeros/as del sexo puesto, el 54,3\% considera que no. Analizando la variable de género apenas se producen diferencias entre las respuestas de ambos sexos. Tanto mujeres como hombres, en mayor medida, niegan que las dificultades sean iguales para unos y otras ( $56 \%$ de hombres y $56,4 \%$ de mujeres). No obstante, los varones consideran en casi 6 puntos más que las mujeres $(30,9 \%)$ que la superación de obstáculos es igual para sus compañeras que para ellos. Especificar que en esta cuestión un elevado porcentaje de mujeres seleccionaron la respuesta no sé/no contesto, el 12,7\%, configurándose como la pregunta que más duda ha provocado entre las personas encuestadas, hombres y mujeres (Tabla 13).

Tabla 13. Consideración acerca de la influencia o no de las barreras en los compañeros/as del sexo opuesto

\begin{tabular}{|l|c|c|c|c|}
\hline & HOMBRE & MUJER & N.d & TOTAL \\
\hline SI & $36 \%$ & $30,9 \%$ & $58,3 \%$ & $35,9 \%$ \\
\hline NO & $56 \%$ & $56,4 \%$ & $41,7 \%$ & $54,3 \%$ \\
\hline NS/NC & $8 \%$ & $12,7 \%$ & - & $9,8 \%$ \\
\hline
\end{tabular}

Fuente: Elaboración propia

Finalmente, se les presentó un listado con 15 aseveraciones, basado en una escala Likert, en el que se les requería que valorasen de 1 (menos incidencia) a 4 (más incidencia) las barreras y obstáculos que aparecían recogidos según consideraban afectaban en mayor o menor medida a la hora de promocionar en la carrera académica. Como se puede observar a continuación, y para facilitar la comprensión y el análisis de los resultados, se diferencian tres tipos de barreras (personales, organizacionales y del contexto social), siguiendo la clasificación realizada por Guil (93):

\section{Barreras personales:}

1.1. Familiares:

1.1.1. Problemas de conciliación debido a la inexistente corresponsabilidad por parte de la pareja

1.1.2. Trabajo doméstico y de cuidados (hijos/as, personas dependientes)

1.2. Profesionales:

1.2.1. Doble jornada laboral 
1.3. Cognitivo-emocionales:

1.3.1. Baja autoestima y autoimagen

1.3.2. Falta de confianza y miedo

1.3.3. Auto-restricción (no promoción por voluntad propia)

1.3.4. Sensación de culpa

\section{Barreras organizacionales:}

2.1. Discriminación directa por parte del profesorado y/o universidad

2.2. Existencia de redes informales de poder

2.3. Existencia de sistemas de cooptación

2.4. Diferenciación en la valoración de méritos según el sexo

2.5. Legislación vigente

2.6. Falta de apoyo y financiación

3. Barreras del contexto social:

3.1. Sociedad patriarcal

3.2. Estereotipos y roles de género

Como se recoge en la Figura 4, en primer lugar, el resultado más significativo consiste en la mayor valoración por parte de las mujeres en comparación con los hombres de todas las barreras, a excepción de aquellas que hacen referencia a los obstáculos personales cognitivo-emocionales, como la baja autoestima y autoimagen y la falta de confianza y miedo. Ambas fueron levemente más valoradas por los hombres ( 2 y 1,9 , respectivamente). Por otro lado, el obstáculo que mayor puntuación alcanzó fue aquel que aludía a la existencia de redes informales de poder, tanto por parte de los hombres como de las mujeres $(2,8)$.

Las barreras que obtuvieron una mayor puntuación por parte de las mujeres, son aquellas que se producen en el contexto social, como la existencia de una sociedad patriarcal $(2,6)$ con unos arraigados estereotipos y roles de género $(2,5)$, junto con barreras organizacionales como la falta de apoyo y financiación $(2,6)$ y la existencia de sistemas de cooptación $(2,5)$. De igual modo, las barreras personales familiares como el trabajo doméstico y de cuidados y la doble jornada laboral fueron puntuados con 2,5.

En el caso de los hombres, no se obtienen resultados que difieran considerablemente de los de las mujeres. Así, los obstáculos que según éstos tienen una mayor incidencia a la hora de promocionar son coincidentes con los de sus compañeras: las barreras organizaciones como son los sistemas de cooptación $(2,5)$ y la falta de apoyo y financiación $(2,3)$. Resulta paradójico que a pesar de lo que muestran las encuestas de usos del tiempo, es decir, que el trabajo no remunerado de cuidados y domésticos son asumidos casi en exclusividad por las mujeres, esta situación y las consecuencias que de ésta se desprenden, 
la doble jornada laboral, sea considerada por los hombres como una dificultad en su camino hacia la cúspide de la pirámide jerárquica, con 2,4 puntos.

La principal diferencia entre sexos se encuentra en la valoración de las causas que emergen del contexto social, fuertemente valoradas por las mujeres, mientras que los hombres le asignan 2 puntos de media. De igual modo, con medio punto de diferencia, se encuentra el sesgo de género en la valoración del mérito (1,6 los hombres y 2,1 las mujeres) y, en la línea de las respuestas anteriores, la discriminación directa por parte del profesorado y/o la universidad. Aunque se continúa produciendo una negación e invisibilización por parte de los hombres docentes (1,6 puntos), las mujeres le otorgan una puntuación de 2,1.

Finalmente, aquellas barreras menos valoradas por ambos sexos fueron la sensación de culpa, la auto-restricción, y la normativa vigente. En el caso de la auto-restricción nos resulta interesante detenernos a comentar la baja puntuación que las mujeres han otorgado, sólo 1,6 puntos. Esto desmonta, así, la falacia de la libre elección, a través de la cual se argumenta la auto-exclusión voluntaria de las mujeres de los procesos de promoción, al priorizar su vida familiar por encima del desarrollo profesional. Este argumento es utilizado para explicar las bajas cifras de participación de las mujeres en los círculos de poder universitarios.

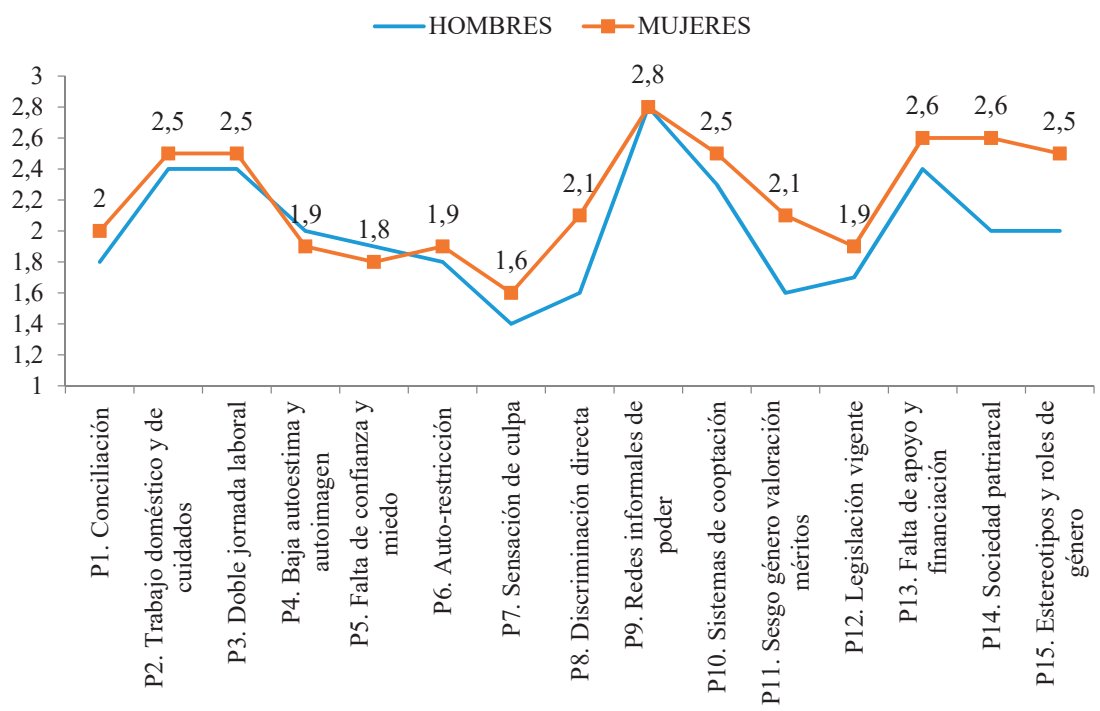

Figura 4. Valoración de las barreras y obstáculos de promoción

Fuente: Elaboración propia 


\section{DISCUSIÓN Y CONCLUSIONES}

Este trabajo ha permitido realizar una primera aproximación a las percepciones y opiniones que el cuerpo docente de la Universidad Nacional de Salta posee acerca de la discriminación de género en el contexto académico. Hemos podido comprobar cómo las cifras estadísticas son claras, mostrando un panorama de desigualdad. Por un lado, se produce una acumulación de mujeres en aquellas áreas para las que son consideradas «aptas», debido a que se constituyen como una extensión de los roles de cuidados y familiares que han asumido tradicionalmente (segregación horizontal).

Por otro lado, y a pesar de que representan una mayoría entre el total del cuerpo docente, éstas son retenidas por los suelos pegajosos, encontrándose sobrerrepresentadas en aquellos puestos bases, como es la categoría de docentes auxiliares. A todo ello se le suma el leaky pipeline, es decir, el descenso en la participación a medida que se avanza hasta los cargos jerárquicos más altos, produciéndose una fuga del potencial femenino y constatándose la existencia del techo de cristal.

En primer lugar, tal y como la literatura ha mostrado (Guil, Solano y Álvarez; Matus y Gallego; Pastor, Belzunegui, Moreno y Mañas; Pérez, Santesmases y Alcalá), podemos confirmar que se produce una invisibilización del problema. Se trata de una negación, además, que es más fuerte por parte de los hombres. Éstos niegan la existencia de cualquier tipo de discriminación de género tanto en el mercado laboral como en la Universidad. En todas las ocasiones en las que son consultados a lo largo del cuestionario, invisibilizan en mayor medida que sus compañeras la situación de desigualdad en la que se encuentran las mujeres, la escasa representación de éstas en los altos cargos y puestos de responsabilidad y poder, y otorgan valores más bajos a todas las barreras y obstáculos del techo de cristal.

Esta situación puede ser explicada debido a que los hombres poseen una conciencia del estigma del género más baja que las mujeres. En una investigación realizada por Pinel, ésta demostró que ciertos grupos, como en este caso las mujeres, poseen una mayor conciencia del estigma, por lo que esperan ser estereotipadas por el hecho de ser mujeres. Además, mientras más alto es el grado de conciencia, mayor es la probabilidad de que los estereotipos y prejuicios de género sean identificados y rechazados.

Los resultados de las encuestas muestran que al contextualizar la discriminación de género en el espacio académico, más de la mitad de los/as consultados/as responden negando la evidencia. Sin embargo, el porcentaje de mujeres que confirma su existencia es mayor durante el proceso de promoción que en el momento del acceso (en los hombres se produce a la inversa). Este 
resultado es coherente si tenemos en cuenta que el estudio ha sido realizado en una universidad con una alta tasa de feminización. De igual modo, la mayor parte cree que la presencia de las mujeres en los puestos de responsabilidad es adecuada al total del profesorado, siendo los hombres los que muestran una mayor satisfacción al valorar dicha presencia.

Por otro lado, la tendencia general consiste en considerar la Universidad como un espacio más meritocrático que el mercado laboral. De este modo, la gran mayoría de mujeres afirma que los obstáculos que deben superar para promocionar en el mercado de trabajo son mayores, sin embargo, más de la mitad de éstas continúan sin aceptar que se produzca ningún tipo de desigualdad en la Universidad.

En segundo lugar, paradójicamente, aunque la discriminación directa o indirecta es negada, al formular la pregunta de un modo más personal y directo, solicitándoles que consideren si se han tenido que enfrentar a obstáculos y barreras para promocionar a lo largo de su carrera, el número de personas que responden afirmativamente se convierte en mayoría. Así, la existencia de redes informales de poder es valorado como el principal obstáculo en las carreras de ambos sexos.

Se trata de redes implícitas de poder contra las que difícilmente se puede luchar (Guil 24), precisamente por la sutileza con la que actúan. En palabras de Ballarín, se configuran como un «entramado de relaciones masculinas donde se sostiene el poder que legitima la teoría» (184). Es por ello que no es casual que sea una de las causas más valorada por las docentes, sin embargo, llama la atención la alta puntuación proporcionada, además, por los hombres.

Finalmente, señalar que las mujeres valoran estas dificultades con mayores puntuaciones que sus compañeros varones, dándole especial importancia a las barreras que emergen del contexto social, como los estereotipos y roles de género en una sociedad patriarcal, junto a la doble jornada laboral (consecuencia de los trabajos domésticos y de cuidados) y, la falta de apoyo y financiación y los sistemas de cooptación, como barreras organizacionales.

En resumen, en este trabajo se ha constatado diferencias en las opiniones y percepciones de los hombres y mujeres docentes. La concienciación y visibilización de los procesos de discriminación de género, junto con el análisis y la profundización en las barreras y obstáculos se constituyen como una tarea fundamental. El diseño e implementación de medidas y estrategias de intervención difícilmente podrán obtener resultados positivos si las personas implicadas no consideran el problema como tal. 


\section{REFERENCIAS BIBLIOGRÁFICAS}

Antón, Susana. Informe Académicas en la Universidad de Alicante. Cuadernos de Trabajo de Investigación 12. Alicante: Universidad de Alicante, 2005.

Bailyn, Lotte «Academic careers and gender equity: Lessons learned from MIT». Gender, Work and Organization 10.2 (2003): 137-153.

Ballarín, Pilar. «Mujeres en el "laberinto de cristal" universitario». Miradas desde la perspectiva de género: estudios de las mujeres. Ed. Isabel de Torres. Madrid: Narcea Ediciones, 2005, 183-194.

Baxter, Janeen y Erik Olin Wright. «The glass ceiling hypothesis: A comparative study of the United States, Sweden, and Australia». Gender and Society 14.2 (2000): 275-294.

Busso, Matias y Dario Romero Fonseca. Female labor force participation in Latin America: Patterns and explanations. Ciudad de la Plata: Universidad Nacional de la Plata, Documentos de Trabajo del CEDLAS, 2015.

Cohen, Philip y Matt L. Huffman. «Individuals, Jobs and Labor Markets: The Devaluation of Women's Work», American Sociological Review 68.3 (2003): 443-463.

Comisión Europea. She Figures 2015. Gender in research and innovation. Bruselas:Dirección General de Investigación e Innovación, 2016. <https:// ec.europa.eu/research/swafs/pdf/pub_gender_equality/she_figures_2015-final. pdf>, consultado el 16-12-2016.

CTIO. Documento de trabajo para el debate en el marco de la CTIO - Género. Argentina: Ministerio de Trabajo, Empleo y Seguridad Social. Presidencia de la Nación, 2016. <http://www.trabajo.gov.ar/downloads/cegiot/Informe_CTIO_ DocumentoDeTrabajo.pdf>, consultado el 03-01-2017.

Estébanez, María Elina, Daniela De Filippo y Alejandra Serial. La participación de la mujer en el sistema de Ciencia y Tecnología en Argentina. Buenos Aires: Documento de Trabajo nro. 8. Proyecto GENTEC. Informe final Grupo REDES. UNESCO-OEI, 2003.

Fernández, Concepción. «La mujer en la Universidad española. Docencia, investigación y poder. Datos y aspectos cualitativos». Revista de Educación 290 (1989): 61-171.

Gallego, Nazareth. «Rompiendo el techo de cristal: la lectura de la tesis doctoral como momento clave.» Mètode: Revista de difusión de la Investigación 91 (2016): 64-71.

Gálvez, Lina y Paula Rodríguez. «El empleo de las mujeres en la España democrática y el impacto de la Gran Recesión», Áreas Revista Internacional de Ciencias Sociales 32 (2013): 105-123. 
Gálvez, Lina, Paula Rodríguez, Astrid Agenjo y Mónica Domínguez. El Trabajo de Cuidados de Mujeres y Hombres en Andalucía. Medición y valoración. Sevilla: Instituto Andaluz de la Mujer, 2013.

García de León, María Antonia. «Las profesoras universitarias: el caso de una élite discriminada». Revista Complutense de Educación 1.3 (1990): 355-372.

Gómez, Carmuca. «Mujeres y trabajo: principales ejes de análisis». Papers: revista de sociologia 63 (2001): 123-140.

Guil, Ana. Techos de Cristal en la Universidad Hispalense. Informe final del proyecto del Plan Nacional I+D+i 2001-2004. Sevilla: Universidad de Sevilla, 2005.

Guil, Ana, Ana Solano y Manuela Álvarez. La situación de las mujeres en las universidades públicas andaluzas. Sevilla: Consejo Económico y Social de la Junta de Andalucía, 2005.

Hartmann, Heidi. «Capitalismo, patriarcado y segregación de los empleos por sexos». Las mujeres y el trabajo. Rupturas conceptuales. Eds. Cristina Borderías, Cristina Carrasco y Carme Alemany. Madrid: Icaria, 1994, 253-294.

INDEC. Encuesta sobre trabajo no remuerado y uso del tiempo. Argentina: Ministerio de Trabajo, Empleo y Seguridad Social. Presidencia de la Nación, 2014. <http:// www.indec.gov.ar/uploads/informesdeprensa/tnr_07_14.pdf>, consultado el 04-01-2017.

INDEC. Encuesta Permanente de Hogares (EPH). Argentina: Ministerio de Trabajo, Empleo y Seguridad Social. Presidencia de la Nación, 2016. <http://www.indec. gob.ar/uploads/informesdeprensa/indicadores_eph_3trim16.pdf>, consultado el 05-01-2017.

Jackson, Jerlando F.L y Elizabeth M. O'Callaghan. «What do we know about glass ceiling effects? A taxonomy and critical review to inform higher education research». Research In Higher Education 50.5 (2009):460-482.

Matus, Mauricio y Nazareth Gallego. «Techo de cristal en la Universidad. Si no lo veo no lo creo». Revista Complutense de Educación 26.3 (2015): 611-626.

Monreal, María del Carmen y Belén Martínez. Esquemas de género y desigualdades sociales, en Intervención Social y Género. Madrid: Narcea Ediciones, 2010.

Morrison, Ann M., Randall White y Ellen Van Velsor. Breaking the Glass Ceiling: Can Women Reach the Top of America's Largest Corporations? New York: AddisonWesley, 1987.

Moser, Caroline y Kate Young. «Women of the working poor.» The IDS Bulletin 12.3 (1981): 1-9.

OEDE. Boletín de estadísticas de género y mercado de trabajo. Argentina: Ministerio de Trabajo, Empleo y Seguridad Social, 2014. <http://www.trabajo.gov.ar/left/ estadisticas/genero/estadisticas.asp>, consultado el 20-11-2016.

Ogbogu, Christina O. «Gender factors affecting female labour input in the Nigerian University System». Gender and Behaviour 8.1 (2010): 2666-2677. 
OIT. Las mujeres en el trabajo: Tendencias de 2016. Ginebra: Oficina Internacional del Trabajo, 2016. <http://www.ilo.org/wcmsp5/groups/public/---dgreports/--dcomm/---publ/documents/publication/wcms_483214.pdf>, consultado el 04-01-2017.

Pastor, Inma, Ángel Belzunegui, Blanca Moreno y Carmen Mañas. «La igualtat d'oportunitats a la universitat: les percepcions del PDI». Papers: revista de sociología 95.2 (2010): 457-481.

Pateman, Carol. El contrato sexual. Barcelona: Anthropos Editorial, 1995.

Pérez, Eulalia, Maria Jesús Santesmases y Paloma Alcalá (Coords.). Mujer y ciencia. La situación de las mujeres investigadoras en el sistema español de ciencia y tecnología. Madrid: Ministerio de Educación y Ciencia. Fundación Española para la Ciencia y Tecnología, 2005.

Pinel, Elizabeth C. «Stigma Consciousness: The Psychological Legacy of Social Stereotypes». Journal of personality and social psychology 76.1 (1999): 114-128.

PNUD. Aportes para el desarrollo humano en Argentina 2014. Género en el trabajo: brechas en el acceso a puestos de decisión. Buenos Aires: Programa de las Naciones Unidas para el Desarrollo, 2014. <http://www.ar.undp.org/content/dam/ argentina/Publications/Desarrollo\%20Humano/PNUD\%20ARGENTINA\%20_ Aportes_8.pdf>, consultado el 10-01-2017.

Probert, Belinda. «I just couldn't fit in: Gender and Unequal Outcomes in Academic Careers». Gender Work and Organization 12.1 (2005): 50-72.

Sarasúa, Carmen y Lina Gálvez. ¿Privilegios o eficiencia?: mujeres y hombres en los mercados de trabajo. Alicante: Universidad de Alicante, 2003.

Sistema RHUN. Área de Recursos Humanos de las Universidades Nacionales. Argentina: Dirección Nacional de Presupuesto e Información Universitaria, 2013.

SPU. Anuario de estadísticas universitarias de Argentina. Ciudad Autónoma de Buenos Aires: Ministerio de Educación de la Nación, 2013. <http://informacionpresupuestaria.siu.edu.ar/DocumentosSPU/Anuario_2013.pdf>, consultado el 10-07-2016.

SPU. Sistema de consultas de estadísticas universitarias. Argentina: Ministerio de Educación de la Nación, 2014. <http://estadisticasuniversitarias.me.gov.ar/\#/ homes, consultado el 12-07-2016.

Tomás, Marina y Cristina Guillamón. «Las barreras y los obstáculos en el acceso de las profesoras universitarias a los cargos de gestión académica». Revista de Educación 350 (2009): 253-275.

Torns, Teresa y Carolina Recio. «Desigualdades de género en el mercado de trabajo entre la continuidad y la transformación». Revista de Economía Crítica 14 (2012): 178-202. 
Torres, Obdulia y Bernadette Pau. «Techo de cristal y suelo pegajoso: La situación de la mujer en los sistemas alemán y español de ciencia y tecnología». CTS: Revista Iberoamericana de Ciencia, Tecnología y Sociedad 6.18 (2012): 35-59.

UNSa. Estadísticas de la planta docente de la Universidad Nacional de Salta. Ciudad de Salta: Departamento de Estadísticas Universitarias, 2015. 
Para enlazar con este artículo / To link to this article:

http://dx.doi.org/10.14198/fem.2017.29.06

Para citar este artículo / To cite this article:

García-Arroyo, Ana. «Realidades y paradojas en la Educación Superior de India: (in)visibilidad de la mujer». En Marcos Jesús Iglesias Martínez e Inés Lozano Cabezas (coords.), La (in)visibilidad de las mujeres en la Educación Superior: retos y desafios en la Academia. Feminismo/s, 29 (junio 2017): 153-171, DOI: 10.14198/fem.2017.29.06

\title{
REALIDADES Y PARADOJAS \\ EN LA EDUCACIÓN SUPERIOR DE INDIA: (IN)VISIBILIDAD DE LA MUJER
}

\author{
REALITIES AND PARADOXES OF INDIA'S HIGHER \\ EDUCATION: WOMAN'S (IN)VISIBILITY
}

\author{
Ana GARCÍA-ARROYO \\ Universitat Rovira i Virgili \\ garciaarroyo7@gmail.com \\ orcid.org/0000-0001-6720-6319
}

\section{Resumen}

En este artículo me propongo analizar los principales problemas de la Educación Superior india, centrándome en los cambios que se han producido con la globalización, a principios de los años noventa, y cómo afectan directamente a las mujeres. Analizaré los datos más relevantes que se desprenden del informe del Gobierno indio del año 2014-15, All India Survey on Higher Education 2014-15, qué representan dichas cifras y a qué realidades y paradojas corresponden, en las que se ve implicada la mujer. Basándome en la filosofía sobre Educación Superior de Martha Nussbaum (2010), el objetivo final de mi investigación es demostrar que las consecuencias derivadas de la implantación de un sistema de Educación Superior, basado en el modelo occidental utilitario y dirigido hacia el mercado, han afectado a la mujer india y continuarán amenazando su calidad académica y su equidad de género-casta-clase.

Palabras clave: mujer india, globalización, educación utilitarista, consecuencias presentes y futuras.

\begin{abstract}
This article analyzes the most important problems of India's Higher Education. It focuses on the changes that have been produced from the arrival of globalization at the beginning of the 1990s until now, which have direct implications on women. I will deal with the most relevant data in All India Survey on Higher Education 2014-15 by
\end{abstract}


the Ministry of Higher Education (Indian Government), paying special attention to what these figures stand for in terms of representing the realities and paradoxes that affect women. Based on Martha Nussbaum's philosophy on Higher Education (2010), the ultimate aim of this research is to demonstrate that the consequences derived from the implementation of a system of Higher Education, based on the market-oriented utilitarian Western model, have directly affected Indian women and will continue threatening their academic quality and their gender-class-caste equality.

Keywords: Indian woman, globalization, utilitarian education, present \& future consequences. 


\section{INTRODUCCIÓN Y OBJETIVOS}

Desde la independencia de India en 1947 y con la implementación de la Constitución, la educación se ha considerado un derecho por excelencia para la población india, independientemente de su casta, religión, género o sexo. Por esta razón, para las castas tradicionalmente más vulnerables (Scheduled Castes) y los grupos tribales también desprotegidos (Scheduled Tribes), se estableció una cuota de admisión en educación y en puestos de trabajo, en las instituciones del Estado. Durante todos estos años el gobierno indio se ha esforzado considerablemente en reforzar el sistema educativo a través de sus diversos planes quinquenales, centrándose principalmente en la educación obligatoria, aunque la Educación Superior también ha dado un salto considerable si tenemos en cuenta que en 2011 había 42 universidades centrales, 275 universidades estatales, 130 universidades deemed ${ }^{1}$ y 90 universidades privadas, a las que además se ha de añadir un número elevado de colleges, públicos y privados. En los últimos años el énfasis principal ha recaído en la potenciación de las áreas de ciencia y tecnología, así como en educación a distancia, que ha dado como resultado el hecho de que los Institutos Superiores de Tecnología, de Comercio, de Empresariales, junto con la Jawaharlal Nehru University en Delhi, hayan obtenido un reconocimiento académico a nivel mundial por su prestigiosa educación. Sin duda, con la mejora de la economía y, sobretodo, desde que India abre sus puertas a los mercados internacionales a principios de los 1990s, con la introducción de las tecnologías de la comunicación y de internet, la educación, en todos sus niveles, pero principalmente la Educación Superior, ha sufrido un cambio radical. También es en este momento cuando el sector privado interviene, creando sus propias universidades, escuelas e institutos, que llegan a abarcar hoy en día el $60 \%$ del total de las instituciones educativas (Shagur). Por otro lado, a pesar de que unas determinadas instituciones académicas indias destaquen a nivel mundial, la otra realidad es que la calidad del sistema de Educación Superior indio se ha cuestionado desde diferentes

1. Universidad deemed (Deemed University) es un término utilizado en India para aludir a una institución de educación superior del mismo nivel de enseñanza que la Universidad.

Feminismo/s 29, junio 2017, pp. 153-171 
posturas y sigue siendo objeto de un arduo debate. Consecuentemente, en el plan diseñado por el gobierno que comprende desde el 2012 hasta el 2017 se ha propuesto como objetivo principal mejorar la calidad de la Educación Superior en todo el país. Si tenemos en cuenta la gran complejidad ${ }^{2}$ de un país como India, podríamos incluso afirmar que, a pesar de que todavía quede mucho por hacer, ha habido una evolución muy positiva con respecto a la Educación Superior y se ha logrado en muy poco tiempo. Por otro lado, sabemos que India está constantemente cambiando y mejorando en derechos sociales y civiles, en todos los campos, aunque, desafortunadamente, todavía sigue siendo un país eminentemente patriarcal. Por esta razón, desde la mirada de los Estudios de Género, una se pregunta qué papel ha tenido la mujer ${ }^{3}$ en el mundo educativo de la Enseñanza Superior, bien como estudiante o como profesora, si ha evolucionado su posición dentro de la institución académica, cuáles son sus principales logros y los problemas mayores a los que se ha enfrentado y si en las expectativas de futuro que el gobierno contempla para la educación y la persecución del 'progreso' también se incluye a la mujer, es decir, si en las mejoras de la calidad académica (quality), también se incluyen mejoras de igualdad de género (equality).

En este artículo me propongo analizar los principales problemas de la Educación Superior india, centrándome en los cambios que se han producido con la globalización, a principios de los años noventa, y cómo afectan a las mujeres. Analizaré los datos más relevantes que se desprenden del informe del Gobierno indio en el año 2014-15, qué representan dichas cifras y a qué realidades y paradojas corresponden, en las que se ve implicada la mujer. El objetivo final de mi

2. Utilizo el término «complejidad» para definir India y referirme a los 1.200 millones de habitantes, sus miles de castas, múltiples cultos religiosos, diferentes etnias, miles de lenguas (oficiales y no oficiales), multiplicidad de tradiciones y costumbres, es decir, toda su diversidad multicultural que hacen del país un lugar muy complejo para gobernar.

3. Este artículo huye de todo tipo de esencialismos y generalizaciones y quiere aclarar que utiliza la terminología de «la mujer india» o «las mujeres indias» indistintamente. Se es consciente y se subraya la complejidad, la diversidad y la diferencia con respecto a 'la mujer' y/o 'las mujeres' indias. Al mismo tiempo la autora considera que 'la mujer india' / 'las mujeres indias', así como 'la mujer', en general, en el mundo de hoy, en cualquier país o cultura, en su diversa condición de raza, clase, casta etc., sigue estando sometida a las normas hegemónicas patriarcales y neocolonialistas locales, nacionales e internacionales, en un grado que puede variar muy ampliamente, según cada persona en particular, y del que ella misma, la mujer, puede tener consciencia de ello o no tenerla plenamente. Esto no significa -como subraya Spivak- que la mujer, como sujeto subalterno, esté desempoderada y no pueda hablar, contestar y desafiar el discurso colonizador; al contrario, la realidad ha demostrado que es lo que ha venido haciendo desde épocas ancestrales y continua haciendo hoy, alterando ese discurso hegemónico y manifestando sus deficiencias y absurdidades. 
investigación es demostrar que las consecuencias derivadas de la implantación de un sistema de Educación Superior, el cual está basado en el modelo occidental utilitario y va dirigido hacia el mercado, ha afectado a la mujer y continuará amenazando su calidad académica y su equidad de género-casta-clase.

\section{LA «INDIA RESPLANDECIENTE» DE LA GLOBALIZACIÓN: PROBLEMAS DE LA EDUCACIÓN SUPERIOR}

Como la gran mayoría de países del mundo, India está inmersa en la atmósfera desenfrenada y mareante de conseguir 'el progreso' a través de un modelo económico competitivo y global. Su actuación hasta ahora ha sido ejemplar y se plasma en su imparable crecimiento económico. El McKinsely Quarterly apunta que si continúa manteniendo el ritmo de crecimiento, para el año 2025 se convertirá en la quinta economía consumidora del mundo (Beinhocker et al.). La revista The Economist también mantiene que India tiene un crecimiento económico mucho más elevado que ningún otro país y seguirá así durante las dos próximas décadas ( 2010 a \& 2010 b). Sin embargo, esta imagen victoriosa de una «India Resplandeciente» (Shining India) también revela otra cara más oscura si nos detenemos a examinar las vidas de millones de personas que no se benefician del actual modelo de crecimiento económico vertiginoso. Todo lo contrario, este modelo económico que ha dado lugar al dominio hegemónico de los Estados Unidos y que ha sido imitado por todo el mundo occidental, ofreciendo sus repercusiones a nivel global, en todos los demás países, poco o casi nada se ha preocupado por establecer una política de igualdad y calidad de derechos, por ejemplo, los relacionados con el género, la raza y la casta principalmente. La filósofa americana Martha Nussbaum, a la que se le concedió el Premio Príncipe de Asturias en 2012 por su labor en el campo de las Ciencias Sociales y las Humanidades, una gran seguidora de la obra del Premio Nobel de Literatura indio, Rabindranath Tagore, demuestra todo esto en su estudio Not for Profit:

Today's India offers a revealing laboratory of such experiments, as some states (Gujarat, Andhra Pradesh) have pursued economic growth through foreign investment, doing little for health, education, and the condition of the rural poor $[\ldots]$ Achievements in health and education, for example, are very poorly correlated with economic growth [...] So producing economic growth does not mean producing democracy. Nor does it mean producing a healthy, engaged, educated population in which opportunities for a good life are available to all social classes (15).

Un siglo antes de que Nussbaum escribiese estas palabras, Rabindranath Tagore, el gran maestro no sólo en el arte literario sino también en la construcción de 
un modelo alternativo de Universidad, donde prima la creatividad y no la competencia y la economía, cuestionaba ya el mercantilismo desbocado y el afán de 'progreso', como serias amenazas para la humanidad y la educación (Tagore).

En la «India Resplandeciente», que quiere estar a la altura en el mercado global, hay también un sentimiento de inquietud debido a las infraestructuras tan pobres con las que todavía cuenta el país, por ejemplo, en lo que respecta a la Educación Superior. En Deepening Democracy Madhu Kishwar comenta que si dejamos a un lado algunos Institutos y Escuelas de Educación Superior, como he mencionado arriba, los/as estudiantes indios/as no acaban sus carreras universitarias con una buena preparación, capaces de ocupar puestos relevantes y sacar a India de la corrupción y la ineficiencia. Kishwar también subraya que los sucesivos gobiernos indios han descuidado y en ocasiones destruido una serie de oficios y conocimientos ancestrales, en lugar de haber modernizado todas esas técnicas y haber proveído a estos profesionales con una Educación Moderna competente. Kishwar subraya que al adoptar un sistema de educación superior basado en el modelo académico inglés, que se introdujo en el país en el siglo XIX, en el que el inglés se convierte no sólo en la lengua dominante, sino en un signo de educación elitista, vinculada a las profesiones más distinguidas, todas aquellas personas que no tienen acceso a una excelente educación en inglés quedan relegadas a un segundo término y son tratadas, en muchos casos, de ignorantes y analfabetas. Consecuentemente, hoy en día, muchos de los estudiantes que van a la Universidad, especialmente los varones, se inclinan hacia carreras que les proporcionen mucho dinero, o que les brinden la posibilidad de optar a puestos administrativos del estado que otorgan prestigio social. Y, sin embargo, estos estudiantes no poseen el talento y conocimiento suficientes para competir en el mercado global, señala Kishwar.

Según el profesor Ram Takwale, los problemas principales de la Educación Superior india de hoy se pueden resumir en los siguientes puntos: a) el mercantilismo de la educación, es decir, el bien social de la educación se ha convertido en objeto de mercado y tiene esta orientación exclusiva, con lo cual se desprestigia toda aquella formación que no va dirigida hacia el mercado y no sea rentable para el gobierno; b) la competitividad global, que significa elevar la calidad y el estándar para poder entrar en una carrera imparable de agresiva competición a nivel mundial; c) débil conexión entre el mundo educativo y el trabajo; d) grandes disparidades de calidad y estándares mínimos en las diferentes instituciones académicas; y e) costes muy caros que ofrecen como resultado la imposibilidad de acceso para un gran número de personas de las clases medias y bajas. 
Fazal Rizvi y Radhika Gorur también comparten estos argumentos con respecto a la Educación Superior india: «a system that remains in a poor shape, characterized by inadequate infrastructure, poor operating conditions and ineffective teaching and learning programs, producing large cohorts of graduates who are barely employable in the professions for which they are ostensibly been trained»(2). En el 2007, incluso el mismo ministro de Desarrollo de Recursos Humanos, Arjun Singh, comparó el sistema de Educación Superior con un «niño enfermizo» en el periódico The Hindu (2007), que no ha mejorado demasiado a pesar de las reformas introducidas en los últimos años. Es muy relevante subrayar que estas reformas no han tenido el éxito que originalmente se esperaba, no porque estuviesen mal encaminadas, o por la falta de recursos económicos, sino más bien porque han chocado contra un conjunto de paradojas y realidades socio-culturales que se resisten a los grandes cambios y que están relacionadas con la casta, la etnia, la clase social, la región y el género. Un ejemplo muy claro lo encontramos en las disparidades e inequidades concernientes a la mujer india que paso ahora a analizar.

\section{REALIDADES Y PARADOJAS: ¿POR QUÉ SE PRODUCEN?}

Primeramente, quiero subrayar una vez más que cuando nos referimos al concepto de 'mujer india', no se debe concebir como un conjunto o categoría homogénea, pues caeríamos en los reduccionismos hegemónicos típicos del colonialismo, que bien apuntó Mohanty en su famoso artículo «Under Western Eyes», entre otros/as estudiosos/as (2008). La clase social, la casta, el grupo tribal y la región son algunos de los factores más importantes que contribuyen a la diferencia y heterogeneidad de las mujeres indias, que también están presentes cuando nos referimos a la Educación Superior. Por otro lado, también es bien cierto que, en términos generales, la mujer india, como sujeto social y político, no disfruta de un estado superior o igual al del hombre y estas mismas categorías de clase, casta, religión, etc., sólo contribuyen a multiplicar sus desventajas e inequidades en todos los terrenos, incluido el de la Educación Superior. Ya he apuntado anteriormente que en la Educación Superior india existe una línea divisoria situada al inicio de los años noventa, que marca el antes y el después de la globalización, que ha transformado el modelo educacional y ha derivado en tremendas consecuencias de género. Karuna Chanana en «Subject Choices and Gender: Women in Higher Education in India» (2005) arguye que desde los 1950s hasta los noventa, el objetivo del gobierno se centraba en identificar los problemas principales de la educación de la mujer, tratar de solventarlos y buscar vías de conexión entre la Universidad y la vida laboral posterior. Igualmente, Sahni and Shakar en «Girls' Higher Education 
in India on the Road to Inclusiveness» arguyen que durante los primeros años después de la independencia india las aulas estaban abarrotadas de estudiantes varones, con lo que la labor del gobierno fue promover la participación de la mujer en la Educación Superior. Incluso las políticas de educación de 1986, conocidas como The National Policy of Education, se propusieron, férreamente, empoderar a las mujeres a través de la educación con el fin de solucionar disparidades e inequidades de género ${ }^{4}$. Un resultado muy positivo lo tenemos en el incremento del número de mujeres matriculadas en la Universidad: entre 1950-55 la cifra era tan sólo del 10,9\% mientras que en el curso de 1991-92 alcanzó el 32\% (Chanana 2005). La mujeres entraban en carreras consideradas tradicionalmente femeninas como Magisterio y Humanidades, incluyendo esta última Lenguas, Literaturas y Ciencias Sociales, dejando a un lado los otros estudios 'más masculinos' como Comercio, Derecho e Ingeniería. En las carreras de Ciencias, un 28.8 \% de mujeres se llegó a matricular en 1980-81 y en Medicina las mujeres alcanzaron una cifra del $31,7 \%$ en $1988-89$. En este último caso, Medicina, debo añadir que en India nunca ha sido una carrera tradicionalmente masculina debido al hecho de que al existir la costumbre, en algunas comunidades, de segregar a las mujeres y alejarlas del contexto de los hombres, también esta misma restricción cultural ha exigido mujeres-médico y ha favorecido el acceso de la mujer india a estos estudios universitarios.

Con el cambio impactante que se produce a partir de 1991, las políticas del gobierno se caracterizan por disminuir la inversión en Educación Superior, realizar una re-estructuración de las universidades públicas y fomentar la autofinanciación de las instituciones académicas a través de capitales privados. También se permite la creación de instituciones de Educación Superior totalmente privadas y autónomas, sin unas normas por parte del gobierno indio que regulen su funcionamiento, para que de esta manera puedan hacer frente al aumento de la demanda de cursos y carreras específicas (Anandkrishnan). La globalización en India, como en el resto del mundo, trae además un aumento de las carreras científico-técnicas orientadas hacia el mercado, en detrimento de las disciplinas que tradicional y mayoritariamente han sido la opción de las mujeres como las Humanidades y las Ciencias Sociales. La división entre Letras y Ciencias se acentúa aún más, pues en la India global las Ciencias se subdividen en Ciencias Puras y Ciencias Aplicables, creándose así una jerarquía

4. Recordemos aquí que ya antes de la independencia, durante la etapa colonial en el siglo XIX, los reformadores indios pusieron sus objetivos en las reformas y mejoras que afectaban a la mujer, liberándolas de tradiciones ancestrales opresoras y dotándolas de educación. Ver: Historia de las mujeres de la India (2009) de Ana García-Arroyo. 
de disciplinas más precisa que dificulta más el acceso y la equidad de la mujer en estas instituciones superiores.

Por otro lado, la globalización y todos sus cambios sociales han conseguido que algunas mujeres indias, por su contexto familiar y social, también se hayan lanzado a realizar estudios de las nuevas disciplinas académicas como apunta Chanana en «Gender and Disciplinary Choices» (2004):

The influence of the so-called economic liberalization and the market demand on women's access to higher education as well as women's choices of subjects because one sees a perceptible change in the choices of women at least in the metropolitan cities in India where they are flocking to the new 'profesional' courses such as management, fashion designing, computers, human resource management etc. (8.)

Según el estudio de Chanana, en el curso 1993-94 el 54,2\% de las mujeres se matriculaba en las carreras de letras, sólo el 19,8\% lo hacía en las de Ciencias y un porcentaje todavía más bajo, el 14,6\% se decantaba por Comercio (Commerce).

Si echamos ahora una ojeada al último informe del Gobierno indio, All India Survey on Higher Education (2014-15), facilitado por el Department of Higher Education, obtenemos una serie de datos más actuales que confirman lo que se está demostrando en este artículo. En el curso 2014-15, el total de los estudiantes varones matriculados en la Educación Superior india era del 54\% frente al 45,5\% de mujeres que lo hacían. Estas cifras representan un 25,3\% de hombres y un 23,2\% de mujeres que son estudiantes entre 18-23 años que acceden a estudios superiores en todo el país.

Me gustaría detenerme ahora en las carreras principales en que estos/as estudiantes se matriculan y el nivel, ya que para este mismo año se observa que el porcentaje más elevado de estudiantes aparece en primer lugar en el Grado de Letras (Bachelor of Arts), seguido del Grado de Comercio (Bachelor of Commerce) y finalmente del Grado de Ciencias (Bachelor of Science). Las cifras también demuestran que la liberalización económica ha facilitado a las mujeres el acceso a las nuevas carreras o a aquellos terrenos considerados tradicionalmente masculinos como Empresariales, Ingeniería, Diseñadora de moda, Informática, Comercio, Recursos Humanos, Tecnologías de la Información, etc., especialmente si éstas habitan en zonas urbanas. No obstante, el número sigue manteniéndose bastante inferior, comparado con el de los estudiantes varones. Algunos ejemplos lo confirman: en el Grado de Ciencias hay un 52,4\% de hombres y sólo un 37,2\% de mujeres; en el Grado de Comercio las cifras son de 54,5\% de hombres y 45,5\% de mujeres; en el Grado de Tecnología el índice se dispara con $73 \%$ de hombres y tan sólo $27 \%$ de mujeres; y en el Grado de 
Ingeniería existe un $71,5 \%$ de varones y un $24,5 \%$ de mujeres. Este Grado de Ingeniería comprende disciplinas como Electrónica, Informática, Ingeniería Mecánica, Ingeniería Electrónica y similares.

Sin embargo, las carreras en las que las mujeres siguen ofreciendo un número de matrículas más elevado son el Grado en Magisterio con un 64\% frente al 36\% de varones, y el Grado de Letras con un 53\% de mujeres y un 47\% de estudiantes varones. También en la carrera de Medicina siguen destacando las mujeres con un 55\% por la razón cultural que he comentado antes. En este Grado de Medicina se incluyen además otras ramas como Farmacia, Medicina Ayurvédica y Odontología.

Es interesante también comprobar que según este informe del gobierno indio de 2014-15, si nos fijamos en el acceso a la Educación Superior por estados indios, se demuestra la tendencia también tradicional, en este caso favorable a las mujeres, de un número más elevado de matrícula para ellas en el estado de Kerala, frente al $42 \%$ de hombres matriculados. En realidad es el único estado indio en el que hay mayor acceso de la mujer al estamento educativo superior, es decir, se confirma el hecho de que Kerala ha sido un estado en el que ha existido una conciencia de mayor igualdad y equidad de derechos de género, que se ha manifestado desde tiempos ancestrales con la existencia del sistema matriarcal y matrilineal mantenido hasta la época moderna; después, durante la India independiente, siempre ha existido esa particular lucha del pueblo por eliminar las costumbres opresoras y hacer que mejoren y prevalezcan los derechos de la mujer

El mismo informe también hace relación al porcentaje total de estudiantes que pertenecen a las distintas castas de intocables (Scheduled Castes) y a las poblaciones tribales (Scheduled Tribes) que logran acceder a los estudios superiores, con sólo un $13,5 \%$ y un $4,8 \%$ respectivamente. No hace especificaciones por género, pero una puede imaginar que el número de mujeres que logran acceder a la Educación Superior es muy bajo.

Teniendo estas cifras presentes la pregunta que una se hace ahora es, ¿por qué ocurre todo esto? ¿Por qué con la globalización y la expansión educativa se ha producido un incremento de las mujeres en la Educación Superior pero éstas optan, en su mayoría, por carreras consideradas tradicionalmente femeninas? ¿Cuál es el contexto indio y las paradojas del mismo sistema que condicionan estas decisiones? A continuación me propongo dar respuestas a estos interrogantes y otros derivados de ellos.

5. Ver, por ejemplo, la obra literaria de la escritora india Kamala Das, donde se narra el poder y, al tiempo, la naturalidad del sistema matriarcal. También ver, «Legacies of Matriliny: The Place of Women and the Kerala Model» de Robin Jeffrey. 
1) Existen una serie de factores físicos que ponen difícil el acceso de la mujer a la Educación Superior como pueden ser la falta de instituciones académicas, la carencia de infraestructuras adecuadas para la mujer, sobre todo en las zonas más rurales y provinciales, como alojamiento económico (hostels), lavabos femeninos y espacios para ellas; carencia de modelos diferentes de mujer que transciendan el patrón tradicional; número bajo de profesoras y de becas; falta de un mayor número de materias en el currículum académico para su elección; carencia de profesorado femenino en puestos de poder (rectorado, administración) con políticas de equidad; reglas excesivamente restrictivas para la mujer. Mi propia investigación en 2008 y 2010 en algunos Colleges de West Bengal y en la Universidad de Rohtak, en el estado de Haryana, confirma lo que expongo ${ }^{6}$. En algunas zonas las infraestructuras son inadecuadas en todos los niveles académicos y humanos. No se contemplan ni las mínimas necesidades básicas de la mujer, como la existencia de lavabos para ellas donde se pueda tener un poco de intimidad y seguridad. Esto demuestra que aún se conciben los estudios universitarios como un espacio masculino, innecesario para la mujer que debe ceñirse a su rol tradicional de esposa y madre. Por otro lado también pude constatar como evidencia que la educación en la Jawaharlal Nehru University en Nueva Delhi es excelente en términos de calidad, como he mencionado arriba, pero si consideramos la equidad, principalmente de género, se siguen produciendo grandes abusos por la carencia de dichas políticas.

Los estudios anteriores de Sahni y Kale por un lado, y de Samal por otro, ya confirmaban mi investigación. Estos autores demuestran que la Educación Superior india no es igual en todas partes del país y establecen diferencias entre zonas: las urbanas/semi-urbanas y las rurales. Como ejemplo citan el estado de Orissa donde en el momento de su estudio había 50 colleges del gobierno en las zonas urbanas, pero ninguno en las rurales.

Otra disparidad a nivel estatal y que vincula directamente al género la encontramos entre los estados del norte de India y los del sur. En el sur el aumento de matrícula de estudiantes mujeres ha coincidido con el incremento de las instituciones académicas por parte del Gobierno, y de capitales

6. La autora se ha dedicado a los Estudios de India durante más de veinte años, con numerosas estancias y viajes por el país, dando como resultado diversos ensayos, traducciones y obra creativa, algunos de los cuales se han apuntado aquí. Ha realizado investigación y ha sido profesora invitada y conferenciante en diversas ocasiones, en distintos lugares de India, por ejemplo, Trivenidevi Bhalotia College, Barjora College, Michael Madhusudan Memorial College, Visva-Bharati University en West Bengal; también en la Universidad de Rohtak y en la Jawaharlal Nehru University; así como en la Pune University. Todo ello le ha permitido establecer un constante diálogo con estudiantes y profesorado de excelencia que ha enriquecido su investigación. 
privados, que han fomentado carreras especializadas y orientadas al mercado. Sin embargo, en los estados del norte las matrículas han subido, hay más mujeres en la Universidad, pero los centros académicos no han aumentado (Sahni y Shakar). De esto se deriva que: «if a girl aspires for the profesional streams, she would have to (1) compete for limited locally available seats or (2) migrate to institution abundant zones in 'south'. While the first option has competitive hurdles, the second option is equally hindered by the resistance to female migration» (244). En otras palabras, que el lugar de donde una mujer india procede o habita también la ofrece mayores o menores desventajas con respecto a las posibilidades de su Educación Superior.

En algunas zonas del norte de India como Rajasthan, Bihar, Jharkhand, Uttar Pradesh, donde la pobreza es más punzante y las prácticas socio-culturales discriminan a la mujer en todos los terrenos, es difícil lograr una actitud positiva de las familias con respecto a la educación de sus hijas. Por un lado está la costumbre cultural de excluir a la mujer de la esfera pública y limitarla al ámbito privado, que se práctica más en los estados del norte que en los del sur. Por otro lado, estos estados del norte han tenido una influencia mayor de los textos ancestrales hegemónicos y brahmánicos, como la épica del Mahabharata y del Ramayana, y el tratado legal de Las Leyes de Manu, que han definido las normas patriarcales, los roles tradicionales para el hombre y la mujer, y la familia patriarcal, que siguen teniendo un peso primordial en nuestros días (García-Arroyo 2009). Se requiere, por tanto, que para mejorar la equidad de género en el futuro tiene que haber una mayor visibilidad y participación de las mujeres en las instituciones superiores educativas y en los puestos académicos y administrativos de poder, en estos estados que tradicionalmente ofrecieron mayor resistencia a los cambios y mejoras en general y, concretamente, las centradas en las propias mujeres.

2) Frecuentemente lo que ocurre es que aquellos que gobiernan las distintas instituciones de Educación Superior tienen una mente muy patriarcal, excesivamente estereotipada, con barreras de género fijas, estáticas y tradicionales, sobre todo en las zonas rurales y provinciales, que no ayuda para que la mujer india tenga un fácil acceso a la educación académica y la integración en el contexto. Un ejemplo sería el hecho de que las estudiantes mujeres participen en juegos y deportes típicos del campus universitario, como el cricket o el fútbol, algo muy común entre los estudiantes varones y que el sistema académico desaprueba por la influencia socio-cultural.

La mente patriarcal también se refleja en la constante discriminación y violencia de género que se produce en las instituciones superiores. El abuso sexual y el acoso, a todos los niveles, siguen siendo muy comunes. Muy a menudo, 
los cargos con poder como vice-rectores, profesores y otros directivos, acosan a sus estudiantes y al profesorado femenino. La prensa india frecuentemente publica este tipo de injusticias porque las mismas mujeres acosadas se resisten al silencio de tiempos pasados y son ellas mismas las que denuncian estas agresiones abiertamente como leemos en The Chronicle of Higher Education, «On India's Campuses, Female Students Speak Out About 'Deep Rooted' Gender Discrimination» (Najar).

3) Otro exponente de esta cultura patriarcal es que en las familias tradicionales, los padres tienden a priorizar el matrimonio frente a la Educación Superior de su hija. Lo que suele ocurrir es que si la familia es de clase social media o alta, es decir, con unos determinados recursos económicos, hoy en día, automáticamente, se asume que irá a la Universidad y recibirá estudios superiores. Orientada por la familia, la joven se matriculará en un Grado de Letras y/o Humanidades y el diploma conseguido al finalizar los estudios servirá como recurso para elevar su estatus social a la hora de buscar marido. Estas familias tradicionales de clase media o alta también conciben la educación de la hija como un respaldo en el caso de que el matrimonio falle, por ejemplo, si la mujer es abandonada por el marido, si fuese necesario el divorcio o si se quedase viuda.

En las familias de recursos más limitados ni siquiera se plantea la dicotomía de elegir entre ahorrar para la educación de la hija o para su dote. Obviamente, la educación supone una inversión considerable de dinero y saben que las carreras de Letras no garantizan que ese dinero invertido dé algún fruto en el futuro y retorne a través de un puesto de trabajo. En las carreras más especializadas, como los Grados en Tecnología, en Ingeniería y todos los que tienen que ver con las Ciencias Aplicadas, la educación supone una inversión muy elevada que estas familias de pocos recursos económicos no pueden costear. Además, se ha de tener también en cuenta que aunque la hija cursase una carrera -cualquiera que fuese- y posteriormente obtuviese un trabajo que compensase todos los gastos invertidos en su educación, según la tradición cultural estos ingresos no irían nunca a parar a la familia de la hija, sino a la del novio cuando se casase.

También se ha de mencionar que ya en la educación Primaria, Secundaria y Bachillerato, muchas de estas familias tradicionales aleccionan a la hija para que no se decante por asignaturas consideradas 'masculinas'. Tampoco se gastarán el dinero en proporcionarles buenas escuelas o en darles clases extraordinarias y lecciones privadas para que ésta obtenga una excelente educación que la haga destacar en las pruebas de nivel y acceso a las instituciones superiores (Chanana 2004). De nuevo, deducimos que la mente patriarcal, 
todavía muy anclada en las viejas costumbres culturales, está bien presente en la vida contemporánea india del siglo XXI.

4) La interrelación de todos estos factores socio-culturales, espaciales y de género que intervienen en la Educación Superior repercute directamente en el mercado laboral donde observamos que, una vez más, las mujeres son menos visibles que los hombres y donde las mismas paradojas e inequidades aparecen abrumadoras. Tomemos como ejemplo el estudio de Louise Morley y Barbara Crossouard, Women in Higher Education Leadership in South Asia, basado en el año académico 2011. Estas estudiosas demuestran que en este año el porcentaje de mujeres académicas en la Universidad india era del 35,7\% frente al 64,3\% de hombres. Si observamos la distribución de mujeres por estados las cifras más elevadas corresponden a Chandigarh (55\%), Meghalaya (53\%), Kerala (52,3\%) y Goa $(49,5 \%)^{7}$. Las cifras más bajas se sitúan en Bihar (15,3\%), Arunachal Pradesh (16,6\%), Jharkhand (26,3\%) y West Bengal $(27,1 \%)$, todos ellos situados en la mitad norte de India. Si nos detenemos a examinar qué puestos académicos ocupa el profesorado según las diferentes escalas se constata, una vez más, que en todas las categorías los porcentajes de las mujeres-profesoras son inferiores a los de sus colegas varones. En la posición más alta de catedrático/a y/o titular existe un 74,5\% de varones frente a la ridícula cifra de 25,5\% de académicas. En los puestos intermedios de Lectorado y/o Profesorado Asociado tenemos un $68,9 \%$ de hombres y un $31,1 \%$ de mujeres. En la plaza más baja de Ayudante (Lecturer / Assistant) hay un 61,5\% de hombres y un $38,5 \%$ de mujeres ${ }^{8}$.

Si comparamos estas cifras con los datos que apunta el informe del Gobierno indio en All India Survey on Higher Education para el año 2014-15 con un $61 \%$ de hombres-profesores en la Universidad y el 39\% de mujeres académicas, deducimos que en tres años de diferencia, del 2011 al 2014, la cifra ha subido un poco a favor de las mujeres, pero sin ni siquiera llegar a la mitad. También es alarmante el número de académicos/as correspondientes a castas bajas de intocables (Scheduled Caste) el 7.1\%, de tribales (Scheduled Tribes) el $2.1 \%$ y de las 'Otras castas pobres' (OBC) el 23\% que han logrado

7. Chandigarh no es un estado, sino una ciudad muy moderna perteneciente al estado de Haryana, pero aparece en el estudio por poseer la cifra más alta. He de comentar también que está situada al norte, igual que el estado de Meghalaya y, por tanto, sería una paradoja más, frente a la realidad expuesta de que los estados del norte suelen ser más tradicionales, donde las inequidades de género son más latentes.

8. Ver Devi, la intocable de Ana García-Arroyo, una novela ambientada en hechos reales que recorre la vida de una mujer intocable y los problemas con los que se enfrenta para acceder a la educación, así como los abusos que tiene que soportar cuando finalmente logra ser profesora (2017 -en proceso de edición-). 
un puesto en la Educación Superior, aunque no se especifique el porcentaje de hombres y de mujeres.

Aunque sabemos que los datos estadísticos pueden variar ligeramente, según las lecturas que se hagan de ellos, sí que reflejan una evidencia abrumadora y preocupante. Por un lado las políticas de Educación Superior del Gobierno indio y los distintos campus académicos deben poner en marcha, y con urgencia, programas de mayor sensibilización de género, visibilidad y empoderamiento de la mujer, estudiante o profesora, de forma que transcienda a la sociedad en general. Por otro lado, el sistema educativo en todas sus etapas debe poner todo su empeño en eliminar las barreras sociales y culturales que impiden a las castas y grupos sociales más desprotegidos (Scheduled Castes, Scheduled Tribes, $O B C$ ) acceder a la educación. Se deben establecer las medidas necesarias para que los comités de selección no estén formados todos por hombres, como suele ocurrir en la mayoría de casos, para que haya trasparencia y exista una paridad y unas normas de selección inclusivas que no discriminen a la mujer, cuando ésta posee requisitos iguales o mejores que sus homólogos varones. Si estos procesos de selección y/o promoción son honestos, transparentes y equitativos, no cabe duda de que la mujer -sea estudiante o académica- tendrá un fácil acceso a cargos y espacios de liderazgo donde pueda intervenir más eficazmente y lograr que las férreas estructuras patriarcales se tambaleen y caigan.

\section{CONCLUSIONES}

Llegados a este punto me gustaría concluir este artículo subrayando que las realidades y paradojas presentadas aquí correspondientes a la (in)visibilidad de la mujer en la Educación Superior en India manifiestan un complejo y multidimensional entramado de barreras sociales, culturales, económicas y estructurales, propias de un país donde el patriarcado todavía se resiste a transmutar y transferir su poder a favor de otras formas, maneras y estructuras alternativas que miran hacia la equidad y la contemplación de los Derechos Humanos. No cabe duda de que la liberalización económica y el propósito desenfrenado del Gobierno indio de ponerse a la altura mundial y conseguir el 'progreso' a través de un modelo económico competitivo no ha logrado que las grandes desigualdades que ya existían desapareciesen o disminuyesen. Es cierto que se ha incrementado el número de mujeres en la Universidad, pero la visibilidad de estas, el empoderamiento y la equidad todavía dejan mucho que desear. Indudablemente, existe la tendencia cada vez más elevada de que las hijas se formen adecuadamente y su educación les brinde una independencia y un puesto de trabajo. De hecho, entre las miles de caras que India nos muestra 
hoy, una concretamente es que cada día se ven más mujeres ocupando puestos en la vida pública, sobre todo en las ciudades, por ejemplo, en bancos, agencias de viajes, universidades, compañías multinacionales, agencias de información, hoteles, hospitales, etc.,, para los cuales es necesario una educación profesional específica y cara. Esto demuestra que desde los años noventa ha habido una transformación social y cultural en la sociedad, en general, y en las familias, en particular, que se ve palpable al menos en un sector de la sociedad. Las expectativas de los padres con respecto a sus hijas y las aspiraciones y sueños de éstas han cambiado. Aunque esta tendencia sea minoritaria y, podría decirse, clasista, ya que está amparada por una estructura mental abierta y un estatus económico aceptable, capaz de hacer frente a una educación relativamente cara, como se ha demostrado en este artículo, el cambio se ha iniciado y una parte de las mujeres indias se han subido al carro del mundo global y de la liberalización del mercado, gracias a la educación especializada recibida. No obstante, no debemos olvidarnos, como se ha mostrado aquí con el ejemplo del profesorado académico, que estas mujeres ocupan puestos inferiores a los de los hombres y aparecen representadas en cifras escasas, siendo casi invisibles en los cargos de poder. Tampoco debemos olvidarnos de las otras tres cuartas partes de la sociedad que hasta ahora no han podido optar a esta Educación Superior 'elitista' / clasista, orientada hacia el mercado y, teóricamente, hacia el 'éxito' y 'prestigio'. ¿Con qué planes cuenta el Gobierno para hacer frente a las innumerables paradojas e inequidades de género y sus intersecciones con la casta, raza, región, etc., en el futuro? Según la Federation of Indian Chambers of Commerce and Industry y su informe Higher Education in India: Vision 2030, en esta fecha se aspira a que India se haya convertido en «a globally dominant economy, with a high quality higher education sector that leads and fulfills the needs of society» (3) $)^{9}$. Mi investigación cuestiona estas expectativas de la Cámara de Comercio e Industria india pues, basándome en lo que se ha demostrado aquí, me decanto más por apoyar y subscribir el pensamiento principal de Martha Nussbaum, de donde he partido, marcado por la idea de que perseguir el crecimiento económico, 'el progreso', como señal de mejora del país, no implica mejorar la democracia, ni las oportunidades que deben tener todas las personas -y no sólo una minoría- con respecto a la educación,

9. Siguiendo la trayectoria anterior, este informe de la Federación de las Cámaras de Comercio e Industria (Federation of Indian Chambers of Commerce and Industry) plantea las metas a conseguir en la Educación Superior para el 2030 basándose en el modelo europeo caracterizado por 1) educación centrada en el alumno/a; 2) énfasis en la tecnología; 3) sistema competitivo y de acreditaciones; 4) internalización de la Universidad; 5) universidad de excelencia. 
el trabajo y los Derechos Humanos en general. ¿De qué sirve la consecución del máximo rendimiento económico si no existe una distribución equitativa de esa riqueza y la relación entre las personas sigue presentando grandes inequidades de género-casta-clase, como se ha reflejado aquí. ¿Quién querría vivir, en el 2030, en un país muy próspero donde no hay libertades ni derechos equitativos para todos sus habitantes? Nussbaum demuestra que el mundo contemporáneo se ha dejado llevar por ese ansia de competición feroz para conseguir el 'progreso' que le ha llevado a una profunda crisis de valores éticos y humanos que son esenciales para la democracia de cualquier país, incluido India como he mostrado aquí.

Desde los años noventa el Gobierno indio ha potenciado una Educación Superior utilitarista, orientada hacia el mercado. La cuestión, como he expuesto arriba, es que parece ser que continuará en la misma línea, incluso potenciándola, según se desprende de la visión de futuro que la Federation of Indian Chambers of Commerce and Industry planea conseguir para el año 2030. Mantener una Educación que se centra principalmente en la producción del mayor beneficio económico conlleva una gran amenaza para la democracia en general, y para la equidad de género en particular, como este artículo ha demostrado. El Gobierno indio está perdiendo la batalla al situarse a favor de la violenta competencia global con fines mercantilistas y su consecuente deshumanización, en lugar de potenciar la igualdad y el respeto a través de un modelo educativo alternativo como, por ejemplo, el que ya inició y practicó en el siglo pasado Rabindrananth Tagore con exitosos resultados. Un modelo que incite a vivir la vida con pensamientos y sentimientos de respeto, igualdad y empatía hacia las demás personas, pues ningún sistema de educación puede ser saludable si sólo beneficia a las minorías poderosas, mientras excluye, invisibiliza y arrincona al resto de la población, especialmente a las mujeres.

\section{REFERENCIAS BIBLIOGRÁFICAS}

All India Survey on Higher Education 2014-2015. New Delhi: Goverment of India. Ministry of Human Resources and Development. Department of Education, 2016. <http://aishe.nic.in/aishe/viewDocument.action?documentId=206>, consultado el 2-10-2016

Anandkrishnan, M. «Private Investments in Technical Education». Private Iniciatives in Higher Education. New Delhi: Sneh Prakashan and Amity Foundation for Learning, 2004.

Beinhocker, Eric, Diana Farrell y Adil Zainulbhai. «Tracking the Growth of India's Middle Class». McKinsey Quaterly. August, 2007. 
Chanana, Karuna. «Gender and Disciplinary Choices: Women in Higher Education in India». The UNESCO Colloquium on Research and Higher Education Policy. Paris, 2004.

Chanana, Karuna. «Subjects Choices and Gender: Women in Higher Education in India». Writing the Women's Movement. A Reader. Ed. Mala Khullar. Delhi: Zubaan, 2005, 269-289.

Das, Kamala. My Story. New Delhi: Harper Collins, 2009.

García-Arroyo, Ana. Historia de las mujeres de la India. Barcelona: Laertes, 2009.

García-Arroyo, Ana. Devi, la intocable. Madrid: Kailas, 2017. En proceso de edición. «Higher Education, a Sick Child». The Hindu. 11 Octubre, 2007.

Higher Education in India: Vision 2030. Federation of Indian Chambers of Commerce and Industry. Summit 2013. <http://www.ey.com/Publication/vwLUAssets/ Higher-education-in-India-Vision-2030/\%24FILE/EY-Higher-education-inIndia-Vision-2030.pdf>, consultado el 20-10-2016

Jeffrey, Robin. «Legacies of Matriliny: The Place of Women and the Kerala Model». Pacific Affairs. University of British Columbia. 77.4 (2005): 647-664.

Kishwar, Madhu. Deepening Democracy. Challenges of Governance and Globalization in India. Oxford University Press, 2005.

Mohanty, Chandra. «Under Western Eyes. Feminist Scholarship and Colonial Discourses». The Post-colonial Studies Reader. Eds. Bill Ashcroft, Gareth Griffiths \& Helen Tiffin. London: Routledge, 2008, 259-263.

Morley, Louise y Barbara Crossouard. Women in Higher Education Leadership in South Asia: Rejection, Refusal, Reluctance, Revisioning. University of Sussex. Centre of Higher Education and Equality Research. <https://www.britishcouncil.org/sites/default/files/morley_crossouard_final_report_22_dec2014.pdf >, consultado el 1-11-2016

Najar, Nida. «On India's Campuses, Female Students Speak Out about 'Deep Rooted' Gender Discrimination». The Chronicle of Higher Education. 22 Abril, 2013. <http://www.chronicle.com/article/Female-Scholars-Describe-Deep/138659/ consultado el 15-11-2016

Nussbaum, Martha. Not for Profit: Why Democracy Needs the Humanities. Princeton University Press, 2010.

Rizvi, Fazal y Radica Gorur. «Challenges Facing Indian Higher Education». Australia India Institute. Two, Winter, 2011.

Sahni R., y S. Kale. «GATS and Higher Education: Some Reflections». Economic and Political Weekly 39 (2004).

Sahni, R., y V. K. Shakar. "Girls' Higher Education in India on the Road to Inclusiveness: On Track but Heading Where?» The International Journal of Higher Education Research 63 (2012): 237-256.

Samal, K. Equity and Financing Education. Globalization and Challenges for Education. NIEPA, 2003. 
Shagur, Obadya Ray. «Higher Education in India. Access, Equity, Quality». EAN World Congress, 2013.

Tagore, Rabindranath. Selected Essays. New Delhi: Rupa \& Co., 2010.

Takwale, Ram. «Challenges and Opportunities of Globalization for Higher Education in India. Alternatives through e-Education». New Delhi: University Grants Commision. Diciembre, 2003. <http://www.ugc.ac.in/oldpdf/pub/lectures/ugc_pro2.pdf >, consultado el 12-10-2016

«Business in India: A Bumpier but Freer Road». The Economist. 20 Sep 2010. <http://www.economist.com/node/17145035>, consultado el 2-11-2016

«India's Surprising Economic Miracle». The Economist. 30 sept 2010. < http://www.economist.com/node/17147648 >, consultado 2-11-2016 

Para enlazar con este artículo / To link to this article:

http://dx.doi.org/10.14198/fem.2017.29.07

Para citar este artículo / To cite this article:

González Gómez, Sara y Andrés Payá Rico. «Ciencia y género: investigadoras en formación a finales del franquismo». En Marcos Jesús Iglesias Martínez e Inés Lozano Cabezas (coords.), La (in)visibilidad de las mujeres en la Educación Superior: retos y desafios en la Academia. Feminismo/s, 29 (junio 2017): 173-200, DOI: $10.14198 / \mathrm{fem} .2017 .29 .07$

\title{
CIENCIA Y GÉNERO: INVESTIGADORAS EN FORMACIÓN A FINALES DEL FRANQUISMO
}

\section{SCIENCE AND GENDER: RESEARCHERS IN TRAINING AT THE END OF FRANCOISM}

\author{
Sara GONZÁLEZ GÓMEZ \\ Universidad de las Islas Baleares \\ sara.gonzalez@uib.es \\ orcid.org/0000-0002-2246-2535 \\ Andrés PAYÁ RiCO \\ Universidad de Valencia \\ Andres.paya@uv.es \\ orcid.org/0000-0001-7646-4539
}

\section{Resumen}

Durante el siglo XX, al compás del incremento en el acceso a los estudios superiores, las mujeres comenzaron a romper barreras en el campo de la investigación. El objetivo principal de este estudio es comprobar la forma en que incidió sobre el acceso de la mujer a la ciencia la primera convocatoria del Plan de Formación de Personal Investigador (1968), inscrito dentro del II Plan de Desarrollo Económico y Social (1968/71), y las sucesivas convocatorias de becas pre y post doctorales, con destino a España y al extranjero, que se resolvieron hasta 1975. Mediante un análisis cuantitativo de los datos, en perspectiva de género, trataremos de determinar las diferentes vías a través de las cuales comenzó a hacerse manifiesta y visible la presencia de la mujer en el mundo científico español, así como comprobar las especialidades o áreas mayormente masculinizadas, feminizadas o en las que se produciría una tendencia hacia la igualdad.

Palabras clave: becas de formación, ciencia, franquismo, mujer, personal investigador.

\begin{abstract}
During the twentieth century, in parallel with the increase in the access to higher education, women began to break barriers in the field of research. The main aim of this
\end{abstract}


study is to check the way in which women's access to science was affected by the first call of the Plan for the Training of Research Personnel (1968), registered under the 2nd Economic and Social Development Plan (1968/71), and successive calls for pre and postdoctoral scholarships to do research in Spain or abroad, which were granted up to 1975. Through a quantitative analysis of the data, from a gender perspective, we will try to determine the different ways in which the presence of women in the Spanish scientific world began to become manifest and visible as well as to check the specialties or areas which were mostly masculinized, feminized or those that showed a clear trend towards equality.

Keywords: training scholarships, science, Francoism, woman, research staff. 


\section{INTRODUCCIÓN}

La escasa visibilidad de las científicas y sus dificultades para obtener reconocimiento durante el siglo XX, cuando ya la presencia de mujeres en las universidades era significativa, apuntan a que el ámbito científico experimental o de ciencias exactas ha sido un terreno menos favorable a la presencia femenina que otros campos del saber, como pudieran ser el humanístico o el de ciencias sociales, en los que las mujeres han adquirido mayor relevancia. De ahí que tienda a establecerse que las carreras científicas no fueron una preferencia de las mujeres universitarias hasta bien avanzado el siglo XX (Canales 112). Partiendo de esta tesis, trataremos de estudiar la forma en que incidió sobre este tipo de aspectos la primera convocatoria del Plan de Formación de Personal Investigador (en adelante PFPI), inscrito dentro del II Plan de Desarrollo Económico y Social (1968/71), y las sucesivas convocatorias de becas pre y post doctorales, con destino a España y al extranjero, que se publicaron y resolvieron hasta el fin del franquismo.

El binomio mujer-ciencia a lo largo de la historia ha sido objeto de estudio por parte de algunos especialistas de los cuales se da sucinta referencia en la bibliografía de este trabajo (entre otros: Becerra y Ortiz; Casado y Salas; Cuesta, Prado y Rodríguez; López; Matilla y Mó). Aun así, el estudio concreto, desde la perspectiva de género, sobre becas de formación de personal investigador convocadas durante el franquismo constituye un tema del todo novedoso.

En consecuencia, el objetivo principal de este trabajo es analizar, desde dicha perspectiva, la distribución de becas para formación de personal investigador publicadas y concedidas en España entre 1968 y 1975. El sondeo de cantidad y distribución nos permitirá comprobar si los datos coinciden con los generales de matrícula universitaria femenina por estudios; determinar las diferentes vías a través de las cuales comenzó a hacerse verdaderamente visible la presencia de la mujer en el mundo científico español; y comprobar las especialidades o áreas mayormente masculinizadas, feminizadas o en las que se produciría una tendencia hacia la igualdad. Toda esta serie de cuestiones nos ayudarán a efectuar una lectura, basada en datos de carácter cuantitativo, del efecto que la formación de personal investigador habría tenido sobre el proceso 
de emancipación, profesionalización y revalorización del rol de la mujer en el campo de la investigación, en una época en la que el destino social de las mujeres y los estereotipos sobre su papel en la sociedad comenzaban, poco a poco, a alejarse del ámbito exclusivamente privado y/o doméstico.

El presente artículo se estructura en tres partes. Un primer apartado introductorio que sirve para delimitar los principales precedentes del PFPI y el estado de la investigación dentro de la Universidad española durante el franquismo; un segundo sobre tres conceptos clave que nos van acercando a nuestro objeto particular de estudio: mujer, estudios superiores y ciencia; y un tercer apartado, núcleo central de la investigación, encabezado por el proceso de puesta en marcha, a partir de 1968, de los PFPI -condiciones, procedimiento, solicitud y concesión- seguido del repaso a los datos cuantitativos de resolución de los mismos, para desgranar el número así como el porcentaje de la presencia de mujeres dentro de cada una de las especialidades contempladas en las sucesivas convocatorias, tanto en las destinadas a cubrir becas en España como en el extranjero.

\section{INVESTIGACIÓN, UNIVERSIDAD Y FRANQUISMO}

La imposición del régimen dictatorial tras el desenlace de la guerra civil española trajo consigo la depuración y el desarme del incipiente sistema científico que con la denominada como «Edad de Plata» (con la Institución Libre de Enseñanza -ILE- y la Junta para Ampliación de Estudios -JAE- como principales promotoras ${ }^{1}$ ) había comenzado a edificarse en España (Otero 146). La distancia entre ciencia, investigación y Universidad se hizo cada vez mayor y la lamentable situación en la que quedó sumido el país a nivel de investigación provocaría un retraso del que tardaríamos años en zafarnos.

Bien es cierto que no podemos obviar algunas diferencias significativas entre la fase inicial de autarquía del franquismo, con una parálisis prácticamente total del sistema de investigación y ciencia, y el periodo desarrollista o tecnócrata, fase en la que comenzará a valorarse la importancia de iniciar

1. Respecto a la concesión de becas de investigación a los mejores expedientes de jóvenes estudiantes, cabe señalar aquí muy brevemente el precedente existente desde inicios del siglo XX de la JAE. Esta iniciativa, creada por la ILE para promover la investigación y la educación científica en nuestro país en 1907, concedió becas, llamadas por entonces pensiones, para viajar al extranjero y conocer así los centros de investigación e innovación más punteros, creando asimismo en España una infraestructura inexistente hasta la fecha de centros de investigación, laboratorios e institutos, en los cuales estos becados pudiesen desarrollar una actividad investigadora a su regreso (Sánchez). La JAE desarrolló esta valiosa y pionera función durante el primer tercio del siglo XX hasta que, en 1939, la dictadura franquista, tras su disolución, creó el CSIC (Puig-Samper). 
medidas encaminadas a su reactivación y en la que se inscribirán las iniciativas de becas de formación que son aquí objeto de estudio.

Pero por encima de todo ello, la Universidad seguía necesitada de una modernización de su modelo de investigación, que consistiría en adecuar tanto sus recursos como sus estructuras a los adelantos extranjeros, aportar una nueva orientación al binomio ciencia-técnica y, sobre todo, pensar en un sistema capaz de formar a nuevos investigadores que vendrían a conformar el futuro de la ciencia española. En esencia, una adaptación al «modelo humboldtiano» propio de la Universidad alemana, para lo cual era necesario la creación de un sistema de becas de formación de personal investigador, invertir en laboratorios de experimentación, sostener bibliotecas, bien dotadas y actualizadas, y garantizar el intercambio de publicaciones y centros de investigación (Hernández 229).

En la década de los sesenta, nuevos aires parecían agitar tanto la política ministerial, encabezada por Lora Tamayo, como el trabajo diario de unos pocos docentes, pero el cambio se produciría muy lentamente. De hecho, las palabras pronunciadas por Felipe Lucena Conde en el discurso inaugural de la Universidad de Salamanca durante el curso 1962/63, atestiguan la situación real que se vivía en la Universidad:

La investigación universitaria no está organizada en España. La estructura tradicional de la Universidad Española está pensada para la función docente ordinaria, no para hacer investigación. La numerosa investigación que se hace, llena de mérito y categoría, se debe en parte importante al esfuerzo individual, no sólo en lo científico sino incluso a veces en lo administrativo (Lucena 11).

Las esclarecedoras palabras del catedrático nos revelan un ambiente poco propicio para la investigación. Debemos tener presente también que el número de alumnos crecía lentamente en la Universidad de la segunda mitad de los cincuenta, si bien este ritmo se aceleró de un modo considerable durante la década de los sesenta y las necesidades docentes se incrementaron con la misma cadencia. Si en los años cincuenta el profesorado ya se quejaba de la falta de recursos materiales y humanos para el correcto desempeño de sus funciones, esta situación no haría más que empeorar y agravarse durante la siguiente década.

Estas condiciones académicas y laborales tendrían su repercusión directa sobre la labor investigadora. Cuando había que hacer frente a clases numerosas, en instalaciones deficientes, el profesorado difícilmente podía atender de un modo adecuado la doble vertiente docente e investigadora. A pesar de la ayuda con la que contaban los catedráticos y el gran peso que recaía sobre adjuntos y 
ayudantes, lo cierto es que una recarga excesiva de sus labores podía ser causa -o excusa- de falta de tiempo y dedicación a labores investigadoras.

Esta radiografía da muestra de la necesidad de adoptar medidas, sin más dilación, para formar a jóvenes investigadores capaces de reconstruir un tejido fundamental para el desarrollo y el progreso del país, así como conectar esa formación con una verdadera carrera universitaria como estamento docente. El Ministro de Educación y Ciencia, José Luis Villar Palasí, ya lo advertía en la introducción del conocido como Libro Blanco de 1969 (MEC 11). En este sentido, si acudimos a los datos relativos a 1968 sobre el número y la situación del profesorado universitario en España, el desigual claustro docente estaba integrado por 923 catedráticos, 112 encargados de cátedra vacante, 211 agregados, 1749 adjuntos, 2000 ayudantes y 1708 encargados de curso, para un total de 105.000 alumnos matriculados en el curso 1966/67. Una ratio profesorado-alumnado universitario poco positiva, con una mayoría de docentes sin vinculación estable, mala remuneración y en el que la mujer, además de representar a una minoría, ocupaba los puestos más bajos del escalafón docente.

Cabe insistir, tal y como apuntábamos anteriormente, que la carrera docente estaba muy poco vinculada a la tarea investigadora del personal universitario, situación que el Libro Blanco referenciaba de forma clara:

La formación de científicos e investigadores, en la proporción que exige la actual sociedad, es una necesidad apremiante en todos los países (...). La Universidad ha de atender también a la formación de los investigadores que nutren la propia actividad docente y que, además, son punto de partida del desarrollo técnico (MEC 102).

Al rebasar esta función formativa a las universidades españolas, el tejido investigador español se reforzará en estos años con la creación de Institutos de investigación y con la labor del CSIC, los cuales conformaron en 1962, junto al Ministerio de Educación, la Comisión para el Fomento de la Investigación en las Universidades, con la misión de subvencionar planes de investigación. La situación de la investigación en España, como veremos más adelante, era muy mejorable, invirtiendo en 1969 únicamente un 0,2\% del producto nacional bruto, y contando con una plantilla de 2800 «hombres de ciencia» (en ningún caso hacen referencia a las mujeres) (MEC 103).

Así pues, en la línea de mejorar la carrera docente e investigadora universitaria, tanto MEC como CSIC se encontraron a finales de los sesenta y principios de los setenta con la necesidad de enfrentarse a la mejora de la investigación como «reto español del cuatrienio», tal y como se expresaba en el monográfico de la revista Didascalia (revista de orientación didáctica e investigación pedagógica) dedicado al III Plan de Desarrollo y el consecuente aumento de 
la inversión educativa. En dicha revista, el presidente de la Asociación de Personal Investigador del CSIC, denunciaba que «el investigador español no tiene la consideración social y económica de otros países. Ni tampoco posee la influencia en los sectores cultural, industrial y económico del país» (Orive 11). Esta situación era tan nefasta que el 14 de octubre de 1971, los becarios investigadores españoles (unos 1300) protestaron realizando dos días de paro, una asamblea y una sentada tras la cual se anunció el compromiso del ministro de educación de elaborar una ponencia para estudiar la futura política de becas.

Con todo ello, las medidas adoptadas desde 1968 y hasta 1975 para paliar la falta de formación de personal investigador no podrían acabar con el lastre arrastrado de décadas anteriores, pues éste resultaba verdaderamente oneroso, pero sí desbrozarían el camino para hacer de la Universidad un verdadero lugar para la formación de investigadores y futuros profesores.

\section{MUJERES, ESTUDIOS SUPERIORES Y CIENCIA}

Pese a la existencia de mujeres estudiosas e investigadoras desde los orígenes del conocimiento científico, las primeras universidades quedaron configuradas a partir de un modelo de lo masculino. El acceso de las mujeres a las universidades se produjo muy lentamente, pues como era una institución pensada y organizada para la formación cultural y profesional de hombres, la transformación de la mentalidad primigenia y la ruptura de una costumbre que se había hecho certeza, costó mucho tiempo y necesitó invertir muchas energías (Flecha 28).

Con la llegada del siglo XX, la situación de la ciencia en general y de las mujeres científicas en particular va a experimentar un cambio radical. Poco a poco, la ciencia deja de ser una actividad individual para institucionalizarse en las universidades, industrias y centros de investigación estatales. Las mujeres, de forma progresiva, van ganando lentamente igualdad de derechos con los hombres, y las puertas de las universidades e instituciones científicas se van abriendo para ellas, comenzando a romperse algunas discriminaciones formales hasta entonces vigentes (Van den Eynde 87).

Sin embargo, la instauración de la dictadura franquista va a suponer un fuerte retroceso en la concepción del papel que la mujer estaba llamada a desempeñar dentro de la sociedad, así como en la orientación de su educación. Durante las primeras décadas, su presencia en las universidades se vio drásticamente reducida, aunque, con el discurrir del tiempo, comenzaron a incrementarse sus datos de matrícula. De hecho, si analizamos con detenimiento el Libro Blanco de 1969, documento base para la posterior elaboración de la Ley General de Educación de 1970, entre los diagnósticos sobre los 
principales problemas y la situación educativa de la educación española, el capítulo 5, dedicado a la enseñanza superior, señala lo siguiente:

Otro aspecto a considerar es el de la participación de la mujer en la enseñanza superior. El tanto por ciento de alumnas ha ido gradualmente aumentando (en 1932-1933, sólo cursaban estudios universitarios 2058 mujeres, es decir, 6\%), y para el consunto de la Universidad representaba en el curso 1966-67 el 30\%, si bien en Filosofía y Letras y Farmacia alcanzaba el 58 y 54 por 100, respectivamente. Los países desarrollados tienen una proporción del orden del 40 al 45 por 100. En la enseñanza técnica la proporción es reducidísima. Alcanza tan sólo un valor del 2 por 100. De hecho, la participación de la mujer en la enseñanza técnica es prácticamente simbólica (MEC 91).

Aunque esta denuncia sobre la desigualdad de acceso de la mujer a los estudios superiores es muy positiva, más si cabe teniendo presente la época y la fuente oficial que la realiza, pronto vemos que el igualitarismo que propone para mejorar estos desequilibrios posee muchas limitaciones y reparos propios de la dictadura:

El principio de igualdad de oportunidades ha de aplicarse también sin ninguna restricción a la población femenina, aun cuando esta afirmación no quiere decir igualdad a secas ente el hombre y la mujer. Si aquel principio, que es, en definitiva, el de la libertad, propugna la posibilidad de que la mujer acceda a niveles superiores de cultura y de responsabilidad con la única limitación de su propia capacidad es la misma que en el hombre en todos los casos, especialmente cuando se trata de ocupaciones que requieren un gran esfuerzo físico (MEC 122).

Un argumentario que guiará la política española respecto a la educación de la mujer en los últimos años del franquismo y que prosigue más adelante con la siguiente consideración estereotipada y de diferenciación de roles de género:

«Sin perjuicio de la igualdad fundamental de la educación para todos, alumnos y alumnas, en el proceso total de la escolaridad, la formación de la niña, la adolescente, la joven y la mujer tendrá en cuenta sus características específicas para acomodar a ellas las intervenciones educativas, especialmente en lo que se refiere a las aptitudes estéticas y a su futuro papel en la familia y en la sociedad. (MEC 234)

A pesar de ese «destino social preestablecido de la mujer», en los años cincuenta y sesenta, éstas empezaron a ocupar, mediante oposición, cátedras universitarias, aunque con una llamativa lentitud. El prestigio social del profesorado universitario, el ambiente mayoritariamente masculino, la dedicación constante al estudio y a la investigación, el tener que viajar para participar en congresos, etc., eran características y condiciones que, desafortunadamente, todavía costaba aceptar como apropiadas para las mujeres. A pesar de todo, 
en el escalafón de cátedras de Universidad, publicado por el Ministerio de Educación en 1974, figurarían once mujeres. La mayoría, siete, catedráticas de facultades de Filosofía y Letras, dos de Ciencias, una de Derecho y otra de Farmacia (Guil y Flecha 137).

Alumnas y profesoras comenzaron de este modo a acceder a los estudios superiores. Veamos a continuación cómo lo hicieron en el campo de la ciencia a través del PFPI iniciado en el año 1968 en España.

\section{LOS PLANES DE FORMACIÓN DE PERSONAL INVESTIGADOR DEL FRANQUISMO}

\subsection{Puesta en marcha}

Tal y como hemos visto, la necesidad de preparar un PFPI capaz de cimentar un buen tejido de base, integrado por profesionales capaces de hacer frente en un futuro inmediato al desarrollo científico que necesitaba España, se hizo más que manifiesta durante la década de los sesenta. El Presupuesto General del Estado para el bienio 1968/69 incluiría en el programa de inversiones públicas tanto becas de formación como la consignación correspondiente para la concesión de ayudas económicas a los centros receptores de becarios. Nacería así el PFPI, inscrito dentro del II Plan de Desarrollo Económico y Social (1968/71) que contempló en su articulado la «estimulación de la investigación científica en todas sus modalidades, concentrando su esfuerzo, con criterio selectivo, en la investigación aplicada y de desarrollo» (Ley 1/1969, de 11 de febrero).

Con ello se pretendía dar respuesta a la situación de precariedad científica de España. La Comisión de Investigación Científica y Técnica de la Comisaría del Plan de Desarrollo, en la memoria elaborada para la ejecución del II Plan, calificaba de «extrema urgencia y condición determinante la formación de personal investigador, la conservación del existente y la recuperación del perdido dentro y fuera del país» (Comisión de Investigación Científica y Técnica, 29). De acuerdo al informe elaborado en el mes de enero de 1968 por la Subcomisión para el Estudio de la Investigación Básica y la Formación de Personal para la Investigación, la mejor escuela para dicha formación, a nivel de postgraduados, se encontraba en la investigación básica, pudiendo afirmarse que un programa de investigación de tres o cuatro años podría convertirse en un «tercer ciclo totalmente obligado para los que vayan a ocupar posiciones de vanguardia en el desarrollo tecnológico de nuestras industrias, en el profesorado de los centros de Enseñanza superior y en los cuadros de los propios centros de investigación» (Comisión de Investigación Científica y Técnica, 30). 
Según los datos que se proporcionaban en la referida memoria, en España existían en aquel momento 8 investigadores por cada 100.000 habitantes, frente a los 145 de Estados Unidos o los 103 de Rusia e Inglaterra. En 1967, según estimaciones de la Comisión de referencia, España tenía unos 2700 investigadores, siendo las previsiones de aplicación del II Plan de Desarrollo, en el marco del PFPI, alcanzar la siguiente progresión: pasar a 3240 en 1968; 3888 en 1969; 4666 en 1970; y 5600 en 1971.

El plan fue sufriendo cambios en las distintas convocatorias, tratando de pulirse iniciales defectos. En la segunda convocatoria se vinculó con el plan de profesorado de enseñanza superior, cuestión que sería tenida en cuenta a partir de entonces, no como una ayuda diferenciada, sino como «uno de los caminos para la obtención de la misma meta, ya que la formación de investigadores promociona la formación de profesores, conjuntando las dos vertientes de hecho separadas hasta el momento: docencia e investigación» (BOE, n. 123, 23 de mayo de 1970). Para ello, se seguiría dando prioridad a las solicitudes que tuvieran por finalidad la preparación de tesis doctorales, aspecto del todo fundamental en el camino hacia la mejora tanto de la docencia como de la investigación desarrollada dentro de las universidades.

La primera convocatoria del PFPI (BOE, n. 220, 12 de septiembre de 1968) preveía la distribución de becas en seis grandes grupos: 1) Ciencias Matemáticas; 2) Ciencias Físicas, Químicas y del Cosmos; 3) Biología y Ciencias Básicas de la Medicina; 4) Ciencias de la Tierra y Tecnología Agrícola; 5) Tecnología Industrial. 6) Economía, Sociología, Humanidades y Ciencias Jurídicas. Esta agrupación de especialidades iría desglosándose con el paso de las convocatorias, contemplándose algunas de ellas en grupos únicos y surgiendo nuevas, hasta llegar a los 20 grupos que veremos en la última convocatoria analizada correspondiente al curso 1974/75 (ver tabla 7).

En cuanto al procedimiento, la solicitud y concesión se realizaría necesariamente a través del centro de investigación, facultad o escuela técnica superior donde el beneficiario de la ayuda fuera a realizar el trabajo objeto de la beca. En el caso de becas en el extranjero, se exigiría igualmente el trámite a través de un centro español. Una vez finalizado el periodo de disfrute de la beca y de sus eventuales prórrogas, el becario quedaría obligado, a petición del centro que lo tuteló, a prestar sus servicios en éste por un periodo igual al del disfrute de la beca, siempre y cuando el centro le ofreciera un puesto fijo en su plantilla de investigación o un contrato en espera de esta situación indefinida. Este aspecto sería modificado en la convocatoria del año 1973, momento a partir del cual los centros de investigación no adquirirían «ningún compromiso en cuanto a 
la posterior incorporación de sus becarios a las plantillas de los mismos» (BOE, n. 210, 1 de septiembre de 1973).

Por otra parte, las becas de formación serían incompatibles con toda situación profesional, con la realización de otros trabajos y estudios, con otras becas y ayudas semejantes y, en general, con cualquier actividad remunerada. Sin embargo, en el caso del área de Matemáticas se contemplaba como excepción el desempeño del cargo de profesor ayudante, adjunto o encargado de cátedra, siempre que se impartieran un máximo de seis horas semanales de clase.

En cuanto a la dotación, para el caso de Matemáticas sería de 10.000 pesetas mensuales para graduados y 5.000 pesetas mensuales para alumnado de quinto de carrera. Para el resto de grupos, la dotación para becas en España se situaría entre 7.000 y 10.000 pesetas. Las del extranjero serían fijadas por la comisión encargada de la resolución de las becas, teniendo en cuenta el país en que fueran a disfrutarse. Estas cantidades se irían incrementando en años sucesivos hasta alcanzar las 15.000 pesetas mensuales para becas en España, contempladas como dotación en la Orden de 16 de octubre de 1974 (BOE, n. 255, 24 de octubre de 1974), las 17.000 pesetas mensuales para becas postdoctorales en Europa occidental y las 21.000 pesetas para América de ese mismo año (BOE, n. 136, 7 de junio de 1974).

\subsection{Becas de Formación de Personal Investigador con destino a España. Distribución por género}

La primera convocatoria de becas del año 1968 asignó ayudas a un total de 253 mujeres que representaban el 28,5\% del total de beneficiarios de las mismas. Porcentualmente, respecto al número global de becados por cada grupo, la mayor presencia de mujeres se concentraba en las ramas de Biología y Ciencias básicas de la Medicina (38,7\%), seguido de Economía, Sociología, Humanidades y Ciencias Jurídicas en donde el sector femenino representaba el 33,5\% del total, y de Ciencias de la Tierra y Tecnología Agrícola con un 30,17\%. Ahora bien, resulta necesario efectuar un desglose de estos tres grandes grupos, pues la mujer no estaba representada del mismo modo en unas y otras especialidades. El único grupo en el que encontramos a mujeres becarias en prácticamente todas las áreas es el de Biología y Ciencias básicas de la Medicina, a diferencia del segundo en el que, mientras que la obtención de becas por parte de mujeres no se vería prácticamente representada en las facultades de Derecho (contabilizamos 4 en total repartidas por las universidades de Granada, Santiago de Compostela, Madrid y Barcelona), sí lo haría especialmente en las de Filosofía y Letras, dentro de las cuales encontramos a investigadoras becadas en prácticamente todas las universidades españolas. En el caso del tercer grupo, las 
mujeres obtuvieron becas especialmente en facultades de ciencias y en diversos institutos del CSIC relacionados con Biología, Geología y Edafología, sin embargo su presencia resultó muy limitada en Ingeniería agrónoma.

Los dos grupos con menor representación femenina serían Matemáticas (12,5\%), con sólo 3 mujeres becadas, y Tecnología industrial (18,3\%) con 31 mujeres repartidas mayoritariamente por institutos del CSIC dedicados al tratamiento de la grasa y sus derivados o al plástico y caucho, así como a institutos de fermentaciones industriales. Veamos de forma sintética todos estos datos en la siguiente tabla (1):

Tabla 1: Hombres/Mujeres PFPI (1968)

\begin{tabular}{|l|c|c|c|c|}
\hline \multicolumn{1}{|c|}{$\begin{array}{c}\text { Convocatoria 1968 } \\
\text { (curso 1968/69) }\end{array}$} & Mujeres & Hombres & Total & $\begin{array}{c}\% \text { mujeres } \\
\text { respecto total }\end{array}$ \\
\hline Matemáticas & 3 & 21 & 24 & $12,5 \%$ \\
\hline $\begin{array}{l}\text { Ciencias Físicas, Químicas y del } \\
\text { Cosmos }\end{array}$ & 47 & 130 & 177 & $26,5 \%$ \\
\hline $\begin{array}{l}\text { Biología y Ciencias Básicas de la } \\
\text { Medicina }\end{array}$ & 69 & 109 & 178 & $38,7 \%$ \\
\hline $\begin{array}{l}\text { Ciencias de la Tierra y Tecnología } \\
\text { Agrícola }\end{array}$ & 51 & 118 & 169 & $30,17 \%$ \\
\hline Tecnología Industrial & 31 & 138 & 169 & $18,3 \%$ \\
\hline $\begin{array}{l}\text { Economía, Sociología, Humanidades y } \\
\text { Ciencias Jurídicas }\end{array}$ & 57 & 113 & 170 & $33,5 \%$ \\
\hline Totales & 253 & 634 & 887 & $28,5 \%$ \\
\hline
\end{tabular}

Elaboración propia a partir de: BOE, n. 280, 21/11/1968 y BOE, n. 289, 02/12/1968

Esta primera convocatoria nos permite apuntar los primeros indicios sobre los campos o las especialidades en las cuales vamos a ir encontrando mayor representación femenina: Ciencias (en áreas como la de Biología) y Letras, las áreas con mayor feminización; pero también sobre los sectores mayormente masculinizados (Matemáticas o Derecho). Al tratarse de una convocatoria con grupos de especialidades tan amplios, conviene seguir sondeando las siguientes para poder ir desgranando con mayor profusión y rigor los datos obtenidos.

La convocatoria del año 1969 vino acompañada de algunas modificaciones, teniendo en cuenta la grave carencia de profesorado que entonces acusaba la Universidad, incapaz de hacer frente al progresivo aumento del alumnado en condiciones de calidad. Por ello, la nueva convocatoria quedaba vinculada a la de profesorado de enseñanza superior «a fin de cubrir las necesidades que en un futuro próximo la enseñanza y la investigación en nuestro país han de plantear» 
(BOE, n. 152, 26 de junio de 1969). Por este motivo, se determinaban ahora un grupo de especialidades mucho más amplio (12) que en la anterior (6).

$\mathrm{Al}$ analizar los datos, observamos cómo algunas de las nuevas especialidades acusan drásticamente la escasa presencia de mujeres. En el área de Tecnología de la construcción no se concede ni una sola beca a una mujer, haciendo patente la clara existencia de patrones y profesiones masculinizadas. Lo mismo sucede con Derecho, en donde sólo se adjudica una ayuda a María Nieves Tarodo Viñuela, con destino a la Universidad de Madrid bajo la dirección del Doctor Antón. Informática es otro claro ejemplo de ello, con sólo 3 mujeres becadas. Similar situación se produce en Física y Tecnología, donde las mujeres representan únicamente el 9,7\% del total. Sin embargo, el reverso de la moneda se manifiesta en otros grupos de especialidades, destacando claramente Biología fundamental y aplicada con 52 mujeres que protagonizan un $41,6 \%$ del total de becados, obteniendo ayudas en la mayoría de subcategorías de especialidades (Bioquímica, Biofísica, Genética, Botánica, Fitotecnia, Zoología, Enología, etc.) y Humanidades con un 39,6\% de becarias. Ambos grupos coinciden con los estudios que en aquel momento son el principal nicho de matriculación de mujeres en todas las universidades españolas. Veamos los números y porcentajes para cada especialidad en la siguiente tabla (2):

Tabla 2: Hombres/Mujeres PFPI (1969)

\begin{tabular}{|l|c|c|c|c|}
\hline \multicolumn{1}{|c|}{$\begin{array}{c}\text { Convocatoria 1969 } \\
\text { curso 1969/70) }\end{array}$} & Mujeres & Hombres & Total & $\begin{array}{c}\% \text { mujeres } \\
\text { respecto total }\end{array}$ \\
\hline Matemáticas & 8 & 37 & 45 & $17,7 \%$ \\
\hline Informática & 4 & 28 & 32 & $12,5 \%$ \\
\hline Física y Tecnología & 7 & 65 & 72 & $9,7 \%$ \\
\hline Química y Tecnológica química & 23 & 82 & 105 & $21,9 \%$ \\
\hline Biología fundamental y aplicada & 52 & 73 & 125 & $41,6 \%$ \\
\hline Geología & 10 & 35 & 45 & $22,2 \%$ \\
\hline Medicina, Farmacia y Veterinaria & 24 & 68 & 92 & $26 \%$ \\
\hline Tecnología de la construcción & 0 & 15 & 15 & $0 \%$ \\
\hline Humanidades & 50 & 76 & 126 & $39,6 \%$ \\
\hline Económicas & 6 & 23 & 29 & $20,6 \%$ \\
\hline Derecho & 1 & 32 & 33 & $3 \%$ \\
\hline Otras especialidades & 12 & 54 & 66 & $18,1 \%$ \\
\hline Totales & 196 & 589 & 785 & $24,9 \%$ \\
\hline
\end{tabular}

Elaboración propia a partir de: BOE, n. 268, 08/11/1969

Feminismo/s 29, junio 2017, pp. 173-200 
A la luz de los datos expuestos, esta segunda convocatoria nos muestra una radiografía de becarias que sufre un leve descenso respecto a la anterior (del $3,6 \%$ ), y todavía mantiene un sesgo muy marcado en cuanto a lo que serían especialidades y profesiones tradicionalmente masculinizadas (Derecho, Física, Matemáticas e Informática) frente a otras en las que ya observamos una clara apertura tendente hacia la igualdad (Biología y Humanidades). Un tercer grupo estaría representado por aquéllas en las que las mujeres comienzan a tener cierta presencia, pero todavía lejos de alcanzar tasas similares a las de varones (Económicas, Química o Geología).

La convocatoria de 1970 se va a producir en un contexto condicionado por dos importantes novedades: por un lado, la entrada en vigor de la Ley General de Educación, que abre nuevas vías en materia educativa, docente e investigadora y, por otro, el principio plenamente establecido de la autonomía universitaria a través de los estatutos de las universidades. Además, esta convocatoria contempla el aumento del número de becas con destino al extranjero. De los 12 grupos de la anterior convocatoria se pasó a 14 al desglosar en diferentes apartados el anterior bloque integrado por Medicina, Farmacia y Veterinaria y al suprimirse el grupo genérico de «otras especialidades» y aparecer, con entidad propia, el de Ciencias de la Educación. Descubramos primero los datos recopilados para cada uno de esos grupos y pasemos después a analizarlos (ver tabla 3):

Tabla 3: Hombres/Mujeres PFPI (1970)

\begin{tabular}{|l|c|c|c|c|}
\hline $\begin{array}{c}\text { Convocatoria 1970 } \\
\text { curso 1970/71) }\end{array}$ & Mujeres & Hombres & Total & $\begin{array}{c}\% \text { mujeres } \\
\text { respecto total }\end{array}$ \\
\hline Informática & 1 & 10 & 11 & $9 \%$ \\
\hline Matemáticas & 2 & 21 & 23 & $8,6 \%$ \\
\hline Física & 3 & 51 & 54 & $5,5 \%$ \\
\hline Química & 33 & 75 & 108 & $30,5 \%$ \\
\hline Biología & 55 & 117 & 172 & $31,9 \%$ \\
\hline Geología & 3 & 19 & 22 & $13,6 \%$ \\
\hline Tecnología & 15 & 112 & 127 & $11 \%$ \\
\hline Medicina & 4 & 27 & 31 & $11,8 \%$ \\
\hline Farmacia & 15 & 1 & 16 & $93,75 \%$ \\
\hline Veterinaria & 1 & 10 & 11 & $9 \%$ \\
\hline Filosofía y Letras & 31 & 88 & 119 & $26 \%$ \\
\hline Ciencias de la Educación & 12 & 10 & 22 & $54,5 \%$ \\
\hline
\end{tabular}




\begin{tabular}{|l|c|c|c|c|}
\hline Economía & 4 & 29 & 33 & $12,1 \%$ \\
\hline Derecho & 2 & 23 & 25 & $8 \%$ \\
\hline Totales & 177 & 596 & 773 & $22,9 \%$ \\
\hline
\end{tabular}

Elaboración propia a partir de: BOE, n. 239, 06/10/1970

Por primera vez, encontramos una especialidad en la que las mujeres representan una abrumadora mayoría: Farmacia. De un total de 16 becas que se conceden a esta especialidad, 15 de ellas son mujeres. Se corroboran aquí los datos ya publicados por Canales (119) en los que se demuestra cómo la facultad de farmacia superaba la paridad entre el alumnado desde los años cincuenta, aspecto que se vería ahora reflejado también en el acceso a la formación de personal investigador. También son mayoría las mujeres en Ciencias de la Educación, aunque en este caso la diferencia respecto a varones es más reducida ( $54,5 \%$ de mujeres frente a $45,5 \%$ de hombres). En ambos casos, nos encontramos con unos estudios tradicionalmente feminizados en los que la presencia de la mujer es superior, debiéndose tener presente la variable de los roles de género como condicionantes en la elección de estudios universitarios.

Sin embargo, como sucedía en el periodo anterior a la guerra civil, en contraste con esta alta feminización de Letras, Educación y Farmacia, se mantendría la práctica exclusión de las mujeres de las carreras que daban lugar al ejercicio profesional de prestigio (Medicina - 4 becarias frente a 27 becarios - y Derecho -2 mujeres frente a 23 hombres becados-), ampliada ahora a las nuevas facultades de Veterinaria, donde únicamente encontramos a una mujer becada, y Ciencias Políticas, especialidad todavía no contemplada en la convocatoria. Tras analizar las tres primeras convocatorias, se va dibujando una tendencia clara en cuanto a la distribución por género de estas becas. Veamos a continuación si ésta se mantiene con el paso del tiempo.

La resolución del PFPI del año 1971 nos ofrece un panorama parecido al descrito en años anteriores, aunque con algunos cambios significativos. Farmacia continúa presentando una abultada mayoría de mujeres, siendo la única especialidad que mantiene esta tendencia, con una becaria más que en la convocatoria precedente (16), pero ahora se incrementa de forma notable el número de varones (pasando de 1 en la anterior a 9 en esta). En Ciencias de la Educación se produce una reducción del número de becarias de 12 a 7 , y éstas ya no representan a la mayoría (35\% respecto al total). Química y Biología, siguiendo la tendencia iniciada previamente, contemplan a un buen número de mujeres entre los adjudicatarios de becas, comenzando a despuntar de forma clara entre las opciones de las mujeres dentro del campo de la investigación 
en Ciencias. Llama la atención, de forma positiva, el porcentaje duplicado de mujeres respecto al año 1970 en la especialidad de Medicina, así como el aumento de mujeres en Informática. A la cola en número de mujeres se situaron en esta ocasión Tecnología, Matemáticas, Veterinaria y Derecho (ver tabla 4).

Tabla 4: Hombres/Mujeres PFPI (1971)

\begin{tabular}{|l|c|c|c|c|}
\hline $\begin{array}{c}\text { Convocatoria 1971 } \\
\text { (curso 1971/72) }\end{array}$ & Mujeres & Hombres & Total & $\begin{array}{c}\% \text { mujeres } \\
\text { respecto total }\end{array}$ \\
\hline Informática & 3 & 8 & 11 & $27,2 \%$ \\
\hline Matemáticas & 3 & 22 & 25 & $12 \%$ \\
\hline Física & 11 & 37 & 48 & $22,9 \%$ \\
\hline Química & 31 & 75 & 106 & $29,2 \%$ \\
\hline Biología & 46 & 63 & 109 & $42,2 \%$ \\
\hline Geología & 7 & 23 & 30 & $23,3 \%$ \\
\hline Tecnología & 11 & 100 & 111 & $9,9 \%$ \\
\hline Medicina & 17 & 60 & 77 & $22 \%$ \\
\hline Farmacia & 16 & 9 & 25 & $64 \%$ \\
\hline Veterinaria & 3 & 21 & 24 & $12,5 \%$ \\
\hline Filosofía y Letras & 56 & 96 & 152 & $36,8 \%$ \\
\hline Ciencias de la Educación & 7 & 13 & 20 & $35 \%$ \\
\hline Economía & 7 & 33 & 40 & $17,5 \%$ \\
\hline Derecho & 5 & 31 & 36 & $13,8 \%$ \\
\hline Totales & 220 & 595 & 815 & $26,9 \%$ \\
\hline
\end{tabular}

Elaboración propia a partir de: BOE, n. 272, 13/11/1971

Para la convocatoria de 1972 se incorporaron en los grupos de especialidades Ciencias agrarias, Literatura y Filología, Historia, Artes plásticas, Ciencias Sociales (que sustituye a la anterior de Ciencias de la Educación), Teología y Arquitectura y Urbanismo, pasando de las 14 a las 20 especialidades. Las mujeres representaban a la mayoría ( $71,4 \%$ respecto al total) en la especialidad de Artes plásticas, ocupando puestos de becarias en el CSIC, Museo Español de Arte Contemporáneo, Museo del Prado y Escuela Superior de Bellas Artes de San Fernando. Por primera vez, una especialidad supera a los datos registrados en Farmacia, en esta ocasión con un 57,7\% de mujeres, a la que sigue Ciencias Sociales con $52,1 \%$ de mujeres. Biología continúa acaparando un número cada vez más próximo a la paridad de reparto en cuanto a género (con un 42,7\%); 
después aparecen Literatura y Filología (40,3\%), Filosofía (38,7\%) e Historia $(35,3 \%)$ (ver tabla 5$)$.

En contraste, continuamos observando áreas de investigación claramente masculinizadas en las que la presencia de la mujer resulta prácticamente anecdótica, teniendo siempre en cuenta que esas pocas mujeres que entonces iniciaban una carrera científica en un mundo de lo masculino, a pesar de la limitación en su número, estaban desarrollando una labor encomiable y abriendo, con su ejemplo, el camino a futuras generaciones. Tecnología es un caso claro con sólo dos mujeres (María Concepción Navarro Moll-Universidad de Granada-y Andrea Brito Alayon -Universidad de La Laguna-) al igual que Física con otras dos (Clementina Bravo Pérez -Universidad de Madrid-y María Dolores Baró Mariné -Universidad Autónoma de Barcelona-). En Teología, sin embargo, no se destina ni una sola beca a mujeres, demostrándose una evidente herencia de carácter histórico por la cual el estudio, la formación intelectual y teológica le estuvieron vedados por mucho tiempo. Lo mismo sucede con Arquitectura y urbanismo que no registra ninguna becaria.

Tabla 5: Hombres/Mujeres PFPI (1972)

\begin{tabular}{|l|c|c|c|c|}
\hline $\begin{array}{c}\text { Convocatoria 1972 } \\
\text { curso 1972/73) }\end{array}$ & Mujeres & Hombres & Total & $\begin{array}{c}\% \text { mujeres } \\
\text { respecto total }\end{array}$ \\
\hline Informática & 3 & 13 & 16 & $18,7 \%$ \\
\hline Matemáticas & 7 & 27 & 34 & $20,5 \%$ \\
\hline Física & 2 & 38 & 40 & $5 \%$ \\
\hline Química & 34 & 77 & 111 & $30,6 \%$ \\
\hline Biología & 53 & 71 & 124 & $42,7 \%$ \\
\hline Geología & 9 & 21 & 30 & $30 \%$ \\
\hline Tecnología & 13 & 95 & 108 & $12 \%$ \\
\hline Medicina & 13 & 54 & 67 & $19,4 \%$ \\
\hline Farmacia & 15 & 11 & 26 & $57,7 \%$ \\
\hline Veterinaria & 4 & 17 & 21 & $19 \%$ \\
\hline Ciencias agrarias & 10 & 26 & 36 & $27,7 \%$ \\
\hline Filosofía & 12 & 19 & 31 & $38,7 \%$ \\
\hline Teología & 0 & 4 & 4 & $0 \%$ \\
\hline Literatura y Filología & 25 & 37 & 62 & $40,3 \%$ \\
\hline Historia & 23 & 42 & 65 & $35,3 \%$ \\
\hline Artes Plásticas & 5 & 2 & 7 & $71,4 \%$ \\
\hline
\end{tabular}




\begin{tabular}{|l|c|c|c|c|}
\hline Ciencias Sociales & 12 & 11 & 23 & $52,1 \%$ \\
\hline Arquitectura y Urbanismo & 0 & 13 & 13 & $0 \%$ \\
\hline Economía & 9 & 21 & 30 & $30 \%$ \\
\hline Derecho & 8 & 34 & 42 & $19 \%$ \\
\hline Totales & 254 & 634 & 888 & $28,6 \%$ \\
\hline
\end{tabular}

Elaboración propia a partir de: BOE, n. 268, 08/11/1972

Continuando con nuestro análisis cronológico, en la convocatoria de 1973 no encontramos ningún grupo de especialidades en el cual la presencia de la mujer sea superior a la del hombre. El reparto es paritario en Farmacia y Artes Plásticas, y de cerca le siguen, continuando la tendencia que ya venimos viendo en las anteriores, Biología (42,4\%), Literatura y Filología (40,2\%), Geografía e Historia $(40,1 \%)$ y Ciencias Sociales $(39,1 \%)$. El incremento continúa siendo progresivo en Química (ahora con 32,2\% de mujeres) y en Tecnología (16,3\%), mientras que en Arquitectura y Urbanismo se conceden dos becas a mujeres. Llama poderosamente la atención el incremento en Medicina que pasa de las 13 becadas en la anterior convocatoria a 25 , tendencia que además seguirá aumentando posteriormente hasta las 27 que vemos en la convocatoria de 1974. Por el contrario, el descenso es drástico en Informática, no adjudicándose ni una sola beca a mujeres, frente a las 3 contempladas en cada una de las dos anteriores convocatorias; finalmente, la reducción del número de becarias es mucho más leve en especialidades como Veterinaria, que pierde un $1,4 \%$, o en Derecho con un decrecimiento del 1,7\% (ver tabla 6).

Tabla 6: Hombres/Mujeres PFPI (1973)

\begin{tabular}{|l|c|c|c|c|}
\hline $\begin{array}{c}\text { Convocatoria 1973 } \\
\text { (curso 1973/74) }\end{array}$ & Mujeres & Hombres & Total & $\begin{array}{c}\text { \% mujeres } \\
\text { respecto total }\end{array}$ \\
\hline Informática & 0 & 15 & 15 & $0 \%$ \\
\hline Matemáticas & 4 & 29 & 33 & $12,1 \%$ \\
\hline Física & 7 & 46 & 53 & $13,4 \%$ \\
\hline Química & 39 & 82 & 121 & $32,2 \%$ \\
\hline Biología & 59 & 80 & 139 & $42,4 \%$ \\
\hline Geología & 12 & 28 & 40 & $30 \%$ \\
\hline Tecnología industrial & 10 & 51 & 61 & $16,3 \%$ \\
\hline Medicina & 25 & 52 & 77 & $32,4 \%$ \\
\hline Farmacia & 17 & 17 & 34 & $50 \%$ \\
\hline
\end{tabular}




\begin{tabular}{|l|c|c|c|c|}
\hline Veterinaria & 3 & 14 & 17 & $17,6 \%$ \\
\hline Ciencias agrarias & 8 & 16 & 24 & $33,3 \%$ \\
\hline Filosofía & 5 & 35 & 40 & $12,5 \%$ \\
\hline Teología & 0 & 5 & 5 & $0 \%$ \\
\hline Literatura y Filología & 37 & 55 & 92 & $40,2 \%$ \\
\hline Geografía e Historia & 43 & 64 & 107 & $40,1 \%$ \\
\hline Artes Plásticas & 3 & 3 & 6 & $50 \%$ \\
\hline Ciencias Sociales & 9 & 14 & 23 & $39,1 \%$ \\
\hline Arquitectura y Urbanismo & 2 & 7 & 9 & $22,2 \%$ \\
\hline Economía & 6 & 15 & 21 & $28,5 \%$ \\
\hline Derecho & 9 & 43 & 52 & $17,3 \%$ \\
\hline Totales & 298 & 671 & 969 & $30,7 \%$ \\
\hline
\end{tabular}

Elaboración propia a partir de: BOE, n. 299, 14/12/1973

Llegamos así a la última convocatoria objeto de nuestro estudio (ver tabla 7), corroborándose la mayor parte de tendencias que hemos venido señalando y que nos permiten presentar una serie de datos sintéticos que servirán para englobar lo descrito hasta el momento.

Tabla 7: Hombres/Mujeres PFPI (1974)

\begin{tabular}{|l|c|c|c|c|}
\hline $\begin{array}{c}\text { Convocatoria 1974 } \\
\text { (año 1975) }\end{array}$ & Mujeres & Hombres & Total & $\begin{array}{c}\text { \% mujeres } \\
\text { respecto total }\end{array}$ \\
\hline Informática & 1 & 7 & 8 & $12,5 \%$ \\
\hline Matemáticas & 2 & 17 & 19 & $10,5 \%$ \\
\hline Física & 7 & 32 & 39 & $17,9 \%$ \\
\hline Química & 18 & 66 & 84 & $21,4 \%$ \\
\hline Biología & 44 & 58 & 102 & $43,1 \%$ \\
\hline Geología & 5 & 18 & 23 & $21,7 \%$ \\
\hline Tecnología industrial & 4 & 21 & 25 & $16 \%$ \\
\hline Medicina & 27 & 41 & 68 & $39,7 \%$ \\
\hline Farmacia & 19 & 6 & 25 & $76 \%$ \\
\hline Veterinaria & 4 & 17 & 21 & $19 \%$ \\
\hline Ciencias agrarias & 9 & 23 & 32 & $28,1 \%$ \\
\hline Filosofía & 9 & 29 & 38 & $23,6 \%$ \\
\hline
\end{tabular}




\begin{tabular}{|l|c|c|c|c|}
\hline Teología & 0 & 6 & 6 & $0 \%$ \\
\hline Literatura y Filología & 30 & 42 & 72 & $41,6 \%$ \\
\hline Geografía e Historia & 28 & 41 & 69 & $40,5 \%$ \\
\hline Artes Plásticas & 3 & 0 & 3 & $100 \%$ \\
\hline Ciencias Sociales & 6 & 11 & 17 & $35,2 \%$ \\
\hline Arquitectura y Urbanismo & 1 & 8 & 9 & $11,1 \%$ \\
\hline Economía & 5 & 27 & 32 & $15,6 \%$ \\
\hline Derecho & 8 & 54 & 62 & $12,9 \%$ \\
\hline Totales & 230 & 524 & 754 & $30,5 \%$ \\
\hline
\end{tabular}

Elaboración propia a partir de: BOE, n. 28, 01/02/1975

A pesar del marcado peso que todavía a finales de los sesenta y principios de los setenta pudieran tener determinados roles impuestos así como una concepción del papel social de la mujer, como madre y esposa, y no tanto como profesional -a pesar del importante avance que habría supuesto la aprobación de la Ley sobre derechos políticos, profesionales y de trabajo de la mujer de 22 de julio de 1961 y el posterior desbloqueo de en los campos de desarrollo de actividades relacionadas con las armas y los cuerpos del Ejército, la Administración de Justicia en los cargos de magistrados, jueces y fiscales y el personal titulado de la marina mercante de diciembre de 1966-, los datos expuestos en este trabajo en relación al acceso de la mujer a una formación como personal investigador nos demuestran cómo, poco a poco, las mujeres fueron perfectamente capaces de abrirse camino por terrenos antes prácticamente impensables para ellas. A finales de los sesenta, comenzaría a aumentar la presencia de la mujer en la Universidad, pero lo cierto es que, por regla general, todavía acotándola a unas carreras que se valoraban como las más adecuadas o idóneas para ellas (especialmente dentro de las facultades de Filosofía y Letras, en detrimento de su presencia en otras especialidades como las de Derecho o Medicina). Sin embargo, su número va incrementándose de forma progresiva en numerosas carreras de Ciencias, aspecto que se vería asimismo plasmado en su acceso a becas de investigación (casos muy evidentes serían los de Biología, Geología e, incluso, Ciencias Agrarias); el crecimiento es significativo en Ciencias Sociales (Geografía, Historia o Educación) y verdaderamente dinámico en un plazo muy breve de tiempo en especialidades como las de Arquitectura y Urbanismo. Por el contrario, seguimos apreciando la existencia de sectores masculinizados, especialidades tradicionalmente copadas por varones y que se mantendrán en esta tendencia, dentro del campo de la investigación, durante años venideros, 
como son los casos de Matemáticas, Economía, Informática o Teología. En Derecho sucedería lo mismo, facultades con una matrícula mayoritariamente masculina y, hasta entonces, cuna de legitimación de los futuros dirigentes del gobierno en las que, el moderado pero incesante aumento en el acceso de la mujer a la educación superior no se vería reflejado, a diferencia de las otras, en buena parte por el blindaje al que todavía en los años cincuenta estuvieron sometidas determinadas profesiones jurídicas para las mujeres.

Aligerar el lastre que aquello acarreaba necesitó del discurrir del tiempo y, sobre todo, de la ruptura de moldes y estereotipos representada por aquellas mujeres que, poco a poco, se fueron adentrando en este campo. De hecho, vemos la inversión de la situación superada la medianía de los años 80 , repartiéndose más del 60\% de las alumnas universitarias, según datos del MEC para el curso 1986/87, entre las facultades de Filosofía y Letras y Derecho (Van den Eynde 91).

Para concluir este apartado, veamos el siguiente gráfico que nos permite observar de modo global las principales tendencias señaladas (gráfico 1):

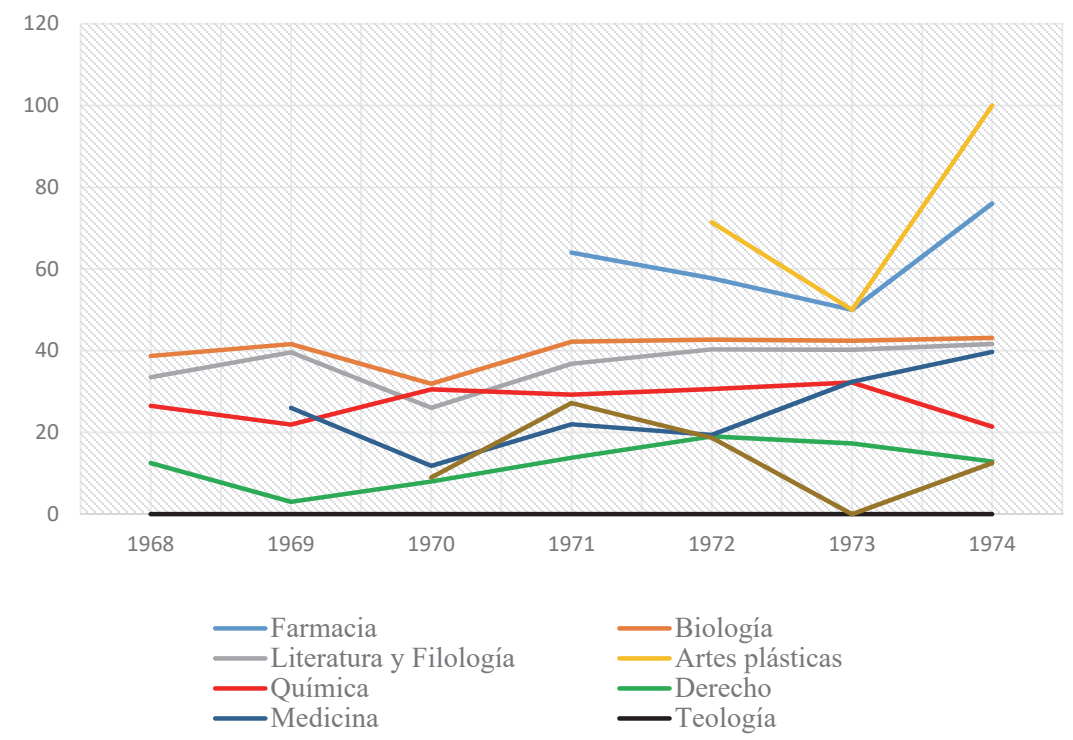

Figura 1: Evolución en la presencia de mujeres becarias por especialidades (1968/74) Elaboración propia 


\subsection{Becas de Formación de Personal Investigador con destino al extranjero}

En el I PFPI se contemplaban, dentro de la misma convocatoria, becas para España y para el extranjero, estas últimas en número reducido, adjudicándose 22 en la de 1969 (sólo una de ellas fue a parar a una mujer), 38 en 1970 (de nuevo con sólo una mujer), 20 en 1971 y 24 al año siguiente. A partir de 1973, el PFPI comenzaría a diferenciarse en dos vertientes y a realizar convocatorias distintas para becas a disfrutar dentro o fuera de España, estas últimas a partir de entonces con un carácter postdoctoral. Estas nuevas becas postdoctorales estarían financiadas por el Fondo Especial de las Naciones Unidas, el Banco Internacional de Reconstrucción y Fomento y la Fundación Ford. El principal objetivo de esta convocatoria era «conseguir que los beneficiarios posean unas cualidades concretas, imprescindibles a todo investigador que haya de salir del país y que garantice un bagaje científico e investigador que permita el mejor rendimiento y fiabilidad en el cumplimiento de su labor en cualquier centro de investigación en el extranjero» (Orden de 17 de mayo de 1973, BOE, n. 126, 26 de mayo de 1973). El incremento del número de becas fue notable, otorgándose 33 en 1973 (6 para mujeres) y 47 en 1974 (16 para mujeres).

A partir de 1973 se crearía una Comisión Nacional de Selección de Becas (CENIDE) encargada del estudio de las solicitudes y adjudicación de las becas destinadas a la formación de personal docente e investigador en el extranjero. La presidencia de esta comisión la ejercía Ángeles Galino Carrillo (Orden de 20 de febrero de 1973, n. 100, 26 de abril de 1973), primera catedrática por oposición en España en la Universidad Complutense de Madrid y, durante toda su vida, profesora, investigadora y especialista en políticas educativas. Desafortunadamente, ella era la única mujer de entre todos los miembros de la comisión.

Veamos en el siguiente gráfico la distribución de becas con destino al extranjero y comprobemos cuál fue la representación de mujeres: 


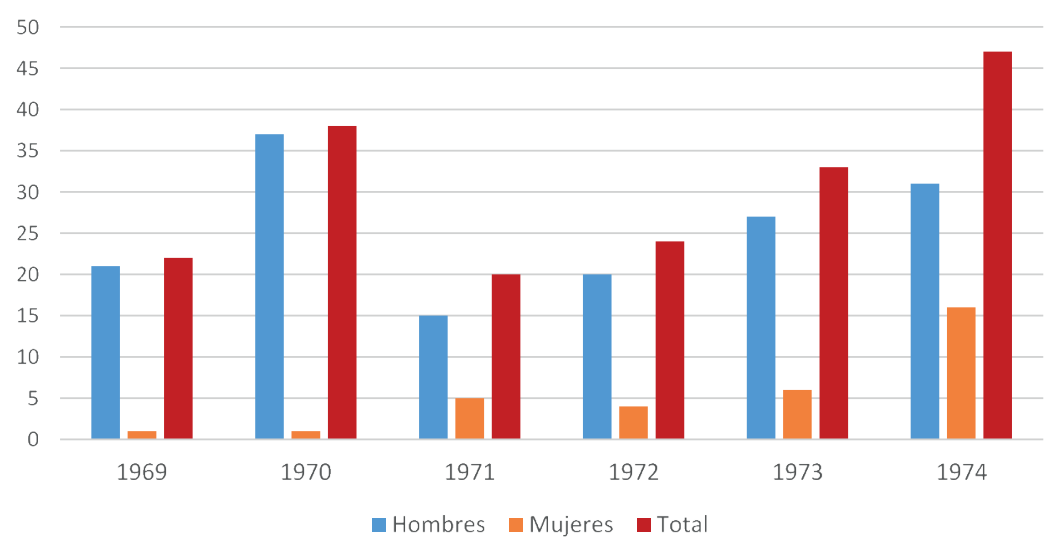

Figura 2: Evolución de becados para el extranjero (1969/74)

Elaboración propia

La presencia de la mujer en becas con destino al extranjero resulta minoritaria y desproporcionada en comparación con la de hombres. De hecho, desde la perspectiva del género, se cumple una evidencia todavía hoy en día vigente en relación a que la movilidad internacional supone un reto más difícil de superar para las mujeres que para sus compañeros varones, y que, por ende, esto tiene repercusiones negativas en la consolidación de sus carreras (Montes y Groves, 114). Aun así, el incremento, con el paso de una única becaria en 1969 a las 16 de 1974, resulta del todo significativo y alentador para la época que se tiene en consideración (tabla 8):

Tabla 8: Relación de becarias con destino al extranjero

\begin{tabular}{|c|l|l|l|}
\hline Conv. & \multicolumn{1}{|c|}{ Nombre y apellidos } & \multicolumn{1}{c|}{ Especialidad } & \multicolumn{1}{c|}{ Destino } \\
\hline 1968 & No se especifica en la resolución & & \\
\hline 1969 & Ana María Martínez Arias & Medicina & Cambridge \\
\hline 1970 & María Isabel Bernárdez Hermida & Biología & Francia \\
\hline \multirow{2}{*}{1971} & Carmen Ríos Camacho & Física & Desconocido \\
\cline { 2 - 4 } & María Rosa Miracle Solé & Biología & Desconocido \\
\cline { 2 - 4 } & María Josefina Rodríguez Enríquez & Biología & Desconocido \\
\cline { 2 - 5 } & Ángela López Pastor & Medicina & Desconocido \\
\cline { 2 - 4 } & María Teresa Miras Portugal & Farmacia & Desconocido \\
\hline
\end{tabular}




\begin{tabular}{|c|c|c|c|}
\hline \multirow[t]{4}{*}{1972} & Carmen Ausán Urtizberca & Informática (CSIC) & Desconocido \\
\hline & Carmen San José Serrán & Biología (CSIC) & Desconocido \\
\hline & Felisa Elizondo Aragón & $\begin{array}{l}\text { CC. Agrarias } \\
\text { (CSIC) }\end{array}$ & Desconocido \\
\hline & Inmaculada Gallastegui Zulaica & Derecho & Desconocido \\
\hline \multirow[t]{6}{*}{1973} & María Antonia Rivas Ponce & Biología & Francia \\
\hline & María del Carmen Martínez López & Biología & Inglaterra \\
\hline & María del Carmen Gutiérrez Martín & Medicina & Estados Unidos \\
\hline & Clara García-Miñor Corbato & Medicina (CSIC) & Estados Unidos \\
\hline & María Inés Avendaño Ruiz & Biología (CSIC) & Estados Unidos \\
\hline & Evangelina Palacios Alaiz & Biología (CSIC) & Inglaterra \\
\hline \multirow[t]{16}{*}{1974} & María Inmaculada Paz Andrade & Química & Gran Bretaña \\
\hline & María Teresa Arranz Santos & Medicina & Francia \\
\hline & Aurora Domínguez Guzmán & Literatura & Francia \\
\hline & Nieves de Diego Otero & Física & Alemania \\
\hline & Otilia Mo Romero & Química & Estados Unidos \\
\hline & Esther Simón Martínez & Biología & Estados Unidos \\
\hline & Magdalena Hugarte Pérez & Farmacia & Estados Unidos \\
\hline & Ana María Yabar Sterling & Economía & Estados Unidos \\
\hline & María Luisa Santos-Gómez Gómez & Filosofía & Méjico \\
\hline & María Concepción Bravo Guerreira & Geografía/Historia & Perú \\
\hline & Julia Barrios Nefra & Química (CSIC) & Francia \\
\hline & Cristina de la Calle Vian & Química (CSIC) & Francia \\
\hline & María Teresa García de Quesada Fort & Química (CSIC) & Francia \\
\hline & María del Carmen García Palacios & Biología (CSIC) & Francia \\
\hline & María Ángeles Vicente Hernández & $\begin{array}{l}\text { CC. Agrarias } \\
\text { (CSIC) }\end{array}$ & Francia \\
\hline & Lucinda Cacicedo Egües & Medicina (CSIC) & Estados Unidos \\
\hline
\end{tabular}

Elaboración propia

A pesar de que la radiografía cuantitativa de la que se ha dado muestra en este trabajo hace visible una presencia todavía minoritaria de la mujer como personal investigador en formación, mucho más acusado en el caso de las becas con destino al extranjero, y que las diferencias entre unas especialidades y otras son bastante acusadas, lo cierto es que el acceso de la mujer a este tipo 
de ayudas resultaría del todo significativo. Así, lentamente y superando trabas e impedimentos (pues el número de becarias se mantiene estable durante todo el periodo), la mujer de finales de los sesenta y principios de los setenta fue rompiendo algunas barreras, abriéndose camino por terrenos difíciles y normalizando una situación que jamás debería haber sido anómala. El número de mujeres universitarias creció considerablemente a lo largo de los años analizados, y también lo hizo el de mujeres que comenzaron a dedicarse a labores de investigación, y es que, como apunta García Lastra (357), este logro debe ser considerado como una «pieza fundamental en la importante transformación acontecida en la situación social de las mujeres, donde precisamente son aquellas que han podido acceder a estudios superiores y desarrollar una profesión acorde a éstos las que representan la punta del iceberg en el proceso de cambio de la «definición social de lo femenino».

\section{CONCLUSIONES}

La incorporación de estas mujeres a una inicial formación como investigadoras representa un paso clave en la ruptura de los moldes estereotipados sobre el género femenino que se mantuvieron durante el franquismo. Asimismo, estas nóveles investigadoras simbolizan la salida de la esfera doméstica para encontrar un lugar con, al menos, cierto reconocimiento social, un paso en firme hacia la visibilidad de su capacidad profesional. Aun así, la desigualdad en el acceso a determinadas especialidades ha quedado reflejada a partir de los datos presentados, observándose áreas claramente feminizadas (Artes Plásticas o Farmacia), sectores masculinizados (Derecho, Matemáticas, Economía, Informática o Teología) y un grupo de especialidades, cada vez más amplio, en el que la presencia de la mujer es progresivamente más frecuente y en mayor número (Biología, Geología, Ciencias Sociales, etc.). Aun así, las mujeres se encontraban todavía lejos de alcanzar la igualdad social, tanto desde el punto de vista de las profesiones a las que podían encaminar su actividad como desde la perspectiva del rendimiento económico y del status que obtendrían de ellas (van den Eynde, 91).

En todo caso, el análisis sobre la distribución de las primeras becas de formación de personal investigador que recayeron sobre mujeres coincide, en buena parte de los casos, tanto con la ocupación de las primeras cátedras por mujeres como con su acceso como estudiantes a la Universidad. Todas estas variables no desmienten ni que las facultades de Letras fueran lugares destacados para la promoción de la mujer en el mundo de la investigación, ni el carácter relativamente favorable de las facultades de Ciencias a la promoción femenina, especialmente en los casos de Biología o Farmacia. 
Ahora bien, cabría preguntarse y dejar abierta como hipótesis de trabajo futuro si en los grupos de investigación en los cuales se integraron estas nuevas becarias en formación no se produciría un reparto de roles entre hombres y mujeres, siguiendo la línea o la tendencia al reparto de roles por sexo que se daba en el resto de responsabilidades y actividades familiares y sociales (Salguera 18). Porque las ya comentadas creencias estereotipadas sobre las capacidades de las mujeres, no son algo ajeno a las prácticas sociales y por lo tanto se reflejan en las políticas discriminatorias organizacionales -en la mayoría de los casos implícitas y por lo tanto difíciles de desterrar-, que admiten con facilidad a las mujeres en los puestos más bajos del escalafón, a la vez que dificultan de manera «naturalizada» el que puedan llegar a asumir los más altos cargos de responsabilidad, obligándolas de forma solapada a constantes renuncias personales y/o familiares si aspiran a puestos directivos; renuncias que jamás se plantean a sus colegas varones (Guil 2007). Ese «techo de cristal» durante la época estudiada estaría verdaderamente presente y serviría como elemento de bloqueo para las aspiraciones de muchas de estas nóveles investigadoras. Pero no en todos los casos, motivo que nos conduce a plantear otra línea de investigación futura relacionada con el estudio de la trayectoria vital y profesional de algunas de estas mujeres que accedieron a finales del franquismo a becas de formación de personal investigador, para comprobar de este modo el tipo de vías que éstas abrieron en sus propias vidas.

\section{REFERENCIAS BIBLIOGRÁFICAS}

Becerra Conde, Gloria y Teresa Ortiz Gómez (Coords). Mujeres de ciencias: mujer, feminismo y ciencias naturales, experimentales y tecnológicas. Granada: Servicio de Publicaciones de la Universidad de Granada, 1996.

Canales Serrano, Antonio Francisco. «Las mujeres y la enseñanza científico-tecnológica en la España del siglo XX». Clepsydra: revista de estudios de género y teoría feminista 5 (2006): 111-128.

Canales Serrano, Antonio Francisco. «Mujer, franquismo y educación científica». Memorias del IX Congreso Iberoamericano de Ciencia, Tecnología y Género. Madrid: Organización de Estados Iberoamericanos, 2012.

Casado, María José y Margarita Salas. Las damas del laboratorio: mujeres científicas en la historia. Barcelona: Debate, 2006.

Comisión de Investigación Científica y Técnica. «Política de investigación y formación de personal en el II Plan de Desarrollo». Revista de Educación - Crónica 195 (1968): 27-33. 
Cuesta Bustillo, Josefina, Ma Luz Prado Herrera y Francisco J. Rodríguez Jiménez (Coords.). ¿Mujeres sabias?: mujeres universitarias en España y América Latina. Limoges: Pulim, Presses Universitaires de Limoges, 2015.

Flecha García, Consuelo. «La mirada de las mujeres al mundo académico». Revista Argentina de Sociología 1.1 (2001): 27-43.

García Lastra, Marta. «La voz de las mujeres en la universidad». RASE. Revista de la Asociación de Sociología de la Educación 3.3 (2010): 357-368.

Guil Bozal, Ana. «Docentes e investigadoras en las universidades españolas: visibilizando techos de cristal». Revista de Investigación Educativa 25/1 (2007).

Guil Bozal, Ana. «1910-2010: Cien años buscando igualdad en la universidad». Aequalitas: Revista jurídica de igualdad de oportunidades entre mujeres y hombres 26 (2010): 16-19.

Guil Bozal, Ana y Consuelo Flecha García. «Universitarias en España: De los inicios a la actualidad». Revista Historia de la Educación Latinoamericana 17.24 (2015).

Hernández Díaz, José M. «El modelo de la universidad alemana en España». La pedagogía alemana en España e Iberoamérica (1810-2010). Coord. Hernández Díaz, José M. Salamanca: Castilla Ediciones, 2010, 225-247.

López de la Cruz, Laura. «La presencia de la mujer en la universidad española». Revista Historia de la Educación Latinoamericana 4 (2002): 291-299.

Lucena Conde, Felipe. La investigación científica en la Universidad. Discurso pronunciado en la solemne apertura del curso académico 1962/63. Salamanca: Talleres Gráficos Cervantes, 1962.

Matilla Quiza, María Jesús y Esperanza Mó Romero (2014). «De la excepción a la normalidad: Mujeres científicas en la Historia». Encuentros multidisciplinares 16.47 (2014): 2-11.

Ministerio de Educación y Ciencia. La educación en España. Bases para una política educativa. Madrid: Secretaría General Técnica del Ministerio de Educación y Ciencia, 1969.

Montes, Estrella y Tamar Groves. «Mujeres académicas y el reto de la internacionalización». Innovación educativa 26 (2016): 113-124.

Orive, Pedro. «Investigación. Reto español del cuatrienio». Didascalia. Revista de orientación didáctica e investigación pedagógica 16 (1971): 11-16.

Otero Carvajal, Luis Enrique. «La destrucción de la ciencia en España. Las consecuencias del triunfo militar de la España franquista». Historia y Comunicación Social 6 (2001): 149-186.

Puig-Samper, Miguel Ángel. Tiempos de investigación: JAE-CSIC, cien años de ciencia en España. Madrid: CSIC, 2007.

Salguera, Margarita. «Mujer y ciencia». Genes, ciencia y dieta: lecciones sobre evolución humana. Eds. Ana Mateos y Alfonso. Madrid: Fundación Tomás Pascual y Pilar Gómez-Cuétara y CENIEH, 2011, 13-24. 
Sánchez, Isidro. Educación, Ciencia y Cultura en España: auge y colapso (1907-1940) Pensionados de la JAE. Ciudad Real: Almud Ediciones, 2012.

Santesmases Navarro de Palencia, María Jesús. Mujeres científicas en España (19401970): profesionalización y modernización social. Madrid: Instituto de la Mujer, 2000 .

Santesmases Navarro de Palencia, María Jesús. «La formación y el trabajo de las mujeres científicas españolas 1940-1970: Historia de una investigación». Seminario Balance y Perspectivas de los Estudios de las Mujeres y del Género. Madrid: Ministerio de Trabajo e inmigración, Instituto de la Mujer, 2003. 208-312.

Van den Eynde, Ángeles. «Género y ciencia ¿Términos contradictorios? Un análisis sobre la contribución de las mujeres al desarrollo científico». Revista Iberoamericana de Educación 6 (1994): 79-101. 
Para enlazar con este artículo / To link to this article:

http://dx.doi.org/10.14198/fem.2017.29.08

Para citar este artículo / To cite this article:

Granada Angulo, Lubi. «Discriminaciones interseccionales: percepciones de mujeres afrodescendientes en espacios de educación superior en Bogotá». En Marcos Jesús Iglesias Martínez e Inés Lozano Cabezas (coords.), La (in) visibilidad de las mujeres en la Educación Superior: retos y desafios en la Academia. Feminismo/s, 29 (junio 2017): 201-220, DOI: 10.14198/fem.2017.29.08

\title{
DISCRIMINACIONES INTERSECCIONALES: PERCEPCIONES DE MUJERES AFRODESCENDIENTES EN ESPACIOS DE EDUCACIÓN SUPERIOR EN BOGOTÁ
}

\author{
INTERSECTIONAL DISCRIMINATIONS: PERCEPTIONS \\ OF AFRODESCENDING WOMEN IN SPACES OF HIGHER \\ EDUCATION IN BOGOTÁ
}

\author{
Lubi GRANADA ANGULO \\ Universidad Pedagógica Nacional \\ Secretaría de Educación Distrital - Bogotá (Colombia) \\ lubigra@yahoo.com \\ orcid.org/0000-0003-0144-9865
}

\section{Resumen}

El presente artículo forma parte de la etapa de exploración del proyecto de Tesis Doctoral de la autora. El propósito, que determina el ejercicio, se centra en la identificación de las percepciones sobre discriminación en espacios de Educación Superior en Bogotá (Colombia), que tienen tres mujeres afrodescendientes. Este trabajo se llevó a cabo utilizando la metodología de los Núcleos de Educación Social (NES), fortalecido a través de aportes teóricos y de investigación relacionados con el tema. Se evidencia de forma importante el peso de la discriminación negativa en la vida académica y laboral de las mujeres afrodescendientes participantes, que se ha constituido a lo largo del tiempo en una interseccionalidad entre categorías susceptibles de discriminación dentro y fuera de la Academia.

Palabras claves: discriminación negativa y positiva, Educación Superior, interseccionalidad, mujeres afrodescendientes. 


\begin{abstract}
This article is part of the exploration phase of the author's Doctoral Thesis project. The purpose of the exercise is to identify perceptions of discrimination in higher education spaces in Bogotá (Colombia), which have three women of African descent. This work was carried out using the methodology of the Nuclei of Social Education (NES), strengthened through theoretical and investigative contributions related to the topic. The weight of negative discrimination in the academic and work life of participating African descendants is evidenced, which has been constituted over time in intersectionality between categories susceptible of discrimination inside and outside the academy.
\end{abstract}

Keywords: negative and positive discrimination, higher education, intersectionality, women of African descent. 


\section{PUNTO DE PARTIDA}

Los estudios que sobre mujeres afrodescendientes se han adelantado en Colombia enmarcan una variedad de temáticas y problemáticas. De ellas resulta sugerente la recreación constante de la discriminación en diferentes discusiones académicas y sociales, a través de las cuales se posibilitan nuevas elaboraciones y preguntas para la reflexión.

En el marco de un proyecto de investigación doctoral ${ }^{1}$ surge como etapa preliminar la identificación de percepciones que sobre discriminación en espacios de Educación Superior tienen tres mujeres autorreconocidas como afrodescendientes, cuyas edades oscilan entre los 40 y 65 años de edad, con estudios de postgrado y trayectoria laboral en espacios de educación superior en Bogotá. Lo anterior con la idea de reconocer las diferentes facetas de la discriminación, así como sus intersecciones, dando cabida a la comprensión de complejas experiencias que sobre el tema se gestan.

A pesar de que este trabajo responde a un análisis que exige la ilación de tres aristas teóricas (mujeres afrodescendientes, Educación Superior y discriminación), para el presente ejercicio solo se retoma el eje de discriminación negativa y positiva desarrollado desde la perspectiva de Eduardo Restrepo, apoyado en aportes de otras y otros investigadores que sobre la materia han concentrado sus intereses, posibilitando así una triangulación con las percepciones de las mujeres afrodescendientes participantes.

Para identificar estas percepciones se emplearon los Núcleos de Educación Social (NES), teniendo en cuenta que es un modelo de investigación participativa, desarrollado a través de grupos (comunitarios, escolares, barriales, juveniles, estudiantes, entre otros), el cual permite conocer, indagar, interpretar, comprender, prevenir y transformar situaciones que pueden ser problemáticas en la realidad de los participantes que conforman los grupos de discusión (García y Guerrero 11).

1. El presente artículo expone reflexiones de una etapa de exploración correspondiente al proyecto doctoral titulado «Mujeres Afrodescendientes y Educación Superior: Estudio Interseccional y Multisituado en Colombia», que se está llevando a cabo en el Doctorado Interinstitucional en Educación, Sede Universidad Pedagógica Nacional (UPN, Bogotá). 
Los NES se construyen a través de 20 sesiones que se organizan en 4 escenarios $^{2}$ : el sujeto, la familia, la educación y los contextos; y 5 etapas ${ }^{3}$ : encuentros, exploratorios, recorridos, desplazamientos y transformaciones (García y Guerrero 37). Cada una de las sesiones del NES es organizada en una matriz con los elementos que se consideran necesarios para poner en evidencia la problemática de forma holística.

Las reflexiones de este artículo surgen a partir de los aportes realizados por tres mujeres afrodescendientes participantes en una sesión NES correspondiente a la etapa exploratoria en el escenario universidad, llevada a cabo en Bogotá, el día 23 de abril del año 2016; y se robustecen con planteamientos teóricos e investigativos que dan cuenta de la constante interseccionalidad entre raza y género en la percepción de discriminación mayoritariamente negativa que ellas identifican.

\section{A PROPÓSITO DE LOS ESPACIOS DE EDUCACIÓN SUPERIOR Y LAS MUJERES AFRODESCENDIENTES EN BOGOTÁ}

El nivel superior de la educación formal en Colombia presenta unas características que lo enmarcan en un sistema educativo consecuente con lineamientos, tiempos y estrategias que les permiten a las mujeres obtener conocimientos, habilidades y competencias para acceder a mejores oportunidades laborales, que en consecuencia traería un incremento en los niveles de calidad de vida. En este sentido, uno de sus tantos objetivos es la transformación y el desarrollo de sus vidas y de la sociedad (Mercado 9).

Sin embargo, el disfrute de esta posibilidad por parte de las mujeres afrodescendientes es vista más como una prerrogativa y no como el derecho del cual todas y todos los ciudadanos deben disfrutar: «Reconozco que es un privilegio llegar a un espacio universitario y encontrar con que el trabajo va a hacer dentro de lo que es relevar y no esconder mi identidad» (Mujer 01, NES Universidad, Sesión 12, 23 de abril de 2016).

Al retomar la participación de formación académica universitaria de las mujeres afrodescendientes en Bogotá, cabe referenciar el estudio titulado «Mujeres enseñando e investigando en la Universidad Nacional de Colombia»

2. Los escenarios corresponden a los lugares sobre los cuales las mujeres reflexionan, en este caso se seleccionó exclusivamente el escenario universidad, porque es el que compete para el presente ejercicio.

3. Corresponden a los momentos de reflexión y discusión que permiten los cambios y los tránsitos en las formas de percibir las problemáticas por parte de las mujeres. En esta oportunidad se desarrolló exclusivamente la etapa exploratoria considerando los intereses de la indagación. 
realizado en dicha institución en el año 2011, donde se menciona que más del $70 \%$ de los docentes son hombres y las mujeres partícipes, pertenecen a carreras consideradas femeninas, tales como humanidades, psicología y educación. Esta realidad tiende a repetirse en la mayoría de las universidades más importantes de Colombia y Latinoamérica. Además, las investigadoras plantean que esta situación es generada por diferentes factores, algunos asociados a la discriminación abierta y la falta de credibilidad entre pares (Munévar y Arana 14).

Con la investigación anterior, se puede establecer que la brecha de participación y liderazgo está presente en la realidad de la mayoría de las mujeres que en este campo se desenvuelven. Ahora bien, sugiere de manera implícita que las distancias en el acceso y participación para cargos de docencia, investigación y coordinación en espacios de Educación Superior para las mujeres afrodescendientes son aún más amplias. Tal como se evidencia en el siguiente relato:

Ahora llegando a la Universidad Nacional, yo fui la primera profesora negra del departamento de nutrición [...] eso fue un año antes de entrar en la convocatoria, porque estuve un tiempo ahí y yo era muy consciente. Lo que tú dices, a raíz de mi concientización en Gran Bretaña, yo llegaba a cualquier espacio y yo enseguida miraba a ver aquí quiénes son negros y siempre estábamos en minoría. (Mujer 02, NES Universidad, Sesión 12, 23 de abril de 2016)

En este sentido, establecer como punto de partida que la participación en los espacios de Educación Superior para mujeres afrodescendientes en Bogotá tiende al privilegio, implica reconocer también que en el disfrute de este derecho, se evidencian diferentes factores que obstruyen de alguna manera su máximo beneficio. Así pues, es importante delinear que dentro de los aspectos más representativos se encuentra la discriminación negativa, orientada con mayor fuerza a la categoría racial, pero haciendo fuertes lazos con el género y las habilidades cognitivas.

\section{ELEMENTOS PARA LA COMPRENSIÓN DE LA DISCRIMINACIÓN NEGATIVA}

Entender la discriminación negativa como un fenómeno que afecta a diferentes miembros de una comunidad, implica relacionar las dinámicas de diferenciación ${ }^{4}$ y exclusión que en ella se establecen. Las primeras, hacen referencia a las maneras de clasificación que se usan para distinguir entre las personas y los grupos. Por otro lado, la exclusión está relacionada con aquellas prácticas de

4. Las dinámicas de diferenciación también son empleadas como estrategias dentro de la discriminación positiva, aspecto que se ampliará más adelante. 
pensamiento o comportamiento que tienden al «rechazo, la negación y desconocimiento de quien es objeto de discriminación» (Restrepo s.f., 1).

De acuerdo con el planteamiento anterior, la diferenciación y la exclusión se convierten en las dos columnas en las que se erige la discriminación, propiciadas por cualquier marcador de diferencia. Como dinámica compleja, la discriminación se afianza con muchas posibilidades de acción en la realidad de las personas, retomando características como raza, género, clase o situación económica, educación, edad, estética, ubicación geográfica, elementos lingüísticos, religiosos, entre muchos otros. Así pues, las tipologías de discriminación son tan variadas como las características susceptibles de diferenciación, pero éstas, así como pueden revelarse de manera independiente, también consiguen relacionarse fuertemente entre ellas, tal como lo plantea Eduardo Restrepo:

No debe perderse de vista que la insistencia en distinguir entre diferentes tipos de discriminación dependiendo del anclaje concreto sobre el que se ejerce, no significa que estas discriminaciones se presenten de manera aislada. Al contrario, en muchas ocasiones nos encontramos con amalgamas de discriminaciones que se articulan y refuerzan mutuamente. Discriminaciones de orden racial se encuentran frecuentemente asociadas a las discriminaciones de clase, lingüísticas (formas de hablar) o geográficas (quienes son discriminados provienen generalmente de regiones marginalizadas y subalternizadas). Esto se debe a que los individuos y poblaciones concretos se encuentran atravesados al tiempo por muchas variables (raciales, sexuales, de clase, etc.) y algunas de éstas tienden a asociarse. (s.f., 2)

Lo anterior se conoce como interseccionalidad ${ }^{5}$, concepción que hace referencia al entrecruce de categorías que permite comprender cómo estas relaciones consolidan las experiencias de vida de las personas otorgando mayores elementos para la oportunidad o por el contrario, para la imposibilidad. Este elemento se convierte en herramienta crucial en la comprensión de las percepciones que las mujeres afrodescendientes tienen sobre la discriminación en los espacios de Educación Superior, pues están determinadas por al menos dos marcadores de

5. El concepto surge en Norteamérica con el artículo titulado: «Demarginalising the intersection of Race and Sex: A Black Feminist Critique of Antidiscrimination Doctrine, Feminist Theory and Antiracist Politics» (Crenshaw 1989). Sin embargo, éste se ha constituido y a la vez ha sido fundamento de las posturas críticas en América, permitiendo la comprensión del complejo entramado de las dinámicas y experiencias diversas de las mujeres en el continente. Desde este enfoque, se pueden reconocer aportes de los feminismos: negro, chicano y afrolatinoamericano (La Barbera 2014). Éstos en su conjunto aportan a la reflexión por medio del análisis de distintas categorías coloniales como los son la raza, la clase, el género, el sexo y la sexualidad principalmente, además de aportar en la comprensión de los efectos de estas variables, que pueden ser asumidas como estables y cambiantes en las sociedades (Curiel 2007, 96). 
diferencia (género y raza) que se relacionan entre sí y del cual emergen otras categorías susceptibles de discriminación como las referidas a las habilidades cognitivas.

\subsection{El racismo: la tipología de discriminación con mayor peso}

El racismo es el tipo de discriminación referido a la raza. Este elemento de análisis que surge en el proceso de colonización de América, y está relacionada con «la categorización de individuos según su nivel de similitud o cercanía respecto de un modelo presupuesto de humanidad ideal» (Mignolo 41).

Tal como lo propone Walter Mignolo, esta diferenciación se basa en una estructuración que ubica lo ideal blanco en el más alto nivel de jerarquía y a los diferentes en un nivel inferior. Este proceso se dio inicialmente a través de las religiones, aproximadamente para el siglo XVI, donde se hablaba principalmente de la "pureza de sangre», luego pasó a ser un proceso relacionado con «el color de piel» en el siglo XIX. Dentro de estos dos momentos de la constitución de la raza, se destaca el predominio de lo físico. Así pues, la raza está referida a «la genealogía sanguínea, genotípica o de color de piel» (Ver 41).

En este sentido, entender el racismo dentro de la lógica de superioridad de una raza sobre otra, implica establecer relaciones de tipo ideológico y práctico, que resuenan en la realidad cotidiana de las mujeres afrodescendientes. Tal como se evidencia en el siguiente apartado, en el que una de las mujeres participantes vincula de forma inmediata la raza con una tipología de discriminación negativa:

En el caso de nosotras como mujeres afro, eh, la discriminación es, lo primero que se presenta, es el color de la piel, -cierto-y entre ese color de la piel está la historia, la historia de la que no nos han reconocido a nuestros ancestros, que queda de los esclavos. (Mujer 01, NES Universidad, Sesión 12, 23 de abril de 2016)

De lo anterior, pareciera que existe una impronta racial difícil de modificar en las percepciones que sobre discriminación tienen las mujeres afrodescendientes entrevistadas. Esta situación puede deberse a la herencia de estigmatización que tiende a reproducirse en los discursos de las mujeres y la sociedad en general. Con esto se logra entender que la permanencia y cristalización de esta ideología se aferra al pensamiento social, se reproduce tanto en el discurso como en la práctica y permanece en los distintos escenarios donde circula. (Hellebrandová 88)

Para las sociedades donde se ha impuesto, manifestado y reproducido jerarquías raciales, resulta complejo desmontar este tipo de dinámicas, considerando que son procesos articulados al pensamiento colectivo que se perpetúan 
en los espacios simbólicos y físicos de la representación y la interacción social, a pesar de las modificaciones que se puedan hacer a las estructuras sociales. Al respecto, Lamus plantea que en Colombia existe una negación consciente del racismo, situación propiciada con el surgimiento del multiculturalismo, pues a través de éste se hace un reconocimiento a la diversidad cultural y se promueve la tolerancia entre los diferentes grupos étnicos. Sin embargo, dicha postura se convierte en una cortina que esconde en el fondo un entramado de discriminaciones basadas en la raza que no ha sido reconocido por la sociedad (163). Este aspecto se evidencia con claridad en la percepción de una de las mujeres:

Cuando yo con mis amigas muy cercanas... digo el racismo tal cosa, me dicen, pero es que no eres tan negra (risas)... Es que tú eres demasiado pasional, tú le estas poniendo mucha tiza a las cosas, ¿quién te discrimina a ti? (Mujer 02, NES Universidad, Sesión 12, 23 de abril de 2016)

Con relación al anterior relato, se puede vislumbrar uno de los elementos más peligros de la discriminación racial, referida la negación o la minimización de la misma, a través de la cual se genera una idea de exageración o victimización por parte de las personas que la perciben, haciendo que este proceso se convierta en un acto de responsabilidad exclusiva de la persona que se siente víctima. Al respecto, se puede afirmar que el racismo no ha desaparecido, sólo ha tomado otras formas y maneras de permanencia en las dinámicas sociales.

Siguiendo con esta idea y retomando los planteamientos de Eduardo Restrepo, se pueden establecer dos modos para ejercer el racismo: el primero, denominado «Manifiesto», en el que se evidencian explícitamente las dinámicas y las prácticas de discriminación a partir del color de piel o los rasgos fenotípicos; y el segundo designado como «Latente», es decir que se encuentra oculto, disfrazado y en muchas ocasiones naturalizado (6). Esta forma de ejercer el racismo, se gesta de manera inconsciente, pero resulta muy efectiva en la perpetuación de desventajas sociales:

La discriminación tiene muchas caras y formas de expresarse, no te podría decir con nombre propio, pero lo único que sí te puedo decir es que son muchas y de muchas formas, y las formas más peligrosas son las accesibles, invisibles y sutiles que no se dejan ver, pero están machacando todos los días lo que somos. (Mujer 03, NES Universidad, Sesión 12, 23 de abril de 2016)

Estas tipologías de racismo coinciden con lo que Hellebrandová presenta como racismo «solapado», del cual se niega su existencia, pues las prácticas discriminatorias no están abiertamente relacionadas al color de piel $(93)^{6}$. Según la

6. Al respecto, es pertinente resaltar que la categoría Raza ha estado relacionada fuertemente con la Etnia, pues esta última tiene que ver con las prácticas humanas que caracterizan 
investigadora, este tipo de prácticas son propias de las relaciones establecidas racialmente en América Latina, generando dificultades al enfrentar el racismo, pues no se evidencian explícitamente, por lo que parecieran inexistentes, pero forjan una «violencia latente» permeando y circulando entre las dinámicas institucionales. Por consiguiente, la discriminación racial tiene efectos evidentes o disimulados en la vida de las mujeres afrodescendientes, todos ellos establecidos en un marco institucional que posibilita su permanencia, prolongación y adecuación a los cambios sociales en tiempo y espacio. A esto se le conoce como «Racismo Estructural», definido exactamente como el

Diseño institucional que mantiene en la práctica la subalternización de unas poblaciones e individuos racialmente articulados. De ahí que esta dimensión del racismo atraviese todo el edificio institucional. Este racismo se encarna en acciones y omisiones concretas que, derivadas del funcionamiento mismo del sistema institucional, tienen el efecto de reproducir las desigualdades y jerarquías entre individuos y poblaciones racializadas. (Restrepo s.f., 7)

El racismo estructural justifica la exclusión y la invisibilización de las diferencias y necesidades de las comunidades racializadas. Esta situación se evidencia cuando institucionalmente se plantea que todas las personas están en las mismas condiciones para acceder a espacios de formación universitaria y las pone en el mismo lugar de competencia meritoria, desconociendo las desventajas acumulativas (en salud, educación, vivienda y acceso a servicios básicos) en las que sujetos y colectivos afrodescendientes se ven enfrentados de forma permanente.

Con este tipo de racismo se garantiza la materialización sistemática de marcos y escenarios geopolíticos, con los cuales se establecen relaciones entre los territorios, la raza y la etnia. Este aspecto se ve reflejado en normatividades como la Ley 70 de 1993, también conocida como ley de Comunidades Negras; en la que se reconoce la existencia de las poblaciones afrodescendientes, estableciendo una relación directa entre identidad étnica y territorio, referenciado específicamente a la región del Pacífico y algunos lugares del Atlántico

a los diferentes grupos que no son considerados dentro del supuesto del ideal humano. Retomando las palabras de Mignolo, la Etnia «incluye la lengua, la memoria y un conjunto de experiencias compartidas pasadas y presentes, por lo que comprende un sentido cultural de comunidad» (42). Este elemento es fundamental, pues ya no se estaría hablando exclusivamente de las características físicas, sino también de las actividades y prácticas relacionadas con lo físico. Así pues, hablar de afrodescendencia implica retomar tanto lo fenotípico (raza) y los elementos y prácticas culturales alrededor de estas caracterizaciones físicas (etnia). 
colombiano $^{7}$. De manera superficial este aspecto tiene efectos de reconocimiento de la diversidad en el país, pero al hacer un análisis de fondo muestra fuertes relaciones entre la distinción geopolítica racializada y las situaciones de precariedad y marginalidad de las personas que habitan en estos territorios ${ }^{8}$. Esta realidad se hace evidente en los planteamientos de una de las mujeres:

La discriminación es una cosa (...) que está anclada en las estructuras sociales y políticas de este país. Es decir, no es gratuitito que las poblaciones afro e indígenas estén confinadas a los márgenes o a los límites de nuestros territorios, casi que los lugares de exclusiones visibles para el país, donde las políticas llegan, pero llegan a medias o no llegan y es bastante complicado. Es decir, que desde que nos conformamos como Nación, ya nos cubrimos la espalda de los que teníamos poco o de los que somos considerados como menos. (Mujer 03, NES Universidad, Sesión 12, 23 de abril de 2016)

Como ya se ha dicho, la discriminación racial es evidente tanto en las prácticas cotidianas como en las institucionales, dejando a su paso una serie de estereotipos o ideas preconcebidas que tienden a homogenizar y exagerar representaciones que sobre las mujeres afrodescendientes se tienen. Estas preconcepciones están relacionadas con la sexualidad, la pobreza, la pereza y el folclor. Al respecto, diferentes estudios comprueban ${ }^{9}$ a partir de entrevistas, relatos e historias de vida, cómo las representaciones que se tienen de mujeres afrodescendientes están vinculadas a comportamientos de marcada disponibilidad sexual, tendencia a la fiesta, el baile y la alegría que se irradia en actividades folclóricas. Como ejemplo del planteamiento anterior, se expone el relato de una de las mujeres participantes en el NES:

El otro día fui a una presentación de los festivales, esa negrita que sacan en el canal de Barranquilla me emputa, discúlpenme. Su gran celebración, su gran aplauso, yo digo, pero es que ella lo que hace es preservar (...) todas esas imágenes (...) Esa propaganda del límpido no sé qué. Entonces, ese racismo en el cine, en las novelas, los roles, por ejemplo: esa mujer que hizo de la costeña y el cachaco, ella dijo, ¡nunca había roles para mí, todos eran de limpiadora!, ella rehusaba todos esos roles hasta que le sacaron un rol para ella. Entonces, toda esa parte del rol, del modelo, de la imagen que tanto las comunidades afrodescendientes, como los otros ven y ayudan a perpetuar. (Mujer 02, NES Universidad, Sesión 12, 23 de abril de 2016)

Sumado a esto, se evidencian imaginarios relacionados con la pereza, la irresponsabilidad, el abandono y la pobreza, dejando a los afrodescendientes

7. Luego con los documentos CONPES 2909 de 1997 y CONPES 3169 de 2002 se reconoce la presencia de la población afro en todo el territorio nacional.

8. Para ampliar ver (Mesa Nacional de Organizaciones Afrocolombianas 2012).

9. Tal es el caso de Lozano 2010; Morales 2012; Hellebrandová 2014; Meneses 2014. 
relegados a percepciones vinculadas con cuestiones de clase (Lamus 156), que desconocen las situaciones en las que se encuentran las mujeres afrodescendientes, tal como se muestra en el siguiente argumento:

Y llego acá, a la universidad (...) al espacio de los profesores y oigo una compañera mía que dice: no, es que yo tengo que buscar una persona para cuidar a mi niño y llega una mujer negra, pero entonces mi marido dice que las negras huelen a feo. Yo escuché ese comentario y mira, yo no (...) ¿cómo así que las negras huelen a feo? ¿Cómo es esto? Mira, me dio tanta rabia, porque indudablemente dije aquí hay discriminación, hay racismo (...) pero ¿por qué?, entonces yo misma empecé la discusión y todo eso (...) yo tenía tanta rabia que me fui para donde una compañera llorando. (Mujer 02, NES Universidad, Sesión 12, 23 de abril de 2016)

Las maneras de establecer las relaciones sociales a partir de la racialización y las implicaciones que ésta posee, dejan como efectos la trasformación del racismo y la prolongación de estereotipos racializados; pero también abren la posibilidad para reflexionar sobre los mecanismos de reacción por parte de las mujeres afrodescendientes, como es el caso del mestizaje y blanqueamiento.

En el marco del proceso de racialización surge la ideología racial del mestizaje que conserva estructuras jerarquizadas de la raza, donde la supremacía blanca se mantiene y establece patrones de lo apropiado, bueno y deseable en la sociedad colombiana. Al presentarse los valores blancos como ideales en las dinámicas sociales, se evidencian reacciones de mujeres afrodescendientes para acercarse a lo que estos preceptos plantean. A esto se le conoce como blanquedad o blanqueamiento (whiteness), entendido como «un proceso continuo e inacabado que dirige los cuerpos en direcciones específicas, determinando la manera como 'ocupan' el espacio». (Ahmed 2007, 155; en Hellebrandová 88)

El mestizaje y el blanqueamiento se presentan como acciones de respuesta y acomodación por parte de la comunidad afrodescendiente frente a dinámicas de jerarquización racial, que pueden estar representadas en negación de las raíces africanas; cambios físicos como cirugías estéticas para modificar rasgos, o estéticos como alisar o cambiar el patrón del cabello; cambios en la forma de hablar y expresarse; búsqueda de vinculación emocional exclusiva con personas no afrodescendientes; entre otros. Ahora bien, vale aclarar que estas tendencias no siempre son realizadas de forma intencional, de hecho, el blanqueamiento se instaura de forma sutil en los diferentes modos de subjetivación.

Debido a la maleabilidad y conveniencia tanto del mestizaje como del blanqueamiento, estas dinámicas resultan en procesos que dan cuenta de endorracismo, es decir, transformaciones en los que de manera inconsciente las mujeres empiezan a interiorizar y naturalizar las diferentes manifestaciones del racismo dejando muchas veces de ser ellas mismas, para querer ser otras: 
Porque yo he tenido, a diferencia de ustedes, yo he estado más blanqueada, he estado más con población blanca. Hay una diferencia, mi contacto con gentes, con comunidades negras ha sido muchísimo menor. Entonces, yo sí creo a veces, que uno encuentra personas negras totalmente blanqueadas, en sus actitudes, discriminando contra la misma gente negra. (Mujer 02, NES Universidad, Sesión 12, 23 de abril de 2016)

Con lo anterior, se entiende que el blanqueamiento posee un poder estratégico para «disimular» el racismo, convirtiéndose así en un artefacto que reproduce estereotipos racistas dentro de las mujeres afrodescendientes como grupo étnico racializado.

Ahora bien, hasta este momento el documento presenta algunos elementos relacionados con el racismo, que no son vinculados directamente con los espacios de Educación Superior, pero revelan matices que permean este contexto, pasando a otros niveles y estableciendo otro tipo de relaciones con categorías como el género.

\subsection{Discriminación de género: en relación persistente con la raza}

Las percepciones de discriminación, relacionadas con el género ${ }^{10}$, se cruzan con dos aspectos diferentes. El primero de ellos corresponde a la feminización o masculinización de las carreras universitarias, aspecto que ha ido cambiando paulatinamente con el tiempo, sin embargo en las historias académicas de las mujeres participantes, fue un elemento determinante, tal como se puede apreciar en el siguiente planteamiento:

En otros espacios universitarios, nos ha tocado dividir, sí, en una forma sutil o en una forma franca, en una forma abierta ¿no?, y es más en mi experiencia en los tiempos que me tocó estudiar. La verdad es que cuando estuve en Cali, no había mucho enfrentamiento, digamos frente a lo que era, ser mujer, por el contrario, era más que todo un enfrentamiento frente a mi identidad de género, porque (...) si las mujeres tenemos que estudiar trabajo social o enfermería, pero los hombres no podían estudiar trabajo social. (Mujer 01, NES Universidad, Sesión 12, 23 de abril de 2016)

Como segundo elemento, se vincula la segregación experimentada al interior de las aulas de clase en el rol de estudiantes, al sentir una profunda invisibilización

10. La categoría género hace referencia a un sistema impuesto en la colonización, a través del cual se establecen los roles y los comportamientos de los sujetos de acuerdo a su sexo. En esta perspectiva, los hombres y las mujeres se convierten en los dos grupos de referencia, estableciendo que son «diferentes pero complementados y se asume como grupos homogéneos y descontextualizados» (Curiel 2011, 10). En este sentido, los comportamientos son asignados y asumidos de acuerdo a las características físicas y biológicas de las personas (Mignolo 41). 
o exclusión, demeritando sus capacidades y habilidades cognitivas. Esta situación puede estar asociada a la conciencia colectiva oculta acerca de las desventajas acumulativas que históricamente han hecho parte de los procesos de la comunidad afrodescendiente. A continuación, se presenta una de las percepciones al respecto:

Claro, cuando llego a Bogotá y me enfrento a que el aula, en el aula por ejemplo soy la única mujer afro y me distinguía, verdad, (risas) desde luego, o me ignoraban (...) Es decir, si alzaba la mano porque yo conocía ese tema, entonces, lo miran a uno ¿será que sí?, o mejor pasan de largo la vista. (Mujer 01, NES Universidad, Sesión 12, 23 de abril de 2016)

Así pues, al chocar con este tipo de dinámicas en los espacios de formación, las mujeres encuentran como alternativa realizar un mayor sacrificio para demostrar sus capacidades, además de mejorar su estatus académico. Este aspecto tiene un gran impacto en las representaciones que se gestan sobre educación por parte de las generaciones venideras, al reconocer las desigualdades en oportunidades y el poco impacto que tiene para ellos adelantar procesos académicos que les permitan mejorar su calidad de vida, pues se crea una imagen en la que las mujeres afrodescendientes en comparación con las mujeres no afro, deben hacer doble esfuerzo para alcanzar las metas que se pretenden (Morales 75).

Bueno, la discriminación, yo sí quisiera opinar sobre cómo se siente, es bajarle y quitarle uno como mujeres afro, siempre la reserva de que ¿esta sí sabrá?, eh, o digamos, o hay que ponerle las cosas bien bajitas para que pueda entenderlas, entonces explican tres veces, mira, ven te explico, ven te ayudo. (Mujer 01, NES Universidad, Sesión 12, 23 de abril de 2016)

A veces con los mismos compañeros de espacio, suele pasar, también uno tiene que demostrar que es bueno para estar al nivel del otro compañero, que tiene igual una maestría como usted, que está en lo mismo que usted y sabe lo mismo (...) pero te miran como la profesora negrita, porque suele pasar como que ... ¿quién es la profesora?, uno se para y entonces, ¿esa es la profesora?, vamos a ver qué nos va a decir o con qué va a salir. (Mujer 03, NES Universidad, Sesión 12, 23 de abril de 2016)

Los relatos anteriores ponen en evidencia cómo estas mujeres afrodescendientes tienen una presión constante por cumplir con los requerimientos esperados o demostrar las capacidades que las hicieron estar en los lugares donde se encuentran; generando en ellas sensaciones de evaluación y contraste entre su etnicidad y sus capacidades cognitivas. Sin embargo, es posible que parte de esta percepción se deba a elementos que han afectado su estima como mujer profesional, este aspecto está mediado por los estereotipos racializados que tiene que romper permanentemente, para sentirse valoradas y respetadas dentro de los contextos académicos en Bogotá. 
Desde esta perspectiva, se establece aquí un fuerte vínculo con los procesos de discriminación pre-mercado y mercado, asociados a desventajas acumulativas que se encuentran ligadas a la categoría étnico-racial. La discriminación pre-mercado hace referencia a «las desigualdades previas: menor cobertura y calidad de la educación y servicios; brechas en el acceso a la educación universitaria; segregación espacial -ubicación en barrios y poblados rurales, etc.» (Lamus 157).

La discriminación de mercado consiste en un «trato diferencial para personas preparadas y aptas, pero discriminadas por características observables como raza, etnia y género» (Ver 157). Este último tipo de discriminación consiste en que mujeres con las competencias para desempeñarse en un empleo sean discriminadas de alguna forma, por ejemplo, recibiendo un pago inferior al de otras personas que están realizando la misma actividad:

En un momento determinado yo me enteré de que a estas personas les estaban pagando más que a mí. Yo dije ipero un momento, el trabajo es el mismo!, ¿por qué yo recibo menos dinero?, entonces yo hice toda una reclamación a mis jefes al respecto, les dije que me parecía el colmo, que era un abuso, que era discriminación, siendo el mismo trabajo ¿por qué razón yo debía tener menos, cuando yo cumplía con todos los requisitos?, entonces en la reclamación dicen que: no sé qué paso... en todo caso, de todas maneras, yo hice mi reclamo y fui consciente de esa discriminación, fue tan molesto. (Mujer 02, NES Universidad, Sesión 12, 23 de abril de 2016)

Con lo anterior, se pone en evidencia una percepción de discriminación a partir de la diferencia en remuneración económica, pero no es claro si ésta se da por su condición de género o raza dentro del contexto en el cual se encuentra. Este elemento se relaciona directamente con otros que ya se han planteado a lo largo del documento, referidos a la interseccionalidad, es decir al cruce y relación constante entre varias categorías, que resultan difíciles de separar, generando experiencias complejas situadas en momentos y lugares particulares.

De acuerdo con lo desarrollado hasta este punto, se entiende que la discriminación negativa tiene diferentes facetas que la hacen protagonista en las vidas de las mujeres afrodescendientes participantes del NES. Sin embargo, es pertinente rescatar un elemento importante en la evolución que ha tenido el tema, referido a la discriminación positiva, como alternativa para mejorar la calidad de vida de las personas que históricamente se han encontrado en desventaja con respecto a otros grupos poblacionales. 


\section{DISCRIMINACIÓN POSITIVA: MÁS QUE UNA APUESTA POLÍTICA DE ACCIONES AFIRMATIVAS}

La discriminación positiva es una apuesta que surge en las ciencias sociales para revertir de alguna forma los procesos de discriminación negativa realizados históricamente con grupos o poblaciones marginalizadas (Restrepo 2013, 8). En la discriminación positiva se retoman las mismas características o marcadores de diferencia susceptibles a la diferenciación y la exclusión, pero en este caso se convierten en elementos que posibilitan la inclusión y el reconocimiento. En Colombia, especialmente en Bogotá, la discriminación positiva para comunidades afrodescendientes se ha visto anclada a políticas de acción afirmativa ${ }^{11}$, considerándolas como:

Un conjunto de Políticas, directrices, programas, proyectos y medidas administrativas, que responden a los derechos y peticiones de la población afrodescendiente del Distrito, para garantizarles condiciones apropiadas de atención y acceso a sus servicios y programas, que no se fundamentan exclusivamente en su condición de población vulnerable, sino que responden a acciones basadas en criterios de razonabilidad histórica dirigidos a garantizar el acceso a mejores oportunidades de desarrollo económico, social y cultural, así como a promover su inclusión, mediante la definición de componentes de atención específica en su beneficio, que integren recursos, procedimientos, indicadores, cupos y porcentajes mínimos de participación, para el mejoramiento de la calidad de vida con fundamento en criterios concertados de aplicación gradual y complementaria. (Alcaldía Mayor de Bogotá 24)

De lo anterior, es importante aclarar que la construcción de esta política distrital fue realizada por la Alcaldía Mayor de Bogotá en cabeza de Luis Eduardo Garzón en el año 2006, con el acompañamiento y asesoría de grupos académicos y organizaciones de comunidades negras, protagonistas en la consolidación de estrategias para el reconocimiento diferencial de la comunidad afrodescendiente.

Este elemento resulta importante en la comprensión del enfoque de la discriminación positiva, pues no es el resultado de una decisión unilateral o exclusiva de las administraciones. Por el contrario, es una apuesta que posibilita dar voz y reconocimiento a la comunidad afectada, con el fin de promover una justicia reparativa o compensatoria (Martínez 211). Esto quiere decir, que existe una conciencia compartida de los problemas históricos de la comunidad

11. Las políticas de acción afirmativa no se establecen exclusivamente para afrodescendientes, también abarca diferentes sectores sociales: mujeres, LGBTI, en situación de discapacidad, grupos étnicos (indígenas, comunidad room) y en situación de vulnerabilidad (desplazados por la violencia). 
afro y la importancia de su participación en búsqueda de soluciones, de tal manera que se emplean estrategias «reestructuradoras que buscan la igualdad efectiva, la participación y la voz democrática sustantiva» (Forester 334). Ahora bien, vale aclarar que no es voluntad espontánea de la administración adelantar este tipo de normativas, por el contrario, es el producto de fuertes presiones por parte de la comunidad afrodescendiente, convirtiéndose este último elemento en «una de las condiciones fundamentales para la existencia de una política» (Hinestroza 13). Tal como lo pone en evidencia el discurso de una de las mujeres:

Hay unos que dicen que, ay que mira la discriminación positiva, cuando se hacen las políticas públicas, cierto y dicen entones, hay dos clases de discriminación, la discriminación positiva porque por eso es que tenemos unas leyes, hay una ley 70, existen unos artículos que predominan la atención a la población, conseguimos un fondo de becas en el Instituto de Crédito para la Educación de los Afrodescendientes, en fin. Entonces dicen: ipero esa es una discriminación positiva!, no, esos son derechos, sí, que estamos reclamando como parte de la reparación y así era que se estaba viendo dentro del artículo transitorio 55. Pero como existen unos poderes, van cambiando la cosa y lo hace siempre ver como si fueran dádivas, sí, y nosotras a veces nos comemos este cuentico de las dádivas. (Mujer 01, NES Universidad, Sesión 12, 23 de abril de 2016)

Al considerar el planteamiento anterior, es claro que las políticas de acciones afirmativas son un interesante vehículo para equiparar las oportunidades entre distintos grupos y colectividades. Pero no pueden ser éstas las únicas estrategias que permitan garantizar los derechos que como colombianas poseen. En otras palabras, la voluntad que se desprende de las acciones afirmativas es un valor agregado que debería generar mayores oportunidades en el acceso y la participación en espacios de Educación Superior, y no ser considerado como la única alternativa para acceder a un derecho que por obligación debe ser reconocido.

Después de todo, este tipo de lineamientos diferenciales en Bogotá emplean mecanismos de sistema de cuotas y trato preferencial para las mujeres afrodescendientes, que en muchas ocasiones quedan a la merced de la voluntad administrativa del momento. En este sentido, las acciones afirmativas son prácticas que pueden ser empleadas o no, en distintos escenarios y de maneras diversas y no siempre están amparadas por las políticas que las obligan. Pero, es necesario resaltar que la movilización y la organización de las comunidades afro generan nuevas posibilidades para que la aplicación de éstas sea efectiva:

Un día el secretario general de la universidad pasó y nos vio sentados en un espacio que se llama el malecón, nos ve, era todos los sábados y el compromiso era que teníamos que ir, esa no era una cosa de que un día iba u otro no, nada, 
ese era el compromiso. Él pasó, fue y nos preguntó, yo veo que los estudiantes negros, dijo él, los veo aquí sentados todos los sábados, ¿ustedes qué es lo que hacen?, entonces le contamos qué era lo que estábamos haciendo, por qué nos reunimos, entonces al señor le pareció genial la idea, y dijo: miren, yo puedo tomar una decisión aquí y la voy a tomar ahora. Todos los estudiantes que pertenecen a Afrocentral de ahora en adelante tienen el 30\% de descuento en su matrícula, pero tiene que demostrarme además que hacen un trabajo con el grupo, pero además el nivel académico también tiene que ser bueno. Es decir, que tienen un descuento en el porcentaje de la matricula porque está en Afrocentral y ya, tienen que demostrar que tienen trabajo con la comunidad y que tienen buenas calificaciones. (Mujer 03, NES Universidad, Sesión 12, 23 de abril de 2016)

De lo anterior, se infiere que la discriminación positiva orientada hacia políticas de acción afirmativa son apuestas para justificar las acciones reparativas para las comunidades afrodescendientes, las cuales parecieran no tener un nivel de obligatoriedad en las diferentes instituciones de la capital colombiana, por el contrario, quedan a la espera de la presión y la lucha de las comunidades discretamente beneficiadas. En este sentido, sería interesante ver cómo el cumplimiento de este tipo de políticas se hace visible en diferentes escenarios, pues la situación que se evidencia en Bogotá, es de un reducido porcentaje de mujeres afrodescendientes en las universidades públicas y privadas; además de una baja representación de maestras, investigadoras y directivas afrodescendientes en espacios de formación y liderazgo.

\section{IDEAS PARA CERRAR LA REFLEXIÓN}

A pesar de la promesa neoliberal donde la educación se convierte en la apuesta más segura para mejorar la calidad de vida, las mujeres afrodescendientes participantes perciben dicha propuesta como un privilegio que pocas pueden obtener y no como el derecho del cual deberían gozar todas y todos los colombianos. Aspecto, entre muchos otros, evidenciado por ellas en la baja representatividad de la población afrodescendiente en los espacios de Educación Superior del país.

El escrito plantea que la discriminación tiene dos connotaciones: una positiva y una negativa, sin embargo, es evidente que las mujeres afrodescendientes participantes la asumen fuertemente desde la segunda perspectiva. Es en este aspecto que la discriminación racial se vincula como el elemento de mayor peso en las dinámicas experimentadas por dichas mujeres. Situación que está anclada a procesos culturales de larga data, referidos específicamente a la invisibilización e inferiorización de las y los sujetos con características fenotípicas ligadas a la ascendencia africana esclavizada. Por tanto, tiende a estar supeditada a un cúmulo de desventajas acumulativas, que han sido parte tanto de 
sus comunidades como de sus historias de vida, marcadas principalmente por la racialización de sus potencialidades y capacidades.

Ahora bien, en la medida que el multiculturalismo como estrategia de armonización cultural se instala en las prácticas institucionales y en las relaciones sociales cotidianas, el racismo se alberga en distintos escenarios, se disfraza, se manifiesta a través de nuevas formas y pareciera inexistente. Sin embargo, sus efectos son impactantes y dejan como únicos testigos a las mujeres que los sufren. Ante esta situación las afrodescendientes no quedan impávidas, por el contrario, asumen actitudes que les permitan entrar en el juego de la dinámica multicultural, a través del mestizaje y el blanqueamiento, convirtiéndose este proceso en una maquinaria de doble filo que, por un lado, les permite acomodarse a las prácticas establecidas por la cultura hegemónica, pero que, por otro lado, terminan naturalizando y reproduciendo aquellas prácticas que las aqueja.

Esta permeabilización racializada se encuentra latente en los contextos académicos en los que ellas se desenvuelven. Aunque las prácticas con matices racistas son encubiertas, tienden a filtrarse a partir de relaciones constantes con los roles de género y las habilidades cognitivas que ellas tienen para el desarrollo de las actividades que emprenden. En esta perspectiva, los efectos se evidencian en la evaluación constante que perciben por parte de pares académicos y estudiantes, en la que parecieran estar sujetas a demostrar permanentemente las capacidades que les han permitido ubicarse en el rol de estudiantes o docentes, en los diferentes espacios de educación superior.

Ahora bien, las acciones reparadoras, pensadas desde la discriminación positiva, son un elemento importante en la dinámica de visibilización e inclusión de las mujeres afrodescendientes en las distintas instituciones. Empero y de acuerdo con las percepciones de las participantes, es claro que sus avances han sido tímidos y conservadores, aspecto que se evidencia en su limitado desarrollo. Además, pareciera que el derecho a la educación para este colectivo debe estar blindado por políticas de acciones afirmativas dependientes de la movilización de la comunidad afrodescendiente que la requiere.

A manera de cierre, resulta interesante ver cómo este tipo de exploraciones permiten descifrar y comprender las dinámicas de discriminación negativa y positiva en los espacios de educación superior desde las percepciones de mujeres afrodescendientes. Empero, también es claro que es una apuesta compleja que debe ser ampliada en posteriores oportunidades, pues los análisis que alrededor del tema se desarrollan, corresponden a entramados de distintas categorías que requieren de: macro comprensiones ancladas a elementos sociales, culturales e históricos de los contextos en los que cada una de las mujeres hace parte; comprensiones micro, es decir, desde las experiencias académicas 
particulares y múltiples de cada una de las mujeres afrodescendientes; y comprensiones meso, que retomen tanto las convergencias como las divergencias suscitadas entre lo macro y lo micro.

\section{REFERENCIAS BIBLIOGRÁFICAS}

Alcaldía Mayor de Bogotá. Política pública distrital y plan integral de acciones afirmativas para el reconocimiento de la diversidad cultural y la garantía de los derechos de los afrodescendientes. Bogotá, 2006.

Castellanos, Gabriela. «La categoría de género y la educación superior: Una mirada a América latina desde Colombia». La Manzana de la Discordia 6 (2011): 25-40.

Crenshaw, Kimberlé. «Demarginalizing the Intersection of Race and Sex: A Black Feminist Critique of Antidiscrimination Doctrine, Feminist Theory and Antiracist Politics». University of Chicago Forum (1989): 139-167.

Curiel, Ochy. «Crítica poscolonial desde las prácticas políticas del feminismo antirracista». Nómadas 26 (2007): 92-101.

Curiel, Ochy. Género, raza y sexualidad. Debates contemporáneos. s.f. <www.urosario.edu.co> urosario-files>, consultado el 30-03-2016.

Forester, John. «La racionalidad limitada y la política de salir del paso». La hechura de las políticas. Ed. Luis Aguilar Villanueva. México: Miguel Ángel Porrúa Librero-Editor, 1992, 315-340.

García, Andrés. «Políticas étnicas afrocolombianas en educación superior: dinámicas identitarias en la Universidad de Antioquia». Afrorreparaciones: Memorias de la esclavitud y justicia reparativa para negros, afrocolombianos y raizales. Bogotá: Ed. Universidad Nacional de Colombia, 2007, 661-689.

García, Bárbara y Javier Guerrero. Núcleos de educación social - NES. Bogotá: Universidad Distrital Francisco José de Caldas, 2012.

Hellebrandová, Klára. «Escapando a los estereotipos (sexuales) racializados: el caso de las personas afrodescendientes de clase media en Bogotá». Revista de Estudios Sociales 49 (2014): 87-100.

Hinestroza, Simón. «Impacto de la política pública de las acciones afirmativas para la población afrocolombiana en Bogotá D.C. En el marco de los derechos étnicos». Corporación Internacional para el desarrollo Educativo 16 (2015): 10-29.

La Barbera, María. Video El Enfoque de la Interseccionalidad: Evolución desafíos y perspectivas. «Espacios desiguales, fronteras invisibles». Ciclo de conferencias sobre interseccionalidad, inclusión social y equidad. En el marco del proyecto MISEAL. México: Universidad Autónoma de México. 2014. < https://www. youtube.com/watch?v=rwTe96gUqYQ>, consultado el 16-03-2016.

Lamus, Doris. «Negras, palenqueras y afrocartageneras. Construyendo un lugar contra la exclusión y la discriminación». Reflexión Política 23 (2010): 152-166. 
Lozano, Betty. «El feminismo no puede ser uno porque las mujeres somos diversas. Aportes a un feminismo negro decolonial desde la experiencia de las mujeres negras del Pacífico colombiano». La Manzana de la Discordia 2 (2010): 7-24.

Martínez, Rocío. «Acciones afirmativas para población afrocolombiana en Bogotá: historia de la formulación de una política pública». Estudios afrocolombianos hoy: aportes a un campo transdisciplinario. Ed. Eduardo Restrepo. Popayán: Editorial Universidad del Cauca, 2013, 207-226.

Meneses, Yeison. «Representaciones sociales sobre etnoeducación y cátedra de estudios afrocolombianos en la formación del profesorado». Enunciación 18 (2013): 45-63.

Meneses, Yeison. «Representaciones sociales sobre afrodescendientes: la aventura cultural, la violencia sexual-género y luchas multidimensionales». Memoria y sociedad 37 (2014): 76-92.

Mercado, Álvaro. «Políticas de acceso de la población vulnerable a la educación superior, una visión desde la experiencia de la Universidad del Magdalena». Clío América 15 (2014): 8-21.

Mesa Nacional de Organizaciones Afrocolombianas. Informe de la situación en derechos humanos de las mujeres afrocolombianas. Colombia: Fondo para la Sociedad Civil Colombiana, 2013.

Mignolo, Walter. La idea de América Latina. La herida colonial y la opción decolonial. Barcelona: Gedisa, 2007.

Morales, Erica. «Black Boundary Lines: Race, Class and Gender among Black Undergraduate Students». UCLA Electronic Theses and Dissertations. 2012. $<$ http://escholarship.org/uc/item/6jr3v45n>, consultado el 20-09-2015.

Munévar, Dora e Imelda Arana. «Mujeres enseñando e investigando en la Universidad Nacional de Colombia». Revista Interamericana de Estudios Feministas 1 (2011): 6-22.

Restrepo, Eduardo. «Acción afirmativa y afrodescendientes en Colombia». Estudios afrocolombianos hoy: aportes a un campo transdisciplinario. Ed. Eduardo Restrepo. Popayán: Universidad del Cauca, 2013, 249-265.

Restrepo, Eduardo. Racismo y Discriminación. s.f. <http://www.ram-wan.net/restrepo/documentos/racismo.pdf>, consultado el 7-02-2016.

Sesión NES No 12. Escenario Universidad. Mujeres Afrodescendientes. Bogotá. 23 de abril de 2016.

Quijano, Aníbal. Colonialidad del poder y clasificación social. Buenos Aires: CLACSO, 2014.

Viáfara, Carlos y Nini Serna. «Desigualdad de oportunidades educativas en la población de 15 a 29 años en Brasil y Colombia, según autoclasificación étnico -racial». Sociedad y Economía 29 (2015): 151-174. 


\title{
LA AUSENCIA DE CORRESPONSABILIDAD, FRENO PARA EL DESARROLLO DE LA CARRERA LABORAL FEMENINA EN LA ACADEMIA
}

\author{
THE LACK OF JOINT RESPONSIBILITY, BRAKE FOR THE \\ DEVELOPMENT OF THE FEMALE CAREER IN ACADEMIA
}

\author{
Estrella MONTES LÓPEZ \\ Universidad de Salamanca \\ estrellamontes@usal.es \\ orcid.org/0000-0002-8226-7504
}

\section{Resumen}

Este artículo presenta parte de los resultados de una investigación sobre el desarrollo de la carrera profesional en la Universidad abordada desde la perspectiva de género. Concretamente, se centra en la relación entre el trabajo académico y la vida familiar a través del análisis de entrevistas en profundidad realizadas a profesorado universitario en una Universidad pública española. Los resultados de investigación muestran, por un lado, la difícil conciliación de la vida laboral y familiar de quienes trabajan en la Academia y, por otro, los discursos de las personas entrevistadas en torno a la ausencia de corresponsabilidad en los hogares como una de las causas de la desigual posición de la mujer en la Universidad.

Palabras clave: Universidad, carrera académica, género, conciliación, corresponsabilidad.

\begin{abstract}
This article presents part of the results of a research on the development of the career in the university. Specifically, it focuses on the relationship between academic work and family life through the analysis of in-depth interviews conducted to academics in a Spanish public university. On the one hand, the results of the research show the difficult work-life balance in academia. On the other hand, they show the discourse of the people interviewed about the lack of joint responsibility in couples as one of the causes of the unequal position of women in university.
\end{abstract}


Keywords: university, academic career, gender, working-life balance, joint responsibility 


\section{INTRODUCCIÓN}

Este artículo es parte de una investigación más amplia sobre el desarrollo de la carrera profesional en la Universidad, abordada desde la perspectiva de género, en la que se desarrollaron entrevistas en profundidad a profesorado universitario para conocer las explicaciones que este aporta en relación a la desigual posición de la mujer. Actualmente, y pese a que las mujeres han representado alrededor del $40 \%$ del profesorado universitario en los últimos años, tienen una desigual presencia en las diferentes categorías laborales. Así, a medida que aumenta la posición en la escalera académica, disminuye la presencia de mujer. La media nacional de mujeres catedráticas de Universidad en las universidades públicas españolas en el curso 2015-2016 era tan solo del 20,88\% (según los últimos datos actualizados del Ministerio de Educación, Cultura y Deporte 2017). De igual modo, la mujer está desigualmente representada en los principales cargos de gestión académica, esto es, como rectoras, como decanas y como directoras de departamento (Tomàs-Folch y Guillamón).

De manera general, las explicaciones aportadas por los participantes en la investigación pueden agruparse en tres grandes bloques: aquellas que defienden que las causas de tal desigualdad recaen en las características de las propias mujeres; las que la explican como resultado de factores relacionados con la propia organización, como la estructura de la carrera, los procesos de reclutamiento y selección en la Universidad o la importancia de las relaciones personales; y las que se centran en poner el foco de atención en un nivel mucho más amplio, el nivel institucional o social, indicando que el problema está en la estructura social y en cómo esta afecta al trabajo. Estas últimas explicaciones son las que se exponen en este artículo. Así, los objetivos que se persiguen son, en primer lugar, visibilizar los problemas de conciliación de la esfera familiar con la laboral que surgen en la Universidad, especialmente en el caso de las mujeres, ya que son ellas las continúan asumiendo principalmente las responsabilidades familiares; y en segundo término, mostrar cómo esta situación de ausencia de corresponsabilidad en los hogares acarrea efectos en la carrera laboral de las mujeres, limitando su desarrollo. 
Este artículo se divide en cinco partes. En primer lugar se expone, con cierta perspectiva histórica, el diferente empleo del tiempo que realizan hombres y mujeres. En segundo término se ahonda en la literatura sobre la división sexual del trabajo doméstico para conocer las consecuencias que esta tiene en las mujeres. En un tercer momento se explica brevemente la metodología de investigación, para posteriormente exponer los resultados de investigación, estructurados en tres grandes bloques, según se refieran a la conciliación de los tiempos de trabajo en general, a la difícil conciliación familiar y laboral en la carrera académica o a la ausencia de corresponsabilidad como causa de la desigual promoción de la mujer en la Universidad. Por último, se exponen las conclusiones y reflexiones que estos hallazgos arrojan.

\section{EL DIFERENTE USO DEL TIEMPO DE HOMBRES Y MUJERES}

El tiempo es una de las dimensiones clave de la organización de la vida humana, y su importancia yace de que «frente a la inmensidad del tiempo posible, el tiempo humano es parcial, acotado» (Durán 1986, 13). Sin embargo, no solo es limitado y escaso, y con ello, de importante valor, sino que además es construido. La construcción personal del tiempo varía en función de la posición que ocupa cada sujeto en la estructura familiar, y este empleo desigual del tiempo genera distintas consecuencias en las diferentes esferas de la vida, esto es, a nivel personal, familiar y laboral. Como señala Durán (2010), el tiempo que dedicamos a dormir nos iguala, «homogeneiza las edades, las clases sociales y los géneros» (34), sin embargo, el tiempo que pasamos despiertos, es tiempo de diferencia.

Durán (1986) revelaba en su obra, hace más de treinta años, la situación de la mujer de la época, adscrita a la producción doméstica a través del cumplimiento de las normas sociales imperantes. Así, la mayor parte del tiempo de las mujeres no era intercambiado en el mercado laboral (como si lo era en el caso de los hombres), sino empleado en la producción de servicios domésticos para la unidad familiar. Su proyecto de vida era un proyecto colectivo que incluía a la familia y acababa en la vejez. Al contrario, la trayectoria laboral de los hombres se concebía como un proyecto a largo plazo, individualizado y ascendente hasta la jubilación.

Treinta y un años después de ese estudio, y tras los grandes cambios sociales acaecidos en España, cabría esperar que los usos del tiempo entre hombres y mujeres fueran muy diferentes en la actualidad. Sin embargo, los múltiples estudios sobre esta temática, y a pesar de la evolución en los usos del tiempo, han ido poniendo en evidencia el mantenimiento de diferencias en el empleo del tiempo entre hombres y mujeres (Ramos; Álvaro 1996a 1996b; Instituto 
de la Mujer 2007; Prieto, Ramos y Callejo; Durán 2010; Domínguez). Estudios recientes muestran que se ha producido una reducción de la desigualdad, pero que siguen existiendo grandes diferencias por sexo: las mujeres siguen empleando más del doble de tiempo que los hombres al trabajo reproductivo, mientras estos trabajaban fuera del hogar una hora y cuarto más y dedican alrededor de 50 minutos más al día que ellas a actividades de ocio. Así, y aunque la diferencia entre la carga global de trabajo (la suma del trabajo productivo y reproductivo) masculino y femenino ha disminuido en relación al pasado, la mujer continúa trabajando tres cuartos de hora más al día que el hombre (Instituto de la Mujer 2013), y disfrutando de casi una hora menos de ocio que él (Conde-Ruiz y Marra). Durán (2010) nos invita a calcular lo que supone el tiempo que la mujer trabaja más que el hombre al día a lo largo de la vida. El resultado equivale a varios años de trabajo que las mujeres realizan a mayores frente a los hombres. Pese a que esto puede considerarse una abultada especulación, bien merece nuestra reflexión, ya que una hora de tiempo, un día, no supone a priori mucho tiempo, sin embargo, su progresiva acumulación es una cuestión diferente.

\section{LA DIVISIÓN DEL TRABAJO DOMÉSTICO Y SUS CONSECUENCIAS PARA LAS MUJERES}

Carrasco considera que el principal conflicto del siglo XXI es el cuidado de la familia y del hogar, debido a que la masiva incorporación de la mujer al mercado laboral no ha ido de la mano de una similar vinculación de los hombres al ámbito reproductivo (Beck y Beck-Gernsheim; Carrasco; García; Tobío 2012; González y Jurado). Actualmente, sigue faltando democracia interna en la familia (Anguita, Alario y Ortiz) y sigue sorprendiendo que pese a que la mujer se haya incorporado al ámbito de lo público, su presencia en el espacio privado sea casi la misma que era en el pasado (Tobío 2012; González y Jurado).

El trabajo de cuidado sigue recayendo principalmente sobre la mujer, que es a quien tradicionalmente se ha socializado para desempeñarlo. Estudios como el desarrollado por el Instituto de la Juventud (2008), reflejan que en el seno de muchas familias se sigue favoreciendo la asunción de determinadas tareas del hogar, consideradas tradicionalmente como femeninas, por parte de niñas y adolescentes, en comparación con sus hermanos varones. El hecho de que el trabajo de cuidado siga recayendo sobre las mujeres genera que cuando estas se incorporan al mercado de trabajo, se produzca una superposición de sus nuevos y antiguos roles laborales, recayendo sobre ellas la responsabilidad de hacerlos compatibles. Así, la conciliación del trabajo productivo y reproductivo se hace a costa de las propias mujeres, asumiendo una mucho 
mayor carga de trabajo, un «doble turno» (Hochschild; Domínguez) o una «doble jornada laboral» (Tobío 2001; Donoso, Figuera y Rodríguez; González y Jurado). Esta «jornada múltiple», como también se refieren a ella Donoso, Figuera y Rodríguez (2011), implica no solo la suma del resto del jornadas, sino «una superposición de estas, con todas las problemáticas que conlleva» (190).

A nivel social, cuando hablamos de «trabajo», solemos entender el intercambio mercantil que se produce entre un empleador y un trabajador, retribuyendo el primero al segundo por su actividad laboral. La no remuneración del trabajo realizado en el seno del hogar genera, por un lado, que este permanezca invisible y, por otro, que se supedite al trabajo asalariado. Fruto de ello, este trabajo no solo no se valora, sino que no se reconoce la doble dedicación que realizan las mujeres (Varella; Tobío 2012) y el conflicto que viven como resultado de ella (Carrasco). Sin embargo, esta doble jornada laboral acarrea efectos sobre la salud (física, psicológica y social), sobre la relación con el trabajo y sobre la imagen social de las mujeres (Barberá y Ramos; Prieto, Ramos y Callejo).

La desigual situación de la que parte la mujer en la sociedad y en el mercado de trabajo en general, también tiene efectos cuando esta desarrolla su trabajo en la Academia. Las profesoras de Universidad, como hacen otras mujeres en otros espacios de trabajo, reproducen los principios y roles sociales aprendidos en la vida académica (Anguita, Alario y Ortiz), lo que genera formas diferenciadas de participación por sexo, pero también su exclusión de algunas etapas del proceso científico. Así, por ejemplo, las mujeres tienen una menor presencia en las redes informales, realizan menos investigaciones en coautoría, o son menos citadas que sus compañeros varones (Reskin; García de León y García de Cortázar). Concretamente, en el siguiente apartado se abordan las dificultades de conciliación de la vida personal y el trabajo en la Universidad, y el efecto que la ausencia de corresponsabilidad en los hogares tiene sobre la carrera académica de las mujeres.

\section{METODOLOGÍA}

Esta investigación, como se ha señalado, forma parte de un estudio más amplio sobre el desarrollo de la carrera académica y género en la Universidad. En él se recogieron y analizaron los testimonios de profesorado de una Universidad pública española para conocer, desde el punto de vista de los propios implicados, cómo se produce el desarrollo de la carrera profesional en la Universidad y las posibles diferencias por sexo. Así, se realizaron 43 entrevistas en profundidad a profesorado universitario teniendo en cuenta cuatro variables para diversificar los discursos de los participantes: su sexo (aplicándose tanto a hombres como a mujeres); las cargas familiares (tener o no tener hijos a cargo); 
la rama de conocimiento en la que desarrolla su trabajo, diferenciando de manera genérica entre Letras (áreas de Artes, Humanidades, Ciencias Sociales y Jurídicas) y Ciencias (áreas de Ciencias, Ciencias de la Salud, Arquitectura e Ingeniería); y el puesto de trabajo dentro de la jerarquía académica universitaria (siendo también entrevistadas personas que estaban ocupando cargos de gestión a nivel departamental, de facultad o en el equipo de gobierno).

El contenido de la entrevista versó acerca de la elección de la carrera académica, del desarrollo de la misma (atendiendo especialmente a las motivaciones, los momentos más relevantes y más gratificantes, y a las barreras y pasos más difíciles), de la relación entre la vida personal y la carrera profesional, y de las posibles diferencias en el trabajo y trayectorias laborales de hombres y mujeres en la Universidad.

Todas las entrevistas en profundidad fueron grabadas y transcritas fielmente. La duración media de las entrevistas fue de una hora y dieron lugar a más de 700 páginas de texto de análisis. El trabajo de sistematización, codificación, exploración, comparación y análisis de las entrevistas fue realizado con el apoyo del programa informático ATLAS.ti y se tomaron como unidades de análisis tanto palabras relevantes, como frases, párrafos o fragmentos del texto. A continuación se exponen los resultados de investigación, acompañados por citas textuales extraídas de los testimonios de las participantes con el objetivo de favorecer su comprensión.

\section{CONCILIACIÓN Y CORRESPONSABILIDAD EN LA UNIVERSIDAD}

En la exposición de resultados se abordan, en primer lugar, los diferentes modelos de relación que existen entre el trabajo productivo y reproductivo; en segundo término, las dificultades de conciliación de la vida familiar y laboral en el caso del trabajo en la Academia; y en último lugar, cómo parte de las personas entrevistadas entienden la ausencia de corresponsabilidad en los hogares como causa de la desigual promoción de la mujer en la Universidad.

\subsection{La conciliación de los tiempos de trabajo}

Como sostienen Prieto y colaboradores, «ningún tiempo social es inteligible en sí mismo, sino sólo en el marco de sus relaciones con los otros» (Prieto, Ramos y Callejo, 355), pero esto no significa que todos los tiempos tengan el mismo peso para las personas, al contrario, los tiempos de trabajo productivo y reproductivo se imponen sobre el resto de tiempos (Acker; Prieto, Ramos y Callejo). Además, aunque se realice una diferenciación entre uno y otro, ambos tienen características comunes: a) suponen esfuerzo y con ello desgaste 
físico-mental; b) requieren ser planificados y organizados; c) necesitan de un aprendizaje específico para su realización y d) conllevan un resultado social a través de la interacción social (Murillo; Lozares, López y Martí).

Lozares, López y Martí describen los diferentes modelos de relación que se producen entre estos dos tipos de trabajo. Uno de los modelos está caracterizado por una doble centralidad segmentada y desigualmente distribuida por género, donde las actividades, tiempos y espacios de trabajo productivo y reproductivo está dividida, correspondiendo el primero a los hombres y el segundo a las mujeres. Este es el modelo estricto de división sexual del trabajo. Otro de ellos, contrapuesto al anterior, estaría constituido por una centralidad negociada entre el hombre y la mujer, donde la carga total de trabajo, y las responsabilidades, tareas y tiempo que lleva anexas, estaría equilibradamente distribuida entre ambos.

Entre estos dos modelos polarizados existe otro intermedio, donde se han producido avances hacia la igualdad, pero aún continua siendo una asignatura pendiente, y en el que pueden diferenciarse dos situaciones. En el primer caso, el hombre tiene centralidad productiva pero no reproductiva, y la mujer tiene una débil centralidad productiva (trabaja fuera del hogar pero su responsabilidad, conocimientos y experiencia son débiles) y una alta centralidad reproductiva. En esta situación, la mujer tiene muchas dificultades para conseguir una centralidad productiva elevada, más allá de la mera realización del trabajo, lo que incidirá perpetuando el desarrollo del trabajo reproductivo sobre ella. En el segundo caso, ambos sujetos tienen la máxima centralidad productiva, pero el hombre tiene una centralidad insignificante en el trabajo reproductivo (realiza mínimas actividades, sin asumir la responsabilidad de la organización y con pocos conocimientos y experiencia), en comparación con la mujer, que tiene también la máxima centralidad reproductiva. Por tanto, esta asume una doble centralidad, que implica doble presencia, doble dedicación, y necesidad de equilibrar ambas esferas. Tanto el trabajo productivo como el reproductivo son «una parte central de su identidad» (Lozares, López y Martí 174), pero su asunción le causará tensiones de compatibilización de tiempos y espacios.

Un reciente estudio coordinado por González y Jurado sobre la corresponsabilidad en parejas jóvenes muestra que existen tres modelos de distribución del trabajo en las parejas, los cuales presentan muchas similitudes con los propuestos por Lozares y sus colaboradores. El primero de ellos, que responde al modelo tradicional, está compuesto por una madre que realiza la mayor parte del trabajo de cuidados mientras el padre cuida solo de manera ocasional debido a su centralidad en el trabajo remunerado. El segundo modelo está en 
transición entre los otros dos. En él, el varón ayuda en las tareas de cuidado pero sin asumir toda la responsabilidad sobre ellas, mientras la mujer asume una alta y doble carga de trabajo, y con ello, la dificultad de conciliar la vida familiar con la laboral. Esto a menudo la obliga a tener que anteponer el trabajo de cuidados al desarrollo profesional. Por último, el tercero es un modelo nuevo en el que ambos padres desarrollan trabajos fuera del hogar a la vez que son corresponsables en el cuidado de los hijos y en la toma de decisiones sobre él. Este estudio también muestra que a pesar de los valores de igualdad en la sociedad, el reparto desigual del trabajo sigue siendo elevado. En él se entrevista a parejas heterosexuales que comparten las tareas del hogar, antes y después de tener su primer hijo. Los autores eligieron el parto como punto de inflexión basándose en la literatura que afirma que la desigualdad en el reparto de tareas aumenta a partir de la llegada de los hijos. Así, y a pesar de que partían de una situación de igualdad, observan que no todas las parejas logran mantener esa distribución, lo que obliga a las mujeres a asumir la doble carga o a realizar renuncias laborales.

Respecto a las entrevistas realizadas para esta investigación, no cabe duda de que las mujeres entrevistadas revelan una alta centralidad productiva, y en el caso de las que tienen hijos, también tienen una alta centralidad reproductiva, aunque el grado de participación de sus parejas varíe desde una mínima a una amplia participación en el trabajo doméstico y de cuidados. Así, las mujeres entrevistadas con cargas familiares se sitúan en el modelo intermedio, asumiendo en la mayor parte de los casos el peso y dificultades de la conciliación laboral. Tan solo una mujer muestra una situación familiar bastante cercana a la corresponsabilidad en el hogar. Por su parte, los profesores varones entrevistados revelan modelos familiares muy dispares, evidenciando ejemplos de los tres tipos. Algunos varones tienen esposas que no trabajan fuera del hogar, y con ello, se ocupan del trabajo reproductivo, eximiéndolos de él. Otros participan en el hogar ayudando a sus parejas en el trabajo doméstico, aunque son ellas las que asumen mayor responsabilidad y dedicación a él. Ningún hombre con hijos manifiesta, ni se desgrana de su testimonio, ser corresponsable, ni siquiera en los casos de los varones más jóvenes.

\subsection{La difícil conciliación familiar y laboral en la carrera académica}

De manera casi unánime, las personas entrevistadas consideran que la conciliación personal y familiar con la carrera académica es muy complicada, principalmente por la necesidad de dedicar tiempo «privado» (el que queda fuera de la jornada laboral legalmente establecida) al trabajo para poder avanzar y promocionar en esta carrera. Usualmente, las personas entrevistadas usan 
metáforas como «carrera de fondo», «carrera de obstáculos» o «contrarreloj» para referirse a la carrera académica, indicando que hay que trabajar mucho y de manera continuada para superar las diferentes etapas con sus correspondientes requerimientos, que a pesar del duro trabajo se tarda mucho tiempo en acumular méritos, y, a su vez, que hay que tratar de conseguirlos en el menor tiempo posible para cumplir los plazos establecidos y competir con los demás. De este modo hacen hincapié en que es una carrera que no permite descanso. Al contrario, se necesita alargar la jornada laboral, trabajar los fines de semana y hasta en vacaciones. Señalan que la jornada laboral diaria apenas da para impartir clases, realizar tutorías, evaluar a los alumnos y cumplir con las múltiples burocracias, quedando muy poco tiempo para la investigación. Así, se requiere utilizar el tiempo que debería ser de ocio o descanso para continuar desarrollándola. Además, esta situación se ve agravada en el caso de quienes ocupan cargos de gestión. Teniendo presente todo ello, gran parte del profesorado entrevistado considera que otras muchas profesiones son más fáciles de conciliar con la vida privada que la Academia:

Hay profesiones y profesiones. A lo mejor una profesión mucho más ordenada, pues un bancario, que tiene sus horas, tiene sus tal, pues es mucho más fácil convivir con este tipo de personas ¿no? Donde sabes que tienes un horario y cuando terminas el horario de trabajo tú puedes disponer de todo tu tiempo, y tu cabeza la vacías porque te dedicas a hacer otras cosas (E.23. Hombre. Contratado doctor. Con hijos. Letras).

Algunas personas entrevistadas llegan a cuestionarse cómo el actual diseño de la carrera académica afecta a la estructura familiar del profesorado universitario. Por ejemplo, el siguiente entrevistado sostiene que las exigencias de dedicación a la carrera académica, que reducen el tiempo disponible haciéndolo muy escaso y dificultando la conciliación, afectan a la vida social del profesorado, llegando a generar rupturas en las relaciones de pareja, que se reduzca el número de hijos a tener (frente al que les gustaría) o incluso que la carrera profesional en la Universidad se considere incompatible con tener hijos:

Me gustaría hacer una encuesta, ¿cuántos profesores de la universidad española, en estos momentos, de menos de 45 años están casados? ¿Cuántos, en qué perfiles de edad? Segunda pregunta ¿cuántos de ellos tienen hijos y cuántos hijos tienen? [...] Yo creo que la situación en la universidad española es muy compleja y ha entrado en un círculo vicioso, un círculo vicioso motivado yo creo por el incrementar la calidad en los indicadores y por reducir los costes salariales (E.24. Hombre. Contratado doctor. Con hijos. Letras).

Hay quien incluso llega a considerar que la carrera universitaria es incompatible con la vida personal: «Claro, yo, la carrera universitaria, en la carrera 
del profesor, es absolutamente incompatible con la vida personal, pero vamos absolutamente» (E.19. Cargo de gestión. Titular de Universidad. Sin hijos. Letras). En unos casos u otros, y dentro de la difícil conciliación de la vida laboral y privada, las personas entrevistadas habitualmente destacan que hacer compatibles ambas esferas es mucho más fácil para aquellos que no tienen cargas familiares, ya que pueden disponer con mayor libertad de su tiempo para ponerlo a disposición de la carrera profesional. Esto ha sido evidenciado por diversos estudios: la carga de trabajo en el ámbito doméstico y de cuidados afecta al ámbito productivo (Gutek y Larwood; Tharenou; Martínez-Pérez y Osca). La siguiente entrevistada habla de su propio caso: «Ser Catedrática requiere dedicar muchísimo tiempo, bueno pues a cuestiones de investigación y también de docencia, y bueno, si una persona es soltera como yo, pues no tiene hijos, y esto hace que yo pueda dedicar más tiempo» (E. 11. Mujer. catedrática de Universidad. Sin hijos. Letras).

La mayor parte de las alusiones a las cargas familiares en esta investigación hacen referencia al cuidado de los hijos, sin embargo, en ocasiones también se destaca la dificultad de conciliación de quienes tienen personas mayores a su cargo. Así, la siguiente entrevistada, por ejemplo, cuenta cómo tuvo que renunciar al cargo gestor que estaba ocupando cuando sus padres enfermaron (era la única hija de una familia numerosa, donde los hijos varones rehusaron de hacerse cargo de sus padres): «Ha habido un momento en el que yo he tenido que cortar eso porque tenía mi madre muy enferma, y mi padre tiene Alzheimer. Pues claro, una situación familiar que era incompatible con mis otras dedicaciones, así que tuve, realmente lo tuve que dejar» (E.19. Cargo de gestión. Titular de Universidad. Sin hijos. Letras). Por su parte, la siguiente entrevistada no solo menciona los problemas de conciliación por cuidado de personas mayores, sino que a su vez, reconoce que esto afectó menos a su carrera de lo que otras cargas familiares pueden afectar a otras personas, porque ella asumió tal responsabilidad cuando ya había alcanzado la categoría de catedrática de Universidad (la entrevistada 20 plantea un situación similar, como se expone más adelante). De este modo, manifiesta también la difícil conciliación y el efecto que tiene en la carrera académica la asunción de responsabilidades familiares cuando la persona se encuentra en los primeros escalones. Particularmente, se refiere a las mujeres y a la maternidad:

Eso sí que condiciona un poco, el tener que conciliar la vida familiar con la vida profesional. A mí me pilla en un momento que tengo que conciliar mi vida familiar con mi vida profesional, en un momento en que digamos, yo ya, desde el punto de vista académica, yo ya soy catedrática. Digamos, he conseguido... Pero, claro, conseguir una, culminar una etapa, eso, no significa que después no tengas que, que seguir al pie del cañón. Entonces, sí que me he 
dado cuenta de la necesidad de esa conciliación merma un poco tus expectativas $i$ no? Por eso puedo entender que cuando esa necesidad se produce en las primeras etapas de tu vida académica, algunas etapas se tengan que retrasar (E.12. Catedrática de Universidad. Sin hijos. Ciencias).

El profesorado entrevistado no solo coincide en indicar que la conciliación de la vida privada y laboral es más complicada para aquellos que tienen cargas familiares, sino que además reconoce que es más duro para las mujeres, debido a que son ellas las que común y principalmente asumen las responsabilidades domésticas y de cuidado de los miembros de la familia. Además de la ausencia de corresponsabilidad en los hogares, la difícil conciliación de ambas esferas se hace aún más complicada por la inexistente conciencia universitaria de tener en cuenta la vida familiar, que hace que los tiempos de trabajo y familia choquen, cuando podría ser fácilmente evitable. Así lo refleja la entrevistada 14 , que expone que la fijación de reuniones en horarios que chocan con los de la familia es una práctica habitual, lo que genera que las mujeres se vean obligadas a abandonar estos encuentros antes de su finalización o a llamar para que alguien solucione la desatención que estar en dicha reunión ocasiona en la familia. Considera, además, que esto no sucede en el caso de los varones. En primer lugar, esta participante ejemplifica una situación de hace años, cuando era más joven:

Solían convocarnos por la tarde, a las seis, o una cosa así, no recuerdo porqué, pero sé que era la hora a la que nos solíamos reunir. Entonces hasta las ocho aguantábamos allí todo el mundo, pero a partir de las ocho pues ya empezaban las obligaciones familiares a llamar ¿no? Y sistemáticamente, um, nos íbamos, o se iban las mujeres. Los hombres no tenían prisa para irse a casa isabes? (E.14. Mujer. Cargo de gestión. Titular de Universidad. Con hijos. Ciencias)

En segundo lugar, cuenta una situación sucedida varios días antes, en la que son convocados por un hombre a una reunión a la hora de comer, que llegadas las tres de la tarde esta aún no ha finalizado, y que las únicas que muestran preocupación por esta situación, porque afecta al ámbito familiar, son las mujeres:

En la vida personal las mujeres seguimos teniendo otra carga, absolutamente distinta. [...] Era la hora de comer, y al Vicerrector de turno que nos había citado no le importaba tenernos a la tres de la tarde esperando, y los compañeros que estaban del grupo, no les importaba. Pero las que éramos mujeres, tenías que llamar a casa «Oye que no sé qué», porque la que tenía organizada la comida eras tú. Entonces, no veo diferencias aquí, pero sí que en nuestra vida personal las mujeres seguimos teniendo un papel diferente y lo notas en todas las compañeras, absolutamente (E.14. Mujer. Cargo de gestión. Titular de Universidad. Con hijos. Ciencias) 
Muchas de las personas entrevistadas consideran que la mujer sigue asumiendo en mayor medida que los hombres las responsabilidades familiares como resultado de la presión social (Ballarín; García). Así, el entrevistado 23 indica: «Socialmente está más presionada, no todas, pero están socialmente más presionadas a hacer más cosas en casa, dedicarse más a la familia o a los hijos» (E.23. Hombre. Contratado doctor. Con hijos. Letras), o el participante 42 señala:

Esto que hablábamos antes de la necesidad de compatibilizar y todo eso. Yo creo que sí, que esa presión sigue estando más en las mujeres que en los hombres y eso a lo mejor lo explica, que a la mujer se le exige que no descuide su vida personal, mientras que en el hombre está como que más aceptado, que es normal, bueno pues que tiene que dedicar tiempo a su carrera y medrar y tal (E.42. Hombre. Cargo de gestión. Contratado doctor. Sin hijos. Letras).

En esta cita el entrevistado también reconoce que al contrario de lo que ocurre con las mujeres, en el caso de los hombres sí está socialmente aceptado que dediquen el tiempo que requieran a su carrera profesional. Por su parte, los discursos de las mujeres también dejan ver la presión social que sufren en relación al cuidado de los hijos. Estas exponen cómo personas muy cercanas a ellas continuamente le hacen comentarios criticando el tiempo que quitan a los hijos para dedicar al trabajo. En ningún caso los testimonios de los varones revelan que dicha presión social recaiga sobre ellos.

Por último, mientras parte del profesorado entrevistado considera a los hombres que colaboran en las tareas domésticas y de cuidado como una excepción; otra parte cree que la dinámica existente en relación al trabajo reproductivo está cambiando en las generaciones más jóvenes a favor de la corresponsabilidad, aunque reconocen que esta aún está lejos de ser una realidad:

Pero hoy en día sí que se están implicando mucho más. Yo lo veo aquí en la facultad, que hay muchos chicos que van a llevar a sus hijos al colegio y todas estas cuestiones, y bueno, las cosas van cambiando paulatinamente también. Se preocupan pero todavía usan la palabra yo ayudo. Lo cual quiere decir que alguien que es el que necesita ser ayudado es el que lleva la responsabilidad (E.9. Mujer. Catedrática de Universidad. Con hijos. Letras).

En síntesis, todo lo expuesto muestra, por un lado, que la conciliación de la vida personal y familiar con el desarrollo de la carrera profesional en la Universidad es muy complicada; y por otro, que especialmente lo es para quienes tienen cargas familiares, sean hijos $u$ otras personas mayores o enfermas a su cargo, y dentro de ellos, para las mujeres, que son quienes principalmente asumen estas funciones. Además, los testimonios también revelan que sigue existiendo presión social hacia el mantenimiento de esta situación 
aunque parte del profesorado se encuentra esperanzado por el cambio hacia la corresponsabilidad.

\subsection{La ausencia de corresponsabilidad como causa de la desigual promoción de las mujeres en la Universidad}

Con base en lo reflejado en el epígrafe anterior, algunos participantes consideran que la causa de la desigual posición de la mujer en la Universidad tiene que ver con su situación familiar (estos argumentos también aparecen en otras investigaciones, como la realizada por García de León y García de Cortázar):

Yo creo que en la universidad no, otra cosa es en la vida familiar. En mi departamento en este momento hay bastantes más mujeres que hombres, como sucede en casi todos los departamentos que hay en la zona de [dos áreas de conocimiento afines], y aquí yo no veo ninguna diferencia. Ahora, que la situación familiar condicione determinados aspectos de la cuestión laboral pues a lo mejor sí. Quiero decir: una mujer si tiene hijos y su situación es ella la que por lo que sea, la que se tiene que hacer cargo de los hijos siempre, pues a lo mejor eso le retrasa determinadas aspiraciones que pueda tener o hay una época ahí que pues escribe menos, que publica menos, que tal. Pero no es cuestión de la universidad, yo creo que es cuestión de la vida familiar que puede influirle ¿no? de cómo se monte la vida familiar (E.35. Hombre. Cargo de gestión. Titular de universidad. Con hijos. Letras).

Los hombres que defienden este tipo de argumentos no se cuestionan por qué la situación es tal, sino que ponen el peso del problema en la mujer o en el sistema social (García de León y García de Cortázar). Al contrario, la siguiente entrevistada incide en que esto sucede porque hay un problema de ausencia de corresponsabilidad en los hogares por parte de los varones, lo que obliga a las mujeres a realizar una doble jornada laboral:

Claro que influye en general la carrera profesional y el ser mujer, porque fundamentalmente, porque para poder conseguir el mismo currículum que un hombre, tú tienes que trabajar el doble de horas, pero no por nada, sino simplemente porque no hay corresponsabilidad en las tareas del hogar. No lo digo yo, lo dice la ONU. Con lo cual yo para publicar ocho artículos tengo que dedicar mucho más tiempo que un hombre que no tiene responsabilidades familiares, por decirlo de alguna manera. Porque él tiene todo el tiempo para dedicarlo a su carrera profesional. La mujer no, la mujer tiene que organizar su casa, tiene que organizar la comida, tiene que cuidar de los niños, tiene que cuidar de los ancianos (E.15. Mujer. Cargo de gestión. Contratada doctora. Sin hijos. Letras).

Cabe mencionar que aunque la entrevistada 15 indica que ella tiene que dedicar más tiempo al trabajo, entendido como la suma del trabajo productivo y reproductivo, que «un hombre que no tiene responsabilidades familiares», no 
se refiere a ello en sentido literal, sino que apela a que los hombres, tengan o no hijos $\mathrm{u}$ otras personas que dependan de su unidad familiar, no asumen las responsabilidades de cuidado sobre ellos, o al menos no en corresponsabilidad con sus parejas. Por su parte, la entrevistada 20 (que ocupa un cargo de gestión, es Titular de Universidad, no tiene hijos y trabaja en un área de Ciencias) reconoce que hay hombres que sí se ocupan de sus hijos, pero considera que no son mayoría. Ella, que no los tiene, cuenta la experiencia de sus compañeras madres, las cuales tienen que distribuir su tiempo de modo muy diferente a cómo lo suelen hacer los hombres que tienen hijos: una vez que acuestan a los niños, regresan al trabajo. Sus compañeros padres, por norma general, no necesitan hacerlo porque distribuyen el tiempo según sus necesidades, y no las de otras personas. La entrevistada se siente identificada con estas mujeres porque ella vivió una situación similar cuando cuidaba a su madre enferma. Durante unos años se vio obligada a finalizar su jornada laboral más temprano de lo que lo hacía habitualmente, y para compensar ese tiempo y continuar progresando en su carrera, volvía al trabajo de noche, cuando acostaba a su madre. De este modo, la entrevistada refleja que las mujeres no quieren dejar de progresar en la carrera académica, sin embargo, tratan de lograrlo desde situaciones de partida y condiciones muy diferentes a sus compañeros varones. Resulta llamativo que aparecen reivindicaciones de las mujeres hacia la falta de corresponsabilidad de sus compañeros de trabajo, debido a que si estos partiesen de una situación similar a la suya, competirían en igualdad de condiciones con ellos. Sin embargo, sus testimonios no reflejan que realicen esa misma reivindicación en sus propios hogares.

Algunas personas entrevistadas ejemplifican los casos de matrimonios en los que ambos miembros de la pareja son profesores de Universidad, como se observa en la siguiente cita extraída de la entrevista 3. En ninguno de ellos los modelos familiares apuntan hacia modelos de responsabilidad compartida. Al contrario, no solo evidencian la desigualdad en el hogar, sino también la desigual trayectoria profesional de unos y otras:

La mujer sigue estando pendiente de lo que ocurre en casa y de lo que ocurre a los hijos. Y yo jamás he visto... En, en mi facultad además se da el caso de que, bueno como pasa en muchas, que hay profesores que son maridos y mujeres, profesores y profesoras que son marido y mujer, y no, no, no. Siguen los patrones de pareja en el que la mujer sigue siendo la responsable de todo lo que ocurre en el ámbito familiar, siguen completamente vigentes [...] Todo sigue recayendo en su persona, en ellas, como mujeres, y no en sus maridos, que además, ¡suelen ser los catedráticos! (E.3. Mujer. Ayudante doctora. Sin hijos. Letras). 
El siguiente testimonio también habla de la experiencia de sus compañeras de trabajo, cuyas parejas son profesores de Universidad, y de cómo mientras ellos desarrollan su trabajo investigador de manera muy activa en todas las diferentes facetas del mismo, ellas se quedan más relegadas en él, por ejemplo, asistiendo a menos eventos de difusión científica que ellos. Esto se produce fundamentalmente como resultado de la asunción de responsabilidades en el seno de la familia. Al contrario, no aparecen testimonios que visibilicen la dinámica contraria:

Esto lo he hablado con más compañeras también profesoras Titulares, que a lo mejor, no es mi caso, o sea, mi marido no está en la universidad, pero tienen maridos en la Universidad, y es el marido al que se va a todos los congresos, cien mil en los años, y tú te quedas un poquito más, más limitada (E.6. Mujer. Titular de universidad. Con hijos. Ciencias).

Las dos siguientes citas provienen de profesoras cuyos maridos sí trabajan en la Universidad. La primera entrevistada señala que las responsabilidades familiares tienen un efecto diferente en la carrera de hombres y mujeres. Reconoce que ha habido ocasiones en las que le hubiera gustado implicarse en nuevos proyectos de investigación o haber ocupado otros cargos de gestión, pero que no ha podido hacerlo por cuestiones familiares. Al contrario, no señala este tipo de renuncias en su marido:

Sí, las mujeres vivimos peor en la universidad, eh, porque aún por muy igualitaria que mantenga las relaciones con la pareja, nunca es igual. Entonces tienes que asumir muchos aspectos de, de la vida doméstica, y de la familia, es decir, eh, preocuparte por los aspectos sentimentales, emocionales de los hijos. O sea ya no solo de intendencia, que normalmente es, sino también los aspectos emocionales. Entonces hay muchas veces, que pues te gustaría participar en un proyecto o cargarte con más responsabilidades en torno a investigación que no puedes, o, o, o gestión misma, eh, porque no puedes. [...] Y eso no significa que el compañero no te ayude ¿eh? Que en todos los casos posiblemente ayudan, pero, pero la carga, es, es, es de la mujer. Sí. (E.13. Mujer. Cargo de gestión. Titular de universidad. Con hijos. Letras).

Por su parte, la segunda entrevistada incide en que el trabajo reproductivo no afecta de igual modo a hombres que a mujeres. Señala que aunque en ocasiones las tareas a realizar finalmente se dividan, la responsabilidad de su organización no es compartida, sino que recae sobre ellas. Esta entrevistada también señala que los remordimientos de actuar de manera diferente a lo socialmente considerado también recaen sobre la mujer (Ballarín; García):

No, no, no, no. No afecta igual. No afecta igual, de ninguna manera. No afecta igual. [...]. Parece que es obligación nuestra, y aunque tu defiendas que no tiene porqué ser exclusiva tu obligación, y es verdad, y parte intentas 
compartirlo, el peso importante lo llevas tú. Aunque se comparta el tiempo. Y la responsabilidad también, la llevas tú. Y, y los remordimientos también los llevas tú. Todo. Aunque luego materialmente el tiempo se comparta, con ellos, ¿vale? Pero el peso, la organización, la distribución, sobre todo toda la organización. Si los niños necesitan tales vacunas, tales meses, hay que hacer no sé qué, hay que liberar ese día, que tengo que hacer no sé qué, tengo que pedirle a alguien que me cambie para que yo pueda ir a la vacuna o a la revisión, a no sé qué... Todo eso lo haces tú, y eso es claro. Claro que es: tensiones, estrés, es... el tener todo el mes ahí delante, para poder organizar, aunque luego sea para decir, es que este día tienes que ir tú, porque yo ya no he podido cambiar más cosas (E.10. Mujer. Catedrática de Universidad. Con hijos. Ciencias).

Cuando esta entrevistada compara su trayectoria profesional con la de su marido, las ve bastantes parejas, sin embargo, reconoce que al inicio de su relación ambos progresaban a la misma velocidad, y que esto cambió con el paso de los años y la asunción de responsabilidades familiares. Así, aunque ella también ha logrado ocupar una cátedra, lo consiguió unos años más tarde que su marido. En esta misma línea, el entrevistado 27, cuya mujer también es profesora de Universidad, reconoce que el efecto que la maternidad y las responsabilidades familiares en la carrera académica ha sido mayores en el caso de su mujer, aunque, en cierto modo, lo justifica: «Yo reconozco que ha tenido más influencia, probablemente, en la carrera académica de mi mujer, que en definitiva es quien ha tenido los niños ¿no?» (E.27. Hombre. Titular de Universidad. Con hijos. Letras). Este entrevistado reconoce que su mujer se doctoró, consiguió las primeras publicaciones y obtuvo las primeras plazas en la Universidad antes que él, logrando así una progresión académica mayor y más rápida hasta el momento en que se queda embarazada por primera vez. Desde entonces, la dinámica se modifica, y él comienza a aventajarla, hasta el punto de llevar años acreditado como catedrático de Universidad, al contrario que ella.

Por último, entre los testimonios de los varones, algunos reconocen haber llegado donde están gracias al apoyo de su mujer. Así lo hace el entrevistado 39, cuya mujer asumió el papel de ama de casa, ocupándose totalmente del trabajo doméstico y de cuidado de los hijos, liberándole a él de tales responsabilidades. Al contrario, ninguna mujer reconoce estar donde está porque su pareja apostara por su carrera laboral:

Si yo he conseguido, he llegado, estoy donde estoy, es, y no es una frase hecha que se suele hacer, es un altísimo porcentaje gracias a ella, porque a mí me ha liberado, me ha liberado de las cuestiones, en fin de lo que es la gestión de los asuntos más familiares, el cuidado de [Nombre de uno de sus hijos], [Nombre del otro de sus hijos], mis hijos. Hemos como marcado así un poco los territorios, pero sabiendo de antemano pues eso... Si no, yo estoy convencido que no 
podría haber hecho muchas de las cosas que he hecho, eso lo tengo clarísimo

(E.39. Hombre. Cargo de gestión. Titular de Universidad. Con hijos. Letras).

En síntesis, los participantes en la investigación consideran que una de las causas de la desigual posición de la mujer en la Universidad tiene que ver con su situación personal y familiar. Su mayor dedicación al ámbito reproductivo, en comparación con el hombre, estaría limitando su desarrollo y progresión en la carrera académica. En esta línea, Tobío (2012) considera que no será posible acabar con la desigualdad laboral por sexo hasta que no se logre una responsabilidad compartida en los hogares, ya que la ausencia de corresponsabilidad condiciona la energía de las mujeres (llegándoles a ocasionar problemas de salud, como ya se había señalado), limita su disponibilidad laboral y afecta a la toma de decisiones de estas en relación al trabajo.

\section{CONCLUSIONES Y REFLEXIONES}

Se ha producido una evolución del empleo del tiempo por sexo, lo que supone un reparto más equitativo del trabajo entre hombres y mujeres. Sin embargo, aún no hemos alcanzado el modelo de corresponsabilidad deseado. Los cambios sucedidos en la esfera pública, con el desarrollo económico y social del país y la masiva incorporación de la mujer al trabajo fuera del hogar, no se han trasladado a la esfera privada. Así, las relaciones existentes en este ámbito continúan constriñendo el tiempo social y generando diferencias significativas en el uso del tiempo en el trabajo remunerado y no remunerado por sexo. Esto genera una mayor carga global de trabajo para las mujeres y ocasiona importantes repercusiones para ellas tanto a nivel personal como laboral, limitando su acceso y promoción en el trabajo.

La conciliación de la vida familiar y el trabajo en la Academia es difícil para todos en la Universidad, por la dedicación de tiempo que esta carrera demanda, pero lo es especialmente para quienes tienen cargas familiares, y dentro de ellos, para las mujeres, ya que mayoritariamente son quienes se ocupan de su cuidado y atención. Además, los testimonios de las personas entrevistadas revelan que la mujer sigue estando socialmente más presionada para hacerse cargo del hogar y de estas tareas de cuidado. Mientras ellas soportan críticas sobre su doble dedicación al trabajo productivo y reproductivo, no parece existir una visión social negativa hacia que los hombres desatiendan el ámbito familiar. Por otra parte, y respecto al cambio en la tendencia en los modelos de reparto de responsabilidades, mientras unos participantes reconocen que se está produciendo dicho cambio, otros se muestran escépticos, considerando la existencia de hombres corresponsables como una excepción. Muchas de las personas entrevistadas consideran que la ausencia de corresponsabilidad en los 
hogares es una de las causas que contribuyen al mantenimiento de la desigual posición de la mujer en la Universidad. La carrera académica, por sus características, requiere de la dedicación de mucho tiempo privado al trabajo para poder progresar en ella. Sin embargo, el tiempo es, como se ha señalado, un recurso desigualmente distribuido. Así, la mayor dedicación al trabajo reproductivo por parte de las mujeres genera, por un lado, que dispongan de menos tiempo para dedicar al trabajo productivo y, por otra, que para progresar en la carrera académica requieran hacer malabares entre unas responsabilidades y otras, llegando incluso a tener que trabajar de noche, una vez que acuestan a los niños. De este modo, las mujeres no quieren dejar de progresar en la carrera académica pero tratan de lograrlo desde situaciones de partida y condiciones muy diferentes a los hombres. Los testimonios de las personas cuya pareja también es académico/a son muy reveladores. Muestran cómo el progreso laboral de ambos se fue produciendo de manera equiparada, o incluso que el ascenso de la mujer era más rápido en los inicios, hasta que aumentan las responsabilidades familiares. Desde entonces, los hombres comienzan a aventajar a sus mujeres en la progresión en la carrera académica.

Estos resultados plantean retos sobre el modelo social y sobre el propio diseño de la carrera académica. Respecto al primero, resulta llamativo, por un lado, el mantenimiento de modelos no corresponsables en parejas donde ambos miembros trabajan, especialmente porque ambos tienen un alto nivel de formación y desarrollan un trabajo muy especializado; por otro, que la ausencia de corresponsabilidad también esté presente en las parejas más jóvenes; y por último, que no haya un mayor reclamo por parte de estas mujeres hacia la corresponsabilidad en sus hogares. Respecto al modelo de carrera académica, estamos ante un tipo de carrera en la que no se puede parar, que requiere de la dedicación excesiva de tiempo para poder progresar en ella, reduciendo el tiempo que debería dedicarse a la familia, el ocio o el descanso. Así, es más fácil alcanzar las principales posiciones para aquellos que menos responsabilidades tienen en el hogar o menos se hacen cargo de ellas, debido a la disponibilidad de emplear su tiempo libre al trabajo. Siendo así, debemos plantearnos si este es el modelo de desarrollo de la ciencia que queremos, a costa de las personas. Teniendo presente todo ello, se requieren aún muchos y profundos cambios sociales para asegurar, por un lado, la responsabilidad compartida entre hombres y mujeres en los hogares, y por otro, las mismas oportunidades laborales para unos y otras. Necesitamos modelos sociales en los que se dé por hecho que todas las personas cuidan (y para lograrlo, políticas sociales que trabajen en esa línea), y con ellos, que se espere y exija a todas la misma dedicación y responsabilidad. Y de manera paralela, necesitamos modelos de carrera que 
tengan esto en cuenta, y que ajusten las demandas que hacen a sus trabajadores para que puedan desarrollarse profesionalmente sin necesidad de desatender el ámbito familiar o de elegir entre ambas esferas. En caso contrario, no solo se mantendrá la desigualdad sino que se está desaprovechando parte del talento de la mitad de la población en su intento de hacer compatible trabajo y familia. Y considero, como afirma Monteserín, que desaprovechar ese talento tiene graves consecuencias para la sociedad, tanto a nivel económico como demográfico y social.

\section{REFERENCIAS BIBLIOGRÁFICAS}

Acker, Sandra. «Gender, leadership and change in faculties of education in three countries». Leadership, gender and culture in education. Ed. John Collard y Cecilia Reynolds. Maindenhead, UK: Open University Press, 2005, 103-117.

Álvaro, Mariano. «Diferencias, en el uso del tiempo, entre hombres y mujeres y otros colectivos.» Revista Española de Investigaciones Sociológicas 74 (1996a): 291-326.

Álvaro, Mariano. Los usos del tiempo como indicadores de la discriminación entre géneros. Madrid: Instituto de la Mujer, 1996.

Anguita, Rocío, Ana Isabel Alario y Teresa Ortiz. Las mujeres en la Universidad de Valladolid. Valladolid: Secretariado de Publicaciones e Intercambio Editorial, Universidad de Valladolid, 2003.

Ballarín, Pilar. La educación de las mujeres en la España contemporánea (siglos XIXXX). Madrid: Síntesis, 2001.

Barberá, Ester y Amparo Ramos. «Liderazgo y discriminación de género.» Revista de la Federación Española de Asociaciones de Psicología 57 (2004): 147-160.

Beck, Ulrich y Elisabeth Beck-Gernsheim. La individualización: el individualismo institucionalizado y sus consecuencias sociales y políticas. Barcelona: Paidós, 2003.

Carrasco, María José. «Participación y poder de las mujeres en las organizaciones educativas.» XXI Revista de Educación 6 (2004): 75-87.

Conde-Ruiz, J. Ignacio e Ignacio Marra. Gender gaps in the Spanish labor market. FEDEA, 2016.

Domínguez, Marta. «La división del trabajo doméstico en las parejas españolas. Un análisis del tiempo.» Revista Internacional de Sociología 70 (2012): 153-179.

Domínguez, Marta. «Parenthood and domestic division of labour in Spain, 20022010.» Revista Española de Investigaciones Sociológicas 149 (2015): 45-62.

Donoso, Trinidad, Pilar Figuera y María Luisa Rodríguez. «Barreras de género en el desarrollo profesional de la mujer universitaria.» Revista de Educación 355 (2011): 187-212.

Durán, María Ángeles. La jornada interminable. Barcelona: Icaria, 1986. 
Durán, María Ángeles. Tiempo de vida y tiempo de trabajo. Bilbao: Fundación BBVA, 2010.

García de León, María Antonia y María Luisa García de Cortázar. Las académicas: Profesorado universitario y género. Madrid: Instituto de la Mujer, 2001.

García, Teresa. «Carrera profesional de las maestras y matrimonio.» Aula Abierta 86 (2005): 87-119.

González, María José y Teresa Jurado. Padres y madres corresponsables. Una utopía real. Madrid: Catarata, 2015.

Gutek, Barbara y Laurie Larwood. «Women's careers are important and different.» Women's career development. Ed. Barbara Gutek y Laurie Larwood. Newbury Park, California: Sage Publications, 1987, 7-14.

Hochschild, Arlie. The second shift: Working families and the revolution at home. New York: Wiking, 1989.

Instituto de la Juventud. Sondeo de opinión. $3 .^{\circ}$ Encuesta. Jóvenes e igualdad de género. Madrid: INJUVE, 2008.

Instituto de la Mujer. Usos del tiempo, estereotipos, valores y actitudes. Madrid: Instituto de la Mujer, 2007.

Instituto de la Mujer. «Estadísticas. Usos del tiempo I», 2013. <http://inmujer.es/ MujerCifras/Conciliacion/UsosdelTiempo.htm>, consultado el 15-12-2016.

Lozares, Carlos, Pedro López y Joel Martí. «La relación entre los tiempos y las actividades del trabajo productivo y reproductivo.» Trabajo 13 (2004): 165-186.

Martínez-Pérez, María Dolores y Amparo Osca. «El éxito profesional desde una perspectiva de género: propuesta de un modelo.» Revista de Psicología General y Aplicada 51.2 (2004): 193-208.

Ministerio de Educación, Cultura y Deporte. 2017. «Estadística de Personal de Universidades (EPU). Curso 2015-2016», 2017. (http://www.mecd.gob.es/ servicios-al-ciudadano-mecd/estadisticas/educacion/universitaria/estadisticas/ personal-universitario.html), consultado el 10-06-2017.

Monteserín, Mariví. «La mujer en la empresa ¿hay una mano invisible?» Mujeres en la alta dirección. La carrera profesional de las mujeres en la empresa, la administración y la Universidad. Ed. Capitolina Díaz y Elena Carantoña. Madrid: Instituto de la Mujer, 2008, 116-119.

Murillo, Soledad. El mito en la vida privada: de la entrega al tiempo propio. Madrid: S. XXI, 1996.

Prieto, Carlos, Ramón Ramos y Javier Callejo. Nuevos tiempos del trabajo: Entre la flexibilidad competitiva de las empresas y las relaciones de género. Madrid: Centro de Investigaciones Sociológicas, 2008.

Ramos, Ramón. Cronos dividido: uso del tiempo y desigualdad entre mujeres y hombres en España. Madrid: Instituto de la Mujer, 1990.

Reskin, Barbara. "Sex differentiation and the social organization of science.» Sociological Inquiry 48.3-4 (1978): 6-37. 
Tharenou, Phyllis. «Is there a link between family structures and women's and men's managerial career advancement?» Journal of Organizational Behavior 20.6 (1999): 837-863.

Tobío, Constanza. «La familia y el empleo: prácticas y discursos de las mujeres.» Cuestiones Actuales de Sociología del Género. Ed. Rita Radl. Madrid: Centro de Investigaciones Sociológicas, 2001, 129-148.

Tobío, Constanza. 2012. «Cuidado e identidad de género. De las madres que trabajan a los hombres que cuidan.» Revista Internacional de Sociología 70.2 (2012): 399-422.

Tomàs-Folch, Marina y Cristina Guillamón. «Las barreras y los obstáculos en el acceso de las profesoras universitarias a los cargos de gestión académica.» Revista de Educación 350 (2009): 253-275.

Varella, Reyes. «Las políticas de igualdad en el ámbito del trabajo: una propuesta de construcción teórica desde el género.» Cuestiones actuales de Sociología del Género. Ed. Rita Radl. Madrid: Centro de Investigaciones Sociológicas, 2001, 105-125. 
Para enlazar con este artículo / To link to this article:

http://dx.doi.org/10.14198/fem.2017.29.10

Para citar este artículo / To cite this article:

Navarro-Astor, Elena, Arianna Guardiola-Víllora y Luisa Basset-Salom. «El profesorado de la Universitat Politècnica de València desde la perspectiva de género». En Marcos Jesús Iglesias Martínez e Inés Lozano Cabezas (coords.), La (in)visibilidad de las mujeres en la Educación Superior: retos y desafios en la Academia. Feminismo/s, 29 (junio 2017): 243-277, DOI: 10.14198/fem.2017.29.10

\title{
EL PROFESORADO DE LA UNIVERSITAT POLITĖCNICA DE VALÈNCIA DESDE LA PERSPECTIVA DE GÉNERO
}

\author{
UNIVERSITAT POLITÈCNICA DE VALÈNCIA'S FACULTY \\ FROM A GENDER PERSPECTIVE
}

\author{
Elena NAVARRO-ASTOR \\ enavarro@upvnet.upv.es \\ orcid.org/0000-0002-1588-9186 \\ Arianna GUARDiOLA-VÍLlORA \\ aguardio@mes.upv.es \\ orcid.org/0000-0003-3234-0547 \\ Luisa BASSET-SALOM \\ lbasset@mes.upv.es \\ orcid.org/0000-0002-3563-7963 \\ Universitat Politècnica de València
}

\section{Resumen}

Medir es conocer: El diagnóstico es un paso imprescindible para la resolución de cualquier problema. En este documento se analiza la situación del profesorado de la UPV, con objeto de determinar el grado de masculinización del Personal Docente e Investigador de sus escuelas y departamentos. Esta descripción cuantitativa de la situación de facto en el momento del estudio muestra el desequilibrio existente en la institución: además de una segregación horizontal, es evidente el importante grado de segregación vertical. La drástica disminución de la proporción de mujeres a medida que se asciende en la jerarquía académica hace que su presencia en alguna de las categorías superiores sea anecdótica. Es indiscutible la existencia del techo de cristal en la carrera docente de las profesoras de la UPV. Este estudio constituye un paso previo para el futuro desarrollo de estrategias, programas y planes necesarios para alcanzar una composición equilibrada de la plantilla docente. 
Palabras clave: desigualdad de género; Educación Superior; estadísticas; profesorado; Universitat Politècnica de València.

\begin{abstract}
To measure is to know: The diagnosis is a prerequisite to solve any problem. In this paper the situation of the UPV's faculty is analized in order to establish the degree of masculinisation of the teaching and research staff in its schools and departments. This quantitative description of the «de facto» situation at the time of the study shows the current imbalance at the institution: in addition to horizontal segregation, significant vertical segregation is evident. The drastic decline in women's proportion as one moves up to the academic hierarchy makes incidental their presence in some of the higher academic ranks. The existence of the glass ceiling in women's academic careers at the UPV is undeniable. This study constitutes a first step for the future development of strategies, programmes and plans to achieve a balanced composition of its faculty.
\end{abstract}

Keywords: faculty; gender inequality; higher education; statistics; Universitat Politècnica de València. 


\section{INTRODUCCIÓN}

En las últimas décadas ha aumentado la conciencia de las sociedades desarrolladas acerca de la igualdad de trato y de oportunidades entre hombres y mujeres, implementándose políticas de género en los diferentes ámbitos de la sociedad (Pastor et al. 2015).

En el ámbito de la Educación Superior hay, por un lado, señales de progreso hacia la igualdad de género entre los estudiantes. Así, en la UE las mujeres representaron de media el $47 \%$ de los estudiantes de tercer ciclo y su participación ha aumentado a mayor velocidad que la de los hombres desde 2003 (European Comission 2016). No obstante, los datos muestran que todavía existen diferencias importantes en función de las disciplinas estudiadas: ingeniería, producción y construcción siguen estando muy masculinizadas, con medias para la UE de $28 \%$ de alumnas de tercer ciclo. Para el caso de informática, su participación se reduce al 21\% (European Comission 2016). En España, «un siglo de historia universitaria ha sido necesario para que el número de estudiantes universitarias sea superior al de sus iguales masculinos» (Lozano Cabezas et al. 2013). En el curso 2013-14 las mujeres matriculadas en los estudios de grado fueron mayoría (54,4\%), al igual que las egresadas (57,3\%) (MECyD 2015a). Estos datos son similares a los de años precedentes, y también la distribución por áreas de conocimiento, con una proporción de hombres muy superior a la de mujeres en ingeniería y arquitectura (74,1\%) (MECyD 2015a).

Por otro lado, las mujeres están sub representadas en los estratos más altos de la jerarquía académica, es decir, existe segregación vertical (European Comission 2016, Lozano Cabezas et al. 2013 y 2016, Guil y Flecha, Pastor et al. 2015, Sánchez de Madariaga 2013, Guil 2008). Así, la representación de las mujeres entre el Personal Docente e Investigador (PDI) de las universidades públicas españolas se reduce al 39,4\%, y a tan solo 20,7\% para el caso de las funcionarias Catedráticas de Universidad (CU) (MECyD, 2015a). En la comparación internacional, España está ligeramente por debajo del promedio de la UE-27 en cuanto a proporción de mujeres CU y eméritas (MEC-UMYC, 2014). Si se analizan los datos por área de conocimiento se observa que las mujeres todavía tienen menor presencia en ingeniería y arquitectura (20,6\% 
del PDI, 15,9\% de los CU). De ahí que se afirme que para el caso del sistema universitario español, el diagnóstico elaborado hace 13 años seguiría siendo apropiado (Matus-López y Gallego-Morón), mostrando la lentitud del cambio.

En este contexto, diversos organismos internacionales señalan la necesidad de promover la integración de las mujeres en la ciencia para defender sus derechos y también para evitar el mal uso de los recursos (Mauleón y Bordons). Así, la Comisión Europea se manifiesta seriamente comprometida con la educación, defendiendo la construcción de un modelo de ciudadanía basado en la igualdad de género (Commission of the European Communities). En su informe de 2012 (European Commission 2012) planteó líneas de acción concretas para poner en práctica una política de género que supusiera un cambio estructural de las universidades europeas. Entre otras medidas, dicho informe recomienda llevar a cabo acciones de sensibilización y concienciación inicial, la construcción de ambientes positivos, el desarrollo de indicadores y estadísticas que contribuyan a visualizar la situación o la financiación de programas y proyectos específicos. Pero para implementar estas estrategias cada universidad debe partir del conocimiento y diagnóstico del propio entorno institucional, además de contar con el apoyo incondicional de su gobierno (Lozano Cabezas et al. 2013). Además, las instituciones europeas han incluido el género como un tema prioritario y transversal en el programa marco de investigación e innovación, Horizonte 2020 (Pastor et al. 2015; MEC-UMYC; Sánchez de Madariaga 2013).

En España, la Ley Orgánica 3/2007, de 22 de marzo, para la igualdad efectiva de mujeres y hombres ha trazado el camino a seguir para alcanzar la igualdad de género, incluyendo la obligación de negociar planes de igualdad en las empresas de más de 250 empleados, previo diagnóstico integral de equidad (Acosta et al.; Marqués et al.; Elizondo et al. 2010). Asimismo, la Ley Orgánica 4/2007 de universidades establece diferentes medidas con el fin de alcanzar la paridad en los órganos representativos y de gobierno en las universidades, y para que las mujeres mejoren su representación en los grupos de investigación y en los puestos más altos (Pastor et al. 2014 y 2015). Además, establece la creación de unidades de igualdad de género, con presupuesto propio, personal técnico especializado en temas de género, y personal administrativo.

Así, en la actualidad, las unidades de igualdad y los planes de igualdad son instrumentos clave para que las instituciones de Educación Superior españolas aborden sus objetivos de igualdad de género (Pastor et al. 2015). No obstante, diferencias relativas a financiación, antigüedad, dimensión, rasgos socio-laborales, presencia de grupos de estudios de género, participación en redes de igualdad, entre otras, influyen en el diseño y puesta en práctica de las políticas de igualdad en cada universidad (Acosta et al.; Pastor y Acosta). 
De hecho, en la actualidad sólo 33 de las 52 universidades públicas españolas tienen un plan de igualdad (Pastor et al. 2015).

\section{ANTECEDENTES Y OBJETIVOS}

Las investigaciones sobre la desigualdad de género en Educación Superior tienen una amplia trayectoria en España, siendo en su mayoría estudios de casos de universidades concretas (Matus-López y Gallego-Morón) que describen exhaustivamente la composición demográfica de los colectivos de integrantes de la institución (estudiantes, académicos o personal administrativo) a través de estadísticas. Estos estudios confirman la persistencia de desigualdades de género, evidenciando la existencia de segregación tanto horizontal (concentración de mujeres en determinadas áreas temáticas) como vertical (menor presencia femenina al ascender en la jerarquía profesional (Mauleón y Bordons). Además, estos análisis con perspectiva de género se llevan a cabo para distintas áreas de conocimiento y titulaciones, mostrando importantes diferencias entre ellas.

Destacan por ejemplo el caso de la Universidad de Sevilla (Guil, 2005), de Valladolid (Anguita), de Málaga (Morales et al.), de Alicante (Antón, Lozano Cabezas et al. 2013), de La Laguna (Jiménez), de Castilla y León (Lecuona), Universitat Autónoma de Barcelona (Izquierdo), Universitat Jaume I en Castellón (Alcañiz), Rovira i Virgili en Tarragona (Pastor-Gosálbez et al.), Universitat de València (Barberá et al., Escolano 2002, Fernández-Coronado y González, Perelló 2012 y 2013) y Universidad Politécnica de Madrid (Sánchez de Madariaga 2014). Asimismo se han llevado a cabo estudios comparativos entre distintas universidades como el de Ion et al. y Tomás et al. que comparan la Universidad de Sevilla con la Universidad Autónoma de Barcelona, el de cuatro universidades catalanas (Tomás y Guillamón) y cinco universidades públicas valencianas (Escolano 2006).

El origen de la UPV se sitúa en el curso 1968-1969 cuando se crea el Instituto Politécnico Superior de Valencia que engloba cuatro centros: la Escuela Técnica Superior de Ingenieros Agrónomos, creada en 1959; la Escuela Técnica Superior de Arquitectura, constituida en 1966; la Escuela Técnica Superior de Ingenieros de Caminos, Canales y Puertos, y la Escuela Técnica Superior de Ingenieros Industriales, ambas de 1968. El máximo rango de Universidad llega en 1971. A partir de ese año se van adhiriendo el resto de centros (Marqués et al.; UPV).

En la actualidad, más de 42.000 miembros pertenecen a la UPV, de los cuales en torno a 37.800 son alumnos, 2.600 PDI y 1.700 personal de la administración y los servicios. Está compuesta por 15 centros universitarios, de 
los que 9 son escuelas técnicas superiores, 2 son facultades y 2 son escuelas politécnicas superiores. Asimismo, cuenta con 3 centros adscritos. La UPV ofrece 35 grados relacionados con diferentes ramas de conocimiento: 1) Arte y Humanidades, 2) Ciencias, 3) Ciencias sociales y jurídicas y 4) Ingeniería y Arquitectura, que es la más representativa, puesto que engloba el $66 \%$ de los grados ofrecidos.

Las primeras referencias a la desigualdad de género en las aulas de la UPV aparecen en forma de anecdotario en el libro «Nacimiento de una universidad, algunos recuerdos» del profesor Santos (1993), Secretario General de la Universidad durante más de una década. En él se indica que en el curso 198081, en Arquitectura Técnica la proporción entre los estudiantes matriculados era de 116 alumnas frente a 892 alumnos, finalizando la carrera 12 mujeres y 100 hombres. En cuanto al profesorado de dicha escuela, se indica que había sólo 2 mujeres entre los 54 docentes.

La UPV ha formado parte de trabajos de carácter amplio sobre el tema de la igualdad de género, participando junto a otras universidades. Así, por ejemplo, en un ranking de igualdad de un total de 70 universidades españolas, la UPV se sitúa casi en el extremo final, ocupando el puesto n. ${ }^{\circ} 65$ (Elizondo et al. 2007), pero por delante de la Politécnica de Cartagena, la Politécnica de Catalunya (UPCT) y la Politécnica de Madrid. También ha sido objeto de estudio para una comparativa de la carrera académica del profesorado en las cuatro universidades politécnicas españolas (Marqués et al.). Esta comparativa coloca a la UPV como la Politécnica con mayor porcentaje de mujeres en su PDI en 2012 (29\%, frente al 19\% en la UPCT). Sin embargo, según Escolano (2006), en 2001 la UPV estaba a la cola del resto de universidades públicas valencianas en cuanto a participación de la mujer, puesto que sólo representaban el 22.3\% de los docentes, frente a la media del $30.9 \%$. La distancia entre sexos era todavía mayor en las áreas de conocimiento con mayor nivel de experimentación y sectores técnicos o tecnológicos. En consecuencia, en muchos departamentos de la UPV la presencia de la mujer era «meramente simbólica» (Escolano 2006, 425). De hecho, $71.5 \%$ de sus departamentos tenían menos del $25 \%$ de profesoras y en 3 departamentos no había ninguna mujer (Ingeniería e Infraestructura de los Transportes, Máquinas y Motores Térmicos y Mecanización y Tecnología Agraria). Por el contrario, sólo 3 departamentos tenían mayoría de mujeres, pero ninguno perteneciente al campo de la Ingeniería y la Arquitectura, sino a Humanidades y Ciencias Básicas.

Hasta la fecha únicamente Basset-Salom et al., Guardiola-Víllora et al. y Estellés-Miguel et al. han abordado la descripción de aspectos relacionados con la desigualdad de género en la UPV. Las primeras estudiaron el caso de la 
Escuela Técnica Superior de Arquitectura y el Departamento de Estructuras desde una perspectiva de género, constatando un incremento lento y moderado en la presencia de mujeres entre el profesorado para el periodo 1987-2008, a pesar de que el porcentaje de egresadas iguala al de egresados desde el año 2000. Las segundas analizan la presencia femenina en los equipos de gestión de la institución (departamentos y escuelas), subrayando que es escasa, y que el cargo de secretario/a es el más feminizado. Por último, Estellés-Miguel et al. estudian la estructura y la distribución por género del PAS (Personal de Administración y Servicios).

La UPV, a través del Vicerrectorado de Asuntos Sociales y Responsabilidad Social Corporativa, publicó en 2011 un documento previo a la constitución de su unidad de igualdad (Santamarina et al.) en el que se describe su retraso respecto al resto de universidades valencianas y de universidades politécnicas españolas en la aprobación e implantación de los planes de igualdad. Se indica que «en marzo de 2008 se realizó un estudio diagnóstico de la presencia por género en las distintas categorías profesionales que integran las plantillas de la UPV, en puestos de responsabilidad y en el alumnado, donde se presenta la evolución académica y profesional de las mujeres de la UPV» (Santamarina et al. 15), no habiendo sido posible acceder a dicho estudio.

El primer plan de igualdad de la UPV fue finalmente aprobado el 17 de enero de 2014, diez años después de algunas universidades públicas catalanas, pioneras en su implantación (Santamarina et al.). Pero tampoco en este plan se recogen datos estadísticos sobre la desigualdad horizontal y vertical segmentados por género en los distintos colectivos de la comunidad universitaria. El Plan sí describe las acciones que deben ser implementadas para alcanzar la igualdad, sin embargo, no se determinan quiénes son las entidades o personas responsables de llevarlas a cabo, y tampoco los recursos humanos y económicos destinados a ellas. Según De los Cobos, esto mediría el grado de compromiso institucional con la igualdad.

Hasta la fecha, en España ha habido escasa conciencia sobre la importancia de desagregar los datos por sexo para conocer realmente la situación de las mujeres (Guil y Flecha). Sin embargo, como indica Carmen Vela, Secretaria de Estado de Investigación, Desarrollo e Innovación, «las cifras nos ayudan a definir, ejecutar y evaluar las políticas» (MEC-UMYC 4). Uno de los factores que contribuyen a la activación de medidas destinadas a la igualdad es la visibilización de la distancia de género a partir de la publicación de datos estadísticos. Estos datos son esenciales para realizar un seguimiento longitudinal, analizar la eficacia de las estrategias implementadas y comparar regiones y países (Mauleón y Bordons). Según Elizondo et al. (2010), la mayoría de 
universidades con unidades de igualdad ya cuenta con diagnósticos publicados, no siento éste el caso de la UPV.

En consecuencia, este estudio vendría a cubrir un vacío investigador, puesto que pretende sacar a la luz cuál es la situación de igualdad de género en la UPV. El conocimiento del propio entorno institucional es la base para empezar a cambiar las cosas, el punto de partida para desarrollar el resto de estrategias. Como señalaba Alonso hace más de una década: «las posibilidades de que esta situación de flagrante desigualdad evolucione, dependerá en buena medida de que se comience siquiera a percibirla y reconocerla» (Alonso 616).

Conocidos estos antecedentes, este trabajo responde a la necesidad de afrontar un desafío contemporáneo e histórico a la vez para las instituciones de Educación Superior: las asimetrías de género. De ahí el propósito principal de documentar y visibilizar de forma exhaustiva por primera vez las diferencias de género en la carrera académica del PDI de la UPV: Este objetivo se concreta en los siguientes sub-objetivos:

Examinar la segregación vertical o posición diferencial en la jerarquía del PDI en base a las categorías profesionales (profesorado de los cuerpos docentes universitarios y profesorado contratado laboral).

Analizar la segregación horizontal por sexo, es decir, la concentración de hombres o de mujeres en cada uno de los centros docentes y de los departamentos.

\section{MATERIAL Y MÉTODOS}

Para este estudio se han utilizado los datos recogidos en el directorio del personal de la UPV, accesible desde la intranet, asumiendo que todos los miembros de la comunidad universitaria están incluidos en el mismo. La información disponible (Diciembre 2015) incluye el nombre, categoría, departamento y centro docente al que se encuentra adscrito el PDI.

Los centros docentes que forman parte de la UPV son las 9 Escuelas Técnicas, 2 facultades y 2 escuelas politécnicas superiores de la tabla 1. Los nombres de los 42 departamentos con sus siglas se recogen en la tabla 2. 
Tabla 1. Centros docentes de la UPV (2016)

\begin{tabular}{|l|c|l|l|}
\hline E.T.S. $^{1}$ de Arquitectura & ETSA & E.T.S. de Ingenieros Industriales & ETSII \\
\hline $\begin{array}{l}\text { E.T.S. de Ingeniería } \\
\text { Agronómica y del Medio } \\
\text { Natural }\end{array}$ & ETSIAMN & $\begin{array}{l}\text { E.T.S. de Ingenieros de } \\
\text { Telecomunicación }\end{array}$ & ETSIT \\
\hline E.T.S. de Ingeniería del Diseño & ETSID & $\begin{array}{l}\text { Facultad de Administración y } \\
\text { Dirección de Empresas }\end{array}$ & FADE \\
\hline $\begin{array}{l}\text { E.T.S. de Ingeniería de } \\
\text { Edificación }\end{array}$ & ESTIE & Facultad de Bellas Artes & FBBAA \\
\hline $\begin{array}{l}\text { E.T.S. de Ingeniería Geodésica, } \\
\text { Cartográfica y Topográfica }\end{array}$ & ETSIGCT & $\begin{array}{l}\text { Escuela Politécnica Superior de } \\
\text { Alcoy }\end{array}$ & EPSA \\
\hline $\begin{array}{l}\text { E.T.S. de Ingeniería } \\
\text { Informática }\end{array}$ & ETSINF & $\begin{array}{l}\text { Escuela Politécnica Superior de } \\
\text { Gandía }\end{array}$ & EPSG \\
\hline $\begin{array}{l}\text { E.T.S. de Ingenieros de } \\
\text { Caminos, Canales y Puertos }\end{array}$ & ETSCCP & & \\
\hline
\end{tabular}

${ }^{1}$ E.T.S. son las siglas de Escuela Técnica Superior

Tabla 2. Departamentos de la UPV (2016)

\begin{tabular}{|c|c|c|c|}
\hline D. Biotecnología & BTC & $\begin{array}{l}\text { D. Comun. Audiovisual, } \\
\text { Documentación e H. }{ }^{2} \text { del Arte }\end{array}$ & HAR \\
\hline $\begin{array}{l}\text { D. Ingeniería Cartográfica } \\
\text { Geodesia y Fotogrametría }\end{array}$ & CGF & $\begin{array}{l}\text { D. Ingeniería Hidráulica y Medio } \\
\text { Ambiente }\end{array}$ & HMA \\
\hline D. Composición Arquitectónica & $\mathrm{CPA}$ & D. Lingüística Aplicada & IDM \\
\hline $\begin{array}{l}\text { D. Conservación y Restauración de } \\
\text { Bienes Culturales }\end{array}$ & CRBC & D. Ingeniería Química y Nuclear & IQN \\
\hline D. Construcciones Arquitectónicas & CSA & $\begin{array}{l}\text { D. Ingeniería Rural y } \\
\text { Agroalimentaria }\end{array}$ & IRA \\
\hline $\begin{array}{l}\text { D. Ingeniería de la Construcción y } \\
\text { de Proyectos de Ingeniería Civil }\end{array}$ & CST & $\begin{array}{l}\text { D. Ingeniería de Sistemas y } \\
\text { Automática }\end{array}$ & ISA \\
\hline D. Ciencia Animal & DCA & D. Matemática Aplicada & MAT \\
\hline D. Comunicaciones & DCOM & $\begin{array}{l}\text { D. Ingeniería Mecánica y de } \\
\text { Materiales }\end{array}$ & $\mathrm{MCM}$ \\
\hline D. Economía y Ciencias Sociales & DECS & $\begin{array}{l}\text { D. Mecánica de los Medios } \\
\text { Continuos y Teoría de } \\
\text { Estructuras }\end{array}$ & MES \\
\hline D. Ingeniería Gráfica & DEGI & $\begin{array}{l}\text { D. Máquinas y Motores } \\
\text { Térmicos }\end{array}$ & MOT \\
\hline D. Dibujo & DIB & D. Organización de Empresas & OMP \\
\hline D. Ingeniería Eléctrica & DIE & D. Pintura & PIN \\
\hline
\end{tabular}




\begin{tabular}{|l|c|l|c|}
\hline $\begin{array}{l}\text { D. Informática de Sistemas y } \\
\text { Computadores }\end{array}$ & DISCA & Dpto. proyectos arquitectónicos & PRA \\
\hline D. Proyectos de Ingeniería & DPI & Dpto. producción vegetal & PRV \\
\hline $\begin{array}{l}\text { D. Sistemas Informáticos y } \\
\text { Computación }\end{array}$ & DSIC & D. Química & QIM \\
\hline D. Ecosistemas Agroforestales & EAF & D. Tecnología de Alimentos & TAL \\
\hline $\begin{array}{l}\text { D. Expresión gráfica } \\
\text { Arquitectónica }\end{array}$ & EGA & D. Termodinámica Aplicada & TER \\
\hline $\begin{array}{l}\text { D. Estadística e Investigación } \\
\text { Operativa Aplicadas y Calidad }\end{array}$ & EIO & $\begin{array}{l}\text { D. Ingeniería e Infraestructura } \\
\text { de los Transportes }\end{array}$ & TRA \\
\hline D. Ingeniería Electrónica & ELN & D. Ingeniería del Terreno & TRR \\
\hline D. Escultura & ESC & D. Ingeniería Textil y Papelera & TXP \\
\hline D. Física Aplicada & FIS & D. Urbanismo & URB \\
\hline
\end{tabular}

El sistema universitario español considera dos categorías principales de docentes dependiendo de su vinculación laboral con la Universidad: profesorado funcionario y no funcionario. La Ley Orgánica 4/2007, de 12 de abril, por la que se modifica la Ley Orgánica 6/2001, de 21 de diciembre, de Universidades reduce los cuerpos de funcionarios docentes universitarios a Catedráticos de Universidad (CU) y Titulares de Universidad (TU), suprimiendo los cuerpos de Catedráticos de Escuela Universitaria (CEU) y Titulares de Escuela Universitaria (TEU). Además se contempla la integración de los cuerpos a extinguir al cuerpo de TU, en el caso de los CEU, automáticamente, previa solicitud, y en el de los TEU, tras su acreditación por la Agencia Nacional de Evaluación de la Calidad y Acreditación (ANECA). De este modo, estas dos categorías han ido paulatinamente desapareciendo (Santos et al.).

Por otra parte, las universidades pueden contratar personal docente e investigador en régimen laboral (no funcionarios). Las modalidades específicas de contratación laboral del ámbito universitario, según el artículo 48, son las correspondientes a las figuras de Ayudante (AYU), Profesor Ayudante doctor (AYUDR), Profesor Contratado doctor (CONDR), Profesor Asociado (ASO) y Profesor visitante (figura no incluida en este estudio puesto que en la fecha de recogida de datos sólo había 1 profesor visitante en toda la UPV), desapareciendo la figura de Profesor Colaborador (COL) contemplada en la LOU $6 / 2001$. Las condiciones y plazos para la convocatoria de plazas de COL a partir de la entrada en vigor de la LO 4/2007 se regularon con el RD 989/2008 de 13 de junio, extendiéndose hasta el 3 de mayo de 2013, de ahí que todavía haya muchos docentes de esta categoría en la UPV. Las categorías del profesorado se 
recogen en la tabla 3, ordenadas de menor a mayor rango y con su equivalente internacional (Sánchez de Madariaga, 2014)

Tabla 3. Categoría del profesorado de la UPV

\begin{tabular}{|l|c|c|}
\hline Asociado & ASO & Grade D \\
Ayudante & AYU & Non PhD Teaching staff \\
Colaborador & COL & Grade C \\
\hline Ayudante doctor & AYUDR & \\
Contratado Doctor & CONDR & Grade B \\
\hline Titular de Escuela Universitaria & TEU & \\
Titular de Universidad & TU & Grade A \\
Catedrático de Escuela Universitaria & CEU & CU \\
\hline Catedrático de Universidad & EME & \\
Emérito & & \\
\hline
\end{tabular}

La Ley de Reforma Universitaria de 1983 estableció la estructura departamental en la Universidad española. El profesorado depende de un departamento y, de éste, parten las decisiones de contratación, siguiendo las directrices generales de la Universidad (Escolano, 2006, 125). Por ello, resulta interesante analizar la situación del profesorado adscrito a los distintos departamentos desde la perspectiva de género.

Se han utilizado las siglas $\mathrm{H}$ para hombres y $\mathrm{M}$ para mujeres además de los símbolos î respectivamente. En los gráficos de barras, su altura representa el número de docentes en valor absoluto, completando este dato con el porcentaje que representan. Los valores de los porcentajes, calculados con decimales, se han redondeado para ajustarlos al $100 \%$.

\section{RESULTADOS Y DISCUSIÓN}

\subsection{Representación de las mujeres en el PDI de la UPV}

Si bien según las estadísticas del Ministerio de Educación Ciencia y Deporte (MECyD 2015a) el porcentaje de mujeres matriculadas en los centros propios de la UPV durante el curso 2014-2015 en estudios de grado, primer y segundo ciclo fue del $35 \%$, el análisis de la totalidad del profesorado de la UPV muestra que sólo el 30\% del PDI son mujeres (Figura la). Este porcentaje es inferior al $39 \%$, correspondiente a la media del PDI de las universidades públicas españolas en 2012 (MEC-UMYC) o al 39,4\%, media nacional en las universidades públicas el curso 2014-15 (MECyD 2015b). Esto podría deberse a que, como se ha mencionado en los antecedentes, la rama de conocimiento Ingeniería y Arquitectura (históricamente masculinizada) es la más representativa, 
englobando al 66\% de los grados ofrecidos. De hecho, en la mayoría de países de la UE la mayor desigualdad de género entre el PDI se da en la Ingeniería, y la menor en las Humanidades (Pastor y Acosta, 2016)

Aunque es superior al porcentaje femenino de las Universidades Politécnicas de Madrid y Barcelona (24\%) es de señalar que apenas ha aumentado un punto desde el año 2012 (Marqués et al.). Así, el cambio está siendo muy lento, a pesar de que a nivel nacional dentro del PDI de Ingeniería y Arquitectura las mujeres tienen más sexenios que sus colegas varones (68,1\% de las funcionarias los tienen, frente al 65,4\% de los hombres). Ingeniería y Arquitectura es, de hecho, la única rama del conocimiento en que ellas les superan (Guil, 2016). Resulta difícil de entender que a día de hoy, pese a estar más preparadas, las mujeres no ocupen al menos las mismas posiciones que los hombres, siendo la única justificación posible que, habiendo copado los hombres dichos puestos en el pasado, y dada la baja tasa de reposición consecuencia de las recientes políticas de austeridad, no salgan plazas a concurso a las que optar.

Según la Figura 1b, más de la mitad del profesorado (59\%) pertenece a los cuerpos de funcionarios docentes. Sin embargo, apenas el 16\% del PDI son profesoras funcionarias, frente al $43 \%$ de los hombres.
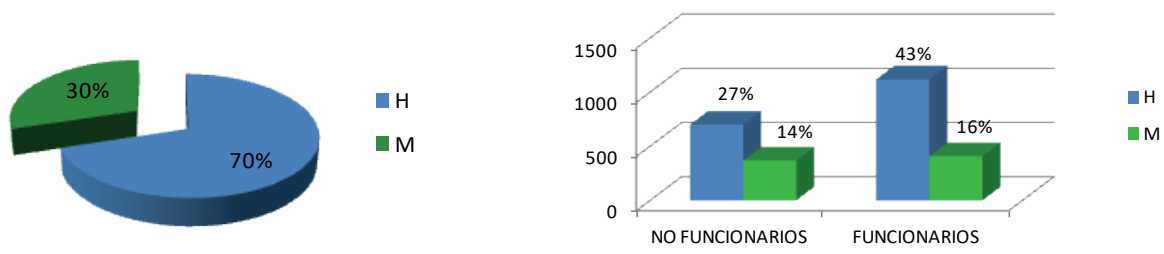

Figura 1a. Distribución del PDI en UPV

Figura 1b. PDI funcionario/contratado en UPV

La Figura 2 refleja la distribución por género de las distintas categorías docentes en la UPV. Una distribución desigual es un indicador de segregación vertical, es decir, de jerarquía laboral, de desigualdad salarial y de desarrollo de mayores niveles de poder en el contexto universitario de un sexo respecto a otro; en este caso, de los hombres respecto a las mujeres.
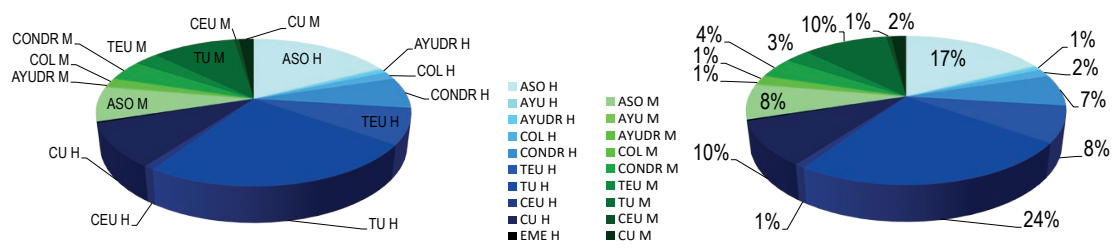

Figura 2 Distribución por género de las categorías docentes en la UPV 
Analizando los datos del PDI por categorías, se puede resaltar el reducidísimo porcentaje de académicas que se encuentran en la cima de la pirámide jerárquica: sólo el 2\% son CU, (equivalente a Grado A), frente al 10\% de los hombres. En cuanto a las categorías correspondientes a Grado B (TEU, TU y CEU), el 16\% son mujeres y el 33\% hombres, y en las categorías del Grado C (no funcionarios), el 5\% de mujeres frente al 8\% de hombres.

En la Figura 3 se comparan, por categorías, el número y porcentaje de profesorado femenino y masculino en la UPV. El diagrama de líneas evidencia las diferencias entre las distintas categorías, siendo la brecha mayor en el cuerpo de CU. No existe en la UPV ninguna categoría profesional que esté feminizada, aunque en las categorías inferiores de AYUDR y COL los porcentajes entre sexos se aproximan algo más. El principal motivo podría ser que estas figuras profesionales son relativamente recientes y, dada su precariedad, las mujeres podían optar a ellas en el momento de su creación. Sin embargo, la llegada de la crisis económica hizo que también fueran demandadas por los hombres alcanzando una cierta paridad.

Es indiscutible que en las figuras más valoradas por su estabilidad y por el conjunto de derechos profesionales que comportan, los hombres siguen siendo una aplastante mayoría, que se incrementa todavía más en el vértice de la pirámide, donde la presencia femenina resulta meramente simbólica.
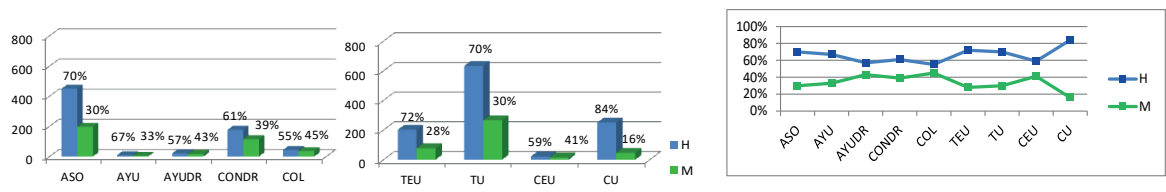

Figura 3. Distribución del profesorado UPV por categorías (no funcionarios/funcionarios)

Según los datos del Instituto Nacional de Estadística de 2006 (INE), nueve años antes había en la UPV un total de 1715 docentes funcionarios, de los cuales 1299 eran hombres y 416 mujeres. En 2015 hay 1520 docentes funcionarios, 1112 hombres y 408 mujeres, produciéndose, por tanto, una reducción total del $11,3 \%$ de profesorado funcionario. Aunque las gráficas de barras de la Figura 4 parecen mostrar que la situación de las mujeres ha mejorado, la gráfica de líneas ilustra bien que la brecha sólo se ha reducido en el colectivo de CEU, categoría a extinguir. Sin embargo, en el resto de las categorías, en las que apenas se ha modificado la brecha, todavía estamos muy lejos de la igualdad.

Los porcentajes obtenidos para la UPV se han comparado con los datos del curso 2013-2014 del resto de las universidades públicas españolas proporcionados por el Ministerio de Educación Ciencia y Deporte (MECyD, 2015b) y 
por el Ministerio de Economía y Competitividad (MEC-UMYC, 2014) y con los datos de las universidades europeas proporcionados por la publicación «She figures 2015» (European Comission, 2016).
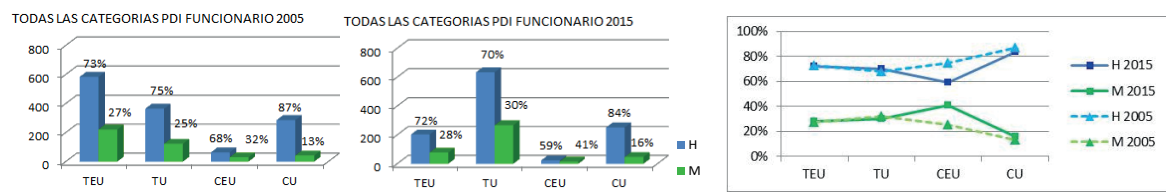

Figura 4. Comparación del profesorado funcionario de la UPV en 2005 y 2015

El denominado «efecto tijera» que hace referencia al hecho de que conforme se va ascendiendo en las responsabilidades y cargos, como cátedras, por ejemplo, aumenta el número de hombres y desciende el de mujeres, queda bien representado en la Figura 5. Asimismo muestra que en el caso de la UPV las hojas de las tijeras están más alejadas que en el resto de España y que en Europa: el 84\% de las cátedras (Grado A) de la UPV está en manos de hombres, y solo el $16 \%$ en manos de mujeres, mientras que en el resto de universidades españolas esta última cifra es 20,7\% y en las europeas $20.9 \%$. El 33\% del PDI de la categoría Grado B (CEU+TU+TEU), son mujeres, de nuevo porcentaje inferior al del resto de universidades españolas $(36,7 \%)$ y europeas $(37,1 \%)$. En cuanto a la categoría C, el $41 \%$ son mujeres, frente al $48,5 \%$ en el caso español y el $45,1 \%$ en el europeo.
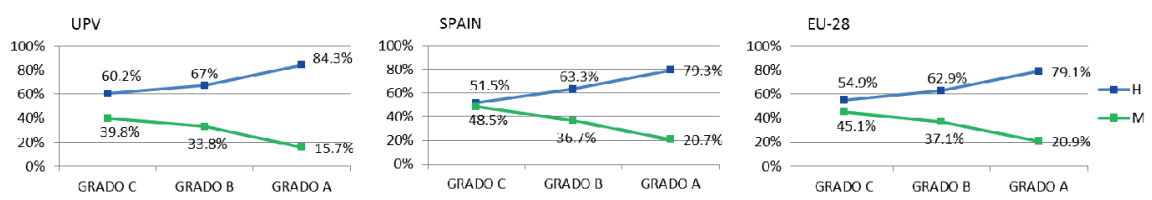

Figura 5. Distribución del profesorado por categorías: UPV, España y Europa-28

\subsection{Representación de las mujeres PDI en los centros docentes de la UPV}

Estudiando las vías de inserción de las profesoras en las distintas disciplinas, puede determinarse si se han superado o se están superando los modelos tradicionales de presencia femenina en el mundo académico. Esto es, si ellas siguen ligadas a carreras extensivas de los roles y tareas domésticas o, utilizando la denominación más común, vinculadas a carreras «de letras», alejadas de las carreras más científicas y técnicas (De los Cobos; Escolano 2006; Lecuona). 
La asignación de la docencia del profesorado de la UPV en sus centros docentes (9 Escuelas, 2 facultades y 2 institutos politécnicos) se representa en la Figura 6, con los centros ordenados de mayor a menor presencia femenina (Figura 6b). Únicamente en la ETSIAMN, en FADE y FBBAA el porcentaje de mujeres PDI supera el $40 \%$. Hay que destacar que ninguna de estas tres instituciones pertenece a la rama de conocimiento de Ingeniería y Arquitectura.
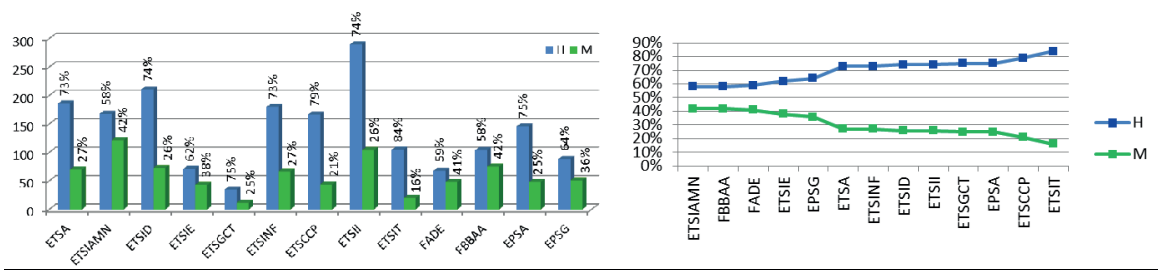

Figura 6 a. Distribución del PDI/centros

Figura 6 b. PDI/centros (\% decreciente de M)

La ETSIAMN pertenece a la rama de Ciencias, y oferta, entre otros, los grados de Ingeniería agroalimentaria y del medio rural, y Ciencia y tecnología de los alimentos. Estos estudios tienen relación con los alimentos, la comida, la nutrición, la restauración y la industria alimentaria en general, áreas tradicionalmente más afines a la mujer y ligadas a los estereotipos de género. Además, los estudios de Ciencia y tecnología de los alimentos cumplen su 20 aniversario en 2017, con lo cual son relativamente recientes y han podido incorporar a más mujeres a medida que han crecido. En cuanto a FADE, está vinculada a Ciencias Sociales y Jurídicas, y FBBAA a Artes y Humanidades, áreas en las que la mujer ha estado siempre más representada (Lecuona).

En el polo opuesto se encuentran la ETSCCP y la de ETSIT, que son las más masculinizadas, con una participación escasa de la mujer (21\% y 16\% respectivamente). Ambas escuelas pertenecen a la rama de conocimiento Ingeniería y Arquitectura. Además, la E.T.S. de Caminos Canales y Puertos mantiene estrecha relación con la construcción, un sector caracterizado por la existencia de numerosas barreras al desarrollo profesional de las mujeres (Navarro-Astor et al.).

Si se analizan estos datos, teniendo en cuenta las distintas categorías entre profesorado funcionario por un lado y no funcionario por otro, se observa (Figura 7) que la brecha es menor entre el profesorado no funcionario, invirtiéndose incluso los valores en la ETSIAMN (53\% de mujeres). Por el contrario, la desigualdad es mayor entre el profesorado funcionario. 

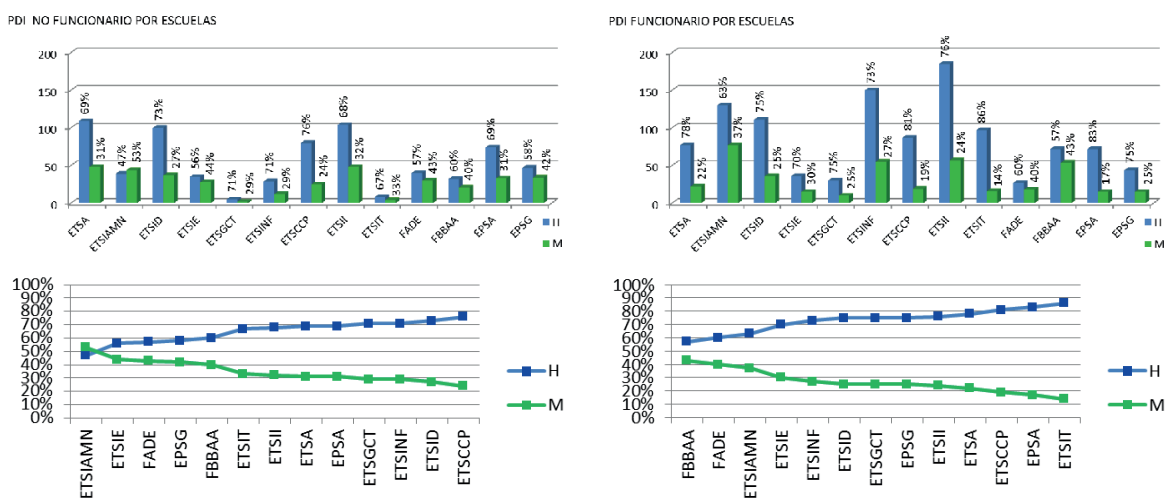

Figura 7. Distribución del PDI no funcionario y funcionario en cada centro docente

Las gráficas de las Figuras $8 \mathrm{a}$ y $8 \mathrm{~b}$ muestran el porcentaje de hombres y mujeres del PDI adscrito a cada centro desagregado por categorías. Los diagramas de barras reflejan los porcentajes de hombres y mujeres de cada categoría y las figuras de la derecha el porcentaje respecto a la totalidad del profesorado adscrito al centro.

Las desigualdades por categorías en cada centro quedan reflejadas en la Figura 9. En la ETSIT, ETSID, ETSINF y EPSG la línea que representa a las mujeres no se cruza en ninguna categoría con la de los hombres, mientras que en la ETSCCP, EPSA y FBBAA hay alguna categoría en la que coinciden ambas (categorías del grado C y D en ETSCCP, EPSA y TU en FBBAA). En la ETSA, ETSIE, ETSIAM y FADE se producen cruces entre las líneas en las categorías de rango inferior (COL, CONDR, AYUDR). Aunque en la ETSII y ETSIGCT las CEU superan a los CEU, no hay que olvidar que es una categoría a extinguir. Finalmente, en FADE, facultad de reciente creación (2002) perteneciente al área de conocimiento de Ciencias Sociales, se iguala el porcentaje de TU, CEU y presenta menor brecha en $\mathrm{CU}$. 


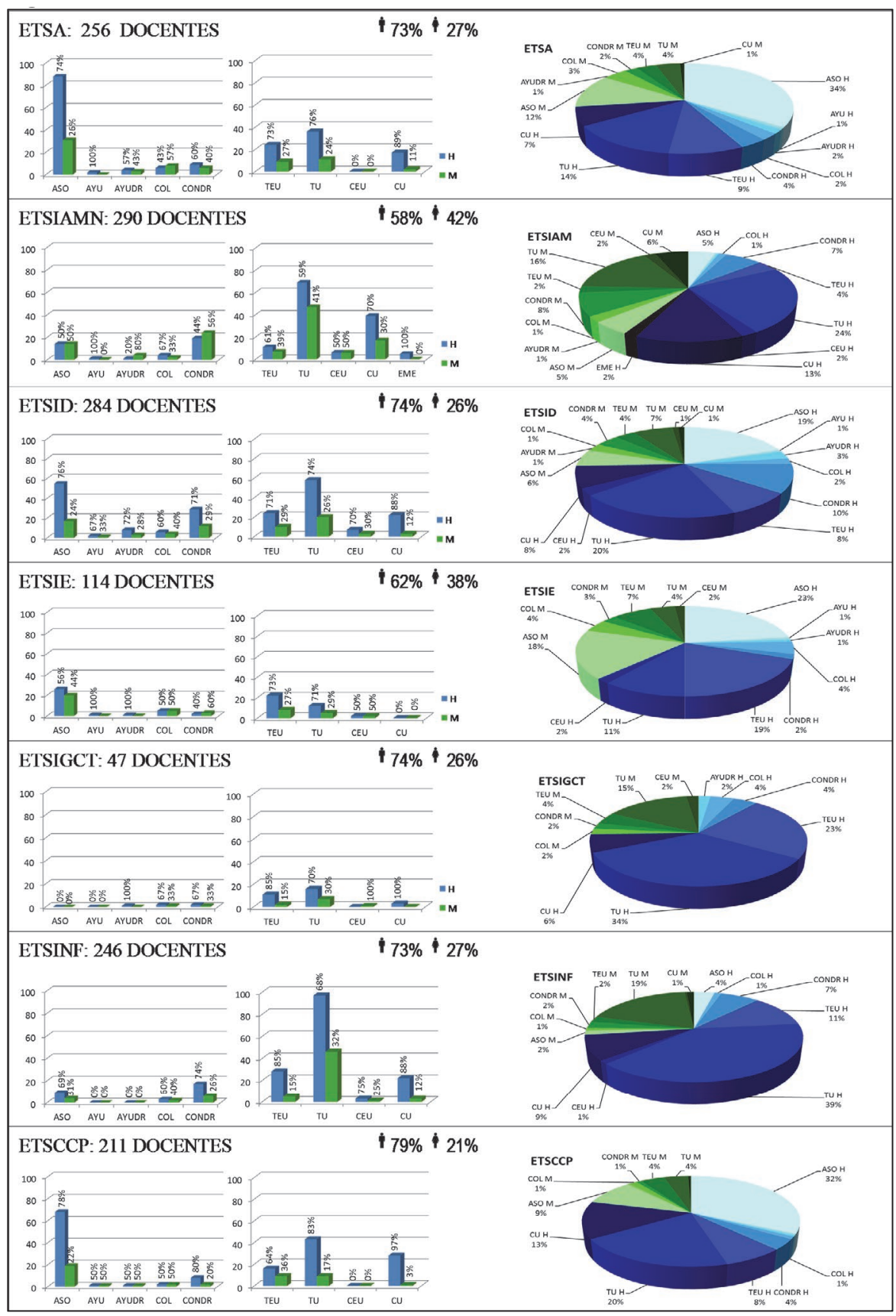

Figura 8a. Distribución del profesorado por categorías (no funcionarios/funcionarios) y centro 


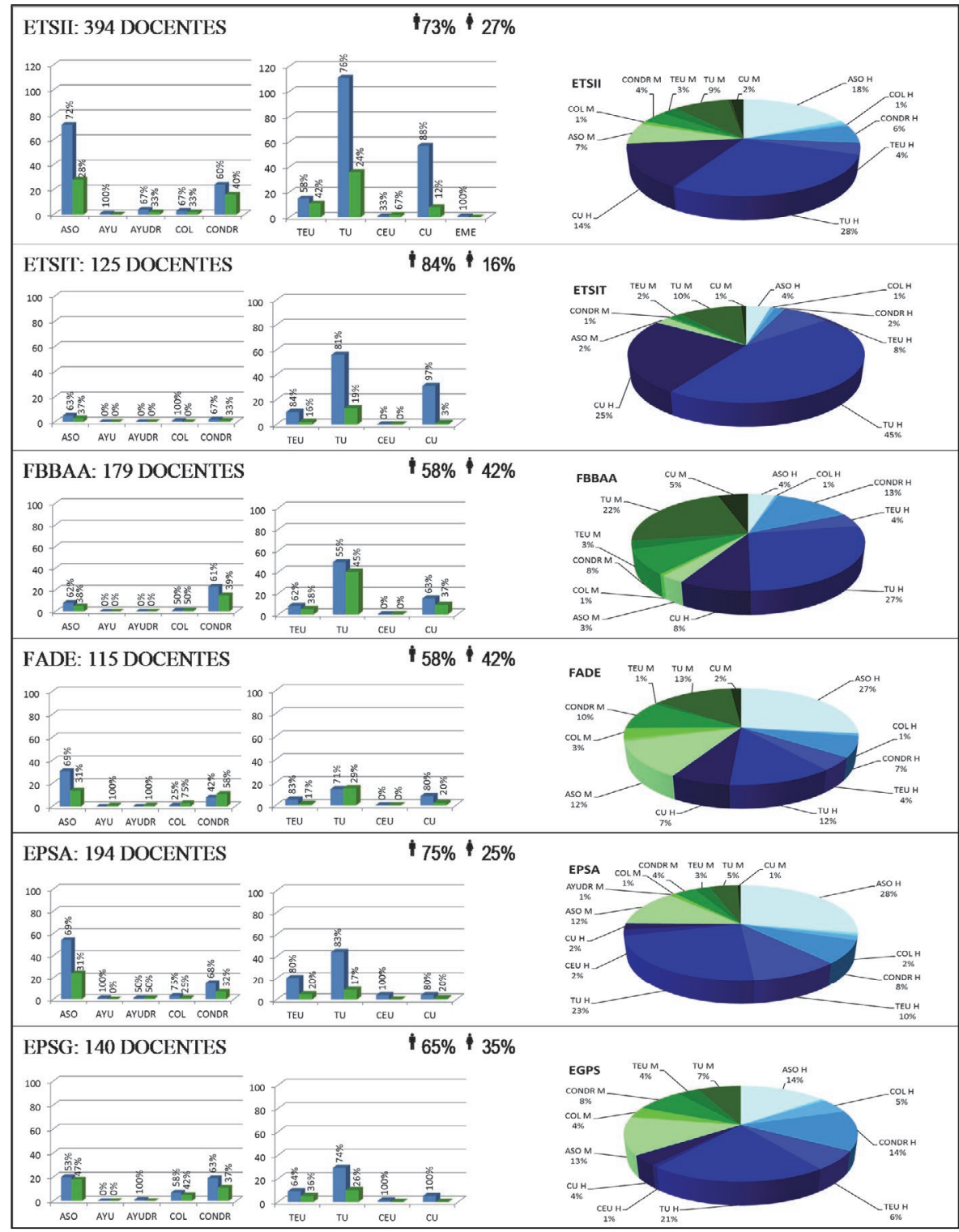

Figura 8b. Distribución del profesorado por categorías (no funcionarios/funcionarios) y centro 

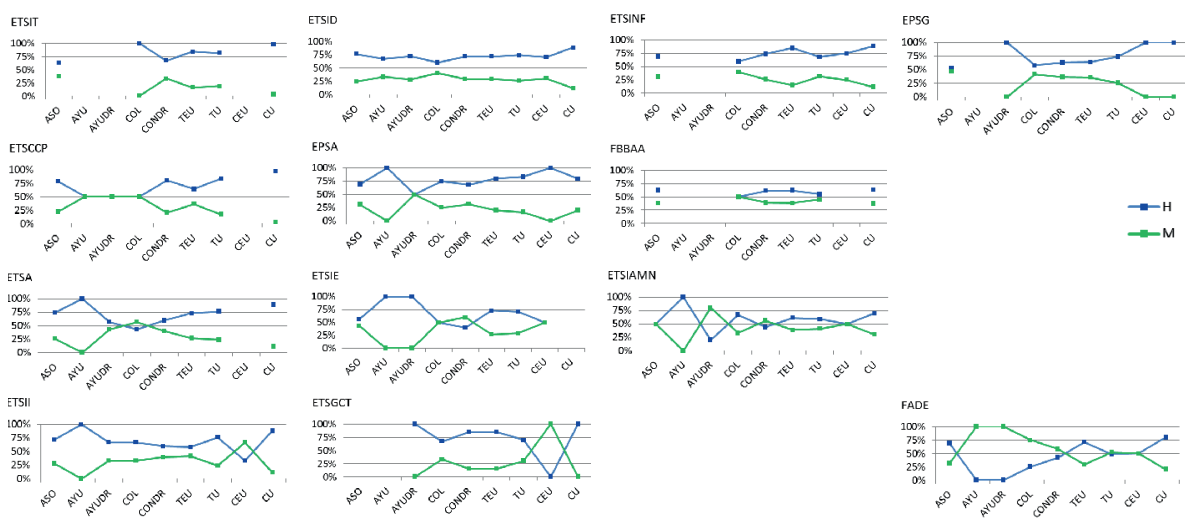

Figura 9. Desigualdades por categorías en cada centro

\subsection{Representación de las mujeres PDI en los departamentos de la UPV}

Dado que son los departamentos los que contratan al personal no funcionario y los que convocan las correspondientes plazas para las figuras de profesor funcionario, tal y como se ha comentado anteriormente, se ha creído conveniente analizar la distribución por sexos del profesorado de los 42 departamentos de la institución objeto de estudio.

Los resultados de este análisis (ver Figura 10) reflejan una gran disparidad entre departamentos: IDM es el más feminizado con mayor porcentaje de profesoras (83\%), mientras que ISA es el más masculinizado, con tan sólo un 4\%.

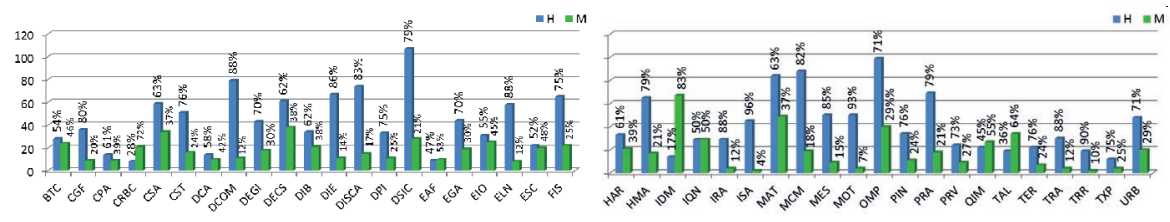

Figura 10. Distribución del PDI por departamentos

Ordenando los departamentos según su participación femenina (Figura 11) se observa que sólo 3 departamentos tienen una cuota femenina de PDI claramente superior a la masculina (IDM, CRBC y TAL). Hay que subrayar que en 2001 los dos primeros ya tenían mayoría femenina y que TAL empleaba un $48.6 \%$ de mujeres (Escolano 2006), y que ninguno pertenece al campo científico de Ingeniería y Arquitectura. 
Tecnología de los Alimentos (TAL) se vincula a Ciencias en general, y al ámbito de la cocina (típicamente femenino). Conservación y Restauración de los Bienes Culturales (CRBC) pertenece a Artes y Humanidades y tiene que ver con el cuidado y mantenimiento de bienes importantes para la sociedad. Finalmente, Idiomas (IDM), del campo de las Ciencias Sociales, ha estado siempre vinculado con la enseñanza, ámbito eminentemente femenino.

La Figura 11 también muestra que 6 departamentos (QIM, EAF, IQN, ESC, BTC, EIO) tienen un reparto bastante igualitario cercano al 50\%. Los 7 departamentos siguientes tienen entre un 40-50\% de mujeres, desde EGA hasta PRA tienen entre el 20 y $30 \%$, mientras que los 12 departamentos restantes tienen menos del $20 \%$ de profesoras.

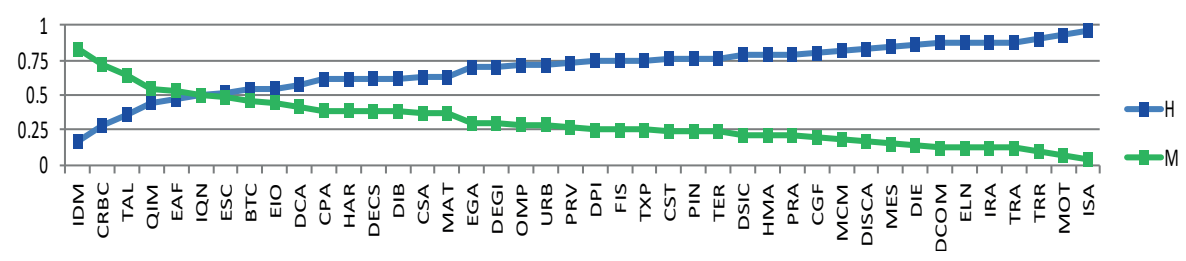

Figura 11. Distribución del PDI por departamentos (orden decreciente de mujeres)

Si este análisis se lleva a cabo distinguiendo entre docentes funcionarios y no funcionarios (ver Figura 12), llama la atención la existencia de dos departamentos que carecen de profesoras funcionarias (TRA y PRA). Además conviene subrayar que el primero, TRA, es también uno de los tres departamentos que carecía de profesoras en 2001 (Escolano, 2006), denotando la ausencia de evolución hacia la igualdad en catorce años.

En cuanto al segundo, PRA, está compuesto exclusivamente por arquitectos, profesión cuyos estudios de grado están feminizados hace muchos años (Basset-Salom et al.; Sánchez de Madariaga 2014). Así, el simple paso del tiempo no ha contribuido a mejorar las cifras de igualdad. Este departamento está siendo objeto de estudio exhaustivo de otra investigación, cuyos resultados preliminares señalan que a igualdad de fechas de graduación y de acceso a la carrera profesional y docente en la figura de profesor asociado, la maternidad ha supuesto una traba en la promoción profesional de las mujeres que no se percibe en los hombres.

Asimismo, se observa que los departamentos con mayor número de funcionarios (DCOM, DIE, DISCA, DSIC, ELN, FIS) presentan porcentajes de profesoras inferiores al 20\%, a excepción de MAT, en el que la cuota femenina alcanza el 35\%. 


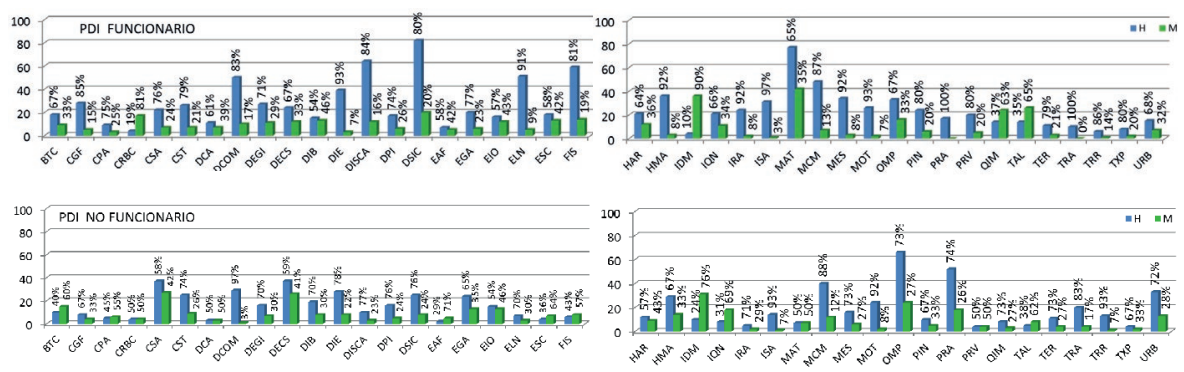

Figura 12. Distribución del PDI funcionario/no funcionario por departamentos

En la Figura 13 se observa que la brecha en el profesorado no funcionario es menos acusada, salvo las singularidades de DIB, DPI, OMP, MCM, DCOM, TRR, MOT, y ISA, además de llamar la atención la inversión en los departamentos de QIM y DPI.

PDI FUNCIONARIO

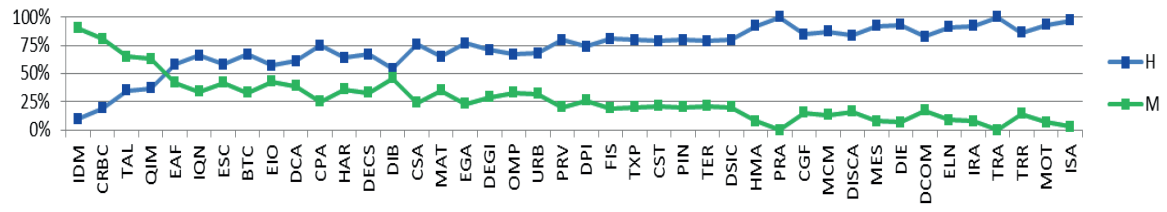

PDI NO FUNCIONARIO

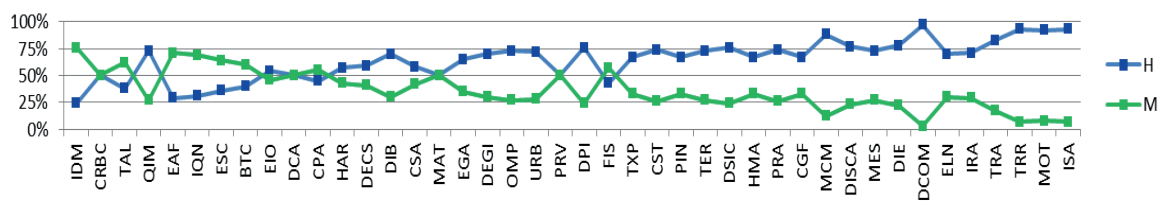

Figura 13. Desigualdades en la distribución del PDI por departamentos

Este análisis se completa calculando los porcentajes para cada una de las categorías de docentes en cada departamento. Los resultados se muestran en las Figuras 14a, 14b, 14c, 14d, 14e y 14 f. 
La Figura 15 evidencia claramente las desigualdades. En un 29\% de los departamentos (enmarcados en rojo) la proporción de hombres es mayor para todas las categorías (aquéllos en los que las líneas no se cortan): CGF, CST, DCOM, DIE, DISCA, DSIC, HMA, ISA, URB, TER, TRR, y MOT, y su profesorado supone el $42 \%$ del PDI de la UPV.

Sólo en 3 departamentos (enmarcados en verde) TAL, CRBC e IDM, el porcentaje de mujeres es superior en todas las categorías. En los restantes predominan en general los hombres especialmente en las figuras de mayor categoría, abriéndose las puntas de las tijeras conforme se acercan a la figura de CU.

Esta descripción de la distribución del profesorado por departamentos es imprescindible y fundamental para reflexionar acerca de las posibles causas de la desigualdad. No hay que olvidar que el director/a de cada departamento es quien solicita a Rectorado la creación de nuevas plazas docentes, y quien nombra las comisiones que han de juzgar los méritos de los aspirantes a las distintas figuras laborales, así como los tribunales para las plazas de funcionario. Además, dichas comisiones están formadas por tres miembros elegidos por el Rector, y dos designados por el Consejo del Departamento al que se adscribe la plaza, todos pertenecientes a cuerpos de funcionarios docentes universitarios y con titulación oficial igual o superior a la de la plaza convocada (colectivos masculinizados, como se aprecia en la Figura 15). Considerando que el 85\% de los directores de los departamentos de la UPV son hombres (Guardiola-Víllora et al.), y habiendo detectado tras un análisis no exhaustivo de la composición de las últimas comisiones de evaluación nombradas en 2016-17, que la mayoría apenas tiene un $20 \%$ de representación femenina, se podría pensar que el colectivo masculino favorece a sus colegas. 
El profesorado de la Universitat Politècnica de València desde la perspectiva de género 265

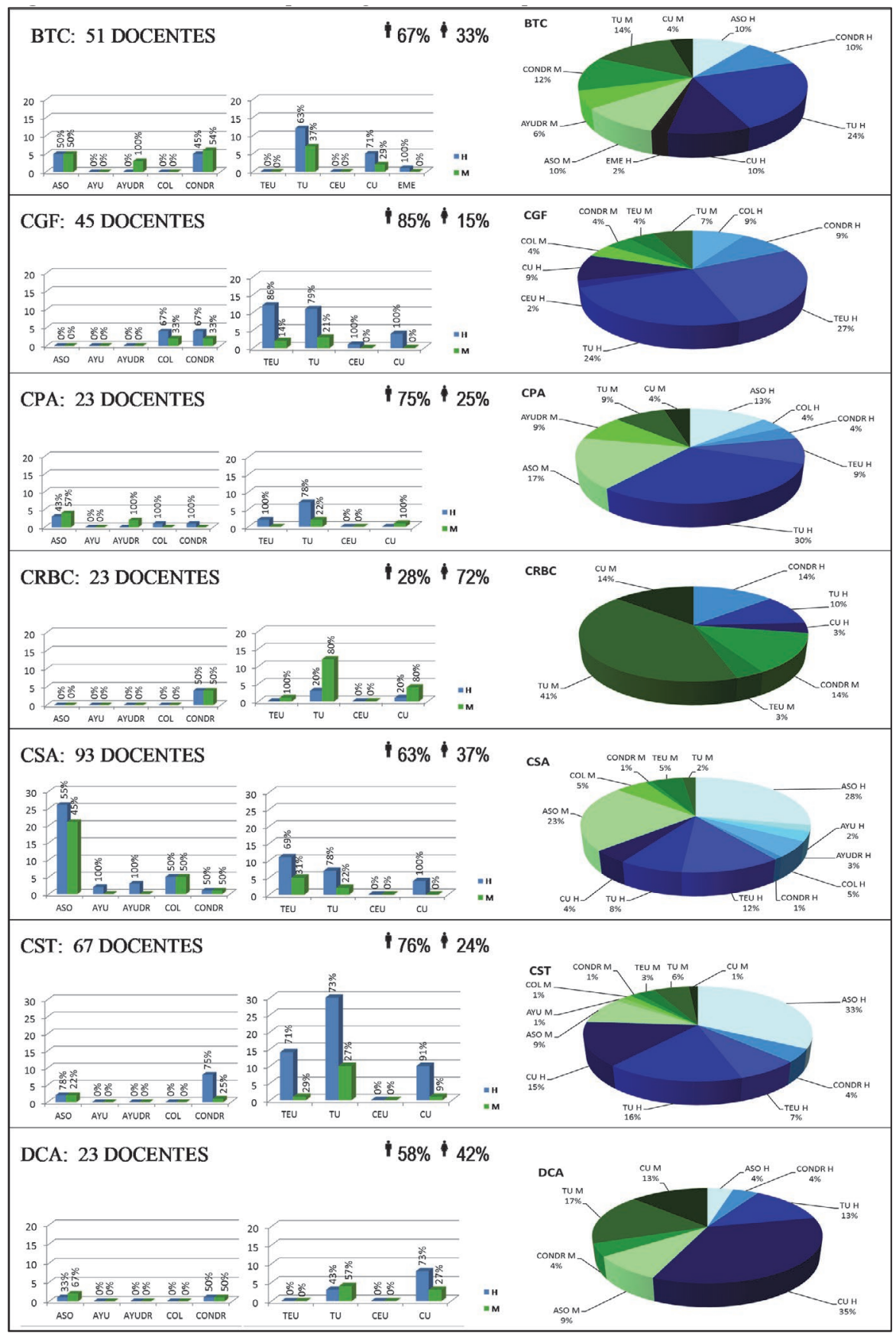

Figura 14a. Distribución PDI por categorías en cada departamento

Feminismo/s 29, junio 2017, pp. 243-277 


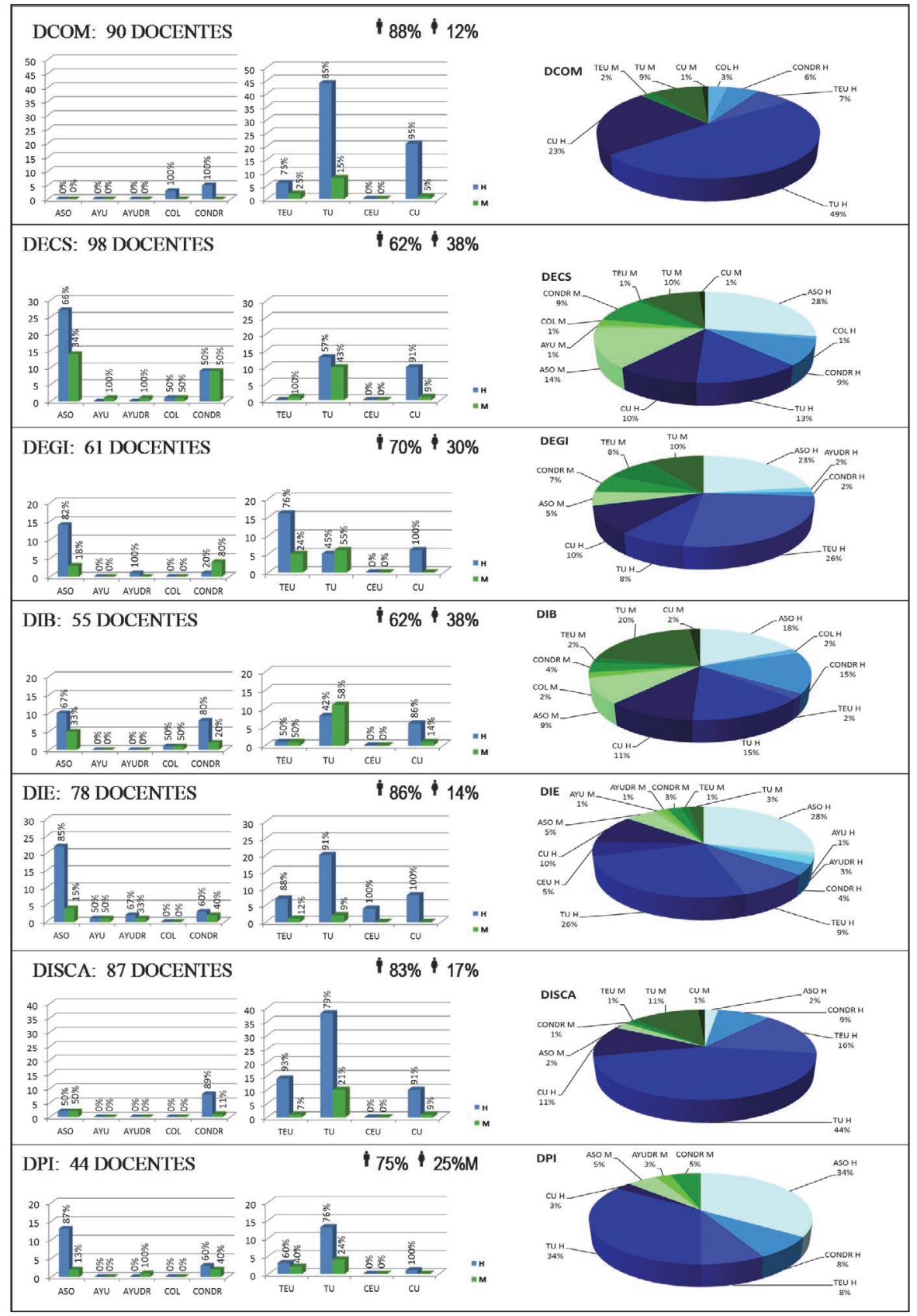

Figura 14b. Distribución PDI por categorías en cada departamento 


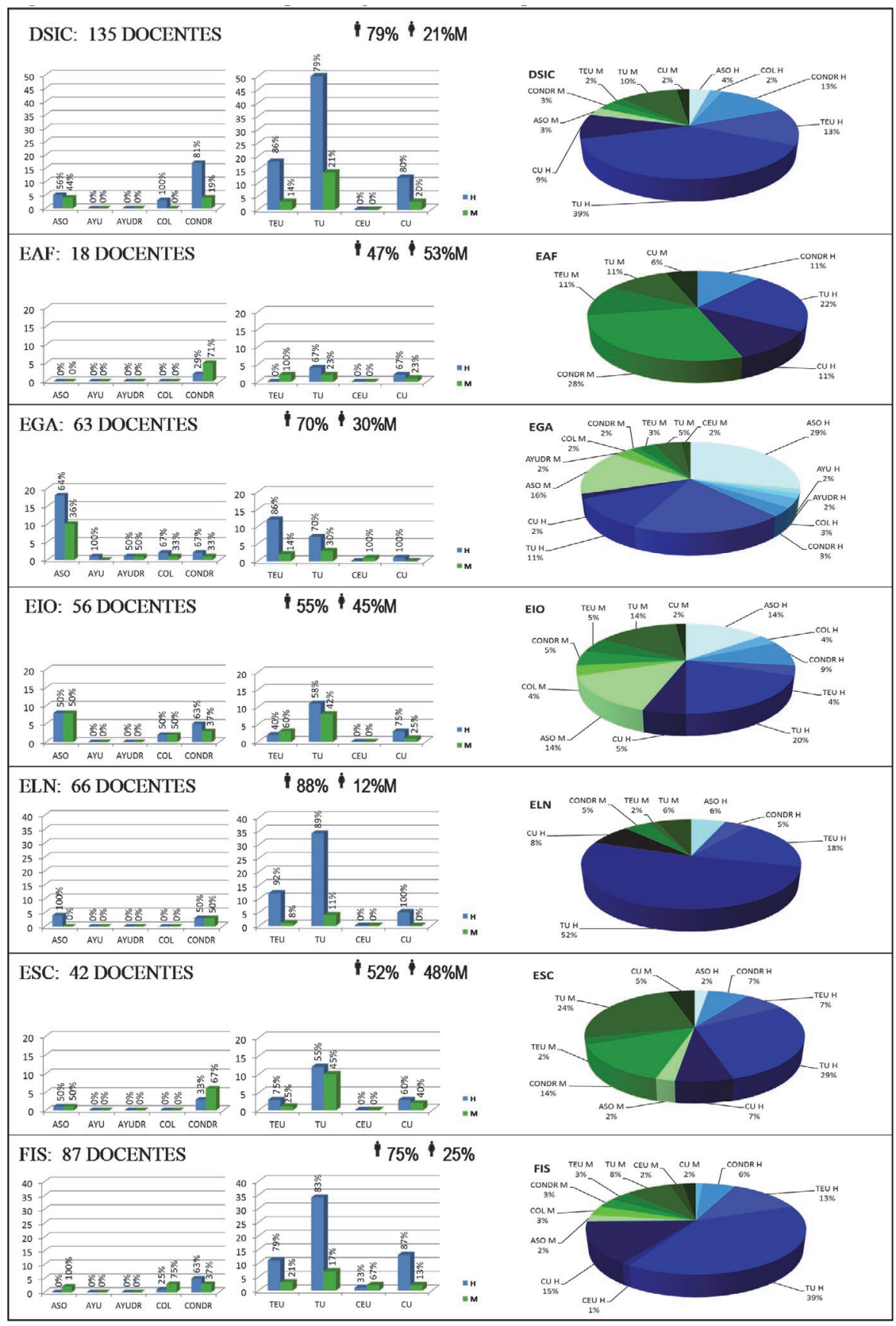

Figura 14c. Distribución PDI por categorías en cada departamento 


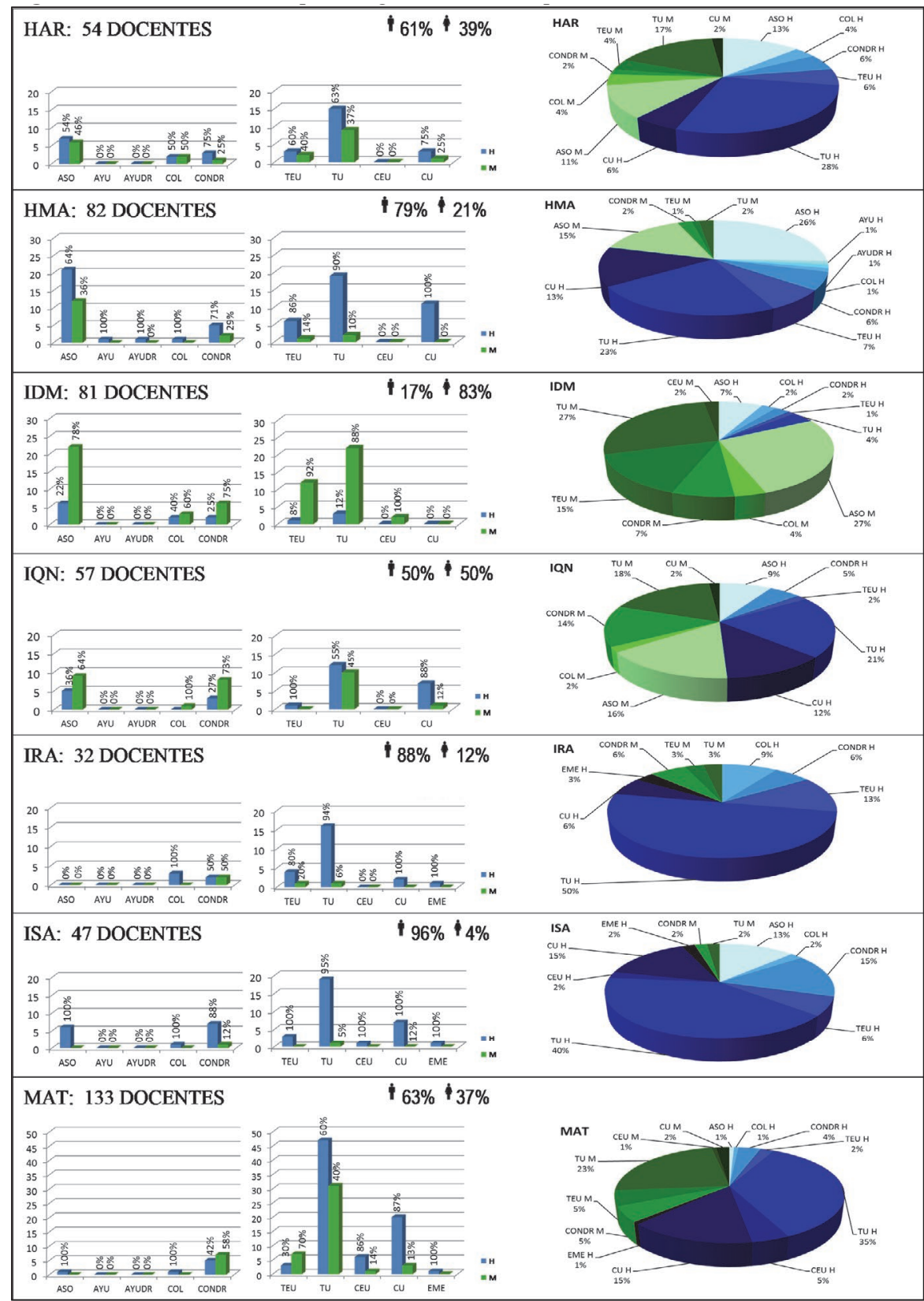

Figura 14d. Distribución PDI por categorías en cada departamento 


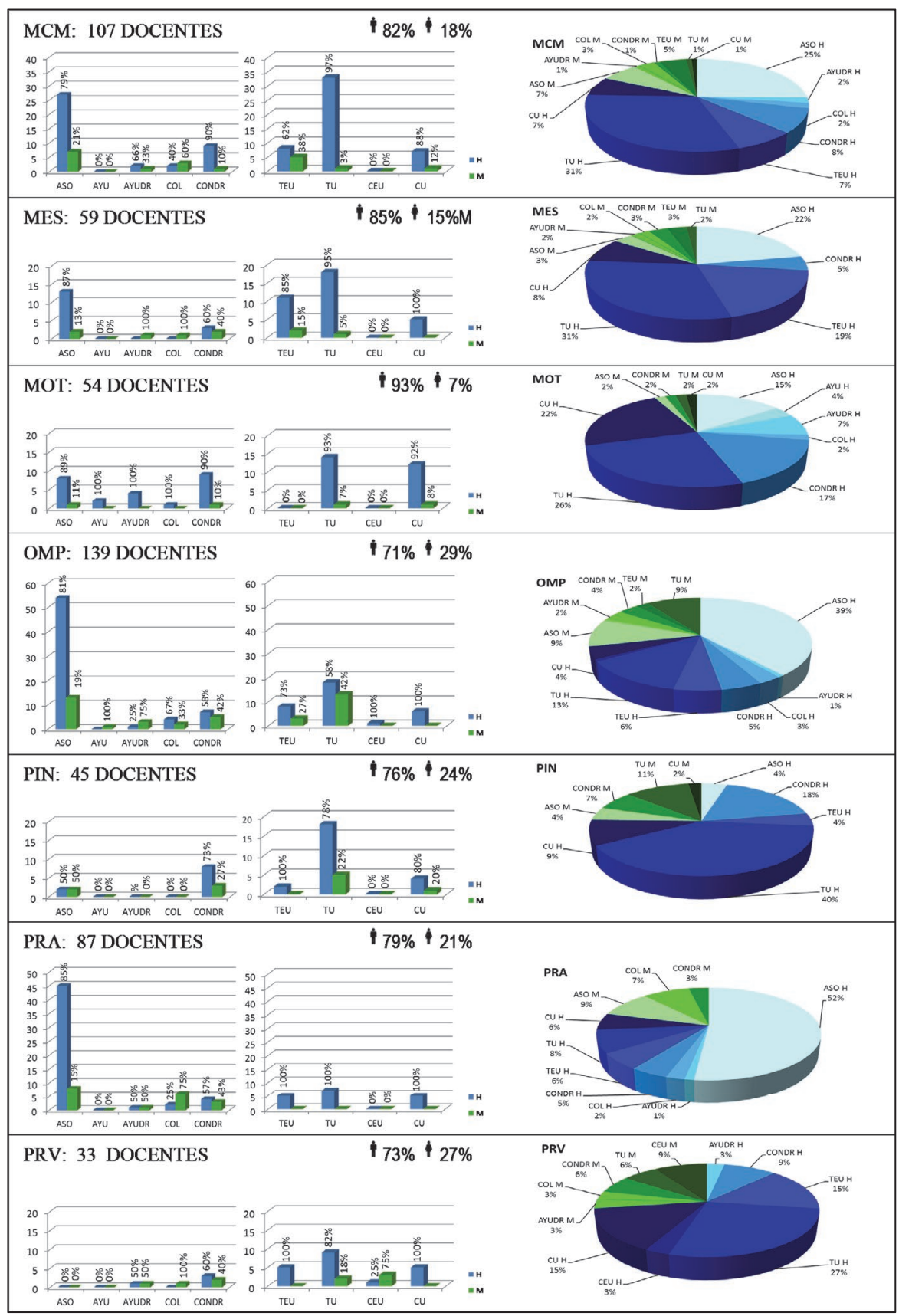

Figura 14e. Distribución PDI por categorías en cada departamento 


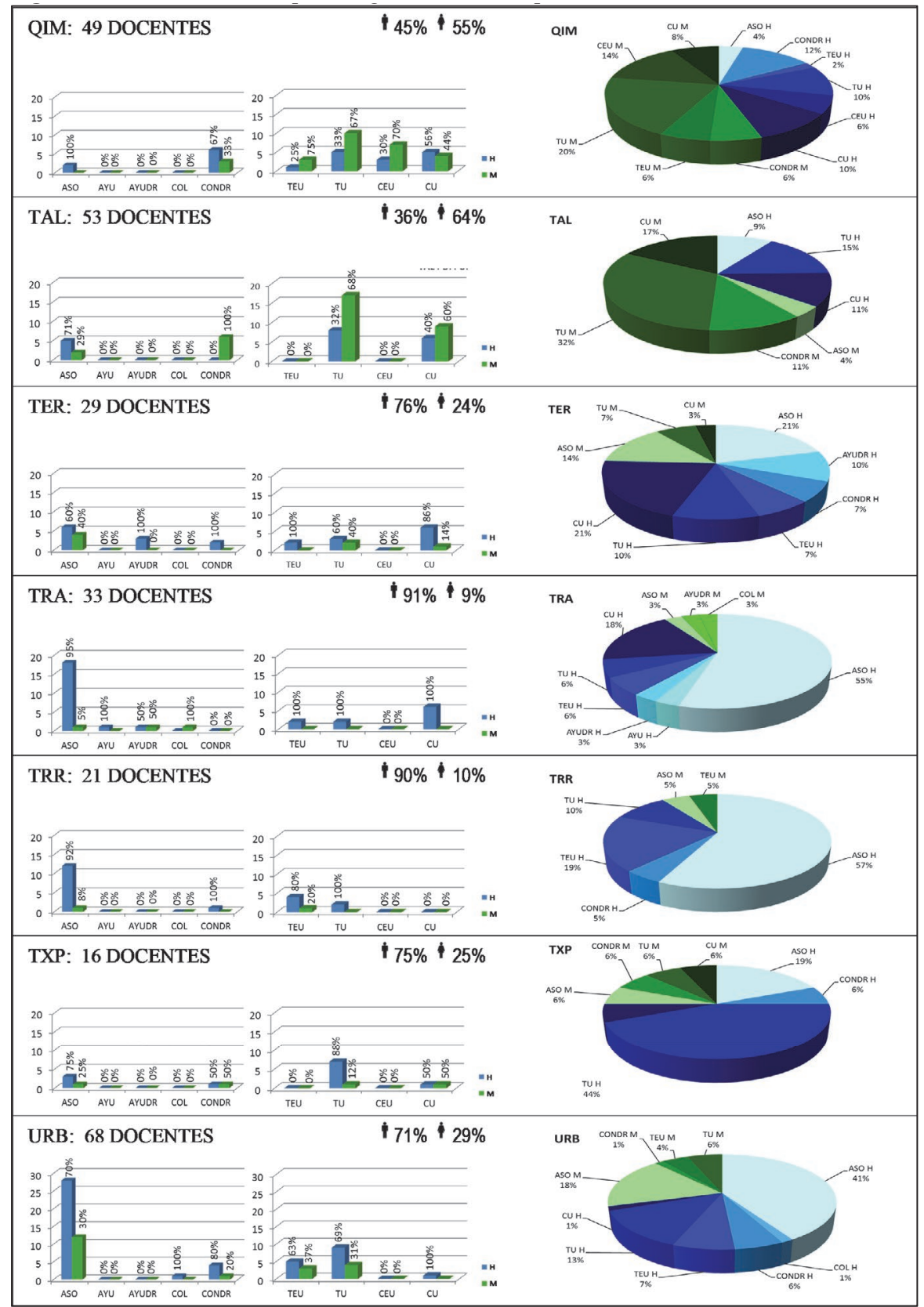

Figura 14f. Distribución PDI por categorías en cada departamento 


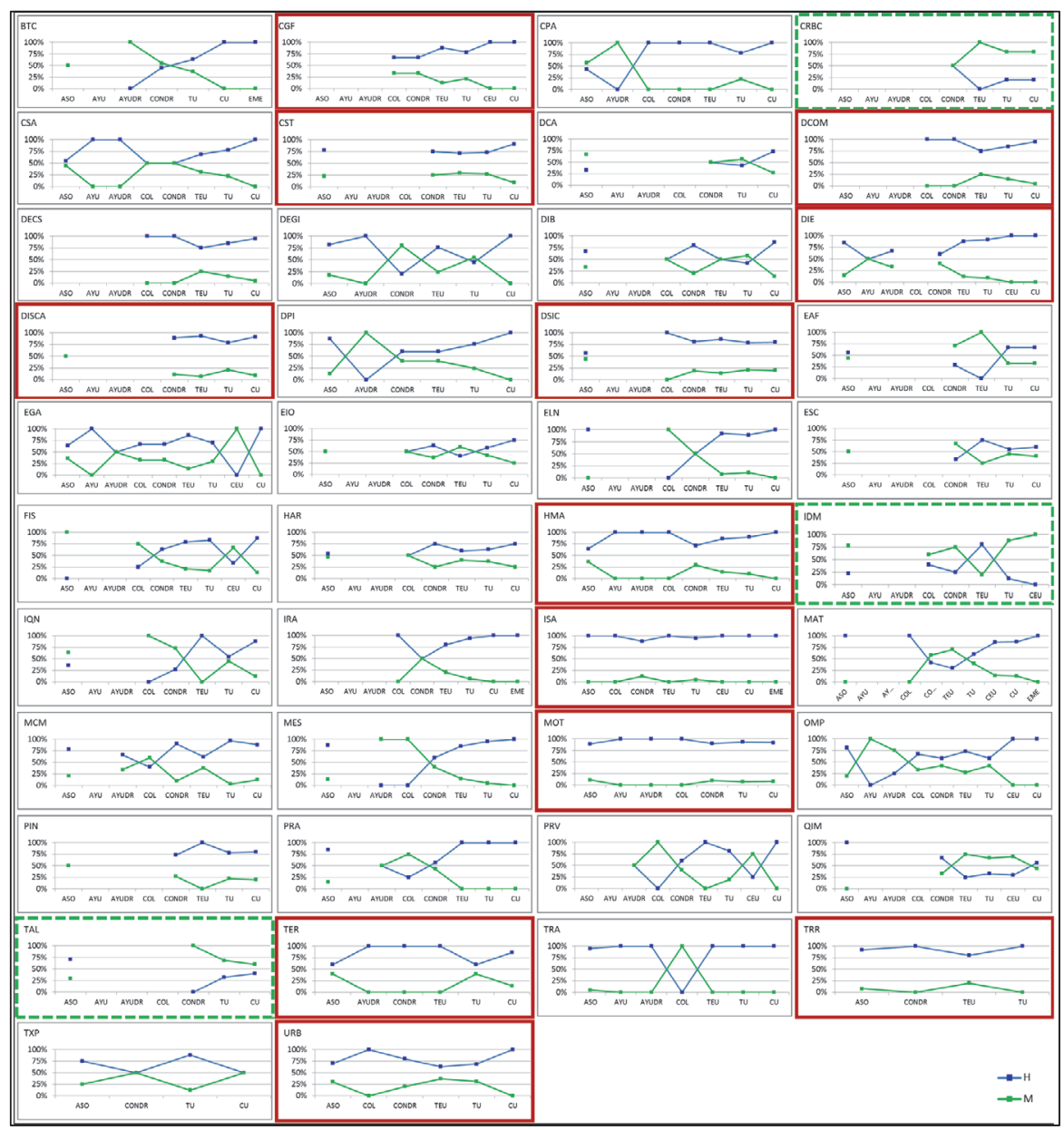

Figura 15. Desigualdades en la distribución PDI por categorías en cada departamento

\section{CONCLUSIONES}

El retrato de la situación del profesorado de la UPV desde la perspectiva de género muestra las siguientes características:

La presencia de las mujeres como docentes está muy alejada de los niveles masculinos, no representando siquiera un tercio (30\%). Esta distribución se aleja de lo que la Ley Orgánica 3/2007 de 22 de marzo, entiende por «composición equilibrada» definida como aquella situación en la que las personas de cada sexo no sean menos del $40 \%$. 
La UPV presenta un importante grado de segregación horizontal: considerando las diversas entidades que la componen (escuelas y facultades), solo tres alcanzan la "composición equilibrada», superando apenas el 40\% (ETSIAMN, FADE y FBBAA), es decir, el 66\% de los centros no alcanza la situación igualitaria. Además, hay que destacar que dos escuelas presentan un porcentaje de profesoras inferior al 25\% (ETSCCP y ETSIT).

En cuanto a los departamentos, se aprecia un ligero avance desde el 2001, en que el $71,5 \%$ de departamentos tenía menos del $25 \%$ de presencia femenina, mientras que en diciembre de 2015, el porcentaje se reduce al $60 \%$ de los departamentos (o un $40 \%$ si se incluye el profesorado no funcionario).

En relación a los departamentos MOT, TRA e IRA, sin mujeres en el 2001, han aumentado ligeramente su presencia, con un $7 \%, 12 \%$ y $12 \%$ respectivamente. Sin embargo, a fecha de hoy, ni el departamento de transportes (TRA) ni el de proyectos arquitectónicos (PRA) cuenta con mujeres entre su profesorado funcionario.

Por otro lado, la UPV presenta sobretodo un importante grado de segregación vertical: a medida que se asciende en la jerarquía académica la proporción de mujeres disminuye. En el análisis del profesorado por categorías, sólo se alcanza el $40 \%$ entre las figuras AYUDR, COL (no funcionarios) y CEU (categoría a extinguir).

Es innegable que la situación ha cambiado desde aquel 7 de julio de 1981 cuando se publicó en el BOE (BOE, 1981) el nombramiento M. ${ }^{a}$ Dolores Climent Morato, primera catedrática de la UPV. Sin embargo, más de tres décadas después sólo un 16\% de los CU de la UPV son mujeres, limitándose su presencia al 55\% de los departamentos, mientras que un 93\% de los departamentos tiene CU hombres.

Este fenómeno refleja la existencia de un «techo de cristal» para las mujeres, con consecuencias en cuanto al grado de estabilidad laboral, niveles de ingresos, control y poder de decisión, asociados a las distintas categorías laborales.

Explorar las causas que han llevado a esta situación de desigualdad en la UPV no es objetivo de este trabajo, pero seguramente coinciden con las de otras instituciones de Educación Superior. En la Universidad actual, a pesar de que formal y aparentemente todos sus miembros están sometidos a un sistema meritocrático, persisten la opacidad de los sistemas de selección y promoción y el sesgo de género en la evaluación de méritos (Castaño; Pastor y Acosta). Además, a estas barreras se añaden las conocidas dificultades para conciliar trabajo y vida personal (Castaño) porque las mujeres siguen responsabilizándose de la mayor parte de la carga reproductiva y de las labores de cuidado (Guil 2016). En consecuencia, la Universidad no puede considerarse una institución 
igualitaria, porque todavía presenta obstáculos invisibles de tipo político, de intereses, de prejuicios, etc. que perjudican y discriminan indirectamente a las mujeres. Pero lo más grave es que estas desigualdades de género tienden a negarse, son inconscientes y, bajo el espejismo de la igualdad formal, se consideran ya resueltas. De ahí la importancia de este diagnóstico como paso previo para favorecer el debate de la comunidad universitaria y para empezar a trabajar en la resolución del problema.

El escaso compromiso político de la UPV como institución, que se ha limitado al mero cumplimiento de las leyes, ha sido determinante de la lentitud del cambio. Un aumento claro de su compromiso con las políticas de igualdad, plasmado a través del apoyo incondicional a su unidad de igualdad, se revela como medida indispensable para la reforma de su cultura institucional y para transformarse en una institución más inclusiva. A partir de ahí medidas concretas podrían dirigirse a evitar sesgos en los procesos de selección y promoción a través de, por ejemplo, formación en conciencia de género para las comisiones de contratación y aumento del porcentaje de mujeres participantes en las mismas, y la consideración de los permisos de maternidad en la valoración de méritos y del currículum. Asimismo, para las escuelas o departamentos con peores cifras de participación femenina podría llevarse a cabo una discriminación positiva temporal, hasta conseguir cifras más equilibradas. A todo ello se sumaría la promoción de prácticas que faciliten la conciliación de hombres y mujeres.

La UPV presume de ocupar puestos destacados en los principales rankings nacionales e internacionales de Educación Superior. Sin embargo, en términos de igualdad se sitúa casi a la cola de las universidades españolas. Aunque su especialización en ingeniería y tecnología, campos tradicionalmente masculinos, supone un desafío adicional, ha llegado el momento de promover la equidad, eliminando barreras estructurales para aumentar la participación de las mujeres, con una perspectiva a largo plazo. No actuar supone mermar la capacidad de innovación y competitividad de la propia institución, desaprovechar parte de la inversión social e individual en capital humano, además de ir contra la justicia social, ¿puede permitírselo?

\section{REFERENCIAS BIBLIOGRÁFICAS}

Acosta, Ana, Inma Pastor y Angel Belzunegui. «Las políticas de igualdad en las universidades españolas: aproximación desde un estudio de redes». 1st International Virtual SBRLab Conference. "Finding solutions for a post-crisis society», Universitat Rovira i Virgili, Tarragona (2015): 291-307. 24-05-2016. 
Alcañiz, Mercedes (ed.). «La conciliación de la vida laboral y familiar en la Universitat Jaume I». Publicacions de la Universitat Jaume I, Servei de Comunicació i Publicacion, 2014. 15-01-2016

Alonso, Maria José. «Las académicas. Profesorado universitario y género». Revista de Educación, 328 (2002): 465-475.

Anguita, Rocio. (coord.). Las mujeres en la Universidad de Valladolid. Universidad de Valladolid, 2003.

Antón, Susana. Informe: Académicas en la Universidad de Alicante. Centro de Estudios sobre la Mujer-Universitat d'Alacant, 2005. 16-10-2015.

Barberá, Ester, Maria Josefa Lafuente y Maite Sarrió. La promoción profesional de las mujeres en la Universidad. Promolibro, Valencia, 1998.

Basset-Salom, Luisa; Arianna Guardiola-Víllora y Begoña Serrano-Lanzarote. «20 años de presencia femenina en la Escuela Técnica Superior de Arquitectura de Valencia y en el Departamento de Estructuras». Jornadas Internacionales de Arquitectura y Urbanismo desde la perspectiva de las arquitectas. Instituto Juan de Herrera (2009).

BOE n. ${ }^{\circ} 232$ del 29 de septiembre de 1981. 20-01-2016

Castaño, Cecilia. «La nueva gestión pública y las políticas de igualdad de género en las universidades». Investigaciones Feministas 7.2 (2016): 225-245.

Comission of the European Communities. Progress towards Lisbon objectives in education and training. SEC. Bruselas, 2005.

De los Cobos, Francisco. «Planes de igualdad en las universidades españolas. Análisis de contenido desde las ciencias sociales». Barataria: Revista CastellanoManchega de Ciencias Sociales 14 (2012): 117-130.

Elizondo, Arantxa, Ainhoa Novo y María Silvestre. «La presencia de mujeres y hombres en las universidades españolas». Aequalitas: Revista Jurídica de Igualdad de Oportunidades entre Mujeres y Hombres 21 (2007): 25-34.

Elizondo, Arantxa, Ainhoa Novo y María Silvestre. Igualdad de mujeres y hombres en las universidades españolas, Universidad del País Vasco, Facultad de Ciencias Sociales y de la Comunicación, Departamento de Ciencia Política y de la Administración. Instituto de la Mujer, 2010.

Escolano, Esther. «Mujeres y función pública. El personal de administración y servicios de la Universitat de València», Publicacions de la Universitat de València Valencia, 2002.

Escolano, Esther. «Entre la discriminación y el mérito: las profesoras en las universidades valencianas». Publicacions de la Universitat de València, València, 2006.

Estellés-Miguel, Sofía, Antonio Navarro-García, Marta E. Palmer Gato y José Miguel Albarracín Guillem. «Gender Inequality in University Administration and Services», Business and Management Research 3.4 (2014): 89-95.

European Commission «Structural Changes in Research Institutions. Final report» Science in Society (2012). 
European Commission. She figures, 2015: Gender in Research and Innovation. Directorate General for Research and Innovation. Brussels, 2016. 21-04-2016 Fernández-Coronado, Rosario y $\mathrm{M}^{\mathrm{a}}$ Eugenia González. Mujeres y hombres en la Universitat de València, Unitatd'Igualtat - Universitat de València, 2009.

Guil, Ana. «Techos de Cristal en la Universidad Hispalense». Informe final del proyecto del Plan Nacional I+D+i 2001-2004 Sevilla, Universidad de Sevilla, 2005. 15-01-2016.

Guil, Ana. «Mujeres y Ciencia: Techos de Cristal». ECCOS Revista de Investigación Científica, Universidade Nove de Julho, Brasil. www.uninove.br/ publicaçoês, (2008): 213-232.

Guil, Ana y Consuelo Flecha.»Universitarias en España: de los inicios a la actualidad». Revista Historia de la Educación Latinoamericana 17.24 (2015): 125-148.

Guil, Ana. «Techos universitarios de cristal blindado». Investigaciones Feministas 7.2 (2016): 25-39.

Guardiola-Víllora, Arianna, Luisa Basset-Salom y Elena Navarro-Astor. «Women's participation in academic management teams: the case of the Universitat Politècnica de València». Proceedings of INTED, (2016): 1880-1887.

Instituto Nacional de Estadística, INE. Estadística para la Enseñanza Universitaria en España, curso 2004-2005: Personal docente de los centros propios de las Universidades Públicas por Área de conocimiento, Sexo y Categoría, 2006. < http://www.ine.es/> consultado el 16-10-2015

Izquierdo, M. ${ }^{a}$ Jesús (dir.). El sexisme a la UAB. Propostes d'actuació i dades per a un diagnòstic. Barcelona, GESES-Universita Autònoma de Barcelona, 2004.

Jiménez, Marta Esther. «El género en el profesorado. El caso de las profesoras universitarias». Clepsydra. Revista de Estudios de Género y Teoría Feminista 2 (2003): 71-101.

Lecuona, María del Pino. «Género y Universidad». Enseñanza E Teaching 23 (2005): 143-160.

Lozano Cabezas, Inés, Marcos Jesús Iglesias Martínez y Ma Ángeles Martínez Ruíz. «La cultura de igualdad de oportunidades en el tejido universitario europeo». Revista Interamericana de Investigación, Educación y Pedagogía 6.2 (2013): 31-59.

Lozano Cabezas, Inés y Marcos Jesús Iglesias Martínez. «La presencia de académicas a lo largo de la historia en la Educación Superior española». Journal for Educators, Teachers and Trainers 5.3 (2014): 204-216.

Lozano Cabezas, Inés, Marcos Jesús Iglesias Martínez y Mª Ángeles Martínez Ruíz. «Un estudio cualitativo sobre los diferenciales de género en la educación superior: percepciones de las académicas en contextos masculinizados». La Manzana de la Discordia 11.1 (2016): 41-54.

Marqués, Marisol, M. Nuria Salán y Silvia Gómez. Estudio comparativo de la carrera académica del profesorado en las universidades públicas politécnicas españolas 
desde una perspectiva de género. Universitat Politècnica de Catalunya, 2012. 16-10-2015.

Matus-López, Mauricio y Nazareth Gallego-Morón. «Techo de cristal en la Universidad. Si no lo veo no lo creo». Revista Complutense de Educación 26.3 (2015): 611-626.

Mauleón, Elba y María Bordons. «Indicadores de actividad tecnológica por género en España a través del estudio de patentes europeas». Revista Española de Documentación Científica, 37(2):e043. (2014). DOI: http://dx.doi. org/10.3989/ redc.2014.2.1093

MEC-UMYC. Científicas en cifras 2013. Estadísticas e indicadores de la (des)igualdad de género en la formación y profesión investigadora. Ministerio de Economía y Competitividad. Unidad de Mujeres y Ciencia, 2014.

MECyD. Datos y cifras del Sistema Universitario Español. Curso 2014/2015. Ministerio de Educación, Cultura y Deporte (2015a). <http://www.mecd. gob.es/dms/mecd/educacion-mecd/areas-educacion/universidades/estadisticas-informes/datos-cifras/Datos-y-Cifras-del-SUE-Curso-2014-2015.pdf>, consultado el 16-10-2015.

MECyD. Avance de la Estadística de estudiantes universitarios. Curso 20142015. Cap III. Datos por Universidad. Ministerio de Educación, Cultura y Deporte (2015b). <https://www.educacion.gob.es/educabase/menu. do? type $=$ pcaxis\&path=/Universitaria/Alumnado/Avance/2014-2015/ CapituloIII/Publicas\&file=pcaxis\&l=s0>, consultado el 16-10-2015.

Morales, M. ${ }^{a}$ Jesús, M. José Luna y Ana Isabel Esteban. «Diagnóstico de paridad en la Universidad: análisis a través de indicadores». Revista de Universidad y Sociedad del Conocimiento 7.2 (2010): 1-14.

Navarro-Astor, Elena, Marisa Román-Onsalo y Margarita Infante-Perea. «Revisión internacional de estudios de barreras de carrera bajo la perspectiva de género en la industria de la construcción». Innovar 26.61 (2016): 103-118.

Pastor, Inma, Paloma Pontón, Angel Belzunegui y Nuria Serret, «Políticas de igualdad en la Universidad: una reflexión sobre los planes de igualdad en América Latina y España». Proceedings V Congreso Universitario Internacional «Investigación y Género», SIEMUS, Universidad de Sevilla (2014): 639-658

Pastor, Inma, Paloma Pontón, Angel Belzunegui y Ana Acosta. «Gender Policies in Spanish Universities: From Regulation to Equality Plans». En: Desivilya H. y Costea, CE (editores): Women's Voices in Management. Identifying Innovative and Responsible Solutions. Palgrave Macmillan (2015): 34-51.

Pastor, Inma y Ana Acosta. «La institucionalización de las políticas de igualdad de género en la Universidad Española. Avances y retos». Investigaciones Feministas 7.2 (2016): 247-271.

Pastor-Gosálbez, Inma, Glòria Solsona, y Francesc Valls. «Desigualtat a la universitat per raó de gènere? La situació de les dones a la Universitat Rovira i 
Virgili: de la diagnosi a les mesures d'igualtat». Revista Catalana de Sociologia 25 (2010): 55-72.

Perelló, Fátima. Asimetrías de género en la Universitat de València. Universitat de València, 2012.

Perelló, Fátima «La vulnerabilidad profesional femenina a la vuelta de la esquina. El caso del personal de administración y servicios de la Universitat de València». Arxius 28.9 (2013): 3-104.

Sánchez de Madariaga, Inés. «Advancing Gender Equality in Research and Innovation in Europe and beyond: COST network genderSTE», Journal of Research in Gender Studies 3 (2013): 131-143.

Sánchez de Madariaga, Inés. Women at UPM. Gender statistics at Universidad Politécnica de Madrid. UPM. (2014). 16-10-2015.

Santamarina, M. Pilar, Ma Rosa Cerdá, Amparo Quilis y Ana Muñoz. Antecedentes y acciones emprendidas en la UPV en materia de igualdad. Vicerrectorado de Asuntos Sociales y Responsabilidad Social Corporativa. UPV, 2011.

Santos, Juan Antonio, David Muñoz-Rodríguez y Manuela Poveda, «En cuerpo y alma. Intensificación y precariedad en las condiciones de trabajo del profesorado universitario». Arxius de Sociología, 32 (2015): 13-44.

Santos, José Luis. Nacimiento de una Universidad (algunos recuerdos). Servicio de Publicaciones UPV. Valencia. Universitat Politècnica de València, 1993. 



\title{
ANDROCENTRISMO ACADÉMICO: LA FICCIÓN DE UN CONOCIMIENTO NEUTRAL ${ }^{1}$
}

\section{ACADEMIC ANDROCENTRISM: THE FICTION OF NEUTRAL KNOWLEDGE}

\author{
Laura NUÑO GÓMEZ \\ lauranunog@hotmail.com \\ orcid.org/0000-0001-6794-5402 \\ ENRIQUE ÁLVAREZ CONDE \\ enrique.alvarez@urjc.es \\ orcid.org/0000-0001-5836-5764 \\ Universidad Rey Juan Carlos
}

\section{Resumen}

Las universidades españolas cuentan en la actualidad con una presencia normalizada de mujeres en las aulas y una legislación que obliga a incorporar los estudios de género y una perspectiva no androcéntrica en la docencia y la investigación. Sin embargo, los techos y paredes de cristal siguen presentes, los estudios de género no se han integrado de forma normalizada y las diferentes disciplinas comparten una visión androcéntrica del conocimiento. Tras la adopción del conocido Plan Bolonia, lejos de acatar tal mandato se ha otorgado un tratamiento periférico a dicha disciplina. Este artículo aborda el estado de la cuestión en las universidades públicas españolas, identifica algunos elementos problemáticos así como posibles soluciones.

Palabras clave: androcentrismo, estudios de género, Educación Superior, políticas de igualdad, teoría feminista.

1. Este trabajo ha sido realizado en el marco del Proyecto «Multisectorial Academic Programme» Ref. JUST/2014/RDAP/AIG/HARM/7937. Programa: Derechos, igualdad y ciudadanía 2014-2020 de la Dirección General de Justicia de la Comisión Europea, dirigido por la autora. 


\begin{abstract}
Spanish universities have a normalized presence of women and are bound by law to incorporate gender studies and a non androcentric perspective in teaching and research. Nevertheless, ceilings and glass walls remain, gender studies have not been mainstreamed and the different disciplines have androcentric views on knowledge. After the adoption of the so-called Bolonia Plan, far from implementing the legal duty, the treatment provided to gender studies in the Higher Education system has been peripheric. This article adresses this situation in public universities, hightlights some problematic elements as well as possible solutions.
\end{abstract}

Keywords: androcentrism, gender studies, higher education, equality policies, feminist theory. 


\section{LA DESPATRIARCALIZACIÓN INCOMPLETA}

En la década de los años sesenta las aulas de las universidades españolas empezaron a contar, por fin, con una presencia femenina reseñable. Atrás quedaba la burla o la peyorativa consideración de las mujeres con pretensiones educativas o intelectuales recogida en novelas tan populares como Las mujeres sabias de Moliere, La culta latiniparla de Quevedo o La dama boba de Lope de Vega (Nuño 150)2. Sin embargo, como señala Flecha, todavía «transitaban un espacio cargado de la tradición de quienes lo habían diseñado, establecido y ocupado con la conciencia de que solo a ellos pertenecía» (224). Medio siglo y una transición política después, la proporción de mujeres no solo es superior entre el alumnado universitario $(55,8 \%)$, sino entre quienes logran graduarse con éxito $(58,3 \%)^{3}$. Cuestión diferente es hasta qué punto o grado la tradición y el androcentrismo originario siguen operando en el sistema universitario español, impidiendo con ello el cumplimiento del mandato legislativo que obliga a promover la igualdad en los órganos de gobierno, el fomento de los estudios de género y la adopción de una perspectiva no androcéntrica en la docencia y la investigación.

La equiparación formativa de las mujeres y el paulatino incremento de su presencia entre el profesorado no se ha visto secundado por una redistribución del poder acorde con la nueva composición de las universidades. Todos los datos revelan una sobrerrepresentación masculina en los órganos de gobierno, máxime en cargos de libre designación (Morales, Luna y Esteban), que se evidencia en el conocido "gráfico tijera» según el cual la presencia femenina va disminuyendo según van siendo superiores las categorías y responsabilidades académicas, situación que se invierte en el caso de los varones. Según

2. El derecho de las mujeres a una instrucción no segregada, alejada del esencialismo rousseauniano, ha sido una pírrica conquista que conviene recordar como tal. No obstante, a lo largo de la historia no solo existió tal veto o segregación, sino que la capacidad intelectual de las mujeres fue sometida a otros mecanismos de extraordinaria eficacia para la ocupación masculina del saber: el determinismo naturalista, la exigencia de demostración, la excepcionalidad y la criba histórica patriarcal (Nuño 151-153).

3. Fuente: Informe «Científicas en cifras 2013». Unidad de Mujeres y Ciencia (UMyC). Ministerio de Economía y Competitividad. 
el último informe "Científicas en Cifras» de la Unidad de Mujeres y Ciencia (UMyC), entre el profesorado Ayudante Doctor/a y Contratada/o Doctor/a casi la mitad son mujeres (48,5\%), mientras que no llegan a la quinta parte entre Catedráticos/as de Universidad y Profesorado Emérito (46). Y, si bien es cierto que la proporción de catedráticas es paulatinamente superior, su participación en los órganos de gobierno se ha estancado durante los últimos años ${ }^{4}$. Todos los datos existentes confirman que las mujeres continúan siendo élites discriminadas (según acepción de García de León, 1990) sobre las que operan múltiples criterios excluyentes, entre otros, los estereotipos de género, la división sexual del trabajo y los techos o paredes de cristal ${ }^{5}$.

La falta de correlación entre la presencia femenina en las aulas y en las cátedras o posiciones que comporten reconocimiento, es un fenómeno que se observa también a escala comunitaria. En el contexto de la Unión Europea las mujeres representan el 59\% del alumnado universitario pero sólo el 20\% de los puestos académicos de alto nivel (Parlamento Europeo 9). Sin embargo, a diferencia del ámbito europeo o internacional, el sistema universitario español se muestra más impermeable a la inclusión del género como área de conocimiento o categoría de análisis. Así, las principales universidades europeas o norteamericanas ofertan, desde hace más de tres décadas, consolidados grados en la materia. Harvard, Columbia, Brown, Yale, París, Oxford, Heiderlberg, Michigan, Cornell, Princeton, Concordia, Toronto, Western Australia, Utrecht, Dublín, Lancashire, Oakland, New Jersey, Illinois, San Francisco, Washington o Sidney representan solo algunos de los centros académicos en los que se puede cursar estudios superiores de género ${ }^{6}$.

4. En el curso 2008-2009 la proporción de mujeres entre catedráticos/as y profesorado emérito representaba el 15,3\% mientras que en el curso 2011-2012 se incrementó en 4,4 puntos porcentuales. Por el contrario la presencia de rectoras se mantiene en el $6 \%$, la de decanas y directoras de escuela en torno al $25 \%$, siendo superior su participación en vicerrectorados y vicedecanatos, con una presencia del $41,3 \%$ y $45,4 \%$, respectivamente). Para un estudio sobre el desequilibrio de género en la ciencia y la universidad consultar, entre otros, García León 1990 y 2002, Müller et al, Caprile o Sánchez de Madariaga et al.

5. Para un análisis sobre cultura académica y desigualdad, consultar Lozano et al.

6. Normalmente reciben la denominación de Studies of Women, Gender and Sexuality. Aunque la existencia de tales titulaciones permite que el alumnado adquiera una titulación superior especializada en la materia, conviene advertir que, como señala De Miguel, la habitual conexión entre género y sexualidad representa un elemento que puede desviar la atención de uno de los aspectos centrales de la desigualdad: la distribución del poder. Fraisse repara, a su vez, en otro elemento problemático en la medida que «remitir a la sexualidad nos hace asimilar con demasiada rapidez orientación sexual y actividad sexual (género y sexualidad-es son palabras pronunciadas profusamente en coloquios y seminarios)» (61) pero «el sexo es mucho más que la sexualidad» (70). La reiterada conexión entre género y sexualidad «mezcla, de manera completamente intencionada, 
En el estado español, el Grado de Igualdad de Género de la Universidad Rey Juan $\mathrm{Carlos}^{7}$ (único existente hasta la fecha), se encuentra en la actualidad en proceso de extinción. Los grados en general carecen de contenidos o perspectiva de género y dicha dimensión no se ha incorporado en los sistemas de evaluación de la docencia o la investigación. El profesorado no interioriza su falta de formación en la materia como un déficit formativo y el androcentrismo en los contenidos, normas y estándares académicos, permea en su conjunto la organización y el funcionamiento del sistema universitario, percibiéndose como si fuera un enfoque objetivo y neutral.

El alumnado universitario, por su parte, procede de un sistema educativo que tampoco incorpora la perspectiva de género como categoría de análisis. La coeducación no se ha hecho efectiva ni en enseñanza primaria ni en secundaria. La formación en igualdad (máxime tras la eliminación de la asignatura «Educación para la ciudadanía») está ausente en la educación formal y determina el denominado currículo oculto (Viveros 195). Todo lo cual provoca que, de forma inevitable, el alumnado naturalice una visión androcéntrica del conocimiento y cuando accede a los estudios universitarios no detecte nada extraño ante la ausencia de una dimensión que desconoce. Un hecho que favorece la reproducción de las ideologías sexuales, la normalización de los estereotipos de género y, como señalan Donoso y Martínez, tiene implicaciones ineludibles en el análisis de la realidad y de los posibles marcos interpretativos (84).

En resumidas cuentas, la desigualdad sexual como objeto de reflexión académica se halla «fuera de campo de los grandes interrogantes de la humanidad, a la intemperie de aquello instituido como pensamiento» (Fraisse 69). La tónica habitual es que sólo las personas con formación en género y políticas de igualdad manifiestan voluntad y capacidad para incorporarla. Por lo general, un reducido número de docentes o discentes, mayoritariamente mujeres ${ }^{8}$, que han de lidiar, desde el conocido techo de cristal y las barreras que supone

orientación sexual y confusión (supuesta) de los sexos, como si ambas cosas fueran necesariamente de la mano» (73).

7. Aprobado por el Consejo de Universidades en marzo de 2010 en un recurso de alzada que contravino el criterio mantenido hasta entonces por la Agencia Nacional de Evaluación de la Calidad y Acreditación (ANECA) según la cual, dichos estudios carecían de la unidad de conocimiento propia de un grado.

8. En este sentido, conviene advertir que existe cierta percepción sobre que «estos temas» son un asunto de mujeres o de feministas, cumpliéndose en la mayoría de las ocasiones ambas suposiciones. Una dinámica que contrasta con otros ámbitos de estudio como la exclusión social, las diásporas migratorias, el racismo, la diversidad funcional o sexual, los estudios sobre infancia, juventud o mayores y otras áreas de conocimiento cuyos/ as especialistas no precisan compartir el perfil o la identidad de la población objeto de estudio para interesarse en el mismo. 
la asimetría relacional en la distribución de las tareas del cuidado (eso que se denomina «conciliación») con departamentos, profesorado y alumnado que perciben la incorporación de una perspectiva de género no como un mandato legislativo, sino como una deriva ideológica o un capricho personal. De forma tal que, el contexto descrito, termina implicando no solo el desconocimiento de dicha perspectiva o campo de estudio sino su consideración como no-ciencia (Fraisse 73-74).

\section{PLAN BOLONIA: CAPITALISMO Y ANDROCENTRISMO ACADÉMICO}

El conocido como Plan Bolonia inició una reforma del sistema universitario orientada, en principio, a homogeneizar la acreditación y cuantificación de la formación recibida (mediante los denominados créditos ECTS ${ }^{10}$ ) con la finalidad de facilitar el intercambio de titulados/as universitarios en el espacio de la Unión Europea. Pero, como acompañamiento a tal reforma, se produjo una auténtica metamorfosis del sistema que permitió que la lógica del mercado empezara a determinar la gestión de la Educación Superior.

El nuevo modelo promocionaría un concepto de excelencia individualizada asociada casi en exclusiva a la investigación (según un parámetro competitivo y cuantitativista estrechamente vinculado a la producción de artículos en medios de difusión académica de impacto según el sistema anglosajón) que empezó a determinar tanto el reconocimiento de las universidades como del profesorado adscrito a las mismas. A partir de entonces la comunidad académica se sometería, en su conjunto, a un abanico variable de evaluaciones y re-evaluaciones según indicadores impuestos externamente encaminados a verificar la supuesta calidad de la investigación, la docencia y las titulaciones.

Con dicho fin y, en cumplimiento de lo establecido en los artículos 31 y 32 de la Ley Orgánica 6/2001, de 21 de diciembre, de Universidades, en julio de 2002 el Gobierno español creó la Agencia Nacional de Evaluación de la Calidad y Acreditación (ANECA) ${ }^{11}$ cuyo objetivo sería coordinar las políticas de gestión de la calidad en las universidades españolas «con el fin de convertir la enseñanza universitaria en excelente y adaptarla a las necesidades de las empresas» (ANECA 32). Las universidades públicas pasaban de

9. Acuerdo adoptado para armonizar el Espacio Europeo de Educación Superior (EEES) que se inició tras la Declaración de Bolonia. Un pacto de carácter no vinculante que firmaron en el año 1999 los ministros/as de Educación de algunos países europeos.

10. European Credit Transfer and Accumulation System.

11. Las administraciones autonómicas en el ejercicio de su atribución competencial en materia de educación crearon, a su vez, agencias similares en su ámbito territorial. 
ser consideradas un referente cultural de la sociedad a ser una institución al servicio de un mercado que, como colofón, no considera la perspectiva ni los estudios de género como un bien o conocimiento mercantilizable.

El nuevo marco fomentó la competición entre instituciones educativas y la pérdida de identidad de los centros de Educación Superior que relegaron la formación como esencia de su actividad, para priorizar la investigación y los conocimientos demandados por el mercado neoliberal globalizado. De forma tal que, el «capitalismo académico», tematizado por Slaughter y Leslie a finales de la década de los años noventa, característico hasta entonces del ámbito anglosajón, empezó a determinar también la organización de nuestro sistema universitario.

La imposición de tal sistema no se acompañó de una equiparación financiera con el modelo anglosajón y, consecuentemente, implicó un notable incremento de la carga de trabajo de las trabajadoras y trabajadores de las universidades. Los sucesivos recortes en la financiación de los centros públicos acometidos con la crisis, no hicieron sino incrementar la dedicación temporal a las tareas de gestión y elevar el stress de aquellas personas con categorías académicas más precarias e inestables (donde la presencia de mujeres es superior).

Tras Bolonia, el sistema de reconocimiento, promoción y remuneración por méritos imputados, transformó radicalmente el funcionamiento de las diferentes universidades. Un individualismo competitivo vinculado a la investigación determinó la evaluación de la carrera profesional del profesorado. Pero, en la medida que la docencia, la gestión y la conciliación de las responsabilidades del cuidado o del curso de la vida (según acepción de Castaño y Webster) son actividades con horarios más rígidos, mientras la investigación permite adaptar mejor los tiempos, el resultado es que las personas que se encuentran obligadas a asumir las tres primeras actividades terminan viéndose forzadas a aplazar su labor investigadora. Un contexto que, inevitablemente, termina afectando a su promoción, reconocimiento y remuneración.

Con todas sus deficiencias, la descentralización que supuso la puesta en marcha del denominado Plan Bolonia podría haber implicado la actualización de los programas académicos y la consecuente incorporación de asignaturas relacionadas con la materia en los nuevos planes de estudio. Sin embargo, aunque el Real Decreto 1393/2007, de 29 de octubre, por el que se establece la ordenación de las enseñanzas universitarias oficiales, reconoce formalmente en su artículo 3.5. a que la igualdad entre mujeres y hombres es un principio que debe inspirar el diseño de las nuevas titulaciones, el anexo II (que recoge las materias básicas en cada rama de conocimiento) no incluyó ninguna asignatura 
coherente con el reconocimiento de tal principio y los sucesivos sistemas de evaluación de las titulaciones no enmendaron tal omisión.

El escenario descrito propició que, tras Bolonia, los estudios de género no se integraran de forma normalizada o sistemática en los nuevos grados. Las licenciaturas fueron sustituidas por grados con competencias diferenciadas según arbitrio de cada universidad y el criterio común fue no otorgar a la perspectiva o los estudios de género la presencia comprometida. Así que, más de una década después de la entrada en vigor de Ley Orgánica 1/2004, de 28 de diciembre, de Medidas de Protección Integral contra la Violencia de Género (LIVG), lejos de haberse fomentado «en todos los ámbitos académicos la formación, docencia e investigación en igualdad de género» (art. 4.7), ésta sigue ausente en la enseñanza superior y su existencia depende del voluntarismo o del interés personal del profesorado.

Pese a la dinámica observada, en el curso 2010-2011 empezó a impartirse el primer y único grado de igualdad en el estado español. Sin embargo, la demanda de profesionalizar la figura del/la Agente de Igualdad fue atendida tres años después regulando sus enseñanzas en el ámbito de la Formación Profesional de grado superior ${ }^{12}$. A finales de noviembre del año 2013 entró en vigor el citado Real Decreto, tres meses y medio después se aprobaba la extinción del grado de igualdad de género de la Universidad Rey Juan Carlos.

Por ello, en la actualidad, en el marco de las titulaciones oficiales, aquellas personas que pretendan obtener una especialización en estudios de género o políticas de igualdad se encuentran con dos opciones: cursar un máster tras finalizar con éxito sus estudios de grado (con el esfuerzo en términos económicos, personales y temporales que supone) o bien olvidarse de la universidad y acceder a los estudios de promotoras/es de igualdad enmarcados en la Formación Profesional. Un tratamiento y consideración que desplaza la formación en género del eje central del sistema universitario y que regula su profesionalización en el ámbito de la Formación Profesional. Una decisión que tiene implicaciones obvias en la categoría o nivel profesional (Grupo B) y la capacidad de decisión de las personas que tienen encomendada la promoción de la igualdad en el ámbito de las Administraciones Públicas ${ }^{13}$.

12. Real Decreto 779/2013, de 11 de octubre, por el que se establece el título de Técnico Superior en Promoción de Igualdad de Género y se fijan sus enseñanzas mínimas.

13. Con carácter general, el subgrupo Al (reservado a licenciados/as universitarios o equivalentes) tiene asignadas tareas de dirección y alta gestión. Para acceder al subgrupo A2 es preciso contar con una diplomatura universitaria o equivalente, desarrollando tareas de ejecución y gestión. Por el contrario, el grupo B solo ejecuta el trabajo encomendado por los subgrupos anteriores, personas en cuya formación la perspectiva de género previsiblemente ha estado ausente o ha ocupado un lugar periférico. 


\section{LA DOBLE VERDAD: RETÓRICA DE LA IGUALDAD Y CULTURA DEL SIMULACRO}

La formación en igualdad en el ámbito de las universidades se enfrenta, por lo general, a la doble verdad que define las políticas de igualdad (De Miguel): la legislación recoge su centralidad y obligatoriedad pero es un mandato que se tiende a posponer. Tanto en declaraciones públicas como en sucesivas leyes orgánicas ${ }^{14}$ se apunta a la educación como herramienta estratégica, esencial e ineludible en la erradicación de las desigualdades, el sexismo, el machismo o la violencia contra las mujeres, pero la formación en la materia tiene un tratamiento periférico, cuando no devaluado. Una consideración que no es ajena a la organización de las instituciones académicas y al diseño de los sistemas de evaluación, formación e investigación presentes en el sistema educativo.

Respecto a la estructura y organización de las universidades españolas conviene advertir que, a diferencia del contexto internacional y, así como no existen grados en estudios de género, tampoco se han creado departamentos específicos que reconozcan dicha especialidad como un área de conocimiento específica. Un aspecto esencial dado que éstos representan las unidades administrativas donde se aprueba el contenido y la distribución de la docencia y se adoptan las decisiones relativas a la inscripción o defensa de las tesis doctorales o la propuesta de contratación y promoción del profesorado. Su inexistencia impide, a su vez, recoger, sistematizar e impulsar un conocimiento que, si bien ha promovido profundos cambios sociales y jurídicos, no ha obtenido todavía el consecuente reconocimiento académico.

La histórica ausencia de tales departamentos fue hábilmente subsanada, desde la década de los años noventa, con la creación de decenas de institutos, observatorios o cátedras de género en las diferentes universidades de todo el territorio estatal ${ }^{15}$. Pero, si bien es cierto que dichas estructuras han permitido impulsar la formación e investigación en la materia ${ }^{16}$, en la medida que carecen de la atribución competencial propia de los departamentos, no pueden intervenir en la docencia reglada, en la contratación y promoción del profesorado

14. Entre otras, la Ley Orgánica 1/2004, la Ley Orgánica 3/2007 y la Ley Orgánica 4/2007, anteriormente citadas. Para un análisis de las disposiciones normativas en materia de igualdad en el ámbito universitario consultar Ventura.

15. Para un interesante análisis sobre el feminismo académico y los observatorios de igualdad consultar Bosch et al.

16. Como señala Grana «En 1991 existían en las universidades españolas 15 grupos de estudios de la mujer, feministas o de género coordinados entre sí. Desde 1991 a 1996, surgen 16 más. Este crecimiento cuantitativo ha ido acompañado de otras transformaciones de carácter cualitativo y de mayor madurez» (132). 
o en el diseño de las nuevas titulaciones. Una limitación competencial a la que se suma la presupuestaria. La escasa financiación con la que cuentan, de existir, suele estar vinculada a subvenciones puntuales. Es decir, aportaciones económicas de carácter coyuntural que tienen por objeto mantener un organismo con vocación estructural y que suponen una elevada carga de trabajo para las personas implicadas en su gestión en la preparación y presentación de posibles proyectos, así como en su ejecución, gestión, justificación y en la atención a las posteriores subsanaciones o requerimientos que habitualmente suelen reclamar las entidades financiadoras.

En paralelo a estas estructuras y, desde la entrada en vigor de la Ley de igualdad ${ }^{17}$ y de la LOMLOU $^{18}$, que establecen que las universidades han de tener unidades de igualdad ${ }^{19}$, casi todas disponen de dicha estructura administrativa y han desarrollado -al menos- un Plan de Igualdad. Sin embargo y pese a que no hay una sola universidad cuyo diagnóstico permita afirmar que existe equilibrio de género, es frecuente que dichos planes tengan un valor puramente formal y que de los objetivos o medidas incluidos se cumplan, fundamentalmente, aquellos cuya responsabilidad recae exclusivamente en las unidades. Una dinámica que se explica si se tiene en consideración que el cumplimiento de los planes precisa de un compromiso por parte del resto de las estructuras académicas que no siempre se observa. Por ello, en la medida que nada señala la legislación respecto a su ejecución y su efectiva evaluación, el esfuerzo que supone su elaboración se acompaña -en muchos casos- de una desidia o indiferencia por parte de las universidades en lo relativo a su implementación y evaluación.

No en vano, las unidades son estructuras administrativas que no gozan de atribución competencial para intervenir en el funcionamiento de los departamentos y grados o en el contenido de las guías docentes. En este sentido, el

17. Ley Orgánica 3/2007, de 22 de marzo, para la Igualdad efectiva de mujeres y hombres. 18. Ley Orgánica 4/2007, de 12 de abril, por la que se modifica la Ley Orgánica 6/2001, de 21 de diciembre, de Universidades.

19. Las funciones comunes de estas nuevas estructuras son, entre otras, el diseño y elaboración del diagnóstico y el plan de igualdad y el seguimiento de su implantación, la promoción de una cultura organizativa a favor de la equidad y de la igualdad de oportunidades de mujeres y hombres en la comunidad universitaria, la elaboración de los programas necesarios para impulsar las políticas de igualdad tanto entre el alumnado como entre las y los trabajadores adscritos a su centro educativo, el impulso de la participación equilibrada de mujeres y hombres en los niveles de responsabilidad y, en particular, en la representación en los órganos de gobierno de la Universidad, la promoción de medidas encaminadas a facilitar la conciliación de la vida personal, familiar y laboral de toda la comunidad universitaria y la periódica evaluación de la efectividad del principio de igualdad en los diversos ámbitos de actuación. 
principio de libertad de cátedra ${ }^{20}$ tan en desuso y maltrecho para otras cuestiones (como en el caso de la obligatoriedad de la homogeneización de las guías docentes) permite, por ejemplo, el bloqueo de una posible supervisión de los contenidos docentes por parte de las unidades. Tiende a olvidarse que la libertad de cátedra representa un derecho subjetivo del docente que habilita a que cada cual oriente los contenidos de la enseñanza como considere oportuno, pero ha de interpretarse «dentro de lo que el amplio marco de principios constitucionales hacen posible ${ }^{21}$, igualdad incluida, y no como un derecho que habilita o permite ignorar cualquier mandato en el contenido de la enseñanza (Simón y Selva). Sin embargo, no es infrecuente que se recurra a la misma como un mantra que permite soslayar cualquier pretensión por transversalizar la perspectiva de género.

A su vez, la financiación de las unidades es muy dispar y, al igual que ocurría con los institutos, observatorios y las cátedras de género, el esfuerzo que supone impulsar las mismas no siempre se acompaña de una descarga horaria y de un reconocimiento económico o académico, por lo que se vuelve a partir de un voluntarismo por parte de las personas que integran las mismas que implica una renuncia a dedicar tiempo y esfuerzo a otros menesteres que sí se valoran convenientemente en su promoción profesional y remuneración.

No se observa otra dinámica respecto a la investigación. El artículo 25 de la Ley Orgánica 3/2007, de 22 de marzo, para la Igualdad efectiva de mujeres y hombres dispone que «en el ámbito de la Educación Superior, las Administraciones Públicas en el ejercicio de sus respectivas competencias fomentarán la enseñanza y la investigación sobre el significado y alcance de la igualdad entre mujeres y hombres» $\mathrm{y}$ «promoverán... la realización de estudios e investigaciones especializadas en la materia». La Ley 14/2011, de 1 de junio, de la Ciencia, la Tecnología y la Innovación establece que «la incorporación del enfoque de género con carácter transversal representa una de las estrategias o medidas para la ciencia del siglo $\mathrm{XXI}_{»^{22}}$. Compromiso reforzado con posterioridad por la Estrategia Española de Ciencia y Tecnología y de Innovación (2013-2020) que incluyó la incorporación de la perspectiva de género en las

20. Reconocido en el artículo 20.1.c de la Constitución española.

21. Como reconoce el Tribunal Constitucional, la libertad de cátedra «habilita al docente para resistir cualquier mandato de dar a su enseñanza una orientación ideológica determinada, es decir, cualquier orientación que implique un determinado enfoque de la realidad natural, histórica o social, dentro de lo que el amplio marco de principios constitucionales hacen posible». Sentencia del Tribunal Constitucional 5/81, de 13 de febrero de 1981.

22. Artículo 33 Ley 14/2011. Mandato que se desarrolla, específicamente, en la Disposición adicional decimotercera de la Ley 14/2011. 
políticas públicas de I+D+i, en la línea apuntada por la Estrategia de Lisboa del Consejo Europeo y el Programa Horizonte 2020 de la Comisión Europea ${ }^{23}$. Pero pese a la proliferación de normas y documentos que obligan a su inclusión, los estudios de género no se recogen entre las casi 200 especialidades académicas que, en mayo de 2015, reconoció el Ministerio de Educación, Cultura y Deporte.

El Real Decreto 415/2015, de 29 de mayo, que modifica el Real Decreto 1312/2007, de 5 de octubre, por el que se establece la acreditación nacional para el acceso a los cuerpos docentes universitarios ${ }^{24}$, reconoce cinco grandes áreas de conocimiento (Ciencias, Ciencias de Salud, Ingeniería-Arquitectura, Ciencias Sociales-Jurídicas y Arte-Humanidades), 21 sub-áreas y 190 comisiones según especialidades por áreas y sub-áreas ${ }^{25}$. Sin embargo, llama poderosamente la atención que no figuren los estudios de género, contraviniendo con ello no solo el mandato estatal y comunitario sino la práctica habitual existente en las principales universidades europeas y norteamericanas que los reconocen -desde hace décadas- como un área específica de conocimiento. En el nuevo Real Decreto el término «género» aparece en una sola y única ocasión: para justificar el uso del lenguaje sexista. Así, la Disposición adicional cuarta establece que «todas las referencias contenidas en este real decreto en género masculino se entenderán realizadas también al género femenino»; no existiendo ninguna otra mención más.

La falta de reconocimiento de los estudios de género provoca que las investigadoras e investigadores especializados en la materia sean evaluados por un sistema que no los contempla como un área específica de conocimiento. Un contexto que tiene un impacto claramente negativo en los periódicos procesos de evaluación a los que se somete el Personal Docente Investigador en la

23. A su vez, en el ámbito comunitario la Comisión Europea en su Comunicación de 2012 sobre el Espacio Europeo de Investigación (EEI o ERA en sus siglas en inglés) estableció cinco prioridades clave, una de las cuales es alcanzar la igualdad de género y la inclusión del género en los contenidos de la investigación, con objeto de promover la excelencia científica mediante el fomento de la diversidad de género. En 2015, en el marco del ERA, el Consejo de Competitividad solicitó a los Estados miembros y a la Comisión Europea actuaciones efectivas encaminadas a corregir tanto los desequilibrios de género existentes en los espacios de toma de decisión de la política de investigación como a mejorar la integración de la dimensión de género en programas y proyectos de $\mathrm{I}+\mathrm{D}$.

24. BOE núm. 144, miércoles 17 de junio de 2015. Cuyo sistema de baremación fue recogido en la Resolución de 24 de noviembre de 2016, de la Comisión Nacional Evaluadora de la Actividad Investigadora, por la que se publican los criterios específicos aprobados para cada uno de los campos de evaluación (BOE núm. 286, sábado 26 de noviembre de 2016).

25. Se contemplan, por ejemplo, estudios Árabes e Islámicos, de Asia Oriental, Hebreos y Arameos. 
medida que sus aportaciones y publicaciones son valoradas por áreas dispares y por expertos/as no especializados ${ }^{26}$.

\section{HACIA UN MODELO DE EXCELENCIA INCLUSIVO}

La pretensión de alcanzar un modelo de excelencia inclusivo ${ }^{27}$ en las universidades españolas se enfrenta, al menos, a cuatro elementos problemáticos. El primero es que el compromiso legislativo con la incorporación de los estudios o la perspectiva de género convive con una suerte de cultura del simulacro que permite que tal mandato se ignore. En materia de políticas de igualdad parece interpretarse que la producción legislativa y la mera aprobación de una ley, representa el final de una política pública, olvidando que la eficacia normativa depende de su efectiva ejecución y evaluación. Una dinámica que probablemente no sea ajena a las resistencias observadas en nuestro país en materia de igualdad.

No podemos ignorar en las políticas de igualdad opera siempre un mecanismo de «suma cero» (Thurow), de forma tal que el poder que gana un colectivo subordinado lo pierde aquel que ejercía el dominio sobre éste. Una redistribución del poder que puede provocar rechazo entre quienes mantienen posiciones hegemónicas ante una merma de privilegios o prerrogativas que interpretan como pérdida de derechos (García Prince). Cuando España se incorporó a la Comunidad Económica Europea no hacía ni una década que habíamos dejado atrás la dictadura franquista y, partiendo de las antípodas del pensamiento igualitario, no eran pocas las tareas pendientes para cumplir las exigencias de la normativa europea en materia de igualdad de género. Como el avance ha sido más rápido, la contestación a las políticas de igualdad es también más intensa y concurrida. Por tanto, la segunda barrera contextual es la amplificación, en el caso español, del efecto de «suma cero» y la reacción frente a la pérdida del monopolio masculino de un espacio de poder o reconocimiento; como es el caso de las instituciones universitarias.

El tercer elemento problemático es que, aunque desde el año 2010 la desigualdad de género ha aumentado, existe cierto espejismo óptico sobre el estado de la cuestión en la materia. En la medida que la socialización normaliza todavía niveles aceptables de desigualdad y sigue operando una naturalización del

26. A todo ello se suma un sistema de evaluación de la calidad de las investigaciones que se ha adaptado a las carreras técnicas, que no se ajusta al ámbito de la producción científica de Humanidades y Ciencias Sociales que es, precisamente, donde es frecuente que se incardinen los estudios de género y, a su vez, superior es la presencia femenina (Vozemberg).

27. En el sentido apuntado por Zippel. 
androcentrismo prácticamente en todos los ámbitos de la vida, existe cierta percepción de que la igualdad de género es un reto alcanzado. Si bien es cierto que, en términos globales, un análisis histórico permite afirmar que ha sido una de las mayores revoluciones sociales del pasado siglo, no lo es menos que hay avances, pero también retrocesos y no es un proceso lineal en constante avance (Faludi), como así parece apuntarse en el caso español.

No en vano, en junio de 2015 el Consejo de Derechos Humanos de Naciones Unidas -en su informe relativo a la discriminación de las mujeres ${ }^{28}$ señaló que los logros obtenidos durante los últimos cuatro decenios están en «riesgo de regresión» (20) y calificó de «nivel intolerablemente alto» (21) la prevalencia de la violencia de género, cuyo origen es -precisamente- la desigualdad de género y la jerarquía sexual. Un retroceso que recoge también el Comité para la Eliminación de la Discriminación contra la Mujer (CEDAW) así como los sucesivos informes anuales del Foro Económico Mundial. Según éstos últimos, en los últimos cinco años, España ha retrocedido catorce puestos en el ranking mundial relativo a la brecha de género, pasando de ser el undécimo país con menor desigualdad entre mujeres y hombres a ocupar la vigesimoquinta posición ${ }^{29}$.

Por último, un cuarto elemento que afecta especialmente al ámbito académico es la naturalización del androcentrismo. Un hecho constatable que, en el mejor de los casos, se niega porque no se percibe y en el peor se defiende como esencia, costumbre o doctrina. El correlato de dicha naturalización es que la pretensión de revisar las distintas disciplinas desde una mirada no androcéntrica, es decir, que incorpore la perspectiva de género, termina interiorizándose como una mirada sesgada y no científica, producto del capricho o la ideología de cada cual. Como apunta Fraisse, la teoría feminista «queda, en este caso descalificada, rebajada al rango de ideología, a saber, que no se trata de una propuesta rigurosa de interpretación del mundo, sino un discurso que generaliza una simple opinión» (73).

Una consideración que se mantiene y retroalimenta por la propia dinámica de las escuelas y las mentorías. Según reza el refranero popular, «caballo viejo no aprende trote nuevo». Una máxima que es más habitual en aquellos espacios

28. En la misma línea se pronunció el Comité para la Eliminación de la Discriminación contra la Mujer (CEDAW).

29. Informe sobre Brecha de género relativo al año 2015, hecho público en 2016. El índice sobre brecha de género o gender gap evalúa la magnitud de la discriminación y diferencia entre mujeres y hombres en cuatro áreas clave: oportunidades-participación económica, educación, sanidad y participación política. En la actualidad incluye información sobre casi el 95\% de la población mundial. 
que sacralizan ciertas dosis de tradición como seña identitaria, como es el caso de las universidades. En la medida que los académicos de alto nivel han sido socializados en un rígido androcentrismo que tiende a interpretar la perspectiva de género como una injerencia ideológica o doctrinal en sus respectivas disciplinas y que las nuevas generaciones de profesores/as e investigadoras/es, por una obvia lógica del reconocimiento y la promoción, se adaptan a su particular punto de vista, la dinámica de las escuelas -salvo algunas excepciones- suele perpetuar el «trote» de sus maestros.

Todo ello provoca que la pretensión por dotar de entidad académica o científica a los estudios o la perspectiva de género en la formación universitaria, se encuentre con un abanico variable de resistencias asociadas a una perspectiva androcéntrica que impregna la producción académica de las diferentes escuelas y a la consideración de la teoría feminista o los estudios de género como no-ciencia. Frente a dicha percepción, quizás convenga recordar que la teoría política feminista y la reflexión sobre la desigualdad, la diferencia o la jerarquía sexual, sobre sus fundamentos y consecuencias, llevan siglos de investigación y análisis ${ }^{30}$.

Por ello, si existe pretensión alguna para cumplir la legislación vigente en lo relativo a la incorporación de la perspectiva de género en la enseñanza universitaria, la primera tarea es evidenciar el sesgo androcéntrico de la sociedad, en su conjunto, y de la producción académica como fruto de la misma. Tarea que no será posible si dicho análisis no se integra de forma efectiva en las competencias curriculares en la etapa educativa previa. Pero también es requisito sine qua non contemplar dicha categoría en los sistemas de evaluación de la docencia y la investigación, porque en su defecto seguirá siendo un acto de voluntarismo considerado una suerte de adoctrinamiento y no una revisión del sesgo androcéntrico de la producción científica, además de un mandato

30. Como señala Frasser, «es representativo de la producción de conocimiento y no de la expresión de opiniones. Se trata de ciencia y no de convicción» (74). Precisamente por la larga producción critico reflexiva que aborda la desigualdad de los sexos y la criba histórica patriarcal de la misma, resulta inviable recoger su legado. No obstante en el s. XV Christine de Pizan recoge en alguna de sus obras (como La Epistola al Dios de Amores del año de 1399 o su conocida La ciudad de las damas de 1405) una brillante reflexión sobre la cuestión. Con posterioridad son referencia obligada Vindicación de los derechos de la mujer (1792) de Mary Wollstonecraft y su coetánea Olympe de Gouges con La Declaración de los Derechos de la Mujer y de la Ciudadana (1791). En el contexto español cabe mencionar la producción teórica de María de Zayas Sotomayor y su relato Tarde llega el desengaño de 1649, María de Guevara con Desengaños de la corte y mujeres valerosas (1664) o la producción de la religiosa mexicana novohispana Juana Inés de Asbaje y Ramírez de Santillana (que recibió el sobrenombre de Sor Juana Inés de la Cruz).

Feminismo/s 29, junio 2017, pp. 279-297 
legislativo o constitucional. La investigación con perspectiva de género debe contemplarse como una destreza específica ponderable a efectos de financiación y evaluación en los proyectos de investigación de carácter competitivo, incorporando evaluadores/as especializados en los tribunales o comisiones que juzgan la calidad y relevancia de los mismos.

Pero tampoco se puede perder de vista que los indicadores y criterios aplicados en la evaluación de la actividad docente del profesorado, condicionan el reconocimiento económico-profesional de cada cual y, por tanto, se tienen en consideración de cara a obtener una buena calificación. El esfuerzo que supone incorporar la perspectiva de género en los contenidos curriculares y formarse en la materia, debe incentivarse reconociéndose como innovación docente e incluirse en el marco de los planes de formación docente que computan a efectos del Docentia.

Obviamente, esta dimensión no debiera incorporarse solo en la valoración de la docencia e investigación del profesorado sino en el diseño de los títulos. Es preciso que la ANECA y los comités de verificaciones o reacreditaciones sean coherentes con lo establecido tanto en el RD 1393/2007 como en la propia Guía para la verificación de Títulos Oficiales de Grados y postgrados de la propia agencia, que recogen la obligatoriedad de que las competencias de las titulaciones tengan en cuenta la igualdad de oportunidades entre hombres y mujeres y que, en consecuencia, se incorpore dicha dimensión en los sistemas de evaluación.

Con todo y con ello, la inclusión de la perspectiva de género y su reconocimiento como área de especialización académica será poco viable mientras no existan departamentos o áreas de conocimiento especializadas en estudios de género, como ocurre en el ámbito internacional. Unidades administrativas y de gestión académica que permiten no solo asumir la docencia en materias que requieran una mayor especialización sino, a su vez, sistematizar y promocionar el saber científico acumulado en la materia e impulsar la efectiva incorporación de la perspectiva de género.

Unos retos que se deben abordar sin perjuicio del necesario fortalecimiento de las unidades de igualdad que precisan no solo recursos económicos y personales para el correcto desarrollo de sus funciones sino de capacidad de decisión, interlocución y coordinación con los departamentos y de competencias reales para el cumplimiento de su encomienda. En su defecto, los planes de igualdad seguirán siendo talentosos brindis al sol con limitada efectividad.

Frente a la debilidad orgánica que en el seno de las universidades suelen tener las estructuras de igualdad, parece ineludible consolidar la coordinación 
y el trabajo en red de las unidades, institutos y observatorios ${ }^{31}$, reforzar su interlocución con la administración educativa y con la CRUE (Conferencia de Rectores de las Universidades Españolas) y redoblar la presencia en los espacios de decisión. Una presencia que implique representación y, que a ser posible, huya de la conocida estrategia de «añádase mujer y agítese».

En resumidas cuentas, la búsqueda de la pretendida excelencia no será tal si no incorpora un enfoque de excelencia inclusiva que erradique las discriminaciones por razón de sexo y contemple una perspectiva no androcéntrica del conocimiento. Sin embargo y, pese a las disposiciones normativas existentes que lo regulan, son retos que todavía se aventuran lejanos. En un artículo titulado «La memoria», Amelia Valcárcel señalaba que «solo lo aprobado como significativo se conserva» (687), el resto tiende a olvidarse. Lo que invita a pensar que la desigualdad entre mujeres y hombres quizás todavía no han adquirido un status significativo y de ahí su recurrente olvido y devaluación. Por ello, es tarea ineludible conseguir que la igualdad de género, la teoría feminista y la perspectiva de género adquieran dicho status y abordar, con ello, el reto conceptual que supone desvelar el sesgo androcéntrico que se oculta tras un conocimiento aparentemente neutral.

\section{REFERENCIAS BIBLIOGRÁFICAS}

ANECA. «El debate sobre las competencias. Una investigación cualitativa en torno a la educación superior y el mercado de trabajo en España». Madrid: ANECA, 2009.

Bosch, Esperanza y Victoria A. Ferrer, Capilla Navarro, Margalida Capellá y José Luis Ortego. «Observatorio de Igualdad de Oportunidades: Un compromiso de la universidad de Islas Baleares». Revista La Ventana 21 (2005): 281-311.

Caprile, María (Coord.) Meta-analysis gender and science research: Synthesis report. Luxemburgo: Oficina de Publicaciones de la Unión Europea, 2012.

Castaño, Celia y Juliet Webster. «Understanding women's presence in ICT: the life course perspective». International Journal of Gender, Science and Technology 3.2 (2011): 364-386.

De Miguel, Ana. Neoliberalismo sexual, el mito de la libre elección. Madrid: Cátedra, 2015.

31. A través de estructuras como la Red de unidades de igualdad de género para la excelencia universitaria (RUIGEU) o la Plataforma Universitaria de Estudios Feministas y de Género. Si bien es cierto que la falta de financiación y de personal dificulta poderosamente unas actividades o actuaciones sostenidas. 
Donoso, Trinidad y Anna Velasco. «¿Por qué una propuesta de formación en perspectiva de género en el ámbito universitario?» Profesorado. Revista de currículum y formación del profesorado 17.1 (2013): 71-88.

Faludi, Susan. Reacción: La guerra no declarada contra la mujer moderna. Barcelona: Anagrama, 1993.

Flecha, Consuelo. «Ciencia y Género: a propósito de los estudios de la mujer en las universidades». Revista de la Facultad de Educación 2 (1999): 223-244.

Fraisse, Geneviève. Los excesos del género. Concepto, imagen, desnudez. Madrid: Cátedra, 2016.

García de León, María Antonia. «Las profesoras universitarias: el caso de una élite discriminada». Revista Complutense de Educación 10.2 (1990): 355-372.

García de León, María Antonia. Herederas y heridas. Sobre las élites profesionales femeninas. Madrid: Cátedra, 2002.

García Prince, Evangelina. «El espejismo de la igualdad: el peso de las mujeres y de lo femenino en las iniciativas de cambio institucional». Revista Otras Miradas 6.1 (2005): 24-30.

Grana, Isabel «La historia de la educación de las mujeres en España: líneas actuales de investigación». Revista de Educación 334 (2004): 131-141.

Lozano Cabezas, Inés, Marcos Jesús Iglesias Martínez y María Ángeles Martínez. «La cultura de igualdad de oportunidades en el tejido universitario europeo». Revista Interamericana de Investigación, Educación y Pedagogía 6.2 (2013): 31-59.

Ministerio de Economía y Competitividad. Científicas en cifras 2013. Madrid: Unidad de Mujeres y Ciencia, 2015.

Morales, María Jesús, María José Luna y Ana Isabel Esteban. «Diagnóstico de paridad en la universidad: análisis a través de indicadores». Revista de Universidad y Sociedad del Conocimiento 7.2 (2010): 1-14.

Müller, Jörg, Cecilia Castaño, Ana González y Rachel Palmén. «Policy towards gender equality in science and research». Brussels economic review-cahiers economiques de Bruxelles 54 (2011): 295-316.

Naciones Unidas. «Informe del Grupo de Trabajo sobre la cuestión de la discriminación contra la mujer en la legislación y en la práctica: misión en España». Comisión de Derechos Humanos de Naciones Unidas. A/HRC/29/40Add.3, 17 de junio de 2015.

Naciones Unidas. «Informe de la Comisión de la CEDAW, relativo al Estado español». Comité CEDAW. CEDAW/C/ESP/CO/7-8, 24 de julio de 2015.

Nuño, Laura. «Desigualdad y educación: modelo pedagógico y mito de la complementariedad» Revista Europea de Derechos Fundamentales 24 (2014): 147-166.

Parlamento Europeo. Proyecto de Informe sobre carreras profesionales en los ámbitos científico y académico y los techos de cristal existentes (2014/2251 (INI)). 
Comisión de los Derechos de la Mujer e Igualdad de Género. Ponente: Elissavet Vozemberg. Bruselas-Estrasburgo: Parlamento Europeo, 2014.

Sánchez de Madariaga, Inés, Sara de la Rica y Juan José Dolado (Coord.). Libro Blanco de la situación de las Mujeres en la Ciencia Española. Madrid: Unidad de Mujeres y Ciencia, 2010.

Simón, María Luisa y Juan Andrés Selva. «Los límites del derecho de libertad de cátedra». Revista de la Facultad de Educación de Albacete 10 (1995): 119-128.

Slaughter, Sheila y Larry L. Leslie. Academic capitalism: politics, policies and the entrepreneurial university. Baltimore: Johns Hopkins, 1997.

Thurow, Lester. La sociedad de suma cero. Barcelona: Orbis, 1998.

Valcárcel, Amelia. «La memoria». Igualdad y democracia: el género como categoría de análisis jurídico. Estudios en homenaje a la profesora Julia Sevilla Merino. Ed. Cortes Valencianas. Valencia: Cortes Valencianas, 2014, 685-694.

Ventura, Asunción. «Normativa sobre estudios de género y universidad». Feminismo/s 12 (2008): 155-184.

Viveros, Mara. Quebradores y cumplidores. Bogotá: Universidad de Nacional de Colombia, 2002.

Zippel, Kathrin, Marx Ferree y Karin Zimmermann. «Gender equality in German universities: vernacularising the battle for the best brains». Gender and Education 28.7 (2016): 1-19. 

Para enlazar con este artículo / To link to this article:

http://dx.doi.org/10.14198/fem.2017.29.12

Para citar este artículo / To cite this article:

Pastor Gosálbez, María Inmaculada, Paloma Pontón Merino y Ana Acosta Sarmiento. «El acceso a la carrera investigadora desde la perspectiva de género ipunto de inflexión?». En Marcos Jesús Iglesias Martínez e Inés Lozano Cabezas (coords.), La (in) visibilidad de las mujeres en la Educación Superior: retos y desafios en la Academia. Feminismo/s, 29 (junio 2017): 299-327, DOI: 10.14198/fem.2017.29.12

\title{
EL ACCESO A LA CARRERA INVESTIGADORA DESDE LA PERSPECTIVA DE GÉNERO ¿PUNTO DE INFLEXIÓN?
}

\section{THE ACCESS TO THE RESEARCH CAREER FROM A GENDER PERSPECTIVE. A TURNING POINT?}

\author{
María Inmaculada PASTOR GOSÁLBEZ \\ inma.pastor@urv.cat \\ orcid.org/0000-0003-4913-0722 \\ PALOMA PONTÓN MERINO \\ paloma.ponton@urv.cat \\ orcid.org/0000-0001-6929-8288 \\ ANA ACOSTA SARMIENTO \\ anacosta08@gmail.com \\ orcid.org/0000-0001-6847-3179 \\ Universitat Rovira i Virgili
}

\section{Resumen}

Las becas pre y postdoctorales son, actualmente, las vías de acceso principales a la carrera académica en el sistema universitario español. Diagnosticar los factores que intervienen en el acceso, desarrollo y mantenimiento diferencial entre mujeres y hombres es un requisito indispensable para la implementación de medidas dirigidas a lograr la igualdad en el trabajo. Así pues, en esta investigación, ponemos la atención en estas posiciones iniciales de la carrera académica. El objetivo perseguido es conocer las condiciones de trabajo y dinámicas que se dan, por mujeres y hombres, durante los primeros años de incorporación del personal docente e investigador en formación, a la Universidad. El estudio se ha basado en una encuesta y entrevista en profundidad a una muestra del Personal Investigador en Formación (PIF) de la Universitat Rovira i Virgili (URV). Los datos indican que existen diferencias en las condiciones de trabajo 
así como en las motivaciones, cargas docentes y expectativas que pueden condicionar el desarrollo diferenciado por género de la carrera investigadora.

Palabras clave: género, carrera académica, Universidad, desigualdades

\begin{abstract}
Pre and postdoctoral fellowships are currently the main access routes to the academic career in the Spanish university system. Diagnosing the factors involved in access, development and differential maintenance between women and men is an indispensable requirement for the implementation of measures aimed at achieving equality at work. Thus, in this research, we focus on these initial positions of the academic career. The objective is to know the working conditions and dynamics that are given by women and men during the first years of incorporation of teaching staff and researcher in training to the university. The study was based on a survey and in-depth interview with a sample of Research Staff in Training (PIF) of the Universitat Rovira i Virgili (URV). The data indicate that there are differences in the working conditions as well as in the motivations, teaching loads and expectations that can condition the differentiated development by gender of the research career.
\end{abstract}

Keywords: gender, academic career, university, inequalities 


\section{INTRODUCCIÓN: LOS DESEQUILIBRIOS DE GÉNERO EN LA UNIVERSIDAD ESPAÑOLA}

Diferentes estudios recientes (Sánchez de Madariaga; Sánchez de Madariaga et al. 2011; Generalitat de Catalunya; Guil) y anteriores (Pérez Sedeño et al.; García de León y García de Cortázar; Izquierdo 2004; Izquierdo 2008; Pastor) han puesto de manifiesto la pérdida de mujeres a lo largo de las diferentes etapas de la trayectoria investigadora y académica: en las primeras etapas representan más de la mitad del conjunto de investigadores pero su peso se va reduciendo hasta llegar a ser sólo el $20 \%$ en las categorías superiores. Aunque hoy en día las mujeres son mayoría entre el alumnado universitario y terminan sus estudios con expedientes académicos mejores, en promedio, que los de sus compañeros, ciertos ámbitos de conocimiento se resisten todavía a la participación femenina. Es el caso de las ingenierías y algunas ciencias experimentales donde la presencia de mujeres es inferior al 30\%. No es menos extremo por conocido el hecho de que en áreas como la Pediatría o la Ginecología y Obstetricia siga sin haber una sola catedrática. En los escalones más altos de la carrera científica y empresarial, el número de mujeres está prácticamente estancado y no refleja en absoluto el potencial de mujeres preparadas, con experiencia y méritos suficientes para acceder a estos puestos. Datos de diversas fuentes (Eurostat, ME, MICINN, INE, CSIC) llevan años demostrando empíricamente el desequilibrio que existe en la proporción, «seniority» y distribución de mujeres y hombres en las diversas ramas y categorías profesionales en el ámbito de la Universidad pública española y en los Organismos Públicos de Investigación.

En el marco español, el Libro Blanco. Situación de las mujeres en la ciencia española (Sánchez de Madariaga et. al. 2011), así como los sucesivos informes del informe del Ministerio de Educación, Cultura y Deporte (Datos y Cifras del Sistema Universitario Español) muestran datos para el conjunto de las universidades españolas y el análisis de las desigualdades por razón de género en el sistema universitario español. Estos documentos demuestran un primer hecho que consideramos relevante: la feminización del alumnado universitario. Para el curso 2013-2014, el 54\% del total de alumnado universitario, fueron mujeres. Este porcentaje sube ligeramente entre la población graduada $(57,3 \%)$. 
También es superior la proporción de mujeres entre el alumnado de máster $(53,7 \%)$. Sin embargo, cuando analizamos los datos por ámbitos de conocimiento, los datos se empiezan a desequilibrarse. Se observa una proporción de hombres muy superior a la de mujeres, en la rama de ingenierías y arquitectura $(74,1 \%)$; al tiempo que las mujeres tienen una presencia muy superior en la rama de ciencias de la salud $(70,7 \%)$.

A pesar de estos datos relativos a alumnado, la feminización de la Universidad no afecta al personal docente e investigador (PDI), ya que las mujeres docentes e investigadoras en España representan una media del 39,9\%. Esta cifra ha variado poco en los últimos veinte años: ya en el curso 1993-94 el porcentaje de mujeres PDI era del 31,09\% (Sánchez de Madariaga et. al., 2011). Del mismo modo que ocurre con el alumnado, el PDI está desigualmente distribuido por sexo según el ámbito de conocimiento, con la diferencia de que los hombres son mayoría en todos los ámbitos. En ingeniería y arquitectura representan un $79,4 \%$; un $55,8 \%$ en ciencias sociales y jurídicas; un $52,4 \%$ en artes y humanidades; un 55,8\% en ciencias de la salud; y un $61,6 \%$ en ciencias.

Si nos fijamos en el caso de las catedráticas, el porcentaje de mujeres se reduce al 20,7\% (según los datos del Ministerio del MECD para el curso 2013-2014). A pesar de la mejora en la cifra en los últimos años (en el curso 2004-2005, el primero en que el MECD publica esta estadística, las mujeres representaban el 13,8\% del total de catedráticos), la presencia de las mujeres en las cátedras sigue siendo muy baja. También lo es en otras posiciones, como las catedráticas de escuela universitaria $(29,3 \%)$.

El impulso, en el ámbito académico, a la aplicación de medidas para eliminar las desigualdades por razón de género ha venido de la mano de diferentes leyes e iniciativas políticas. En concreto, en el ámbito español se han tomado medidas y se han desarrollado acciones para mejorar la situación de las mujeres en la ciencia. Cabe destacar las siguientes leyes:

- Ley Orgánica 3/2007, de 22 de marzo, para la igualdad efectiva de mujeres y hombres, que fue publicada en el BOE n. ${ }^{\circ} 71$ de 23/3/2007 en páginas 12611 a 12645. Esta Ley, en su artículo 25, dedicado a la igualdad en la Educación Superior, apunta que las «Administraciones públicas en el ejercicio de sus respectivas competencias fomentarán la enseñanza y la investigación sobre el significado y alcance de la igualdad entre mujeres y hombres». Además se promueve la inclusión, en los planes de estudio en que proceda, de enseñanzas en materia de igualdad entre mujeres y hombres así como la creación de postgrados 
específicos y la realización de estudios e investigaciones especializadas en la materia.

- Ley Orgánica 4/2007, de 12 de abril, por la que se modifica la Ley Orgánica 6/2001, de 21 de diciembre, de Universidades publicada en el BOE» núm. 89, de 13 de abril de 2007, páginas 16241 a 16260, que en su Disposición adicional duodécima «Unidades de igualdad», define que «las universidades contarán entre sus estructuras de organización con unidades de igualdad para el desarrollo de las funciones relacionadas con el principio de igualdad entre mujeres y hombres».

- La Ley 14/2011 de la Ciencia, la Tecnología y la Innovación, publicada en el BOE num.131 de 2 de junio de 2011, páginas 54387 a 54455, en su disposición adicional decimotercera dedicada al desarrollo de la perspectiva de género, apunta que la perspectiva de género se promoverá como una categoría transversal en la investigación científica y técnica, que debe ser tenida en cuenta en todos los aspectos del proceso para garantizar la igualdad efectiva entre hombres y mujeres. Además, se establecen medidas concretas para la igualdad en este ámbito.

Por su parte, las instituciones europeas han mostrado su compromiso, también en el ámbito de la ciencia y la tecnología, con el desarrollo de actuaciones que promuevan la transformación de la realidad anteriormente descrita y hagan posible la igualdad efectiva entre hombres y mujeres. Cabe destacar que desde 2012, la igualdad y la transversalidad de género en los programas de investigación es una de las cinco prioridades planteadas por el European Research Area (ERA) ${ }^{1}$. Por su parte, el programa Horizonte 2020 (H2020) recoge el compromiso de la Comisión Europea de alcanzar la igualdad entre hombres y mujeres y establece 4 objetivos ${ }^{2}$ específicos de trabajo para hacerla posible:

- Lograr la igualdad en los equipos de investigación.

- Alcanzar la igualdad en los diferentes niveles de toma de decisión.

- Integrar el análisis de género/sexo en el contenido de la investigación y la innovación.

- Lograr la igualdad en el monitoreo y la evaluación de los proyecto de investigación.

Para alcanzar la igualdad de género en todas sus dimensiones es imprescindible identificar los factores que pueden estar incidiendo en esta pérdida de talento

1. Ver: http://ec.europa.eu/research/era/index_en.htm (Consultada en 10-07-2017)

2. Ver: http://www.eshorizonte2020.es/mas-europa/ciencia-con-y-para-la-sociedad/igualdadde-genero-en-la-investigacion-y-la-innovacion (Consultada en 10-07-2017) 
femenino, especialmente, en las primeras etapas de la carrera académica. Así, desde hace años, diversas autoras han llevado a cabo estudios para identificar las causas de las persistentes desigualdades que mantienen a las mujeres alejadas de determinadas posiciones profesionales, aquellas con más carga de responsabilidad, decisión, liderazgo y poder. También son numerosos los informes que se han llevado a cabo en diferentes países para medir dicha desigualdad y cuantificar la pérdida de mujeres en el desarrollo de las carreras académicas ${ }^{3}$. Asimismo, cabe sumar el esfuerzo de las propias universidades que a través de sus estructuras de igualdad (unidades, observatorios, centros, oficinas), se han encargado de desarrollar las medidas necesarias que garanticen, de manera efectiva, la igualdad de oportunidades para mujeres y hombres.

En esta línea, podemos destacar el experimento realizado por MossRacusin y colaboradores, que demostró el sesgo de género hacia las mujeres en los departamentos de ciencia. Para este estudio, se pidió a una serie de investigadores que enviaran un mismo plan de estudios, en algunos casos con nombre masculino y en otros con nombre femenino, solicitando un puesto como gerente de laboratorio. Las evaluaciones fueron diferentes según el sexo del solicitante a pesar de tener los mismos méritos. Para los hombres, las evaluaciones fueron mejores, sus currículums estuvieron mejor valorados, y se les propusieron mejores salarios de base, y más posibilidades de formación $\mathrm{y}$ ascenso.

En España, sin embargo, no contamos con suficientes estudios que den cuenta de las dificultades académicas, laborales y organizativas que se encuentran hombres y mujeres en los primeros estadios del desarrollo de la trayectoria académica. Y concretamente se echan de menos estudios sobre el colectivo de becarios y becarias predoctorales que analicen sus condiciones de trabajo, sus expectativas profesionales y los mecanismos que empiezan a generar las desigualdades en este momento incipiente de la carrera académica.

Cuando se trata de encontrar las causas de la mayor expulsión de mujeres de la carrera académica se suelen exponer diferentes líneas argumentales. Una de ellas apunta que es el peso de la maternidad lo que fundamentalmente incide en que ellas abandonen la carrera profesional. Otras líneas argumentales apuntan a la menor acumulación, por parte de ellas, de méritos suficientes para mantener expectativas de éxito profesional. A nuestro entender ninguna de estas líneas ha mostrado suficientes evidencias -especialmente cuando se refiere al grupo de investigadores hombres y mujeres, más jóvenes- como para

3. En Pastor y Acosta (2016: 251) se puede ver una tabla resumen de los informes más destacados que se han realizado en diferentes países europeos en los últimos años. 
resultar irrefutables. Consideramos que existen otros factores que pueden tener más peso en la creación de desigualdades. Así pues, nuestra hipótesis general es que no hay grandes diferencias de actitud, aspiraciones o interés entre hombres y mujeres, sino que el funcionamiento organizativo con sesgo de género de las propias universidades es lo que acabará produciendo desigualdades entre hombres y mujeres. Este sesgo de género de las organizaciones, ha sido estudiado profusamente por autoras como Acker, Nicolson, Ely y Meyerson o Barberá et al. En esta línea hipotizamos que son los siguientes factores los que tendrán un mayor papel en ese sesgo: el peso de las redes masculinas que perjudica directamente a las mujeres (Méndez), una división sexual del trabajo académico que también las penaliza (García de León), una falta de transparencia en los criterios de selección y unos criterios poco meritocráticos (Lara; Sánchez de Madariaga, 2011). Además, los sesgos de género se manifiestan a nivel directo en la forma que se atribuyen las competencias científicas a los hombres y las mujeres. Existen estándares diferentes para valorar el desempeño académico y científico de los hombres y las mujeres en las universidades y los centros de investigación en el área de la docencia, la gestión y la investigación científica (Foschi). Todos estos factores no han estado, a nuestro entender suficientemente estudiados en las universidades españolas entre el colectivo que es objeto de nuestra reflexión, las becarias y los becarios predoctorales.

En este artículo se presenta un estudio centrado en una universidad y ofrece una aproximación a la realidad laboral y académica del colectivo citado; jóvenes que dan los primeros pasos en el desarrollo de la trayectoria académica y que van recibiendo un trato, una información, unos estímulos, unas recompensas y unos castigos diferenciados por género y que tienen un impacto importante sobre su carrera profesional en la Universidad. Asimismo, se ofrecen los resultados de una investigación centrada en los becarios y becarias de la URV pero también se presentan ideas y conocimientos fruto de investigaciones anteriores centradas en el estudio de las desigualdades de género en la universidad así como de las políticas de igualdad desarrolladas en ellas.

Este artículo representa una aproximación a un objeto de estudio que, a nuestro entender, requiere de un estudio más exhaustivo, incluyendo la lógica diacrónica para recoger los cambios generacionales y el análisis del potencial impacto de las leyes y las transformaciones que la universidad española está experimentando. 


\section{EL GÉNERO DE LAS BECAS EN LA UNIVERSIDAD}

Como se describió en el apartado anterior, a pesar de la importancia de las becas o ayudas predoctorales y postdoctorales para el inicio de la carrera investigadora en el ámbito universitario, existen pocos estudios dedicados a los mismos. Por otra parte, la propia diversidad de esta figura de investigador novel, ha llevado a que incluso normativamente se presente como un colectivo poco regulado, hasta la aprobación del Real Decreto 1326/2003 por el que se aprueba el Estatuto del becario de investigación. Tres años más tarde se aprobaría el Real Decreto 63/2006, que amplía el concepto de becario de investigación y lo enmarca, fijando su relación jurídica contractual de acuerdo al marco vigente:

Tienen la condición de personal investigador en formación aquellos graduados universitarios que sean beneficiarios de programas de ayuda dirigidos al desarrollo de actividades de formación y especialización científica y técnica a través, como mínimo, de los correspondientes estudios oficiales de doctorado, sin perjuicio de las especialidades previstas en la Ley 44/2003, de 21 de noviembre, de ordenación de las profesiones sanitarias.

En cuanto a los estudios recientes que han dedicado atención al colectivo de becarios cabe destacar el Libro blanco. Situación de las mujeres en la Ciencia Española (2011). En esta publicación se dedica un apartado a analizar específicamente las diferencias por género en las ayudas públicas a la formación de postgrado y de postdoctorado en España. El estudio ofrece datos tanto de la concesión de becas como de su solicitud y su evolución entre los años 2002 y 2009, si bien en algunas modalidades de beca también se ofrece información de años anteriores. Estos datos nos permiten contar con un punto de partida para situar nuestra aproximación. Sin embargo, mantenemos la necesidad de ampliar este tipo de estudios recogiendo tanto la opinión de los sujetos en relación a algunos aspectos muy relevantes de sus opciones de carrera académica, como de las condiciones de trabajo y su vivencia, como hombres o como mujeres, del funcionamiento de la Universidad. Esta información también arrojaría luz sobre un proceso que diversos expertos apuntan como clave en la Universidad española en las últimas dos décadas, nos referimos a la precarización de una parte de las plantillas docentes y su impacto en la organización.

Las principales conclusiones del Libro blanco son:

- En el período 1998-2007 se mantiene la elevada sobrerrepresentación de universitarias en educación, ciencias de la salud y humanidades; en contraposición con la infrarrepresentación de este colectivo en 
ingenierías y ciencias y matemática. Es de destacar que en el período analizado se observaron sutiles cambios a favor de carreras más equilibradas.

- Se puede apreciar mayor presencia de mujeres como becarias predoctorales que posdoctorales. Excepto en el programa Fulbright, tanto predoctoral como posdoctoral, en el cual no ha habido incrementos mantenidos en la participación de mujeres.

- En el programa de becas predoctorales, a pesar de ser las que cuentan con una mayor representación de mujeres, se encuentran un $10 \%$ por debajo de proporción de mujeres calificadas para disfrutar de esta modalidad de beca.

- Los programas Juan de la Cierva y Ramón y Cajal cuentan con cifras notablemente negativas para las mujeres, encontrando incluso retrocesos respecto a sus primeros programas.

Más allá de estos datos, no se han encontrado otros estudios que abarquen a la totalidad de la Universidad española, por lo que, los datos que expondremos a continuación, a pesar de abarcar el universo de la URV, pueden considerarse relevantes a modo de aproximación a esta temática.

\subsection{Becarios y becarias en la URV}

En la URV se reproducen, aunque amortiguados, estos desequilibrios. El alumnado que se matricula en la URV es mayoritariamente femenino (59\%). No obstante, encontramos áreas de conocimiento absolutamente polarizadas. Por ejemplo, para el curso 2014-2015, sólo 18 chicas se matricularon en el Grado de Ingeniería Eléctrica (donde se matricularon 208 chicos) y 28 al Grado de Ingeniería Mecánica (donde se matricularon 261 chicos). Por el contrario, 149 chicos se matricularon en el Grado de Enfermería (donde lo hicieron 648 chicas) y 45 chicos se matricularon en el Grado de Educación Infantil (donde lo hicieron 781 chicas). Si miramos las matrículas de Máster y Postgrado, vemos que ellas siguen siendo mayoría, con un 53\%. Pero también encontramos diferencias por áreas de conocimiento. Por ejemplo, sólo 1 chica se matriculó en el Máster en Ingeniería industrial (lo hicieron 49 chicos) y 9 chicos se matricularon en el Máster en Investigación en Ciencias de la Enfermería (donde lo hicieron 50 chicas). En los estudios de Doctorado, las chicas siguen siendo mayoría (un 56\%). La balanza se empieza a decantar en las tesis leídas: para el curso 2013-14, las tesis leídas por mujeres representaron el 48\% del total. A partir de este momento, la realización de la tesis, el número de mujeres 
comienza a decrecer hasta llegar a las categorías más altas: las mujeres catedráticas representan sólo el $28 \%$ de las cátedras. Así pues, pasamos de una mayoría femenina (59\%) en las fases iniciales de la carrera académica a una minoría en las posiciones más altas (28\%). A partir de esta breve diagnosis inicial, vamos a profundizar en las dinámicas y barreras de la universidad que están generando este desequilibrio.

En la URV, en diciembre de 2014, 279 personas formaban parte del colectivo «Personal Investigador en Formación» (PIF). Según la clasificación del Servicio de Recursos (SRH) de la universidad, existen 10 categorías de PIF. Las mujeres representan el 53,8\% (150) del PIF, mientras que los hombres son el $46,2 \%$ (129). Si analizamos las categorías según sexo obtenemos los siguientes datos (Tabla 1) ${ }^{4}$ :

Tabla 1. Personal Investigador en Formación según tipo de beca y sexo

\begin{tabular}{|l|l|l|}
\hline Tipo de PIF & Hombres & Mujeres \\
\hline 1 Ayudante Doctor / a & 33.3 & 66.7 \\
\hline 2 Beca Predoctoral MEC & 50 & 50 \\
\hline $\begin{array}{l}\text { 3 Beca Predoctoral } \\
\text { MEC-FPU-S.Social }\end{array}$ & 100 & 0 \\
\hline 4 PIF. MEC.FPI- contrato & 63.3 & 36.4 \\
\hline 5 PIF. MEC.FPU-contrato & 28.6 & 71.4 \\
\hline 6 PIF, & 42.9 & 57.1 \\
\hline 7 PIF. FPI, & 76.9 & 23.1 \\
\hline 8 PIF. FPU & 0 & 100 \\
\hline 9 PIF. URV & 48.9 & 51.1 \\
\hline 10 Personal Investigador Novel & 38.8 & 61.2 \\
\hline
\end{tabular}

Esta diferencia por tipo de beca no es especialmente significativa, ya que en la mayoría de casos, la modalidad de beca corresponde al año de doctorado en el que se encuentre que el PIF. Donde las diferencias sí son significativas es en la distribución del PIF por sexo y departamento. Cuando hacemos este análisis, observamos que existen departamentos altamente feminizados o masculinizados. En un extremo, tenemos departamentos como Ingeniería Electrónica, Eléctrica y Automática o Ingeniería Mecánica, muy masculinizados. En el otro extremo, tenemos departamentos como Bioquímica y Biotecnología o Medicina y Cirugía, muy feminizados. A la vez, en algunos departamentos se mantiene la paridad, como Química Analítica y Química Orgánica o en Ingeniería Química. Veamos estos datos en la Tabla 2.

4. Todas las tablas y figuras son de elaboración propia. Los datos relativos a la URV han sido proporcionados por el SRH de la misma universidad. 
Tabla 2. Personal Investigador en Formación según departamento y sexo

\begin{tabular}{|c|c|c|c|}
\hline Rama de conocimiento & Departamento & Hombres & Mujeres \\
\hline \multirow[t]{3}{*}{ Ciencias de la salud } & Ciencias médicas y básicas & 5 & 11 \\
\hline & Enfermería & 0 & 2 \\
\hline & Medicina y cirugía & 0 & 7 \\
\hline \multirow{9}{*}{$\begin{array}{|ll|}\begin{array}{l}\text { Ciencias } \\
\text { jurídicas }\end{array} & \text { sociales } \\
\end{array}$} & Antropología, trabajo social y filosofia & 1 & 5 \\
\hline & Derecho privado, procesal y financiero & 0 & 1 \\
\hline & Derecho público & 1 & 5 \\
\hline & Economía & 1 & 11 \\
\hline & Estudios de comunicación & 1 & 2 \\
\hline & Geografia & 4 & 8 \\
\hline & Gestión de empresas & 2 & 9 \\
\hline & Pedagogía & 2 & 3 \\
\hline & Psicología & 2 & 5 \\
\hline \multirow[t]{3}{*}{ Ciencias } & Química analítica y orgánica & 0 & 9 \\
\hline & Química física e inorgánica & 11 & 11 \\
\hline & Bioquímica y biotecnología & 3 & 25 \\
\hline \multirow[t]{5}{*}{ Ingeniería y arquitectura } & Ingeniería electrónica, eléctrica y automática & 20 & 5 \\
\hline & Ingeniería informática y matemática & 11 & 5 \\
\hline & Ingeniería mecánica & 14 & 5 \\
\hline & Ingeniería química & 18 & 19 \\
\hline & Arquitectura & 0 & 5 \\
\hline \multirow[t]{4}{*}{ Artes y humanidades } & Estudios ingleses y alemanes & 2 & 2 \\
\hline & Filología catalana & & \\
\hline & Filologías románicas & 0 & 1 \\
\hline & Historia e historia del arte & 4 & 4 \\
\hline
\end{tabular}

En cuanto a la edad del PIF de la URV, la mayoría se sitúan en el rango comprendido entre los 20 y los 29 años: un $71,3 \%$ de las mujeres, y un 63,6\% de los hombres.

\section{METODOLOGÍA}

Para la realización del presente estudio, en primer lugar, se han analizado todos los datos disponibles de la URV sobre PIF, datos que han sido proporcionados por el SRH de la propia universidad. Estos datos ofrecen información relevante pero insuficiente para conocer las condiciones de desarrollo profesionales de los becarios de manera que se nos presentó como imprescindible llevar a cabo una recogida de información específica para contrastar las hipótesis que, en tanto que investigadoras, hemos ido planteando en relación a este colectivo. Para ello se diseñó y envió una encuesta a todo el PIF de la universidad. Esta encuesta ha llegado a 279 personas (total PIF URV) y ha sido contestada por 
un $26,2 \%$ (de las cuales un $38,4 \%$ hombres y un $61,6 \%$ mujeres). La encuesta se dividió en 5 grandes bloques de preguntas:

- Bloque 1. Datos personales

- Bloque 2. Datos de la beca

- Bloque 3. Condiciones de trabajo

- Bloque 4. Vida cotidiana

- Bloque 5. Perspectivas de futuro

Finalmente, a todas las personas que contestaron la encuesta, se les propuso hacer una entrevista en profundidad. El nivel de participación en las entrevistas fue del $9,6 \%$, de las cuales un $28,6 \%$ hombres y un $71,4 \%$ de mujeres. El objetivo de las entrevistas era complementar y profundizar en los resultados obtenidos de la encuesta. Las entrevistas se organizaron a partir del mismo esquema de bloques de la encuesta. Se hizo hincapié en el Bloque 2 (Datos de la beca) para conocer mejor los detalles de la vía de acceso a la carrera académica y los motivos de optar a una beca; en el Bloque 3 (Condiciones de trabajo) para profundizar en el día a día de la carrera académica, las características y la valoración que hace el PIF de su trabajo; y en el Bloque 5 (Expectativas de futuro) para detectar las percepciones respecto al mantenimiento en la carrera académica. Es decir, a partir de la entrevista hemos podido obtener más información sobre el acceso, el desarrollo y el mantenimiento en la universidad. En los apartados que siguen presentamos el resultado y análisis de la encuesta y de las entrevistas.

Para la realización de este estudio hemos agrupado las 10 categorías con que trabajan SRH en 5 más categorías más funcionales, eliminando de la muestra la figura de Ayudante Doctora/a, por la poca representatividad (sólo 3 personas ocupan esta categoría). La recategorización queda como muestra la Tabla 3 .

Tabla 3. Recategorización

\begin{tabular}{|l|l|}
\hline Tipo de PIF & Recategorización \\
\hline 1 Ayudante Doctor / a & 5. Otras \\
\hline 2 Beca Predoctoral MEC & 1 . FPI \\
\hline 3 Beca Predoctoral MEC-FPU-S.Social & 2. FPU \\
\hline 4 PIF. MEC.FPI- contrato & 1. FPI \\
\hline 5 PIF. MEC.FPU-contrato & 2. FPU \\
\hline 6 PIF, AGAUR & 3. AGAUR \\
\hline 7 PIF. FPI, & 1. FPI \\
\hline 8 PIF. FPU & 2. FPU \\
\hline 9 PIF. URV & 2. FPU \\
\hline 10 Personal Investigador Novel & 4. URV \\
\hline
\end{tabular}




\section{IDENTIFICANDO LAS BARRERAS DE GÉNERO EN LAS ETAPAS INICIALES DE LA ACTIVIDAD INVESTIGADORA}

Las personas encuestadas son 28 hombres $(38,4 \%)$ y 45 mujeres $(61,6 \%)$. La muestra queda ligeramente desequilibrada respecto al universo, donde tenemos un $46,2 \%$ de hombres y un $53,8 \%$ de mujeres. En cuanto a la edad, en términos globales, el PIF encuestado se sitúa mayoritariamente $(65,8 \%)$ en el rango de edad 20-29 años. El siguiente rango de edad con mayor presencia es el de 30-39 (30,1\%). No han sido encontradas diferencias significativas por sexo en cuanto a la edad.

En cuanto a la universidad de procedencia (Tabla 4), el 63\% de los encuestados ha cursado los estudios previos al Doctorado en la misma URV. Si nos fijamos en los datos desagregados por sexo, vemos que las mujeres provienen en su mayoría de la misma universidad donde han cursado el máster o estudio que les ha dado acceso al Doctorado. En el caso de los hombres, la procedencia está más repartida entre URV, Universidades catalanas y Universidades españolas.

Tabla 4. Universidad de procedencia del PIF por sexo

\begin{tabular}{|c|c|c|c|c|}
\hline \multirow{2}{*}{$\begin{array}{l}\text { Universidad de } \\
\text { procedencia }\end{array}$} & \multicolumn{2}{|c|}{ Mujeres } & \multicolumn{2}{|c|}{ Hombres } \\
\hline & Total & $\%$ & Total & $\%$ \\
\hline URV & 32 & 72.7 & 13 & 46.4 \\
\hline Univ. catalana & 2 & 4.5 & 5 & 17.9 \\
\hline Univ. Española & 4 & 9.1 & 6 & 21.4 \\
\hline Univ. Europea & 2 & 4.5 & 1 & 3.6 \\
\hline Univ. no Europea & 4 & 9.1 & 3 & 10.7 \\
\hline Total & 44 & 100 & 28 & 100 \\
\hline
\end{tabular}

\subsection{Acceso: decidir optar a una beca predoctoral}

El PIF presentan diversas motivaciones para optar a una beca predoctoral, condicionadas por factores diferentes en cada caso. Sintetizando, los motivos que se hacen explícitos en las entrevistas son:

1. Para hacer el doctorado / Dedicarse a la investigación y docencia universitaria. Los argumentos dentro del primer grupo estarían ligados a la vocación, a diferencia de los del segundo grupo que serían argumentos más prácticos, donde la vocación sería más el efecto que la causa del inicio de la carrera académica.

2. Para tener un trabajo / Cambiar de trabajo / Consolidar una situación profesional. Los argumentos dentro de este grupo se sitúan más en el plano instrumental, en el que optar a hacer el doctorado es visto como 
una opción laboral más o un cambio respecto a la situación laboral presente.

Parece que los hombres se sitúan en el plano vocacional más que las mujeres. Es decir, la opción de los hombres de empezar la carrera académica es más activa, en el sentido que se inicia por iniciativa propia. Por lo tanto, se muestra un mayor grado de interés al inicio, y unas mejores expectativas futuras.

A partir de los resultados de la encuesta se puede apreciar que hay una diferencia significativa entre mujeres y hombres, a favor de ellas, en la modalidad de becas FPI, FPU y AGAUR, convocatorias mucho más competitivas que las becas URV, donde se concentran mayoritariamente los hombres (Tabla 5).

Tabla 5. Tipo de beca del PIF por sexo

\begin{tabular}{|l|l|l|l|l|}
\hline \multirow{2}{*}{ Tipo de beca } & Mujeres & Hombres \\
\cline { 2 - 5 } & Total & $\%$ & Total & $\%$ \\
\hline FPI & 5 & 11.4 & 3 & 10.7 \\
\hline FPU & 2 & 4.5 & 0 & 0 \\
\hline AGAUR & 12 & 27.3 & 5 & 17.9 \\
\hline URV & 22 & 50 & 17 & 60.7 \\
\hline Otras & 3 & 6.8 & 3 & 10.7 \\
\hline Total & 44 & 100 & 28 & 100 \\
\hline
\end{tabular}

En cuanto a la vía de conocimiento de las becas (Tabla 6), la mayoría de mujeres han conocido las becas a través de su director o directora de tesis, mientras que los hombres la han conocido a través de la universidad donde cursaron el máster. Es significativo que ninguna mujer ha conocido la beca a través del grupo de investigación, mientras que sí lo han hecho el 14,3\% de los hombres. Este dato sustenta la hipótesis del mayor uso que hacen los hombres de las redes de contactos personales.

Tabla 6. Medio de conocimiento de la beca predoctoral

\begin{tabular}{|l|l|l|l|l|}
\hline \multirow{2}{*}{ Fuente de información } & \multicolumn{3}{|l|}{ Mujeres } & \multicolumn{3}{l|}{ Hombres } \\
\cline { 2 - 5 } & Total & $\%$ & Total & $\%$ \\
\hline Universidad donde cursaron el Máster & 12 & 27.3 & 11 & 39.3 \\
\hline Director/a de tesis & 19 & 43.2 & 8 & 28.6 \\
\hline Entidad financiadora de la beca & 8 & 18.2 & 5 & 17.8 \\
\hline Grupo de investigación & 0 & 0 & 4 & 14.3 \\
\hline Otras & 5 & 11.4 & 0 & 0 \\
\hline Total & 44 & 100 & 28 & 100 \\
\hline
\end{tabular}


Si nos fijamos en los departamentos a los que están adscritos los encuestados, la distribución es la siguiente (Figura 1):

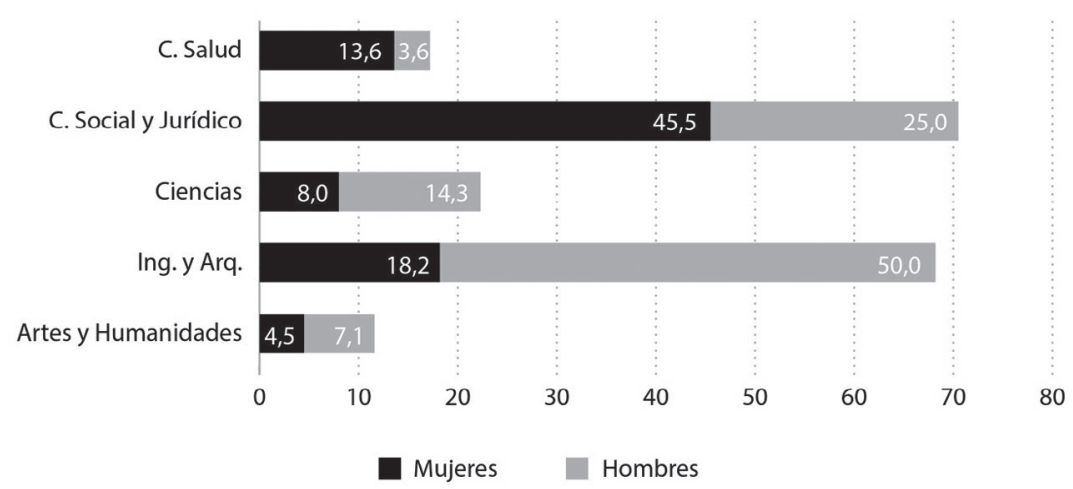

Figura 1. Distribución de encuestados por sexo y ámbito de conocimiento (\%)

\subsection{Desarrollo: características y valoración del trabajo}

En este bloque se quiso conocer cuáles son las condiciones de trabajo del PIF en la universidad. Concretamente, los pedimos información sobre su carga docente, sobre su participación en grupos de investigación y proyectos de investigación ajenos a la tesis y, finalmente, sobre si han realizado o tienen previsto hacerlo, una estancia de investigación superior a 3 meses. Es de destacar, en este sentido, lo que establece el real Decreto 63/2006, anteriormente citado:

El personal investigador en formación que desarrolle su actividad en una universidad podrá colaborar en tareas docentes, dentro de los límites que se establezcan en la correspondiente convocatoria, sin que en ningún caso pueda desvirtuarse la finalidad investigadora y formativa de las becas. En todo caso, no se le podrá atribuir obligaciones docentes superiores a 60 horas anuales.

Los datos recogidos nos muestran diferencias significativas en cuanto a carga docente (Tabla 7). Los resultados nos dicen que hay más hombres que mujeres sin carga docente. Además, si nos fijamos en cuántos créditos está asumiendo cada colectivo, encontramos que un 40,9\% de hombres tienen menos de 3 créditos, mientras que las mujeres que imparten menos de 3 créditos son el $26,3 \%$. Es decir, las mujeres asumen más docencia que los hombres e imparten más créditos. Esta tendencia suele extenderse a lo largo de la carrera académica, encontrando en el colectivo de mujeres una mayor carga de créditos. 
Tabla 7. Carga docente del PIF

\begin{tabular}{|l|l|l|l|l|}
\hline \multirow{2}{*}{ Fuente de información } & Mujeres & \multicolumn{3}{l|}{ Hombres } \\
\cline { 2 - 5 } & Total & $\%$ & Total & $\%$ \\
\hline No imparten docencia & 6 & 13.6 & 6 & 21.4 \\
\hline Imparten docencia & 38 & 86.4 & 22 & 78.6 \\
\hline$-\quad$ Menos de 3 créditos & 10 & 26.3 & 9 & 40.9 \\
\hline$-\quad$ Entre 3 y 6 créditos & 28 & 73.7 & 12 & 54.5 \\
\hline$-\quad$ Más de 6 créditos & 0 & 0 & 1 & 4.5 \\
\hline Total & 44 & 100 & 28 & 100 \\
\hline
\end{tabular}

En cambio, en cuanto a participación en grupos de investigación y en proyectos (Figura 2), no encontramos diferencias significativas. La amplia mayoría de PIF participa en grupos de investigación y aproximadamente la mitad en proyectos de investigación ajenos a su tesis. Hay que apuntar que estas dinámicas responden a una política científica general de la Universidad española en las que se está impulsando la participación en grupos de investigación para todo el conjunto del PDI. Es decir, no se debe a una dinámica específica de departamento o rama de conocimiento sino que las propias políticas de financiación de la investigación han impulsado la incorporación del personal en formación

\section{Participación en grupos de investigación}
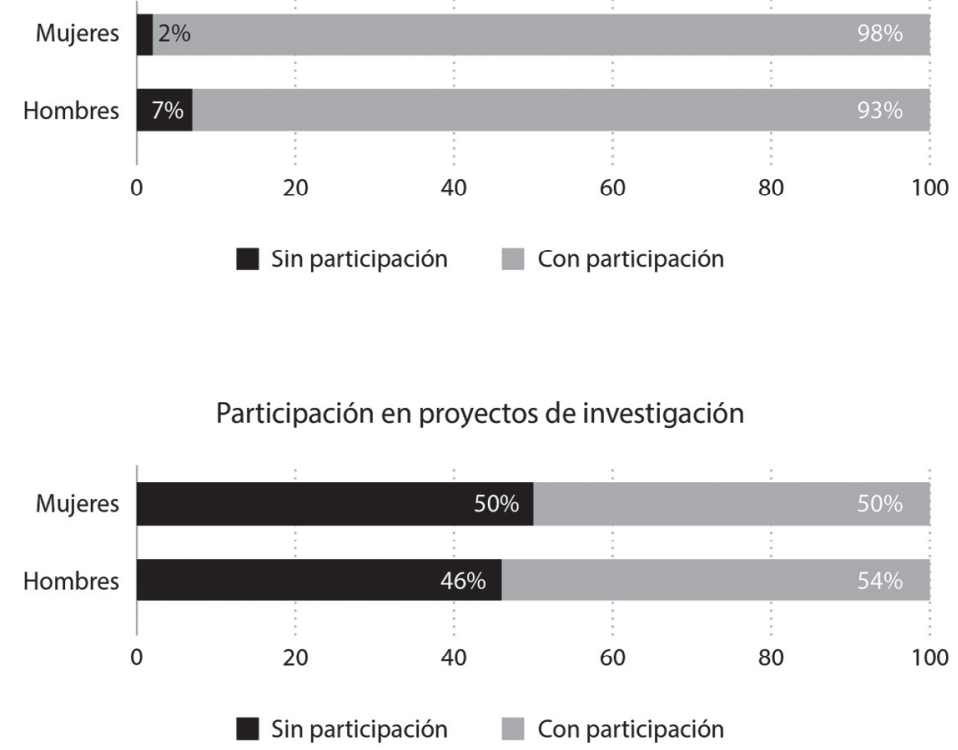

Figura 2. Participación del PIF en grupos y proyectos de investigación 
en los grupos y proyectos de investigación. Ponemos esto de manifiesto porque muestra una de nuestras líneas argumentales a la hora de explicar el impacto de las medidas a favor de la igualdad de género: cuanto más transparentes y meritocráticos sean los procesos de financiación de los grupos de investigación, los proyectos y las propias estructuras de las universidades, menos espacio habrá para la desigualdad de género. Línea argumental que está en consonancia con lo expuesto por otras investigadoras como Wennerås y Wold, en su, ya clásico, estudio sobre nepotismo y sesgos sexistas en la selección de investigadores.

En cuanto a las estancias de investigación en el extranjero (Figura 3), tampoco encontramos diferencias significativas: el 84\% de mujeres y el $85 \%$ de hombres han hecho o tienen previsto hacer una estancia. Este dato incide en nuestras hipótesis: las diferencias entre hombres y mujeres son fruto, sobre todo, de las dinámicas organizativas de las propias universidades y no están generadas por una manera de ser diferente de hombres y mujeres. Otra cosa será lo que finalmente puedan o no puedan hacer hombres y mujeres según su situación personal, como por ejemplo la carga de trabajo doméstico o las cargas familiares.

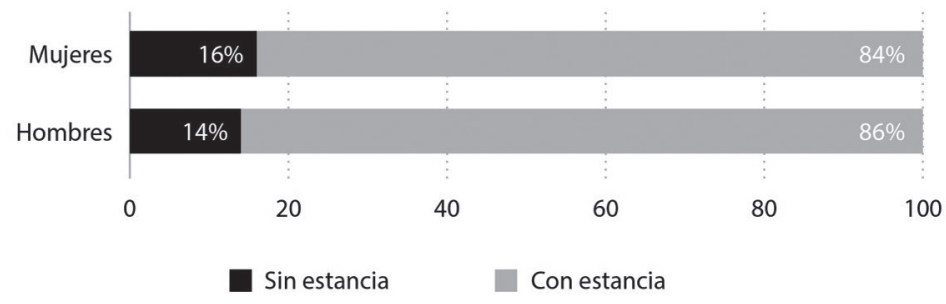

Figura 3. Estancias de investigación del PIF

En este apartado prestamos especial atención a una cuestión central en la actividad académica del PIF: la compaginación de la tesis doctoral con su trabajo cotidiano en el grupo de investigación y departamento en el que están adscritos. A partir de las respuestas, obtenemos la valoración que hace el PIF de su trabajo y de su experiencia personal como becaria o becario. En este apartado también profundizamos en la estancia de investigación en el extranjero, como una de las metas que la mayor parte del PIF de la URV pretende alcanzar (un $85 \%$ han hecho o tienen previsto realizar una estancia de investigación).

Como se observó anteriormente, la mayoría del PIF realiza alguna tarea de apoyo a la docencia, como impartir clases teóricas o prácticas, realizar sustituciones o colaborar en labores de vigilancia de exámenes. En cuanto a la 
investigación, a parte de la tesis se realizan también otras actividades, como la ayuda en proyectos o experimentos de otros investigadores/as, colaboración con el grupo de investigación, asistencia a congresos, etc. En este sentido, no parece que los entrevistados muestran diferencias por sexo, y no se les atribuyen cargas de trabajo diferentes.

En cuanto al trabajo cotidiano, nos centramos en cómo la carga docente y la participación en proyectos de investigación ajenos a la temática de la tesis (cuando los hay) impactan en la elaboración de la tesis doctoral. Estos son los dos factores que identifican los entrevistados como más problemáticos para realizar la tesis doctoral, ya que a menudo hacen detener por completo, durante un tiempo determinado, su realización. Vemos que, además de las tareas de investigación y docencia, en algunos casos hay que sumar cargas de actividades de gestión.

La docencia y la participación en proyectos de investigación ajenos a la tesis, sin embargo, también pueden ser vistas como positivos, en el sentido que, aunque supongan más carga de trabajo, instrumentalmente es positivo para el currículo académico. El otro punto de vista es el de las personas que no tienen asignada docencia ni colaboran en proyectos de investigación ajenos a su tesis doctoral. En este caso, la situación es vista como óptima, ya que el tiempo de dedicación exclusiva a la tesis aumenta.

En cuanto a la estancia de investigación, la mayoría de los entrevistados han hecho o tienen previsto realizarla, bien sea porque optan al título de doctores/ as con mención internacional, bien sea para vivir la experiencia de trabajar un tiempo en otra universidad. Desde la perspectiva de género debemos destacar, como bien apuntan otras investigaciones (por ejemplo, Mora, 2007), la incidencia de la maternidad y la conciliación de la vida personal, laboral y familiar en la decisión de realizar estancias de investigación, que afecta negativamente a las mujeres. Entre las personas entrevistadas, tenemos el caso de $G$, que ilustra esta dificultad:

No haré ninguna estancia, es imposible, tengo dos niños pequeños. Por las mismas condiciones económicas de la beca sería imposible. No me lo planteo. Como mucho, pensaría en hacer alguna estancia cerca, en Barcelona, en Lleida, pero no más lejos. (G. Mujer. 42 años)

\subsection{Vida cotidiana}

El bloque 4 tiene por objetivo profundizar en cómo es la vida cotidiana del PIF, especialmente en cuanto a la composición del hogar, a las fuentes de ingresos del hogar y la dedicación al trabajo reproductivo (trabajo doméstico, de atención y cuidado). 
En cuanto al tipo de hogar (Tabla 8), encontramos que las mujeres viven mayoritariamente con su pareja $(43,2 \%)$, mientras que los hombres viven mayoritariamente solos o con compañeros/as de piso (46,4\%). Para el resto de tipología de hogar, no hay diferencias significativas

Tabla 8. Tipo de hogar (convivencia)

\begin{tabular}{|l|l|l|l|l|}
\hline \multirow{2}{*}{ Fuente de información } & Mujeres & \multicolumn{3}{l|}{ Hombres } \\
\cline { 2 - 5 } & Total & $\%$ & Total & $\%$ \\
\hline Con los padres & 5 & 11.4 & 4 & 14.4 \\
\hline Solo/a o con compañeros de piso & 15 & 34.1 & 13 & 46.4 \\
\hline Con la pareja & 19 & 43.2 & 8 & 28.6 \\
\hline Solo/a + hijos & 0 & 0 & 0 & 0 \\
\hline Pareja e hijos & 4 & 9.1 & 3 & 10.7 \\
\hline Otros & 1 & 2.3 & 0 & 0 \\
\hline Total & 44 & 100 & 28 & 100 \\
\hline
\end{tabular}

En la fuente principal de ingresos del hogar encontramos diferencias entre mujeres y hombres: los hombres muestran una mayor dependencia de los padres ( $14,3 \%$, frente al $6,8 \%$ de las mujeres) y de su pareja (10,7\%, frente al $6,8 \%$ de las mujeres). En todo caso, tanto para hombres como para mujeres, la fuente principal de ingresos del hogar es uno/a mismo/a. En el cuidado y atención a personas dependientes (Tabla 9), encontramos que hay más mujeres que hombres que asumen esta responsabilidad, si bien en ambos colectivos el porcentaje de personas que tienen cargas de cuidado y atención es bajo: un $77,3 \%$ de las mujeres dice no tener cargas, frente al $89,3 \%$ de hombres.

Tabla 9. Cuidado y atención a personas dependientes

\begin{tabular}{|l|l|l|l|l|}
\hline \multirow{2}{*}{ Fuente de información } & Mujeres & Hombres \\
\cline { 2 - 6 } & Total & $\%$ & Total & $\%$ \\
\hline No & 34 & 77.3 & 24 & 85.8 \\
\hline $\mathrm{Si}$ & 10 & 22.7 & 4 & 14.2 \\
\hline$-\quad$ Padres & 4 & 9.1 & 2 & 7.1 \\
\hline$-\quad$ Hijos & 4 & 9.1 & 2 & 7.1 \\
\hline$-\quad$ Otros & 2 & 4.5 & 0 & 0 \\
\hline Total & 44 & 100 & 28 & 100 \\
\hline
\end{tabular}

La vigencia de la división sexual del trabajo, incipiente en este colectivo, pero que se va haciendo cada vez más evidente a medida que avanza la edad, constituye uno de los elementos destacados por numerosos investigadores para justificar la pérdida de mujeres a la largo de la carrera (Alcañiz; Arranz; León).

Cuando preguntamos por el principal responsable del trabajo reproductivo en el hogar (Tabla 10), encontramos que en ambos casos, el principal 
responsable del trabajo se comparte entre uno/a mismo/a y los dos miembros de la pareja por igual. Aunque la representación es anecdótica, vale la pena hacer notar que un hombre ha contestado que la persona responsable de las tareas de cuidado y domésticas es su pareja.

Tabla 10. Responsabilidad hacia el trabajo reproductivo en el hogar

\begin{tabular}{|l|l|l|l|l|}
\hline \multirow{2}{*}{ Fuente de información } & Mujeres & \multicolumn{3}{l|}{ Hombres } \\
\cline { 2 - 5 } & Total & $\%$ & Total & $\%$ \\
\hline Uno mismo & 18 & 40.9 & 13 & 46.4 \\
\hline La pareja & 0 & 0 & 1 & 3.6 \\
\hline Todos por igual & 22 & 50 & 10 & 35.7 \\
\hline Toda la familia igual & 2 & 4.5 & 3 & 10.7 \\
\hline Otros & 2 & 4.5 & 1 & 3.6 \\
\hline Total & 44 & 100 & 28 & 100 \\
\hline
\end{tabular}

\subsection{Mantenimiento: expectativas de futuro}

En este bloque se han querido conocer cuáles son las perspectivas laborales del PIF, ya sean dentro o fuera del ámbito universitario. Igualmente se ha querido identificar los canales a través de los cuales el PIF obtiene información sobre las salidas laborales una vez terminado el doctorado, y cuál es la valoración de la información recibida.

En primer lugar, queremos conocer qué proyecciones laborales tiene el PIF (Tabla 11):
A. Continuar vinculado al ámbito universitario y hacer carrera académica en la URV.
B. Continuar vinculado al ámbito universitario y hacer carrera académica en otra universidad.
C. Desvincularse de la universidad y optar por otras opciones profesionales.
D. No sabe.
E. Otros

Tabla 11. Perspectivas laborales después del Doctorado

\begin{tabular}{|l|l|l|l|l|}
\hline \multirow{2}{*}{ Fuente de información } & \multicolumn{3}{l|}{ Mujeres } & \multicolumn{3}{l|}{ Hombres } \\
\cline { 2 - 5 } & Total & $\%$ & Total & $\%$ \\
\hline OPCIÓN A & 12 & 27.3 & 5 & 17.9 \\
\hline OPCIÓN B & 6 & 13.6 & 6 & 28.6 \\
\hline OPCIÓN C & 5 & 11.4 & 5 & 17.9 \\
\hline OPCIÓN D & 19 & 43.2 & 8 & 26.6 \\
\hline OPCIÓN E & 2 & 4.5 & 2 & 7.1 \\
\hline Total & 44 & 100 & 28 & 100 \\
\hline
\end{tabular}


Observamos una gran diferencia en las respuestas: mientras que las respuestas de los hombres están muy divididas entre las 4 primeras opciones, las mujeres contestan mayoritariamente que no saben qué harán cuando finalicen el doctorado. Parece que la preferencia de las mujeres es continuar vinculadas a la URV y hacer carrera académica, mientras que los hombres se decantan por hacerlo en una universidad distinta.

Respecto a la posibilidad de desarrollar la carrera académica en la URV (Figura 4), queremos conocer cómo valora el PIF esta situación. El PIF encuestado ha valorado las perspectivas laborales en la URV en una escala que va de 1 (muy malas) a 5 (muy buenas). EL resultado es que, en términos generales, el PIF ve las oportunidades laborales en la URV muy malas $(36,1 \%)$. Sólo un $5,6 \%$ lo valora como bueno y un $2,8 \%$ como muy bueno.

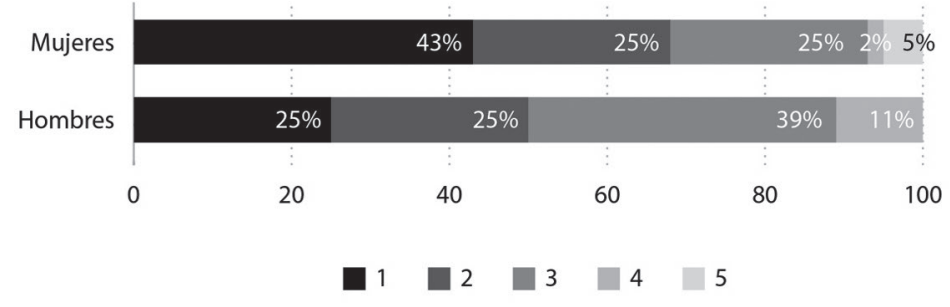

Figura 4. Valoración del futuro en la URV

Observamos, de nuevo, diferencias significativas entre mujeres y hombres. La mayoría de mujeres (un 43\%) ven su futuro en la URV muy mal, mientras que la mayoría de hombres (un 39\%) lo sitúan en el 3 de la escala de valoración. Es significativo contrastar esta pregunta con la anterior. Las mujeres apuestan preferiblemente para hacer carrera en la URV, pese consideran que las oportunidades son muy malas. Si en lugar de hacer el análisis de las perspectivas laborales por sexo, lo hacemos por área de conocimiento, vemos que el PIF más optimista respecto a su carrera en la URV es el de Ingeniería y Arquitectura, donde un 18,2\% considera que su futuro es bueno o muy bueno. Por otra parte, el PIF de Artes y Humanidades es el que peor valora su futuro en la URV: un $75 \%$ lo considera malo o muy malo.

En cuanto a la fuente de información de las salidas laborales, vemos que las mujeres reciben más información sobre salidas laborales que los hombres (52,3\% frente al 39,3\% de los hombres), tal como se muestra en la Figura 5. 


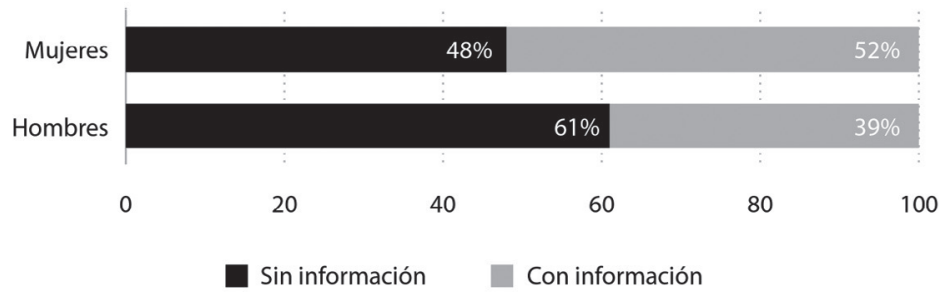

Figura 5. Reciben información adecuada

Sobre la procedencia de esta información (Tabla 12), vemos que para las mujeres un canal de comunicación relevante son los compañeros y compañeras de trabajo, mientras que los hombres reciben la información mayoritariamente a través de su director/a tesis. La segunda fuente de información relevante para las mujeres es el director/a de tesis, mientras que para los hombres, lo son las redes académicas y profesionales en el que están inscritos.

Tabla 12. Procedencia de la información sobre salidas laborales postdoctorales

\begin{tabular}{|l|l|l|l|l|}
\hline \multirow{2}{*}{ Fuente de información } & Mujeres & Hombres \\
\cline { 2 - 5 } & Total & $\%$ & Total & $\%$ \\
\hline Director de tesis & 15 & 34.1 & 9 & 32.1 \\
\hline Grupo de investigación & 10 & 22.7 & 2 & 7.1 \\
\hline EPD & 4 & 9.1 & 2 & 7.1 \\
\hline Otras instancias de la URV & 8 & 18.2 & 2 & 7.1 \\
\hline Compañeros/as de trabajo & 17 & 38.6 & 3 & 10.7 \\
\hline Redes académicas o profesionales & 10 & 22.7 & 4 & 14.3 \\
\hline Total & 44 & 100 & 28 & 100 \\
\hline
\end{tabular}

Todos los entrevistados coinciden en sus expectativas de hacer carrera académica, ya sea dentro o fuera de la URV. Es común en las entrevistas, independientemente del sexo y del ámbito de conocimiento, el reconocimiento de las dificultades que existen para poderse mantener en la carrera académica. El objetivo último, en todos los casos, es el de poder estabilizarse y ocupar un lugar permanente en el mundo académico. En términos generales, tal como muestran los resultados de la encuesta, la percepción de las posibilidades laborales dentro del ámbito universitario y, en concreto en la URV, son malas o muy malas. A partir de las entrevistas vemos cómo a medida que el PIF va conociendo mejor la dinámica universitaria, es más consciente de las dificultades de la carrera académica. Así, el PIF del primer año de beca se muestra más optimista que el PIF de los últimos años de beca. Además, aparece un factor 
determinante en la valoración del futuro académico, que es la relación con el grupo del departamento.

Tanto hombres como mujeres, en sus prospectivas para el futuro, visualizan un escenario difícil. Ambos evocan a la cuestión de la beca postdoctoral como un requisito para la estabilización en la Universidad. Para algunos es un tema prioritario tras doctorarse, mientras que para otros es un tema presente pero aún no resuelto. Vemos que los hombres se sitúan más en la primera opción, mientras que ellas muestran más dudas, motivados por el hecho de tener pareja y/o familia, tal como se ilustra en los siguientes fragmentos:

Me gustaría hacer una postdoc en la URV pero que pudiera ser flexible (...) Mi intención es tener una postdoc aquí pero flexible para estar en otro sitio. Mi pareja es de Austria (...) Me gustaría vivir en Viena, con mi pareja, porque él tiene empleo fijo. Por lo tanto la movilidad sería más bien mía hacia allá, que no al revés. (E. Mujer. 33 años)

El tema de la pareja sería algo a hablar. Él también es investigador. Está en la misma situación. A la hora de plantearme la movilidad postdoc, pues lo tendríamos que hablar. Dada la situación actual: iríamos donde la fuente de ingresos sea más fuerte, se priorizará eso. Porqué al final, no es que los dos vayamos a tener unos súper Trabajos, es que en el mejor de los casos uno de los dos tiene un trabajo normal. Y entonces ya verá el otro en que trabaja. (B. Mujer. 32 años)

Me gustaría hacer una postdoc en Cataluña, para no estar muy lejos de la URV (...) Además, vivo con mi pareja. Por ejemplo en la UB. Quizás estancias cortas más a menudo que no una estancia larga de 2 años. (F. Mujer. 25 años)

Por temas familiares, no me planteo una postdoc larga fuera de aquí, tal vez en las universidades de Barcelona o Lleida sí. (G. Mujer. 42 años)

Si bien la estancia postdoctoral se identifica como algo importante en la carrera académica, cuando pedimos que identifiquen otros factores importantes, todos coinciden en publicar con impacto (en dos entrevistas se repite la máxima del «publish or perish» de la carrera académica) y presentar comunicaciones a congresos. Sin embargo, algunos también reconocen la importancia de tener una buena red de contactos y buena relación con la universidad y el departamento. Así pues, para el PIF, el éxito en su carrera académica dependerá de 5 grandes factores: publicaciones, docencia, Estancias predoctorales, participación en congresos y red de contactos.

En cuanto a la información que el PIF recibe sobre las salidas profesionales una vez terminado el doctorado, las personas entrevistadas coinciden con los resultados de la encuesta en que las fuentes de las que se obtiene información son los compañeros y compañeras de trabajo y el director/a de tesis. Con todo, 
hay una idea generalizada de que si quieres saber información, debes ser autónomo para buscarte tú mismo las oportunidades.

\section{CONCLUSIONES}

Es un hecho constatado la progresiva desaparición de las mujeres de la carrera académica a medida que nos desplazamos hacia las categorías profesionales superiores. Lo que apuntan las estadísticas para el conjunto de universidades españolas y europeas se reproduce también en la URV. Como encarar esta realidad es el reto de las universidades para dejar de perder el talento femenino.

Tradicionalmente, el esfuerzo de las investigaciones en esta temática se ha centrado en identificar los factores externos a las mujeres, como la discriminación directa o indirecta, o los sesgos de género en los procesos de evaluación (Comisión Europea 2004). A pesar de estos factores tienen importancia, es necesario profundizar en los factores internos, es decir, analizar el proceso de selección social diferencial de hombres y mujeres y reflexionar críticamente sobre el impacto de la Universidad en su función socializadora.

En este trabajo hemos presentado una descripción estadística de la plantilla del personal investigador en formación de la URV, para dimensionar el fenómeno. Por otra parte, hemos presentado los resultados cuantitativos y cualitativos del trabajo de campo llevado a cabo. La idea principal del estudio que hemos expuesto es que si bien cada vez más hombres y mujeres comparten espacios en las primeras etapas como profesorado e investigadores de las universidades, se perciben diferencias en algunos aspectos de esta primera experiencia profesional dentro de la actividad académica. Diferencias que, mantenemos, no harán más que agrandarse a lo largo de los años de desarrollo profesional. Las diferencias encontradas en esta primera etapa se encuentran en aspectos como:

- El tipo de beca conseguida: hay una diferencia significativa entre mujeres y hombres, a favor de ellas, en la modalidad de becas FPI, FPU y AGAUR, convocatorias mucho más competitivas que las becas URV, donde se concentran mayoritariamente los hombres

- La vía de conocimiento de las becas: la mayoría de mujeres han conocido las becas a través de su director o directora de tesis, mientras que los hombres la han conocido a través de la universidad donde cursaron el máster. Es significativo que ninguna mujer ha conocido la beca a través del grupo de investigación, mientras que sí lo han hecho el $14,3 \%$ de los hombres. Este dato sustenta la hipótesis del mayor uso que hacen los hombres de las redes de contactos personales. También 
estaría mostrando las diferencias entre hombres y mujeres para acceder a la información.

- La carga docente: las mujeres hacen más docencia que los hombres e imparten más créditos. Esta tendencia suele extenderse a lo largo de la carrera académica, encontrando en el colectivo de mujeres una menor descarga de créditos asociados a los sexenios vivos, cargos de gestión y otras ventajas profesionales.

- También se dan diferencias en el tipo de hogar en el que viven: las mujeres viven mayoritariamente con su pareja mientras que los hombres viven mayoritariamente solos o con compañeros o compañeras de piso. En relación a la fuente principal de ingresos del hogar encontramos diferencias entre mujeres y hombres: los hombres muestran una mayor dependencia de los padres (14,3\% frente al $6,8 \%$ de las mujeres) y de su pareja (10,7\% frente al $6,8 \%$ de las mujeres). En todo caso, tanto para hombres como para mujeres, la fuente principal de ingresos del hogar es uno/a mismo/a. También se dan diferencias en el cuidado y la atención a personas dependientes ya que encontramos que hay más mujeres que hombres que asumen esta responsabilidad, si bien en ambos colectivos el porcentaje de personas que tienen cargas de cuidado y atención es bajo: un $77,3 \%$ de las mujeres dice no tener cargas, frente al $89,3 \%$ de hombres.

- El estudio realizado nos muestran también diferencias en aspectos muy relevantes por su impacto en la carrera profesional. En concreto el estudio muestra diferencias en cuanto a la fuente de información de las salidas laborales: las mujeres reciben más información sobre salidas laborales que los hombres.

A la luz de estas diferencias destacadas y como idea central del estudio que hemos llevado a cabo debemos decir que existe un consenso generalizado entre el PIF a favor de una cultura de la transparencia. Es de destacar que este es un discurso fundamentalmente de las mujeres. Son las mujeres las que protagonizan el discurso de la reivindicación de la claridad y transparencia de las «reglas de juego». Sin embargo, es imprescindible apuntar que la transparencia por sí sola no hará mejorar las posibilidades de promoción de las mujeres a no ser que, conjuntamente con la transparencia, se trabaje para asegurar que la Universidad como organización asume una política de erradicación de la arbitrariedad en los procesos.

La cuestión de los criterios a aplicar está estrechamente relacionada con la influencia del capital social en el desarrollo de la carrera profesional. Los 
comportamientos de networking 5 no tienen el mismo impacto sobre el desarrollo de la carrera académica de los hombres y mujeres en la creación de capital social. Se puede decir que estas acciones de networking se traducen en una ganancia de visibilidad interna y en una participación en actividades profesionales (que ayudan a la promoción profesional, participación en congresos, publicaciones, etc.). Estas diferencias podrían explicar las dificultades de acceso de las mujeres a toda una serie de recursos sociales principalmente controlados por los hombres. En este sentido, dominar o no las reglas del juego vinculadas a la práctica del ejercicio del poder es el eje alrededor del cual se articulan las diferencias de género.

Las mujeres difícilmente penetran en las redes profesionales y en los círculos de poder académico, en parte porque no han copiado las estrategias y ambiciones masculinas. Los obstáculos que se encuentran en el desarrollo de su trayectoria laboral las marginan y contribuyen a que ellas mismas en muchas ocasiones opten por renunciar, como una alternativa ante la dificultad para adherirse a los patrones masculinos de gestión con el que no se encuentran cómodos. Las mujeres en general, y las académicas en particular, no han conseguido «aculturalizarse» en un universo profesional dominado por unos códigos que no sienten como propios, ya que no han sido socializadas; podríamos decir que ellas son poco hábiles controlando las reglas no escritas implícitas en el ejercicio del poder.

A partir de los testimonios recogidos se ha observado que, bajo la apariencia de un sistema de promoción profesional formalmente igualitario, basado en las calificaciones (méritos) y la experiencia, aparecen unas limitaciones formales e informales en el desarrollo de la carrera profesional que configuran las expectativas y los horizontes profesionales de los becarios y las becarias.

Procurar la igualdad de género en el sistema universitario no es sólo una cuestión de justicia social (democrática) sino que, tal y como apunta el informe ETAN, es un indicativo de excelencia en la comunidad científica. Es por ello que la comunidad universitaria debería adoptar y utilizar estrategias y medidas concretas que eviten la discriminación por razón de género, especialmente para aquellas de carácter implícito (indirecto o inconsciente), alejándose de enfoques bien pensantes o benevolentes (hacer concesiones, de ayudar o que tratan como víctimas). La evaluación de la calidad en el entorno universitario debería pasar para controlar los sesgos de género que se producen en la

5. Ver: https://blogs.iadb.org/y-si-hablamos-de-igualdad/2015/04/23/por-que-los-hombresse-les-da-mejor-el-networking/ (Consultada el 10/07/2017) 
Academia, ya que la calidad de la ciencia pasa por desarrollar una investigación más sensible al género.

Debemos entender este trabajo como un primer diagnóstico, a partir de la cual desarrollar un plan de acción que nos permita modificar la situación desigual de hombres y mujeres que se constata en cada etapa de la carrera investigadora. Proponemos continuar este trabajo profundizando en, como mínimo, los siguientes tres aspectos que nos darían claves para la comprensión del fenómeno, como son:

- El impulso de la vocación científica de hombres y mujeres y su implicación con los estereotipos de género en el mundo de la ciencia.

- El impacto diferenciado de la paternidad y la maternidad y la conciliación de la vida académica con la vida familiar.

- Las barreras estructurales, formales e informales, a los que se enfrentan las mujeres a lo largo de la carrera académica, especialmente las que tienen lugar dentro de la propia universidad.

A la vez que hay que seguir haciendo investigación en torno a este fenómeno, hay que hacer visible el sexismo en la carrera académica entre la comunidad universitaria y hay que velar para que tanto el acceso como el desarrollo y la promoción de la carrera académica tengan lugar en un escenario de igualdad de oportunidades.

\section{REFERENCIAS BIBLIOGRÁFICAS}

Acker, Joan. «Hierarchies, Jobs, Bodies: A Theory of Gendered Organizations». Gender and Society, 2.4 (1990): 139-158.

Alcañiz, Mercedes. La conciliación de la vida laboral y familiar en la Universitat Jaume I. Castellón de la Plana: Publicaciones de la Universitat Jaume I, 2014. Arranz, Fátima. «Hombres y mujeres en el profesorado: un análisis de género en las académicas». En García de León, M. y García de Cortázar, M., Las académicas (profesorado universitario y género). Madrid: Instituto de la Mujer, 2001.

Barberá, Ester y Amparo Ramos. Mujeres directivas: promoción profesional en España y el Reino Unido. Vol. 2. Institut Universitari d'Estudis de la Dona, Universitat de València, 2000.

BOE (2007) Ley Orgánica 3/2007, de 22 de marzo, para la igualdad efectiva de mujeres y hombres, publicada en el BOE núm. 71, de 23 de marzo de 2007, páginas 12611 a 12645.

BOE (2007) Ley Orgánica 4/2007, de 12 de abril, por la que se modifica la Ley Orgánica 6/2001, de 21 de diciembre, de Universidades publicada en el BOE» núm. 89, de 13 de abril de 2007, páginas 16241 a 16260. 
BOE (2011) La Ley 14/2011 de la Ciencia, la Tecnología y la Innovación, publicada en el BOE num.131 de 2 de junio de 2011, páginas 54387 a 54455.

Comisión Europea. Gender and excellence in the making. Bruselas: Directorate General for Research Information and Communication Unit, 2004.

Ely, Robin J., y Debra E. Meyerson. «Theories of gender in organizations: A new approach to organizational analysis and change». Research in Organizational Behavior 22 (2000): 103-151.

ETAN. Política Científica de la Unión Europea. Promover la excelencia mediante la integración de la igualdad entre géneros. Bruselas: Comisión Europea, 2001.

Foschi, Martha. «Blocking the use of gender-based double standards for competence». En European Commission. Gender and Excellence in the Making, 51-56. Bruselas: Comisión Europea, 2004.

Generalitat de Catalunya. Doctes, doctores i catedràtiques. Cent anys d'accés lliure de la dona a la universitat. Barcelona: Consell Interuniversitari de Catalunya, 2010.

García de León, M. Antonia; Marisa García de Cortázar (Eds.). Las académicas (Profesorado universitario y género). Madrid: Instituto de la Mujer - MTAS, 2002.

Guil, Ana. «Techos universitarios de cristal blindado». Investigaciones Feministas 7.2 (2016): 25-39.

Izquierdo, María Jesús. El sexisme a la UAB. Propostes d'actuació i dades per a una diagnòstic. Bellaterra: Publicacions UAB, 2004.

Izquierdo, María Jesús. Cuidado y provisión: el sesgo de género en las prácticas universitarias y su impacto en la función socializadora de la universidad. Madrid: Ministerio de Igualdad, 2008.

Lara, Catalina. «La perspectiva de género en los sistemas de evaluación de la producción científica». Revista de Investigación Educativa 25.1 (2007):133-148.

León, Consuelo. «La mujer trabajadora y la nueva realidad laboral. El reto de armonizar trabajo y familia hoy». En Generalitat de Catalunya. Doctas, doctoras y catedráticas. Cien años de acceso libre de la mujer a la universidad. Barcelona: Consell Interuniversitari de Catalunya, 127-138, 2010

Ministerio de Educación, Cultura y Deporte. Datos y Cifras del sistema universitario español. Curso 2005-2006. Madrid: MECD, 2006.

Ministerio de Educación, Cultura y Deporte. Datos y Cifras del sistema universitario español. Curso 2014-2015. Madrid: MECD, 2015.

Méndez, Lourdes. «Administrando la desigualdad entre los sexos: ¿los estudios de género a la deriva?» En García Selgas, F. J. y Romero Bachiller, C. (Eds.), El doble filo de la navaja: Violencia y representación, Editorial Trotta. Madrid, 169-187, 2006.

Mora, Enrico. Diagnosi de la trajectòria acadèmica del personal becari de la UAB des de la perspectiva de gènere. Bellaterra: Publicacions UAB, 2006. 
Moss-Racusin, Corinne A., John F. Dovidio, Victoria L. Brescoll, Mark J. Graham, and Jo Handelsman. «Science faculty's subtle gender biases favor male students.» Proceedings of the National Academy of Sciences 109.41 (2012): 16474-16479

Nicolson, Paula. Poder, género y organizaciones: ¿Se valora a las mujeres en la empresa?, Madrid: Narcea Ediciones, 1997.

Pastor, Inma (Ed.). Cent anys de dones a la universitat. Tarragona: Publicaciones URV, 2011.

Pastor, Inma y Ana Acosta. «La institucionalización de las políticas de igualdad de género en la Universidad española. Avances y retos». Investigaciones Feministas 7.2 (2016): 247-271.

Pérez Sedeño, Eulalia, María Jesús Santesmases y Paloma Alcalá. Mujer y Ciencia. La situación de las mujeres investigadoras en el Sistema Español de Ciencia y tecnología. Madrid: Ministerio de Economía, Industria y Competitividad, 2007.

Sánchez de Madariaga, Inés (Coord.). Científicas en cifras. Madrid: Ministerio de Economía y Competitividad, 2014.

Sánchez de Madariaga, Inés, Sara de la Rica y Juan José Dolado. Libro Blanco. Situación de las mujeres en la ciencia española. Madrid: Ministerio de Ciencia e Innovación, 2011.

Wennerås, Christiney Agnes Wold. «Nepotism and Sexism in Peer-Review». Nature 387.22 (1997). 

Para enlazar con este artículo / To link to this article:

http://dx.doi.org/10.14198/fem.2017.29.13

Para citar este artículo / To cite this article:

Rausell Guillot, Helena y Talavera Ortega, Marta. «Dificultades de la coeducación en la formación del profesorado». En Marcos Jesús Iglesias Martínez e Inés Lozano Cabezas (coords.), La (in)visibilidad de las mujeres en la Educación Superior: retos y desafíos en la Academia. Feminismo/s, 29 (junio 2017): 329-345, DOI: 10.14198/fem.2017.29.13

\title{
DIFICULTADES DE LA COEDUCACIÓN EN LA FORMACIÓN DEL PROFESORADO ${ }^{1}$
}

\section{DIFFICULTIES IN COEDUCATION IN TEACHING TRAINING}

\author{
Helena RAUSELL GUILLOT \\ helena.rausell@uv.es \\ orcid.org/0000-0003-1803-3487
}

Marta TALAVERA ORTEGA

marta.talavera@uv.es orcid.org/0000-0002-1250-0200

Universitat de València

\section{Resumen}

La situación de la implementación del género y la diversidad sexual en las etapas de Educación Infantil y Primaria es heterogénea en el conjunto de España. El presente estudio se centra en analizar la situación de la perspectiva de género en el Máster de Investigación en Didácticas Específicas de la Universitat de València, como parte de la formación especializada que se oferta desde la Facultad de Magisterio para futuros docentes y otros formadores. También trata de hacer una propuesta metodológica para contribuir a la formación especializada en investigación desde la perspectiva de género.

Palabras clave: coeducación, género, igualdad, formación inicial del profesorado, didáctica.

1. Este trabajo ha contado con financiación del Plan Nacional de I+D+i del Gobierno de España (EDU2015-65621-C3-1-R ) y cofinanciado con fondos FEDER de la Unión Europea.

Aquest treball ha estat realitzat en el marc del programa de Doctorat en Educació de la Universitat Autònoma de Barcelona. 


\begin{abstract}
Introducing gender perspective and sexual diversity in primary and early school education is heterogeneous right now in Spain. Our study focuses on gender implementation in the Master of Specific Didactics in the University of Valencia, as a part of the specialized teaching and researching training which is offered by the Teaching Training Faculty. The article also tries to design a methodological proposal in order to contribute to a specialized researching training from gender perspective.
\end{abstract}

Keywords: coeducation, gender, equality, teacher training, didactics. 


\section{APROXIMACIÓN TEÓRICA}

La coeducación se entiende como un proceso educativo intencionado que tiene el objetivo de desarrollar de forma integral a las personas, pero que parte de la consideración de que éstas tienen una realidad diferenciada según su sexo. El término se ha venido aplicando tradicionalmente a la educación en compañía de alumnos y alumnas en un mismo centro escolar, aunque coeducar puede también entenderse como educar fuera del modelo dominante, el simbólico patriarcal, pensando de nuevo, desde otros referentes, qué significa ser una mujer o ser un hombre, en el contexto histórico en el que vivimos (Blanco 20). Nos situaríamos, de este modo, en un proceso en el que se trataríamos de formar a estas personas para una convivencia social igualitaria, para lo cual la escuela mixta es un necesario punto de partida (Heredero de Pedro 139) y la implementación de estudios de género, una necesidad.

Sin embargo, la situación de la implementación del género y la diversidad sexual en las etapas de Educación Infantil y Primaria es heterogénea en el conjunto de España, a pesar de que, en algunas comunidades autónomas, en los últimos años, se ha dado un cierto impulso a las temáticas de género. Es el caso de Andalucía y, recientemente, también de Cataluña, donde, por ejemplo, en los centros es obligatoria la existencia de un responsable de coeducación y la inclusión de la perspectiva de género en el Plan de Desarrollo del centro (Romero 50). En la Comunidad Valenciana, recientemente, se ha publicado la Instrucción por la que se establece el protocolo de acompañamiento para garantizar el derecho a la identidad de género, la expresión de género y la intersexualidad (27 de diciembre de 2016). En otras comunidades, sin embargo, no se contempla ninguna actuación al respecto o bien se han implementado programas de coeducación que son voluntarios para los centros y que están dotados de escaso presupuesto.

Esto mismo se repite a nivel de la formación inicial del profesorado, a pesar de que estos procesos formativos son una oportunidad clave para entrenar la mirada y hacerla capaz de captar lo más fielmente posible la realidad y las necesidades de cada aula (Jaramillo 9). De hecho, un buen número de estudios recientes se ha centrado en la relevancia de las propuestas para la 
formación inicial y continua del profesorado y en la dignificación de su trabajo como personal autónomo, crítico y creativo, con capacidad de tomar decisiones sobre el por qué, el qué y el cómo enseñar (Pagès 47). También en la importancia de una adecuada selección de contenidos y materiales que contribuya a desarrollar el pensamiento crítico en el alumnado, entendiendo por tal la capacidad de problematizar lo evidente, de presentar en forma problemática a los estudiantes los contenidos, saber relacionar los hechos con valores o buscar la comprensión. Por todo ello, consideramos que a pesar de que el género está presente en algunas de las guías docentes de los grados de educación, su presencia podría y debería ser mucho más evidente y relevante en los planes de formación (Rebollar 159).

En el caso de la Universitat de València, no aparece ninguna referencia al género en el plan de estudios para Grado en Maestro/a en Educación Primaria y sólo en las competencias específicas (CE33) se hace una alusión a «conocer, comprender y respetar las distintas culturas y las diferencias entre las personas, la igualdad de derechos y oportunidades de hombres y mujeres y la no discriminación de personas con discapacidad». También podemos encontrar una mención a la coeducación (CE7) como la capacidad de «conocer la dimensión pedagógica de la interacción con los iguales y los adultos, la relacionada con la coeducación, y saber promover la participación en actividades colectivas, el trabajo cooperativo y el esfuerzo individual.»

Por tanto, en lo tocante a las propuestas y cuestionamientos que son planteados a los docentes durante su formación, así como en lo que respecta a las conclusiones del análisis de las políticas de igualdad nos encontramos en un momento crucial para su avance en las universidades, un momento en el que el objetivo debiera ser no sólo la mejora en la actuación por la igualdad, sino también una oportunidad para que la Universidad se convirtiese en líder y modelo para la sociedad en la lucha por la igualdad (Elizondo 44)

Un gran obstáculo a la implementación de estas temáticas es la falta de materiales y métodos. A pesar de que en los últimos años han aparecido cuentos, materiales didácticos y audiovisuales, éstos aún no son suficientes, tal como indican los datos analizados (Romero 51). Sin embargo, a nivel legislativo se ha dado impulso a los temas de igualdad de género. En concreto, la Ley de Igualdad aprobada en marzo de 2007 contempla en su artículo 23 diversas actuaciones educativas a favor de la igualdad de género y la introducción del mainstreaming de género en la educación. Concretamente, uno de sus apartados hace mención a la integración del estudio y aplicación del principio de igualdad en los cursos y programas para la formación inicial y permanente del 
profesorado aunque queda por determinar de qué modo se concretarán los aspectos de esta ley en los centros de formación.

Esto viene completado, a su vez, por la Ley Orgánica 8/2013, de 9 de diciembre, de mejora de la calidad educativa, que hace suya la Recomendación (2002) 12 del Comité de Ministros del Consejo de Europa a los estados miembros sobre la educación para la ciudadanía democrática, de fecha 16 de octubre de 2002, que señala que la educación para la ciudadanía democrática es esencial para promover una sociedad libre, tolerante y justa y contribuye a defender los valores y principios de la libertad, el pluralismo, los derechos humanos y el imperio de la ley, que son los fundamentos de la democracia.

Creemos que es esencial, en este sentido, que los docentes en formación entiendan que el género es un elemento clave tanto de la socialización primaria como de la socialización secundaria, que está obviamente presente ya en la primera construcción identitaria de los individuos, junto a otros elementos significativos como el lenguaje, la nacionalidad, la clase social o la religión. También que sean conscientes del papel jugado por la interacción con sujetos ajenos al entorno familiar e instituciones como la escuela, como parte de un proceso de socialización secundaria igualmente influyente.

Dentro de esta formación y dentro de la oferta de postgrado de la Facultad de Magisterio de la Universitat de València se incluye, además de otros, el Máster en Investigación en Didácticas Específicas como título oficial. Este título está enfocado a formar investigadores especializados en interrogantes didácticos relacionados con las diferentes áreas curriculares de las enseñanzas no universitarias, por ejemplo, los procesos de aprendizaje, los estilos de enseñanza, la actividad del profesorado en ejercicio, etc., igualmente en cuestiones didácticas de las enseñanzas universitarias y de cualquier otro contexto relacionado con la enseñanza y el aprendizaje de estas áreas curriculares, por ejemplo la formación inicial de profesorado, aspectos socio-culturales, elementos de historia, etc. Su objetivo último es formar investigadores que se incorporan a las comunidades investigadoras nacional e internacional de su especialidad mediante la integración en equipos existentes o la creación de nuevos equipos. Este máster está dirigido a personas licenciadas o graduadas en especialidades curriculares que tienen entre sus salidas profesionales la enseñanza en Educación Infantil, Educación Primaria o Educación Secundaria, además de estar destinada al profesorado de las áreas de conocimiento universitarias responsables de las diferentes especialidades y a aquellos que aspiren a ser profesores en estas áreas de conocimiento.

En un curso de especialización en investigación didáctica como éste creemos que es necesario poner de manifiesto el papel jugado por las mujeres en 
la investigación científica y enfatizar cómo, desde la primera manifestación por los derechos de la mujer en 1908, el número de mujeres que acceden a la Universidad ha crecido de manera continua. Sin embargo, esto no se ha acompañado de un crecimiento similar en el número de mujeres que ocupan posiciones de liderazgo en la Universidad (Menéndez 331; Rausell 37).

La razón de proponer una materia con perspectiva de género dentro del Máster de Didácticas Específicas descansa en la relevancia que consideramos que el concepto de género tiene para la investigación y la formación de los futuros docentes, pero también para una educación basada en la justicia social y el fomento de la igualdad. Se apoya, igualmente, en la creencia de que la renovación en la enseñanza de las ciencias y de todos los saberes en general pasa, necesariamente, por dar voz a otros protagonistas de las Ciencias Experimentales y Sociales y por recuperar el papel de aquellos sujetos que hasta ahora habían sido relegados al anonimato y a la invisibilidad (Valls 44; Blanco 20).

Por todo ello, desde el Departamento de Didáctica de las Ciencias Experimentales y Sociales de la Facultad de Magisterio de la Universitat de València se propone una línea de formación dentro del Máster de Investigación en Didácticas Específicas donde se trabajarían las cuestiones relacionadas con las identidades de género, la coeducación y la igualdad de manera transdisciplinar desde las áreas de conocimiento de Didáctica de las Ciencias Experimentales y Didáctica de las Ciencias Sociales.

\section{IMPORTANCIA DE LA INVESTIGACIÓN EN GÉNERO}

\subsection{Desde la perspectiva de la Didáctica de las Ciencias Experimentales}

En el caso del área de la Didáctica de las Ciencias Experimentales, el interés ha estado centrado en resaltar el papel de las mujeres en el mundo de la ciencia y su transmisión, analizando sus roles y representatividad en las diferentes disciplinas científicas, para, de este modo, conocer cómo las mujeres, una vez que consiguen entrar en el mundo universitario y hacerse un hueco en él, pueden hacer valer sus títulos e investigaciones y contribuir a la enseñanza y a la didáctica de las Ciencias Experimentales.

Por ello se pretende impulsar el desarrollo de trabajos que tengan como objetivo conocer de qué manera se pueden integrar los estudios de ciencias en los currículos académicos elementales, de manera que estos conocimientos puedan ser realmente asimilados por los alumnos y alumnas. De este modo, se pretende generar un interés por el "cómo enseñar bien», dados los retrasos existentes no sólo en la acumulación de conocimientos sino en la capacidad de discurrir y de solucionar problemas de metodologías pedagógicas que no tiene en cuenta la coeducación en las clases de ciencias. 


\subsection{Desde la perspectiva de la Didáctica de las Ciencias Sociales}

Desde el área de la Didáctica de las Ciencias Sociales se aborda la cuestión del género, en primer lugar, a partir de una reflexión sobre los usos públicos de las Ciencias Sociales y su función socio-educativa. Este tema está relacionada con el modo en el que las Ciencias Sociales participan en el proceso de socialización del individuo y aparece vinculado, más concretamente, con cómo éstas contribuyen a la construcción de las identidades en general y de las identidades de género en particular, a través de la contraposición entre identidad y alteridad, entre nosotros y ellos, entre femenino y masculino.

Para ello, creemos que podemos empezar por presentar los orígenes de la perspectiva de género en las Ciencias Sociales a partir de las críticas realizadas por el feminismo o el marxismo en los años setenta del siglo XX que señalaron la invisibilidad de las mujeres en la historia y en las restantes Ciencias Sociales. También por subrayar que una de sus principales aportaciones ha sido la necesidad de considerar la diferencia de los sexos como un asunto relevante en el análisis de las sociedades. Nuestro objetivo sería tratar de conseguir que el alumnado entendiese que las categorías de feminidad y masculinidad no son algo natural, algo dado, sino que por el contrario poseen un carácter plenamente histórico y contingente y que su significado varía de unas sociedades y culturas a otras, además de evolucionar en el tiempo. De hecho, las relaciones entre los sexos y el papel de las mujeres en cada sociedad se construyen a través de discursos y prácticas, de ordenamientos legales, instituciones, costumbres, imágenes y símbolos, formulándose en términos de diferencia o de complementariedad e incluyendo elementos de desigualdad y jerarquía y diferentes formas de inclusión y exclusión, de colaboración y dependencia (Amelang y Nash 43).

Por todo lo expuesto, el objetivo del presente trabajo sería, por una parte, poner de manifiesto la presencia creciente de las mujeres en la Universidad y, por otra, realizar una propuesta metodológica concreta para contribuir a la formación especializada en investigación dentro del marco del Máster de Investigación en didácticas específicas de la Universitat de València.

\section{METODOLOGÍA}

\subsection{Análisis de la presencia de mujeres en el Máster de Didácticas Específicas}

Para realizar el análisis de la presencia femenina en el Máster de Didácticas Específicas de la Universitat de Valencia, se estudió su plan de estudios, las competencias básicas propuestas y la composición de su equipo directivo y docente. Este examen se realizó en base a los indicadores propuestos en la Guía 
de Coeducación del Instituto de la Mujer (2011), donde se incluye una batería de indicadores para llevar a cabo el seguimiento de algunos de los aspectos que resultan claves en la igualdad de oportunidades en la educación de niños y niñas. Éstos están desarrollados como parte de sus contenidos, a modo de resúmenes breves y manejables de otros estudios y publicaciones impulsados por el Instituto de la Mujer sobre la Coeducación en España y que se valieron, a su vez, de una extensa bibliografía para su realización.

En este caso, se utilizan los indicadores para la formación del profesorado que se indican en la siguiente tabla (tabla 1).

Tabla 1. Indicadores de coeducación en la formación del profesorado

\begin{tabular}{|c|c|}
\hline Indicador & $\begin{array}{l}\text { Preguntas a responder por las } \\
\text { autoridades educativas }\end{array}$ \\
\hline $\begin{array}{l}\text { Grado de importancia otorgado por el } \\
\text { futuro profesorado a la formación en } \\
\text { IGOP }\end{array}$ & $\begin{array}{l}\text { ¿Cuál es la valoración general de los } \\
\text { futuros profesores y profesoras sobre la } \\
\text { importancia de la formación en IGOP? } \\
\text { (referente a todo el alumnado, cursen o no } \\
\text { asignaturas relativas a IGOP) }\end{array}$ \\
\hline $\begin{array}{l}\text { Proporción de tiempo asignado en } \\
\text { materias troncales a la IGOP }\end{array}$ & $\begin{array}{l}\text { Del total de créditos de asignaturas } \\
\text { troncales por especialidad y curso ¿qué } \\
\text { porcentaje representan las dedicadas a la } \\
\text { formación en IGOP? }\end{array}$ \\
\hline $\begin{array}{l}\text { Proporción de tiempo lectivo asignado a } \\
\text { asignaturas sobre IGOP, entre las propias } \\
\text { ofertadas por el centro, al margen de las } \\
\text { troncales. }\end{array}$ & $\begin{array}{l}\text { Del total de créditos de las asignaturas no } \\
\text { troncales y ofertadas por el Centro ¿qué } \\
\text { porcentaje representan las dedicadas a la } \\
\text { formación en IGOP? }\end{array}$ \\
\hline $\begin{array}{l}\text { Proporción de plazas cubiertas sobre las } \\
\text { ofertadas en las asignaturas de IGOP } \\
\text { optativas y de libre elección. }\end{array}$ & $\begin{array}{l}\text { Del total de plazas ofertadas en las } \\
\text { asignaturas optativas y/o de libre elección } \\
\text { ofertadas por el centro ¿qué porcentaje se } \\
\text { ha cubierto? }\end{array}$ \\
\hline $\begin{array}{l}\text { Proporción de alumnas matriculadas en } \\
\text { cada especialidad y curso }\end{array}$ & $\begin{array}{l}\text { Del total del alumnado matriculado en } \\
\text { cada especialidad y curso ¿qué tanto por } \\
\text { cien corresponde a mujeres? }\end{array}$ \\
\hline $\begin{array}{l}\text { Proporción de profesoras por especialidad } \\
\text { y curso }\end{array}$ & $\begin{array}{l}\text { ¿Qué porcentaje representan las mujeres } \\
\text { entre el total del personal docente? }\end{array}$ \\
\hline $\begin{array}{l}\text { Presencia femenina en cargos de } \\
\text { representación del profesorado y } \\
\text { directivos }\end{array}$ & $\begin{array}{l}\text { ¿Qué tanto por cien de cargos directivos } \\
\text { y de representación son ocupados por } \\
\text { mujeres? ¿Existe representación femenina } \\
\text { en todos los niveles? }\end{array}$ \\
\hline
\end{tabular}


Se trata de instrumentos de seguimiento que sirven para medir algunos de los aspectos de coeducación y que configuran las dimensiones de la escuela educativa (la intervención directa en el aula, los contenidos educativos, la formación del profesorado en igualdad, etc.), pero que se sitúan, igualmente, en el ámbito de actuación de los distintos agentes (dirección del centro, personal docente, instituciones para la igualdad, etc.). Las tablas agrupan los indicadores a partir de dos variables: 1) En función del agente que ha de contestar a las preguntas formuladas para dar respuesta a los indicadores planteados: profesorado, alumnado, profesorado y alumnado de forma conjunta y las autoridades educativas en distintos niveles; 2) En función de las distintas dimensiones de la educación a analizar, caso de la intervención directa profesorado-alumnado, los valores, los estereotipos sexistas reproducidos, la escuela como agente para el cambio y la formación del profesorado en Igualdad de Oportunidades (en adelante IGOP). A su vez, dentro de cada una de éstas, se diferencian los distintos ámbitos en los que se centra dicho análisis.

Uno de estos indicadores es la Proporción del tiempo asignado en materias troncales a la igualdad de Oportunidades (IGOP) y propone computar el total de créditos de asignaturas troncales por especialidad y curso para señalar qué porcentaje representan las consagradas a la formación en IGOP. Otro indicador es la Proporción de tiempo lectivo asignado a asignaturas sobre IGOP, entre las propias ofertadas por el centro, al margen de las troncales, es decir, del total de créditos de las asignaturas no troncales y ofertadas por el centro qué porcentaje representan las dedicadas a la formación en IGOP.

En el caso del Máster de Investigación en Didácticas Específicas, no se cumple con ninguno de estos indicadores ya que no aparecen asignaturas específicas dedicadas a la igualdad de género (tabla 2). Lo único que se detalla en las guías docentes es un apartado, dentro de las competencias a trabajar, en el que se indica la necesidad de «crear espacios de investigación y aprendizaje con especial atención a la equidad, la educación emocional y en valores, la igualdad de derechos y oportunidades entre hombres y mujeres, la formación ciudadana y el respeto de los derechos humanos que faciliten la vida en sociedad, la toma de decisiones y la construcción de un futuro sostenible.» Esta competencia también se recoge entre las competencias transversales especificas (CT2) incluidas para el conjunto del Máster (tabla 2), con 60 Créditos totales, 46 de carácter Obligatorio y 14 Optativos. 
Tabla 2. Desglose de asignaturas con créditos y carácter de las mismas

\begin{tabular}{|c|c|c|}
\hline Nombre & Créditos & Carácter \\
\hline Bases científicas & 6 & Obligatorio \\
\hline Bases didácticas 1 & 9 & Obligatorio \\
\hline Bases didácticas 2 & 7 & Obligatorio \\
\hline Bases para la innovación docente & 6 & Obligatorio \\
\hline Métodos de investigación didáctica & 6 & Obligatorio \\
\hline Trabajo fin de máster & 12 & Obligatorio \\
\hline Optatividad & 14 & Optativo \\
\hline $\begin{array}{l}\text { Investigación en didáctica de las Ciencias } \\
\text { Experimentales elementales }\end{array}$ & 7 & Optativo \\
\hline Investigación en didáctica de la Educación Física & 14 & Optativo \\
\hline Investigación en didáctica de las Artes Visuales & 14 & Optativo \\
\hline Investigación en didáctica de las CC. Sociales: geografía & 7 & Optativo \\
\hline Investigación en didáctica de las CC. Sociales: historia & 7 & Optativo \\
\hline $\begin{array}{l}\text { Investigación en didáctica de las Ciencias } \\
\text { Experimentales superiores }\end{array}$ & 7 & Optativo \\
\hline $\begin{array}{l}\text { Investigación en didáctica de las Matemáticas } \\
\text { elementales }\end{array}$ & 7 & Optativo \\
\hline $\begin{array}{l}\text { Investigación en didáctica de las Matemáticas } \\
\text { superiores }\end{array}$ & 7 & Optativo \\
\hline Investigación en Educación lingüística & 3,5 & Optativo \\
\hline Investigación en Educación literaria & 3,5 & Optativo \\
\hline Investigación en Educación musical & 14 & Optativo \\
\hline $\begin{array}{l}\text { Investigación fundamental en didáctica de las Ciencias } \\
\text { Experimentales }\end{array}$ & 7 & Optativo \\
\hline $\begin{array}{l}\text { Investigación fundamental en didáctica de las } \\
\text { Matemáticas }\end{array}$ & 7 & Optativo \\
\hline Metodología de la Educación lingüística & 3,5 & Optativo \\
\hline Metodología de la Educación literaria & 3,5 & Optativo \\
\hline
\end{tabular}

Otro indicador propuesto es la proporción de alumnas matriculadas en cada especialidad y curso del total del alumnado matriculado en cada especialidad y curso, que trata de determinar qué porcentaje corresponde a mujeres. En el caso del máster que nos ocupa, de las 92 personas inscritas este curso el $57^{\circ} 6 \%$ son mujeres. El siguiente indicador que se propone recoger es la proporción 
de profesoras por especialidad y curso, midiendo qué porcentaje representan las mujeres entre el total del personal docente, así como la presencia femenina en cargos de representación del profesorado y directivos, que trata de establecer qué tanto por cien de cargos directivos y de representación son ocupados por mujeres y si existe representación femenina en todos los niveles. En este sentido, las profesoras representan el $31 \%$ del total de personal docente, el mismo porcentaje que en cargos directivos, aunque consideramos especialmente destacable que sea una mujer quien dirija el Máster (tabla 3).

Tabla 3. Número y porcentaje de representatividad por sexos en el personal docente y directivo en el Máster de Didácticas Específicas de la Universitat de València

\begin{tabular}{|l|r|r|r|r|c|}
\hline \multicolumn{1}{|c|}{ Nivel } & \multicolumn{2}{|c|}{ Hombres } & \multicolumn{2}{c|}{ Mujeres } & Totales \\
\hline & $\mathrm{n}$ & $\%$ & $\mathrm{n}$ & $\%$ & \\
\hline Dirección & 0 & & 1 & & 1 \\
\hline Comisión Académica del Máster & 5 & & 2 & & 7 \\
\hline Secretaría & 1 & & 0 & & 1 \\
\hline Coordinadores de Especialidad & 5 & & 2 & & 7 \\
\hline Total Puestos directivos & 11 & $69 \%$ & 5 & $31 \%$ & $16(100 \%)$ \\
\hline Profesorado Educación Física & 4 & & 1 & & \\
\hline Profesorado Lengua y Literatura & 6 & & 8 & & \\
\hline Profesorado música & 4 & & 1 & & \\
\hline Artes visuales & 2 & & 1 & & \\
\hline Profesorado Ciencias Experimentales & 10 & & 4 & & \\
\hline Ciencias Sociales & 6 & & 0 & & \\
\hline Profesorado Matemáticas & 5 & & 2 & & \\
\hline & 37 & $69 \%$ & 17 & $31 \%$ & \\
\hline Total docentes & 48 & $69 \%$ & 22 & $31 \%$ & $70(100 \%)$ \\
\hline
\end{tabular}

En el análisis total de la representación femenina en el Máster (gráfico 1), se aprecia una clara preponderancia del género masculino sobre el femenino en todos los ámbitos del mismo, salvo entre el profesorado de Lengua y Literatura, donde hay dos mujeres más que hombres dentro del equipo docente. 


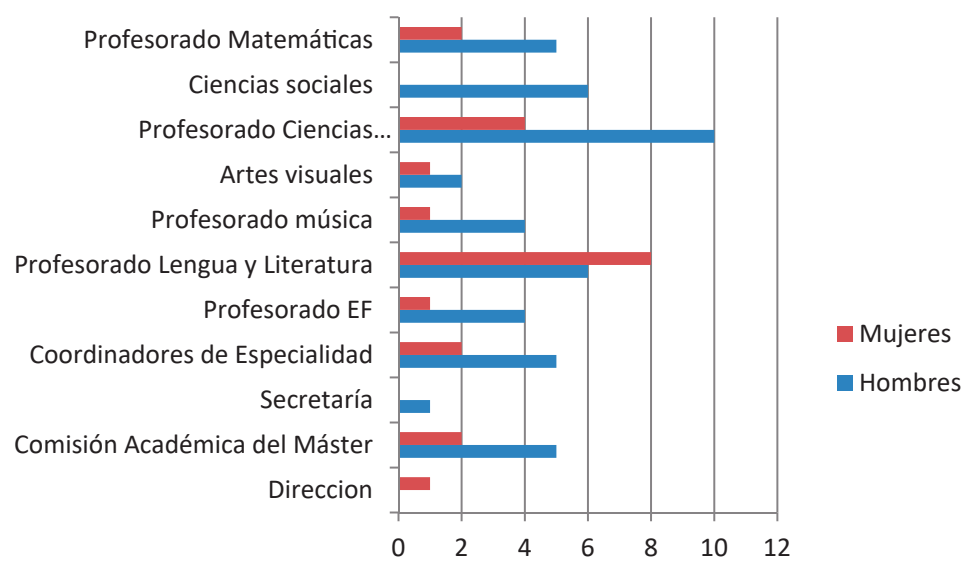

Figura 1. Representación total de las mujeres en el Máster de Investigación

\subsection{Materiales y actividades propuestas}

Los materiales son fundamentales en el proceso de transmisión cultural, porque concretan la selección con la que vamos a trabajar, la que vamos a presentar a los y las estudiantes (Blanco 12). En este sentido, consideramos que una selección pensada de los mismos puede ser determinante para alcanzar los objetivos deseados. También para crear un contexto de enseñanza-aprendizaje que intente potenciar en el aula "procesos cognitivos más ricos que los que se dan en una simple situación de transmisión oral cuya finalidad sería su posterior restitución por parte de los alumnos» (Dalongeville 5), para conseguir un aprendizaje más significativo o para contribuir a un trabajo competencial.

Por ello, la propuesta de trabajo que se plantea para incorporar el género dentro el Máster de Investigación de Didácticas Específicas estaría concebida a partir del desarrollo de los siguientes apartados:

1. Una primera aproximación que permita evidenciar y hacer patentes las representaciones sociales de nuestro alumnado a través de los estereotipos de masculino y femenino. La razón es que «los alumnos aprenden por reestructuraciones sucesivas que integran lo sabido y lo nuevo, lo reinterpretan y modifican su sentido» (Benejam 76). Por ello, no puede haber un aprendizaje significativo en el que las representaciones no emerjan en un primer momento y en las que éstas no sean puestas en 
tela de juicio, para que no se conviertan en un obstáculo que impida que la construcción de nuevos conocimientos (Dalongeville 5 y 8 ).

2. Un sondeo a los conocimientos previos de nuestro alumnado, en relación con el papel de las mujeres en las Ciencias Experimentales y Sociales.

3. Una reflexión acerca de los roles y estereotipos de género, entendidos como el conjunto de normas sociales y comportamentales generalmente percibidas como apropiadas para los hombres y las mujeres en un grupo o sistema social dado, en función de la construcción social que se tiene de la masculinidad y femineidad.

4. Un análisis de una selección de textos, de diferentes autores clave en la cultura occidental, en la que éstos reflexionan sobre la condición y el papel social de las mujeres. Estos dos últimos pasos adaptarían algunas actividades propuestas por la guía didáctica Mujeres en la Historia publicada por el Instituto Asturiano de la Mujer (2010).

Querríamos comenzar realizando un trabajo previo sobre las representaciones sociales de nuestro alumnado desde la perspectiva de género, cuestionándoles sobre aquello que, en su opinión, el entorno social actual demanda a los hombres y a las mujeres. El objetivo es positivar y/o hacer evidentes las demandas a las que nos someten nuestras sociedades y sistemas culturales en función de las identidades de género, pero también, por qué no, tratar de subvertir los roles. Se concibe como una actividad planteada para cuestionar los estereotipos, entendidos como imagen o idea aceptada comúnmente por un grupo o sociedad con carácter inmutable.

A continuación, se planteará un ejercicio que evidencie la invisibilidad de las mujeres para la historia y las Ciencias Experimentales y Sociales. Se trata de una actividad en la que pediríamos al alumnado que escribiera el nombre de veinte hombres y veinte mujeres que considerasen importantes en el transcurso de la historia, la geografía y/o la historia del arte y el nombre de veinte mujeres científicas. Trataríamos con ello de revisar el concepto tradicional de «protagonista» de la historia y también el de científico y/o científica vinculados aún hoy en día a una noción androcéntrica y tradicional (Fernández Valencia 61).

Otro de los ejercicios presentaría, en forma de tabla o esquema, los roles o funciones sociales tradicionalmente asignados a los diferentes géneros en las sociedades patriarcales, para ver hasta qué punto nuestros alumnos y alumnas se identifican con ellos o consideran que siguen estando vigentes en las sociedades actuales. Los primeros asociarían a la mujer con el espacio privado, la invisibilidad, la pasividad, la naturaleza, la emotividad, la debilidad física y 
la inteligencia emocional. Los segundos la contrapondrían a un concepto de hombre y de masculino vinculado a la esfera pública, la visibilidad, la actividad, la cultura y la creación artística, la razón, la fuerza física y la inteligencia racional.

Por último, quisiéramos proponer el análisis de una selección de textos breves, suscritos, como señalábamos, por diferentes autores clave en la cultura occidental (VVAA 2010). Entre ellos se cuentan autores clásicos como Aristóteles, Pitágoras o Platón, pero también ilustrados célebres (Rousseau), filósofos contemporáneos (Nietzsche) o médicos (Gregorio Marañón). Igualmente, fragmentos extraídos del Nuevo Testamento o suscritos por reformadores protestantes como Lutero. Su incorporación responde al hecho de que consideramos el trabajo con fuentes como una herramienta esencial en clase, pero también a que los discursos son uno de las prácticas fundamentales para construir la diferencia de género. Por ello consideramos que es necesario conocerlos, para poder decodificarlos y ser capaces de adoptar, con posterioridad, una postura crítica frente a los mismos.

En esta selección de textos, autores considerados canónicos y destacados como referentes dentro de diferentes disciplinas presentan, literalmente, a la mujer como inferior al hombre y a éste como superior y como «director» frente a ella (Aristóteles). También se las vincula con un principio «malo», creador del caos, la oscuridad y la mujer (Pitágoras), o como reencarnación en una segunda vida de aquellos hombres que fueron cobardes en la primera (Platón). Igualmente, se reclama su silencio y su sumisión (Nuevo Testamento), se la compara con la «mala hierba» (Lutero), se le exige dulzura y sometimiento al «tratamiento injusto» del marido (Rousseau), sumisión sexual (Nietzsche) o aceptación incondicional de la maternidad como característica básica de su sexo (Marañón). Se trata, en suma, de ofrecer al alumnado algunos de los textos que articulan el discurso de la misoginia, entendida como aversión a las mujeres y que, a lo largo de la historia, han configurado la visión de «la mujer» en las sociedades occidentales, utilizando la biología, la religión, la filosofía, la ciencia, etc., para argumentar su inferioridad.

\section{CONCLUSIÓN}

Del análisis presentado se puede deducir que, en el caso del Máster de Investigación en Didácticas Específicas de la Universitat de València, la dedicación académica al tema de la coeducación, así como la presencia equitativa de ambos sexos en la composición docente y directiva del Máster no es considerada como prioritaria, ya que a lo largo del periodo formativo no hay una 
atención exclusiva al tema de igualdad entre hombres y mujeres ni se cumplen las relaciones equitativas de género. Creemos que, tratándose de un máster que posee una doble vertiente de formación y de investigación, la falta de formación con perspectiva de género va a dificultar, a la larga, el poder dotar al alumnado de un marco de interpretación de la realidad que sea capaz de encajar con mayores elementos de justicia social. Además, ha quedado expuesto y avalado por la bibliografía existente (Donoso-Vázquez 76) que la formación en género en la formación superior se impone por varios motivos, entre los más importantes, que construye un mundo más equitativo y humano. Por lo que respecta a la vertiente investigativa, el no dotar al alumnado de esta perspectiva, la que supone la introducción de una categoría de análisis como género, dificulta que éstos puedan ampliar sus concepciones, abrir nuevas líneas de investigación y, sobre todo, cuestionar y revisar algunas de las conclusiones establecidas desde una posición androcéntrica.

Nuestra propuesta de actividades está por tanto dirigida a trabajar la coeducación en los procesos de aprendizaje y a incentivar una investigación con perspectiva de género, con la finalidad de que los avances en la construcción social del conocimiento sean difundidos y conocidos por el conjunto de la sociedad, porque a ella pertenecen. De lo contrario, éstos permanecen como un bagaje de conocimiento exclusivo y cerrado de la comunidad científica de las diferentes disciplinas. Puesto que la educación posee, entre otras, la función social de transmitir el conocimiento y la cultura científica a los más jóvenes a través de la educación formal, creemos que es necesario que esta educación, inicial o especializada, incorpore el género y sus derivaciones en todas las propuestas y ámbitos.

Sólo con una experiencia de formación en perspectiva de género se pueden conseguir cambios en los procesos mentales que se dan en el alumnado que contribuyan a modificar sus representaciones sociales. Los estudiantes debe asimilar y hacer suyos los conceptos asociados al género, además de ser capaz de generar respuestas genuinas, críticas y activas propias. De conseguirlo, los cambios sugeridos implicarían el desarrollo de una conciencia de la perspectiva de género, un análisis crítico de las realidades contextualizadas y una motivación que podría llegar a ser determinante para impulsar aquellos cambios que creemos son tan necesarios en nuestra sociedad. 


\section{REFERENCIAS BIBLIOGRÁFICAS}

Amelang, James y Mary Nash (comps.). Historia y género. Las mujeres en la Europa moderna y contemporánea. Valencia: IVEI, 1990.

Benejam, Pilar. «La selección y secuenciación de los contenidos sociales». Enseñar y aprender Ciencias Sociales, Geografía e Historia en la educación secundaria. Benejam, Pilar y Joan Pagès (coord.). Barcelona: Institut de Ciències de la Educació, (1997): 71-95.

Blanco García, Nieves. «Coeducación: la apuesta por una pedagogía de sujetos visibles». Kikiriki. Cooperación Educativa 54 (1999): 19-20.

Blanco García, Nieves. «Los saberes de las mujeres y la transmisión cultural en los materiales curriculares». Investigación en la escuela 65 (2008): 11-22.

Conselleria de Educación, Investigación, Cultura y Deporte. «Instrucción del 15 de diciembre de 2016, del Director General de Política Educativa, por la que se establece el protocolo de acompañamiento para garantizar el derecho a la identidad de género, la expresión de género y la intersexualidad». [2016/10425] del 27 del 12 de 2016.

Dalongeville, Alain. «Noción y práctica de la situación-problema en historia» Enseñanza de las Ciencias Sociales 2 (2003): 3-12.

Donoso-Vázquez, Trinidad y Anna Velasco-Martínez. «¿Por qué una propuesta de formación en perspectiva de género en el ámbito universitario?» Profesorado. Revista de Curriculum y Formación del Profesorado 17. 1 (2013): 71-88.

Elizondo, Arantxa, Ainoa Novo y María Silvestre. «Igualdad de mujeres y hombres en las universidades españolas». Madrid: Instituto de la mujer. Ministerio de Sanidad, Política Social e Igualdad, 2010.

Fernández Valencia, Antonia. Las mujeres en la enseñanza de las Ciencias Sociales. Madrid: Síntesis, 2001.

Heredero De Pedro, Carmen y Esther Muñoz Hernández. «Más y mejor coeducación». Experiencias. CEE Participación educativa 11 (2009): 139-145.

Hidalgo, Encarna, Dolores Juliano, Monserrat Roset y Àngels Caba. Repensar la enseñanza de la geografía y la historia. Una mirada desde el género. Barcelona: Octaedro, 2003.

Jaramillo Guijarro, Concepción. «Formación del profesorado: igualdad de oportunidades entre chicas y chicos». Madrid: Ministerio de Trabajo y Asuntos Sociales. Instituto de la mujer, 1999.

Menéndez, Cristobal. «El papel de la mujer en la investigación científica y médica en el siglo XXI: un debate necesario». Aten Primaria 43 (2011): 331-2.

Pagès, Joan. «La didáctica de las Ciencias Sociales y sus retos». Vallés, Joan, Álvares, Dolores y Rickennmann, Réné (eds.). La activitat docent. Intervenció, innovació, investigació. Gerona: Documenta universitaria, 2011, 45-62. 
Rausell Guillot, Helena. El papel de las mujeres en la sociedad actual. Madrid: Santillana, 2016.

Rebollar Sánchez, Edith Mariana. El género en los planes de estudio de los grados de educación de las universidades públicas españolas. Tesis doctoral. Universidad Autónoma de Barcelona: Barcelona, 2013.

Red2 (red de consultores s.l.). Guía de coeducación. Documento de síntesis sobre la educación para la igualdad de oportunidades entre mujeres y hombres. Madrid: Instituto de la Mujer. Observatorio para la igualdad de oportunidades, 2007.

Romero, Alfons y Paco Abril. «Género y formación del profesorado en los estudios de educación infantil». REIFOP 11.3 (2008): 43-51. Disponible en: <http:// www.aufop.com/> Consultado el 19-05-2017.

Valls, Rafael. «La exaltación patriótica como finalidad fundamental de la historia en la educación obligatoria: una aproximación histórica». Didáctica de las Ciencias Experimentales y Sociales 5 (1991): 33-47.

VVAA. Mujeres en la Historia. Guía didáctica. Oviedo: Instituto Asturiano de la Mujer, 2010. 



\title{
GENDER INEQUALITIES IN ITALIAN ACADEMIA. WHAT FUTURE FOR FEMALE ACADEMICS?
}

\author{
DESIGUALDADES DE GÉNERO EN LA ACADEMIA ITALIANA. \\ ¿CUÁL ES EL FUTURO PARA LAS MUJERES ACADÉMICAS?
}

\author{
Emanuela SALA \\ University of Milano Bicocca (Italy) \\ emanuela.sala@unimib.it \\ orcid.org/0000-0003-2988-579X \\ Roberta BOSISIO \\ University of Turin (Italy) \\ roberta.bosisio@unito.it \\ orcid.org/0000-0002-1091-0038
}

\begin{abstract}
In the last 20 years, the Italian Ministry of Education, University and Research (MIUR) has enacted two major reforms and passed a number of parliamentary acts that have radically changed the Italian academic system, e.g., the role of the permanent researcher was abolished and different types of fixed-term researchers were introduced. So far, very little is known on the effects of these reforms on men and women's career progressions. Using a unique dataset that includes information on the whole Italian academic staff, this paper aims to provide an overview of the changes that the reforms introduced in the academic system and compare male and female scholars' conditions within the university. The focus of the paper is on the young cohorts of academics who work as researchers. The main finding is that, in a context in which the selection and recruitment processes are not exclusively based on merit, the «gender neutral» MIUR reforms are contributing to the reproduction of the female disadvantage.
\end{abstract}

Keywords: women in science, gender inequalities, early career researchers, university reforms, women's career. 


\section{Resumen}

En las últimas dos décadas, el Ministerio italiano de Educación, Universidad e Investigación (MIUR) promulgó dos reformas y aprobó un gran número de procedimientos parlamentarios que cambiaron radicalmente el sistema académico italiano, por ejemplo, el papel del investigador permanente fue suprimido y fueron introducidos varios tipos de investigadores a plazo fijo. Hasta aquí, muy poco es conocido sobre los efectos de estas reformas en las progresiones de carrera de hombres y mujeres. A través de un único conjunto de datos, lo cual incluye informaciones sobre el personal académico interno de Italia, éste artículo tiene como objetivo proporcionar un resumen de los cambios en el sistema académico introducidos por las reformas y una comparación entre las diferentes condiciones de los académicos hombres y mujeres en la Universidad. El foco de esta investigación está en las cohortes más jóvenes de académicos que trabajan como investigadores. El principal hallazgo es que, en un contexto donde los procesos de selección y reclutamiento no están basados exclusivamente en el mérito, las reformas de género neutral del MIUR están contribuyendo a la reproducción de la desventaja femenina.

Palabras clave: mujeres en la ciencia, desigualdades de género, jóvenes académicos, reformas universitarias, carrera de mujeres 


\section{INTRODUCTION ${ }^{1}$}

Academia should be the «reign of meritocracy». In theory, selection and promotion processes should only be based on meritocratic criteria, i.e., the evaluation of the academic's productivity and teaching ability. However, reality seems to be quite different. In Italy, male and female career progressions seem to be governed by social mechanisms that have little to do with individual merit and somehow end up favouring men. In a previous work, we have drawn a quantitative picture of men and women's conditions in Italian universities, focusing on the ranks of full and associate professor and university researcher (Sala and Bosisio 2007). Since 2005, the Italian Ministry of Education, University and Research (MIUR) has enacted major reforms that have radically changed the Italian academic system, modifying the associate and full professors' promotion processes, abolishing the role of permanent researcher, and introducing different types of fixed-term researchers (i.e. with a dependent employment relationship with a duration of three years, eventually renewable). The overall aim of this work is to analyse men and women's conditions in the Italian academia, focusing, in particular, on the tenure and non-tenure researchers. After providing an overview of the legislative framework and discussing the MIUR reforms, we look at men and women's condition within the university (i. e., the horizontal and vertical segregation) and evaluate the impact of the recent reforms on their career paths.

\section{GENDER INEQUALITIES IN ENTERING THE ACADEMIC CAREER. STILL AN UNDERRESEARCHERD TOPIC}

We know very little about men and women's conditions within Italian universities. The few studies on this topic are quite dated. A publication by the Italian National Statistical Institute (ISTAT, 2001) has provided a detailed overview of male and female career patterns, documenting that the men's careers are faster than women's and the chances of making a career in academia are dependent

1. Although this paper is a joint work, Emanuela Sala wrote section 1, 2, 4, 5 and 6 and Roberta Bosisio section 3. 
on the disciplinary field in which academics work. In addition, the research has also shown the gendered nature of the recruitment processes, e. g., women are more likely to be hired through public competitions based on merit. Carabelli et al. (1999), investigating the factors driving male and female economists' differential professional outcomes, claim that gender differences in career paths cannot be traced to differences in men and women's work commitment. These differences may rather be brought back to the characteristics of the recruitment and promotion processes that are based on the principle of the so-called oldboys' network (mainly constituted by men). Bianco (2002) assessed the impact of the 1998 university reform on men and women's chances of professional growth. She concludes that the reform did not have any impact on the disparities in men and women's career progressions, although there was an increase in the number of women promoted to the role of associate professor. The role of family commitments on female academics' career is still unclear and appears to be more complex than expected. Facchini and Schmitz (1997) showed that having a family hampers women's career in academia whereas Rosselli (1999) found no differences in career progressions when comparing childless women to female academics with two or more children.

Despite of the shortage of scientific publications, issues concerning men and women's careers in academia are often discussed in the so-called "grey literature». Lavoce.info published a number of short reports that assessed the impact of the new promotion processes on male and female academics (see the next section). De Paola, Ponzo and Scoppa have shown that although men are more likely than women to apply for the national accreditation to associate professorships (2014a), there are no gender differences in the likelihood of being accredited (2014b). However, once accredited, men are more likely than their female colleagues to be recruited as associate or full professor (De Paola, Ponzo and Scoppa 2015). Another interesting contribution is by Bagues, Sylos Labini and Zinovyeva (2014). The authors have shown that the presence of women in the evaluating panel for the national accreditation has a negative impact on women's likelihood to be accredited to associate or full professor. The blog Return on Academic Research (ROARS) is also active in debating issues concerning the Italian academic system. In his contribution, Baccini (2014) found further evidence that supports De Paola, Ponzo and Scoppa's results (2014b); there are no gender differences in the likelihood of being accredited as associate or full professor. 
To the best of our knowledge, there are no scientific publications that look at the condition of young male and female researchers in Italian academia ${ }^{2}$. When considering the major Italian sociological journals (i. e., Polis, Rassegna Italiana di Sociologia and Quaderni di Sociologia), we found no papers published on these topics, at least since 2010. The Italian journal About Gender, which publishes contributions on gender issues, has not published any papers on young male and female academics' conditions either. There are research reports on gender inequalities in Italian universities. Although Frattini and Rossi's work focuses on women's career progressions, the authors do not analyse young male and female researchers' career paths (2012). The Italian Economic Society, which is particularly active in monitoring gender inequalities in the economic profession, did perform an analysis on male and female Ph.Ds' career progressions (Corsi 2014 and 2016), but it did not focus on young tenure and non-tenure researchers. It is also worth mentioning that the Italian Association of Ph.D students and Ph.D holders (ADI) has published a number of reports in which they look at young researchers' work conditions within Italian academia. However, they do not usually tackle gender issues in their reports. The situation may change in the near future: the GARCIA project (Gendering the Academy and Research: combating Career Instability and Asymmetries) has recently ended and some interesting papers may be published soon. Our work rests within this research context. Given the lack of knowledge in this area, it is meant to contribute to fill in this gap.

\section{THE RESEARCHER IN ITALIAN UNIVERSITIES: CREATION AND EVOLUTION OF THE ROLE}

Teaching and research staff in the Italian university system currently consists of tenured professors and researchers hired under a fixed-term or permanent employment contract, and temporary/occasional research and teaching staff whom the university engages under a range of contractual arrangements with no proper guarantees. It is important to notice that the recruitment procedures for tenured academic teaching and research staff are established at the national level.

Since the '80s, tenured staff has consisted of full professors at the top of the hierarchy, followed by associate professors and researchers (Presidential Decree 382/80). Pursuant to the legislative framework in force at that time, access to full and associate professorships was gained through competitive examinations which, after determining whether the candidates' academic qualifications were

2. When talking about young researchers we refer to early career researchers.

Feminismo/s 29, junio 2017, pp. 347-368 
appropriate, also entailed a teaching demonstration and a discussion of their publications.

Before Law 230/2005 (the so-called Moratti reform) was promulgated, researchers - like associate professors and full professors - were employed under an open-ended contract, receiving tenure after successfully passing a review held three years after their initial appointment. ${ }^{3}$ The researcher role was introduced for those who were involved in specific research activities although, in practice, it represented the lowest rank of the academic teaching staff (David 1994).

Law 230/2005 established September 30, 2013 as the final deadline for filling vacant researcher positions using the procedures contemplated by Law $210 / 1998$, and introduced the role of fixed-term researcher. This law was later affected by the most recent academic reform, Law 240/2010 (the so-called Gelmini reform), which made further changes to the status of university researchers.

Consequently, the term researcher covers a disparate population whose prerogatives are not always clear. Indeed, this role's introduction in 1980 (Presidential Decree 382/80) has been followed, as we have mentioned, by a succession of legislative measures, which, on the one hand, modified the recruitment procedures and duties of permanent researchers, and on the other hand introduced three types of fixed-term researcher contracts.

Currently, several types of researcher thus coexist in the Italian university system: permanent researchers (pursuant to Presidential Decree 382/80 as amended by Law 210/1998); fixed-term researchers established by the Law 230/2005, and Type A and Type B fixed-term researchers established by the Law 240/2010.

We will now look at the prerogatives, rights and duties associated with these positions (see Table 1).

\subsection{Permanent researchers}

Under the terms of Presidential Decree 382/1980, competitive examinations for posts as researchers were announced at the local level. The examining board, consisting of a full professor named by the Faculty Board (the internal member) together with a full professor and an associate professor drawn from a group designated by the National University Council, assessed candidates on the basis of two written and one oral test designed to gauge the candidates' aptitude for

3. Presidential Decree 382/1980 and Law 210/1998 (the Berlinguer Reform) governed their recruitment and legal status. 
research as well as their scientific and teaching qualifications. The National University Council defined the tests, assessment criteria and scoring system.

With Law 210/1998, the composition of the board of examiners for candidate researchers was changed to include one full professor, one associate professor and one researcher. The faculty board retains the right to name an internal member (either a full or an associate professor), while the other two members are elected by their colleagues of equal rank.

Assessment has also changed over time: assessment consisting of a review of academic qualifications and publications, plus written and oral tests ${ }^{4}$ has given way to assessment «based on the candidates' academic qualifications as illustrated and discussed before the board, and their publications, including doctoral dissertations, using internationally recognized parameters». ${ }^{5}$

With regards to researchers' duties, while it was originally planned that they would be chiefly engaged in research, their teaching responsibilities have come to occupy an increasingly significant proportion of their time over the years. Whereas researchers were initially given only supplementary teaching and tutoring assignments, since 2010 they have been «assigned courses and modules in the regular curriculum, with their consent and with no change in their legal and contractual status and salary». ${ }^{6}$ The gradual reduction in teaching staff ${ }^{7}$ and the importance of teaching to career advancement, moreover, have meant that researchers' acceptance of assigned courses and modules can be taken for granted.

Advancement to associate professor is generally contingent to participation in competitive examinations conducted according to the procedures laid down in Law 210/1998 and Presidential Decree 117/2000, and to the regulations adopted by each university.

However, the Gelmini reform states that until December 31 of the sixth year following its entry into force, universities can promote permanent researchers on their faculty who have received national accreditation to associate professorships. ${ }^{8}$

4. Presidential Decree $382 / 80$ as amended by Law 210/1998.

5. Law $1 / 2009$.

6. «Each university, to the extent permitted by its budget and on the basis of criteria and procedures set forth in its own regulations, shall determine the additional compensation paid to researchers to whom modules or courses in the regular curriculum are assigned with their consent» (Article 6, Law 240/2010).

7. According to the 2016 Report by the Fondazione Res (Viesti, 2016), the number of researchers and full or associate professors with teaching duties in Italian universities dropped by over 7,800 between 2008 and 2015 .

8. In accordance with the procedure contemplated by clause 5, Article 24 of Law 240/2010.

Feminismo/s 29, junio 2017, pp. 347-368 


\subsection{Fixed-term researchers ('Moratti contracts' as per Law 230/2005)}

The Moratti reform, in addition to phasing out open-ended contracts for researchers, introduced fixed-term researcher positions for the first time. Article 14 of the law requires that for the research and supplementary teaching activities hitherto included among the duties of permanent researchers, universities must establish «dependent employment relationships by entering into fixed-term contracts» with a maximum duration of three years and renewable for a total of up to six years. For this purpose, comparative assessment procedures governed by each university's regulations shall be used to recruit individuals with «high scientific qualifications»: candidates «having a $\mathrm{PhD}$ or postgraduate specialization, or who have taught a university course under the terms of a contract entered into pursuant to the provisions applying at the time this law comes into force will be given preferential consideration».

Remuneration for this type of fixed-term researcher is $120 \%$ of the starting salary of permanent researchers. ${ }^{9}$

\subsection{Type A and Type B fixed-term researchers ('Junior Gelmini' and 'Senior Gelmini' contracts as per Law 240/2010)}

The fixed-term researchers established by the Moratti reform - like that of permanent researchers - is being phased out, as the Gelmini reform repealed Article 1 of Law L. 230/2005, bringing further changes for researchers' recruitment and status. Like the previous law, the Gelmini reform also requires that research, teaching, supplementary teaching and student assistance be carried out by individuals selected by means of public assessment procedures and employed under fixed-term contracts. ${ }^{10}$

Two types of fixed-term contract are contemplated. The first, or Type A, are three year contracts that can be extended for a further two years $(3+2)$, at a salary equal to that of permanent researchers.

The second, or Type B contract, is also for three years but cannot be renewed. Candidates who can apply for these positions include those who have previously had: a) a Type B fixed-term contract; b) a research grant for at least three years (not necessarily consecutive) $;{ }^{11}$ or c) postdoctoral fellowships. ${ }^{12}$

9. Article 2, Interministerial Decree 94/2009.

10. Article 24 of Law 240/2010 established criteria and procedures for selecting candidates. It should be emphasized that these criteria include experience in teaching and in coordinating national and international research groups.

11. Article 51 of Law 449/1997.

12. Article 4, Law 398/1989. 


\begin{tabular}{|c|c|c|c|c|}
\hline 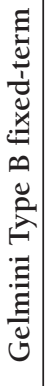 & 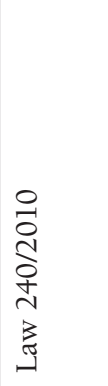 & 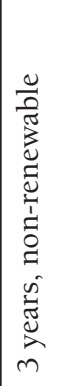 & 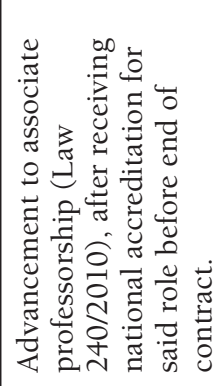 & 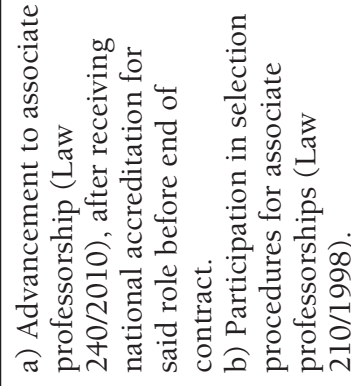 \\
\hline 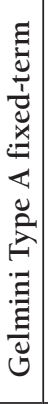 & 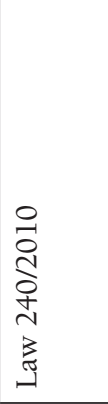 & 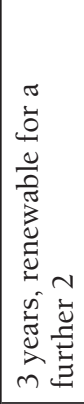 & 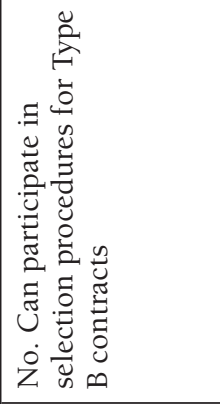 & 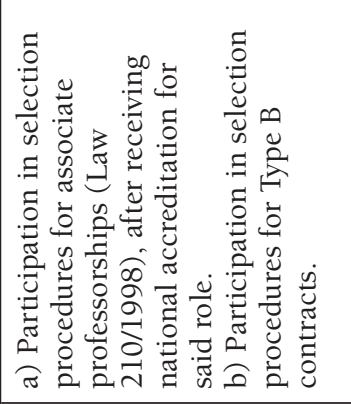 \\
\hline 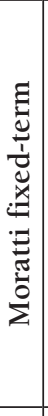 & 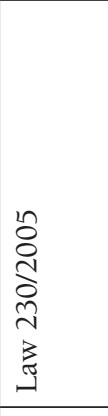 & 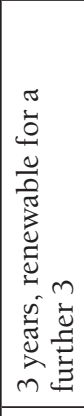 & 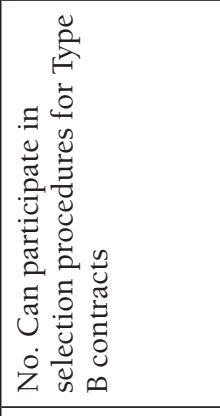 & 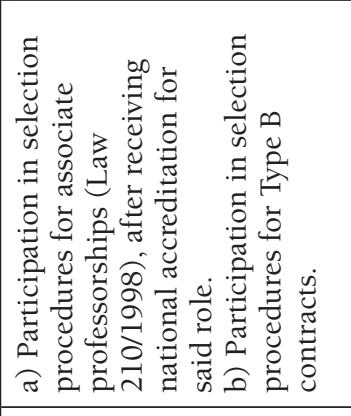 \\
\hline 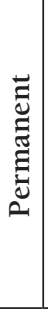 & 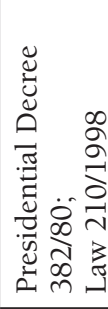 & 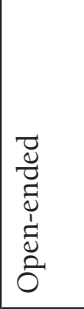 & 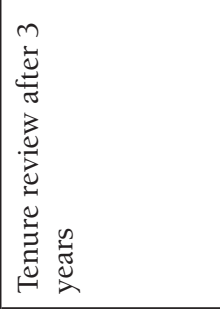 & 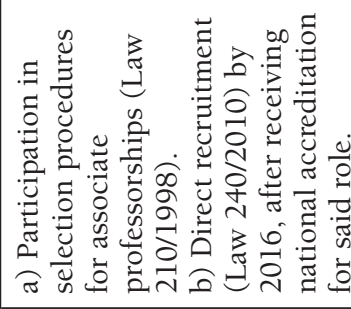 \\
\hline 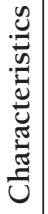 & 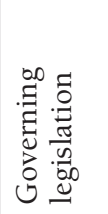 & 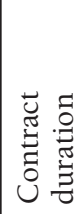 & 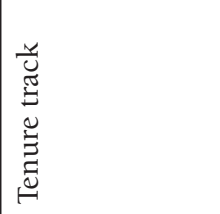 & 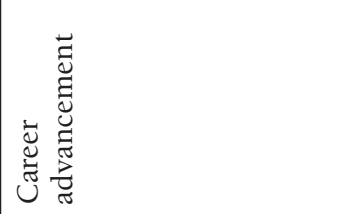 \\
\hline
\end{tabular}

Feminismo/s 29, junio 2017, pp. 347-368 
Calls for this type of contract are open to those who have had a Type A contract or held an equivalent position for at least three years, even if they do not have a PhD (ROARS Editorial Board, 09.09.2016).

If the researcher has received national accreditation for employment as an associate professor before the end of the third year of the contract, the university will assess his or her curriculum vitae «for purposes of recruitment for associate professorships» at the time the Type B contract expires. ${ }^{13}$

For researchers with Type B contracts, compensation is equal to that of permanent researchers, and can be increased by a maximum of $30 \%$.

In summery, in Italian universities there are currently four types of researchers: permanent researchers, Moratti fixed-term researchers (who are being phased out), and type A and B Gelmini fixed-term researchers.

The major difference amongst the three types of fixed-term contracts lies in the career opportunities associated to these roles; the Moratti and Gelmini Type A researchers do not offer any chances of university career progression, whereas the Gelmini Type B researcher is an «entry ticket» into the academic profession. Once their contract expires, most of the Moratti and Gelmini Type A researchers will need to apply for another researcher position whereas most of the Gelmini Type B researcher will become associate professors.

In the remaining part of this paper, we use the terms tenure track researcher and non-tenure researcher when referring to Gelmini Type B and A researcher, respectively.

\section{DATA}

We use administrative data from the databases University Search (Cerca Università) and Temporary Teaching Staff and Administrative Staff (Banca Dati del Personale Docente a Contratto e Tecnico Amministrativo) run by the Italian Ministry of Education, University and Research (MIUR). These databases collect information on the university staff that work in all public and private universities in Italy; the data refer to 31 of December of each year. The first one collects the following information on university teachers: role, tenure, sex, disciplinary field, faculty or department, and university. The data are available since 2000. The second one collects information on research fellows' sex and university affiliation and is available since 2003. The two databases are available at http://cercauniversita.cineca.it/ and http://statistica.miur.it/, respectively.

13. Article 24, clause 5, Law 240/2010. For a critical analysis of this procedure, see: Bellavista A., Il reclutamento dei professori e dei ricercatori universitari dopo la legge «Gelmini», http://www.roars.it/online/, 21-10-2012 


\section{RESULTS}

\subsection{Women in academia: Still a minority and still disadvantaged}

Table 2 shows the composition by sex of the Italian academic staff in 2016. As the data in column «Total» shows, the academic body is rather equally distributed among the different ranks; the full professors and the associate professors constitute $23.7 \%$ and $36.8 \%$ of the academic staff, respectively, whereas the researchers are $29.9 \%$. It is worth noting that the majority of the researchers have permanent positions.

There are strong differences in men and women's presence in academia. First, men's distribution amongst the different academic ranks is more equal than women's; the former is cone-shaped, the latter is markedly pyramid-shaped. Second, female academics are still in a minority; women are only $37.2 \%$ of the whole university staff. The feminisation rate, i.e., the percentage of women in a given category, is not constant but varies amongst the different ranks, showing a linear and negative trend. Indeed, women are $22.1 \%$ of the full professors, $37.1 \%$ of the associate professors and $47.9 \%$ of the researchers with a permanent position. Despite of this, women's presence within Italian academia has very slowly but constantly increased over time; the feminization rate has increased from 30.0 to 37.2 in 16 years (see also Section 4.3). The gender differences in the Italian university are due to a combination of factors: gender discrimination the delayed entry of women in the university career, the cultural and structural obstacles that women face when entering a world that is mainly dominated by men, and the lack of specific policy interventions to support women's careers (Bianco, 1997).

Researchers with temporary positions are currently $9.6 \%$ of the academic staff; female scholars seem to be overrepresented in this rank, being $10.7 \%$ of the university researchers and teachers compared to $9 \%$ of men. Interestingly, even within the younger cohorts of academics, we find the same pattern of gender differences that we have described in the previous paragraphs. Women are a minority in the three temporary positions that we consider, although since 2010 there have been no gender differences in the composition of the research fellow rank. In addition, when female academics manage to get a temporary position, they are more likely than men to be in the non-tenure research track. In the long run, this mechanism will have a detrimental impact on the gender composition of the academic staff. As already mentioned, non-tenure researchers have no future in Italian universities; when their contract expires, they will need to find another job (within or outside academia). When the tenure researchers' contract expires, they are likely to be promoted to associate professors. 
To sum up, Italian academia is still characterised by a strong degree of vertical segregation. This situation is also mirrored in the younger cohort of academics.

Table 2. Academic staff in Italian universities (2016). Column percentages and feminilization rate

\begin{tabular}{|c|c|c|c|c|c|}
\hline \multirow[t]{2}{*}{ Academic rank } & \multicolumn{2}{|c|}{ Sex } & \multirow[t]{2}{*}{ Total } & \multirow{2}{*}{$\begin{array}{l}\text { Feminilization } \\
\text { rate }\end{array}$} & \multirow{2}{*}{$\begin{array}{c}\text { Feminilization } \\
\text { rate } 2000\end{array}$} \\
\hline & Men & Women & & & \\
\hline \multicolumn{6}{|l|}{ Panel A } \\
\hline \multicolumn{6}{|l|}{ Permanent positions } \\
\hline Full professor & 29.4 & 14.1 & 23.7 & 22.1 & 15,4 \\
\hline Associate professor & 36.8 & 36.7 & 36.8 & 37.1 & 27,7 \\
\hline Researcher & 24.8 & 38.5 & 29.9 & 47.9 & 41,7 \\
\hline \multicolumn{6}{|l|}{ Temporary positions } \\
\hline Tenure researcher & 3.2 & 3.5 & 3.3 & 39.8 & $\mathrm{n} / \mathrm{a}$ \\
\hline Non-tenure researcher & 5.5 & 6.7 & 5.9 & 42.1 & $\mathrm{n} / \mathrm{a}$ \\
\hline Moratti researcher & 0.3 & 0.5 & 0.4 & 48.5 & $\mathrm{n} / \mathrm{a}$ \\
\hline $\mathrm{N}$ & 34,009 & 20,118 & 54,127 & 37.2 & 30.0 \\
\hline \multicolumn{6}{|l|}{ Panel B } \\
\hline Research fellow & 10201 & 10467 & 20668 & 50.6 & 52.6 \\
\hline
\end{tabular}

Source: University Search Database and Temporary Teaching Staff and Administrative Staff. Retrieval date: 8/12/2016.

Note: Data on the number of research fellows refer to 2015 and 2003. Retrival date: 06/02/2017.

\subsection{Women in academia: Disciplinary fields can make the difference}

As Table 3 shows, there is wide variation in the female presence amongst the different disciplinary fields. Indeed, the feminization rate varies between $16.5 \%$ for industrial engineering (9) and 54.3\% for the humanities (10). However, when analysing these data more carefully, we can clearly identify three distinct clusters of disciplines: a predominantly male cluster, where women are less than 30\% (physics, geology and engineering), a cluster with an intermediate female presence (e. g., medicines, law, economics, etc.), and a cluster with a relevant female presence, where women are at least 45\% (e.g. the humanities). 
For all disciplines, the characteristics of these clusters are particularly marked when considering the full professors and become less distinct when focusing on the associate professors and, especially, the researchers who hold permanent positions. Overall, the pattern we have just described is also reflected in the gender composition of the researchers with temporary position. For example, the feminization rate of the non-tenure researchers varies between 19\% for industrial engineering and information and communication technology (9) and $52.6 \%$ of the humanities (10).

Analysing more in detail the data on the temporary staff, two main findings stand out. First, for most of the disciplines, the percentage of female tenure track researchers is higher than the total feminization rate of a given discipline. For example, female tenure track researchers in the medical field (6) are $41.1 \%$, compared to $32.3 \%$ of all female medics. Physics (2), chemistry (3), biology (5), humanities (11), political and social sciences (14) are exceptions to this trend. Although the increase in the presence of women academics is good news, we would be careful in concluding that Italian universities will be more gender balanced in the future; indeed, it is worth recalling that women are the majority of the research fellows. Unfortunately, we have no data on the gender composition of this group of academics by disciplinary fields and, therefore, we cannot perform a more in-depth analysis.

Second, for most of the disciplinary fields there are differences in the presence of women amongst the three temporary position ranks. When comparing the feminization rate of the tenure and non-tenure researchers, we find that women are underrepresented in nine disciplinary fields. The differentials in the presence of women between the two ranks are particularly marked for chemistry (3), sociology and political science (14) where the differences in the two feminization rates are 16.9 and 20.8 percentage points, respectively. Interestingly, there seems to be an association between the gender differences in the tenure and non-tenure track researchers and the presence of women in a given discipline; the disciplines with a high presence of women (i. e., chemistry, sociology and political science) are also the disciplines with the highest differentials. On the contrary, the disciplines with the lowest feminization rates are amongst the disciplines with the lowest differences in the presence of women between tenure and non-tenure researchers, i. e., physics (2) and industrial engineering (9). As the non-tenure researchers have very little chances of career progression within the university, we conclude that, for some disciplines, the marked differentials in the feminization rate of tenure and non-tenure researchers will accentuate the existing gender differences. Overall, Italian academia is still characterised by a high degree of horizontal segregation. 


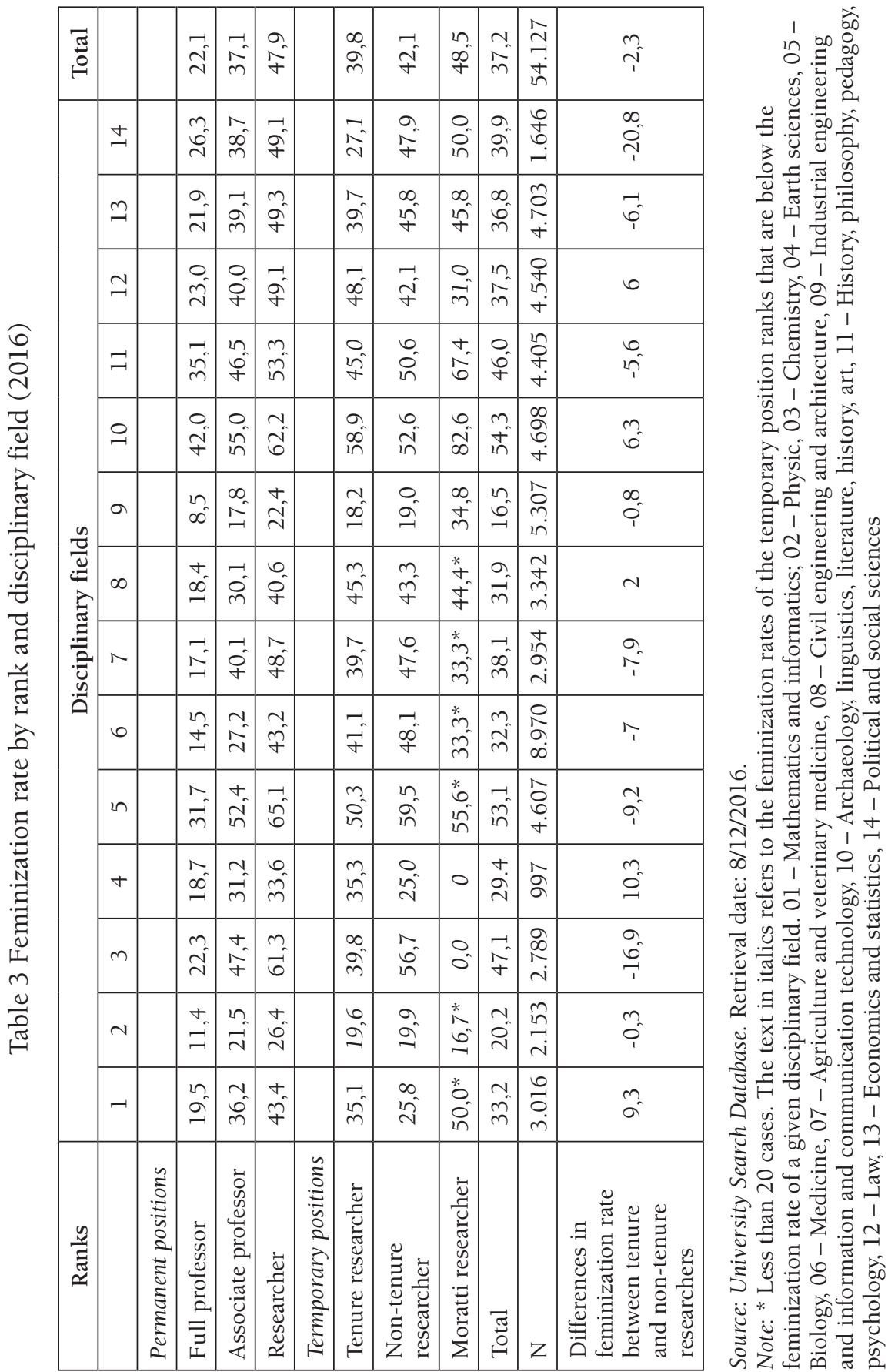




\subsection{Women in academia: changes over time}

We aim to assess the impact of the so-called Moratti and Gelmini reforms on female academics' career opportunities and, in particular, on young researchers' ones. We therefore limit our analysis to the 2010-2016 data.

The data in Graph 1 and Table 4 show a constant reduction in the size of the university staff; the number of professors and researchers shrunk from 58,884 to 54,127 units between 2010 and 2016 (see also Pavolini and Viesti 2016). This reduction has mainly concerned the ranks of the full professors and the permanent researchers. The factors that are driving these changes are different. The reduction in the number of the full professors can be brought back to structural reasons, i. e., the retirement of (mainly male) professors as well as the lack of economic incentives to hire/promote new full professors. The reduction in the size of the permanent researchers is a direct consequence of the university reform that abolished this rank. The case of the associate professor is particularly interesting; after an initial decrease, the size of the associate professor rank started to increase sharply in 2014. This increase is due to a special recruitment plan financed by the MIUR, the so-called Piano Straordinario per il reclutamento degli Associati. As one may expect, the increase in the size of the associate professors corresponds to the decrease in the number of permanent researchers.

Despite the changes that occurred between 2010 and 2016, women's condition within the Italian university has not undergone major changes. However, the analysis of the feminization rates shown in Table 4 indicates a slow but constant increase in the presence of women within the ranks of the full and associate professors and the permanent researchers. For example, between 2010 and 2016, the percentage of female full professors increased by 2 percentage points, from $20.1 \%$ to $22.1 \%$. Similar to what we stated previously, we would be careful in concluding that Italian academia is turning into a «land of equal opportunities». Rather, we would speculate that a number of structural factors has contributed to the increase in feminization rates. For the female full professors, the increase is due to the retirement of the mainly male professors (recall that there have been very few new recruitments of full professors recently). For the associate professors and the permanent researchers the reasons that lead to the increase in feminization rates can be brought back to the aforementioned special recruitment plan of the associate professors. Although men, more than women, benefitted from these new career opportunities, some women were also successfully promoted/hired as associate professors. This has led to an increase in the percentage of female associate professors but at the same time, an increase in the proportion of female permanent researchers. 


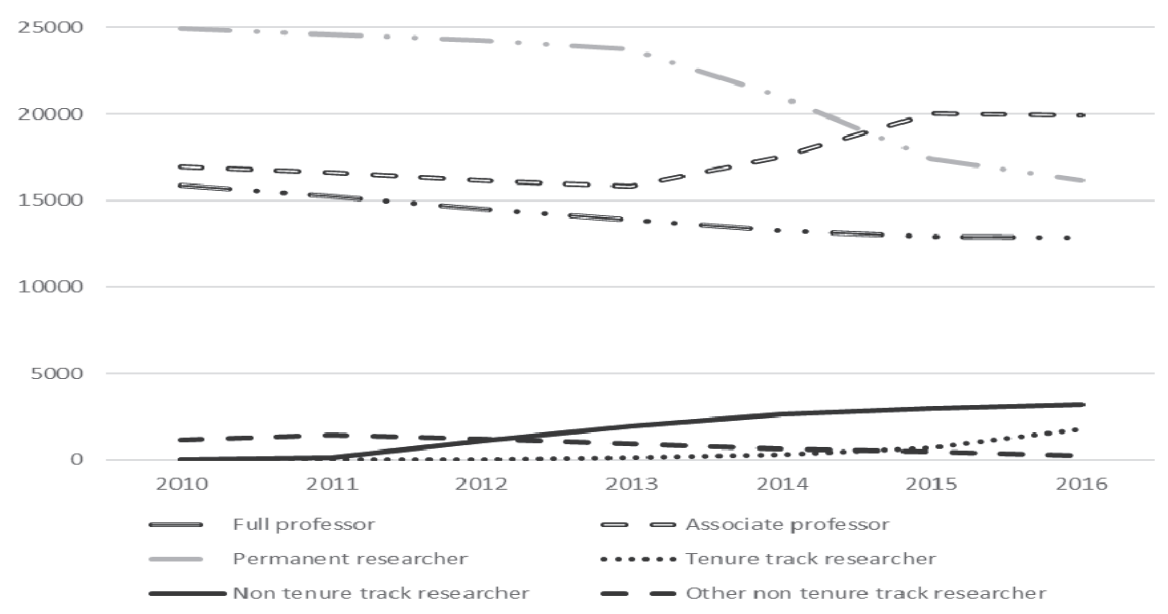

Figure 1. Changes in the composition of the university staff (2010-2016)

As consequence of the introduction of the Gelmini reform, the number of researchers employed with fixed-term contacts has been constantly increasing over time. This increase is due to the increase in the number of the tenure and, especially, non-tenure researchers. As hiring tenure researchers is more expensive than recruiting non-tenure ones, universities prefer to recruit young academics without tenure. This is also apparent when looking at the gap between the number of tenure and non-tenure researchers, shown in the graph and in Table 3. In 2016, the MIUR financed a special recruitment plan, the so-called Piano straordinario per il reclutamento di ricercatori di tipo $B$, that aimed to hire new tenure researchers. This plan was successful in reducing this gap, which, however, still persists at the end of 2016.

When focusing on young female scholars' career opportunities, we limit our analysis to the years 2013-2016. The analysis of the feminization rates of the three ranks shows a clear pattern, i. e., women are underrepresented within the tenure researchers and overrepresented within the non-tenure track researchers, especially within the «Moratti» researcher. For example, in 2015 the percentages of female academics within these three ranks were $38.1 \%, 43.3 \%$ and $46.6 \%$, respectively. It is worth noticing that the presence of women within the «Moratti» researchers is constantly increasing over time; between 2010 and 2016, the femilization rate has increased from $40.2 \%$ to $48.5 \%$. Similar to what we stated previously, we speculate that this can hardly be seen as an improvement in women's chances to make an academic career. We rather believe that most of the male researchers originally employed with 


\begin{tabular}{|c|c|c|c|c|c|c|c|c|c|c|c|c|c|}
\hline \multirow{14}{*}{ 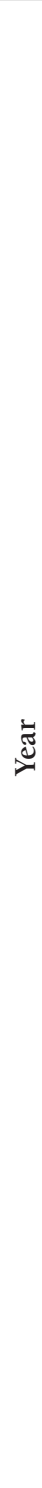 } & \multirow{2}{*}{ 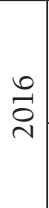 } & 点 & & & $\begin{array}{l}\vec{n} \\
\infty \\
\tilde{c}\end{array}$ & $\begin{array}{l}\tilde{N} \\
\tilde{\sigma} \\
\sigma\end{array}$ & $\begin{array}{l}\hat{0} \\
6 \\
-1\end{array}$ & $\begin{array}{l}\infty \\
\infty \\
-1 \\
-1\end{array}$ & $\begin{array}{l}0 \\
\stackrel{1}{0} \\
\text { m }\end{array}$ & તิ & 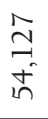 & & $\stackrel{\pi}{a}$ \\
\hline & & 嵒 & & & $\overrightarrow{\stackrel{\sim}{*}}$ & $\underset{m}{n}$ & $\stackrel{9}{+}$ & $\begin{array}{l}\infty \\
\dot{m} \\
\dot{m}\end{array}$ & $\underset{\mathfrak{H}}{\stackrel{4}{4}}$ & $\begin{array}{l}n \\
\infty \\
+\infty\end{array}$ & $\underset{m}{\stackrel{N}{n}}$ & & $\stackrel{\pi}{a}$ \\
\hline & \multirow{2}{*}{$\stackrel{n}{\circ}$} & $\stackrel{\widetilde{\pi}}{0}$ & & & $\begin{array}{l}2 \\
\infty \\
1 \\
-1\end{array}$ & $\begin{array}{l}\text { fn } \\
\text { O } \\
\text { ¿ }\end{array}$ & $\begin{array}{l}\stackrel{+}{m} \\
\stackrel{+}{s} \\
\stackrel{-}{-}\end{array}$ & 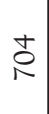 & $\begin{array}{l}\hat{a} \\
\text { aे } \\
\text { ì }\end{array}$ & $\underset{+}{+}$ & \begin{tabular}{l} 
in \\
\multirow{f}{+}{} \\
$\dot{H}$ \\
in
\end{tabular} & & $\begin{array}{l}\infty \\
8 \\
0 \\
0 \\
0 \\
0\end{array}$ \\
\hline & & $\frac{\alpha}{I I}$ & & & $\stackrel{0}{\vec{\lambda}}$ & $\begin{array}{l}n \\
\tilde{n} \\
m\end{array}$ & $\begin{array}{l}0 \\
\dot{f} \\
\dot{f}\end{array}$ & $\begin{array}{c}-1 \\
\infty \\
m\end{array}$ & $\stackrel{m}{\ddot{q}}$ & $\begin{array}{l}0 \\
\dot{b}\end{array}$ & 官 & & $\begin{array}{l}0 \\
\text { in }\end{array}$ \\
\hline & \multirow{2}{*}{$\underset{⿱}{\stackrel{ \pm}{N}}$} & $\stackrel{\widetilde{\pi}}{0}$ & & & $\begin{array}{l}\vec{b} \\
\stackrel{D}{2} \\
\end{array}$ & $\begin{array}{l}\infty \\
\stackrel{+}{+} \\
\stackrel{n}{n} \\
\end{array}$ & 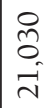 & $\stackrel{8}{\circ}$ & $\begin{array}{l}\text { oे } \\
\text { o } \\
\text { î }\end{array}$ & $\begin{array}{l}0 \\
\hat{\sigma}\end{array}$ & $\begin{array}{l}\text { ஜ } \\
\text { mे } \\
\text { in }\end{array}$ & & $\begin{array}{l}\tilde{a} \\
\text { on } \\
\text { ja }\end{array}$ \\
\hline & & $\frac{\alpha}{I I}$ & & & $\stackrel{+}{\dot{v}}$ & $\begin{array}{l}\dot{0} \\
i n \\
m\end{array}$ & $\begin{array}{l}t \\
\dot{\sigma}\end{array}$ & $\begin{array}{l}\infty \\
\infty \\
m\end{array}$ & $\begin{array}{l}\ddot{q} \\
\dot{y}\end{array}$ & $\stackrel{q}{i q}$ & $\begin{array}{l}\infty \\
\dot{0} \\
m\end{array}$ & & in \\
\hline & \multirow{2}{*}{$\begin{array}{l}m \\
\stackrel{\nu}{2}\end{array}$} & $\begin{array}{l}\vec{\pi} \\
0 \\
\ominus\end{array}$ & & & $\begin{array}{l}\infty \\
\infty \\
\infty \\
\\
\sim\end{array}$ & $\begin{array}{l}\Delta \\
\infty \\
10 \\
-1\end{array}$ & $\begin{array}{l}\text { P } \\
\stackrel{1}{1} \\
\tilde{\lambda}\end{array}$ & $\stackrel{\beth}{\beth}$ & $\begin{array}{l}\hat{\sigma} \\
\sigma \\
-i\end{array}$ & ๙ૂ & 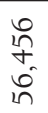 & & $\begin{array}{l}+ \\
\infty \\
\infty \\
\text { ¿ }\end{array}$ \\
\hline & & $\frac{\alpha}{\underline{I}}$ & & & $\stackrel{-}{\vec{\lambda}}$ & $\begin{array}{l}0 \\
i n\end{array}$ & $\begin{array}{l}0 \\
i f \\
f\end{array}$ & $\stackrel{\sim}{\vec{q}}$ & $\stackrel{n}{\tilde{q}}$ & $\stackrel{\sim}{\stackrel{f}{*}}$ & $\begin{array}{l}n \\
\ddot{n}\end{array}$ & & in \\
\hline & \multirow{2}{*}{ 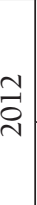 } & 胥 & & & $\begin{array}{l}\vec{\sim} \\
\tilde{n} \\
\pm \\
\pm\end{array}$ & $\begin{array}{l}0 \\
\stackrel{+}{0} \\
\stackrel{0}{-1}\end{array}$ & 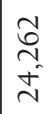 & $\stackrel{m}{ }$ & $\begin{array}{l}0 \\
= \\
=\end{array}$ & 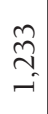 & $\begin{array}{l}\infty \\
\text { o } \\
\text { ñ } \\
\text { in }\end{array}$ & & 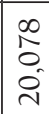 \\
\hline & & $\underset{I I}{q 1}$ & & & $\begin{array}{l}\stackrel{0}{0} \\
\grave{\lambda}\end{array}$ & 官 & in & $\begin{array}{c}0 \\
\dot{n} \\
\end{array}$ & $\stackrel{m}{\tilde{q}}$ & $\stackrel{\sim}{\dddot{q}}$ & $\vec{b}$ & & $\begin{array}{l}\infty \\
\stackrel{\infty}{\circ}\end{array}$ \\
\hline & \multirow{2}{*}{$\vec{\nabla}$} & $\stackrel{\vec{\pi}}{0}$ & & & $\underset{\mathfrak{\sim}}{\stackrel{\sim}{\sim}}$ & 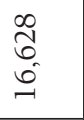 & $\begin{array}{l}\stackrel{2}{\infty} \\
\stackrel{2}{+} \\
\stackrel{+}{\sim}\end{array}$ & 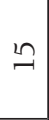 & 㽦 & $\stackrel{m}{\vec{F}}$ & $\begin{array}{l}\hat{n} \\
0 \\
\infty \\
i n\end{array}$ & & $\begin{array}{l}8 \\
\stackrel{0}{m} \\
\infty \\
\infty\end{array}$ \\
\hline & & $\frac{q}{I I}$ & & & $\stackrel{i}{0}$ & $\begin{array}{l}0 \\
\dot{m}\end{array}$ & $\stackrel{n}{q}$ & $\stackrel{m}{m}$ & $\begin{array}{l}0 \\
\dot{q}\end{array}$ & $\underset{\mathfrak{H}}{\stackrel{\sim}{f}}$ & $\stackrel{i}{n}$ & & $\begin{array}{l}\text { in } \\
\text { in }\end{array}$ \\
\hline & \multirow{2}{*}{$\begin{array}{l}\stackrel{0}{\circ} \\
\stackrel{i}{N}\end{array}$} & $\begin{array}{l}\vec{\pi} \\
0 \\
\ominus\end{array}$ & & & $\begin{array}{l}2 \\
\infty \\
\infty \\
n \\
n\end{array}$ & \begin{tabular}{l}
$\infty$ \\
\multirow{2}{\alpha}{} \\
$\underline{0}$
\end{tabular} & 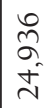 & $a$ & $n$ & $\begin{array}{l}\stackrel{0}{J} \\
\underset{-}{-}\end{array}$ & $\begin{array}{l}+\infty \\
\infty \\
\infty \\
\infty \\
i n\end{array}$ & & 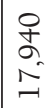 \\
\hline & & $\frac{\alpha}{I I}$ & & & $\vec{i}$ & $\stackrel{m}{m}$ & $\stackrel{m}{i n}$ & $\stackrel{m}{m}$ & Oे & $\stackrel{?}{\circ}$ & $\stackrel{\sim}{n}$ & & $\begin{array}{l}0 \\
\text { in }\end{array}$ \\
\hline 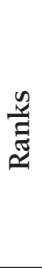 & & & 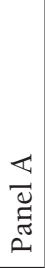 & 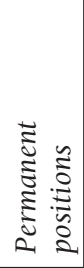 & 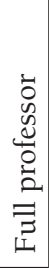 & 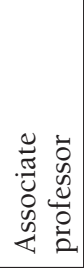 & 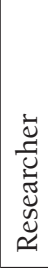 & 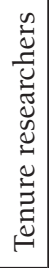 & 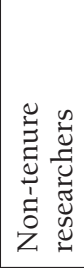 & 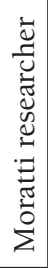 & $\stackrel{\widetilde{\sigma}}{\varrho}$ & $\frac{ص}{\stackrel{\oplus}{\tilde{\Xi}}}$ & 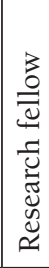 \\
\hline
\end{tabular}


this type of contract (that was the only available till 2011) is likely to have «moved up» the career ladder, «empting» this university rank and leaving their female colleagues trapped in a position that offers no career prospects.

We can fully describe the size of the female disadvantage when comparing these data to the percentage of young female research fellows. As Table 4 shows, the feminization rate of this rank has been constant over time and in 2015 is $50.6 \%$. This clearly shows that a minority of young female academics is successful in obtaining a post as temporary researcher and, in particular, as tenure track researcher.

\section{CONCLUSIONS}

In the last ten years, the Parliament has introduced a number of university reforms that have radically transformed the characteristics of Italian academia. In particular, the so-called Riforma Moratti and Riforma Gelmini have changed the characteristics of the university researcher, the lower rank of the academic career, abolishing the rank of permanent researcher and replacing it with different types of temporary researchers (i., e., tenure and non-tenure researchers). Although academia, as mentioned in the introduction, should be the «land of meritocracy», previous research has shown that the numerous reforms of the Italian universities, being gender neutral, end up favouring men's career progressions. Against this background, the aim of this work is to assess the impact of these changes on men and women's career opportunities, focusing, in particular, on young academics.

In the first part of the paper we described the characteristics, in terms of stability of the post and career opportunities, of the different types of university researchers. The Italian university system is currently constituted of two groups of researchers, those who hold permanent positions (i. e., researchers hired before the two reforms were enacted) and those with temporary contracts (i. e. tenure and non-tenure researchers, recruited after the reforms). Although the Gelmini reform did also introduce important changes in the recruitment processes of full and associate professors, these continue to hold permanent positions.

In the second part of the paper, we analysed the condition of women within the Italian university. Using data on the whole academic staff, we have documented the high level of vertical segregation that still persists in Italian universities. For example, in 2016, women constitute $22.1 \%$ of full professors. Surprisingly, when focusing on researchers who hold temporary contracts, we found a similar pattern; although there are no differences in the gender composition of research fellows, in 2016 female academics are $39.8 \%$ and $42.2 \%$ of tenure and non-tenure track researchers, respectively. 
Our analysis has also thrown light on another aspect of gender inequalities, the concentration of female and male scholars within different disciplines, documenting the high level of horizontal segregation of Italian academia that also distinguishes the presence of young female researchers within the university. For example, women are $19.6 \%$ of tenure researchers in physics compared to $58.9 \%$ in the humanities. We have also shown that there are strong gender differences in the career opportunities of young academics who work in different disciplinary fields. In particular, there are no gender inequalities in disciplines with low female presence, such as physics or industrial engineering and information and communication technology, whereas we find strong differences in academic fields with high feminization rates. For example, in political and social sciences there is a difference of 20 percent points between the percentage of men and women who hold tenure and non-tenure research posts. The situation that we have documented in our paper is similar to the one of other European countries, as described in the EU publications She Figures.

In the last part of this work, we have shown that despite the changes that occurred between 2010 and 2016, women's condition within the Italian university has not undergone major changes. For example, male academics benefitted more than their female colleagues did from the special recruitment plan of the associate professors financed by the MIUR. The female disadvantage is particularly striking for the younger cohort of academics; although $50 \%$ of the research fellows are women, about $40 \%$ of them are employed as tenure researchers.

Taken together, these data suggests that Italian academia is far from being a «land of equal opportunities» for men and women, and, in particular, for the generation of young female researchers. Although the MIUR databases are a unique research resource, they have limitations, as they do not provide information on other aspects that need to be taken into consideration to fully disentangle the mechanisms that are driving the differences in male and female scholars' career progressions. For example, they do not collect information on academics' productivity (e. g., number of publications) or on caring responsibilities (e. g., number of children). Therefore, little is known on the factors behind the high levels of vertical and horizontal segregation that still persist in the Italian academia.

One could speculate that women did not «make it to the top» because of a delayed entry into the university career. In other words, there are fewer women than men in the full-professor rank because fewer women graduated 40 years ago. Although this may be true for the older generation of women, this does not hold true for the younger cohort of female graduates; in some 
disciplines, women are the majority of graduates as well as the majority of researcher fellows. Drawing on economic theories, one may state that women choose not to make an academic career, because of the commitment (in terms of time and energies) it involves and the difficulties in balancing career and family. We do not have any data to test this hypothesis; however, for some disciplines, we found no differences in the percentage of female tenure and non-tenure researchers (see Table 3). This would suggest that, at least in some cases, this hypothesis does not find empirical support. Unless we believe that young female academics' aspirations and work commitment vary by disciplinary field and that, in some cases, women may deliberately choose to apply for precarious positions rather than for more permanent ones (which is somewhat irrational), the economic theories can hardly explain the differences in men and women's career paths.

It is therefore quite likely that the factors that are driving these differences lie elsewhere and lie, in particular, within the university itself and, more specifically, in the formal and informal rules that govern the academics' selection and career advancement processes. In a legislative context characterized by gender-neutral norms (as documented in Section 3), informal mechanisms that are not based on meritocratic criteria end up favouring men's careers. The reforms that the MIUR enacted, ignoring the gender dimension, reinforced these mechanisms and contributed to the reproduction of the female disadvantage within Italian academia. These reforms will have unexpected and possibly unwanted long-term effects for many young female researchers.

\section{REFERENCES}

Bagues, Manuel F, Mauro Sylos Labini and Natalia Zinovyeva. «Le quote rosa non superano l'abilitazione», Lavoce.Info, 24-06-2014. Available at: http://www. lavoce.info/archives/20626/quote-rosa-non-superano-labilitazione, consulted on 20-12-2016.

Baccini, Alberto. «Le donne sono state discriminate dall'abilitazione scientifica nazionale?», Roars, 28-10-2014. Available at: http://www.roars.it/online/ le-donnesono-state-discriminate-nellabilitazione-scientifica-nazionale/, consulted on 20-12-2016.

Bianco, Maria Luisa. Donne al lavoro: cinque itinerari fra le diseguaglianze di genere, Torino: Scriptorium, 1997.

Bianco, Maria Luisa. "Effetti della riforma dei concorsi universitari su carriere accademiche e dinamiche di genere», Polis 16.3 (2002): 417-441. 
Carabelli, Anna Maria, Daniela Parisi and Annalisa Rosselli (a cura di). Che genere di economista? La professione di economista nell'università italiana, Bologna: il Mulino, 1999.

Corsi, Marcella. «Soci SIE: uno sguardo di genere», Commissione di genere, Società Italiana degli Economisti, 2014. Available at: http://www.ingenere.it/ricerche/ soci-sie-uno-sguardo-di-genere, consulted on 20-12-2016.

Corsi, Marcella. «Soci SIE: uno sguardo di genere», Commissione di genere, Società Italiana degli Economisti, 2016. Available at: http://www.siecon.org/online/ wpcontent/uploads/2014/10/SIE_-report-di-genere_151014_MC.pdf, consulted on 20-12-2016.

David, Patrizia. «La scienza al femminile» in Patrizia David and Giovanna Vicarelli (a cura di). Donne nelle professioni degli uomini, Milano: Angeli, 1994: 267-301.

De Paola, Maria, Michela Ponzo and Vincenzo Scoppa. «Donne sull'orlo di una crisi di competizione», Lavoce.Info, 29-07-2014a. Available at: http://www. lavoce.info/archives/29143/donne-competizione-universita/, consulted on 20-12-2016.

De Paola, Maria, Michela Ponzo and Vincenzo Scoppa. «La parità di genere non sale in cattedra», Lavoce.Info, 11-03-2014b. Available at: http://www.lavoce. info/archives/18070/profilo-nuovi-professori-concorso-gelmini/, consulted on 20-12-2016.

De Paola, Maria, Michela Ponzo and Vincenzo Scoppa. «Chi sale in cattedra», Lavoce.Info, 16-06-2015. Available at: http://www.lavoce.info/archives/35703/ la-parita-di-genere-non-sale-in-cattedra/, consulted on 20-12-2016.

EC (European Commission). She Figures 2013. Statistics and Indicators on Gender Equality in Science, Luxemburg: Publication Office of The European Union, 2014. Available at: http://ec.europa.eu/research/swafs/pdf/pub_gender_equality/she_figures_2015-final.pdf, consulted on 20-12-2016.

Facchini, Carla and Nora Schmitz. «Il ruolo della famiglia nella carriera di uomini e donne» in Roberto Moscati (a cura di). Chi governa l'università? Il mondo accademico tra conservazione e mutamento, Napoli: Liguori editore, 1997.

Frattini, Romana and Paolo Rossi. «Report sulle donne nell'università italiana», Meno di zero, 8-9, 2012.

ISTAT. Donne all'università, Bologna: il Mulino, 2001.

Pavolini, Emmanuele and Gianfranco Viesti. «Università: ricercatori in bilico», Lavoce.Info, 15-04-2016. Available at: http://www.lavoce.info/archives/40642/ sempre-meno-docenti-alluniversita/, consulted on 20-12-2016.

ROARS Editorial Board. «I 'ricercatori Moratti' non possono essere esclusi dai concorsi per RTD B», Roars, 09-09-2016. Available at: http://www.roars.it/ online/i-ricercatori-moratti-non-possono-essere-esclusi-dai-concorsi-perrtd-b/, consulted on 20-12-2016. 
Rosselli, Annalisa. «Introduzione», in Anna Carabelli, Daniela. Parisi and Annalisa Rosselli (eds.). Che genere di economista, Bologna: il Mulino, 1999: 7-21.

Sala, Emanuela and Roberta Bosisio. «The Role of Formal and Informal Rules in Italian Academics' Careers. Are there Equal Opportunities for Men and Women?» in Renata Siemienska and Annette Zimmer (eds.). Gendered Career Trajectories in Academia in Cross National Perspective, Warsaw: Wydawnictwo Naukowe Scholar, 2007: 129-160.

Viesti, Gianfranco. Università in declino. Un'indagine sugli atenei da Nord a Sud. Rapporto Fondazione Res, Roma: Donzelli, 2016. 


\title{
EL LIDERAZGO EN LA UNIVERSIDAD: EL PAPEL QUE TIENEN ELLAS
}

\section{LEADERSHIP IN UNIVERSITY: THE ROLE THAT WOMEN HAVE}

\author{
Marina TOMÀS-FOLCH \\ Universitat Autònoma de Barcelona \\ marina.tomas@uab.cat \\ orcid.org/0000-0001-5445-4823
}

\section{Resumen}

En este artículo presentamos tres factores que determinan en gran parte la igualdad de oportunidades en las universidades con respecto al género: la cultura organizativa en la Universidad, la participación en la gestión universitaria y el ejercicio del liderazgo. Se presentan tres estudios mixtos (cuantitativos y cualitativos) cuyo objetivo es obtener la percepción que tiene el profesorado universitario de la cultura institucional con respecto al género, al liderazgo y a la participación en la toma de decisiones. Los resultados muestran que persiste una percepción sobre modelos estereotipados del estilo de liderazgo de las personas que ejercen la dirección departamental que se identifican con la construcción social de lo masculino, que existen formas de participación en las reuniones de los órganos de gobierno diferenciados según el género de quien participa y de quien lidera, que se encuentran ciertos rasgos en las motivaciones y formas de ejercer los cargos de dirección en la Universidad en función del género y que el liderazgo de la investigación está mayoritariamente en manos del género masculino.

Palabras clave: liderazgo, Universidad, mujeres, participación, toma de decisiones.

\begin{abstract}
In this article we present three factors that determine in great part the equality of opportunities in universities with respect to the gender: the organizational culture in the university, the participation in the university management and the exercise of leadership. Quantitative and qualitative studies have been carried out in order to obtain professors' perception of the institutional culture regarding gender, leadership and
\end{abstract}


participation in decision making. The results show that there's a persistant perception about stereotyped models of the leadership style of the departmental leaders identified with the social construction of the masculine, that there are forms of participation in the meetings of the governing bodies differentiated by the gender of the professors who participate and by the professor who lead, that certain features are found in the motivations and ways of exercising management positions in the university according to gender and that the leadership of the research is mostly in the hands of the male gender.

Keywords: leadership, university, women, participation, decision making. 


\section{INTRODUCCIÓN}

En este artículo presentamos, de una manera transversal, los resultados de tres investigaciones realizadas por equipos de investigación dirigidos por la autora con el correspondiente estado de la cuestión respecto a los tópicos de: liderazgo en la Universidad tanto en la gestión académica como en la investigación, la participación en la toma de decisiones y la cultura organizativa.

\subsection{La cultura universitaria: una rémora para la igualdad de oportunidades de género}

Desde la mirada de la cultura organizacional universitaria, es lógico que nos interesemos por su relación con el género. El género es una construcción cultural y, como tal, debería aparecer como elemento indispensable en cualquier análisis de la cultura organizativa. En la Universidad, como en cualquier otra organización, se construyen y reproducen significados culturales con un contenido de género. Algunos análisis sugieren que las culturas organizativas suelen privilegiar significados masculinos que son adoptados como referentes de lo que es «normal», «natural» o simplemente valioso en las organizaciones.

Respecto a las razones extrínsecas que explican la desigual e infrarrepresentada presencia de las mujeres en los cargos directivos de la Universidad observamos la existencia de una cultura masculinizada que frena la iniciativa de la mujer para acceder a cargos de gestión. Las mujeres manifiestan tener que demostrar ser muy buenas en el ejercicio de sus roles para ser reconocidas y aceptadas en sus cargos de gestión. Estos hallazgos coinciden con los expuestos por Carli y Eagly y Johannsen-Schmidt para explicar la (in)visibilidad de las mujeres en puestos de poder así como con los de Kram y Humpton quienes consideran que el predominio de una cultura masculinizada constituye una dificultad para que las mujeres accedan a posiciones de poder en las universidades (Sánchez-Moreno, Tomàs-Folch y Lavié).

Sin embargo, salvo contadas excepciones, los análisis de las culturas organizativas son notorios por su falta de atención a las cuestiones relacionadas con el género. Esto, por otra parte, tampoco debería extrañarnos: la teoría 
organizativa ha estado tradicionalmente de espaldas a las cuestiones de género, y sólo en los últimos años ha comenzado a desarrollar una mayor sensibilidad hacia tópicos relacionados con el mismo. Los análisis de género se han preocupado tradicionalmente por cuestiones de representatividad numérica o por las formas distintivas de hacer de las mujeres en puestos de gestión. Sin desmerecer estos planteamientos, el estudio de la Universidad desde una perspectiva de género debe estar guiado también por un interés por desvelar el sustrato de género que informa a los significados culturales. En definitiva, sobre la cuestión del análisis de la cultura organizativa en la Universidad desde una óptica de género podemos concluir lo siguiente:

- No disponemos de abundantes estudios sobre cultura organizativa y género, si bien es previsible que la incorporación de una perspectiva de género en el análisis de la cultura organizativa haga visible la manera en que las culturas y los elementos simbólicos de una organización pueden marginalizar a las mujeres.

- La dificultad de identificar y definir las barreras culturales relacionadas con el género, como elementos simbólicos, no debe ignorar su análisis y estudio en profundidad.

La investigación en torno al techo de cristal ha puesto de manifiesto las múltiples dificultades con las que se encuentran muchas mujeres en su progresión en la escala organizativa. En el contexto universitario las cifras son concluyentes, el género persiste como criterio diferenciador de poder. Así pues será preciso «repensar» nuestra propia cultura organizacional, para conocer los roles inter géneros y la aceptación de cada uno de ellos, fortaleciendo la institución desde el enriquecimiento por:

- Los preocupados por identificar las barreras que encuentran las mujeres en sus intentos por avanzar profesionalmente en el marco de la dirección.

- Aquellos interesados en documentar las estrategias puestas en juego por las mujeres que logran cierto éxito en el contexto empresarial.

- Los que procuran definir un «estilo femenino» en el ejercicio del liderazgo que aporta la diversidad de ideas, valores, costumbres, hábitos y formas de proceder (Caceres, Sachicola e Hinojo). 


\subsection{El liderazgo y la dualidad «igualdad versus diferencia entre géneros»}

En el campo de las organizaciones empresariales, a diferencia de lo que ha sucedido en el de las educativas, muchas investigaciones se han preocupado de analizar la incidencia de la variable género. Su enfoque - fiel a la perspectiva tecnocrática que acostumbran a adoptar este tipo de estudios- ha sido predominantemente descriptivo de las diferencias en el comportamiento, el trato o el desarrollo de los hombres y de las mujeres en estas organizaciones.

Desde el liderazgo como también desde otras facetas profesionales se considera la dualidad «igualdad versus diferencia» entre géneros. En un extremo encontramos lo que podríamos llamar un enfoque centrado en reclamar la igualdad de hombres y mujeres en el ejercicio del liderazgo y en el otro, los enfoques orientados a reclamar la diferencia. De acuerdo con el primer enfoque, hombres y mujeres son esencialmente iguales, por lo que el problema puede definirse como de acceso a estructuras y procesos que se consideran neutrales. La desigualdad de las mujeres se entiende, pues, como resultado de restricciones de orden social e institucional, que se pueden erradicar desmantelando estas barreras estructurales a la igualdad. La lógica subyacente a este discurso es que, al eliminar las barreras estructurales y procedimentales, una buena parte de mujeres tendrá acceso, por su propio mérito, al poder formal. Desde este enfoque, por tanto, hermanado con la teoría política liberal y el feminismo liberal, se ha reclamado el acceso a puestos de responsabilidad basado en el mérito individual. Las estrategias de igualdad de género promovidas desde esta perspectiva se centran fundamentalmente en cambiar a las mujeres de manera individual, no a las culturas donde trabajan, para que se parezcan más a los hombres: formación para adquirir las destrezas propias de un campo del que, hasta el momento, habían sido ajenas. Para asegurar la igualdad de oportunidades, las mujeres deben ser formadas para cubrir las carencias propias de su socialización diferencial y llegar, de este modo, a un nivel y desempeño comparable al de sus colegas varones. Hay que desarrollar las destrezas y estilos que se consideran necesarios para el éxito. Desde esta perspectiva, el feminismo liberal ha perseguido la eliminación de los estereotipos asociadas al género.

De acuerdo con esta perspectiva, las mujeres con éxito en puestos de liderazgo son las que logran una integración -en lugar de polarización- de rasgos tanto femeninos como masculinos (Park). Se resuelven de esta manera las percepciones negativas que suelen atribuirse al liderazgo femenino, una de las principales razones argumentadas para justificar la escasa representación de las mujeres en los puestos de gestión educativa. En el extremo opuesto, a diferencia de lo que ocurre con los planteamientos que buscan mejorar 
las deficiencias de la mujer para el liderazgo, se ensalza la diferencia como constitutiva del género, y se enfatiza el valor positivo de las cualidades tradicionalmente asociadas a las mujeres. Partiendo de esta diferenciación clásica de los roles femeninos y masculinos, se asume que hay ciertas cualidades que se identifican con un estilo de liderazgo «femenino»o «masculino». Aunque cualquiera de estos estilos puede ser adoptado tanto por hombres como por mujeres, la asunción básica y las expectativas que de ella se derivan es que los hombres desarrollan un estilo predominantemente masculino, mientras que las mujeres uno fundamentalmente femenino. De acuerdo con esta asunción, los hombres en puestos de responsabilidad tienden a desarrollar estilos más autoritarios, orientados a la tarea y transaccionales, mientras que las mujeres exhiben estilos más democráticos, interactivos u orientados a las relaciones, y transformacionales (Eagly y Johannesen-Schmidt). Actualmente existe un considerable volumen de trabajos que tienden a revalorizar «lo femenino» en contextos organizativos que tradicionalmente han operado sobre asunciones y patrones de comportamiento típicamente masculinos. Se trata de un discurso que tiende a ganar popularidad en círculos empresariales, educativos y, hasta cierto punto, en el sentido común, y que reclama la celebración de los valores femeninos y la valoración de la diversidad en la coyuntura actual de la gestión empresarial. Este discurso es convergente -en apariencia- con los «nuevos» y más suaves discursos sobre gestión que se centran en la buena gestión de las personas como la nueva fuente de productividad en las organizaciones flexibles posmodernas. Los textos de gestión -fundamentalmente los destinados a un público no académico- hablan, en este sentido, de la «ventaja femenina» en el liderazgo.

De acuerdo con la autora feminista (Helgesen), los talentos, las experiencias y las destrezas que poseen las mujeres son precisamente lo que se necesita para el liderazgo en la economía postindustrial, lo que está creando oportunidades sin precedentes para que las mujeres ocupen un rol crucial en liderar el cambio transformacional en organizaciones y comunidades. Desde esta perspectiva, por tanto, la presencia de las mujeres en puestos de responsabilidad se justifica por su capacidad de desarrollar estilos de liderazgo de acuerdo con los nuevos modelos organizativos «postmodernos» centrados en las relaciones horizontales y el trabajo en equipo. Las aproximaciones que acabamos de considerar al abordar las relaciones entre género y liderazgo ofrecen posibilidades y abren vías de análisis que permiten redirigir nuestra atención hacia cuestiones tradicionalmente silenciadas en el estudio de las instituciones. Sin embargo, presentan también limitaciones que restringen las posibilidades de ofrecer alternativas a los discursos dominantes. El enfoque igualitario, por 
un lado, centrado en erradicar los estereotipos de sexo y afirmar la igualdad esencial entre hombres y mujeres, ha tendido a soslayar el significado socialmente construido del género, y se ha traducido comúnmente en una estrategia de asimilación de los modelos establecidos que no cuestiona las relaciones de poder existentes. Por su parte, el enfoque centrado en celebrar la diferencia femenina, ampliamente reconocido en los planteamientos actuales sobre el liderazgo, socava las posibilidades de pensar sobre el cambio en las relaciones de género al distraer la atención de las relaciones de género/poder imbricadas en la vida organizativa, los valores, las estructuras y los procesos. Se trata, además, de un discurso fácilmente cooptable por las lógicas dominantes de la gestión empresarial.

Para concluir este apartado nos vienen muy bien las palabras de Nájera «esas dos modalidades tradicionales del feminismo están agotadas y se hace necesario explorar un camino alternativo que se aleje de esencialismos y que ha de desbordar forzosamente categorizaciones poco flexibles».

\subsection{El liderazgo de equipos de investigación}

Uno de los indicadores de éxito de la carrera investigadora de las académicas es que dirijan equipos de investigación puesto que ello significa, a grandes rasgos, que tienen un reconocimiento como investigadoras a nivel de la comunidad científica local e internacional.

En los últimos años algunas aproximaciones a la investigación desde la perspectiva de género han ayudado a esclarecer como mínimo la distribución por sexos del personal investigador (Pérez-Sedeño; Miqueo, Barral y Magallón), así como las categorías profesionales que ocupan globalmente las mujeres y hombres aunque hasta el momento carecemos de datos mínimamente fiables sobre la productividad e impacto de su trabajo.

Efectivamente, y así lo expresa el informe MEC: Académicas en cifras 2007 que pretende servir de instrumento de trabajo para conocer la situación real de las mujeres en el sistema universitario español: «Ellas son mayoría entre los titulados en la universidad pública (60\% en el curso 2005-2006), mientras que el número de catedráticas no alcanza el 14\%».

Las investigaciones que se han llevado a cabo en el tema, hasta el momento contemplan tópicos tales como los roles académicos y el género, los obstáculos que las mujeres investigadoras tienen en su carrera y los factores que contribuyen al éxito.

Se presentan a continuación las principales conclusiones realizadas en el ámbito universitario sobre las diferencias otorgadas al género: 
- Existe una relación tradicional entre lo masculino y las ciencias. La Academia se percibe de manera tradicional como elitista, masculina y patriarcal (Asmar; Poole y Langan-Fox; Rutherford) a pesar de que en los últimos años se han experimentado progresos, estas percepciones siguen estando presentes (Amancio; Asmar; Bagilhole).

- La literatura pone de manifiesto que, a pesar de que se han hecho progresos en la participación de las mujeres en la Educación Superior, todavía hay diferencias de género en cuanto a los roles que tienen en las universidades (Sagaria y Agans; Saunderson;Smeby y Try).

- La presencia de las mujeres en la gestión universitaria y en los núcleos de poder es claramente minoritaria. Los escalones superiores siguen dominados por hombres (Bagilhole; Rutherford)

- Las universidades son «bastiones» de los hombres y la discriminación aún existe en forma de redes, especialmente de investigación (Kyvik y Teigen; Webster)

- Las mujeres tienen menos productividad investigadora que los hombres (Olssen y Peters)

Sintetizamos a su vez los obstáculos que las mujeres investigadoras tienen en su carrera en la revisión de estudios realizada:

- La división de género en la actividad académica (las mujeres se dedican más a la docencia y los hombres más a la investigación (Bagilhole y White; Park).

- Las mujeres tiene menos confianza en sus habilidades y menos acceso a las redes académicas (Britton; Dean, Johnson, Jones y Lengkeek; Doherty y Manfredi).

- La existencia de presiones entre la vida personal y la profesional (Forster; Probert).

- La falta de redes y de trabajo colaborativo que provoca que el acceso a la financiación sea reducido (Lafferty y Fleming).

- Las mujeres obtienen menos financiación, menos recursos y tienen menos ayudantes de investigación (Toren).

- En ciencias sociales y humanidades la cultura organizativa es tradicionalmente más individualista (Asmar).

- Las mujeres producen menos publicaciones y esto genera que haya menos financiación para sus proyectos- el ciclo de la productividad de la investigación- (Soliman y Soliman). 
La investigación dedicada al estudio de los factores de éxito de las profesoras que han llegado a cierto grado de reconocimiento como investigadoras en sus áreas de conocimiento se ha orientado a detectar factores tales como:

- El análisis de los programas de mentoring en los que pueden participar las mujeres para mejorar sus capacidades investigadoras.

- El análisis de la formación recibida por las investigadoras a nivel formal e informal.

- El análisis de las estrategias, las culturas de trabajo y los contextos asociados al éxito (Dever y Morrison).

- La flexibilidad asociada al nivel de autonomía y la capacidad de gestionar el tiempo de forma efectiva.

- Se analiza la satisfacción asociada al trabajo investigador. Las mujeres perciben sus condiciones de trabajo como más satisfactorias en términos de satisfacción «intrínseco-subjetiva» frente a los hombres que se dejan conducir por motivación «extrínseca-objetiva» como: estatus, sueldo, condiciones de trabajo (Poole y Langan-Fox).

\subsection{La participación de las mujeres en los órganos de gobierno o comisiones delegadas}

A pesar de que la participación femenina en los órganos de gobierno universitarios es una cuestión poco explorada por la investigación, sí se dispone de todo un cuerpo de estudios que, bajo la rúbrica general de «mujeres en la gestión» (women-in-management), se ha ocupado de analizar el acceso de la mujer a las posiciones más altas dentro de las estructuras organizativas existentes y de contribuir a la ruptura del «techo de cristal» que impide a muchas mujeres participar en la gestión de las organizaciones.

Aunque como se ha dicho anteriormente no existen muchos trabajos que exploren la participación de la mujer en procesos de toma de decisiones en el seno de los órganos de gobierno de la Universidad, sí se dispone, en cambio, de un amplio abanico de estudios que abordan el papel del género en la interacción grupal durante la toma de decisiones.

La participación de la mujer en los órganos de gobierno no hay que justificarla sólo por cuestiones técnicas o instrumentales, sino también por razones de democracia participativa. La cuestión de la representación de la mujer en los diversos órganos de gobierno de nuestra sociedad constituye el tema central del trabajo de Phillips: «Engendering democracy», donde se explora la intersección entre la teoría feminista y la teoría democrática. En abierto contraste con la 
teoría democrática más tradicional, que presupone un concepto de ciudadanía abstracto y donde el género está ausente, Phillips sostiene que la auténtica igualdad entre hombres y mujeres sólo puede conseguirse si se reconocen las diferencias de género. En cambio, para Phillips, tal reconocimiento constituye sólo una fase necesaria, aunque transitoria, hacia una sociedad en la que el género llegue a ser irrelevante. Para que esta transición hacia una sociedad en la que el género es irrelevante tenga lugar, las mujeres deben convertirse primero en participantes plenas de la vida política, entendida en sentido amplio. Un argumento similar puede extrapolarse al ámbito de la gestión y participación universitarias.

A pesar de que en su conjunto la investigación sobre comportamiento comunicativo no consigue identificar diferencias tajantes y replicables en función del género, sí existe mayor acuerdo en afirmar que, lejos de ser un elemento neutral, el género ejerce una influencia considerable en los procesos de toma de decisiones. En concreto, podemos agrupar estos trabajos en tres grandes ámbitos de estudio que ponen en relación la toma de decisiones con el género: (1) el interesado propiamente en las diferencias conductuales en función del género; (2) el preocupado por la capacidad de influencia asociada al género durante la toma de decisiones, y (3) el orientado a determinar los efectos de la composición del grupo en el proceso de toma de decisiones.

En cuanto a las diferencias en los comportamientos grupales en función del género, la literatura apunta -aunque no de forma concluyente- ciertas diferencias de género en la comunicación. Un rasgo distintivo en el estilo conversacional femenino es el mantenimiento de la conversación, orientado a establecer conexión con los demás a través del diálogo. De manera similar, plantear cuestiones es un medio para estimular la inclusión y la conexión durante la comunicación grupal, valores éstos distintivamente femeninos. Parece, en este sentido, que esta preocupación de las mujeres por la conexión las conduce a plantear cuestiones a sus compañeros para incluirlos en la interacción grupal. En síntesis, las mujeres valoran la conexión, la cooperación y la expresión de las emociones más que los hombres. Sin embargo, pueden existir ciertas diferencias de género en cuanto al modo en que se formulan las preguntas.

El trabajo de Hawkins y Power aborda directamente esta última cuestión, resultando de especial interés para esta investigación tanto por los problemas que plantea como por la metodología empleada. Su estudio analiza la interacción en 18 pequeños grupos de toma de decisiones para responder a la pregunta de si existen diferencias de género en cuanto al número y contenido de las 
cuestiones realizadas en contextos grupales pequeños de toma de decisiones. Para el análisis de esta cuestión plantean el uso de la escala de Bales, que se reconoce como la taxonomía más utilizada en la investigación interesada por el análisis de la interacción dentro de grupos pequeños. Sin embargo, se reconoce la utilidad de esta escala para capturar las funciones más importantes de las preguntas dentro de la toma de decisiones dentro de grupos pequeños, en los que el intercambio de información es crucial. La escala de Bales está complementada con otra taxonomía que evalúa el grado de apertura de la interacción personal. En su conjunto, el instrumento observacional empleado se muestra útil para analizar las diferencias de género en la realización de preguntas, ya que algunas investigaciones indican que los hombres tratan de controlar la introducción y el desarrollo de los tópicos más que las mujeres.

Los resultados de la investigación de Hawkins y Power indican que las preguntas juegan un papel importante en la toma de decisiones dentro de los pequeños grupos y que el género constituye un factor relevante en su producción. Aunque hombres y mujeres presentan una probabilidad similar de plantear preguntas, sí es posible identificar diferencias significativas en el tipo de preguntas que se realizan durante el proceso de toma de decisiones. Así, las mujeres presentan una probabilidad mayor de realizar preguntas de tipo exploratorio que sus compañeros hombres. Este tipo de preguntas invitan a la elaboración de argumentos, a compartir la información y la opinión. Aunque algunos trabajos pueden relacionar este tipo de comportamiento comunicativo con la inseguridad y la necesidad de autoafirmación, Hawkins y Power lo vinculan a un doble objetivo: estimular la implicación en la interacción y la participación, y obtener detalles de la información necesaria para hacer mover el grupo hacia la consecución de su objetivo. En este sentido, se puede argumentar el impacto de la participación femenina en la eficacia de la toma de decisiones grupales, en tanto que sirve al doble propósito de obtener el detalle necesario para servir de base a una decisión eficaz e implicar al grupo en una evaluación crítica de sus propias asunciones y opiniones, desvelando así informaciones falsas o razonamientos erróneos que podrían conducir a decisiones de baja calidad.

Otras investigaciones apoyan esta idea de que comportamientos como el fomentar la participación de otros y buscar visiones opuestas guardan relación con la percepción de eficacia y calidad en la toma de decisiones por parte del grupo. Mayer, por ejemplo, plantea que comportamientos tales como estimular a los miembros a participar, buscar visiones opuestas y presentar evidencia de las sugerencias se relacionan con la percepción de calidad en la toma de 
decisiones. Similarmente, los comportamientos socioemocionales negativos se perciben disfuncionales para la eficacia de la decisión, mientras que los positivos la mejoran.

Otras investigaciones, centradas en el análisis de los procesos de negociación, ponen de manifiesto que los estereotipos de género favorecen la construcción del «buen negociador» en términos preferentemente masculinos. Así, el trabajo de Kray y otros identifican la asertividad, la capacidad de solución de problemas, la consideración de los propios intereses y el conocimiento como atributos típicamente masculinos que tienden a configurar una «ventaja masculina» durante las negociaciones grupales.

Con independencia de las causas, un buen número de trabajos parten de la tesis de que las personas, al interactuar en procesos grupales de toma de decisiones, perciben diferencias entre los participantes en función del género. Balwell y Berger, por ejemplo, determinan que el papel del género en la interacción cara a cara puede venir determinado por distintas concepciones que usan los participantes, pudiéndose detectar diferencias en cuanto a la cantidad de tiempo que se está hablando, la frecuencia de los gestos, las estructuras de iniciación de la conversación, o la fijación de la mirada mientras se habla o escucha. Similarmente, Smith-Lovin y Brody analizan las estructuras de interrupción como factor relativo a la calidad en la toma de decisiones, concluyendo que los hombres tienen mayor tendencia a interrumpir las mujeres y que la composición del grupo se configura como uno de los elementos más relevantes para explicar los procesos de interacción.

En cuanto a la capacidad de influencia durante la toma de decisiones, las investigaciones tienden a resaltar la menor influencia femenina como consecuencia del estereotipo social de menor competencia instrumental que suele atribuirse a la mujer. Algunos trabajos, sin embargo, matizan esta afirmación aludiendo a determinados rasgos propios del estilo femenino de toma de decisiones que permiten moderar la incidencia de dichos estereotipos, como puede ser la demostración de destrezas específicas relacionadas con la tarea, la motivación hacia la cooperación, y la atención a soluciones de alta calidad (Shackelford, Wood y Worchel). Carli señala que las mujeres son menos influyentes cuando utilizan formas dominantes de comunicación, mientras que los hombres ejercen menor influencia en dominios tradicionalmente asociados al rol femenino o en grupos que cuentan con una mayor presencia femenina. Asimismo sugiere que los hombres tienden a resistir más la influencia ejercida por parte de las mujeres, especialmente cuando éstas hacen uso de estilos de comunicación altamente competentes, aunque esta resistencia puede verse 
reducida cuando las mujeres equilibran su competencia en muestras de calidez y orientación comunitaria. En definitiva, pues, estos trabajos muestran que, a pesar de que los estereotipos femeninos funcionan restando protagonismo a la mujer en los procesos grupales, algunos de los rasgos que suelen atribuirse a un estilo femenino de toma de decisiones, en presencia de determinados factores contextuales y grupales, contribuyen a moderar el efecto negativo de tales estereotipos.

Finalmente, en cuanto a los efectos de la composición del grupo en el proceso de toma de decisiones, las investigaciones coinciden en señalar el papel moderador que la característica del grupo (tamaño, proporción de hombres y mujeres,...) tiene sobre el género y su influencia en la interacción. Lépine y otros, por ejemplo, reexaminan las conclusiones sobre la superioridad de los equipos masculinos en tareas tradicionalmente consideradas masculinas, e ilustran cómo, en algunos contextos, los equipos de toma de decisiones dominados por hombres pueden constituir la peor composición de género. Además, en su trabajo también incluyen que a medida que el porcentaje de hombres se incrementa, aumenta exponencialmente la tendencia a tomar decisiones de tipo agresivo. Otros trabajos, en cambio, inciden en que los estudios sobre interacción entre iguales con similar poder y estatus muestran pocas diferencias de género en el comportamiento, y que la mayoría de las interacciones entre hombres y mujeres ocurren en el contexto estructural de roles o relaciones de estatus que son desiguales. Son estas diferencias de poder y estatus que a menudo se confunden con el género en sí mismo las que crean efectos reales en la interacción (Ridgeway y Smith-Lovin).

\section{METODOLOGÍA}

Se presenta en este artículo una síntesis de tres investigaciones sobre el liderazgo y la participación en los órganos de gobierno de la Universidad con el objetivo de contribuir a averiguar las razones por las cuáles en la Universidad persisten diferencias en función del género del profesorado.

Presentamos a groso modo los objetivos y metodologías seguidas en dichas investigaciones en la tabla 1. 
Tabla 1. Resumen de objetivos y metodologías sobre liderazgo, participación y género en la Universidad de investigaciones dirigidas por Marina Tomàs

\begin{tabular}{|c|c|c|c|}
\hline $\begin{array}{l}\text { Proyecto de Investigación } \\
\text { Personas equipo } \\
\text { Institución subvencionadora }\end{array}$ & Objetivos & $\begin{array}{l}\text { Instrumentos } \\
\text { y técnicas de } \\
\text { recogida y análisis } \\
\text { de información }\end{array}$ & Informantes \\
\hline $\begin{array}{l}\text { La perspectiva del género en } \\
\text { las universidades y el ejercicio } \\
\text { de cargos académicos. } \\
\text { Tomàs, M (Coord.); Durán, } \\
\text { M.M; Guillamón, C. y Lavié, } \\
\text { J.M. } \\
\text { ICD, } 2002\end{array}$ & $\begin{array}{l}\text { 1. Conocer la } \\
\text { percepción del } \\
\text { profesorado sobre } \\
\text { el liderazgo que } \\
\text { ejercen las mujeres } \\
\text { cuando dirigen sus } \\
\text { departamentos } \\
\text { 2. Obtener evidencias } \\
\text { de la forma de liderar } \\
\text { de las mujeres para } \\
\text { contribuir a discernir } \\
\text { si existen estilos de } \\
\text { liderazgo en función } \\
\text { del género. }\end{array}$ & $\begin{array}{l}\text { - Cuestionario al } \\
\text { profesorado cuyo } \\
\text { departamento es } \\
\text { dirigido por una } \\
\text { directora. } \\
\text { - Entrevistas a } \\
\text { directoras. }\end{array}$ & $\begin{array}{l}150 \\
\text { cuestionarios } \\
\text { profesorado } \\
18 \text { entrevistas }\end{array}$ \\
\hline $\begin{array}{l}\text { Estudio de las dinámicas en } \\
\text { el seno de los órganos de } \\
\text { gobierno de las universidades } \\
\text { desde la perspectiva de género. } \\
\text { Tomàs, M (Coord.) } \\
\text { Duran,M.M; Feixas,M; } \\
\text { Guillamón,C. y Lavié,J.M } \\
\text { AGAUR, } 2007\end{array}$ & $\begin{array}{l}\text { 3. Observar el tipo de } \\
\text { participación en los } \\
\text { órganos colegiados } \\
\text { en donde se toman } \\
\text { decisiones en función } \\
\text { del género. }\end{array}$ & $\begin{array}{l}\text {-Observación de } \\
\text { scripts y roles } \\
\text { en reuniones de } \\
\text { distintos órganos } \\
\text { de gobierno y } \\
\text { focusgroups. }\end{array}$ & $\begin{array}{l}8 \text { órganos de } \\
\text { gobierno } \\
\text { (199 personas } \\
\text { observadas de las } \\
\text { cuales } 97 \text { eran } \\
\text { mujeres y } 102 \\
\text { hombres) } \\
2 \text { focusgroup } \\
\text { (un total de } 16 \\
\text { expertos) }\end{array}$ \\
\hline $\begin{array}{l}\text { La investigación académica de } \\
\text { las investigadoras en Ciencias } \\
\text { Sociales en las universidades } \\
\text { UAB y UB. } \\
\text { Tomàs,M (Coord.) } \\
\text { Bernabeu,D.; } \\
\text { Castro,D; } \\
\text { Duran,M.M.; } \\
\text { Ion,G; } \\
\text { Vlachopoulos,D. y } \\
\text { Mentado,T. } \\
\text { ICD. Ref. U-45/10 }\end{array}$ & $\begin{array}{l}\text { 4. Conocer el perfil } \\
\text { de las investigadoras } \\
\text { que dirigen grupos } \\
\text { de investigación de } \\
\text { prestigio. }\end{array}$ & $\begin{array}{l}\text {-Entrevistas } \\
\text { focalizadas a nivel } \\
\text { individual. } \\
\text {-Análisis del } \\
\text { discurso en } \\
\text { la producción } \\
\text { científica. }\end{array}$ & 14 entrevistas \\
\hline
\end{tabular}


Se han llevado a cabo todas ellas en las universidades metropolitanas de Barcelona.

Respecto al objetivo 1 y 2 de la primera investigación se elaboró un cuestionario ad hoc a fin de averiguar las oportunidades de desarrollo profesional de las directoras de departamentos universitarios y los atributos que se otorgaban al liderazgo femenino.

En cuanto a las entrevistas se diseñó un guión dividido en tres bloques: datos biográficos de la entrevistada, contexto de desempeño del cargo y, finalmente, el ejercicio de dirección y las preferencias de liderazgo.

Respecto al objetivo 3 correspondiente a la segunda investigación presentada se realizaron ocho observaciones a diferentes órganos de gobierno de dos universidades tales como: Comisión de investigación, 4 Consejos de departamento (de diferentes áreas de conocimiento), 2 Juntas permanentes y 1 Comisión académica. Tres de ellas estaban dirigidas por mujeres y cinco por hombres. Mientras que las profesoras han dirigido un grupo pequeño, uno mediano y uno grande, en el caso de sus compañeros, cuatro han dirigido un grupo de tamaño mediano y uno, un grupo de tamaño grande.

En las observaciones se siguió la teoría de la interacción de R. F. Bales (Vendrell). Esta aproximación entiende los grupos como sistemas de individuos que interactúan. La actividad del grupo se concibe como una secuencia de acciones y reacciones que se consideran interacciones. Concretamente, la interacción en un grupo se divide en un conjunto de actos microscópicos. Un acto es una comunicación o una manifestación expresiva, verbal o no verbal, que en su contexto puede ser entendida por otro miembro como equivalente a una frase sencilla. Para Bales, todas las acciones del grupo se consideran interacciones y se pueden analizar mediante la observación sistemática.

Para las observaciones se han definido 8 categorías, de las cuales cuatro se consideran roles (Rol iniciador, Rol co-iniciador, Rol opositor, Rol seguidor) y cuatro, scripts (Script asertivo, Script no asertivo, Script agresivo y Script «de huida»).

Respecto al objetivo 4 correspondiente a la tercera investigación presentada, en cuanto a las entrevistas se diseñó un guión que comprendía los siguientes aspectos: antecedentes y contexto actual del profesional, el rol de las personas que investigan y de las otras funciones académicas, factores de éxito, liderazgo de grupo de investigación y difusión del conocimiento y de la investigación. 


\section{RESULTADOS}

Se aporta una síntesis de los resultados de cada una de las investigaciones que tienen que ver con los factores de la Universidad que impiden esta igualdad de oportunidades. Es decir es una selección transversal de resultados en base a este propósito.

\subsection{Factores relativos al liderazgo en relación a la igualdad de oportunidades de género en la Universidad}

Se identifica la existencia de dificultades tanto externas a la propia mujer, como internas a ella, que nos indican posibles explicaciones sobre la escasa presencia del género femenino en la gestión universitaria. Entre las dificultades externas, la cultura organizativa de la Universidad aparece como un elemento resistente al cambio que fomenta un entorno predominantemente dominado por valores masculinos y que puede justificar la auto-exclusión de algunas mujeres de la gestión universitaria. Asimismo, se identifica los principales atributos con los que las mujeres participantes describen su propio rol en la gestión y como creen que éste contribuye a un liderazgo eficaz en la Universidad. Por un lado las oportunidades de desarrollo profesional que las directivas manifiestan haber tenido en sus carreras profesionales universitarias así como las destrezas y los atributos de liderazgo que las personas de la comunidad universitaria consultadas asignan a sus directivas y directivos. Por otra parte, las experiencias de gestión de las mujeres gestoras en el puesto de trabajo: barreras que han encontrado, percepciones experimentadas en torno a su rol y destrezas de liderazgo.

Se ha observado la presencia de una serie de rasgos de liderazgo en las mujeres que ejercen cargos académicos en la Universidad así como de interés de los liderados por el tipo de liderazgo presente en su directora de departamento. Sin ánimo de comparación y a título orientativo se han extraído los siguientes rasgos. En la tabla n. ${ }^{\circ} 2$ se presenta en la columna de la izquierda (a) las características que creían que deberían tener sus directoras de departamento y en la columna de la derecha (b) los rasgos y características más frecuentes en sus directoras de departamento. 
Tabla 2. Características que deberían tener (a) y que tienen (b) las directoras de departamentos universitarios (Guillamón, Cristina y Marina Tomàs, 2002)

\begin{tabular}{|c|c|}
\hline $\begin{array}{l}\text { Características que deberían tener las } \\
\text { directoras de departamento (a) }\end{array}$ & $\begin{array}{l}\text { Características presentes en sus } \\
\text { directoras de departamento (b) }\end{array}$ \\
\hline - Tener espíritu de ambición & - Ser responsable \\
\hline - Ser una persona competitiva & - Ser resistente a los frustraciones \\
\hline - Ser resistente a las frustraciones & - Ser asertivo/va \\
\hline - Actuar como persona dialogante & - Ser diplomático/a \\
\hline - Tener habilidades comunicativas & $\begin{array}{l}\text { - Capacidad por pensar y hacer diversas } \\
\text { cosas a la vez }\end{array}$ \\
\hline $\begin{array}{l}\text { - Ejercer un liderazgo de estilo } \\
\text { democrático }\end{array}$ & $\begin{array}{l}\text { - Poner atención en las relaciones } \\
\text { personales }\end{array}$ \\
\hline $\begin{array}{l}\text { - Preocupación por el propio desarrollo } \\
\text { profesional }\end{array}$ & $\begin{array}{l}\text { - Actuar como persona dialogante y de } \\
\text { consenso }\end{array}$ \\
\hline \multirow{3}{*}{$\begin{array}{l}\text { - Gestionar con eficacia y eficiencia los } \\
\text { recursos del departamento }\end{array}$} & - Tener habilidades comunicativas \\
\hline & $\begin{array}{l}\text { - Gestionar con eficacia y eficiencia los } \\
\text { recursos del departamento }\end{array}$ \\
\hline & $\begin{array}{l}\text { - Capacidad por obtener recursos } \\
\text { económicos para el departamento }\end{array}$ \\
\hline
\end{tabular}

Entre las barreras que impiden a las profesoras universitarias ejercer cargos de gestión encontramos algunas de tipología interna y otras de tipología externa. Entre las internas se pueden citar las propias de los procesos de socialización: diferencias en la educación de niños y niñas, miedo a defraudar las expectativas del papel femenino, falta de modelos donde mirarse, poco interés por el estilo de liderazgo tradicional o baja autoestima. Entre las externas podemos citar la cooptación, la dificultad de conciliación entre vida profesional y familiar, la cultura sexuada de las universidades y los estereotipos ligados al género femenino y el liderazgo.

Las participantes en nuestra investigación afirman no sentirse a gusto con los valores y las estrategias de acción existentes en los órganos de poder de sus universidades por el hecho de ser claramente ajenos a ellas en tanto que no han participado en su generación. Esto ocasiona poca vinculación a la institución y poco deseo de liderarla. El rechazo a los modelos tradicionales de liderazgo imperantes las desmotiva para postularse como candidatas al ejercicio de cargos. 
Respecto las percepciones de las directivas sobre su propio comportamiento de liderazgo y los efectos que éste produce, las respuestas de las participantes no son unánimes. Algunas niegan las diferencias en función de género y las atribuyen exclusivamente a la individualidad de cada cual y mencionan la necesidad de considerar otras variables además del género al estudiar el tema del liderazgo. Otras reconocen un discurso popular que atribuye a las mujeres un modo de liderar más participativo y basado en la comunicación interpersonal.

Ahora bien, en lo que sí coinciden todas las participantes es en afirmar que ocupar un lugar de poder sirve para «poder hacer algo, poder cambiar algo». Se desprecia el «poder sobre alguien» pero se aprecia el «poder para algo»y el «poder con alguien». Ello nos lleva a considerar las destrezas y habilidades que las participantes atribuyen a las mujeres que ejercen cargos directivos.

Uno de los principales rasgos que se les reconocen a las mujeres que lideran es su capacidad para controlar la realización de los programas ("poder para»), seguido de la capacidad para desburocratizar los procedimientos y atender a las necesidades de las personas lideradas y el contar con éstas para el ejercicio del cargo («poder con»). El trabajo en equipo y la preocupación por conseguir un clima de trabajo positivo, son cualidades que las participantes en el estudio atribuyen a las mujeres líderes.

Las entrevistadas han mostrado, en su mayoría, haber estado sujetas a procesos de evaluación y promoción construidos en referencia a una norma 'masculina' que las discriminaba abiertamente.

\subsection{Factores relativos al liderazgo de equipos de investigación en relación a la igualdad de oportunidades de género en la Universidad}

El análisis de los grupos de investigación consolidados nos ayuda a aproximarnos al campo del estudio de las élites académicas. Se trata de académicos y académicas que han llegado a un alto nivel de desarrollo de su carrera profesional investigadora. Como apuntan otros estudios (ver por ejemplo García de León) el estudio de las elites forma parte de la sociología del poder, tema substancial en ciencias sociales y llama la atención sobre cómo se distribuye el poder en la ciencia. Las elites son la «punta del iceberg» de los procesos de cambio aunque la Universidad actual catalana ha conocido en los últimos años cambios importantes, este proceso no va acompañado por un cambio en la distribución igualitaria entre hombres y mujeres en el ámbito de la investigación en general y en ciencias sociales en especial.

En la distribución por género de los equipos de investigación consolidados, en casi todos los casos, el número de grupos liderados por hombres es superior al número de grupos liderados por mujeres. Concretamente, del total de 
grupos reconocidos (1078) por la Generalitat de Catalunya en el 2007, solo unos 241 están liderados por mujeres frente a 847 que están liderados por hombres, cosa que en porcentajes representa que sólo un $27,6 \%$ de los grupos están coordinados por investigadoras.

Con el objetivo de conocer los elementos que favorecen y que dificultan la producción científica de las mujeres en la Universidad se identifica como una dificultad el hecho mismo de ser mujer, dado que en la cultura universitaria todavía se consideran ciertas actividades como más propias del género masculino que del femenino, por ejemplo la organización de congresos científicos. En este sentido se ve la conveniencia de hacer redes entre las mujeres para darse soporte mutuo.

Lo que se puede afirmar de lo que piensan las investigadoras que dirigen grupos consolidados es lo siguiente:

- El tiempo dedicado a la gestión más bien preocupa que no interesa a las investigadoras. En general las entrevistadas lo consideran 'un mal necesario'.

- Valoran de forma muy positiva las estancias de investigación y estudio en universidades extranjeras así como la posibilidad de tener relaciones con personal académico de otros países. Dan una importancia especial a la posibilidad de colaborar en redes de trabajo internacional en donde ellas participen por su expertez.

- Las investigadoras que lideran grupos son partidarias de delegar tareas y responsabilidades en los miembros de sus equipos. Consideran que deben procurar un clima del grupo positivo en el que trabajar de forma agradable.

- Todas las investigadoras coinciden en la necesidad de distribuir el liderazgo puesto que favorece la producción científica.

- El establecer normas de funcionamiento claras y compartidas por todos los miembros del grupo es una preocupación común entre las entrevistadas.

- Un buen clima es necesario para asegurar la creación de conocimiento que comporta una cultura de colaboración entre los miembros.

- La autoevaluación del equipo de trabajo se considera muy importante para la mejora de la actividad investigadora.

- Parece que el hecho de ser hombre o mujer, condiciona el tipo de tareas que se asumen dentro del grupo de investigación, de acuerdo con parámetros socialmente aceptados desde un modelo masculino. 
3.3. Factores relativos a los roles en la participación en relación a la igualdad de oportunidades de género en la Universidad

Una de las primeras cuestiones que ocupan el debate sobre las relaciones entre órganos de gobierno en la Universidad y género es la falta de presencia de mujeres en los cargos de gestión, especialmente en los de más alto nivel. La presencia de las mujeres en los órganos de gestión se justifica, en cualquier caso, tanto por cuestiones de justicia e igualdad social como por motivos de eficiencia y calidad en la toma de decisiones.

Se constata que, aparte de la creciente incorporación de la mujer a la educación universitaria e, incluso, la feminización de determinadas áreas de conocimiento, la representación femenina en los órganos de gobierno universitarios sigue siendo sensiblemente inferior en comparación con la población masculina. En este sentido, la Universidad se sitúa detrás de otras organizaciones en el desarrollo e implantación de políticas de igualdad de género.

Si bien el género no puede convertirse en una categoría absoluta para la explicación de todas las diferencias en los modos y estilos de participación, la influencia del género es incuestionable. Además de los factores de orden intrapsíquico y educativos, la clase social genera también su propio código relacional.

Es importante señalar el papel del contexto como moderador de estas posibles diferencias vinculadas al género. Por un lado, pensar en la Universidad como contexto y de actuación implica asumir que todos los miembros de la comunidad universitaria, hombres y mujeres, han sido sometidos a un proceso de socialización similar derivado del entorno académico que conduce a la masculinización.

Por otra parte, no es lo mismo hablar de diferencias relativas al estilo de gestión o liderazgo, que de aquellas que hacen referencia a los estilos de participación o intervención en los foros de toma de decisiones. En este último caso, las diferencias hombre/mujer parecen ser evidentes, a pesar de que el contexto (micro) grupal ejerza una influencia considerable en la definición de las pautas de intervención.

Teniendo en cuenta todas estas precisiones en torno a las diferencias entre estilos femeninos y masculinos, y la importancia que en su definición tienen los factores contextuales y grupales, los argumentos debatidos en los focusgroup establecen una caracterización de lo que podríamos denominar una «clave femenina» de participación en la toma de decisiones que se sintetiza, en primer lugar, por exhibir un estilo directo y conciso en cuanto a la participación. Es decir, las mujeres tienden a realizar menos intervenciones públicas, y éstas, en cuanto las realizan, suelen tener un carácter más concreto y resolutivo, en el 
sentido de que suelen estar más orientadas a la resolución del problema que se discute y estar fundamentadas en «razonamientos más consistentes».

Otra característica de este estilo femenino de participación se relaciona con el mayor pragmatismo que las mujeres suelen mostrar en sus intervenciones. Esta actitud pragmática que adoptan muchas mujeres en la toma de decisiones suele traducirse en la relatividad de las ideas geniales y brillantes. El estilo femenino de toma de decisiones puede caracterizarse, pues, como más realista en la consideración de las diferentes posibilidades de actuación y, por tanto, en tonalidad más conservadora.

Forma parte de esta sensibilidad femenina una atención a los aspectos relativos al proceso y ocupar «el espacio fronterizo». Esta atención al proceso se relaciona, por un lado, con una preocupación por el desarrollo de la reunión y de la dinámica del grupo pero también tiene relación con una concepción más amplia sobre el trabajo en grupo y los elementos que pueden optimizar su funcionamiento. En este sentido, la distinción tradicional que caracteriza el liderazgo masculino como «orientado a la tarea» y el liderazgo femenino como «orientado a las relaciones», puede reproducirse en lo que se refiere a los modos de intervención y participación en los procesos grupales de toma de decisiones. Las mujeres, en general, muestran una mayor preocupación por crear «una determinada atmósfera» que facilite el proceso de trabajo colectivo.

Las causas que explican las diferencias se podrían agrupar según se ponga el énfasis en la participación e implicación de las mujeres en los órganos de gobierno, en el interés por acceder a los órganos de gobierno, o atribuibles al grado de satisfacción en la toma de decisiones en los órganos de gobierno.

De algún modo las diferencias existentes en la participación entre hombres y mujeres en los órganos de gobierno pueden depender de un conjunto de causas como tipología de contexto (reuniones a nivel de departamento, facultad, rectorado,...), composición del grupo (tamaño, género,...) y características personales (categoría profesional, status, estado civil,...).

Respeto al número de intervenciones clasificadas en scripts no se aprecian diferencias respecto al género. Sólo en el caso de intervenciones con script agresivo, que parecen patrimonio del género masculino.

Con respecto a los roles se observa una tendencia a que el género masculino sea más iniciador y juegue un rol de opositor con mayor frecuencia. Por otra parte quedan más representados por el género femenino los roles de co-iniciadora y seguidora.

A pesar de que los resultados no son concluyentes, y deben ser matizados en cualquier caso por la influencia de variables contextuales y personales, es posible identificar una serie de comportamientos diferenciales en los 
procesos de toma de decisiones asociados al género de los participantes como la estructura de iniciación-participación, la estructura de interrupciones, los comportamientos no verbales exhibidos, o la taxonomía de preguntas que se realizan durante el proceso de toma de decisiones. Igualmente, es posible identificar una serie de variables moderadoras del papel del género en los procesos de interacción grupal, como la composición del grupo, el tipo de tareas a realizar y las decisiones que se deben adoptar.

Más que el género per se, hay una serie de factores relacionados con el género que ejercen una influencia considerable en los procesos de interacción grupal, como el poder y el estatus de los participantes, los estereotipos asociados al género, etc. y los estereotipos sociales de género ejercen influencia a la hora de conceder una cierta «ventaja masculina» en la toma de decisiones.

\section{DISCUSIÓN Y CONCLUSIONES}

La incorporación de la mujer en la gestión universitaria se justifica tanto por razones de justicia e igualdad social como por motivos de eficiencia y calidad en la toma de decisiones.

La Universidad no es pionera en la asunción y representación de cargos de gestión por parte de las mujeres. A pesar de la creciente presencia de la mujer en los órganos de gobierno universitarios, la figuración femenina sigue siendo menor que la masculina.

Los motivos que pueden explicar esta menor presencia de la mujer en la gestión universitaria son múltiples y se relacionan tanto con factores estructurales como culturales. La categoría profesional y la edad, la experiencia en gestión, las responsabilidades familiares o atención a terceras personas son algunas de las causas que explican la menor participación de las mujeres en los órganos de gobierno.

El género, como aspecto constitutivo de las relaciones interpersonales, a veces está presente de manera tácita en las dinámicas que se generan en el interior de los órganos de gobierno, lo que invita a reconsiderar cualquier definición de calidad en la toma de decisiones en términos puramente técnicos.

Aunque la influencia del género en las formas y estilos de participación resulta incuestionable, éste no puede convertirse en la única explicación de las diferencias de comportamiento perceptibles en los procesos de participación y toma de decisiones.

Es posible identificar una serie de factores que modulan la forma en que el género se manifiesta en la participación en las comisiones u órganos de participación en la Universidad. Así, la tipología y composición del grupo, la experiencia profesional, la categoría profesional de los participantes, etc. 
influyen en la manera de tomar decisiones. La cantidad de personas que componen una reunión resulta una variable muy influyente en la calidad de la participación pudiendo decir que cuando el grupo es pequeño o mediano existe más participación, proporcionalmente hablando, que cuando el tamaño es muy grande. El estilo de liderazgo de la persona que coordina es otro factor que parece condicionar el tipo de intervención. Por ejemplo, en las reuniones coordinadas por mujeres parece que hay mayor participación de las mujeres ejerciendo el rol de co-iniciadoras y seguidoras. En general podríamos decir que cuando la reunión es dirigida por una mujer hay más participación y ésta es más homogénea (entre hombres y mujeres, de todos los roles y todos los scripts,...). Por lo tanto podríamos decir que la dirección de reuniones por parte de las mujeres aumentaría la calidad de la toma de decisiones si entendemos que ésta se ve beneficiada por la mayor y mejor distribución de la participación. Además del género de quien coordina una reunión parece que influye decisivamente en la calidad de la participación y de la toma de decisiones, el estilo de coordinación y/o tipo de liderazgo de quién dirige la reunión. A grandes rasgos, y con la debida cautela, es posible caracterizar un «estilo femenino» de participación en la línea que señalan Eagly y Johannsen-Schmidt. Éste vendría definido por el uso de intervenciones directas y concisas, la búsqueda del diálogo y el consenso, la articulación de planteamientos más pragmáticos, y la preocupación por los aspectos relacionados con el proceso y no sólo con el contenido de la toma de decisiones y esto afecta positivamente a la participación.

La calidad en la toma de decisiones depende tanto del grado en que la decisión adoptada contribuye a la consecución de los objetivos del grupo, como del proceso mismo de participación a través de cómo se toma la decisión. Entre los factores procesuales, revisten especial importancia la representación de los diferentes intereses implicados y la participación en términos de igualdad.

La dirección de grandes equipos de investigación sigue siendo patrimonio del género masculino mientras que no lo es la tarea investigadora. El liderazgo de grupos grandes de investigación lleva asociado una serie de funciones que no resultan atractivas para las investigadoras como por ejemplo la organización de grandes congresos que proporcionan gran visibilidad lo que no resulta de especial interés para ellas que sin embargo aprecian más satisfacción en lo intrínseco (Poole y Langan-Fox).

La existencia de cierta invisibilidad de las mujeres en las universidades estudiadas aparece como consecuencia de las características socioculturales que han impregnado la vida de las académicas universitarias así como de las circunstancias estructurales imperantes en la Universidad española (Sánchez, Tomàs y Lavié). 


\section{AGRADECIMIENTOS}

Este artículo no hubiera sido posible sin la colaboración de mis colegas en las diversas investigaciones de las que es fruto a quien quiero agradecer su inestimable implicación además de las personas informantes que las han hecho posible.

\section{REFERENCIAS BIBLIOGRÁFICAS}

Amancio, Lígia. «Reflections on science as a gendered Endeavour: changes and continuities». Social Science Information 44.1 (2005): 65-83.

Asmar, Christine. "Is there a gendered agenda in academia? The research experience of female and male $\mathrm{PhD}$ graduates in Australian universities». Higher Education 38.3 (1999): 255-273.

Bagilhole, Barbara. «Challenging women in the male academy: think about draining the swamp». Challenges and negotiations for women in higher education. Eds. Pamela Cotterill, Sue Jackson y GayleLetherby. Dordrecht: Springer, 2007, 21-32.

Bagilhole, Barbaray Kate White. «Created in their image: An analysis of male cultural hegemony in higher education in Australian and the United Kingdom». Re-searching research agendas: women, research and publication in higher education. In B. Groombridgey V. Mackie (eds.), Proceedings of the Australian Technology network-women's executive development (ATN-WEXDEV) 2003 Research Conference (1-12). Perth: Curtin University of Technology Learning Support Network. (2003).

Balwell, James W. y Joseph Berger. «Gender, status, and behavior in task situations».Social Psychology Quarterly 59.3 (1996): 273-283.

Britton, Carolyn. «Supporting women in research». Women, research and careers. Eds. Sue Hatt, Julie Kent y Carolyn Britton. Houndsmills: Macmillan (1999): 69-88.

CaceresReche, María Pilar, Antonio Sachicola y María Angustias Hinojo Lucena. «Análisis del liderazgo femenino y poder académico en el contexto universitario español.» European Scientific Journal ESJ 11 (2015): 296-313.

Carli, Linda L. «Gender and social influence». Journal of Social Issues 57 (2001): 725-741.

Dean, Elizabeth, Lesley Johnson, Gar Jones y Nicola Lengkeek. Women, research and research productivity in the post-1987 universities: Opportunities and constraints. University of Western Sydney, Nepean: Department of Employment, Education, Training and Youth Affairs, Evaluations and Investigations program, Higher education Division, (1996).

Dever, Marianne y Zoë Morrison. «Women, Research Performance and work Context». Tertiary Education and Management 15.1 (2009): 49-62. 
Doherty, Liz y Simonetta Manfredi. «Women's Progression to Senior Positions in English Universities». Employee Relations 28.6 (2006): 553-572.

Eagly, Alice H. y Mary C. Johannesen-Schmidt «The leadership styles of women and men», Journal of Social Issues 57.4 (2001): 781-797.

Forster, Nick. "A case study of women academics'views on equal opportunities, career prospects and work-family conflicts in a British university». Women in Management Review 15.7 (2000): 316-330.

Guillamón, Cristina y Marina Tomàs-Folch. El porqué del bajo porcentaje de mujeres directoras en la enseñanza. Trabajo de Investigación. UAB. 2002.

Hawkins, Katherine y Christopher B. Power. «Gender differences in questions asked during small decision-making group discussions». Small Group Research 30.2 (1999): 235-256.

Helgesen, Sally. The Female Advantage: Women's Ways of Leadership. Kindle Edition, 1990.

Kyvik, Svein, y Mari Teigen. «Child care, research collaboration, and gender differences in scientific productivity». Science, Technology \& Human Values 21.1, (1996): 54-71.

Kray, Laura J., Adam D. Galinsky y Leigh Thompson.»Reversing the gender gap in negotiations: an exploration of stereotype regeneration». Organizational Behavior and Human Decision Processes 87.2 (2002): 386-409.

Lafferty, George y Jenny Fleming. «The restructuring of academic work in Australia: Power, management and gender». British Journal of Sociology of Education 21.2 (2000): 257-267.

LePine, Jeffrey A., John R. Hollenbeck, Daniel R. Ilgen, Jason A. Colquitt y Aleksander Ellis. «Gender composition, situational strength, and team decision-making accuracy: a criterion decomposition approach». Organizational Behavior and Human Decision Processes 88.1 (2002): 445-475.

Mayer, Michael E. «Behaviors leading to more effective decisions in small groups embedded in organizations». Communication Reports 11.2 (1998): 123-132.

MEC (Unidad de Mujeres y Ciencia). Académicas en cifras 2007. 2007. 23 de abril del 2017.

Miqueo, Consuelo, María José Barral Morán y Carmen Magallón. Estudios iberoamericanos de género en ciencia, tecnología y salud: GENCIBER. Prensas Universitarias de Zaragoza. 2008.

Nájera, Elena. «¿Feminismo de la igualdad y feminismo de la diferencia?» Feminismo/s 15 (2010): 9-14

Olssen, Mark y Michael Peters. «Neoliberalism, higher education and the knowledge economy. From the free market to knowledge capitalism». Journal of Education Policy 20.3 (2005): 313-345.

Park, Shelley M. «Research, Teaching and service. Why shouldn't women's work count?». Journal of HigherEducation 67.1 (1996): 46-84. 
Pérez Sedeño, Eulalia. Las mujeres en el Sistema de Ciencia y Tecnología.» Estudio de casos. Madrid: Organización de Estados Iberoamericanos (OEI) (serie Cuadernos de Iberoamérica), 2001.

Pérez Sedeño, Eulalia. «Sociedad, Cultura y Tecnologías Reproductivas». Actas del IV Congreso de la Sociedad de Lógica, Metodología y Filosofía de la Ciencia en España. Valladolid: Sociedad de Lógica, Metodología y Filosofía de la Ciencia en España. 2004: 438-441.

Pérez Sedeño, Eulalia. Los programas de formación y movilidad del personal investigador de flujo directo e inverso: Problemas, retos y soluciones. Informe del Proyecto EA, 2005.

Phillips, Anne. Engendering democracy. University Park: Pennsylvania State University Press, 1991.

Poole, Millicent y Janice Langan-Fox. Australian women and careers: Psychological and contextual influences over the life course. Cambridge: Cambridge University Press, 1997.

Probert, Belinda. «Gender and unequal outcomes in academic careers». Gender, Work and Organisations 12.1 (2005): 50-72.

Ridgeway, Cecilia L. y Lynn Smith-Lovin. «The gender system and interaction». Annual Review of Sociology 25 (1999): 191-216.

Rutherford, Sarah. «Organizational cultures, women managers and exclusion». Women in Management Review 16.8 (2001): 371-382.

Sagaria, Mary y Lyndsay Agans. «Gender equality in US higher education: International framing and institutional realities». In Keiko Yokoyama (Ed.), Gender and higher education: Australia, Japan, the UK and USA. Ed. KeikoYokoyama. Hiroshima: Higher Education Institute Press, (2006): 47-68.

Sánchez-Moreno, Marita, Marina Tomás-Folch y José Manuel Lavié Martínez. «Visibilidad y poder de las mujeres en instituciones universitarias». Archivos Analíticos de Políticas Educativas 21.32 (2013).

Saunderson, Wendy. «Women, Academia and Identity: Constructions of Equal Opportunities in the 'New Managerialism'- A Case of 'Lipstick on the Gorilla'? » Higher Education Quarterly 56.4, ( 2002): 376-406.

Shackelford, Susan, Wendy Wood y Sthephen Worchel. «Behavioral styles and the influence of women in mixed-sex groups». Social Psychology Quarterly 59.3, (1996): 284-293.

Smeby, Jens-Christian y Suerre Try. «Departmental contexts and faculty research activity in Norway». Research in Higher Education 46.6 (2005): 593-619.

Smith-Lovin, Lynn y Charles Brody. «Interruptions in group discussions: the effects of gender and group composition». American Sociological Review, 54.3 (1989): 424-435.

Soliman, Izabel y Hani Soliman. Academic workload and quality. Assessment and Evaluation in Higher Education, 22.2 (1997), 135-157. 
Toren, Nina. «The temporal dimension of gender inequality in academic». Higher Education, 25.4 (1993): 439-455.

Webster, Berenika M. «Polish women in science: A bibliometric analysis of Polish science and its publications, 1980-1999». Research Evaluation 10.3, (2001):185-194.

Vendrell, Esteve. Dinámica de Grups i Psicologia dels Grups. Barcelona: UB, 1999. 

Para enlazar con este artículo / To link to this article:

http://dx.doi.org/10.14198/fem.2017.29.16

Para citar este artículo / To cite this article:

Torrado Martín Palomino, Esther y Ana M. González Ramos. «Redes de cooperación: una herramienta para minimizar las desigualdades de género en la ciencia». En Marcos Jesús Iglesias Martínez e Inés Lozano Cabezas (coords.), La (in) visibilidad de las mujeres en la Educación Superior: retos y desafios en la Academia. Feminismo/s, 29 (junio 2017): 397-415, DOI: 10.14198/fem.2017.29.16

\title{
REDES DE COOPERACIÓN: UNA HERRAMIENTA PARA MINIMIZAR LAS DESIGUALDADES DE GÉNERO EN LA CIENCIA
}

\author{
COOPERATION NETWORKS: A TOOL TO MINIMIZE \\ GENDER INEQUALITIES IN SCIENCE
}

\author{
Esther TORRADO MARTÍN-PALOMINO \\ Instituto Universitario de Estudios de las Mujeres \\ Universidad de La Laguna \\ estorra@ull.edu.es \\ orcid.org/0000-0002-9144-5616 \\ Ana M. GONZÁLEZ RAMOS \\ Universitat Oberta de Catalunya \\ agonzalezram@uoc.edu \\ orcid.org/0000-0003-1808-0291
}

\section{Resumen}

Los mensajes triunfalistas sobre la incorporación de mujeres en ámbitos científicos, sin embargo, ocultan una realidad invisible, que sólo los estudios feministas han abordado y demostrado con evidencias. Estos estudios aportan perspectivas analíticas que revelan las complejas relaciones entre mujeres y hombres, marcadas por las estructuras del poder masculino. Un examen crítico de la realidad, revelará que la igualdad formal no ha supuesto una igualdad real y que, al contrario, sirve de justificación de las actuales discriminaciones de género. La objetividad y la meritocracia ocultan desigualdades entre los hombres y las mujeres en la ciencia. Este artículo se centra en el análisis de la situación de las mujeres investigadoras y en las estrategias para alcanzar mayores metas en sus carreras. En ese sentido, analizamos la utilidad de las redes de cooperación, que pueden ser institucionales, como las unidades de igualdad, institutos y grupos de estudios de género, o informales, donde un grupo de mujeres capitaliza su experiencia, mediante la información o apoyo emocional en beneficio de otras mujeres. Para desarrollar estas tesis, nos hemos apoyado en distintas fuentes bibliográficas, en los resultados de la encuesta realizada a 700 mujeres y hombres que desempeñan trabajos 
de investigación en las universidades y centros de investigación, y en diez estudios de casos dentro del proyecto Genera: Generación de una economía del conocimiento más inclusiva y competitiva ${ }^{1}$. Los resultados muestran que, si bien no son la única estrategia, las redes basadas en la sororidad y la cooperación proporcionan ventajas para mejorar sus logros y también para reducir los costes personales de perseguir una carrera altamente competitiva y fuertemente marcada por una estructura de poder masculina.

Palabras claves: estudios feministas, redes, sororidad, cooperación, mentorazgo, carreras científicas, patriarcado.

\begin{abstract}
The triumphalist messages on the incorporation of women in scientific fields however, it hides an invisible reality that only the feminist studies have addressed and displayed evidence. These studies provide analytical perspectives that reveal complex relationships between women and men shaping by male perspective of the power structures. A critical examination will reveal that formal equality does not yield real equality and, on the contrary, justifies the current discrimination based on gender. Objectivity and meritocracy veils men and women inequalities in science. This article focuses on the analysis of the situation of women researchers and the strategies to pursue high goals in their careers. In that sense, we analyze the usefulness of cooperation networks, institutional such as equality units, gender, or informal where a group of women capitalizes on their experience, through information or emotional support for other women's benefits. For developing this argument, we are based on different bibliographic sources, the results of the survey of 700 women and men who perform research in universities and research centers, and ten case studies carried out in the project Genera: Generation of a more inclusive and competitive knowledge economy. The findings show that it is not the unique strategy, the networks based on sorority and cooperation provide advantages to improve achievements and to reduce personal costs of pursuing a high competitive career shaping by male-dominated structure of power.
\end{abstract}

Keywords: feminist studies, networks, sisterhood, cooperation, mentoring, scientific careers, patriarchy.

1. El Proyecto Genera: Generación de una economía del conocimiento más inclusiva y competitiva está financiado por el Ministerio de Economía y Competitividad. Programa Retos FEM2013-48225-C3-1-R. 


\section{INTRODUCCIÓN}

Los estudios de género sobre la desigualdad de las mujeres investigadoras en España (Flecha; Ortiz y Becerra; Santesmases 2000; García de León 2002; Pérez Sedeño; Pérez Sedeño y Alcalá Cortijo) se inician con cierto retraso con respecto a los europeos y norteamericanos, señalando esas discriminaciones apoyándose en investigaciones históricas y biográficas. En España, éstos estudios han dado lugar a otras investigaciones corte empírico (García de León 2002, 2005; Miqueo et al.; Arranz; Magallón; Agudo; García de Cortázar et al.), donde los resultados revelan, por un lado, la desigual incorporación de las mujeres en las áreas del conocimiento dedicados a las ingenierías, y, por otro, la brecha de género existente en las posiciones de poder (categorías de catedrática y en las posiciones de gobernanza de las instituciones científicas), así como la necesidad de estudiar las desigualdades que se producen en las trayectorias profesionales de las mujeres en la investigación y las razones por las éstas aún persisten.

A pesar del esfuerzo que realizan las mujeres para equipararse a los hombres en la esfera profesional, estos sesgos y desigualdades continúan, como demuestra la desproporción en la distribución de sexos según categorías profesionales. En ese sentido, se observa en el Informe sobre Mujeres investigadoras del Ministerio de Economía y Competitividad, dirigido por la Unidad de Mujeres y Ciencia (González Orta et al.) y en el Libro Blanco de las mujeres en la ciencia (UMYC) que la situación de las mujeres en la investigación ha ido mejorando lentamente en las posiciones intermedias, sin embargo, sigue siendo muy escasa en posiciones de mayor relevancia. Así, el número de mujeres en las categorías de ayudante doctor o similares se ha equiparado al porcentaje de hombres de esa misma categoría, mientras que las mujeres que ocupan posiciones de catedrático o profesor de investigación representan un escaso 15 por ciento, porcentaje que ha aumentado ligeramente hasta un 21 por ciento, muy lejos de eliminar la brecha de género.

Por ello, en este artículo queremos enfatizar, mediante el análisis, la importancia que tienen las redes de cooperación en la ciencia, como instrumento para la inclusión de las mujeres en la Academia y como medio para optimizar sus 
esfuerzos durante las diversas etapas de sus carreras profesionales. Se parte de la hipótesis de que aquellas mujeres investigadoras que han contado con redes de apoyo, sean institucionales o informales, han logrado minimizar los riesgos, soportar mejor los embates del poder patriarcal, y obtener mejores resultados.

\section{LA NECESIDAD DE IDENTIFICAR Y CONCEPTUALIZAR LAS DESIGUALDADES DE GÉNERO EN LAS TRAYECTORIAS CIENTÍFICAS}

La necesidad de identificar y conceptualizar las razones por las que persisten las desigualdades de género, están íntimamente ligadas a la necesidad de identificar los discursos y prácticas de las organizaciones científicas. Los argumentos que justifican las asimetrías de género son diversos, el primer hilo argumental apela a razones de índole natural o cultural relacionadas con la diferente socialización de mujeres y hombres, y que tiene un marcado origen histórico. Según éste, las tasas de participación de mujeres y hombres en distintas áreas del conocimiento, se deben a una simple cuestión de libre elección de las mujeres, y a sus preferencias por cierto tipo de actividades y carreras (Eccles; Ceci y Williams). El segundo, de corte comprensivo-benévolo, hace referencia a la lentitud que tienen las organizaciones por asumir e incorporar procesos de cambios sociales. Por tanto, se reconocen las desigualdades, pero se apela a la comprensión y la paciencia de todos los miembros de la organización, para que depositen su confianza en un futuro mejor. Por último, el tercero esgrime justificaciones, fundamentadas en elementos objetivos y neutrales como capacidades y méritos. En base a este argumento, las cuestiones de género y de clase son entendidas como ajenas y por tanto, invisibilizadas en las organizaciónes y en la distribución del poder de las instituciones científicas. En su lugar, ese mérito y capacidad serán los baluartes para justificar los desequilibrios entre las personas, incluso ignorando los mejores resultados formales que obtienen las mujeres y que sin embargo, no se trasladan a una consecución efectiva de su reconocimiento, debido a una decisión colegiada (González Ramos et al.). De este modo, se encubre las responsabilidades de las estructuras androcéntricas, su modo de organizar y distribuir el poder en las instituciones científicas, así como en la situación de inferioridad en la que quedan relegadas muchas veces las mujeres en la ciencia (Arranz). No obstante, observamos como los discursos y las praxis dominantes de las organizaciones, tratan de imponernos un espejismo de igualdad normativa, que no se corresponde con la situación real de hombres y mujeres en la ciencia (Haraway).

En ese sentido, la perspectiva crítica feminista aborda el problema desde un punto de vista estructural y pone su foco en las estructuras científicas, en la cultura dominante de las instituciones y no exclusivamente en las mujeres. 
Por eso, se apela a que son las instituciones científicas las que han de cambiar, y no las mujeres, dado que éstas ya han hecho un esfuerzo muy importante en adaptarse a las estructuras masculinas. La actual distribución de las mujeres en la ciencia, parece indicar que sólo se les reserva un espacio si se ajustan a esa cultura androcéntrica dominante. Sin embargo, las mujeres forman parte de las instituciones tanto cuantitativamente, representan la mitad de las personas, como cualitativamente, trasladan una perspectiva propia, diferente a la mirada masculina (Harding; Schiebinger). El Proyecto Genera: Generación de una economía del conocimiento más inclusiva y competitiva examina estas barreras estructurales que, pueden estar detrás de la desigualdad de género en las instituciones científicas. Para ello, se analizan sesgos relacionados con la actividad científica realizada por las mujeres, sus trayectorias científico-profesionales y los ambientes y cultura de trabajo donde desarrollan sus carreras profesionales. Estos objetivos, se refieren más específicamente a los objetivos 2 y 3 del proyecto, donde se examinan los ambientes de trabajo de hombres y mujeres en universidades y centros de investigación, identificando factores claves en sus trayectorias profesionales.

La metodología aplicada en el objetivo 2 consiste en un cuestionario en español e inglés (para que el personal de investigación extranjero que trabaja en las instituciones científicas españolas pudiese responder el cuestionario), con 25 preguntas que analizan distintas dimensiones de su actividad profesional. El cuestionario está diseñado en seis secciones, que abordan las características de su categoría laboral, cultura del lugar de trabajo, características sobre el acceso y promoción a la carrera científica, políticas institucionales, dimensiones de la vida familiar y laboral y, por último, perfil de la persona encuestada. La tasa de respuesta alcanzó a más de 700 mujeres y hombres de universidades y centros de investigación. La metodología del tercer objetivo se desarrolló con diez estudios de casos, elegidos para caracterizar culturas científicas diversas según áreas de conocimiento, sectores de actividad y regiones geográficas. El estudio de casos emprendido requirió, en primer lugar, de un análisis exhaustivo de la documentación relativa a los procedimientos de contratación y promoción, la misión e imagen del centro. En segundo lugar, se realizaron entrevistas individuales para describir las trayectorias de vida y profesionales del personal con grado de doctor (eligiendo a un hombre y una mujer en cada una de las etapas de la carrera científica). En tercer lugar, se realizó una entrevista grupal con los miembros de las comisiones de contratación donde se simulaban una contratación de personal (utilizando currículos ficticios de dos personas de diferente sexo para estimular la discusión que se promovería en el departamento o grupo de investigación investigado). Además, durante las entrevistas 
individuales se realizaron diagramas de ego, donde se mostraba gráficamente aquellos elementos, circunstancias y personas que apoyaron o dificultaron los logros alcanzados durante su trayectoria profesional, señalando tanto aspectos profesionales como personales y familiares.

De los resultados de estos dos trabajos de campo, este artículo ha utilizado aquellos aspectos que contribuyen a responder nuestra pregunta de investigación, esto es, la estrategia de incorporación y promoción de las mujeres, y la contribución de las redes de colaboración entre las investigadoras en activo del sistema de ciencia y tecnología español.

A pesar de que los estudios del género en la ciencia han venido destacando esa infrarrepresentación de las mujeres en la investigación y la falta de reconocimiento de sus trabajos y aportaciones a lo largo de la historia (González García), este trabajo centra el foco de análisis precisamente en esas estrategias adoptadas por las mujeres de forma individual o colectiva, para eludir las discriminaciones y sesgos de género. Por tanto, se trata de repensar, como sugiere Santesmases (2001), en un modelo alternativo de ciencia feminista, basado en modelos y medidas de incorporación de mujeres en la ciencia como a medio plazo, así como estrategias para minimizar los costos asociados a la competencia desigual, en una institución dominada por la cultura masculina. Ello permitiría, a largo plazo, instituciones más justas y, tal vez, una ciencia feminista que incluya la mirada y la perspectiva de las mujeres (Harding; Santesmases 2001). Como ha dicho Sanz, para ello se precisan enfoques no meramente cuantificadores de las desigualdades numéricas entre sexos, sino centrados en la interconexión entre la producción del conocimiento y los intereses de las mujeres. Junto a los estudios cuantitativos, que reflejan diferencias entre mujeres y hombres y los intereses de las mujeres, es importante incorporar el análisis de esas trayectorias profesionales, sus estrategias y los aspectos que han influido en el desigual acceso y permanencia en las instituciones académicas. Así, la clase social y el capital social, reflejado en el nivel de instrucción de sus progenitores y su profesión, constituyen elementos fundamentales de influencia de sus propias trayectorias profesionales. Las mujeres, no solo parten de condiciones desiguales que propician las lógicas y prácticas de las instituciones de investigación, sino aquellas que están interseccionadas por el capital cultural heredado y las redes sociales previas con las que cuentan. Este es un elemento central, pues conforman estructuras invisibles que dificultan el acceso a un mercado laboral elitista, con altas dosis de adscripción y profundamente androcéntrico, junto a la suma de circunstancias favorables o desfavorables que van encontrándose o generando paulatinamente durante sus carreras profesionales. 
En cuanto al primer aspecto, relacionado con la clase social y el origen de las mujeres investigadoras, la encuesta del proyecto Genera proporciona datos valiosos. En primer lugar, se observa que el nivel de estudios de las progenitoras es menor que el de los padres. Así, el 11.9\% de las madres carecen de estudios frente al $8.9 \%$ de los padres. Con respecto a los progenitores con titulación universitaria superior, el porcentaje de madres sigue siendo menor que el de los padres (12.4\% frente al $17.9 \%$ ), y aún menor en la categoría estudios de doctorado (1,3\% de madres frente al $6.2 \%$ de padres). En segundo lugar, en cuanto a la profesión de los progenitores, las madres trabajan casi exclusivamente en el hogar familiar mientras que la mayoría de los padres realizan un trabajo remunerado. Además, el $11.6 \%$ de las madres y el $16.7 \%$ de los padres son técnicos y profesionales científicos e intelectuales, lo cual apoya la tesis de que es una profesión con la que contar con el capital social de los progenitores es una ventaja. Ello parece especialmente importante si se es mujer, las mujeres investigadoras presentan una diferencia de casi seis puntos más que en el caso de los hombres relacionados con la profesión científica e intelectual de sus progenitores. Ello sugiere una mayor adscripción femenina a las profesiones relacionadas con la investigación, y una fuerte influencia del capital social y las redes previas provenientes del origen familiar. También una mayor dificultad de aquellas personas, mujeres y hombres, que eligen las profesiones científicas provenientes de una clase social más humilde. El análisis cualitativo de las biografías de mujeres y hombres científicos en este proyecto confirma este segundo aspecto.

En cuanto a los factores y circunstancias favorables o desfavorables que las investigadoras van encontrándose a lo largo de sus vidas, podemos destacar varias. Un primer elemento favorable podría ser el crecimiento del área de conocimiento, lo cual proporciona oportunidades para la incorporación de mujeres jóvenes en la carrera de investigación. Otro elemento positivo es la estructura familiar de las investigadoras, el número de hijos/as, el momento en que se tienen, las necesidades de cuidado de otras personas de la familia, y la corresponsabilidad en el cuidado y la gestión familiar que se establece entre los miembros de la familia (González Ramos y Torrado). Por tanto, también tiene una importante influencia la elección de la pareja, que permite o dificulta avanzar en la carrera científica, o alcanzar logros (González Ramos 2014a). En la encuesta del proyecto Genera, se observa que más de la mitad de las mujeres y hombres dedicados a la investigación tienen descendencia (51.2\%). De éstos, el $21 \%$ tiene uno/a o dos hijos/as, el $25.2 \%$ dos y el $4.6 \%$ tres. Así, descendencia y carrera científica están estrechamente relacionadas, sobre todo en el caso de las 
mujeres. De hecho, una de cada cuatro mujeres no tiene hijos/as, y las mujeres tienen una probabilidad menor que los hombres de tener descendencia.

También se encuentran diferencias entre sexos en lo que se refiere a la elección de las parejas. El $84.5 \%$ del personal de investigación tiene alguna pareja, uno de cada tres investigadores/as tienen además una pareja del mundo científico (34\%). No obstante, los hombres parecen elegir a parejas de cualquier tipo en mayor medida que las mujeres, quienes eligen en mayor medida parejas científicas (32.2\% frente al 23\%). Las diferencias de género, sugieren un patrón relacionado con las mujeres investigadoras. En primer lugar, las mujeres presentan una mayor tendencia a ser solteras y, en segundo lugar, cuando son casadas, tienden a tener parejas investigadoras en mayor medida que los hombres. Esto puede ser interpretado como que las mujeres optan con mayor frecuencia por no ser madres o no tener parejas. Y, en el caso de que sí la tengan, optan por la elección de una pareja que se dedica al mundo de la ciencia, que pueden entender con más facilidad su actividad (que requiere extensas jornadas de trabajo, viajes frecuentes o cambios de domicilio) y compatibilizar sus estilos de vida en función de las necesidades profesionales de sus carreras. Por el contrario, ellos optan en mayor medida por establecer relaciones de parejas que no están sujetas a su perfil profesional, pueden o no estar fuera del ámbito de la ciencia, porque no tienen problemas de conciliación, ni están adscritos a los roles de género que generan expectativas diferentes a los que se han propuesto como profesionales (González Ramos y Torrado). Estos datos coinciden con los resultados de otros estudios como los de Xie y Shauman en Estados Unidos, que subraya esa tendencia de las mujeres investigadoras a no contraer matrimonio ni tener descendencia, en mayor medida que los hombres. Por último, el análisis cualitativo de los estudios de caso también confirma que las mujeres y hombres que forman una pareja científica, comparten en mayor grado las responsabilidades del hogar, sobre todo en lo que se refiere a la recogida de los/as hijos/as del colegio y la realización de otras tareas, eso sí, según su estatus social. Estas nuevas estrategias familiares pueden ser una tímida respuesta a lo que implican esos cambios producidos por la inclusión lenta pero progresiva de las mujeres al mundo del trabajo.

\section{DIFICULTADES EN EL ACCESO Y LA PROMOCIÓN DE LAS MUJERES EN LA CIENCIA}

Para que la ciencia llegue a ser de calidad, necesita incluir a las mujeres y producir relaciones igualitarias en las estructuras de poder. En la actualidad, las desigualdades en las instituciones de investigación persisten, al igual que ocurre en otros sectores profesionales (Claramunt). Resulta sorprendente que 
tras la muerte de la científica Hipatia de Alejandría hace más de 1.600 años, las científicas actuales sigan siendo grandes desconocidas para la sociedad en su conjunto, y que sus aportaciones sean infravaloradas con respecto a los hallazgos científicos de los hombres. La invisibilización de esas aportaciones de las mujeres incide en sus condiciones de exclusión y es parte de la raíz del problema, con resultados de abandono de sus carreras o la renuncia a perseguir los mismos logros científicos que los hombres (Pérez Sedeño y Alcalá Cortijo; Miqueo et al.; Magallón; García de León 2005; Etzkowitz y Ranga; González Ramos 2014b). La relegación de las mujeres a posiciones de menor influencia y prestigio, se produce por praxis cotidianas y diversas, así por ejemplo, la aceptación de normas de estilo androcéntricas como las utilizadas en referencias bibliográficas y donde se omite el nombre de las mujeres, contribuyendo a su invisibilidad. Estas normas y estilos se reproducen cada vez que participamos en conferencias y eventos donde los ponentes son exclusivamente hombres, como si pareciese que determinadas materias o disciplinas fueran ellos los únicos con autoridad para decir y decidir. Así mismo, se reproducen en la concesión de premios y reconocimientos donde son las mujeres las eternas olvidadas, por ejemplo en los Nobel, tan sólo el 5\% de las galardonadas eran mujeres y en los premios Príncipe de Asturias solo el 10\% (González Orta et al.).

Este modelo masculinizado dominante de la ciencia, tiene impactos muy importantes para las mujeres, como demuestra el informe She Figures (Comisión Europea), que refleja que el 59\% de las personas licenciadas son mujeres en Europa y sin embargo, sólo el $40 \%$ son profesoras titulares de Universidad y el 20\% catedráticas. El estudio de Moss-Racusin demuestra con su conocido experimento John y Jennifer, que hombres y mujeres no son valorados con igual criterio, a pesar de seguir un método aparentemente cuantitativo y objetivo. Moss-Racusin y sus colaboradores pidieron a profesores de la Universidad de Yale de distintas facultades (ciencias, ingeniería, tecnología y matemáticas) que valoraran un currículum ficticio exactamente iguales, excepto en que uno estaba asociado a un nombre de hombre y el otro a un nombre de mujer. En los resultados se encontraron importantes sesgos de género, incluso en una selección basada en un modelo objetivo de medición de méritos e igualdad. El experimento demostró además que hombres y mujeres estaban igualmente atravesados por los estereotipos de género. Así, los miembros de las comisiones de evaluación, independientemente de su género, puntuaron más favorablemente el currículum asignado a un nombre masculino, en contra del currículum asignado a un nombre femenino, que obviamente consiguió una puntuación menor. Este experimento demostró que 
los prejuicios trascienden el igualitarismo normativo y que están impregnados en el conjunto de la sociedad, guiando nuestras decisiones hacia resultados que pueden ser discriminadores. El modelo meritocrático basado en medidas cuantitativas, justifica ese modelo supuestamente objetivo, que nos mantiene en la falsa creencia de que el género no influye en los procesos de evaluación, contando en las valoraciones sobre el desempeño profesional de las mujeres, lo que contribuye a justificar y fortalecer el techo de cristal, que impide seguir avanzando a las mujeres en la investigación.

Una manera de avanzar en la eliminación de esos sesgos subjetivos de los/as evaluadores/as, es el fomento de procedimientos más transparentes. Cierto es que la transparencia favorece el acceso de las mujeres a las categorías profesionales, ya que evidencia los resultados comparativos entre hombres y mujeres. En las instituciones científicas, según la encuesta del proyecto Genera, los procesos más frecuentes de incorporación de las mujeres a la ciencia son el examen, la entrevista personal y la baremación de méritos. El 43,2\% del personal científico accedió a su actual categoría laboral mediante un examen, entrevista o concurso con evaluadores externos, el 19\% mediante la baremación de sus méritos y el 12,2\% mediante un examen, entrevista o concurso con evaluadores de la propia institución. Estas dos últimas categorías son las más frecuentemente citadas por las mujeres investigadoras (21.1\% y $14.4 \%$ respectivamente). Las mujeres encuestadas valoraron muy positivamente el acceso a la información que suelen recibir acerca de becas $(56.1 \%$ consideraron la información recibida muy accesibles o accesibles) y la financiación de proyectos ( $51.2 \%$ consideraron la información recibida muy accesibles o accesibles). Sin embargo, se muestran más críticas con la información recibida sobre proyectos y fuentes de financiación de sus investigaciones, valorando inaccesible o muy inaccesible la información (13.2\%) frente a los hombres (tan sólo el 7.3\%). En cuanto al acceso a la información sobre los contratos, también las mujeres tienen una opinión más negativa que los hombres, lo que se refleja en seis puntos de diferencia sobre la información recibida sobre sus posibilidades de promoción (ocho puntos de diferencia entre hombres y mujeres). No obstante, hombres y mujeres consideran la normativa y la reglamentación de contratación y acceso a las instituciones científicas muy transparentes (37.4\%) o transparente (28.9\%). Pero si las mujeres investigadoras perciben como fácil el acceso a la información de becas y contratos, es quizá porque se les ha permitido avanzar a los primeros niveles de la carrera científica, generalmente más precarizados, no siendo así en las categorías de mayor relevancia. Si ellas perciben más críticamente la inaccesibilidad y la escasa información sobre financiación de proyectos de investigación, es porque 
normalmente esta carencia de información las aleja en parte de los puestos de liderazgo o de la dirección de los proyectos I+D, mermando su capacidad de progresar a otras categorías laborales de mayor responsabilidad y visibilidad. Respecto a la valoración de los sistemas de promoción, las mujeres opinan que es muy transparente (30.7\%) o transparente (22.6\%) y el sistema de selección de los tribunales o paneles de evaluación como transparente o muy transparente (47.1\%). Pero, aun valorándolos positivamente, también su opinión es más crítica que la de los hombres con respecto a la transparencia de los procesos, con una diferencia de tres puntos respecto a ellos en la valoración «nada transparente»o «no transparente». Esta opinión más crítica sugiere que, frente al ideal normativista basado en la medición objetiva de los méritos, las mujeres mantienen una valoración más compleja debido a las condiciones en la que desarrollan sus carreras científicas.

La competitividad y la exigencia de acumulación de méritos a lo largo de la trayectoria de investigación choca con sus roles de género, referidos a la conciliación de la vida personal y familiar, y a la presión a la que se las somete en su doble papel de mujeres y profesionales. En comparación con los hombres, las mujeres están sometidas a una doble desventaja, mientras ellos pueden desarrollar su trayectoria profesional sin tanta carga de trabajo y presión, respondiendo satisfactoriamente y según los roles tradicionales de género, a lo que se espera de ellos. Esta presión se ha observado tanto en la encuesta como en los estudios de casos, donde las mujeres no se lamentan de su doble rol como mujeres/madres y profesionales y donde los hombres parecen asumir ciertas responsabilidades en el cuidado familiar. Por el contrario, las referencias relacionadas con las dificultades que supone la maternidad o el cuidado de personas dependientes, están relacionadas con la imposibilidad de seguir el ritmo estresante que cada vez más se impone en las carreras científicas. Si bien la causa visible es el cuidado, la verdadera razón procede de la inadaptación de las estructuras de la científica, para entender las diversas circunstancias de las mujeres, valorando una realidad y circunstancias diferentes a lo largo de toda su carrera. Las prácticas dominadas por el modelo masculino invisibilizan las causas de la discriminación de las mujeres en los procesos de promoción y permanencia en las carreras de investigación.

Como se ha mencionado con anterioridad, la cultura de las organizaciones científicas, las condiciones familiares y el ciclo vital, dificultan o facilitan el acceso y permanencia en las instituciones científicas, interseccionando aspectos como las redes relacionales, el mentorazgo o el acceso a las redes de información dispensadas. Así, en la encuesta, un tercio de la muestra (34\%) dice haber experimentado alguna interrupción a lo largo de su carrera profesional, de las 
cuales el 26\% son mujeres frente al $8 \%$ hombres. Entre las razones principales por las que justificaron esas «paradas profesionales» se encuentran los embarazos con un porcentaje del $23 \%$ ( $40 \%$ mujeres frente a $5 \%$ hombres), el cuidado de personas dependientes, un $8,7 \%$. (2.9\% hombres frente a $14.5 \%$ mujeres), el estrés o necesidad de descanso, un 6,7\% (5.5\% de hombres frente a $8 \%$ mujeres), enfermedad laboral $7 \%$ (4\% hombres frente al $9.5 \%$ de las mujeres), y el acoso o discriminación laboral 3,4\% (2.62\% hombres frente al 4.23\% mujeres). El tiempo medio de estas interrupciones laborales fueron aproximadamente de 7.3 meses cuando el motivo está relacionado con el embarazo, 11 meses por cuidado de un familiar, 5.4 meses por estrés o necesidad de descanso, 5.4 meses por enfermedad laboral y 10.7 meses por acoso o discriminación laboral. Estos datos reflejan una tendencia mayor de las mujeres frente a los hombres a interrumpir su carrera profesional, derivada de los roles de género asignados a las mujeres respecto al cuidado, pero también respecto a otras razones relacionadas con la enfermedad, la necesidad de descanso y el acoso laboral. La incidencia de ello es mayor en las mujeres, quienes tienden con mayor frecuencia a interrumpir sus carreras, por la presión y por un modelo de investigación que no se ajusta a las circunstancias de vida a la que se deben enfrentar diariamente. Además, puede afirmarse que las interrupciones más largas tienen que ver con factores de género, tales como el embarazo, el cuidado de familiares y el acoso o discriminación laboral. Así, las circunstancias más complejas a las que deben enfrentarse las mujeres, perfilan las causas del abandono de la carrera científica y su decisión de dejar de perseguir mayores logros profesionales y promociones dentro de ella. Es ampliamente aceptado, por aquellas personas que justifican la menor presencia de mujeres en las categorías de mayor responsabilidad, que se debe a decisiones personales de las mujeres. Para validar esta afirmación, incluimos una pregunta en el cuestionario, con la intención de conocer si las mujeres científicas contemplan en su agenda nuevas promociones. Los resultados indican que las mujeres representan el $57.5 \%$ frente al $42.4 \%$ de los hombres, lo cual no parece avalar de manera concluyente la afirmación anterior. El personal de investigación que ha decidido no seguir concursando a plazas de mayor categoría o sexenios, afirma que se debe a la falta de interés o desmotivación por los procesos competitivos (8.3\%), la excesiva carga docente y de gestión (6.3\%), la exigencia de las condiciones de promoción (6.2\%), los problemas de conciliación familiar y laboral (5.7\%), la falta de confianza en su propio currículum (4.3\%), otras razones relacionadas con el bienestar (3.3\%), y otras razones no relacionadas con las anteriores (2.4\%). Las diferencias de género más destacadas aparecen por orden en el argumento de excesiva exigencia de las promociones laborales, 
los problemas de conciliación y la importancia de otros factores relacionados con el bienestar. En esas categorías, las mujeres puntúan con algo más alto, con diez puntos de diferencia respecto a los hombres. Estos resultados apoyan la idea de que las mujeres se sienten más presionadas que los hombres por los procesos de competitividad, su doble rol de género y el hecho de que valoran de manera diferente su bienestar.

\section{ESTRATEGIAS DE SUPERVIVENCIA: REDES DE COOPERACIÓN VERSUS INVESTIGADORAS SOLITARIAS}

A partir del trabajo de campo realizado durante los estudios de casos, hemos observado que, frente a las dificultades de acceso y permanencia de las mujeres en la ciencia, los apoyos institucionales constituyen una formula eficaz para frenar el abandono de sus carreras y la promoción profesional. La mentoría y las redes de cooperación (sororidad) funcionan como un factor de amortiguación y minimización de los efectos negativos, casi siempre derivados de prácticas competitivas, neoliberales y patriarcales características de las actuales estructuras de las instituciones de investigación. Así, a través de las entrevistas en profundidad y los diagramas de ego, se pudo determinar la importancia que ha tenido en sus carreras profesionales el apoyo de otras mujeres. García de León (2002) en su libro Herederas y Heridas, clasifica las limitaciones a las que muchas mujeres se enfrentan en su acceso al poder. Las élites femeninas son apoyadas por hombres, que las tratan como subalternas o como hijas o por políticas de acción positiva, como por ejemplo las cuotas. Sin embargo, suelen ser poco valoradas por la mayoría de los hombres y algunas mujeres en posiciones de poder. En el caso de las mujeres investigadoras, también se ha hablado del papel que juegan las parejas (González Ramos 2014a), como hombres antagonistas o colaboradores con el proyecto profesional de sus compañeras. En los estudios de casos, hemos encontrado el modelo de mujeres solitarias, que inician y desarrollan sus carreras sin apoyos, avaladas exclusivamente por sus méritos y algunas circunstancias favorables de incorporación en las instituciones científicas, la mayoría de las veces frente a otros candidatos que oponen una resistencia importante. Este modelo frecuente, carente de redes de apoyo, lleva a las mujeres a un doble esfuerzo, a la ralentización profesional, alcanzando limitados logros científicos y, en el peor de los casos, al abandono de la carrera científica (González Ramos y Torrado).

A pesar de los datos que demuestran esta dificultad, muy pocas instituciones mantienen medidas institucionales de cooperación, como las relaciones de mentorazgo y acciones positivas como las cuotas, es más, éstas son fuertemente criticadas tanto por los hombres como por las mujeres. Un espurio interés sobre 
su objeto, lleva a entender que las cuotas permiten que mujeres menos eficaces que los hombres accedan a posiciones y categorías de responsabilidad; por el contrario son necesarias para rectificar los sesgos que influyen negativamente a las mujeres a lo largo de toda su carrera profesional. En la actualidad, se han incorporado y normalizado otras medidas institucionales como las de conciliación, que justifican la igualdad de los hombres y las mujeres en el mundo laboral. En cambio, se mantiene un modelo de trabajo competitivo, que impone un ritmo de trabajo estresante que perjudica sobre todo a las mujeres. Los modelos de trabajo cooperativo son penalizados frente a los modelos de tipo individual y la toma de decisiones discrecional o antidemocrática que siguen apoyando la incorporación de los hombres en posiciones de poder, frente a las mujeres (como las decisiones sobre quién ocupará una posición de relevancia en el equipo de rectorado o del decanato).

Las estrategias de cooperación y sororidad son minoritarias, de carácter circunstancial y puntual, no constituyendo parte de una estrategia política de las instituciones de la ciencia. Su desarrollo se corresponde con la voluntad individual de las participantes o circunstancias particulares de las mujeres científicas, que perciben estas redes como un elemento ventajoso. Por ejemplo, según nuestros estudios de casos, en ambientes tradicionalmente muy masculinizados como las carreras de ingeniería, la llegada de un grupo de mujeres a las aulas propicia la conformación de una red de sororidad donde las mujeres se van acompañando y apoyando mutuamente a lo largo de las diferentes etapas de la carrera de investigación. También existen grupos de mujeres que tienen perspectiva de género, que normalmente se sitúan fuera de las esferas de poder, puesto que los estudios de género no son muy reconocidos en las distintas ramas del conocimiento. Sin embargo, estos grupos de mujeres ejercen presión para establecer medidas y políticas de igualdad dirigidas a paliar las discriminaciones y dificultades que impiden a las mujeres acceder a las categorías de poder y minimizar su invisibilización en las instituciones científica. A través del trabajo de campo cualitativo, se ha constatado que en aquellas instituciones de investigación que han incorporado este tipo de medidas de igualdad y aquellas otras instituciones con programas de mentaría, son más amigables y propicias para el desarrollo de las mujeres. Estas estrategias constituyen instrumentos de gran utilidad, minimizando los obstáculos que se producen por razones de género. Por tanto, estas redes constituidas en el seno de los institutos de investigación, grupos de investigación formales o grupos de personas informales son de suma importancia. El liderazgo de mentoras que ofrece información, apoyo, consejos y su experiencia personal, es en sí mismo una de las bases fundamentales para rentabilizar los enormes esfuerzos que 
las mujeres tienen que hacer para conseguir logros profesionales y posiciones de mayor relevancia.

En la encuesta Genera, las mujeres admiten participar menos en las redes de influencia en la investigación: sólo el 19.1\% de las mujeres frente al 24.1\% de los hombres forman parte de asociaciones profesionales. En la encuesta no se pregunta acerca de las razones por las que no se participa en ellas, aunque puede ser que se carezca de los contactos necesarios para ser invitadas a participar de dichas redes. Ciertos aspectos de la estructura de la ciencia, como la pertenencia a asociaciones profesionales, tienen un claro matiz de género que se plasma en la escasa participación de las mujeres en las redes de poder. Frente a esta realidad actual, habría que contraponer la experiencia aún minoritaria pero prometedora de las redes de sororidad que han sido descritas en los párrafos anteriores.

\section{CONCLUSIONES}

Los estudios actuales sobre trayectorias y carreras científicas siguen mostrando la brecha de género vigente entre mujeres y hombres. Se ha teorizado bastante sobre las condiciones materiales que impiden el acceso y la permanencia de las mujeres (dobles jornadas, embarazo y parto, cuidado de personas en dependencia, acoso, ausencia de redes de mentorazgo) en los entornos científicos en condiciones de igualdad. También sobre el establecimiento de esas condiciones formales que faciliten el acceso supuestamente de forma igualitaria y objetiva (examen, entrevistas, valoración de currículos). En este sentido, este trabajo incide en esas líneas de trabajo, aportando evidencias desde la perspectiva de género y con la intencionalidad de influir en la ciencia para hacer sus espacios más feministas (Harding; Santesmases 2001). La importancia de las redes de cooperación feministas o el impacto de la sororidad entre las mujeres en el ámbito de la Academia, ha sido un objeto de estudio de menor relevancia, pero esencialmente importante para el desarrollo de las carreras de las mujeres en la ciencia. Por ello hemos introducido este aspecto, presentándolo como un instrumento eficaz para reducir los efectos negativos de las prácticas patriarcales en un modelo androcéntrico, en ocasiones, difícilmente apreciables, pero que impide el acceso y el logro al éxito de las mujeres en sus carreras de investigación.

Estos resultados, a través de la encuesta y los estudios de casos, muestran que las mujeres valoran más críticamente que los hombres los actuales estilos de trabajo y el acceso a la información para la redistribución de los recursos destinados a la investigación. Por otra parte, la infrarrepresentación de las mujeres en las redes e instituciones científicas no puede circunscribirse 
exclusivamente a una debilidad de las mujeres en las redes de influencia, sino a una manifestación de desigualdad en las organizaciones e instituciones de la ciencia. Su mayor participación en las redes científicas de mujeres, podrían actuar como resorte frente a las lógicas patriarcales de comunicación y producción del conocimiento ya que promueven y facilitan no sólo la consecución del logro personal, sino el desarrollo de sinergias de inclusión, evitando el aislamiento y el eventual abandono de sus carreras. También supone una estrategia política de resistencia contra una ciencia patriarcal, altamente masculinizada en categorías de mayor relevancia, que va más allá de un impacto cuantitativo. Con frecuencia este modelo científico ignora la perspectiva de las mujeres y su producción de conocimientos.

Frente a estas sinergias tradicionales, con resultados escasamente exitosos para las mujeres y que no se puede imputar exclusivamente a elementos relacionados con la familia y el cuidado, se deben abordar las otras razones por las que se encuentran relegadas a espacios de subordinación e invisibilización. Uno de los argumentos explicativos se deriva de los modelos de competitividad y de la falta de incentivos a las mujeres, por lo que tienen frecuentemente que adoptar modelos androcéntricos de trabajo en sus organizaciones. Las mujeres muestran que los problemas que inciden en su desarrollo profesional no sólo son de índole relacionada con la conciliación familiar y personal, sino que apuntan a otras razones como la insatisfacción, derivada de las excesivas demandas curriculares de los procesos de promoción, así como la búsqueda de bienestar más allá de lo que ofrece el actual modelo de carrera científica. También, algunos hombres se alinean con esta posición crítica, por lo que entendemos que un modelo de ciencia diferente sería también avalado por algunos investigadores de sexo masculino. Mientras tanto, algunas mujeres desarrollan estrategias de supervivencia y resistencia ante culturas científicas que constituyen una amenaza, excluyéndolas e impidiendo su promoción. Una de ellas consiste en su integración individual en organizaciones institucionales relacionadas con los estudios de género, tales como institutos de estudios de las mujeres o asociaciones de mujeres científicas. Estos grupos constituyen una potente red de redes, con apoyos científicos y de resistencia ante los embates de la ciencia androcéntrica que invisibiliza a las mujeres en la ciencia.

Por tanto, estas redes de apoyo de mujeres constituyen uno de los instrumentos de cambio más revolucionarios en las carreras de investigación de las mujeres. Se trata de organizaciones imprescindibles para minimizan los costos personales de perseguir una carrera científica exitosa en una cultura científica patriarcal. Hasta el momento, seguir la cultura científica tradicional no ha presentado resultados muy halagüeños para las mujeres, pues las brechas de 
género persisten, y el techo de cristal que impide el acceso a ciertas estructuras y recursos de poder. Ante el espejismo de la igualdad formal, estas brechas de género demuestran cierta ineficiencia de estas medidas y la necesidad de adoptar nuevos modelos de organización en la ciencia. La sororidad o cooperación informal entre mujeres también parece ser una estrategia adoptada por aquellas mujeres que se enfrentan a culturas altamente masculinizadas y constituye un instrumento de apoyo mutuo y de colaboración y cooperación como compañeras, frente a las lógicas masculinas que pueden invisibilizar su trabajo y producción de conocimientos.

\section{REFERENCIAS BIBLIOGRÁFICAS}

Agudo Arroyo, Yolanda. «El lado oscuro de la mujer en la investigación científica: ¿es la ciencia una 'empresa' masculina?». Cuestiones de Género: de la igualdad y la diferencia 1 (2006): 15-51.

Arranz Lozano, Fátima. «Las mujeres y la universidad española: estructuras de dominación y disposiciones feminizadas en el profesorado universitario». Politica y Sociedad 41 (2004): 203-221.

Ceci Stephen J. y Wendy M. Williams. «Understanding current causes of women's underrrepresentation in science». Proceedings of the National Academy of Sciences 108. 8 (2011): 3157-3162.

Claramunt Vallespí, Rosa María. «Mujeres en Ciencias». Revista de Investigación Universitaria 4 (2003): 19-37.

Comisión Europea. She Figures 2012. Gender in Research and Innovation. Statistics and indicators. Bruselas: Comisión Europea, 2013.

Eccles, Jackeline S. «Gender Roles and Women's Achievement-related Decisions». Psychology of Women Quarterly 11 (1987): 135-172.

Etzkowitz, Henry y Marina Ranga. «Gender dynamics in science and technology: From the «Leaky Pipeline» to the «Vanish Box». Brussels Economic Review, Special Issue «Beyond the leaky pipeline - Challenges for research on gender and science» 54 (2011): 131-148.

Flecha, Consuelo. Las primeras universitarias en España. Madrid: Narcea, 1996.

García de Cortázar, M. Luisa et al. Mujeres y hombres en la ciencia española. Una investigación empirica. Madrid: Instituto de la Mujer, 2006.

García de León, M. Antonia et al. Las académicas: profesorado universitario y género. Madrid: Instituto de la Mujer, 2001.

García de León, M. Antonia. Herederas y Heridas. Sobre las élites profesionales femeninas. Madrid: Catedra, 2002.

García de León, M. Antonia. La excelencia científica. Hombres y mujeres en las Reales Academias. Madrid: Instituto de la Mujer, 2005. 
González García, Marta I. «Género y conocimiento». Ciencia, tecnología y sociedad en el cambio de siglo Ed. López Cerezo, Juan Antonio y Sánchez Ron, José Manuel. Madrid: Biblioteca Nueva-OEI, 2001.

González Orta, Lydia, Capitolina Díaz Martínez y Araceli Gómez Ruiz. Las mujeres en los premios científicos en España 2009-2014. Madrid: UMYC, 2015.

González Ramos, Ana M. «Inclusion of Women in Science. Long-term strategies for alone or with partners' women». Géneros. Multidisciplinary Journal of Gender Studies 3.3 (2014): 459-482.

González Ramos, Ana M. «Victoria y la ciencia: El papel de las mujeres en la ciencia contemporánea». Mujeres Construyendo la Sociedad del Conocimiento: Ciencia, Tecnología y Género. Dir. Cecilia Castaño. Barcelona: Editorial Aresta, 2014b.

González Ramos, Ana M., José Navarrete Cortés and Esther Cabrera Moreno. «Dancers in the Dark: Scientific Careers According to a Gender-Blind Model of Promotion». Interdisciplinary Science Reviews 40. 2 (2015): 182-202.

González Ramos, Ana y Esther Torrado Martín-Palomino. «Familia e Investigación. Estrategias familiares y de género de las investigadoras españolas». En Todo sobre mi familia. Perspectiva de género, Revista Feminismo/s 23 (2014): 193-207.

Haraway, Donna. Primate Visions. Gender, Race, and Nature in the World of Modern Science. New York-London: Routledge, 1989.

Harding, Sandra. Ciencia y feminismo. Madrid: Editorial Morata, 1996.

Magallón, Carmen. Pioneras españolas en las ciencias. Las mujeres del Instituto Nacional de Física y Química. Madrid: Consejo Superior de Investigaciones Científicas, 2004.

Miqueo, Consuelo, M. José Barral, Isabel Delgado, Teresa Fernández-Turrado y Carmen Magallón. «Del Análisis Crítico a la Autoridad Femenina en la Ciencia». Feminismo/s 1 (2003): 195-216.

Moss-Racusin, Corine, John Dovidiob, Victoria Brescollc, Mark Grahama y Jo Handelsman. «Science faculty's subtle gender biases favour male students. Proceedings of the National Academy of Sciences of the United States of America». PNAS 109. 41 (2012): 16474-16479.

Ortiz Gómez, Teresa y Gloria Becerra Conde (Eds.). Mujeres de ciencias. Mujer, feminismo y ciencias naturales, experimentales y tecnológicas. Granada: Universidad de Granada, 1996.

Pérez Sedeño, Eulalia, Ed. Las mujeres en el Sistema de Ciencia y Tecnología. Estudios de casos. Madrid: OEI, 2001.

Pérez Sedeño, Eulalia y Paloma Alcalá Cortijo. (Eds.) Ciencia y Género. Madrid: Facultad de Filosofía de la Universidad Complutense, 2001.

Santesmases, M. Jesús. Mujeres científicas en España (1940-1970). Profesionalización y modernización social. Madrid: Instituto de la Mujer, 2000. 
Santesmases, M. Jesús. «¿Ciencias femeninas o carreras feministas?». Ciencia y Género. Pérez Sedeño, Eulalia y Alcalá Cortijo, Paloma. (eds). Facultad de Filosofía de la Universidad Complutense, Madrid, 2001.

Sanz Merino, Noemí. «Dona Haraway. La redefinición del feminismo a través de los estudios sociales sobre ciencia y tecnología». Eikasia. Revista de Filosofía 39 (2011).

Schiebinger, Londa. Has Feminism Changed Science? Cambridge: Harvard University Press, 2001

Unidad de Mujeres y Ciencia [UMYC]. Libro Blanco. Situación de las mujeres en la Ciencia Española. Madrid: Ministerio de Ciencia e Innovación, 2011.

Xie, Yie y Kimberlee A. Shauman. Women in Science: Career Processes and Outcomes, Cambridge/Massachusetts: Harvard University Press, 2003. 



\section{RESEÑA BIO-BIBLIOGRÁFICA DE LAS/OS COLABORADORAS/ES}

\section{Ana ACOSTA SARMIENTO}

Estudiante predoctoral en la Universidad Rovira i Virgili, donde está desarrollando su tesis doctoral sobre «Las políticas de igualdad en las universidades españolas: un estudio de análisis de redes». Máster en Política, Institucional y Comunicación Corporativa en entornos de crisis y riesgo (Universidad Rovira i Virgili 2012). Es parte del grupo de investigación Social \& Business Research Lab. Ha participado en proyectos, eventos y publicaciones sobre comunicación y salud. En el campo de la cooperación internacional fue parte del Departamento de Comunicaciones de UNICEF en Cuba (2008-2011), trabajando en temas como la infancia, adolescencia, género y participación. Participó en el Proyecto «EQUASPIN: La participación laboral de las mujeres El caso de spin-off universitarias de España.» (Ministerio de Economía y Finanzas). Sus principales líneas de investigación son: políticas de comunicación, la igualdad y la igualdad de género.

\section{Enrique ÁLVAREZ CONDE}

Catedrático de Derecho Constitucional de la Universidad Rey Juan Carlos, centro en el que dirige el Instituto de Derecho Público. Experto en derechos y libertades, cuenta desde hace un quinquenio con seis sexenios y es autor de casi un centenar de artículos, capítulos y libros sobre Derecho Constitucional, con especial atención a la Igualdad de género como valor superior del ordenamiento jurídico.

\section{Mónica ARENAS RAMIRO}

Licenciada y Doctora en Derecho por la Universidad de Alcalá (2005) con la Tesis «El derecho fundamental a la protección de datos personales en Europa» (Premio nacional AEPD (2005), Premio Doctorado (2007), y publicada por 
Tirant lo Blanch (2006). Profesora de Derecho Constitucional de la Universidad de Alcalá desde 1999, así como de diversos Másteres y Cursos. Como complemento de su actividad docente, ha participado en más de una veintena de proyectos de investigación e innovación docente, consiguiendo diversos premios en este último terreno. También ha realizado estancias de investigación en prestigiosos centros nacionales e internacionales (Alemania, Italia y Estados Unidos). Y ha desarrollado numerosas labores de gestión académica (actualmente Vocal de la Comisión de Protección de Datos de la Universidad de Alcalá e Inspectora Adjunta en la Inspección de Servicios) y ha participado en Congresos, Seminarios, e impartido Conferencias a nivel nacional e internacional.Sus principales líneas de investigación son los derechos fundamentales, la igualdad, extranjería, medios de comunicación, nuevas tecnologías, protección de datos y transparencia. Sobre ellas ha publicado numerosas obras como su monografía (2006); un artículo sobre la brecha digital de género (Anuario de la Facultad de Derecho de la Universidad de Alcalá, 2012); un Capítulo sobre el consentimiento en las redes sociales on line (Derecho y Redes Sociales, 2. ${ }^{a}$ ed., 2012); el estudio sobre el uso del burka (Anuario de Derecho Eclesiástico del Estado, 2014); el análisis del pronunciamiento del TJUE al caso Google sobre el derecho al olvido (Revista Teoría y Realidad Constitucional, 2014); un artículo sobre el Régimen jurídico de los medios de comunicación en Alemania (Revista Teoría y Realidad Constitucional, 2015); o el capítulo sobre las Causas y consecuencias de la mayoría cualificada en la Ley orgánica (Decidir por Mayoría, 2016).

\section{Manuela BALCÁZAR FINES}

Doctora en Educación por la Universidad Nacional del Este. Especialista en Gestión y Administración Educacional - DGES. Especialista en Didáctica e Investigación Universitaria, por la UNE. Especialista en Ciencias de la Educación, por la Ca Foscari de Venecia. Licenciada en Ciencias de la Educación por la Universidad Nacional de Asunción. Máster en Formación del Profesorado de Calidad por la Universidad Ca'Foscari de Venecia - Italia y la Universidad Católica de Asunción. Profesora Investigadora de la Escuela de Posgrado de la UNE y miembro del Núcleo de Investigación Mujer, Trabajo y Ciudadanía de la Escuela de Posgrado - UNE de la Red Equality, hasta el 2016. Docente de la Facultad de Filosofía de la UNE. 


\section{Luisa BASSET-SALOM}

Arquitecta por la ETSAV (especialidades de Edificación y Urbanismo) y doctora por el Departamento de Ingeniería del Terreno. Titular de Universidad imparte docencia sobre diseño y cálculo de estructuras de edificación y sobre patología y rehabilitación estructural en la Escuela Técnica Superior de Arquitectura de Valencia, tanto en el Grado como en el Máster, siendo una de sus líneas de investigación la perspectiva de género en los campos del Urbanismo, la Arquitectura y la Investigación. Constatando en primera persona la desigualdad y el machismo existentes en la UPV, y la falta de voluntad política para modificar dicha injusticia social, en 2015 se unen con el objetivo de visibilizar la situación en la que se encuentra el colectivo de mujeres PDI en la UPV.

\section{Roberta BOSISIO}

Is lecturer in Sociology and Sociology of deviance at the Department of Cultures, Politics and Society at the University of Turin. Her main research interests concern sociology of childhood, children's rights and new family forms, representations of rights and justice in children and young people, child poverty, gender studies, gender related violence. Among her publications: Children's Right to Be Heard. What Children Think (2012), «Who is in your family?» Italian Children with Non-heterosexual Parents Talk About Growing Up in a Non-conventional Household (2016, with P. Ronfani), Children and Access to Rights and Justice (2016, with J. Long).

\section{Tomás J. CAMPOY ARANDA}

Doctor en Psicopedagogía por la Universidad de Jaén (España). Licenciado en Filosofía y Ciencias de la Educación por la Universidad de La Laguna (Tenerife). Maestro Primera Enseñanza por la Escuela de Profesorado de Jaén. Máster en Psicoterapia por la Universidad de Comillas (Madrid, España). Máster en Orientación Familiar (Universidad de Navarra, España). Investigador de la Escuela de Posgrado UNE.

\section{Aurelia FLORES HERNÁNDEZ}

Ph.D Phisolophiae por la Université Laval, Québec Canadá. Se ha especializado en estudios de las mujeres rurales en el Centro Internacional MASHAV en Tel Aviv, Israel. Reconocida en el Nivel 1 del Sistema Nacional de Investigadores (SNI) del Consejo Nacional de Ciencia y Tecnología (CONACYT) y Perfil Deseable del Programa para el Desarrollo Profesional Docente (PRODEP) de 
la Secretaría de Educación Pública (SEP) de México. Profesora e investigadora de tiempo completo en Centro de Investigaciones Interdisciplinarias sobre Desarrollo Regional (CIISDER) de la Universidad Autónoma de Tlaxcala, México (UAT). Representante desde el año 2007 del Cuerpo Académico Consolidado Estudios de Género, Educación y Juventud. Autora de los libros: Marcas de género». Universidad, Educación y Violencia; A las mujeres por la «ley» no nos tocan tierras. Género, tierra, trabajo y migración en Tlaxcala; Nadie se muere por parir». Muerte Materna en Guerrero. Un programa en Perspectiva; Se van muchos y regresan pocos. Economía Política Feminista, acercamiento a la migración. Y sus recientes artículos: «Discriminación de género en el aula universitaria y en sus contornos» en Revista Ra Ximhai (2016) y «La práctica docente como herramienta para transversalizar la perspectiva de género en la UAT» en Oximora Revista Internacional de Ética y Política (2015).

\section{Aquilina FUEYO GUTIÉRREZ}

Profesora Titular de Tecnología Educativa en la Facultad de Formación del Profesorado y Educación de la Universidad de Oviedo. Durante 7 años ha sido la Decana de dicha Facultad. Desde 1988 hasta la actualidad ha desarrollado diversas actividades docentes y de investigación en las materias de Tecnología Educativa, Educación para los Medios de Comunicación, Género y Educación, Formación y enseñanza online, etc. Participa en varios Másteres oficiales y Programas de Doctorado de diferentes universidades sobre estas materias. Es profesora, entre otros, del Máster GEMA-Erasmus Mundus y del Máster Oficial Género y Diversidad de la Universidad de Oviedo. Es una investigadora activa en las áreas de Educación Mediática y Competencia Digital, Aprendizaje Virtual y Educación para el Desarrollo. Ha participado y dirigido diversos proyectos de I+D de ámbito nacional e internacional financiados en convocatorias competitivas. Así mismo, en relación con su actividad investigadora en los ámbitos señalados, ha publicado diferentes artículos en revistas indexadas y de divulgación, así como diferentes capítulos y libros sobre las temáticas señaladas entre los que cabe destacar «Los territorios de la Educación Mediática. Experiencias en el ámbito de la Educación Formal», «Hacer visible lo cotidiano a través del cine: la perspectiva de género en la Educación para el desarrollo», «Pedagogía y Cine», «Curriculum Paralalelo y Alfabetización Audiovisual Crítica», «Competencia Mediática», etc. Actualmente es la Directora del Área de Innovación Docente de la Universidad de Oviedo. 


\section{Nazareth GALLEGO-MORÓN}

Diplomada en Educación Social y Trabajo Social. Máster en Género e Igualdad y Doctoranda en el Programa Desarrollo y Ciudadanía con la tesis titulada «Techo de cristal en las Universidades Españolas». Actualmente disfruta de un contrato predoctoral de Formación del Profesorado Universitario (FPU) concedido por el Ministerio de Educación. Miembro del Observatorio GEP\&DO (Gender, Economics, Politics and Development Observatory) y del Grupo de Investigación EcoEcoFem (SEJ507) «Economía Ecológica, Feminista Y Desarrollo» de la Universidad Pablo de Olavide. Sus principales líneas de investigación giran en torno al análisis de la discriminación de género y participación de las mujeres en los mercados de trabajo, la discriminación laboral por género en ámbito universitario, los usos del tiempo, y la participación de las mujeres en la Educación Superior.

\section{Ana GARCIA-ARROYO}

Es escritora y profesora del departamento de Estudios Ingleses en la Universitat Rovira i Virgili, especializada en literaturas y culturas postcoloniales. Sus áreas habituales de trabajo son la literatura y el género en India. Durante más de 20 años ha vivido y viajado por diferentes partes de India, llevando a cabo diferentes estudios y trabajos creativos, que ha dado lugar a diferentes artículos y 8 libros, por ejemplo, una traducción, Fábulas feministas (2003); varios ensayos críticos como Alternative Sexualities in India (2006 \& 2010); Orissa, templos y tribus (2008); e Historia de las mujeres de la India (2009). En su faceta de escritora destacan, Madre India (2012); y Cuentos para educar el género (2014). Ha sido profesora invitada por diferentes universidades en India, Ecuador, España, Inglaterra y Australia.

\section{Sara GONZÁLEZ GÓMEZ}

Doctora en Ciencias de la Educación por la Universidad de Salamanca (USAL) y profesora del Departamento de Pedagogía y Didácticas específicas de la Universidad de las Islas Baleares (UIB). Es miembro del Grupo de Estudios de Historia de la Educación (IRIE/UIB) y de los grupos Ágora de Educación (Universidad de Valladolid) y Memoria y proyecto de la educación (USAL). Es coeditora de las revistas Espacio, Tiempo y Educación y Foro de Educación y pertenece al consejo de redacción de Educació i Història - Revista d'Història de l'Educació. Entre sus principales líneas de investigación se encuentran la historia de las universidades, prensa pedagógica, opinión pública sobre la educación a través de la prensa diaria y uso de la fotografía como fuente histórico-educativa. 


\section{Ana M. GONZÁLEZ RAMOS}

Investigadora sénior de la Universitat Oberta de Catalunya. Coordinadora del grupo de investigación reconocido por la Generalitat de Cataluña, GENTIC: Relaciones de género y tecnologías de la información y la comunicación en la Sociedad del Conocimiento (2014SGR1199). Ha sido profesora visitante en las universidades de Costa Rica, PREST Manchester Institute of Innovation Research (UK), Institut für Hörere Studien de Vienna (Austria), Escola de Servico Social in Universidad Católica de Pelotas (Brasil) y Department of Sociology of the Universidad de La Habana (Cuba). Ha publicado en revistas españolas (RIS, Política y Sociedad, Papers, Feminismo/s, Sociología y Tecnociencia) y extranjeras (Gender, Place and Culture; Interdisciplinary Science Reviews, Tertiary Education and Management, Papeles de Población, Géneros. Multidisciplinary Journal of Gender Studies, Business and International Management, Brussels Economic Review, International Journal of Gender, Science and Technology) entre otras.

\section{Lubi GRANADA ANGULO}

Magister en Educación Universidad Pedagógica Nacional. Licenciada en Psicología y Pedagogía Universidad Pedagógica Nacional. Cursando estudios en el Doctorado Interinstitucional en Educación (DIE)- Sede Universidad Pedagógica Nacional (UPN), énfasis de Educación, Cultura y Sociedad, grupo de investigación Equidad y Diversidad en Educación. Docente de la Secretaría de Educación Distrital, Bogotá - Colombia. Formación académica y experiencia laboral enfocada en procesos pedagógicos e investigativos en educación formal y no formal. Asesora en programas de ejercicio de acción política y educativa en grupos de mujeres y étnicos.

\section{Arianna GUARDIOLA-VÍLLORA}

Arquitecta por la ETSAV con las especialidades de Edificación y de Urbanismo. Doctora por el Departamento de Mecánica de Medios Continuos y Teoría de las Estructuras. Titular de Universidad imparte docencia relacionada con el diseño y cálculo de estructuras de edificación en la Escuela Técnica Superior de Arquitectura de Valencia. Una de sus líneas de investigación incluye la perspectiva de género en los campos del Urbanismo, la Arquitectura y la Investigación.

\section{Marcos Jesús IGLESIAS MARTÍNEZ}

Doctor en Investigación Educativa (premio extraordinario de Doctorado) y licenciado en Filosofía por la Universidad de Oviedo. Ha trabajado como 
educador y profesor de enseñanza secundaria. Actualmente es profesor contratado doctor en el área de Didáctica y Organización Escolar y secretario del departamento Didáctica General y Didácticas Específicas de la Universidad de Alicante. Es miembro y secretario del Grupo Interdisciplinar en Docencia Universitaria (GIDU) y del Instituto Universitario de Investigación de Estudios de Género. Desde un enfoque cualitativo sus líneas de investigación están orientadas en los diseños de procesos educativos, formación inicial del profesorado y practicum, desarrollo profesional docente, género y diversidad, en los distintos niveles del sistema educativo.

\section{Lorena JIMÉNEZ MONTES}

Maestra en Análisis Regional y Licenciada en Ciencias para el Desarrollo Humano por la Universidad Autónoma de Tlaxcala. Realizó una Estancia de Movilidad en el Instituto de Investigaciones Gino Germani de la Universidad de Buenos Aires, Argentina. Ha sido becaria del Consejo Nacional de Ciencia y Tecnología (CONACYT-México), ponente en foros académicos nacionales e internacionales tales como el Primer Coloquio Internacional y Tercero Nacional sobre Violencia, Actores y Enemigos del Estado. Actualmente labora en el diseño y la capacitación para la formación docente en contacto con personas con necesidades especiales de la Secretaría de Educación Pública (SEP) del estado de Tlaxcala, México.

\section{Inés LOZANO CABEZAS}

Doctora en Investigación Educativa: Desarrollo Curricular y Profesional (premio extraordinario de Doctorado). Ha sido colaboradora en el Proyecto de Redes dedicado a la investigación en docencia universitaria en el Instituto de Ciencias de la Educación de la Universidad de Alicante. Actualmente, vicedecana de Educación Infantil en la Facultad de Educación y profesora contratada doctora el Departamento de Didáctica General y Didácticas Específicas de la Universidad de Alicante. Es miembro del Grupo Interdisciplinar en Docencia Universitaria (GIDU) y del Instituto Universitario de Investigación de Estudios de Género (IUIEG). Sus líneas de investigación se centran en los diseños de procesos educativos, formación inicial del profesorado, desarrollo profesional docente, género y diversidad, en los distintos niveles del sistema educativo. En este último punto defendió su tesis doctoral bajo el título «El discurso de la igualdad de las académicas: estudio de caso en la Universidad de Alicante». 


\section{Estrella MONTES LÓPEZ}

Investigadora FPI del Departamento de Sociología y Comunicación de la Universidad de Salamanca. Diplomada en Trabajo Social, Licenciada en Sociología y Máster en Servicios Públicos y Políticas Sociales por la Universidad de Salamanca. Sus líneas de investigación se centran en el estudio de las organizaciones, del mercado de trabajo y de las relaciones de género, atendiendo especialmente a la dificultad de acceso de la mujer a las posiciones altas en el ámbito laboral, público y privado. Paralelamente está interesada en la historia de las Mujeres, en el estudio de la identidad y en la investigación en derechos de la infancia. Sobre estos temas tiene diversas publicaciones y ha realizado múltiples ponencias en congresos nacionales e internacionales, además de en otros espacios, como el Parlamento Europeo.

\section{Elena NAVARRO-ASTOR}

Licenciada en Ciencias Económicas y Empresariales por la UV, especialidad en ciencias económicas, y doctora en organización de empresas por la Universitat Politècnica de Valéncia. Titular de Universidad, imparte docencia sobre Economía y Gestión de Recursos Humanos en la Escuela Técnica Superior de Ingeniería de Edificación y en la Escuela Técnica Superior de Arquitectura de Valencia, a nivel de grado y de máster. Estando sensibilizada con la igualdad de género, ha incorporado la perspectiva de género a sus investigaciones que se han centrado en el mercado laboral de la construcción y de la arquitectura, sectores tradicionalmente muy masculinizados en los que la mujer ha sido históricamente invisible y discriminada. También ha dirigido varios Trabajos Fin de Grado y de Máster con perspectiva de género.

\section{Laura NUÑO GÓMEZ}

Profesora titular de la Universidad Rey Juan Carlos, centro en el que dirige el Observatorio de Igualdad, la Cátedra de Género del Instituto de Derecho Público y el Grado en Igualdad de Género. Miembro, en calidad de directora del observatorio, de la Unidad de Igualdad de la URJC. Puso en marcha el máster de estudios Interdisciplinares de igualdad que dirigió con Ana de Miguel hasta su extinción. Miembro de la comisión de doctorado del programa interuniversitario «Estudios Interdisciplinares de Género», del equipo de dirección del título propio «Género y políticas de igualdad entre mujeres y hombres», del Consejo Asesor de la Fundación Primero de Mayo y del Consejo Estatal de Participación de la Mujer (en calidad de experta). Ha participado como vocal en comisiones 
de reacreditación de grados y másteres (verifica) de la AVAP. Ha publicado más de medio centenar de artículos, capítulos y libros sobre género y feminismo.

\section{María Inmaculada PASTOR GOSÁLBEZ}

Profesora de Sociología de la Universitat Rovira i Virgili y directora del Observatorio de la Igualdad de esta universidad. Es doctora en Sociología por la Universitat Autònoma de Barcelona y miembro de Social \& Bussiness Research Laboratory de la Universitat Rovira i Virgili. En estos momentos dirige una red internacional de universidades europeas y latinoamericanas para impulsar la docencia en políticas de igualdad, la red Jean Monnet G-NET, Equality training network: EU contributions to gender mainstreaming and citizenship, financiada por el Programa Erasmus+. Ha sido la coordinadora del equipo español del proyecto EQUALITY-Strengthening Women Leadership in Latin American HEI's and Society, financiado por la Comisión Europea dentro del Programa Alfa III (2011-2014) y la coordinadora del módulo Jean Monnet Integración europea y género entre 2011 y 2014. Dentro del Plan Nacional I+D+i ha dirigido proyectos como «La participación laboral de las mujeres. El caso de las spin-off universitarias en España (2012-2014)» y «Mujeres en la sanidad: trayectorias profesionales y acceso a cargos de responsabilidad». También ha participado en diversos congresos nacionales e internacionales con un centenar de ponencias y comunicaciones y ha publicado más de 70 contribuciones entre artículos en revistas, libros y capítulos de libros.

\section{Andrés PAYÀ RICO}

Profesor Contratado Doctor (acreditado a Titular de Universidad) y Director del Departamento de Educación Comparada e Historia de la Educación de la Universidad de Valencia. Profesor consultor de la Universitat Oberta de Catalunya (UOC). Coeditor de las revista Espacio, Tiempo y Educación y miembro del consejo de redacción de Educació i Història. Revista d'Història de l'Educació. Sus líneas de investigación se han centrado en torno a la historia de la educación española contemporánea, historia y memoria de la educación valenciana, el juego y la educación, así como la didáctica e innovación educativa en historia de la educación.

\section{Paloma PONTÓN MERINO}

Doctora en Sociología (Universidad Rovira i Virgili de Tarragona). Licenciada en Periodismo (Universitat Autònoma de Barcelona, 2007) y Máster en Antropología Urbana (Universitat Rovira i Virgili, 2010). Su tesis doctoral 
«Igualdad de género y organizaciones. Una evaluación de los contenidos de género en la negociación colectiva de las industrias químicas del sur de Cataluña» fue dirigida por la Dra. Inma Pastor y recibió una puntuación de Excelente Cum Laude. Ha trabajado desde 2007 en diferentes universidades catalanas, en áreas relacionadas con la documentación, la historia, la memoria oral, la igualdad de género y las políticas de género. Ha formado parte de los equipos de investigación de diversos proyectos competitivos nacionales y europeos. Actualmente trabaja en la gestión de un proyecto Horizonte 2020 (MSCA), es parte del grupo de investigación Social \& Business Research Lab, y colaboradora del Observatorio de la Igualdad de Género de la URV.

\section{Helena RAUSELL GUILLOT}

Doctora en Geografía e Historia por la Universitat de Valencia (1999). Ha recibido el Premio Extraordinario de Licenciatura (1996), el Premio Extraordinario de Doctorado (2000) y el Premio Nacional de Terminación de Estudios Universitarios del Ministerio de Educación (1996). Ha realizado diferentes estancias de investigación en la École des Hautes Études des Sciènces de l’Homme de París y en las Universidades de Viena y Estrasburgo. Es autora de diferentes publicaciones de historia y de didáctica de las ciencias sociales. En la actualidad es docente en la Facultad de Magisterio y profesora en el Master de Formación del Profesorado de Secundaria.

\section{Emanuela SALA}

Is an associate professor at the University of Milano-Bicocca, where she teaches Research Methods and Questionnaire Design. She is currently one of the vice-presidents of the Research Committee 33, Logic and Methodology of the International Sociological Association and is one of the board members of the International Journal of Social Research Methodology. Her research interests mainly focus on the accuracy of pre-electoral polls, different aspects of measurement error in longitudinal studies, gender studies, and women's career in science.

\section{Marta TALAVERA ORTEGA}

Licenciada en Ciencias Biológicas por la Universitat de Valencia (1999) y doctora de Didáctica de las Ciencias Experimentales (2008). Cuenta con una amplia trayectoria en el ámbito de las Ciencias Básica y la Salud, así como en la investigación en género y violencia y en formación de profesorado y personal docente sobre estas temáticas. Actualmente es docente en la Facultad de 
Magisterio y profesora en diferentes cursos, masters y postgrados de especialización en temas de Mediación Docente, Violencia de género, Formación del Profesorado y Salud.

\section{Marina TOMÁS-FOLCH}

Maestra, licenciada en Pedagogía y Doctora en Ciencias de la Educación por la Universidad de Barcelona. Ha escrito numerosos libros y artículos en revistas españolas e internacionales. Profesora Titular de la Universidad Autónoma de Barcelona. Acreditada Catedrática por ANECA en 2011. Dirige desde 1999 el equipo de Gestión del cambio que ha llevado a cabo diferentes investigaciones regionales, nacionales y europeas sobre el liderazgo, el género, la innovación y el cambio de cultura en la Universidad. Respecto a los estudios de género llevados a cabo han recibido el soporte del Instituto de la Mujeres y del Institut de les dones además de AGAUR. Coordina el libro La Universidad vista desde el punto de vista del género Ed. Octaedro que compila diversos estudios sobre género que ha dirigido o en los que ha participado. Forma parte de la comisión asesora del Observatorio de género de su universidad

\section{Esther TORRADO MARTÍN-PALOMINO}

Profesora-investigadora de la ULL. Departamento de Sociología y Antropología. Miembro del IUEM (Instituto Universitario de Estudios de las Mujeres). Miembro del grupo de investigación «Género, ciudadanía y culturas. Aproximación desde la teoría feminista. Licenciada en Ciencias Políticas y Sociología. Doctora en Sociología. Formación Especializada en Sociología del Género: Migraciones, Explotación Sexual y Trayectorias Científicas. Participante en proyectos de investigación nacionales I+D sobre Género, migraciones y tráfico y trata de seres humanos y en proyectos de investigación nacionales e internacionales I+D sobre trayectorias científicas y género

\section{Viviana VEGA DUETTE}

Abogada y Especialista en Ciencias Políticas por la Universidad Nacional del Este. Miembro del Núcleo de Investigación «Mujer, Trabajo y Ciudadanía» de la Escuela de Posgrado de la UNE, hasta el año 2015. Docente de la Carrera de Derecho y Encargada de la Dirección de Evaluación y Gestión de Calidad de la Facultad de Derecho y Ciencias Sociales de la misma Universidad. 



\section{CÓMO PRESENTAR UN ORIGINAL}

1. Los trabajos serán el resultado de una investigación original y deberán contener conclusiones novedosas apoyadas en una metodología debidamente planteada y justificada. Sólo se admitirán trabajos inéditos que no estén en proceso de evaluación por otras revistas.

2. La extensión de los trabajos presentados no excederá de 9000 palabras, incluidas notas y bibliografía.

3. El número y extensión de las notas al pie se reducirá a lo indispensable.

4. Los autores someterán sus artículos en Word a través del correo electrónico de la revista (revistafeminismos@ua.es) y deberán aportar imprescindiblemente:

- Título del trabajo.

- Nombre del autor o de la autora, institución a la que pertenece, dirección profesional completa y dirección electrónica.

- Archivo del texto en formato Word, omitiendo el nombre del autor o autora, con:

- El título en español y en inglés.

- Un resumen de unas 150 palabras en español, y su correcta versión inglesa. Este resumen deberá atenerse al siguiente esquema: objetivos del trabajo, metodología y conclusiones o tesis.

- Cinco palabras-clave en español, y su correcta versión inglesa.

- El texto del original.

- Un breve C.V. (como máximo 300 palabras).

5. Los trabajos se someterán a un proceso de selección y evaluación anónimo y por pares, según el procedimiento y los criterios hechos públicos por la revista. 


\section{NORMAS EDITORIALES Y ESTILO DE LA REVISTA FEMINISMO/S}

1. Los artículos estarán redactados en Word con letra Times New Roman, tamaño de 12 puntos y con un interlineado de un espacio y medio.

2. La extensión no excederá de 9000 palabras, incluidas notas y bibliografía.

3. La primera línea de cada párrafo irá sangrada.

4. Las notas, que deberán reducirse a lo indispensable y se utilizarán sólo para información suplementaria, serán a pie de página, con letra de 10 puntos e interlineado sencillo. La llamada en el texto irá antes del signo de puntuación.

5. Las referencias bibliográficas irán entre paréntesis en el texto del artículo, no en las notas, siguiendo las siguientes indicaciones:

5.1. Referencia a una idea de un autor/a cuyo nombre no se cita expresamente en el texto:

- «En la cultura renacentista y humanística italiana este debate sobre los sexos tuvo una muy especial viveza» (Blanco 265).

- El debate sobre los sexos fue muy vivo en la cultura del Renacimiento y del Humanismo italianos (Blanco 265).

No se pone coma [,] entre el nombre y el número de página.

5.2. Referencia a una idea de un autor cuyo nombre sí se cita en el texto:

- Según Moi, «la obra de Kristeva no se puede considerar fundamentalmente feminista» (174).

5.3. Si el autor solo tiene una obra citada, no se incluye el año de edición.

5.4. Si se menciona más de una obra de un mismo autor, inclúyase la fecha de edición de cada una, detrás del nombre. Debe insertarse una coma [,] SOLAMENTE entre el año y la página:

- «En la cultura renacentista y humanística italiana este debate sobre los sexos tuvo una muy especial viveza» (Blanco 1997, 265).

5.5. Empleen «ver» o «Ver». No empleen «cfr.», «véase», «vid.» o «comp.». En ningún caso se emplean indicaciones como «op. cit.», «art. cit.», «loc. cit.», «id.», «ibid.», «supra», «infra», «passim», «et alii». 
6. Las citas extensas (cuatro o más líneas) se destacan del texto mediante un párrafo sangrado. No se usan comillas. El punto irá en este caso delante del paréntesis que contiene la referencia bibliográfica y no después.

7. Los diferentes apartados del texto se ordenarán siguiendo la numeración arábiga $(1,2,3, \ldots)$ y el título de cada uno de ellos irá en letra mayúscula y en negrita. Los subapartados se enumerarán de la siguiente manera: 1.1, 1.2, 1.3, etc. y sus títulos irán en minúscula y en negrita.

8. Las fotografías e imágenes deben entregarse en formato digital, separadas del texto, en formato tif, con una calidad de 300 puntos por pulgada. Deben ir identificadas convenientemente según sean citadas en el texto.

9. Lista de obras citadas:

9.1. Las entradas bibliográficas aparecerán al final del documento, ordenadas alfabéticamente y con sangría francesa.

9.2. Los nombres de los autores y editores se darán completos, y nunca en mayúsculas.

9.3. Al incluir una obra de varios autores, solo en el primero se hace preceder el apellido.

9.4. Cuando se incluye más de una obra de un mismo autor, se ordenan cronológicamente; en todos los casos se hace constar el nombre del autor.

9.5. En las revistas, el número de volumen y fascículo se dará siempre con caracteres arábigos.

9.6. Cada entrada se organizará de la siguiente manera:

\section{A. LIBROS}

- Con un/a solo/a autor/a o editor/a: Apellido, Nombre. Título del libro en cursiva. Edición utilizada. Número de volúmenes [si más de uno]. Nombre de la serie o colección [si procede]. Lugar de publicación: Nombre de la editorial, Fecha de publicación.

Bloom, Harold. Poetry and Repression: Revision from Blake to Stevens. New Haven: Yale University Press, 1976.

Moi, Toril (ed.). The Kristeva Reader. Oxford: Blackwell Publishers, 1986.

- Con varios/as autores/as o editores/as: Apellidos, Nombre, y Nombre Apellidos. Título en cursiva. Ciudad: Editorial, año. 
Anderson, Bonnie, y Judith P. Zinsser. Historia de las mujeres: una historia propia. 2 vols. Barcelona: Crítica, 1991.

Perrot, Michelle, y Georges Duby (eds.). Historia de las mujeres. Madrid: Taurus, 1991.

\section{B. ARTÍ́CULOS}

- Con un/a solo/a autor/a: Apellidos, Nombre. «Título». Revista en cursiva n. ${ }^{\circ}$ volumen en arábigo. Fascículo en arábigo (año): páginas (sin p./pp.).

Valcárcel, Amelia. «El primer ensayo feminista de una teoría del poder». Panorama 9 (1990): 59-64.

Vogel, Lisa. «Erotica, the Academy and Art Publishing: A Review of Woman as Sex Object. Studies in Erotic Art, 1730-1970, New York, 1972». Art Journal 35.4 (1976): 378-385.

- Con varios/as autores/as: Apellidos, Nombre, y Nombre Apellidos. «Título». Revista en cursiva n. ${ }^{\circ}$ volumen en arábigo. Fascículo en arábigo (año): páginas (sin p./pp.).

López-Zafra, Esther y Rocío García Retamero. «Mujeres y liderazgo: ¿discapacitadas para ejercer el liderazgo en el ámbito público?». Feminismo/s 13 (2009): 85-104.

C. COLABORACIÓN EN LIBRO COLECTIVO: Apellido del autor/ de la autora, Nombre del autor/ de la autora. "Título de la colaboración». Título del libro en cursiva. Ed./Eds. Nombre y apellidos del editor o de la editora. Edición utilizada. Número de volumen [si más de uno]. Lugar de publicación: Nombre de la editorial, fecha de publicación. Páginas.

Smith-Rosenberg, Carroll. «Writing History: Language, Class and Gender». Feminist Studies. Ed. Teresa de Lauretis. Bloomington: Indiana University Press, 1986, 31-54.

\section{TÍTULOS DE LIBROS CON VARIOS VOLÚMENES}

- Si cada volumen tiene un título propio, se hará constar así:

Díaz-Diocaretz, Myriam, e Iris M. Zavala (coords.). Breve historia feminista de la literatura española (en lengua castellana), I: Teoría feminista: discursos y diferencias. Barcelona: Anthropos, 1993. 
- Si cada volumen no tiene título propio:

Pardo Bazán, Emilia. Obras completas. Vol. 2. Ed. Federico Carlos Sainz de Robles. Madrid: Aguilar, 1957.

E. CITAS DE PRENSA: Apellido del autor, Nombre del autor. "Título del trabajo». Nombre del periódico en cursiva [caso de que no sea universalmente conocido: Ciudad, País] Día Mes Año: páginas.

Lara, Fernando. «Victoria Kent, una mujer de suerte». Triunfo, 22 octubre 1977: 62.

F. PUBLICACIÓN EN INTERNET: Apellido del autor, Nombre del autor. «Título del trabajo». Nombre de la publicación en cursiva Volumen. Número (Año): páginas [si tiene]. Fecha de acceso.

Safa Barraza, Patricia, y Juan Manuel Ramírez Sáiz. «Deterioro urbano y calidad de vida en las grandes urbes: la participación de las mujeres en las organizaciones vecinales». La ventana 54 (2011): 110-145. 20 de abril de 2015.

G. Las WEBS se citarán de acuerdo al siguiente modelo:

<http://www.cis.es/cis/opencms/ES/2_barometros>, consultado el 19-06-2008

\section{CÓMO PROPONER UN MONOGRÁFICO}

La propuesta de un monográfico para la revista Feminismo/s se hará llegar a la directora de la revista (Helena.Establier@ua.es) y contendrá la siguiente información:

1. Título provisional del monográfico.

2. Un C.V. completo de la coordinadora/del coordinador (o de las coordinadoras/los coordinadores) del mismo.

3. Una descripción de sus objetivos y una justificación de la oportunidad del tema propuesto (300 palabras). 
4. Un listado provisional de participantes en el volumen, acompañado de una breve reseña bio-bibliográfica de cada una/uno de ellas/os y de los títulos de los trabajos previstos (a ellos se sumarán posteriormente aquellos recibidos a través del call for papers y que superen, como los anteriores, el proceso de evaluación de la revista).

5. Las propuestas serán consideradas por el Consejo de Redacción de Feminismo/s en el plazo máximo de un mes a partir de la fecha de recepción de las mismas.

\section{PROCESO DE EVALUACIÓN}

1) Los originales recibidos son valorados, en primera instancia, por el Consejo de Redacción de la revista para decidir sobre su adecuación a las áreas de conocimiento y a los requisitos que la revista ha publicado para los/las autores/as.

2) El Consejo de Redacción envía los originales, sin el nombre del autor o de la autora, a dos revisores/as externos/as al Consejo Editorial, quienes emiten su informe en un plazo máximo de seis semanas. Sobre esos dictámenes, el Consejo de Redacción decide rechazar o aceptar el artículo o solicitar modificaciones al autor o autora del trabajo. Los/las autores/as reciben una notificación detallada y motivada donde se expone, retocado, el contenido de los informes originales, con indicaciones concretas para la modificación si es el caso. Feminismo/s puede enviar a los/las autores/as los informes originales recibidos, íntegros o en parte, siempre de forma anónima. En el caso de discrepancia en los informes de evaluación, la revista se reserva el derecho de someter el trabajo a la valoración de la Coordinadora/del Coordinador del volumen y del Consejo de Redacción, o de solicitar una tercera evaluación del mismo.

3) El informe emitido por los/las revisores/as incluye:

a) una valoración global del artículo y de los resúmenes.

b) una valoración cuantitativa de la calidad (buena | aceptable | insuficien-

te) según estos cinco criterios: originalidad e interés del tema; pertinencia en relación con las investigaciones actuales en el área; rigor metodológico y articulación expositiva; bibliografía significativa y actualizada; pulcritud formal y claridad de discurso.

c) una recomendación final: publicar | solicitar modificaciones | rechazar. 


\section{COBERTURA, DIFUSIÓN Y PRESENCIA EN BASES DE DATOS}

La revista está indizada en las bases de datos ISOC (Base de datos del Centro de Información y Documentación Científica del CSIC), ERIH PLUS (European Reference Index for the Humanities and Social Sciencies), MLA (Modern Language Association), CIRC, DICE, MIAR, Latindex, Dialnet.

\section{PRINCIPIOS ÉTICOS DE PUBLICACIÓN}

La publicación de artículos en una revista con revisión por pares es un reflejo directo de la calidad del trabajo de sus autoras/es, y del compromiso y cualificación de los investigadoras/es que actúan como revisoras/es. Por ello Feminismo/s es una publicación comprometida con los principios éticos de la actividad científica en los siguientes términos:

\section{Publicación y autoría}

Todos los artículos deben incluir un listado de referencias, así como indicar si han recibido apoyo económico. Los trabajos deben estar libres de plagio o fraude científico, cuyos supuestos* se enumeran de manera no exhaustiva a continuación:

- Plagio: copia literal sin entrecomillar y citar la fuente; copia sustancial (materiales de investigación, procesos, tablas...); parafrasear o reproducir ideas sin citar la fuente y/o cambiando el significado original; reutilizar y enviar textos propios ya publicados sin indicar la fuente y el parafraseo abusivo incluso citando la fuente.

- Fraude científico: no reconocimiento de todas/os las/los investigadoras/es participantes en la elaboración del trabajo, el envío simultáneo a varias publicaciones, la división de un trabajo en partes diferentes que comparten las mismas hipótesis, población y métodos, así como la utilización de datos falsos o no probados. Finalmente, las/los autoras/es deben declarar a la revista los potenciales conflictos de interés cuando envían un trabajo.

* Fuente: http://www.ethics.elsevier.com/ 


\section{Responsabilidad de las/los autoras/es}

- El envío de trabajos a Feminismos/s supone la lectura y aceptación de las normas editoriales y de publicación de la revista, incluida la participación en un proceso anónimo de evaluación por pares.

- Todas/os las/los autoras/es que firman un trabajo deben haber contribuido de manera significativa a su elaboración y deben estar de acuerdo con el resultado final y con el envío del trabajo para su evaluación.

- Los trabajos deben reconocer a todas/os las/los autoras/ que han participado en su elaboración.

- Los datos utilizados en el artículo deben ser reales y auténticos.

- Las/los autoras/es asumen la obligación de corregir y/o retractarse ante posibles errores detectados posteriormente.

- Los artículos han de ser inéditos y no pueden ser enviados simultáneamente a ninguna otra publicación.

\section{Proceso de revisión}

Todos los artículos enviados a la revista se someten a un proceso de revisión por pares con las siguientes características:

- La selección de los revisores se realiza en función de normas y principios previos basados tanto en su cualificación como en la calidad de su producción científica.

- El proceso de revisión será totalmente anónimo tanto para las/ los autoras/es como para las/los revisoras/es. Los artículos y sus revisiones serán tratados confidencialmente.

- Las/los revisoras/es consideran, entre sus criterios de evaluación, el respeto a los principios éticos esenciales en la investigación científica.

- Los juicios expresados en las revisiones deben ser objetivos.

- Tanto autoras/es como revisoras/es deben revelar las relaciones y fuentes de financiación que puedan generar potenciales conflictos de intereses.

\section{Responsabilidades de las editoras/editores}

- El equipo editorial tiene la responsabilidad y la autoridad para aceptar o rechazar un artículo basándose en las revisiones.

- El equipo editorial revelará en su caso las relaciones o fuentes de financiación que puedan ser potencialmente consideradas como conflictos de intereses respecto a los artículos que rechaza o acepta. 
- Sólo se aceptarán los artículos en los que existe una evidencia cierta sobre el cumplimiento de las normas editoriales.

- El Consejo de Redacción de Feminismo/s se reserva el derecho de retirar cualquier trabajo recibido, aceptado o ya publicado en caso de constatarse plagio, falsificación o publicación duplicada, así como los diversos supuestos de fraude científico anteriormente enumerados. Del mismo modo, promoverá la publicación de correcciones o retractaciones frente a errores detectados.

- El equipo editorial se compromete a preservar el anonimato de las/ los revisoras/revisores de manera que nunca puedan asociarse con los artículos revisados.

\section{Cuestiones éticas de publicación}

El equipo editorial se compromete a:

- Vigilar y preservar los principios éticos de publicación.

- Mantener la integridad del expediente académico.

- Evitar la publicación de material plagiado o elaborado de manera fraudulenta.

- Estar abierto a la publicación de correcciones, clarificaciones, retractaciones y disculpas siempre que sea necesario.

- Ofrecer apoyo en el proceso de retractación de artículos.

- Realizar todas las acciones necesarias para cumplir los estándares de compromiso intelectual y ético.

\section{Aviso legal}

A efectos de lo estipulado en los artículos 138-143 de la Ley de Propiedad Intelectual, la publicación de un trabajo que atente contra dichos derechos será responsabilidad del autor/a. El equipo editorial de Feminismo/s no se hace responsable, en ningún caso, de la credibilidad y autenticidad de los trabajos. Del mismo modo, las opiniones y hechos expresados en cada artículo son de exclusiva responsabilidad de sus autoras/es y Feminismo/s no se identifica necesariamente con ellos. 


\section{CÓMO OBTENER LA REVISTA}

La revista se vende a un precio de 12 euros a través del Servicio de Publicaciones de la Universidad de Alicante

\section{Ventas:}

Teléfono: 965909445

Fax: 965909445

E-Mail: Publicaciones.Ventas@ua.es

La revista mantiene intercambios con publicaciones pertenecientes a otras instituciones académicas y/o investigadoras, españolas y extranjeras. 


\section{COM PRESENTAR UN ORIGINAL}

1. Els treballs seran el resultat d'una investigació original i hauran de contenir conclusions noves recolzades en una metodologia plantejada i justificada degudament. Només s'admetran treballs inèdits que no estiguen en procés d'avaluació per altres revistes.

2. L'extensió dels treballs presentats no excedirà de 9000 paraules, inclosent-hi notes i bibliografia.

3. El nombre i extensió de les notes al peu es reduirà a l'indispensable.

4. Els autors sotmetran els seus articles en Word a través del correu electrònic de la revista (revistafeminismos@ua.es) i hauran d'aportar imprescindiblement:

- Títol del treball.

- Nom de l'autor o de l'autora, institució a la qual pertany, adreça professional completa i adreça electrònica.

- Arxiu del text en format Word, que no continga el nom de l'autor o autora, amb:

- El títol en espanyol i en anglès.

- Un resum d'unes 150 paraules en espanyol, i la seua correcta versió anglesa. Aquest resum haurà d'atenir-se a l'esquema següent: objectius del treball, metodologia i conclusions o tesis.

- Cinc paraules clau en espanyol, i la seua correcta versió anglesa.

- El text de l'original.

- Un breu CV (com a màxim 300 paraules).

5. Els treballs se sotmetran a un procés de selecció i avaluació anònim i per experts, segons el procediment i els criteris fets públics per la revista. 


\section{NORMES EDITORIALS I D'ESTILS}

1. Els articles estaran redactats en Word amb lletra Times New Roman, mida de 12 punts i amb un interlineat d'un espai i mig.

2. L'extensió no excedirà de 9000 paraules, incloent-hi notes i bibliografia.

3. La primera línia de cada paràgraf anirà sagnada.

4. Les notes, que s'hauran de reduir a l'indispensable i s'utilitzaran només per a informació suplementària, seran a peu de pàgina, amb lletra de 10 punts i interlineat senzill. La crida en el text anirà abans del signe de puntuació.

5. Les referències bibliogràfiques aniran entre parèntesis en el text de l'article, no en les notes, seguint les indicacions següents:

5.1. Referència a una idea d'un autor/a el nom del/la qual no se cita expressament en el text:

- «En la cultura renacentista y humanística italiana este debate sobre los sexos tuvo una muy especial viveza» (Blanco 265).

- El debate sobre los sexos fue muy vivo en la cultura del Renacimiento y del Humanismo italianos (Blanco 265).

No es posa coma [,] entre el nom i el número de pàgina.

5.2. Referència a una idea d'un autor el nom del qual sí se cita en el text:

- Según Moi, «la obra de Kristeva no se puede considerar fundamentalmente feminista» (174).

5.3. Si l'autor solament té una obra citada, no s'inclou l'any d'edició.

5.4. Si se cita més d'una obra d'un mateix autor, cal incloure la data d'edició de cadascuna, darrere del nom. Ha d'inserir-se una coma [,] SOLAMENT entre l'any i la pàgina:

- «En la cultura renacentista y humanística italiana este debate sobre los sexos tuvo una muy especial viveza» (Blanco 1997, 265).

5.5. Utilitzeu «ver» o «Ver». No empren «cfr.», «véase», «vid.» o «comp.». En cap cas s'usen indicacions com «op. cit.», «art. cit.», «loc. cit.», «id.», «ibid.», «supra», «infra», «passim», «et alii». 
6. Les cites extenses (quatre o més línies) es destaquen del text mitjançant un paràgraf sagnat. No s'usen cometes. El punt anirà en aquest cas davant del parèntesi que conté la referència bibliogràfica i no després.

7. Els diferents apartats del text s'ordenaran seguint la numeració aràbiga $(1,2,3, \ldots)$ i el títol de cadascun anirà en lletra majúscula i en negreta. Els subapartats s'enumeraran de la manera següent: 1.1, 1.2, 1.3, etc. i els seus títols aniran en minúscula i en negreta.

8. Les fotografies i imatges s'han de lliurar en format digital, separades del text, en format tif, amb una qualitat de 300 punts per polzada. Han d'estar identificades convenientment segons siguen citades en el text.

9. Llista d'obres citades:

9.1. Les entrades bibliogràfiques apareixeran al final del document, ordenades alfabèticament i amb sagnat francès.

9.2. Els noms dels autors i editors es donaran complets, i mai en majúscula.

9.3. Quan s'incloga una obra de diversos autors, solament en el primer es fa precedir el cognom.

9.4. Quan s'inclou més d'una obra d'un mateix autor, s'ordenen cronològicament; en tots els casos es fa constar el nom de l'autor.

9.5. En les revistes, el número de volum i fascicle es donarà sempre amb caràcters aràbics.

9.6. Cada entrada s'organitzarà de la manera següent:

\section{A. LLIBRES}

- Amb únic/a autor/a o editor/a: Cognom, Nom. Títol del llibre en cursiva. Edició utilitzada. Número de volums [si més d'un]. Nom de la sèrie o collecció [si escau]. Lloc de publicació: Nom de l'editorial, data de publicació.

Bloom, Harold. Poetry and Repression: Revision from Blake to Stevens. New Haven: Yale University Press, 1976.

Moi, Toril (ed.). The Kristeva Reader. Oxford: Blackwell Publishers, 1986.

- Amb diversos/es autors/es o editors/es: Cognoms, Nom, i Nom Cognoms. Títol en cursiva. Ciutat: Editorial, any. 
Anderson, Bonnie, y Judith P. Zinsser. Historia de las mujeres: una historia propia. 2 vols. Barcelona: Crítica, 1991.

Perrot, Michelle, y Georges Duby (eds.). Historia de las mujeres. Madrid: Taurus, 1991.

\section{B. ARTICLES}

- Amb un/a únic/a autor/a: Cognoms, Nom. «Títol». Revista en cursiva núm. Volum en aràbic. Fascicle en aràbic (any): pàgines (sense p./pàg.).

Valcárcel, Amelia. «El primer ensayo feminista de una teoría del poder». Panorama 9 (1990): 59-64.

Vogel, Lisa. «Erotica, the Academy and Art Publishing: A Review of Woman as Sex Object. Studies in Erotic Art, 1730-1970, New York, 1972». Art Journal 35.4 (1976): 378-385.

- Amb diversos/es autors/es: Cognoms, Nom, i Nom Cognoms. «Títol». Revista en cursiva núm. volum en aràbic. Fascicle en aràbic (any): pàgines (sense p./pàg.).

López-Zafra, Esther y Rocío García Retamero. «Mujeres y liderazgo: ¿discapacitadas para ejercer el liderazgo en el ámbito público?». Feminismo/s 13 (2009): 85-104.

C. COL·LABORACIÓ EN LLIBRE COL.LECTIU: Cognom de l'autor o de l'autora, Nom de l'autor o de l'autora. «Títol de la col-laboració». Títol del llibre en cursiva. Ed./Eds. Nom i cognoms de l'editor o de l'editora. Edició utilitzada. Número de volum [si més d'un]. Lloc de publicació: Nom de l'editorial, data de publicació. Pàgines.

Smith-Rosenberg, Carroll. «Writing History: Language, Class and Gender». Feminist Studies. Ed. Teresa de Lauretis. Bloomington: Indiana University Press, 1986, 31-54.

\section{TÍTOLS DE LLIBRES AMB DIVERSOS VOLUMS}

- Si cada volum té un títol propi, es farà constar així:

Díaz-Diocaretz, Myriam, e Iris M. Zavala (coords.). Breve historia feminista de la literatura española (en lengua castellana), I: Teoría feminista: discursos y diferencias. Barcelona: Anthropos, 1993. 
- Si cada volum no té títol propi:

Pardo Bazán, Emilia. Obras completas. Vol. 2. Ed. Federico Carlos Sainz de Robles. Madrid: Aguilar, 1957.

E. CITES DE PREMSA: Cognom de l'autor, Nom de l'autor. «Títol del treball». Nom del periòdic en cursiva [cas que no siga universalment conegut: Ciutat, País] dia mes any: pàgines

Lara, Fernando. «Victoria Kent, una mujer de suerte». Triunfo, 22 octubre 1977: 62 .

F. PUBLICACIÓ EN INTERNET: Cognom de l'autor, Nom de l'autor. «Títol del treball». Nom de la publicació en cursiva Volum. Número (Any): pàgines [si en té]. Data d'accés.

Safa Barraza, Patricia, y Juan Manuel Ramírez Sáiz. «Deterioro urbano y calidad de vida en las grandes urbes: la participación de las mujeres en las organizaciones vecinales ». La ventana 54 (2011): 110-145. 20 de abril de 2015.

G. Les WEBS se citaran d'acord amb el model següent: $<$ http://www.cis.es/cis/opencms/ES/2_barometros>, consultado el 19-06-2008.

\section{COM PROPOSAR UN MONOGRÀFIC}

La proposta d'un monogràfic per a la revista Feminismo/s es farà arribar a la directora de la revista (Helena.establier@ua.es) i contindrà la informació següent:

1. Títol provisional del monogràfic.

2. Un CV complet de la coordinadora o del coordinador (o de les coordinadores o coordinadors) del monogràfic.

3. Una descripció dels objectius i una justificació de l'oportunitat del tema proposat (tres-centes paraules). 
4. Una llista provisional de participants en el volum, acompanyat d'una breu ressenya biobibliogràfica de cadascun o cadascuna i dels títols dels treballs previstos (als quals se sumaran posteriorment els rebuts a través de la convocatòria de comunicacions i que superen, com els anteriors, el procés d'avaluació de la revista).

5. Les propostes seran considerades pel Consell de Redacció de Feminismo/s en el termini màxim d'un mes a partir de la data de recepció.

\section{PROCÉS D'AVALUACIÓ}

1) Els originals rebuts són valorats, en primera instància, pel Consell de Redacció de la revista per a decidir sobre l'adequació a les àrees de coneixement $\mathrm{i}$ als requisits que la revista ha publicat per als autors o autores.

2) El Consell de Redacció envia els originals, sense el nom de l'autor o de l'autora, a dos revisors o revisores externs al Consell Editorial, els quals emeten el seu informe en un termini màxim de sis setmanes. Sobre aquests dictàmens, el Consell de Redacció decideix rebutjar o acceptar l'article o sol-licitar modificacions a l'autor o autora del treball. Els autors o autores reben una notificació detallada i motivada en què s'exposa, retocat, el contingut dels informes originals, amb indicacions concretes per a la modificació si és el cas. Feminismo/s pot enviar als autors o autores els informes originals rebuts, íntegres o en part, sempre de manera anònima. En cas de discrepància en els informes d'avaluació, la revista es reserva el dret de sotmetre el treball a la valoració de la coordinadora o coordinador del volum i del Consell de Redacció, o de sol-licitar-ne una tercera avaluació.

3) L'informe emès pels revisors o revisores inclou:

a) una valoració global de l'article i dels resums.

b) una valoració quantitativa de la qualitat (bona | acceptable | insuficient) segons aquests cinc criteris: originalitat i interès del tema; pertinència en relació amb les investigacions actuals en l'àrea; rigor metodològic i articulació expositiva; bibliografia significativa i actualitzada, netedat formal i claredat de discurs.

c) una recomanació final: publicar | sol-licitar modificacions | rebutjar. 


\section{COBERTURA, DIFUSIÓ I PRESÈNCIA EN BASES DE DADES}

La revista està indexada en les bases de dades d'ISOC (Base de dades del Centre d'Informació i Documentació Científica del CSIC), ERIH PLUS (European Reference Index for the Humanities and Social Sciencies), MLA (Modern Language Association), CIRC, DICE, MIAR, Latindex, Dialnet.

\section{PRINCIPIS ÈTICS DE PUBLICACIÓ}

La publicació d'articles en una revista amb avaluació d'experts és un reflex directe de la qualitat del treball dels/de les autors/es i del compromís i la qualificació dels/de les investigadors/es que actuen com a revisors/es. Per això Feminismo/s és una publicació compromesa amb els principis ètics de l'activitat científica en els termes següents:

\section{Publicació i autoria}

Tots els articles han d'incloure una llista de referències, com també indicar si han rebut suport econòmic. Els treballs han d'estar lliures de plagi o frau científic. Els supòsits* de plagi i frau científic són els esmentats a continuació:

- Plagi: còpia literal sense usar les cometes i citar la font; còpia substancial (materials d'investigació, processos, taules...); parafrasejar o reproduir idees sense citar la font o canviant el significat original; reutilitzar i enviar textos propis ja publicats sense indicar la font $i$ parafrasejar de manera abusiva fins i tot citant la font.

- Frau científic: no reconeixement de tots/es els/les investigadors/es que participen en l'elaboració del treball; l'enviament simultani a diverses publicacions; la divisió d'un treball en parts diferents que comparteixen les mateixes hipòtesis, població i mètodes, com també la utilització de dades falses o no provades. Finalment, els/les autors/ es han de declarar a la revista els potencials conflictes d'interès quan envien un treball.

* Font: http://www.ethics.elsevier.com/ 


\section{Responsabilitat dels/de les autors/es}

- L'enviament de treballs a Feminismo/s implica la lectura i l'acceptació de les normes editorials i de publicació de la revista, incloent-hi la participació en un procés anònim d'avaluació d'experts.

- Tots/es els/les autors/es que signen un treball han d'haver contribuit de manera significativa en l'elaboració i han d'estar d'acord amb el resultat final i amb l'enviament del treball perquè siga avaluat.

- Els treballs han de reconèixer a tots/es els/les autors/es que hi han participat.

- Les dades utilitzades en l'article han de ser reals i autèntiques.

- Els/les autors/es assumeixen l'obligació de corregir o retractar-se davant possibles errors detectats posteriorment.

- Els articles han de ser inèdits i no poden ser enviats simultàniament a cap altra publicació.

\section{Procés de revisió}

Tots els articles enviats a la revista se sotmeten a un procés d'avaluació d'experts amb les característiques següents:

- La selecció dels/de les revisors/es es fa d'acord amb les normes i els principis previs basats tant en la seua qualificació com en la qualitat de la seua producció científica.

- El procés de revisió serà totalment anònim tant pels/per els autors/es com pels/per les revisors/es. Els articles i les revisions seran tractats confidencialment.

- Els/les revisors/es consideren, entre els criteris d'avaluació, el respecte als principis ètics essencials en la investigació científica.

- Els judicis expressats en les revisions han de ser objectius.

- Tant autors/es com revisors/es han de revelar les relacions i les fonts de finançament que puguen generar potencials conflictes d'interessos.

\section{Responsabilitats dels/de les editors/es}

- L'equip editorial té la responsabilitat i autoritat per a acceptar o rebutjar un article basant-se en les revisions.

- L'equip editorial revelarà, si escau, les relacions o les fonts de finançament que puguen ser potencialment considerades com a conflictes d'interessos pel que fa a l'acceptació o el rebuig dels treballs. 
- Només s'acceptaran els articles en els quals hi ha una evidència certa sobre el compliment de les normes editorials.

- El Consell de Redacció de Feminismo/s es reserva el dret de retirar qualsevol treball rebut, acceptat o ja publicat en cas de constatar-se plagi, falsificació o publicació duplicada, com també els diversos supòsits de frau científic anteriorment enumerats. De la mateixa manera, promourà la publicació de correccions o retractacions davant errors detectats.

- L'equip editorial es compromet a preservar l'anonimat dels/de les revisors/es de manera que mai puguen ser associats/des amb els articles revisats.

\section{Qüestions ètiques de publicació}

L'equip editorial es compromet a:

- Vigilar i preservar els principis ètics de publicació.

- Mantenir la integritat de l'expedient acadèmic.

- Evitar la publicació de material plagiat o elaborat de manera fraudulenta.

- Estar obert a la publicació de correccions, aclariments, retractacions i disculpes sempre que siga necessari.

- Oferir suport en el procés de retractació d'articles.

- Fer totes les accions necessàries per a complir els estàndards de compromís intel-lectual i ètic.

\section{Avís legal}

D'acord amb el que estableixen els articles 138-143 de la Llei de propietat intel-lectual, la publicació d'un treball que atempte contra aquests drets serà responsabilitat de l'autor/a. L'equip editorial de Feminismo/s no es fa responsable, en cap cas, de la credibilitat i autenticitat dels treballs. De la mateixa manera, les opinions i els fets expressats en cada article són de responsabilitat exclusiva dels/de les autors/es i Feminismo/s no s'identifica necessàriament amb aquests. 


\section{COM ES POT OBTENIR LA REVISTA}

La revista es ven a un preu de 12 euros a través del Servei de Publicacions de la Universitat d'Alacant

\section{Vendes:}

Telèfon: 965909445

Fax: 965909445

E-mail: Publicaciones.ventas@ua.es

La revista manté intercanvis amb publicacions pertanyents a altres institucions acadèmiques o investigadores, espanyoles i estrangeres. 


\section{HOW TO SUBMIT A MANUSCRIPT}

1. The works submitted should be unpublished under no evaluation process by other journals and must contain novel conclusions supported with a duly proposed and justified methodology.

2. The length of the papers should not exceed 9,000 words, including notes and bibliography.

3. The number and length of footnotes should be reduced to the minimum necessary.

4. Authors should submit their articles in Word via electronic mail (Revistafeminismos@ua.es) along with the following documents:

- Title of the work.

- Name of the author, the institution they belong to, full professional address and electronic mail.

- Text file in Word format, omitting the name of the author with:

- The title in Spanish and English.

- A 150-word abstract in Spanish and its correct English version. This abstract should follow the following outline: objectives of the paper, method and conclusions or thesis.

- Five key words in Spanish and its correct English version.

- Original text.

- A short curriculum vitae (maximum of 300 words).

5. Papers will will undergo a process of anonymous selection and evaluation peer review, according to the procedure and criteria published by the journal. 


\section{EDITORIAL GUIDELINES AND STYLE}

1. Articles should be drafted in Word with Times New Roman font, 12-point size with with one-and-a-half line spacing.

2. Length should not exceed 9,000 words, including notes and bibliography.

3. First line of each paragraph shall be indented.

4. Notes, which should be reduced to the minimum necessary and used only for supplementary information, will only be footnoted, with 10-point font and single spacing. Footnote number in the text should go before the punctuation mark.

5. Bibliographical references should go between parentheses in the text, and not in the notes, according to the following instructions:

5.1. Reference to an idea of an author whose name has not been expressly quoted in the text:

- «In the Italian Renaissance and humanistic culture, this debate on gender had a very special liveliness» (Blanco 265).

- This debate on gender had a very special liveliness in the Italian Renaissance and humanistic culture (Blanco 265).

No comma is used [,] between the name and page number.

5.2. Reference to an author's idea whose name is quoted in the text:

- According to Moi, «Kristeva's work cannot be considered fundamentally feminist» (174).

5.3. Should the author has an only work published, the year of publication will not be included.

5.4. Should more than work by the same author be mentioned, each year of publication should be included after the author's name. A comma should be used [,] ONLY between the year and the page number:

- «In the Italian Renaissance and humanistic culture, this debate on gender had a very special liveliness» (Blanco 1997, 265). 
5.5. Use «see» and not «cfr.», «véase», «vid.» o «comp.». Under no circumstances expressions such as «op. cit.», «art. cit.», «loc. cit.», «id.», «ibid.», «supra», «infra», «passim», «et alii» will be used.

6. Large figures (four or more lines) are highlighted in the text with an indented paragraph. Inverted commas are not used. Full stop goes, in this case, in front of the parentheses containing the bibliographical reference but never behind.

7. The different sections of the text are organised following the Arabic numerals $(1,2,3, \ldots)$ and the title for each section shall be capitalised in italics. Subsections shall be numbered as follows: 1.1, 1.2, 1.3, etc. and their titles shall be lowercase in Italics.

8. Photographs and images shall be submitted in a 300 pixels resolution as a.tiff, aside from the text. They should be duly identified according to the way they have quoted in the text.

9 List of quoted works:

9.1. Bibliographical references shall be mentioned at the bottom of the document, in alphabetic order with hanging indentation.

9.2. The names of authors and publishers shall be given in full and never capitalised.

9.3. In the case of a work with several authors, the surname shall only precede the first one.

9.4. In the case of more than work by the same author, a chronological order is needed and their name shall be mentioned in all cases.

9.5. In the case of journals, the number of issue and part shall be always given in Arabic numerals.

9.6. Each reference shall be organised as follows:

\section{A. BOOKS}

- With only one author or publisher: Surname, Name. Title of the book in Italics. Edition used. Number of volumes [if more than one]. Name of the series or collection [if appropriate]. Place of publication: Name of the publishing firm, Date of publication. 
Bloom, Harold. Poetry and Repression: Revision from Blake to Stevens. New Haven: Yale University Press, 1976.

Moi, Toril (ed.). The Kristeva Reader. Oxford: Blackwell Publishers, 1986.

- With several authors or publishers: Surnames, names and Names Surnames. Title in Italics. City: Publishing firm, year.

Anderson, Bonnie, and Judith P. Zinsser. Historia de las mujeres: una historia propia. 2 vols. Barcelona: Crítica, 1991.

Perrot, Michelle, and Georges Duby (eds.). Historia de las mujeres. Madrid: Taurus, 1991.

\section{B. ARTICLES}

- With one author : Surname, Name. «Title». Revista en cursiva volume no. in Arabic numerals. Issues in Arabic numerals (year): pages (without pg./pgs.).

Valcárcel, Amelia. «El primer ensayo feminista de una teoría del poder». Panorama 9 (1990): 59-64.

Vogel, Lisa. «Erotica, the Academy and Art Publishing: A Review of Woman as Sex Object. Studies in Erotic Art, 1730-1970, New York, 1972». Art Journal 35.4 (1976): 378-385.

- With several authors Surnames, Name, and Name surnames. «Titles». Revista en cursiva volume no. in Arabic numerals. Issues in Arabic numerals (year): pages (without pg./pgs).

López-Zafra, Esther and Rocío García Retamero. «Mujeres y liderazgo: ¿discapacitadas para ejercer el liderazgo en el ámbito público?». Feminismo/s 13 (2009): 85-104.

C. COLLABORATIVE BOOK: Author's surname, author's name. «Title of the collaboration». Title of the book in Italics. Publisher's name and surname. Edition no. Volume no. [if more than one]. Place of publication: Name of the publishing firm, publication date. Pages.

Smith-Rosenberg, Carroll. «Writing History: Language, Class and Gender». Feminist Studies. Ed. Teresa de Lauretis. Bloomington: Indiana University Press, 1986, 31-54. 


\section{BOOK TITLES WITH SEVERAL VOLUMES}

- Should every volume have its own title, state them as follows:

Díaz-Diocaretz, Myriam, and Iris M. Zavala (coords.). Breve historia feminista de la literatura española (in Spanish), I: Teoría feminista: discursos y diferencias. Barcelona: Anthropos, 1993.

- Should every volume have different titles:

Pardo Bazán, Emilia. Obras completas. Vol. 2. Ed. Federico Carlos Sainz de Robles. Madrid: Aguilar, 1957.

E. PRESS QUOTES: Author's surname, author's name. «Title of the article». Name of the newspaper in Italics [if not universally recognised: City, Country] Day Month Year: pages

Lara, Fernando. «Victoria Kent, una mujer de suerte». Triunfo, 22 October 1977: 62.

F. PUBLICATION IN THE INTERNET: Author's surname, author's name. «Title of the work». Name of the periodical in Italics. Volume. No. (Year): pages [if any]. Date of consultation.

Safa Barraza, Patricia, and Juan Manuel Ramírez Sáiz. «Deterioro urbano y calidad de vida en las grandes urbes: la participación de las mujeres en las organizaciones vecinales ». La ventana 54 (2011): 110-145. 20 April 2015.

G. WEB SITES shall be quoted according to this model:

<http://www.cis.es/cis/opencms/ES/2_barometros>, consulted on 19-06-2008

\section{HOW TO PROPOSE A MONOGRAPH}

The proposal for a monograph for Feminismo/s journal should be submitted to the editor of the journal (Helena.Establier@ua.es) with the following information:

1. Provisional title of the monograph.

2. A comprehensive CV of its coordinator/s. 
3. A description of their objectives and a justification for the timing of the proposed topic (300 words).

4. A provisional list of participants in the volume, along with a brief bio-bibliographical review of each participant and titles of the planned papers (and added to those submitted through our call for papers provided they pass the journal selection process).

5. Proposals will be considered by the Editorial Board of Feminismo/s within a maximum period of one month from the date of receipt.

\section{ASSESSMENT CRITERIA}

1) Original papers are firstly assessed by the Editorial Board of the journal on their suitability to the fields of knowledge and the requirements established for authors by the journal.

2) The Editorial Board submits originals (without the author's name written down) to two external reviewers, who shall release a report within six weeks. On these views, the Editorial Board decides on rejecting or accepting the article or apply for modifications to the author. Authors are given a detailed and reasoned notification where the content of original reports (retouched) is exposed with specific indications for modifications if appropriate. Feminismo/s can send authors the original reports submitted, either complete or in part and always anonymously. In the case of a discrepancy with assessment reports, the journal reserve the right to submit the paper for either assessment of the Issue Coordinator and the Editorial Board or to request a third party assessment.

3) The report submitted by reviewers includes:

a) a global assessment of both the article and abstracts.

b) a quantitative assessment of the quality (good | acceptable | insufficient) according to 5 criteria: originality and interest of the issue; appropriateness with respect to current research in the area; methodological rigour and expository articulation; relevant and updated bibliography; formal neatness and clear discourse.

c) a final recommendation: publish | apply for modifications | reject. 


\section{COVERAGE DISSEMINATION AND PRESENCE IN DATABASES}

The journal is indexed in ISOC (Database of CSIC's Scientific Information Documentation Centre, ERIH PLUS (European Reference Index for the Humanities and Social Sciencies), MLA (Modern Language Association), CIRC, DICE, MIAR, Latindex, Dialnet.

\section{PUBLICATION ETHICS AND MALPRACTICE STATEMENT}

The publication of articles in a peer-review journal is a direct reflection of the quality of the work of their authors, and the commitment and qualifications of the researchers who act as reviewers. Therefore Feminismo/s is a publication committed to the ethical principles of scientific activity on the following terms:

\section{Publication and authorship}

All manuscripts must include a list of references, and indicate whether they have received financial support. Works must be free of plagiarism or scientific fraud. Illustrative cases* of plagiarism and scientific fraud can be consulted in a non-exhaustive list below:

- Plagiarism: literal copy without quoting and referencing the source; substantial copying (research materials, processes, tables...); paraphrasing or reproducing ideas without citing the source and/or changing the original meaning; text-recycling (reusing a published own text) without indicating the source, and abusive paraphrasing even quoting the source.

- Scientific fraud: no recognition of all the participating researchers in the study, simultaneous submission to several publications, the division of a work in different parts ('slices') that share the same hypotheses, population and methods, as well as the use of false or unproven data. Finally, the authors should disclose potential conflicts of interest to the journal when a manuscript is sent.

* Source: http://www.ethics.elsevier.com/ 


\section{Authors' Responsibility}

- The manuscripts submission to Feminismo/s involves reading and acceptance of the journal publishing guidelines, including participation in an anonymous peer-review process.

- All authors signing a work must have contributed significantly to its development and must agree both with the end result and with the manuscript submission for evaluation.

- Manuscripts must acknowledge all authors who have participated in their elaboration.

- Data used in the article must be real and authentic

- The authors assume the obligation to retract/correct when possible errors are later detected.

- Articles must be original and cannot be sent simultaneously to any other publication.

\section{Review Process}

All articles submitted to the journal are subjected to a peer review process with the following characteristics:

- The selection of reviewers is done according to rules and principles based on both their qualification and the quality of their scientific production.

- The review process will be totally anonymous both for authors and for reviewers. Manuscripts and reviews will be treated confidentially.

- Reviewers will take into account for their evaluation criteria the respect for the ethical principles that are essential in scientific research.

- The judgments expressed in the reviews should be objective.

- Authors and reviewers should disclose all relationships and funding sources that could generate potential conflicts of interest.

\section{Editors' Responsibilities}

- The editorial board has the responsibility and authority to accept or reject a manuscript based on the peer reviews.

- The editorial board will reveal any relationships or funding sources that could potentially be considered conflicts of interest regarding the rejection or the acceptance of manuscripts.

- The journal only accepts manuscripts when reasonably certain of compliance with editorial standards. 
- The Editorial Team reserves the right to remove any received, accepted or already published work where plagiarism, falsification, duplicate publication or scientific fraud is found. Similarly, it will encourage the publication of retractions or corrections to errors detected.

- The editorial team is committed to preserve the anonymity of the reviewers so that they can never be associated with the reviewed manuscripts.

\section{Publishing ethical Issues}

The editorial board is committed to:

- Monitoring and maintaining the publishing ethics.

- Maintaining the integrity of the academic record.

- Avoid publishing plagiarized or fraudulently prepared material.

- Be willing to publish corrections, clarifications, retractions and apologies when needed.

- Provide support in the process of retracting articles.

- Perform all actions required to meet the standards of intellectual and ethical commitment.

\section{Disclaimer}

Regarding the provisions in articles 138-143 of the Spanish Law on Intellectual Property, the publication of a work prejudicial to those rights shall be the responsibility of the author. The editorial team of Feminismo/s is not responsible, in any case, for the credibility and authenticity of the works. In the same way, the opinions and facts expressed in each article are the sole responsibility of the authors and Feminismo/s does not necessarily agree with them. 


\section{HOW TO GET THE JOURNAL}

The journal is on sale at $€ 12$ through the University of Alicante Publications Service

Sales:

Tel. 965909445

Fax: 965909445

E-Mail: Publicaciones.Ventas@ua.es

The journal exchanges publications with other journals from Spanish and international academic and/or research institutions. 


\section{Números anteriores publicados}

Feminismo/s 1. Feminismo y multidisciplinariedad. Helena Establier (coord.)

Feminismo/s 2. Imagin/ando a la mujer. Pilar Amador Carretero (coord.) y Mónica Moreno Seco (ed.)

Feminismo/s 3. Mujer y participación política. Mónica Moreno Seco y Clarisa Ramos Feijóo (coords.)

Feminismo/s 4. Writing, memoirs, autobiography and history. Silvia Caporale Bizzini (coord.)

Feminismo/s 5. Habitar / escribir / conquistar el espacio. Teresa Gómez Reus (ed.)

Feminismo/s 6. Violencia estructural y directa: mujeres y visibilidad. Carmen Mañas Viejo (coord.)

Feminismo/s 7. Hèléne Cixous: Huellas de intertextos. Maribel Peñalver Vicea y Rosa María Rodríguez Magda (eds.)

Feminismo/s 8. Mujeres y derecho. Nieves Montesinos Sánchez y M. ${ }^{a}$ del Mar Esquembre Valdés (coords.). Nieves Montesinos Sánchez (ed.)

Feminismo/s 9. Género, conflicto y construcción de la paz. Reflexiones y propuestas. Eva Espinar Ruiz y Eloisa Nos Aldás (coords.)

Feminismo/s 10. Medicines i Gènere. El torsimany necessari. Elizabeth Mora Torres, Albert Gras i Martí (coords.)

Feminismo/s 11. La representación/presencia de la mujer en los Medios de Comunicación. Sonia Núñez Puente (coord.) y Helena Establier Pérez (ed.)

Feminismo/s 12. Mujeres en democracia. Nieves Montesinos Sánchez y M. ${ }^{a}$ del Mar Esquembre Valdes (coords. y eds.)

Feminismo/s 13. Mujeres y diversidad funcional (discapacidad): construyendo un nuevo discurso. Carmen Mañas (coord.)

Feminismo/s 14. Género y nuevas tecnologías de la información y la comunicación. Eva Espinar Ruiz (Coord.)

Feminismo/s 15. ¿Feminismo de la igualdad y feminismo de la diferencia? Elena Nájera (Coord.)

Feminismo/s 16. Género e imagen del poder en la historia contemporánea. Mónica Moreno Seco y Alicia Mira Abad (Coords.) 
Feminismo/s 17. La arquitectura y el urbanismo con perspectiva de género. María Elia Gutiérrez Mozo (Coord.)

Feminismo/s 18. Salud pública desde la perspectiva de género: Hitos e innovación. María Teresa Ruiz Cantero (Coord.)

Feminismo/s 19. Mirada/s trans/identitarias. Ángel Amaro (Coord.)

Feminismo/s 20. La Diosa y el poder de las mujeres. Reflexiones sobre la espiritualidad femenina en el siglo XXI. Angie Simonis (Coord.)

Feminismo/s 21. Mujeres, actividad física, deporte y ocio. Juan Tortosa Martínez y Lilyan Vega Ramírez (Coords.)

Feminismo/s 22. Ecofeminismo/s: Mujeres y Naturaleza. Lorraine Kerslake y Terry Gifford (Coords.)

Feminismo/s 23. Todo sobre mi familia. Perspectivas de género. Adrián GrasVelázquez (Coord.)

Feminismo/s 24. Género y humor en discursos de mujeres y hombres. G. Angela Mura y Leonor Ruiz Gurillo (Coords.)

Feminismo/s 25. Violencia escolar y género. Almudena Iniesta Martínez (Coord.)

Feminismo/s 26. Feminismos en las sociedades árabes. Eva Lapiedra Gutiérrez (Coord.)

Feminismo/s 27. Comunicación y relaciones de género: prácticas, estructuras, discursos y consumo. Alejandra Hernández Ruiz y Marta Martín Llaguno (Coords.)

Feminismo/s 28. Laicidad y creencias. Nieves Montesinos Sánchez y Beatriz Souto Galván (Coords.) 




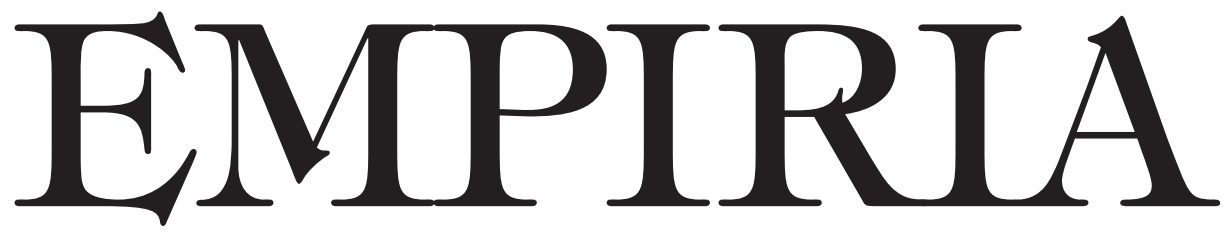

\section{REVISTA DE METODOLOGIA DE CIENCIAS S O C I A L E S}

\section{$\mathrm{N}^{\circ} 34-2016$ mayo-septiembre}

ISSN 1139-5737
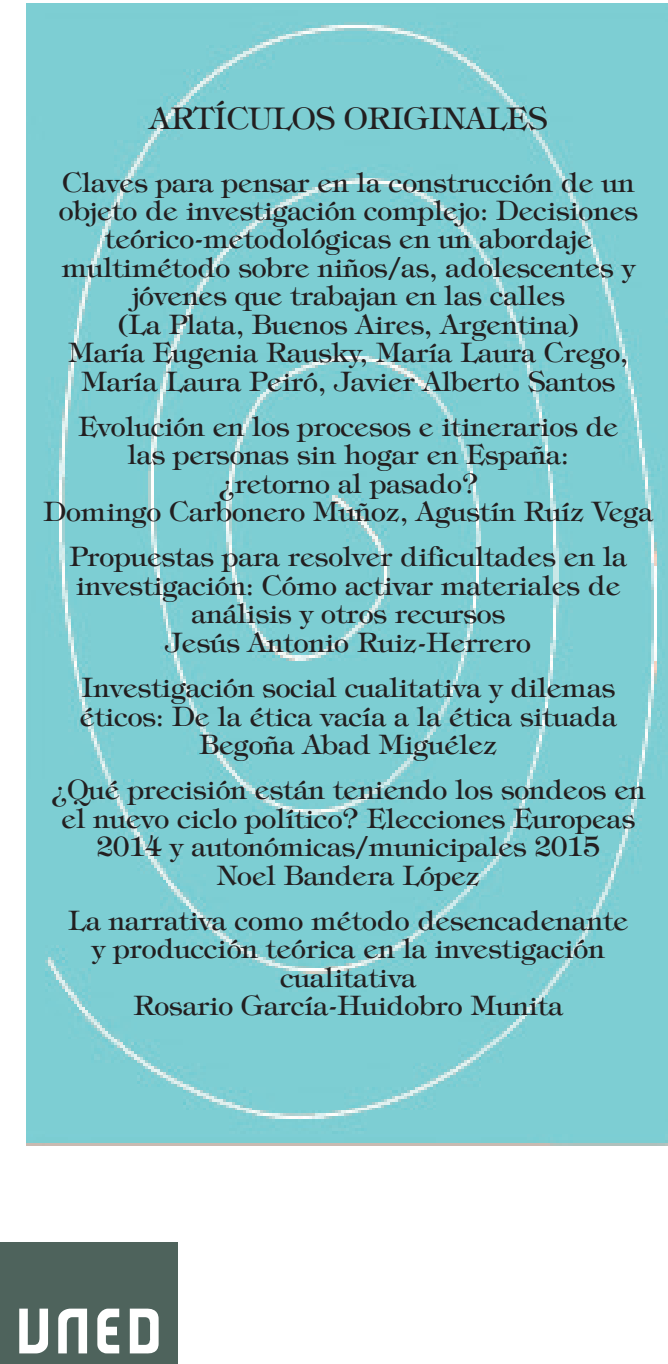

UNIVERSIDAD NACIONAL

DE EDUCACIÓN A DISTANCIA 
